\title{
PERFORMANCE ASSESSMENT FOR CONTINUING AND FUTURE OPERATIONS AT SOLID WASTE STORAGE AREA 6
}

September 1997

\author{
Prepared by \\ OAK RIDGE NATIONAL LABORATORY \\ Oak Ridge, Tennessee 37831 \\ managed by \\ LOCKHEED MARTIN ENERGY RESEARCH CORP. \\ for the \\ U.S. DEPARTMENT OF ENERGY \\ under Contract No. DE-AC05-96OR22464
}




\section{DISCLAIMER}

This report was prepared as an account of work sponsored by an agency of the United States Government. Neither the United States Government nor any agency thereof, nor any of their employees, makes any warranty, express or implied, or assumes any legal liability or responsibility for the accuracy, completeness, or usefulness of any information, apparatus, product, or process disclosed, or represents that its use would not infringe privately owned rights. Reference herein to any specific commercial product, process, or service by trade name, trademark, manufacturer, or otherwise does not necessarily constitute or imply its endorsement, recommendation, or favoring by the United States Government or any agency thereof. The views and opinions of authors expressed herein do not necessarily state or reflect those of the United States Government or any agency thereof. 


\section{DISCLAIMER}

Portions of this document may be illegible electronic image products. Images are produced from the best available original document. 


\section{CONTENTS}

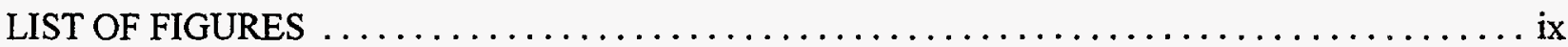

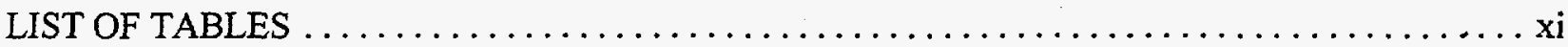

ABBREVIATIONS AND ACRONYMS $\ldots \ldots \ldots \ldots \ldots \ldots \ldots \ldots \ldots \ldots \ldots \ldots \ldots \ldots \ldots \ldots \ldots \ldots$

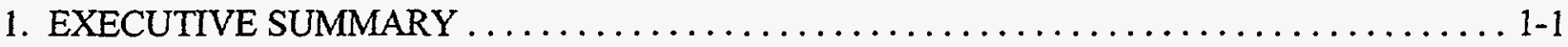

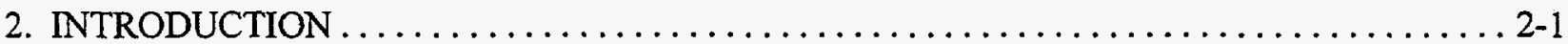

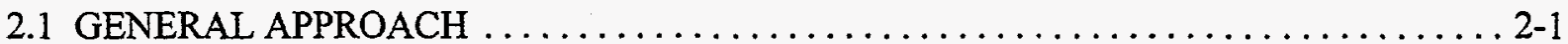

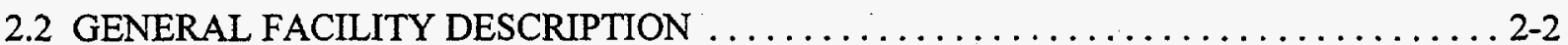

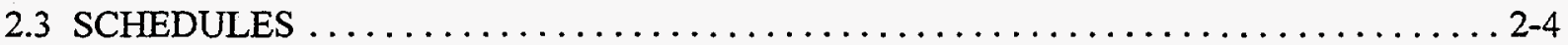

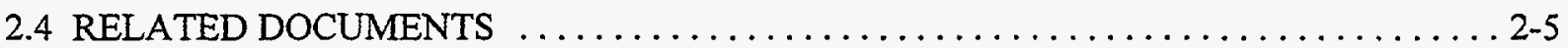

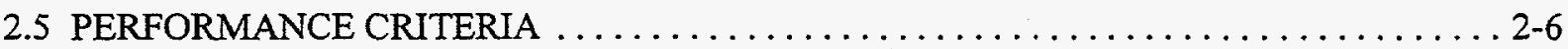

2.5.1 Public Protection Performance Objective ..................... 2-6

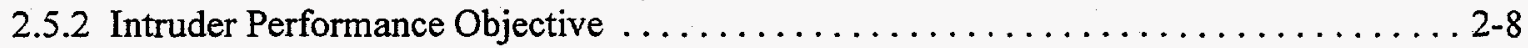

2.5.3 Water Resources Protection Performance Objective . . . . . . . . . . . . . 2-9

2.6 SUMMARY OF KEY ASSESSMENT ASSUMPTIONS $\ldots \ldots \ldots \ldots \ldots \ldots \ldots \ldots \ldots .2-11$

2.6.1 Waste Form Assumptions . . . . . . . . . . . . . . . . . . . . 2-11

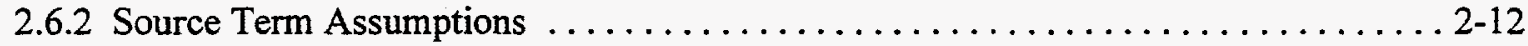

2.6.2.1 Radionuclide Release ......................... 2-12

2.6.2.2 Disposal Unit Degradation and Performance $\ldots \ldots \ldots \ldots \ldots \ldots \ldots . .$.

2.6.3 Site Assumptions . . . . . . . . . . . . . . . . . . . . . . . . 2-14

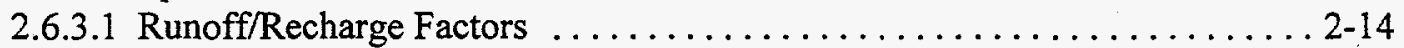

2.6.3.2 Areal Recharge Estimates for Groundwater Modeling ... . . . . . . 2-15

2.6.3.3 Assumptions in Surface Water Analyses ................. 2-16

2.6.3.4 Assumptions in Groundwater Analyses . . . . . . . . . . . . . . . 2-16

2.6.3.5 Retardation in the Subsurface .................... 2-17

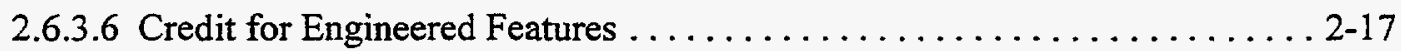

2.7 METHODOLOGICAL MODIFICATIONS AND CORRECTIONS TO THE REVISED

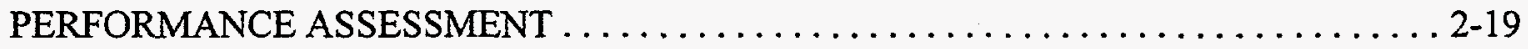

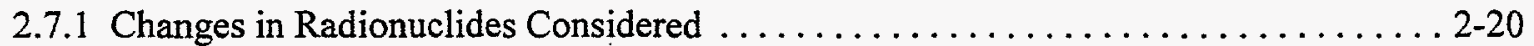

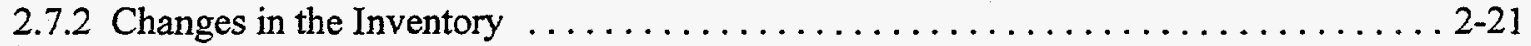

2.7.3 Changes in Source Term Modeling . . . . . . . . . . . . . . . . . . 21

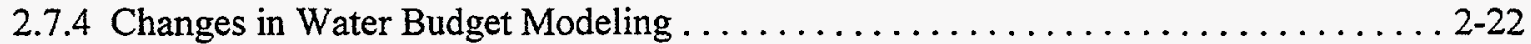

2.7.5 Changes in Shallow Subsurface Transport Modeling $\ldots \ldots \ldots \ldots \ldots \ldots \ldots \ldots 2-22$

2.7.6 Changes in Groundwater Transport Modeling ................... 2-22

2.7.7 Changes in Exposure Scenarios for Off-Site Individuals . . . . . . . . . . . . . . 2-23

2.7.8 Changes in Exposure Scenarios for Inadvertent Intruders . . . . . . . . . . . . . 2 2-24

2.7.9 Changes in Parameter Values for Exposure Pathway Models . . . . . . . . . . 2-25

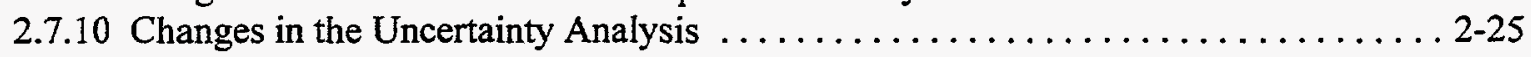

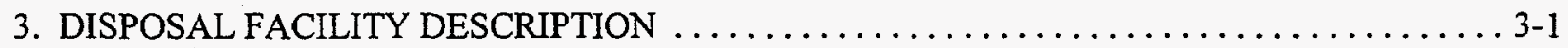

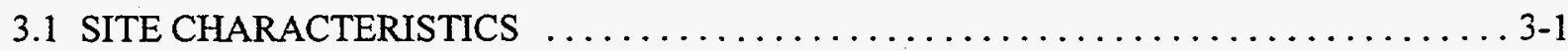




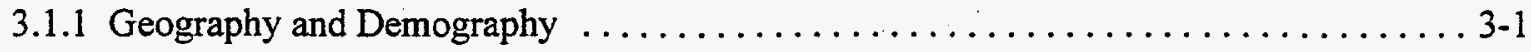

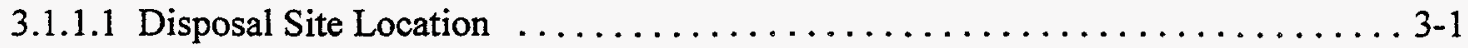

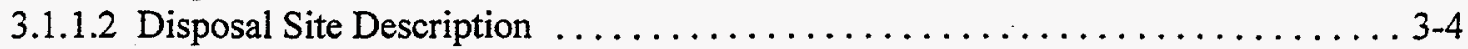

3.1.1.3 Population Distribution $\ldots \ldots \ldots \ldots \ldots \ldots \ldots \ldots \ldots \ldots \ldots \ldots \ldots \ldots, 4,4$

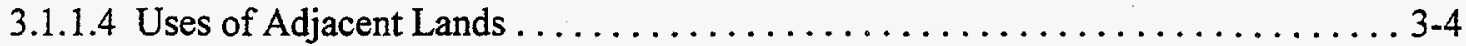

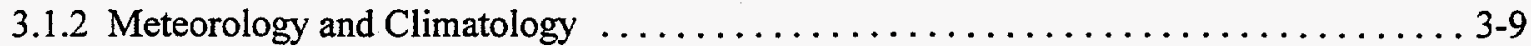

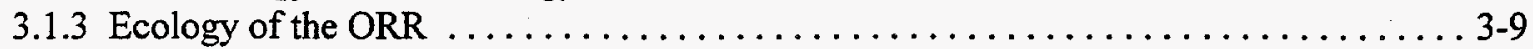

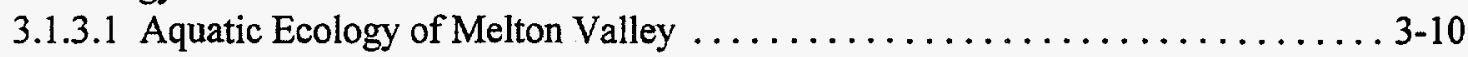

3.1.3.2 Terrestrial Ecology of Melton Valley ......................... 3-11

3.1.4 Geology, Seismology, and Volcanology ......................... 3-11

3.1.4.1 Regional and Site-Specific Geology and Topography $\ldots \ldots \ldots \ldots \ldots \ldots \ldots 3-12$

3.1.4.2 Seismology $\ldots \ldots \ldots \ldots \ldots \ldots \ldots \ldots \ldots \ldots \ldots \ldots \ldots \ldots \ldots \ldots \ldots \ldots \ldots \ldots \ldots \ldots, 23$

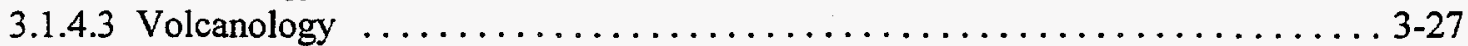

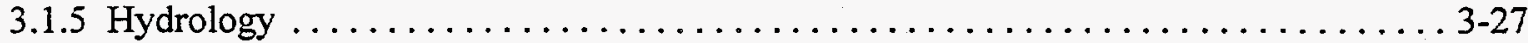

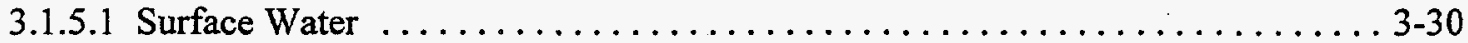

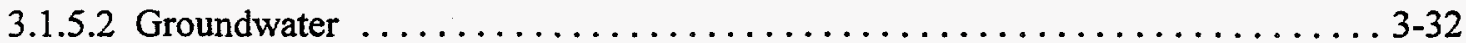

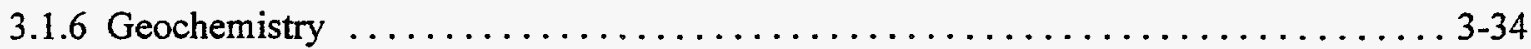

3.1.7 Natural Resources .................................... 3-34

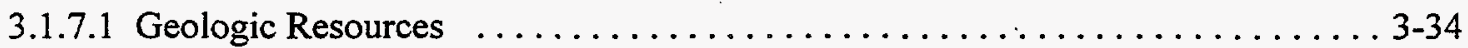

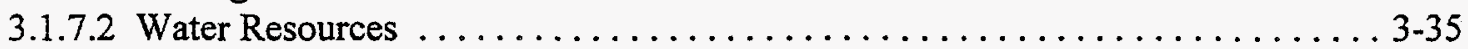

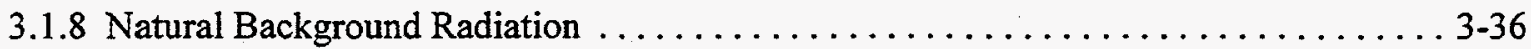

3.1.8.1 Average Radiation Doses in U.S. Population ................... 3-36

3.1.8.2 Natural Radiation Environment on the Oak Ridge Reservation ........... 3-36

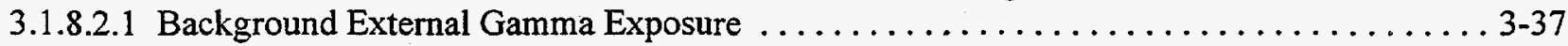

3.1.8.2.2 Background Levels of Radionuclides in Air . ................. 3-38

3.1.8.2.3 Background Levels of Radionuclides in Surface Water ........... 3-38

3.1.8.2.4 Background Levels of Radionuclides in Groundwater ........... 3-40

3.1.8.2.5 Background Levels of Radionuclides in Soil $\ldots \ldots \ldots \ldots \ldots \ldots \ldots .430$

3.2 PRINCIPAL FACILITY DESIGN FEATURES $\ldots \ldots \ldots \ldots \ldots \ldots \ldots \ldots \ldots \ldots \ldots, 45$

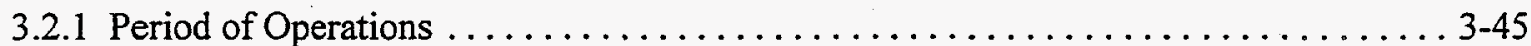

3.2.1.1. Below-Grade Disposal Units . . . . . . . . . . . . . . .

3.2.1.1.1 Low-Range and High-Range Silos $\ldots \ldots \ldots \ldots \ldots \ldots \ldots \ldots \ldots \ldots \ldots$

3.2.1.1.2 Asbestos Silos ................................... 3-53

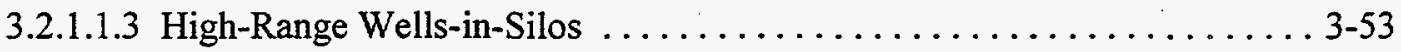

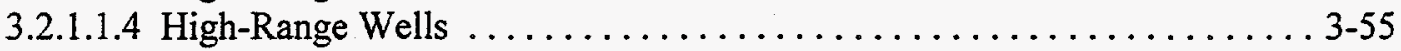

3.2.1.1.5 Fissile Wells .................................. 3-59

3.2.1.1.6 Biological Trenches ............................. 3-60

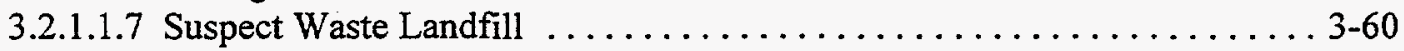

3.2.1.1.8 Quadrex Trenches ............................... 3-61

3.2.1.2 Above Grade Tumulus Disposal Units ....................... 3-61

3.2.1.2.1 Low-Level Waste Disposal Development and

Demonstration Program .............................. 3-62

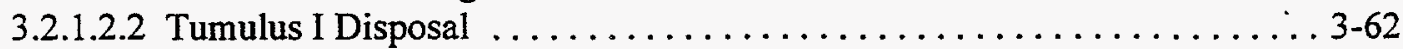

3.2.1.2.3 Tumulus II Disposal . . . . . . . . . . . . . . . . . .

3.2.1.3 The Interim Waste Management Facility . . . . . . . . . . . . . . . . 65

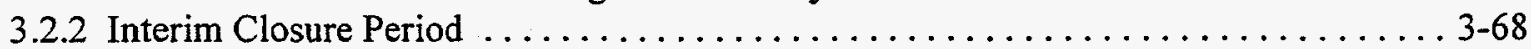

3.2.3 Closure ............................................... 3-69

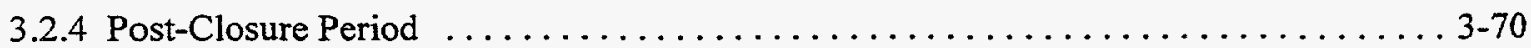




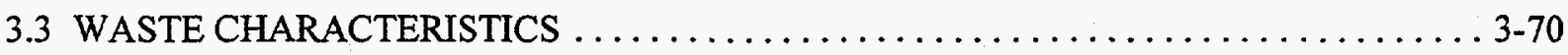

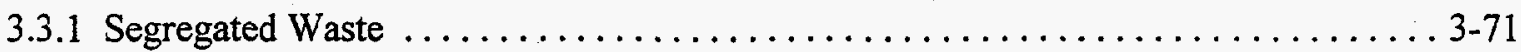

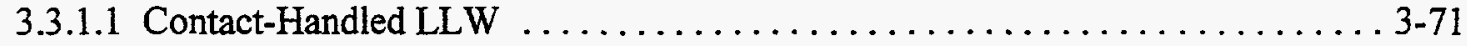

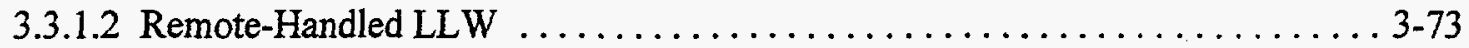

3.3.1.3 Fissile Waste $\ldots \ldots \ldots \ldots \ldots \ldots \ldots \ldots \ldots \ldots \ldots \ldots \ldots \ldots \ldots \ldots \ldots \ldots \ldots \ldots, 74$

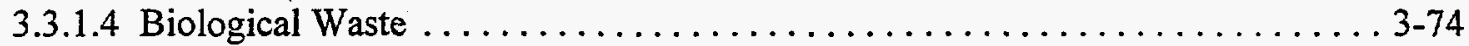

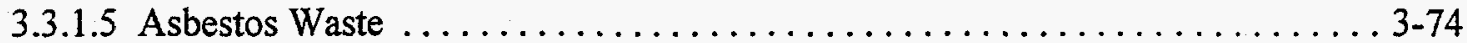

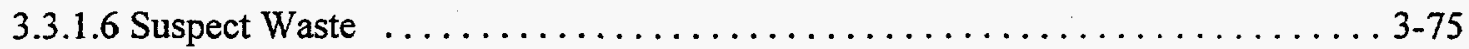

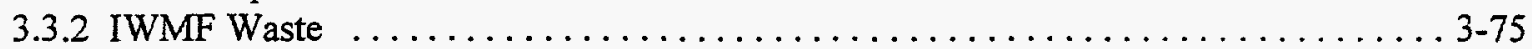

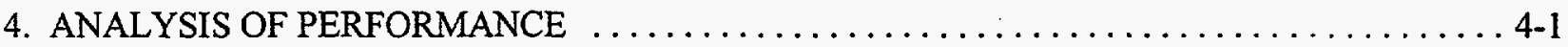

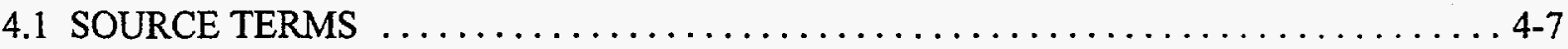

4.1.1 Source Terms for All-Pathways Analysis $\ldots \ldots \ldots \ldots \ldots \ldots \ldots \ldots \ldots \ldots \ldots, 4,7$

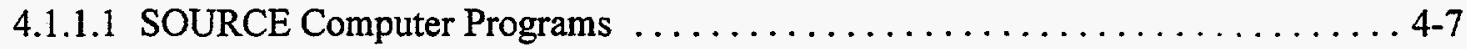

4.1.1.1.1 Overview of the Conceptual Model ...................... 4-8

4.1.1.1.2 Revisions to SOURCE1 and SOURCE2 $\ldots \ldots \ldots \ldots \ldots \ldots \ldots \ldots .4-10$

4.1.1.2 Input Parameters for the SOURCE1 and SOURCE2 Computer Programs . . . . . 4-12

4.1.1.2.1 Physicochemical Parameters ........................ 4-12

4.1.1.2.2 Radionuclide Transport Parameters $\ldots \ldots \ldots \ldots \ldots \ldots \ldots \ldots \ldots, 4-12$

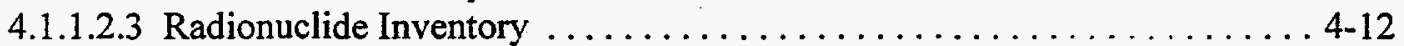

4.1.1.2.4 Water Seepage Rates $\ldots \ldots \ldots \ldots \ldots \ldots \ldots \ldots \ldots \ldots \ldots \ldots \ldots \ldots \ldots \ldots \ldots, 17$

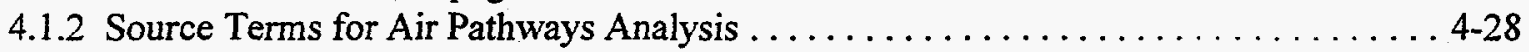

4.1.3 Source Terms for Water Resources Protection Analysis . . . . . . . . . . . . . . 4-28

4.1.4 Source Terms for Direct Intrusion $\ldots \ldots \ldots \ldots \ldots \ldots \ldots \ldots \ldots \ldots \ldots \ldots \ldots, 4,28$

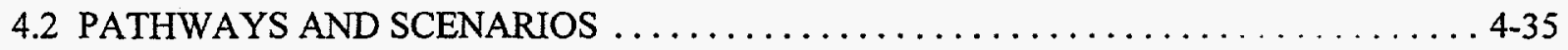

4.2.1 Pathways and Scenarios for All-Pathways Analysis $\ldots \ldots \ldots \ldots \ldots \ldots \ldots \ldots .36$

4.2.1.1 Closure Scenario ................................... 4-36

4.2.1.2 Releases from Disposal Units to Environmental Pathways ............ 4-37

4.2.1.3 Environmental Transport via Biotic Pathways ................... . 4 4-39

4.2.1.4 Exposure Pathways Resulting from Biotic Recycling $\ldots \ldots \ldots \ldots \ldots \ldots .4 .39$

4.2.1.5 Environmental Transport Pathways . ......................... 4-41

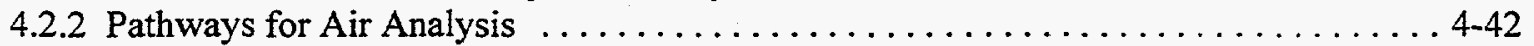

4.2.3 Pathways and Scenarios for Water Resources Protection Analysis . . . . . . . . . . 4-43

4.3 ANALYSIS METHODOLOGY $\ldots \ldots \ldots \ldots \ldots \ldots \ldots \ldots \ldots \ldots \ldots \ldots \ldots, 4.43$

4.3.1 All-Pathways Analysis Methodology $\ldots \ldots \ldots \ldots \ldots \ldots \ldots \ldots \ldots \ldots \ldots, 4.44$

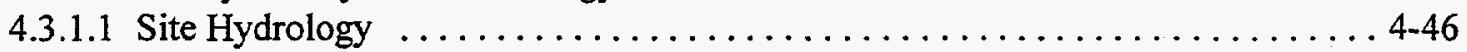

4.3.1.1.1 Terrain Analysis . ............................... 4-46

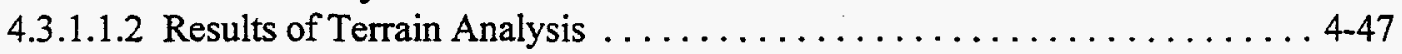

4.3.1.1.3 Water Budget Modeling........................... 4-47

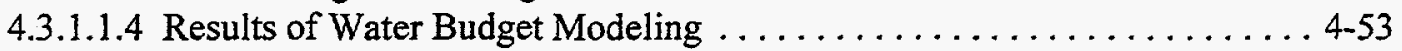

4.3.1.2 Environmental Transport ............................. 4-60

4.3.1.2.1 Shallow Subsurface Transport ......................... 4-63

4.3.1.2.2 Contaminant Transport in Groundwater ................. 4-66

4.3.1.2.3 Transport of Contaminants in Surface Water ................ 4-67

4.3.1.3 Exposure Pathway Modeling and Dose Estimation $\ldots \ldots \ldots \ldots \ldots \ldots \ldots .4 .68$

4.3.2 Air Pathways Analysis Methodology $\ldots \ldots \ldots \ldots \ldots \ldots \ldots \ldots \ldots \ldots \ldots . .4 .71$

4.3.2.1 Analysis for Volatile Radionuclides . . . . . . . . . . . . . . . . . . . 4 42

4.3.2.2 Analysis for Radon Emanation ........................... 4-72 


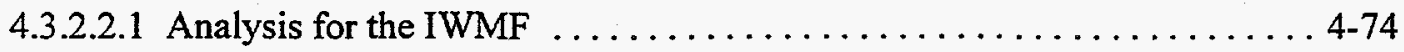

4.3.2.2.2 Analysis for Other Disposal Units . . . . . . . . . . . . . .

4.3.2.2.3 Summary of Analysis for Radon . . . . . . . . . . . . . . 4-77

4.3.3 Water Resources Protection Analysis Methodology ................ . 4-78

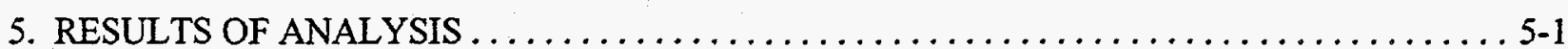

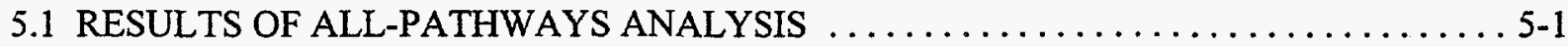

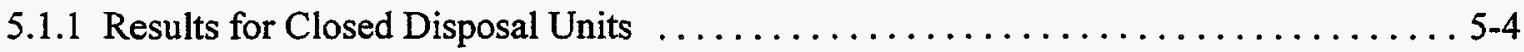

5.1.1.1 Output from the Modeling of Releases from Closed Disposal Units . . . . . 5-4

5.1.1.2 Output from the Modeling of Shallow Subsurface

Transport for Closed Disposal Units . . . . . . . . . . . . . . . 5-9

5.1.1.3 Output from Modeling of Groundwater and Surface Water for Closed

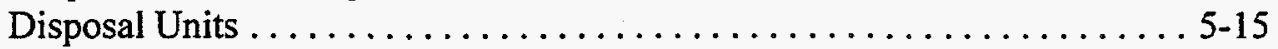

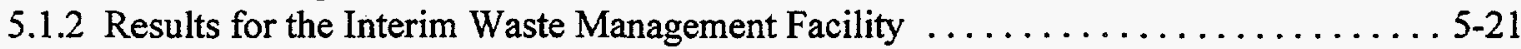

5.1.2.1 Output from the Modeling of Releases from IWMF $\ldots \ldots \ldots \ldots \ldots \ldots$ 5-21

5.1.2.2 Output from Modeling of Shallow Subsurface

Transport for IWMF . . . . . . . . . . . . . . . . . . . . . . 5-21

5.1.2.3 Results of the Water Pathway Analyses for All Disposal Units . . . . . . . . 5-23

5.1.3 Discussion of Results of the Hydrologic Transport Analysis . . . . . . . . . 5-30

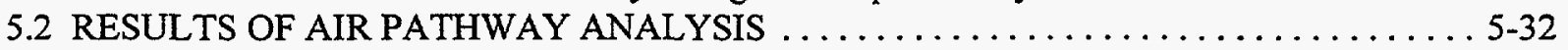

5.3 RESULTS OF WATER RESOURCES PROTECTION ANALYSIS $\ldots \ldots \ldots \ldots \ldots \ldots \ldots 5-32$

5.4 RESULTS OF SENSITIVITY AND UNCERTAINTY ANALYSIS $\ldots \ldots \ldots \ldots \ldots \ldots .5-33$

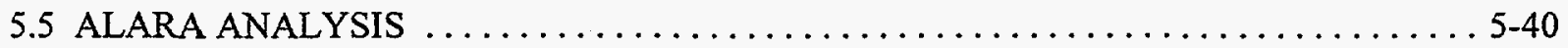

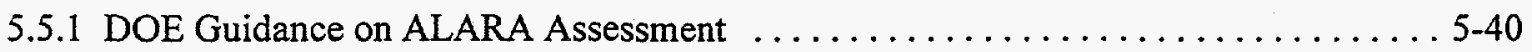

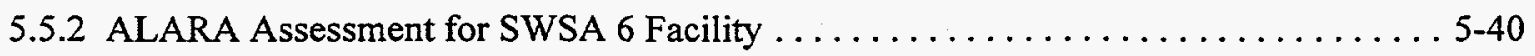

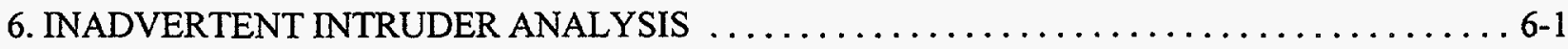

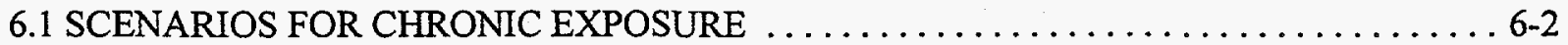

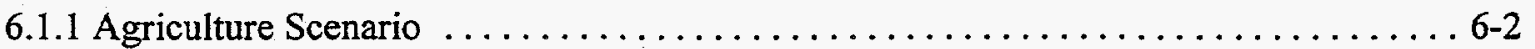

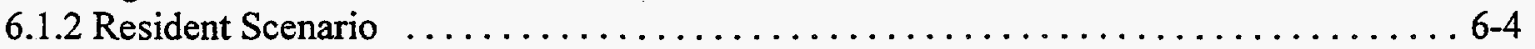

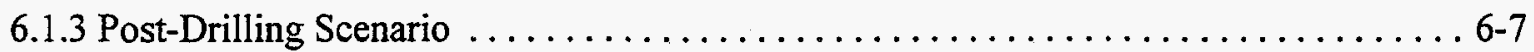

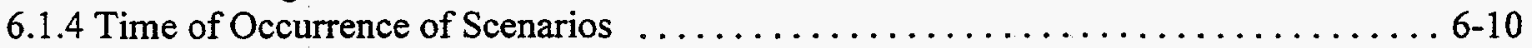

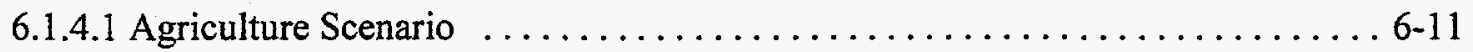

6.1 .4 .2 Resident Scenario . . . . . . . . . . . . . . . . . . . . . 6-12

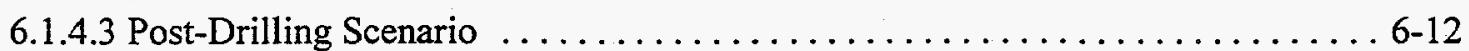

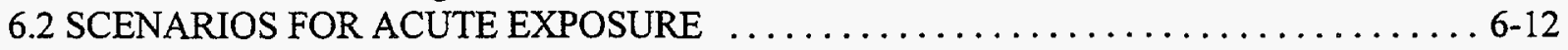

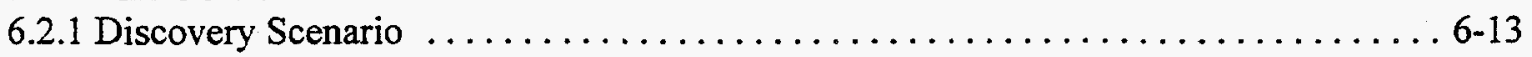

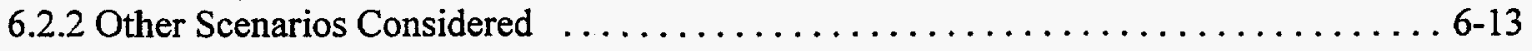

6.3 RESULTS OF INTRUDER DOSE ASSESSMENT $\ldots \ldots \ldots \ldots \ldots \ldots \ldots \ldots \ldots \ldots \ldots 6-15$

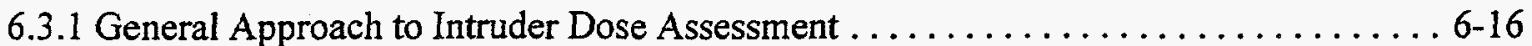

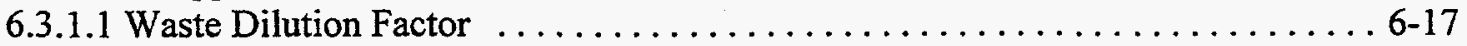

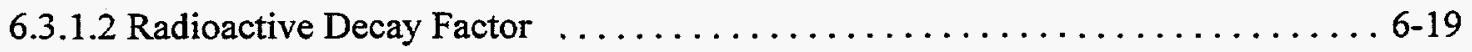

6.3.1.3 Mobilization and Transport Factor . . . . . . . . . . . . $\ldots \ldots \ldots \ldots \ldots \ldots$

6.3.2 Intruder Dose Assessment for IWMF . . . . . . . . . . . . . . . . . 6-24

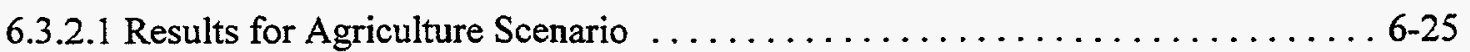

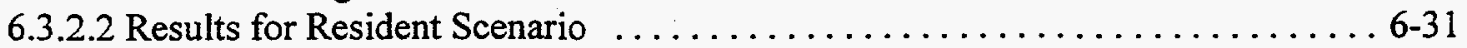

6.3.2.3 Results for Post-Drilling Scenario . . . . . . . . . . . . . . . . . . 61

6.3.2.4 Disposal Limits Based on Intruder Dose Assessment . . . . . . . . . . 6-35 
6.3.2.5 Application of Disposal Limits to Mixtures of Radionuclides $\ldots \ldots \ldots \ldots \ldots 6-36$

6.3.3 Intruder Dose Assessment for Other Disposal Units . . . . . . . . . . . . . . 6-39

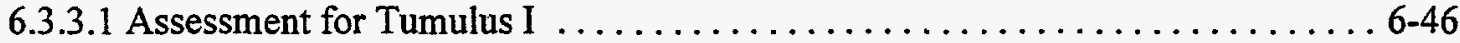

6.3.3.2 Assessment for Tumulus II . . . . . . . . . . . . . . . . . . . . 6-47

6.3.3.3 Assessment for Low-Range Silos . . . . . . . . . . . . . . . . . . 6-48

6.3.3.4 Assessment for High-Range Silos . . . . . . . . . . . . . . . . . . . 6-49

6.3.3.5 Assessment for Asbestos Silos . . . . . . . . . . . . . . . . . . . . . . . . . 6-49

6.3.3.6 Assessment for High-Range Wells . . . . . . . . . . . . . . . 6-50

6.3.3.6.1 Dose Assessment for Agriculture Scenario . . . . . . . . . . 6-50

6.3.3.6.2 Dose Assessment for Resident Scenario .............. . 6-53

6.3.3.6.3 Dose Assessment for Post-Drilling Scenario . . . . . . . . . . . . . 6-53

6.3.3.6.4 Dose Assessment for Discovery Scenario . . . . . . . . . . . 6-54

6.3.3.7 Assessment for Fissile Wells . . . . . . . . . . . . . . . . . . 6-55

6.3.3.7.1 Dose Assessment for Agriculture Scenario . . . . . . . . . . 6-55

6.3.3.7.2 Dose Assessment for Resident Scenario . . . . . . . . . . . . . 6-56

6.3.3.7.3 Dose Assessment for Post-Drilling Scenario . . . . . . . . . . . . 6-56

6.3.3.7.4 Dose Assessment for Discovery Scenario . . . . . . . . . . . . 6-57

6.3.3.8 Assessment for Quadrex Trenches .......................... 6-57

6.3.3.9 Assessment for Biological Trenches ..................... 6-58

6.3.3.10 Summary of Results ........................ $6-58$

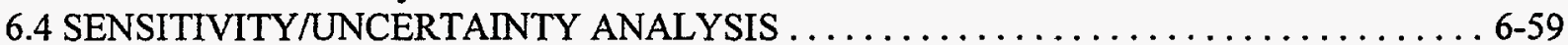

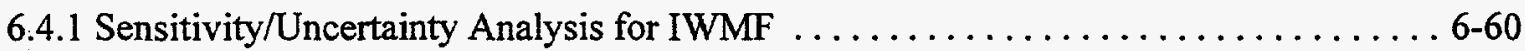

6.4.1.1 Sensitivity/Uncertainty for Radionuclide Inventories . . . . . . . . . . 6-60

6.4.1.2 Sensitivity/Uncertainty for Photon-Emitting Radionuclides . . . . . . . . 6-61

6.4.1.3 Sensitivity/Uncertainty for Other Radionuclides . . . . . . . . . . . 6-61

6.4.1.3.1 Sensitivity/Uncertainty for Vegetable Pathway ........... 6-61

6.4.1.3.2 Sensitivity/Uncertainty for Soil Ingestion Pathway ........ 6-63

6.4.1.3.3 Sensitivity/Uncertainty for Inhalation Pathway. . . . . . . . . 6-63

6.4.2 Sensitivity/Uncertainty Analysis for Other Disposal Units . . . . . . . . . . . . 6-64

6.4.2.1 Sensitivity/Uncertainty for Radionuclide Inventories . . . . . . . . . . . . 6-64

6.4.2.2 Sensitivity/Uncertainty for Exposure Pathway Models . . . . . . . . . . 6-66

6.4.3 General Consideration of Uncertainties in Dose Assessment Models . . . . . . . . . 6-66

7. PERFORMANCE EVALUATION $\ldots \ldots \ldots \ldots \ldots \ldots \ldots \ldots \ldots \ldots \ldots \ldots \ldots \ldots \ldots \ldots \ldots .1$

7.1 COMPARISON OF RESULTS TO PERFORMANCE OBJECTIVES $\ldots \ldots \ldots \ldots \ldots \ldots 7-1$

7.2 USE OF PERFORMANCE ASSESSMENT RESULTS $\ldots \ldots \ldots \ldots \ldots \ldots \ldots \ldots \ldots \ldots . \ldots \ldots$

7.2.1 Summary of Assumptions Relevant to Operation of the IWMF $\ldots \ldots \ldots \ldots \ldots \ldots$. $7-9$

7.2.2 Allowable Disposals for Radionuclides Not Analyzed in the

PA for the IWMF . . . . . . . . . . . . . . . . . . . $7-13$

7.2.2.1 Summary of Disposal Limits for Radionuclides Analyzed in the PA . . . . . . 7-13

7.2.2.2 Exclusion of Radionuclides with Half-Lives Less Than 5 Years ......... 7-14

7.2.2.3 Screening of Radionuclides with Half-Lives Greater Than 5 Years . . . . . . . 7-16

7.2.2.3.1 Screening of Radionuclides Based Only on Half-Life . . . . . . . . . . 7-18

7.2.2.3.2 Further Screening of Radionuclides Based on Decay Properties . . . . . . 7-19

7.2.2.4 Summary of Screening Criteria . . . . . . . . . . . . . . . . . $\ldots \ldots \ldots$

7.2.3 Application of Initial PA Results to IWMF Disposal . . . . . . .

7.2.4 Recommendations Concerning Current and Future Operations at the IWMF . . . . . . . . . . . . . . . . . . . . . . . . . 
7.2.4.1 Buffer Zone Expansion

7.2.4.2 Post-Assessment Restriction in Disposal Limits for

Problematic Radionuclides .............................. $7-27$

7.2.4.3 Vault Removal ................................. $7-28$

7.2.4.4 Discontinue Use of the MPA Factor ....................... 7-29

7.2.4.5 Develop Off-Site Disposal Capacity ........................ 7-29

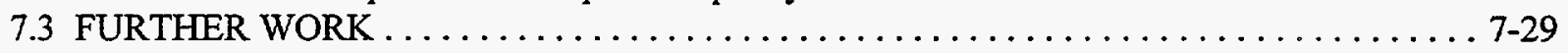

8. QUALITY ASSURANCE $\ldots \ldots \ldots \ldots \ldots \ldots \ldots \ldots \ldots \ldots \ldots \ldots \ldots \ldots \ldots \ldots \ldots \ldots \ldots .1$

8.1 VERIFICATION AND VALIDATION OF UTM $\ldots \ldots \ldots \ldots \ldots \ldots \ldots \ldots \ldots \ldots .6,1$

8.2 VERIFICATION AND VALIDATION OF SOURCEI AND SOURCE2 $\ldots \ldots \ldots \ldots \ldots \ldots 8-3$

8.3 VERIFICATION AND VALIDATION OF PADSIM AND HOLSIM $\ldots \ldots \ldots \ldots \ldots \ldots 8-4$

8.4 VERIFICATION AND VALIDATION OF USGS MOC $\ldots \ldots \ldots \ldots \ldots \ldots \ldots \ldots \ldots 8-4$

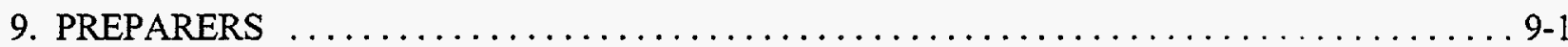

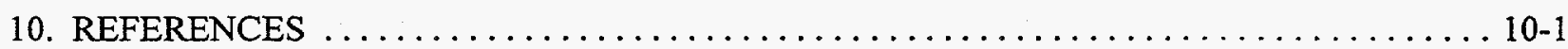

APPENDIX A: Radionuclide Inventory Data and Evaluation of Uncertainty in Inventory Data in Support of the SWSA 6 Performance Assessment .......... A-1

APPENDIX B: Description of the SOURCE1 and SOURCE2 Computer Programs .......... B-1

APPENDIX C: Transport-Related Properties of Radionuclides in Waste and Concrete use in the Performance Assessment of SWSA 6 Disposal Facilities .............. C-1

APPENDIX D: Hydrology and Subsurface Transport Modeling $\ldots \ldots \ldots \ldots \ldots \ldots \ldots \ldots \ldots \ldots \ldots$

APPENDIX E: Groundwater Flow and Contaminant Transport Modeling for the SWSA 6 Performance Assessment . . . . . . . . . . . . . . .

APPENDIX F: Predicted Amounts of Radionuclides Leached from SWSA 6 Disposal Units and Corresponding Surface Water Concentrations at the White Oak Dam F-1

APPENDIX G: Dose Analysis for Off-Site Individuals and Inadvertent Intruders $\ldots \ldots \ldots \ldots \ldots$ G-1

APPENDIX H: Analysis of Atmospheric Emissions from the SWSA 6 Disposal Units . . . . . . . H-1

APPENDIX I: Sensitivity and Uncertainty Analysis for the SWSA 6 Performance Assessment ..... I-1

APPENDIX J: Responses to Comments and Recommendations .................. J-1 


\section{FIGURES}

Fig. 3.1. General location map for Oak Ridge Reservation, Oak Ridge National

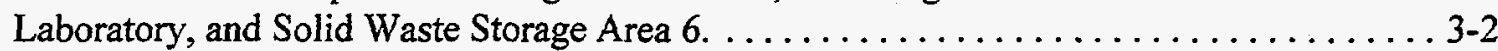

Fig. 3.2. Location of the SWSA 6 modeling area within White Oak Creek watershed. ......... 3-3

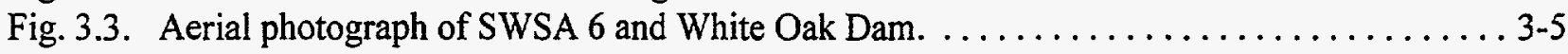

Fig. 3.4. Location of individual disposal units in SWSA 6 made after September $26,1988 \ldots \ldots \ldots$. . . 6

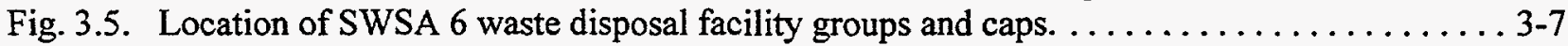

Fig. 3.6. Locations and populations of counties near Oak Ridge Reservation. . . . . . . . . 3-8

Fig. 3.7. Locations and populations of towns near Oak Ridge Reservation. . . . . . . . . . 3-8

Fig. 3.8. Topographic map of Oak Ridge Reservation and the surrounding area. $\ldots \ldots \ldots \ldots \ldots 3-13$

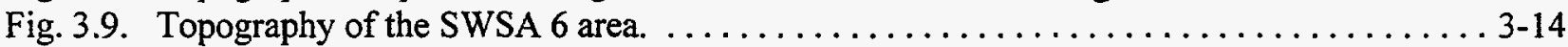

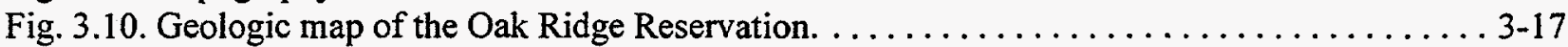

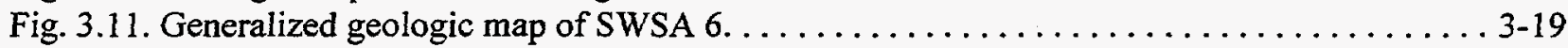

Fig. 3.12. Geologic cross section through Melton Valley and SWSA $6 . \ldots \ldots \ldots \ldots \ldots \ldots \ldots$ 3-20

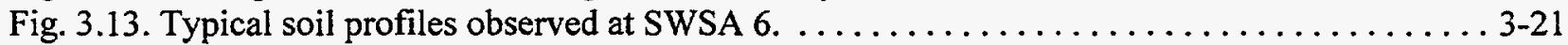

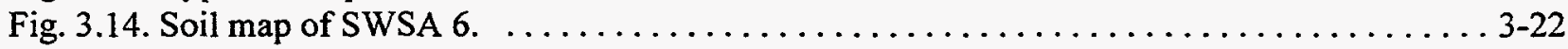

Fig. 3.15. Schematic profile showing subsurface flow zones and intervals, general thickness ranges, estimated relative water flux, and change in water type with depth for the aquitard of SWSA 6 in comparison to the aquifer of the Knox geological formation. ......................... 3-29

Fig. 3.16. Record of surface water discharge at White Oak Dam. . . . . . . . . . . . . 3-31

Fig. 3.17. Assignment of waste disposal zones used in the performance assessment. . . . . . . 3-47

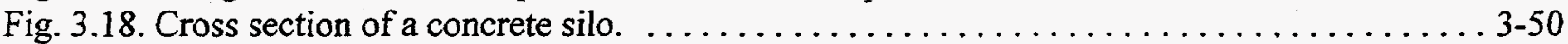

Fig. 3.19. Location of low-range silos, high-range silos, fissile wells and Quadrex Trenches in SWSA 6. ........................

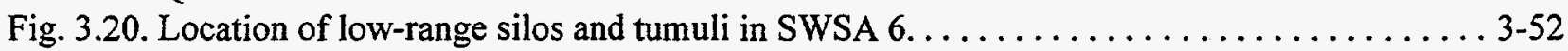

Fig. 3.21. Location of asbestos silos and biological trenches in SWSA $6 \ldots \ldots \ldots \ldots \ldots \ldots \ldots \ldots$

Fig. 3.22. Cross section of a concrete silo with high-range wells. $\ldots \ldots \ldots \ldots \ldots \ldots \ldots \ldots \ldots$

Fig. 3.23. Location of high-range wells and wells-in-silos in SWSA $6 \ldots \ldots \ldots \ldots \ldots \ldots \ldots \ldots .57$

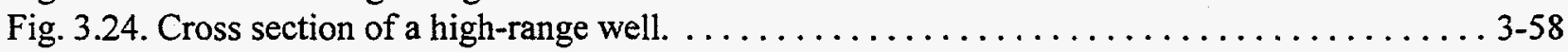

Fig. 3.25. Generic concrete vault for tumulus disposal operations. $\ldots \ldots \ldots \ldots \ldots \ldots \ldots \ldots \ldots 3-63$

Fig. 3.26. Interim Waste Management Facility showing vaults of low-level waste, drain lines, and final cover. . . . . . . . . . . . . . . . . . . . . 3-66

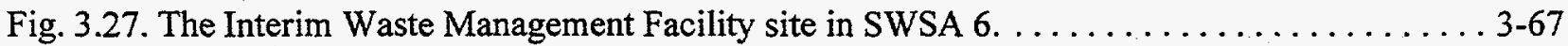

Fig. 4.1. Iterative analysis method for releases to the environment for the SWSA 6 performance assessment. . . . . . . . . . . . . . . .

Fig. 4.2. Logic flow of the SOURCE1 and SOURCE2 computer programs. . . . . . . . . 4-9

Fig. 4.3. Logic flow of the concrete-degradation and-cracking subroutines for the SOURCE1 and SOURCE2 computer programs. ..................... 4-11

Fig. 4.4. Fraction of initial radionuclide inventory remaining in the IWMF as

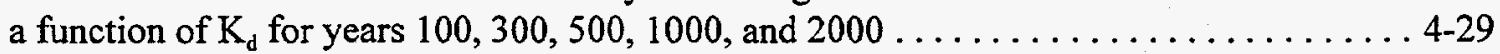

Fig. 4.5. Fraction of initial radionuclide inventory remaining in the IWMF as a function

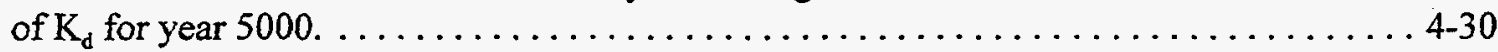

Fig. 4.6. Fraction of initial radionuclide inventory remaining in the IWMF as a function of $K_{d}$ for year 10,000 
Fig. 4.7. Fraction of initial inventory remaining in the IWMF as a function of time for $\mathrm{K}_{\mathrm{d}}=40,000 \mathrm{~mL} / \mathrm{g}$.

Fig. 4.8. Linkage of simulation results from four simulation models for quantifying nuclide transport in the environment and surroundings of SWSA 6.

Fig. 4.9. The landscape surface generated from the digital elevation model of the SWSA 6 site.

Fig. 4.10. Map and frequency distribution of topographic index for the SWSA 6 site used for estimation of spatial variation in groundwater recharge. $\ldots \ldots \ldots \ldots \ldots \ldots$ 4-49

Fig. 4.11. Annual recharge rates used in the groundwater modeling of SWSA 6. 4-50

Fig. 4.12. Flow chart of the major components of hydrologic simulation with the Unified Transport Model..

Fig. 4.13. The properties and structural equations of the PROSPER component of the Unified Transport Model used for calculation of evapotranspiration and soil water drainage.

Fig. 4.14. Diagram of a disposal unit area (A) in relation to its upslope watershed area (B) and the soil volumes in the vertical path to groundwater and the lateral path to a receiving stream channel.

Fig. 4.15. Receptor locations for the water pathway based on a $100-\mathrm{m}$ buffer zone. ........ 4-61

Fig. 4.16. Receptor locations for the water pathway based on the expanded buffer zone. . . . . . . 4-62

Fig. 4.17. Essential features of PADSIM and HOLSIM in the linkage between SOURCE1 and SOURCE2, and MOC for nuclide transport to groundwater and for lateral subsurface transport to surface water. . . . . . . . . . . . . . 44

Fig. 4.18. Receptor locations for the air pathway based on the expanded buffer zone. 4-73 


\section{TABLES}

Table 2.1 Performance objectives for low-level radioactive waste disposal $\ldots \ldots \ldots \ldots \ldots \ldots . .1$

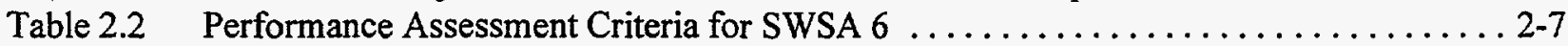

Table 2.3 Element-specific soil/water partition coefficients used for environmental

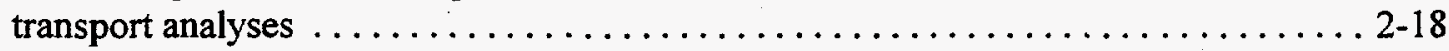

Table 3.1 Stratigraphic column of Cambro-Ordovician Rocks, White Oak Mountain thrust block, Oak Ridge, Tennessee ....................... 3-15

Table 3.2 Annotated list of earthquakes that have affected the Oak Ridge

Reservation or the eastern Tennessee vicinity ..................... 3-24

Table 3.3 Average annual effective dose equivalents in U.S. population from exposure

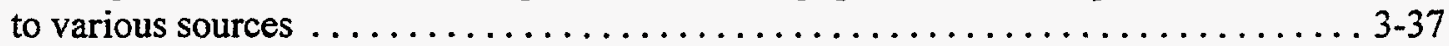

Table 3.4 Measured concentrations of radionuclides in air near the Oak Ridge Reservation . . . . . . . . . . . . . . . . . . . . . . . 39

Table 3.5 Measured concentrations of radionuclides in surface water near

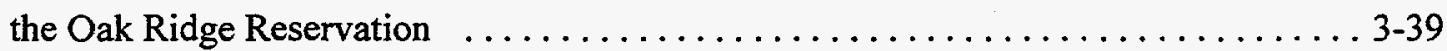

Table 3.6 Measured concentrations of radionuclides in groundwater near

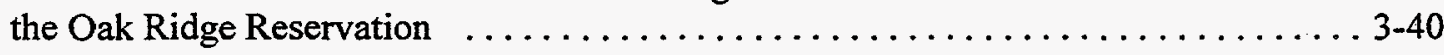

Table 3.7 Measured concentrations of radionuclides in soils

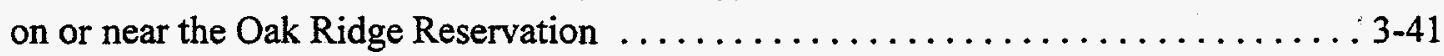

Table 3.8 Zone, disposal unit type, number of units, and volume of waste for

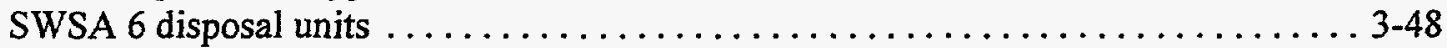

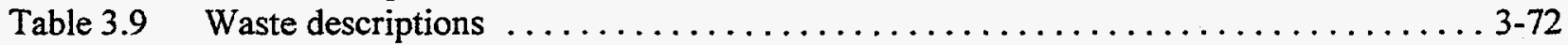

Table 4.1 Complete list of radionuclides which have been or could be disposed of at the Interim Waste Management Facility . . . . . . . . . . . . . . . . . $4-2$

Table 4.2 Radionuclide-specific physical data used throughout the SWSA 6 performance assessment $\ldots \ldots \ldots \ldots \ldots \ldots \ldots \ldots \ldots \ldots \ldots \ldots \ldots \ldots \ldots \ldots \ldots \ldots \ldots .4$

Table 4.3 Physicochemical parameters used in the SOURCE1 and SOURCE2 simulations

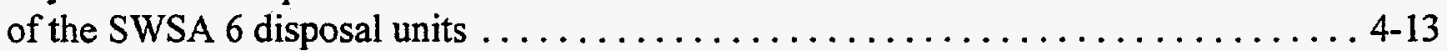

Table 4.4 Radionuclide-specific input data to SOURCE1 and SOURCE2 for the

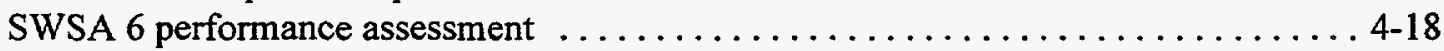

Table 4.5 Radionuclide inventory by zone and disposal unit for radionuclides disposed of in SWSA 6 after September $1988 \ldots \ldots \ldots \ldots \ldots \ldots$. . 20

Table 4.6 Radioactivity of radionuclides by zone and disposal unit for radionuclides disposed of in SWSA 6 after September $1988 \ldots \ldots \ldots \ldots \ldots \ldots$. . . . . 22

Table 4.7 Concentration of radionuclides by zone and disposal unit for radionuclides disposed of in

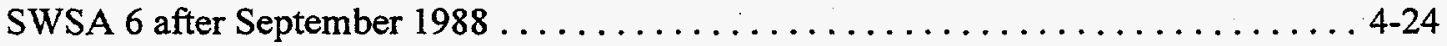

Table 4.8 Simulated monthly seepage results used in SOURCE1 calculations

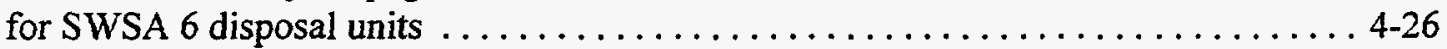

Table 4.9 Simulated monthly seepage results used in SOURCE2 calculations for SWSA 6 disposal units $\ldots \ldots \ldots \ldots \ldots \ldots \ldots \ldots \ldots \ldots \ldots \ldots \ldots \ldots \ldots \ldots \ldots .27$

Table 4.10 Year of vault failure from environmental transport calculations and from direct

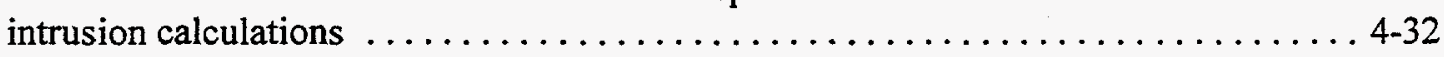

Table 4.11 Waste distribution coefficient $\left(K_{d}\right)$ values for intruder scenario

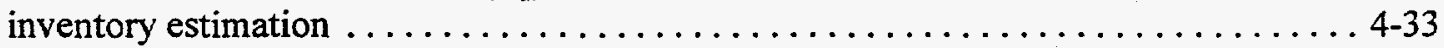

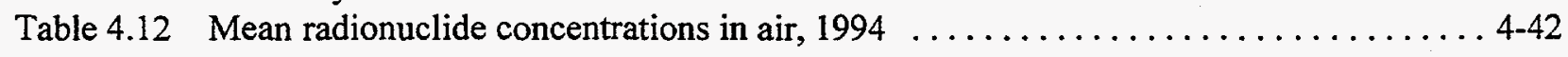


Table 4.13 Estimates of diffuse recharge to the groundwater system $\ldots \ldots \ldots \ldots \ldots \ldots \ldots$. $\ldots \ldots 1$

Table 4.14 Monthly precipitation, soil water drainage, lateral subsurface flow, and surface runoff results from the UTM for three sets of weather conditions (dry, average, and wet) and five periods of waste site operation . . . . . 4-55

Table $4.15 \quad \mathrm{~B} / \mathrm{A}$ ratios for SWSA 6 waste disposal units $\ldots \ldots \ldots \ldots \ldots \ldots \ldots \ldots \ldots . . \ldots \ldots$

Table 4.16 Distances to groundwater and receiving streams for SWSA 6 disposal units . . . . . 4-65

Table 4.17 The proportion of bypass flow for selected vertical and lateral flow path lengths and the maximum first-year transport distance through the soil

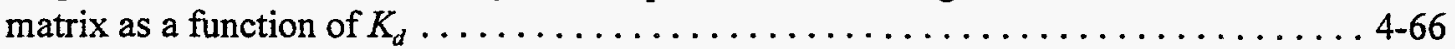

Table 4.18 Annual increment in soil matrix path length and times to full matrix exposure to nuclides as a function of $K_{d}$ for selected vertical

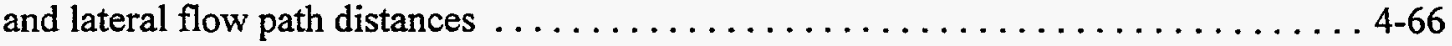

Table 4.19 Drinking water pathway effective dose equivalents and corresponding maximum allowable concentrations in drinking water . . . . . . . 4-70

Table 5.1 Maximum annual release rate from a single high-range silo in Zone 3 and year of occurrence for vertical and lateral release components

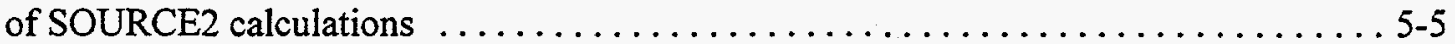

Table 5.2 Maximum annual release rate from a single high-range well in Zone 5 and year of occurrence for vertical and lateral release components

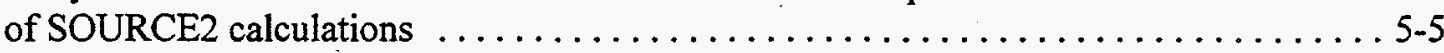

Table 5.3 Maximum annual release rate from a single high-range well-in-silo in Zone 5 and year of occurrence for vertical and lateral release

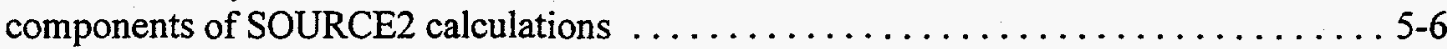

Table 5.4 Maximum annual release rate from a single fissile well in Zone 7 and year of occurrence for vertical and lateral release components of

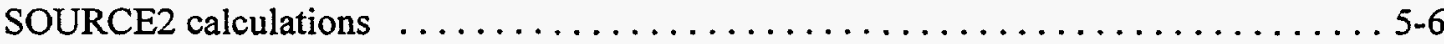

Table 5.5 Maximum annual release rate from a single Quadrex trench in Zone 8 and year of occurrence for vertical and lateral release components of

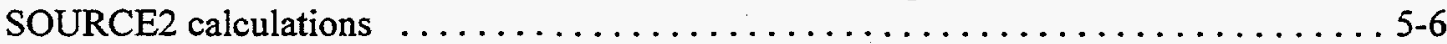

Table 5.6 Maximum annual release rate from a single low-range silo in Zone 8 and year of occurrence for vertical and lateral release components of SOURCE2 calculations . ............................... $5-7$

Table 5.7 Maximum annual release rate from a single biological trench in Zone 15 and year of occurrence for vertical and lateral release components

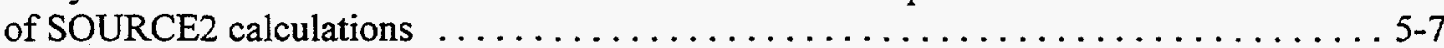

Table 5.8 Maximum annual release rate from a single asbestos silo in Zone 16 and year of occurrence for vertical and lateral release components

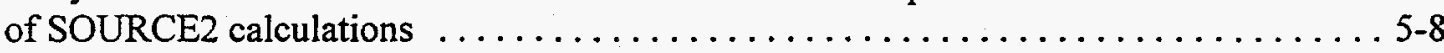

Table 5.9 Maximum annual release rate from a single biological trench in Zone 20 and year of occurrence for vertical and lateral release

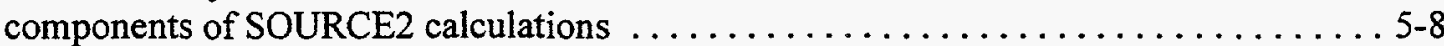

Table 5.10 Maximum annual release rate from Tumulus II in Zone 26 and year of occurrence for vertical and lateral release components of SOURCE1 calculations

Table 5.11 Maximum annual release rate from Tumulus I in Zone 27 and year of occurrence for vertical and lateral release components of

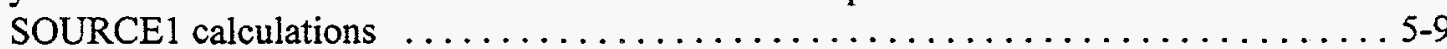


Table 5.12 Maximum annual release rate from a single low-range silo in Zone 30

and year of occurrence for vertical and lateral release components

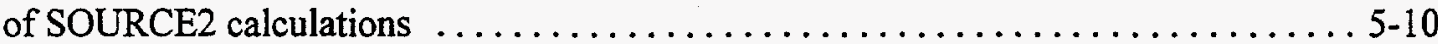

Table 5.13 Simulated annual peak flux and concentration of radionuclides

in soil solution and the years of occurrence in the recharge and lateral flow paths obtained from HOLSIM for the high-range silos in Zone $3 \ldots \ldots$. $5-11$

Table 5.14 Simulated annual peak flux and concentration of radionuclides in soil solution and the years of occurrence in the recharge and lateral flow paths obtained from HOLSIM for the high-range wells in Zone $5 \ldots \ldots \ldots \ldots$ 5-11

Table 5.15 Simulated annual peak flux and concentration of radionuclides in soil solution and the years of occurrence in the recharge and lateral flow paths obtained from HOLSIM for the high-range wells-in-silos in Zone $5 \ldots \ldots$ 5-12

Table 5.16 Simulated annual peak flux and concentration of radionuclides in soil solution and the years of occurrence in the recharge and lateral flow paths obtained from HOLSIM for the fissile wells in Zone $7 \ldots \ldots \ldots$. $5-12$

Table 5.17 Simulated annual peak flux and concentration of radionuclides in soil solution and the years of occurrence in the recharge and lateral flow paths obtained from HOLSIM for the Quadrex trenches in Zone $8 \ldots \ldots \ldots \ldots \ldots \ldots$. 5 -12

Table 5.18 Simulated annual peak flux and concentration of radionuclides in soil solution and the years of occurrence in the recharge and lateral flow paths obtained from HOLSIM for the low-range silos in Zone $8 \ldots \ldots \ldots \ldots$. $\ldots$-13

Table 5.19 Simulated annual peak flux and concentration of radionuclides in soil solution and the years of occurrence in the recharge and lateral flow paths obtained from HOLSIM for the biological trenches in Zone $15 \ldots \ldots$. . 5-13

Table 5.20 Simulated annual peak flux and concentration of radionuclides in soil solution and the years of occurrence in the recharge and lateral flow paths obtained from HOLSIM for the asbestos silos in Zone $16 \ldots \ldots \ldots \ldots$.

Table 5.21 Simulated annual peak flux and concentration of radionuclides in soil solution and the years of occurrence in the recharge and lateral flow paths obtained from HOLSIM for the biological trenches in Zone $20 \ldots \ldots$. . 5-14

Table 5.22 Simulated annual peak flux and concentration of radionuclides in soil solution and the years of occurrence in the recharge and lateral flow paths obtained from PADSIM for Tumulus II in Zone $26 \ldots \ldots \ldots \ldots \ldots \ldots$. 14

Table 5.23 Simulated annual peak flux and concentration of radionuclides in soil solution and the years of occurrence in the recharge and lateral flow paths obtained from PADSIM for Tumulus $I$ in Zone $27 \ldots \ldots \ldots \ldots$. $5-15$

Table 5.24 Simulated annual peak flux and concentration of radionuclides in soil solution and the years of occurrence in the recharge and lateral flow paths obtained from HOLSIM for the low-range silos in Zone $30 \ldots \ldots \ldots \ldots$ 5-16

Table 5.25 Maximum groundwater concentrations at the 100-meter buffer zone due to closed disposal units inside SWSA 6 (excluding IWMF) $\ldots \ldots \ldots \ldots \ldots \ldots$ 5-17

Table 5.26 Maximum surface water concentrations at WOD due to closed

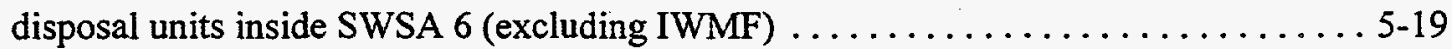

Table 5.27 Maximum groundwater concentrations at the expanded buffer zone due to closed disposal units inside SWSA 6 (excluding IWMF) $\ldots \ldots \ldots \ldots \ldots \ldots$-20 
Table 5.28 Maximum annual release rate from a single IWMF pad and year of occurrence for vertical and lateral release components of

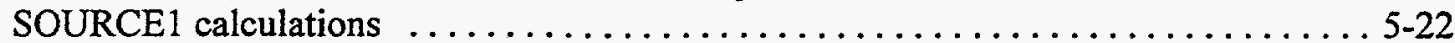

Table 5.29 Calculated annual peak flux and concentration of radionuclides in soil solution and the years of occurrence in the recharge and lateral flow paths obtained from PADSIM for IWMF . . . . . . . . . . . . . 5-24

Table 5.30 Allowable limits on inventories of radionuclides at IWMF based on groundwater concentrations at the 100 -meter buffer zone. . . . . . . . . 5 -26

Table 5.31 Allowable limits on inventories of radionuclides at IWMF based

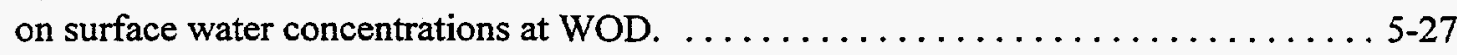

Table 5.32 Allowable limits on inventories of radionuclides at IWMF based on groundwater concentrations at the expanded buffer zone. $\ldots \ldots \ldots \ldots \ldots \ldots 5-28$

Table 5.33 Allowable limits on inventories of radionuclides at IWMF based on all drinking water pathways. . . . . . . . . . . . . . . . . . . . 5 5 .29

Table 5.34 Allowable limits on inventories of radionuclides at IWMF based on air concentrations at the expanded buffer zone. ................. 5-30

Table 5.35 Probabilities and associated entropy-based uncertainties that maximum groundwater concentrations at selected receptor locations are equal to or less than the concentration corresponding to the 4-mrem per year EDE limit. . . . . . . . . . . . . . . . . . 5 -34

Table 5.36 Probabilities and associated entropy-based uncertainties that maximum surface water concentrations at selected receptor locations are equal to or less than the concentration corresponding to the 4-mrem per year EDE limit . . . . . 5 5-35

Table 5.37 Changes in the probabilities and associated entropy-based uncertainties that maximize groundwater concentrations at selected receptor locations $\leq 4$ mrem drinking water limit due to inclusion of subjective uncertainties associated with each segment of the modeling process $\ldots \ldots \ldots \ldots \ldots$ 5-36

Table 5.38 Changes in the probabilities and associated entropy-based uncertainties that maximize surface water concentrations at selected receptor locations $\leq 4$ mrem drinking water limit due to inclusion of subjective uncertainties associated with each segment of the modeling process $\ldots \ldots \ldots \ldots \ldots \ldots \ldots .38$

Table 6.1 Summary of exposure scenarios for inadvertent intrusion

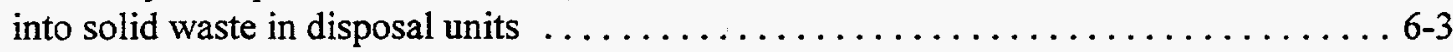

Table 6.2 Annual effective dose equivalents to inadvertent intruders from all exposure pathways per unit concentration of radionuclides in

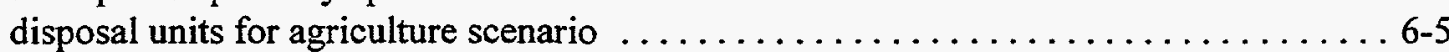

Table 6.3 Annual effective dose equivalents to inadvertent intruders per unit concentration of radionuclides in disposal units for resident scenario $\ldots \ldots \ldots \ldots \ldots 6-7$

Table 6.4 Annual effective dose equivalents to inadvertent intruders from all exposure pathways per unit concentration of radionuclides

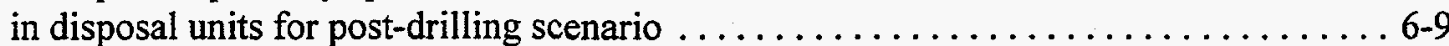

Table 6.5 Effective dose equivalents to inadvertent intruders per unit concentration of radionuclides in disposal units for discovery scenario $\ldots \ldots \ldots \ldots 6$ 6-14

Table 6.6 Waste dilution factors applied in dose assessment for inadvertent intruders . . . . . . 6-20

Table 6.7 Reductions in inventory of elements in IWMF due to mobilization and transport in infiltrating water $\ldots \ldots \ldots \ldots \ldots \ldots \ldots \ldots \ldots \ldots \ldots \ldots \ldots \ldots \ldots .23$

Table 6.8 Reductions in inventory of actinide elements in all disposal units due to mobilization and transport in water 
Table 6.9 Solubility limits and solubility-limited release rates of actinide elements for all disposal units

Table 6.10 Allowable limits on concentrations and inventories of radionuclides for IWMF based on agriculture scenario for inadvertent intruders $\ldots \ldots \ldots \ldots \ldots 6$ 6-26

Table 6.11 Allowable limits on concentrations and inventories of radionuclides for IWMF based on resident scenario for inadvertent intruders $\ldots \ldots \ldots \ldots \ldots \ldots 6$ 6-32

Table 6.12 Allowable limits on concentrations and inventories of radionuclides for IWMF based on post-drilling scenario for inadvertent intruders

Table 6.13 Allowable limits on concentrations and inventories of radionuclides for IWMF based on dose assessments for inadvertent intruders $\ldots \ldots \ldots \ldots \ldots \ldots 6-37$

Table 6.14 Estimated annual effective dose equivalents to inadvertent intruders for agriculture scenario for closed disposal units in the SWSA 6 facility . . . . . . 6-41

Table 6.15 Estimated annual effective dose equivalents to inadvertent intruders for resident scenario for closed disposal units in the SWSA 6 facility $\ldots \ldots \ldots \ldots \ldots 6-43$

Table 6.16 Estimated annual effective dose equivalents to inadvertent intruders for post-drilling scenario for closed disposal units in the SWSA 6 facility . . . . . . . 6-44

Table 6.17 Estimated effective dose equivalents to inadvertent intruders for discovery scenario for closed disposal units in the SWSA 6 facility $\ldots \ldots \ldots \ldots 6-45$

Table 6.18 Summary of estimates of effective dose equivalents to inadvertent intruders for assumed exposure scenarios $\ldots \ldots \ldots \ldots \ldots \ldots \ldots \ldots \ldots \ldots .6 \ldots \ldots 6.46$

Table 7.1 Allowable limits on inventories of radionuclides at the Interim Waste Management Facility based on the performance assessment ............... $7-3$

Table 7.2 Existing radionuclide loadings at the Interim Waste Management Facility. . . . . . . 7-4

Table 7.3 Sum of fractions calculations for existing radionuclide loadings at the Interim Waste Management Facility. . . . . . . . . . . . . . . .

Table 7.4 Radionuclides with no limit for disposal at the Interim Waste Management Facility . . . . . . . . . . . .

Table 7.5 Criteria for screening radionuclides not included in the performance assessment (PA) for the Interim Waste Management Facility (IWMF) . . . . . . $7-25$

Table 7.6 Radionuclides to be restricted to $1 \%$ of the performance assessment (PA) disposal limits . 7-28 



\section{ABBREVIATIONS AND ACRONYMS}

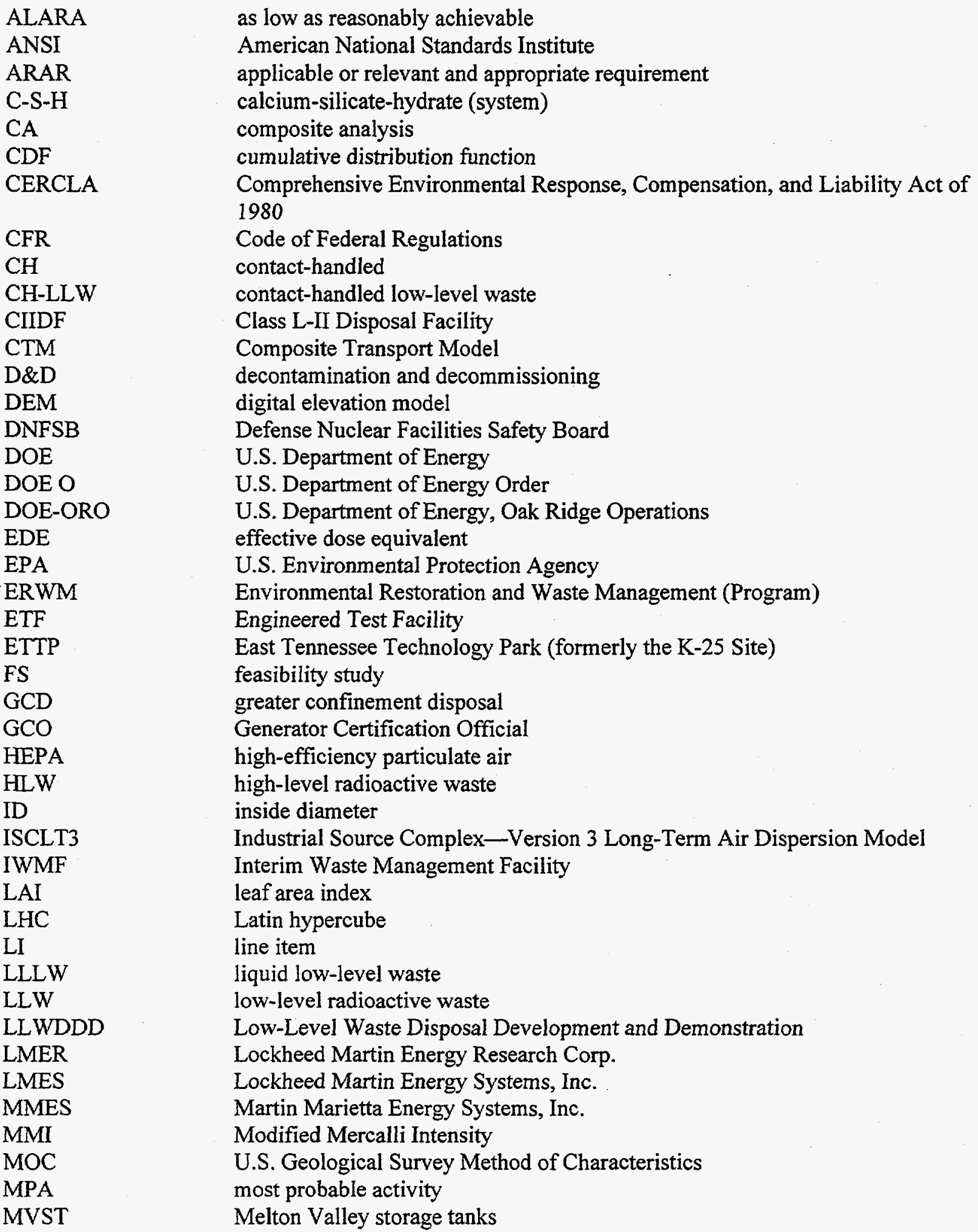


NARM

NCRP

NEPA

NESHAP

NPDES

NRC

OD

ORGDP

ORMWI

ORNL

ORR

PA

POC

PVC

PWTP

RCRA

RFI

RH

RH-LLW

RI

ROD

RSWO

SDCF

SLLW

SWIMS

SWSA 6

SWSA

TA

TB

TDDP

TDEC

TDHE

TH

THW

TL

TRU

TSD

USGS

UTM

VLA

VOC

WAC

WAG

WCR

WEAF

WEC

WF naturally occurring and accelerator-produced radioactive material

National Council on Radiation Protection and Measurements

National Environmental Policy Act

National Emission Standards for Hazardous Air Pollutants

National Pollutant Discharge Elimination System

U.S. Nuclear Regulatory Commission

outside diameter

Oak Ridge Gaseous Diffusion Plant [now East Tennessee Technology Park

(ETTP), formerly the Oak Ridge K-25 Site]

Oak Ridge Mixed Waste Incinerator

Oak Ridge National Laboratory

Oak Ridge Reservation

performance assessment

probability of compliance

polyvinylchloride

Process Waste Treatment Plant

Resource Conservation and Recovery Act of 1976

Remedial Feasibility Investigation

remotely handled

remotely handled low-level waste

remedial investigation

Record of Decision

Radioactive Solid Waste Operations

scenario dose conversion factor

solid low-level waste

Solid Waste Information Management System

Solid Waste Storage Area 6

solid waste storage area

asbestos silo

biological trench

Tumulus Disposal Demonstration Project

Tennessee Department of Environment and Conservation

Tennessee Department of Health and Environment

high-range well

high-range wells/silos

low-range silo

transuranic

treatment, storage, and disposal

U.S. Geological Survey

Unified Transport Model

very low activity

volatile organic compound

waste acceptance criteria

waste area grouping

water-cement ratio

Waste Examination and Assay Facility

waste evaluation criteria

fissile well 
WH

WHA

WMRAD-WTS

WOC

WOD

WOL

WTS double-walled pipe well

high-range wells

Waste Management Remedial Action Division's Waste Tracking System

White Oak Creek

White Oak Dam

White Oak Lake

Waste Tracking System (database) 


\section{EXECUTIVE SUMMARY}

This revised performance assessment (PA) for the continued disposal operations at Solid Waste Storage Area (SWSA) 6 on the Oak Ridge Reservation (ORR) has been prepared to demonstrate compliance with the performance objectives for low-level radioactive waste (LLW) disposal contained in U.S. Department of Energy (DOE) Order 5820.2A. This revised PA considers disposal operations conducted from September 26, 1988, through the projected lifetime of the disposal facility. The performance objectives of DOE $O 5820.2 \mathrm{~A}$ require the disposal facility be managed to accomplish the following:

1. Protect public health and safety in accordance with standards specified in applicable EH Orders and other DOE Orders.

2. Assure that external exposure to the waste and concentrations of radioactive material which may be released into surface water, ground water, soil, plants and animals results in an effective dose equivalent that does not exceed $25 \mathrm{mrem} / \mathrm{yr}$ to any member of the public. Releases to the atmosphere shall meet the requirements of 40 CFR 61. Reasonable effort should be made to maintain releases of radioactivity in effluents to the general environment as low as is reasonably achievable.

3. Assure that the committed effective dose equivalents received by individuals who inadvertently may intrude into the facility after the loss of active institutional control (100 years) will not exceed $100 \mathrm{mrem} / \mathrm{yr}$ for continuous exposure or $500 \mathrm{mrem}$ for a single acute exposure.

4. Protect ground water resources, consistent with Federal, State and local requirements.

This revised PA has been prepared in accordance with the guidance provided by DOE in the Interim Format and Content Guide and Standard Review Plan for U.S. Department of Energy Waste Disposal Facility Performance Assessments (DOE 1996c), which outlines the presentation of the analysis conducted for this revised PA. This revised PA has been prepared in response to the review of the initial PA for SWSA 6 (ORNL 1994) and is responsive to the commitments made by DOE to the Defense Nuclear Safety Board (DNFSB) in the Implementation Plan, Defense Nuclear Safety Board Recommendation 94-2 (DOE 1996b). The review of the initial PA required a revision to be prepared to address the changes made to waste management operations in response to the initial PA and to include the additional material developed in the review of the initial PA. This revised PA includes cross references to the initial PA, where appropriate, to indicate the changes that have been made to waste management operations and to many of the conclusions of the initial PA. Changes were also made to the methodology used in the analysis to provide results of greater utility to the development of revised waste acceptance criteria (WAC) and waste disposal operations. This revised 
PA along with the Composite Analysis for the SWSA 6 Facility (ORNL 1997b) provide the basis for the issuance of a Disposal Authorization Statement for the continued disposal operations at SWSA 6, providing these two documents are determined to be acceptable to DOE after their review by DOE.

SWSA 6 is located about $3 \mathrm{~km}$ ( 2 miles) south of Oak Ridge National Laboratory (ORNL) on the DOE ORR. The facility is located on a 27.5 -ha (68-acre) tract of land with rolling terrain. Approximately 12 ha ( 30 acres) of the site are suitable for disposal operations. Most of the site's capacity was used before September 26,1988 . The facility is projected to continue operations until the currently operating Interim Waste Management Facility (IWMF) disposal unit is filled to capacity. The IWMF is currently filled to $50 \%$ capacity. Those portions of the facility associated with historical disposal operations are presently subject to remediation under the Comprehensive Environmental Response, Compensation, and Liability Act of 1980 (CERCLA). Following the guidance for preparation of this revised PA, the PA has been prepared without the consideration of disposal operations performed prior to the issuance of DOE O 5820.2A. This PA considers five different types of disposal units: unlined trenches, concrete wells in silos, concrete silos, lined wells, and tumulus units. Each disposal unit and the wastes placed in the disposal unit or planned to be placed in the disposal unit are considered separately. The analysis integrates the results of all of the disposal units to evaluate compliance with DOE O 5820.2A for existing disposals which are subject to the order and to provide limits on future disposals that will meet the performance objectives of DOE O 5820.2A. The analysis of each disposal unit assumes normal or expected performance. Accidental releases or abnormal operations are considered in the safety documentation for the facility and are not part of the PA.

In applying the performance objectives of DOE O 5820.2A, performance measures or performance criteria about points of compliance, times of compliance, and dose objectives for groundwater resource protection were developed that are consistent with the guidance on the preparation of performance assessments (DOE 1996c). The all-pathways performance objective of 25 mrem per year, excluding doses from radon and progeny, was applied at the land use boundary for the SWSA 6 facility, which is considered to be the fence surrounding SWSA 6. Current land use planning on the ORR is being conducted with the expectation that some portions of the ORR will be released to the public by DOE. As a conservative measure to provide defense in depth, the land use boundary was selected as the buffer zone boundary for SWSA 6 until formal land use plans for the ORR are completed. The performance objective for the air pathway of $10 \mathrm{mrem}$ per year was also applied beyond the edge of the buffer zone for SWSA 6. For the consideration of radon and progeny the average flux of $20 \mathrm{pCi} / \mathrm{m}^{2} / \mathrm{s}$ was used as a performance criterion and was applied at the disposal facility surface. The performance criteria for the protection of the hypothetical inadvertent intruder of $100 \mathrm{mrem}$ per year from chronic exposure and $500 \mathrm{mrem}$ from a single event were applied to the SWSA 6 facility. For groundwater protection, the performance criterion of 4 mrem per year effective dose equivalent (EDE) was selected based on the lack of other rules or requirements for groundwater protection on the ORR; this dose is consistent with the U.S. Environmental Protection Agency proposed revision of the drinking water standards (EPA 1991). This groundwater protection performance criterion was applied outside of a 100-m buffer zone around each disposal unit, which 
was modified to include a small tract of land within SWSA 6. The groundwater performance measure was extended to surface water because of the rapid communication of contaminated groundwater to surface water and the presence of ephemeral streams within the SWSA 6 facility. This surface water performance criterion was applied at the White Oak Dam (WOD), which is located adjacent to the SWSA 6 facility boundary, upstream of the White Oak Creek (WOC) Embayment and the Clinch River. The results of the PA indicate that the groundwater and surface water performance criteria are more restrictive than the all-pathways performance criterion, and the air-pathway performance criterion is not important for evaluating acceptable disposals at SWSA 6 .

Calculations of contaminant transport were performed to determine the magnitude and timing of the peak dose at the point of compliance. The time of occurrence of the peak dose was then examined against the 1000-year time of compliance specified in the guidance for preparing PAs. While several radionuclides have peak doses at some time in excess of 1000 years, the determination of compliance for all radionuclides was based on doses occurring at 1000 years, and potential longterm impacts beyond 1000 years were addressed. For the analysis of the inadvertent intruder, the time of compliance was specified as greater than 100 years but less than 1000 years for all radionuclides. For radionuclides with radiologically significant long-lived decay products (e.g., isotopes of uranium), potential long-term impacts beyond 1000 years also were addressed, but these results were not used in determinations of compliance. This is consistent with the guidance for preparing PAs.

Approximately $2000 \mathrm{~m}^{3} /$ year $\left(75,000 \mathrm{ft}^{3} /\right.$ year) of LLW is managed at ORNL, with the IWMF being the only operating disposal unit. Waste not acceptable for disposal at the IWMF is stored for disposal at some other facility. Waste accepted for disposal at the IWMF is contact-handled $(\mathrm{CH})$ waste $(<200 \mathrm{mrem} / \mathrm{h}$ dose rate at the surface). This waste includes debris from ORNL operations, research and development activities, environmental restoration, and decommissioning and demolition activities. Waste disposed of in low-range silos and tumulus disposal units included $\mathrm{CH}$ waste, while remotely handled $(\mathrm{RH})$ waste ( $>200 \mathrm{mrem} / \mathrm{h}$ at the surface) was disposed of in high-range silos and concrete wells. $\mathrm{RH}$ waste included debris from reactors and hot cell operations. $\mathrm{RH}$ waste with $<1 \mathrm{rem} / \mathrm{h}$ was disposed of in silos, and $\mathrm{RH}$ waste with $>1 \mathrm{rem} / \mathrm{h}$ was disposed in metal lined wells with concrete plugs. Fissile waste from research and development activities using enriched uranium was disposed of in separate metal lined wells with concrete plugs. Biological waste consisting of excrement and animal carcasses was disposed of in biological trenches. Asbestos waste generated from demolition and maintenance was disposed of in concrete silos. All below-grade disposal operations at SWSA 6 were discontinued in 1994.

Wastes generated at ORNL are subject to the ORNL Waste Certification Program, which requires the wastes to be characterized prior to their acceptance by ORNL Waste Management. Wastes are accepted for disposal at the IWMF providing they meet the WAC for the IWMF. Wastes not acceptable for disposal are stored for disposal at some later date and location. The Waste Certification Program provides procedures for radiological characterization, procedures for meeting WAC for the IWMF, and the structure and waste certification methods to be used by waste generators. Characterization data are also recorded and maintained as part of the waste manifesting system at ORNL. Prior to disposal, most wastes are subject to volume reduction including 
compaction, incineration, and metal melting. Wastes disposed of at the IWMF are generally packaged in metal boxes of approximately $90 \mathrm{ft}^{3}$ capacity prior to placement inside of a concrete vault. Other metal containers are allowed on a case by case basis.

The waste characteristics used for assessing the performance of SWSA 6 were defined using the existing data records from the ORNL Waste Management Program and did not use the most probable activity factors (MPA), which were applied to the reported inventories in the initial PA. While the data from these records are imperfect, they represent the best source of information on waste disposals. These records have been reviewed and corrected where obvious errors were identified. The uncertainty associated with the disposed inventory was analyzed as part of the PA. The radionuclides considered in detail in this revised PA include all those identified from waste management records and all radionuclides which can be reasonably expected to be present in ORNL wastes. Radionuclides with half-lives less than 5 years were not considered in this revised PA because the potential contribution to dose could not be significant. A total of 63 radionuclides was considered in detail to fulfill three objectives: (1) to demonstrate that the disposals that have occurred at SWSA 6 since September 26, 1988, in currently closed disposal units are in compliance with the performance objectives of DOE O $5820.2 \mathrm{~A}$; (2) to demonstrate that the wastes previously disposed of at the currently operating IWMF disposal unit are in compliance with the performance objectives of DOE O 5820.2A; and (3) to determine the disposal inventory limits to be applied to future waste disposals at the IWMF disposal unit that will demonstrate compliance with the performance objectives of DOE O $5820.2 \mathrm{~A}$.

The methodology used to analyze the performance of SWSA was based on the available data on the waste disposed of at SWSA 6, the disposal methods used at SWSA 6, and SWSA 6 site characteristics. In analyzing the site performance, the results of the source-term modeling (which provide estimates of releases of contamination from the disposal units) were used as input to the shallow subsurface model. The contamination released to the shallow subsurface was diluted with upslope shallow subsurface drainage, which was estimated from terrain analysis and moisture transport through soils to disposal units. The shallow subsurface model provided estimates of the transport of contamination in soils to surface water, the percolation of contaminants to groundwater, and estimates of uncontaminated recharge to groundwater. The groundwater model used the contaminated and uncontaminated water fluxes as input to estimate the transport of contamination to a well at the edge of the expanded buffer zone surrounding the waste disposal units in SWSA 6 and to estimate the discharge of contaminated groundwater to surface water. The resulting concentrations in groundwater and surface water were used to estimate the dose from the use of water resources from existing disposals at SWSA 6 and to establish inventory limits on future disposals at IWMF that would meet the performance criteria for SWSA 6.

The analysis for SWSA 6 required the use of assumptions to supplement the available site data when the available data were incomplete for the purposes of analysis. Assumptions were made to define the partitioning of recharge to runoff from each disposal unit, the aquifer properties, the sorption characteristics of disposal units and the site, the geometry of waste configurations, and the degradation and cracking of concrete. These assumptions were selected to provide a reasonable yet 
conservative representation of facility performance and were based on the limited information available for the disposal units.

The long-term performance of SWSA 6 was analyzed using a series of linked models to provide estimates of the doses attributable to LLW disposals from closed disposal units as well as the evaluation of allowable inventories for future IWMF disposals that are consistent with meeting the performance objectives. The long-term performance of SWSA 6 was evaluated for the hydrologic and atmospheric transport of contamination from each disposal unit. Transport through these media provided the basis for demonstrating compliance for the all-pathways, air pathway, and the water resource performance criteria.

The hydrologic transport of contamination from SWSA 6 considers the release of contamination from the individual disposal units using the SOURCE1 and SOURCE2 computer programs. For the purpose of demonstrating compliance with the performance objectives for off-site releases, the parameter values were selected with the intent of overestimating actual releases from disposal units. These verified codes estimated the release rate of contamination by considering the wetting of the waste by infiltration of water into the waste, and the subsequent leaching and transport of radionuclides from the waste form by diffusion and advection. The complex forms of wastes, disposal units, and concrete barriers were approximated, including the behavior of the concrete pad and drainage systems for the tumulus type disposal units. The process of degradation and cracking of concrete over time were included in the analysis and were used to identify the hydrologic isolation to be credited to the various disposal units in SWSA 6.

Contamination released from the disposal units was analyzed for transport through the environment using the Unified Transport Model (UTM) and the U.S. Geological Survey Method of Characteristics (USGS MOC) computer programs. The transport of contamination in surface water and groundwater took into account precipitation, shallow subsurface transport in soils, infiltration, percolation, recharge, sorption, streamflow, and radioactive decay. A projected closure plan was utilized that was derived from the Accelerated Cleanup Plan developed for the ORR. The computer programs used for analyzing the environmental transport of contamination are documented, verified, and validated to the extent that they provide reasonable representations of site performance. The results of these programs were used to estimate potential doses from existing waste disposal operations and to estimate additional waste loadings to IWMF that would permit SWSA 6 to meet the performance criteria for the all-pathways and water resources performance criteria.

Contamination released from disposal units by atmospheric transport of volatile radionuclides $\left({ }^{3} \mathrm{H}\right.$ and $\left.{ }^{14} \mathrm{C}\right)$ was also analyzed to the extent needed to demonstrate compliance with the air pathway performance criterion. This very conservative approach presumed the release of radionuclides by diffusion through the media overlying the disposal units, with all volatile releases being in the chemical forms of ${ }^{14} \mathrm{CO}_{2}$ or ${ }^{3} \mathrm{H}_{2} \mathrm{O}$. The results of this analysis were used to estimate potential doses from existing waste disposal operations, but no limitations on future waste disposals were identified that were not bounded by other exposure pathways. Non-volatile radionuclides were shown to not contribute to the total dose for the air pathway. 
The analysis of potential doses to off-site individuals and inadvertent intruders attributable to disposal facility operation were estimated using several assumptions. For individuals residing outside the SWSA 6 buffer zone, which is either a 100-m buffer zone surrounding the SWSA 6 disposal units, or an expanded buffer zone that includes additional small tracts of land within SWSA 6, annual doses were estimated for direct ingestion of contaminated water, ingestion of milk and meat obtained from dairy and beef cattle that drink contaminated water, external exposure from swimming in contaminated water, and ingestion of fish obtained from contaminated water. In addition, doses to off-site individuals due to atmospheric releases of the volatile radionuclides ${ }^{3} \mathrm{H}$ and ${ }^{14} \mathrm{C}$ were evaluated. Following the 100-year active institutional control period, inadvertent intruders were assumed to be exposed according to one of four different scenarios - the "agriculture," "resident," "post-drilling," and "discovery" scenarios-all involving direct intrusion into disposal units. The discovery scenario was assumed to occur once in an individual's lifetime, whereas the other scenarios were assumed to involve continuous exposure. The agriculture scenario was assumed to occur at 300 years after the disposal for all disposal units constructed with engineered barriers, but at 100 years after disposal for the biological trenches constructed without engineered barriers. The resident, post-drilling, and discovery scenarios were assumed to occur at 100 years after disposal for all disposal units, but were not considered relevant for the biological trenches. The dose analysis for inadvertent intruders includes considerations of mobilization and transport of radionuclides from the various disposal units prior to the time intrusion was assumed to occur, based on the results of the SOURCE1 model. For the purpose of the intruder dose assessment, the parameter values used in the code were selected with the intent of overestimating the quantities of radionuclides remaining in the disposal units over time.

Although the results of the PA indicate that existing disposals at IWMF are in compliance with the performance objectives of DOE O 5820.2A and, thus, that the IWMF can continue to accept waste in the future, the results of this revised PA indicate that all closed disposal units at SWSA 6 and the existing disposals at IWMF are in compliance with all of the performance objectives of DOE O 5820.2A. The results also provide allowable inventory limits per pad for the disposal of LLW on the unused portions of the IWMF. Of the 63 radionuclides considered in detail, one radionuclide is limited by the specific activity of the radionuclide, two are limited by the groundwater performance criterion, and the remaining 60 radionuclides are limited by the criteria for the protection of a hypothetical inadvertent intruder. These limits were determined by using the composite model for SWSA 6 to evaluate the additional loading of each radionuclide on IWMF that would yield the dose prescribed by the performance criteria for SWSA 6 for the groundwater pathway, surface water pathway, air pathway, all-pathways, and inadvertent intruder analysis. The most restrictive limit for each radionuclide determined the allowable inventory of each radionuclide at the IWMF. For the evaluation of existing wastes on the IWMF, which contain multiple radionuclides, the sum-offractions rule was applied to each pad on the IWMF to verify the acceptability of the wastes currently disposed of on the IWMF.

The sensitivity and uncertainty of the results are important in interpreting these results and evaluating compliance of SWSA 6 with the performance objectives of DOE O 5820.2A. Sensitivity 
analyses were used to identify the modeling parameters that had the greatest effect on the results. The identified parameters were used in the uncertainty analysis to determine the confidence to be attributed to the results. The uncertainty analysis incorporated the subjective evaluation of the acceptability of each component of the modeling of site performance as well as the quantitative evaluation of the model component uncertainty. The results of the uncertainty analysis indicate that the greatest source of uncertainty is associated with the waste inventory and that uncertainty in the calculated results increased as the time increased. Furthermore, the uncertainty in the waste inventory was greatest with the waste previously disposed of in the SWSA 6 disposal units.

The question of whether releases of radionuclides from SWSA 6 to the general environment would be as low as reasonably achievable (ALARA) was considered in the revised PA. Based on an assumption that a population the size of the city of Oak Ridge would use the water from the Clinch River near the discharge of White Oak Creek as a drinking water supply, and taking into account that SWSA 6 would comply with the performance objective for protection of surface water at WOD, the projected collective dose over 1000 years was sufficiently low that the expected number of health effects would be zero. Furthermore, the maximum individual dose from the use of water in the Clinch River is expected to be less than 1 mrem per year. Therefore, the projected impacts from waste disposals in SWSA 6 are sufficiently low that further efforts to reduce releases from SWSA 6 based on the ALARA objective are unwarranted.

The results of the PA suggest the need for changes in the current and future operations at the IWMF to address the concerns of the DNFSB and to ensure compliance with the performance objectives of DOE O 5820.2A. A recommended strategy for future IWMF operations has been developed to provide the needed assurance that the performance objectives will be maintained. The strategy has five parts: (1) buffer zone expansion, (2) restricted disposal limits for problematic radionuclides, (3) removal of selected vaults, (4) discontinuation of the most probable activity factor, and (5) development of off-site disposal capacity.

The recommended expanded buffer zone, which was applied to this revised PA, reduces the compliance requirements for groundwater protection within SWSA 6 but provides a consolidated area for waste management and environmental compliance that is within the SWSA 6 facility boundary. Some radionuclides were identified as problematic with respect to compliance with the performance objectives in the initial PA, and the results of this revised PA for these radionuclides, as shown in the uncertainty analysis, become less certain as time increases. These two factors suggest the reduction of the inventory limits for the disposal of these problematic radionuclides to $1 \%$ of the limits calculated in the PA. This substantial reduction in the disposal limits for future disposals at IWMF provides additional assurance that the performance objectives will be met, and it significantly reduces the potential uncertainty of compliance. Furthermore, the land use boundary for SWSA 6 may extend well beyond the existing facility boundary once the revised land use plan for the ORR is completed. The existing buffer zone boundary for SWSA 6 , that extends slightly beyond the SWSA 6 facility boundary, was used as the point of assessment for this revised PA, which adds an additional margin of safety. These reduced disposal limits are to be applied to the vaults currently disposed of on the IWMF. Vaults that are identified as exceeding these modified disposal limits are to be 
removed from the IWMF. Waste characterization practices at ORNL have significantly improved since the publication of the initial PA, such that the use of a most probable activity factor, which artificially increases the inventory of radionuclides in each vault, is no longer justified and is to be discontinued. Finally, the use of SWSA 6 as a disposal facility will be discontinued once the IWMF is filled to capacity with waste. Once the IWMF is filled, future disposal of waste generated at ORNL will be performed at an off-site disposal facility. These recommendations are to be adopted as part of the waste disposal operations at the IWMF. 


\section{INTRODUCTION}

This section provides the descriptive information for understanding the analysis presented as part of this performance assessment (PA) for Solid Waste Storage Area (SWSA) 6 at Oak Ridge National Laboratory (ORNL), which includes the continuing and future operations of the Interim Waste Management Facility (IWMF). This section addresses the approach taken in the PA, provides a general description of the IWMF and other disposal units examined at SWSA 6, discusses the performance criteria used for evaluating their performance, and gives an overview of the major assumptions incorporated into the PA.

\subsection{GENERAL APPROACH}

Site-specific radiological PAs are required by U.S. Department of Energy (DOE) Order 5820.2A for the disposal of low-level radioactive waste (LLW) at DOE facilities. The purpose of this revised PA is to demonstrate compliance with the performance objectives for LLW contained in Chapter III, paragraph 3a, of the order (reproduced below in Table 2.1). The methodology used in this revised PA considers hypothetical exposures to both inadvertent intruders and receptors of radionuclides transported by environmental pathways.

\section{Table 2.1. Performance objectives for low-level radioactive waste disposal}

1. Protect public health and safety in accordance with standards specified in applicable EH Orders and other DOE Orders.

2. Assure that external exposure to the waste and concentrations of radioactive material which may be released into surface water, ground water, soil, plants and animals results in an effective dose equivalent that does not exceed $25 \mathrm{mrem} / \mathrm{yr}$ to any member of the public. Releases to the atmosphere shall meet the requirements of 40 CFR 61 . Reasonable effort should be made to maintain releases of radioactivity in effluents to the general environment as low as is reasonably achievable.

3. Assure that the committed effective dose equivalents received by individuals who inadvertently may intrude into the facility after the loss of active institutional control ( 100 years) will not exceed $100 \mathrm{mrem} / \mathrm{yr}$ for continuous exposure or $500 \mathrm{mrem}$ for a single acute exposure.

4. Protect ground water resources, consistent with Federal, State and local requirements. 
Sources of contamination include wastes disposed of at SWSA 6 after September 26, 1988, including future disposal operations at the IWMF, the only operating disposal unit at SWSA 6. The results presented include allowable radionuclide concentration limits for current and future waste disposals at the IWMF. These limits will be incorporated into the waste acceptance criteria (WAC) for the IWMF to ensure compliance with the DOE Order 5820.2A. Those wastes disposed of in other facilities at SWSA 6 prior to September 26,1988, as well as other radioactive sources outside of SWSA 6 which augment its dose to the public and the environment, are addressed in the Composite Analysis for Solid Waste Storage Area 6 (the CA) (ORNL 1997b), a companion document to this revised PA.

This revised PA has been prepared using the Interim Format and Content Guide and Standard Review Plan for U.S. Department of Energy Low-Level Waste Disposal Facility Performance Assessments (DOE 1996c). The revision is based on the initial PA (ORNL 1994), which was submitted to DOE for review and approval. The review identified issues in need of resolution and called for a revision of the document (DOE 1995) to provide assurance that continued operations at IWMF will comply with the performance objectives in Table 2.1 . This revision also addresses commitments made by DOE in response to the Defense Nuclear Facilities Safety Board (DNFSB) Recommendation 94-2. These commitments are included in the Implementation Plan for the DNFSB Recommendation (DOE 1996b). This revised PA includes sufficient detail to allow an understanding of the evaluation of facility performance, with descriptive and technical material presented as concisely as possible. Technical discussions and supporting data relevant to understanding the material presented in the PA are included as appendices. Additional background on the development of this PA methodology is contained in the initial PA (ORNL 1994) and a scoping analysis for PA preparation at ORNL (Lee and Kocher 1990). The analyses developed for this PA are a result of the ongoing application of performance assessment to waste disposal operations at ORNL and the evolution of the PA following the issuance of DOE Order 5820.2A. Future revisions of this PA are to be prepared as part of the PA Maintenance Program required by Maintenance of U.S. Department of Energy LowLevel Waste Assessments (DOE 1996d). Future revisions will also address any additional requirements from the revision of DOE Order 5820.2A.

\subsection{GENERAL FACILITY DESCRIPTION}

The IWMF, the is located at SWSA 6 in proximity to a variety of closed disposal facilities. SWSA 6 is located on 28 ha (68 acres) of rolling terrain in Melton Valley, between two prominent linear ridges just south of ORNL in the southern quadrant of the Oak Ridge Reservation (ORR), as shown in Fig. 3.1. The SWSA 6 site occupies the southern slopes of a mid-valley knoll, bordered on the south by White Oak Lake (WOL), on the east by a perennial stream, on the west by State Highway 95, and on the north by the crest of the knoll (Fig. 3.2). The ORR is bounded on the west, south, and east by the Clinch River and is topographically dominated by a series of linear valleys and ridges trending roughly $35^{\circ}$. The land surrounding the ORR is predominantly rural with low 
population densities. Site description, land use, and surrounding populations are discussed in greater detail in Sect. 3.1.

SWSA 6 has accepted waste since 1969. It has been the only active waste disposal facility for ORNL-generated wastes since 1973 (Coobs and Gissel 1986). Approximately 12 ha (30 acres) of the site is useable for waste disposal operations, with most of the total site capacity having been used prior to September 26, 1988. Prior to September 1988 a variety of disposal methods were used at SWSA 6, with the bulk of waste materials buried in shallow, unlined trenches. Wastes disposed of since that time have been emplaced in excavated trenches for biological materials; below-grade, concrete-lined, silos for bulk waste materials; engineered wells for fissile and high-range ( $>200 \mathrm{mrem} / \mathrm{hr}$ ) materials; and tumulus disposal units for containerized wastes. Current and future disposal operations at the IWMF use the tumulus disposal technology. Detailed descriptions of these types of disposal units are presented in Sect. 3.2.

Below-ground trench disposal methods for radioactive waste were discontinued in 1985 for all but biological waste, having been deemed unacceptable. As a result, a large portion of SWSA 6 is now subject to remediation under the Comprehensive, Environmental, Response, Compensation, and Liability Act of 1980 (CERCLA). Interim closure of many of the historical disposal units and a remedial investigation study were completed in response to the requirements of the Resource Conservation and Recovery Act of 1976 (RCRA) prior to designation of SWSA 6 as a CERCLA site. In February 1993, the Deferred Action Alternative was selected in response to the Interim Proposed Plan for CERCLA remediation. This alternative involves enhanced site monitoring and technology demonstration and development. Action has been deferred until the risks to public health and the environment warrant remedial action. A Letter of Agreement between the U.S. Environmental Protection Agency (EPA), the State of Tennessee's Department of Environmental Conservation (TDEC), and DOE outlining the details of the Deferred Action Alternative has been prepared. Ultimately, the entire site will be remediated in accordance with the regulatory requirements of CERCLA.

Wastes generated at ORNL are characterized according to requirements of the Waste Certification Program (ORNL 1997c) by the generators, and include a broad spectrum of waste types from research and development activities at ORNL. Wastes currently disposed of at SWSA 6 must meet WAC for the IWMF (ORNL 1996). WAC assign limits to the radioactive contents and physical and chemical characteristics of wastes acceptable for disposal. WAC have been revised as a result of findings from previous PA analyses, and future revisions of WAC will incorporate the findings of this revised PA. Wastes which meet WAC are packaged, treated (when appropriate), and placed in concrete vaults with a steel liner. The void between the liner and the vault wall is filled with grout. Vaults are then closed with a bitumen-sealed concrete lid, and the contents are recorded prior to the placement of the vault on the IWMF disposal pad. Each of the six pads of the IWMF have a capacity of 330 vaults. As of this writing, the IWMF is filled to just over $50 \%$ capacity. Current loading rates for the IWMF suggest the unit will reach capacity in 2003 , after which it will be closed. The final closure plan has yet to be developed and is to be addressed as part of the CERCLA actions at SWSA 6. 


\subsection{SCHEDULES}

Past operations at SWSA 6 relevant to this revised PA include LLW disposal in biological trenches, low- and high-range silos, asbestos silos, high-range wells in silos, high-range wells, fissile wells, the suspect waste landfill, Quadrex trenches Tumulus I and Tumulus II, and the currently loaded pads of the IWMF. At the time of the issuance of the initial PA, other SWSA 6 disposal units were still operating, but currently only the IWMF is accepting LLW.

Disposal operations at the suspect waste landfill began in the 1970 s and were discontinued in December 1992. The landfill accepted wastes for disposal that were potentially contaminated but could not be demonstrated to be contaminated. This waste category no longer exists and these wastes are now treated by compaction or incineration and disposed of at IWMF. Disposal operations at Tumulus I began in April 1988 and were discontinued in June 1990, when the disposal unit was filled to capacity with 291 vaults. Tumulus II disposal operations began in October 1990 and were discontinued in March 1992, when this disposal unit was filled to capacity with 220 vaults. Disposal of biological wastes in unlined biological trenches began in the 1970s, was discontinued for animal wastes in 1992, and was discontinued for other biological wastes in early 1993 in response to negotiations with the State of Tennessee. Disposal of waste in the Quadrex trenches began in January 1987 and was discontinued in May 1989. Disposal of wastes in silos and wells was initiated in 1986 following the discontinuation of shallow land burial of wastes in unlined trenches and auger holes at SWSA 6. Disposal of wastes in silos and wells was phased out beginning in 1992 and discontinued in January 1994 in response to concerns expressed by the State of Tennessee and the findings of the initial PA for SWSA 6. Since January 1994, disposal operations at SWSA 6 have been performed only at the IWMF. Disposal operations at the IWMF are expected to continue until the disposal unit is filled to capacity with 1980 vaults on six separate disposal pads. At that time disposal operations at SWSA 6 will be discontinued, and no additional disposal operations are anticipated on the ORR for wastes generated from ORNL activities.

Closure of SWSA 6 is to be performed under the CERCLA process, which is being applied to large portions of the ORR that have been subdivided into several waste area groupings (WAGs). WAG 6 (the WAG associated with SWSA 6) was initially scheduled for early decision making, but action has been deferred until SWSA 6 becomes a greater risk to the public and the environment. Consequently, this revised PA assumes a reasonably conservative closure scenario for the purposes of the analysis, recognizing that changes may occur in the CERCLA process which may require revisions to the PA.

Postclosure activities at SWSA 6 are similarly undefined and subject to the outcome of the CERCLA process. For the purposes of this analysis, 100 years of active institutional control is assumed. In addition, engineered barriers in all disposal units except unlined trenches are assumed to maintain their integrity for 200 years beyond the active institutional control period. The additional credit for engineered barriers is based on the assumption that concrete is not likely to deteriorate rapidly, and it is applied in evaluating releases from engineered disposal units into water and in evaluating the time at which excavation into the waste by an inadvertent intruder could occur. 


\subsection{RELATED DOCUMENTS}

This revised PA is prepared within the regulatory context of LLW management at ORNL. The constraints imposed by DOE $05820.2 \mathrm{~A}$ are the primary control on operations, and establish the requirements for most elements of the LLW management program. Additional related requirements include the DOE O 5480 series and DOE O 5400 series.

Currently, the safety documentation for SWSA 6 disposal operations is contained in the Basis for Interim Operation: Interim Waste Management Facility (ORNL 1997a), which was prepared to fulfill the requirements of DOE $O 5480.2 \mathrm{~A}$. This document was prepared using the graded approach for safety analysis prescribed by DOE and provides the necessary limitations on working conditions and responses to accidents that could occur during disposal operations.

The plan for the protection of groundwater at SWSA 6 is documented in the ORNL Plant Site Groundwater Protection Program Management Plan (Baxter 1993), which was prepared to fulfill the requirements of DOE O 5400.1. Activities at SWSA 6 which could impact groundwater resources must be approved prior to initiation, and routine surveillance is performed to ensure that groundwater resources are not being adversely impacted by ongoing disposal operations. The current groundwater protection program management plan does not include requirements for the ultimate closure and longterm performance of SWSA 6.

While the above-mentioned documents are relevant to waste disposal operations, they do not have an influence on the methodology or results presented in this revised PA, because their focus is on existing operations and real-time impacts to the public health and the environment. The primary programmatic influence on the long-term performance of SWSA 6 is the potential effect of CERCLA decisions on the closure of SWSA 6, which have yet to be documented and are discussed in Sect. 2.2. Once the CERCLA process has defined any actions to be taken at SWSA 6, and these conclusions are documented in a Record of Decision (ROD), this PA will probably need to be revised to reflect the consequences of the ROD on the long-term performance of SWSA 6. The current revision has been prepared using the assumptions incorporated into the Accelerated Cleanup Plan for the ORR. While these assumptions do not constitute a regulatory commitment with respect to the closure of SWSA 6 , they provide a reasonable basis for evaluating the long-term performance of SWSA 6.

Land use plans currently under development for the ORR include the potential reduction of the footprint of DOE operations and the release of federal lands to the public. While these plans have not been documented, the release of the SWSA 6 facility to the public is not being considered in the planning process. The duration of the long-term commitment of federal control of the SWSA 6 facility and other contaminated land within the ORR has not been resolved and is largely contingent on the CERCLA process. For the purposes of this revised PA, a conservative approach to long-term land use has been applied in allowing for an active institutional control for 100 years after closure. Should the land use plans for the ORR ultimately identify longer periods of institutional control, additional credits can be incorporated into the analysis presented in the PA. Nevertheless, this PA demonstrates compliance with the performance objectives of DOE O 5820.2A without invoking extended credits for federal land use control of the SWSA 6 site. 
Preexisting contamination and potential contamination from IWMF is the subject of the CA (ORNL 1997b), which has been prepared as a separate document following the guidance issued by DOE headquarters (DOE 1996a) and according to the schedule presented in the Implementation Plan for DNFSB Recommendation 94-2 (DOE 1996b). The CA estimates the potential cumulative impacts to a hypothetical future member of the public from disposal of waste at the IWMF and any other planned disposal units (including those for environmental restoration activities), as well as other sources of radioactive material in the ground that may interact with exposures from disposal activities at IWMF.

\subsection{PERFORMANCE CRITERIA}

This section provides the explicit criteria for assessing the performance of the SWSA 6 facility. The performance objectives presented in Table 2.1 are the basic criteria to be used for assessment. The following sections provide the details of the locations and times of assessment used to demonstrate compliance with the performance objectives for the all-pathways, intruder, and water resources analyses. A summary of the performance criteria discussed in this section is presented in Table 2.2 .

\subsubsection{Public Protection Performance Objective}

The public protection performance objective considers all exposures that a member of the public could potentially receive from the disposals of LIW after September 26, 1988, at SWSA 6. The demonstration of compliance with the public protection performance objective is considered in detail for the all-pathways dose of 25 mrem per year, and the method for analyzing the potential doses to a member of the public is discussed in detail in Sect. 4 . The method of analysis for potential exposures from the atmospheric transport of contamination is addressed separately in Sect. 4 and presented in detail in Appendix $\mathrm{H}$.

The guidance for preparing PAs (DOE 1996c) specifies that the point of compliance is to be the land use boundary for the all-pathways analysis. For SWSA 6, the current land use boundary is the boundary of the ORR in the Clinch River. The all-pathways dose from disposals in SWSA 6 to a member of the public located at the land use boundary is derived from the exposures to effluents from WOC, the outlet of all surface waters and groundwaters from SWSA 6. Exposures from direct consumption of contaminated surface water or groundwater are limited to 4 mrem per year (Sect. 2.5.3). Exposures from the air pathway are limited by 40 CFR 61 to less than 10 mrem per year, excluding doses from radon. Because the all-pathways performance objective is 25 mrem per year, exposures from all other pathways (e.g., fish, swimming, gardening, etc.) are limited to less than the remaining $11 \mathrm{mrem}$ per year. The discussion of the exposure pathways and scenarios for this revised PA is presented in detail in Sect. 4. 
Table 2.2. Performance Assessment Criteria for SWSA 6

\begin{tabular}{|c|c|c|}
\hline Component & Measure & Point of Compliance \\
\hline All-Pathways & $\begin{array}{l}\leq 25 \text { mrem per year, not including } \\
\text { doses from radon and progeny }\end{array}$ & Expanded Buffer Zone boundary \\
\hline \multirow[t]{2}{*}{ Air Pathway } & $\begin{array}{l}\leq 10 \text { mrem per year, not including } \\
\text { doses from radon and progeny }\end{array}$ & Expanded Buffer Zone boundary \\
\hline & $\begin{array}{l}\text { For radon- } 220 \text { and radon-222, an } \\
\text { average flux of } \leq 20 \mathrm{pCi} / \mathrm{m}^{2} / \mathrm{s}\end{array}$ & Disposal Facility surface \\
\hline \multirow[t]{2}{*}{$\begin{array}{l}\text { Hypothetical } \\
\text { Inadvertent Intruder }\end{array}$} & $\begin{array}{l}100 \text { mrem per year from chronic } \\
\text { exposure }\end{array}$ & Disposal Facility \\
\hline & 500 mrem from a single event & Disposal Facility \\
\hline $\begin{array}{l}\text { Water Resource } \\
\text { Protection }\end{array}$ & $\begin{array}{l}\leq 4 \text { mrem per year from direct } \\
\text { consumption of } 2 \mathrm{~L} / \mathrm{d}\end{array}$ & $\begin{array}{l}\text { Expanded Buffer Zone Boundary for } \\
\text { groundwater; White Oak Dam for surface } \\
\text { water }\end{array}$ \\
\hline
\end{tabular}

The current land use boundary for the ORR is being reviewed with the intent that some portions of the ORR may be released to the public in the future. Because the future land use boundary is uncertain, a conservative point of assessment closer to the disposal facility is considered for the purposes of this revised PA. The location of the off-site individual for this revised PA is outside a buffer zone for the disposal units in SWSA 6, which is within the current land use boundary of the ORR. The buffer zone for SWSA 6 was initially assumed to surround each disposal unit with a 100-m buffer zone. The overlapping buffer zone for the many disposal units in SWSA 6 considered in this revised PA were combined to form a unified $100-\mathrm{m}$ buffer zone (Fig. 4.15). Also considered in this revised PA is an expanded buffer zone which incorporates small parcels of land that are largely interior to the SWSA 6 facility (Fig. 4.16), which form a consolidated buffer zone. For the purposes of demonstrating compliance with the performance objectives of DOE O 5820.2A, the expanded buffer zone boundary is used. The potential dose to a member of the public is determined at any time after disposal and is presented at the time and place beyond the perimeter of the expanded buffer zone where the exposure is the greatest. This point of assessment is applied separately to exposures from contaminated groundwater, surface water, and air, and is not necessarily in the same location for each evaluation. By evaluating the all-pathways performance objective at the expanded buffer zone boundary instead of the current land-use boundary, additional assurance is provided that the performance objective is met, and the potential release of land to the public by DOE is addressed.

The performance objective of meeting the requirements of 40 CFR 61 is discussed in detail in Appendix $\mathrm{H}$ and Sect. 4. ORNL currently meets the requirements of the National Emission Standards for Hazardous Air Pollutants (NESHAP) for all operations performed on the ORR. Data collected from an air monitoring station at White Oak Dam (WOD), which is adjacent to SWSA 6, show that current radioactive emissions from all sources (stacks at ORNL, historical disposal facilities, the Y-12 Plant, 
the East Tennessee Technology Park, and private enterprises such as SEG, Inc.) result in exposures to an individual that are less than $0.10 \mathrm{mrem}$ per year, excluding any doses that might be attributable to volatile radionuclides in disposed waste. Volatile radionuclides in wastes, such as ${ }^{14} \mathrm{C}$ and tritium $\left({ }^{3} \mathrm{H}\right)$, that might lead to additional doses from atmospheric transport are considered in detail in Appendix $\mathrm{H}$ and are shown to be less than the performance objective in 40 CFR 61 . The addition of potential doses from atmospheric transport of contamination are considered in the all-pathways analysis for a member of the public.

The performance objectives for off-site individuals of 25 mrem per year from all release and exposure pathways and 10 mrem per year from airborne releases alone do not include contributions to dose from inhalation of radon (i.e., ${ }^{222} \mathrm{Rn}$ and ${ }^{220} \mathrm{Rn}$ ) and its short-lived decay products (DOE 1996c). Rather, consistent with the requirements of $40 \mathrm{CFR} 61$, Subpart $\mathrm{H}$, a separate performance objective specifying a limit on average emanation rate of radon at the ground surface of $20 \mathrm{pCi} / \mathrm{m}^{2} / \mathrm{s}$ is imposed, and this performance objective is assumed to apply for 1,000 years after disposal (DOE 1996c). The analysis of potential emanation of radon from the various disposal units in SWSA 6 is presented in Sect. 4.3.2.

For the assessment of the public protection performance objective, as discussed in detail in Sect. 4, the methodology used in this revised PA estimates the potential doses from non-IWMF disposed waste from September 26, 1988, to the present, then determines those allowable inventories of radionuclides in the IWMF that will meet the performance objective for protection of the public. This method is also applied to the other performance objectives discussed below. The most restrictive allowable inventory determined from the consideration of each performance objective will be applied to WAC for the IWMF.

\subsubsection{Intruder Performance Objective}

The intruder performance objective of 100 mrem per year (Table 2.1) is applied to chronic exposure from a selection of scenarios that are described in detail in Sect. 6.1. Scenarios involving contact with intact engineered barriers or drilling through disposal units are assumed to occur at the end of the active institutional control period at 100 years after disposal. A scenario involving largescale exhumation of waste is assumed to occur at 300 years after disposal for engineered disposal units but at 100 years for unlined trenches. The extension in time prior to direct intrusion by excavation into engineered units is based on the assumption that the physical integrity of engineered barriers will be maintained beyond the active institutional control period. This performance objective is applied to each disposal unit in SWSA 6 in order to establish potential doses from disposed waste and to determine inventory limits for IWMF disposals which will ensure that the performance objectives for LLW disposal are met.

The intruder performance objective of 500 mrem per year (Table 2.1) is applied to acute exposure from scenarios described in detail in Sect. 6.2. The acute exposure scenario resulting from an attempt to excavate through engineered barriers used in constructing disposal units is considered to be the most restrictive and is assumed to occur 100 years after the end of disposal operations. 
The current guidance for preparing performance assessment (DOE 1996c) specifies that the relevant exposure scenarios to be used in evaluating compliance with the performance objective for inadvertent intruders are those involving exposure to solid waste in disposal units, but exposure scenarios involving use of contaminated groundwater or surface water on the disposal site need not be considered. Exposures to contaminated water can be excluded form the intruder dose analysis because the impacts of groundwater and surface water contamination are considered separately in the allpathways analysis, the groundwater resource protection analysis, or both (DOE 1996c). In essence, by basing the intruder dose analysis only on scenarios involving exposure to solid waste in disposal units, compliance with all of the performance objectives listed in Table 2.1 involves achieving a balance between (1) allowable releases of radionuclides from disposal units into the environment, as determined by the all-pathways analysis, air pathway analysis, and groundwater resource protection analysis, and (2) allowable residual levels of radionuclides in disposal units, as determined by the intruder dose analysis.

There are two additional justifications for excluding pathways for exposure to groundwater and surface water from the intruder dose analysis. First, when compliance with the performance objective for inadvertent intruders is based on scenarios involving exposure to solid waste in disposal units, the resulting doses from use of contaminated groundwater or surface water on the disposal site would be limited to a small fraction of the performance objective for inadvertent intruders. Second, exposures to radionuclides in groundwater or surface water on the disposal site and exposures to radionuclides remaining in the disposal units generally would occur at different times, and the doses for the two cases would not be additive. Therefore, compliance with the performance criteria for inadvertent intruders reasonably can be based on scenarios involving exposure to solid waste in disposal units, without the need to consider exposures to contaminated groundwater or surface water on the disposal site.

The current guidance for performance assessment (DOE 1996c) also specifies that doses form exposure to radon and its short-lived decay products need not be considered in the dose analysis for inadvertent intruders. Exposures of inadvertent intruders to radon and its decay products are controlled separately by the performance criterion specifying a limit on radon release rate at the ground surface, as described in the previous section.

\subsubsection{Water Resources Protection Performance Objective}

The groundwater protection performance objective for SWSA 6 was established using the hierarchy presented in the Interim Format and Content Guide and Standard Review Plan for U.S. Department of Energy Low-Level Disposal Facility Performance Assessments (DOE 1996c). The State of Tennessee and local governments do not have laws, regulations, or other legally applicable requirements for groundwater protection. No formal agreements applicable to groundwater protection have been made with state or local officials. Lacking these two conditions, assumptions have been used to establish groundwater protection criteria (which have been discussed with the state) for this revised PA. 
The ORNL Plant Site Groundwater Protection Management Plan (Baxter 1993) addresses the needed monitoring requirements and plans for the ORR, but does not present groundwater protection criteria. The State of Tennessee, which is an agreement state, has issued implementing regulations for the Safe Drinking Water Act limiting the dose in drinking water for community waste supplies to 4 mrem per year. Proposed revisions of EPA's drinking water standards for radionuclides (EPA 1991) include a limit on EDE of 4 mrem per year. Based on these considerations, this regulatory limit has been regarded as the appropriate limit for the protection of groundwater resources in this revised PA. Compliance with this limit for the protection of groundwater resources ensures protection of potential future sources of drinking water in accordance with drinking water standards established by the EPA.

The guidance for preparing performance assessments (DOE 1996c) specifies the point of compliance as the land use boundary for the water resources performance objective, unless constrained by applicable laws, regulations, agreements or the groundwater protection management program and plan. The current DOE land use boundary that relevant to SWSA 6 is the Clinch River, at the mouth of WOC. There is no data to suggest that groundwater which may be contaminated from disposal at SWSA 6 travels beyond the current DOE land use boundary. The existing data on the ORR suggest that all contaminated groundwater from SWSA 6 discharges to surface water upstream of WOD. Consequently, the point of compliance for water resources protection, as suggested in the guidance, is the confluence of WOC with the Clinch River, which is equivalent to the discharge from WOD.

As discussed in Sect. 2.5.1, the current DOE land use boundary is being reviewed with the intent that some portions of the ORR may be released to the public in the future. To address the potential uncertainty associated with the land use boundary in the future and to ensure the protection of water resources, this revised PA utilizes a buffer zone boundary well within the current land use boundary for determining the point of compliance. A $100-\mathrm{m}$ buffer zone boundary surrounding all disposal units in SWSA 6 is used as the most restrictive boundary (Fig. 4.15). An expanded buffer zone boundary, which incorporates small parcels of land interior $t$ the SWSA 6 facility (Fig. 4.16) is also considered. By applying the performance measure of 4 mrem per year EDE to groundwater at a point of compliance established beyond the buffer zone for SWSA 6, but within the current land use boundary for the ORR, defense in depth is provided that water resources are protected both now and in the future.

Because SWSA 6 is to be remediated under CERCLA, the use of the 4 mrem per year dose limit for groundwater protection is reasonable. CERCLA has the intent of remediating sites to a usable condition without consideration of institutional control, and CERCLA specifically identifies drinking water standards as applicable or relevant and appropriate requirements (ARARs) for cleanup of groundwater at Superfund sites. Furthermore, proposed regulatory actions by the EPA in attempting to establish groundwater resource protection limits suggested the use of the 4 mrem per year limit. Future regulatory developments may resolve the appropriate limit for groundwater resource protection, but lacking this guidance, the 4 mrem per year limit has been adopted as the proper value for groundwater resource protection in this revised PA.

WOD, which impounds WOL, is located near the southwest corner of SWSA 6. The State of Tennessee has established National Pollutant Discharge Elimination System (NPDES) limits for 
discharges over WOD that do not include radioactivity. The discharges over WOD include releases from SWSA 6, previously closed disposal facilities which are upstream of SWSA 6, and all discharges from the ORNL main plant area. SWSA 6 is a minor contributor to the discharge over WOD, which could potentially be a drinking water supply to an individual or small community at some time in the distant future. Considering this possible scenario, for the purposes of this revised PA, the 4 mrem per year groundwater resource protection performance objective has been extended to surface water discharged over WOD, which is a conservative representation of the discharge from WOC Embayment. While this extension of the performance objective is not explicitly required, the protection of surface water resources consistent with groundwater resources is expected to encompass any additional requirements on the protection of water resources by the CERCLA remediation of SWSA 6.

\subsection{SUMMARY OF KEY ASSESSMENT ASSUMPTIONS}

This section provides a listing of the important assumptions which have been incorporated into this revised PA. Assumptions related to waste form, source terms, site characteristics, and the engineered disposal technologies are identified. Assumptions related to the analysis on inadvertent intrusion by a hypothetical individual are discussed in Sect. 6. These assumptions are selected to provide a reasonable but conservative representation of the long-term performance of SWSA 6 .

\subsubsection{Waste Form Assumptions}

The waste disposed of in a tumulus-type disposal unit is placed inside a metal box which, in turn, is placed inside a concrete disposal vault. The annular space between the inner wall of the vault and the outside of the metal box is filled with grout before the lid is placed on the vault. Similarly, the silos, wells, and wells-in-silos have metal barriers and are filled with grout after the emplacement of the wastes. The trenches contain no engineered barriers and are essentially a mixture of waste packages and soil. To develop waste transport parameters, each disposal unit was assumed to contain a uniform composition of waste and grout (or in the case of a trench, soil). Within a group of a given type of disposal unit, the waste radionuclides were assumed to be uniformly distributed. The density of the waste-grout (and waste-soil) mixture was assumed to be $1.76 \mathrm{~g} / \mathrm{cm}^{3}$ with a porosity of 0.35 . The concrete used in the construction of the tumulus-type vaults, the silos, and the wells-in-silos was assumed to have a density of $2.34 \mathrm{~g} / \mathrm{cm}^{3}$ with a porosity of 0.15 . Radionuclide transport parameters (e.g., solubility, distribution coefficient, and diffusion coefficients) were developed for the assumed composition of the waste and grout and are described in Appendix $\mathrm{C}$. The grout used in filling the disposal units was assumed to contain no special additives for retarding the movement of specific radionuclides. As a result, with the exception of the actinides, the same transport parameters used for the waste-grout mixtures were used for waste-soil mixtures (in trenches). For actinides in trenches, a different set of transport parameters was used because the $\mathrm{pH}$ inside the unit would not be basic since 
there would likely be little or no grout present. A special case is the Quadrex trenches. These trenches consist of large metal boxes that were filled with LLW, and then the voids were filled with grout. The hydrologic characteristics of these grout monoliths are not known and, therefore, these monoliths may not provide the same degree of hydrologic isolation of wastes as do engineered units such as tumulusor silo-type units. To be conservative, for the environmental transport calculations, the Quadrex trenches were treated as mixtures of wastes and soils, and no credit was taken for hydrologic isolation by engineered barriers. However, the monolith should serve as an intruder barrier and credit is taken for such a barrier in the intruder analysis (Sect. 6).

Finally, the release of radionuclides is influenced by the amount of water saturation of the disposal unit (i.e., the waste and concrete containment). The relative saturation of the waste (i.e., volume of water per volume of waste) can range from zero up to the porosity of the waste. In this assessment, the relative saturation of waste is taken to be equal to the porosity of the waste (0.35). In other words, the pores in the waste are full of water (i.e., saturated). The assumption that a disposal unit is saturated represents conservatism for environmental transport calculations in that it gives the largest release by advection and diffusion with all other parameters fixed.

\subsubsection{Source Term Assumptions}

This section describes the assumptions used in calculating source terms for this performance assessment. Sect. 2.6.2.1 describes assumptions related to radionuclide release; Sect. 2.6.2.2 presents assumptions about facility degradation and performance. Potential source terms from the disposal of volatile radionuclides are discussed in detail in Appendix $\mathrm{H}$.

\subsubsection{Radionuclide Release}

The total radionuclide release from a disposal unit is assumed to be the sum of the advective and diffusive releases. This total release is limited by the solubility limit for the assumed chemical form of the waste radionuclide. Complex forms of waste and barriers are approximated as simpler forms (e.g., slabs). As a result, both the advection and diffusion models are one-dimensional.

Advective transport of radionuclides is modeled as a first-order leaching process that accounts for both sorption and decay. A linear isotherm model [e.g., constant distribution coefficient $\left(K_{d}\right)$ ] is used to mimic sorption processes in the waste.

Diffusive transport of radionuclides is modeled as diffusion through a two-layered system. The inner layer (i.e., the waste) is initially uniformly contaminated. The outer layer (e.g., the vault wall for a tumulus-type disposal unit) is initially uncontaminated. Diffusion calculations also account for radionuclide decay and sorption. Retarded diffusion coefficients incorporate the sorption behavior of the radionuclide.

Estimates of distribution and diffusion coefficients are based on appropriate literature values using the methodology outlined by Godbee (1996) and in Appendix C. This method adjusts the literature values to system-specific values for SWSA 6 facilities. In the absence of data for a given radionuclide, Godbee (1996) provides a methodology for transport-parameter estimation. 
The water flow rate through the disposal units is assumed to be the minimum of the input seepage rate and either the saturated hydraulic conductivity of concrete (for intact units) or the saturated hydraulic conductivity of the soil backfill (for units that have cracked or failed). Water seepage values are provided for each month of the year to reflect seasonal variations. Additionally, the water seepage values are updated as required to reflect environmental changes (e.g., growth of vegetation on top of the disposal unit and degradation of the cap on the disposal unit).

The release of radionuclides is calculated in monthly time-steps. Based on knowledge of the site hydrology, the total release is partitioned into two components: a vertical component available for recharge to groundwater and a lateral component available for shallow, subsurface transport. The total release is partitioned first to the vertical component because drainage from the disposal unit is assumed to move vertically at a low recharge rate throughout a calculation. Any excess water (i.e., because the seepage rate in the disposal unit is greater than the recharge rate under the unit) moves laterally away from the unit. The fraction of the radionuclide release partitioned to the vertical component is determined by the ratio of the saturated hydraulic conductivity for the soil under the disposal unit to the water seepage rate into the unit. The saturated hydraulic conductivity of shallow subsurface materials is assumed to be $1.9 \times 10^{-5} \mathrm{~cm} / \mathrm{s}$ under the IWMF, $1.5 \times 10^{-5} \mathrm{~cm} / \mathrm{s}$ under Tumulus I and II, and $5.8 \times 10^{-7} \mathrm{~cm} / \mathrm{s}$ under the remainder of the facilities in SWSA 6 (see Appendix D, Sect. D.2, Table D.2; soil layer $=400$ to $500 \mathrm{~cm}$ ). The higher conductivity values for the tumulus facilities are selected to represent the disturbed soils resulting from pad construction and the high hydraulic conductivities of the subsoils inundated by shallow water tables. The radionuclide releases not transported to groundwater, if any, are partitioned to the lateral path.

\subsubsection{Disposal Unit Degradation and Performance}

The degradation of concrete is assumed to be caused by sulfate attack of the concrete, calcium hydroxide leaching from the concrete, and corrosion of reinforcing steel. Metal barriers (e.g., metal waste containers used in tumulus-type vaults and metal liners used in wells and silos) are assumed to degrade linearly as a function of time.

The effect of concrete cracking on the leaching of radionuclides is delayed until structural degradation (i.e., the formation of through-wall cracks) of the disposal unit occurs. Hydraulic failure (i.e., through-wall cracking) of one component (e.g., roof, wall, or floor) in a unit results in a step change in the hydraulic conductivity of the unit. Because of the increased flow rate of water through the unit that results, advection becomes the dominant radionuclide transport mechanism.

Metal barriers are assumed to attenuate the release of radionuclides from the disposal units. As these barriers degrade, the allowed radionuclide release is increased proportionally.

The trenches, which contain no engineered barriers, are assumed to perform as if they were silos (i.e., equivalent volume and surface area). The input parameters for these "silos" are selected such that they will fail hydraulically at the beginning of the calculation. Hence, any water that penetrates the cap on the trench is immediately available to flow through the waste in the trench and to transport radionuclides away from the waste. 
For the tumulus-type disposal units, the degradation of the concrete pad and leachate collection system is represented by a linear failure model. The functionality of the pad and collection system determines how much of the calculated release from the disposal vaults is available for transport in the environment. For the IWMF, the pad and collection system are assumed to be initially $80 \%$ functional, degrading linearly to $0 \%$ functionality at the end of the institutional control period (100 years). The pads and collection systems for Tumulus I and II are not as elaborate as that for the IWMF. For Tumulus I and II, the pads and collection systems are assumed to be initially $50 \%$ functional, degrading linearly to $0 \%$ functionality at the end the 100 -year institutional control period. The degradation of the tumulus-type concrete pad is also calculated with the sulfate attack and calcium hydroxide leaching concrete degradation models. The estimate of pad failure is based on the reinforcement ratio, which is primarily a function of the concrete thickness above the steel reinforcement in the cover and the concrete strength. The sulfate attack model updates the cover thickness, while the concrete strength is updated with the calcium hydroxide leaching model. If failure of the pad (as determined by comparing the calculated reinforcement ratio with the limiting reinforcement ratio) occurs before the end of the institutional control period, the functionality of the pad and collection system is set to zero.

\subsubsection{Site Assumptions}

WOC is the receiving stream for contamination released from SWSA 6 by water pathways to the environment. The hydrogeological behavior of the ORR results in the relatively rapid transport of contamination from waste sites to surface water by shallow subsurface transport, groundwater transport, and ephemeral creek discharges. This site-specific characteristic makes surface water an important pathway for human exposure and a major indicator of disposal unit performance.

Modeling the behavior of natural systems requires the use of simplifying assumptions. The following sections describe the assumptions made for the PA analyses, including hydrologic and hydrogeologic analysis, and credit taken for engineered features.

\subsubsection{Runoff/Recharge Factors}

The monthly water flow contacting waste units is estimated from hourly water budget simulations obtained for the average environmental conditions in the area. The nuclides released from waste units are dissolved in the monthly water volumes, and the solution is partitioned into vertical and lateral subsurface flow. Groundwater is preferentially recharged each month up to a maximum rate with the nuclide leachate, and monthly values are summed to give annual recharge values used in the groundwater modeling. The remainder of monthly leachate fluxes, if any, are summed to an annual total and used in lateral shallow subsurface transport calculations.

In shallow subsurface transport, chemicals pass through the soils of the storm flow and vadose zones, and chemical adsorption is calculated during transport. The maximum soil volume associated with the recharge pathway to groundwater is determined from the waste zone area multiplied by the 
average depth to the water table obtained from calibrated groundwater simulations (Appendix E). In the case of lateral flow, the average path length from waste units to the nearest surface drainage channel is determined from site contour maps. This path length is multiplied by one-quarter of the waste zone area to give the maximum soil volume interacting with chemicals moving laterally in shallow subsurface flow. This method gives estimates of soil volumes used in chemical adsorption calculations during lateral subsurface flow.

The calculations of lateral subsurface transport through the shallow subsurface zone did not specifically account for the effects of matrix diffusion. This mechanism can cause a difference between the time of first arrival (a small effect) of chemical during a transport event and the time of peak concentration (delayed and at a reduced concentration) in the flow paths (Solomon et al. 1992). Matrix diffusion acts as a buffer that "smears out" the transport of chemicals by diffusive uptake of solutes from flow paths into the microporosity of the matrix. These solutes may be released as a secondary source from the matrix after decline in the chemical concentration from the primary source (e.g., leaking vaults). Annual time steps are adopted for chemical transport in the shallow subsurface zone, and a quasi-matrix diffusion effect is provided by mixing the new input of chemical to the shallow subsurface transport paths in a given year, with the soil solution retained by capillary forces in the flow path (field capacity) in the previous time step.

Bypass (macropore or preferential) flow is calculated for chemical transport to surface water through lateral subsurface and vertical recharge paths. This results in proportions of the leachate bypassing the soil matrix during subsurface transport. These calculations depend on the length of the lateral transport path and the soil/water $K_{d}$ of the nuclide. Nuclides with higher adsorption had less bypass flow. These bypass proportions provide conservative approximations for an important transport mechanism applicable to the SWSA 6 site. Preferential flow below $3 \mathrm{~m}$ depth in the soil profile was not shown in the field study of Wilson et al. (1993). This result, combined with the rapid decline in hydraulic conductivity with depth, provides the rationale for not including preferential flow through vertical paths greater than $3.5 \mathrm{~m}$ to the water table. These approximations provide calculated results that are consistent with field observations and eliminates the need for the application of a numerical transport model, which is viewed as unjustified given the limitations of the available data and the uncertainties in parameter values used in waste containment degradation and environmental transport.

\subsubsection{Areal Recharge Estimates for Groundwater Modeling}

Recharge to groundwater is estimated from water budget and modeling methods, providing values for natural recharge in the range of 70 to $180 \mathrm{~mm} /$ year (Tucci 1986; Bailey and Lee 1991; Solomon et al. 1992). These estimates are used as a guide for comparison with estimates obtained with the Unified Transport Model (UTM) hydrologic model. Recharge volumes through disturbed areas such as disposal units are generally much higher. Recharge is assumed to be steady-state throughout the period of calculations.

Terrain analysis (Appendix D) is used to identify convergent flow areas with enhanced recharge along ephemeral stream channels and footslope areas. In this analysis the topographic map of 
SWSA 6 is digitized to provide a digital elevation model (DEM), and this model is used to determine topographic indices that identify convergent flow zones. The map of topographic indices is gridded at $50-\mathrm{ft}$ intervals to match the grid structure of the groundwater model. The various grid cells are then assigned recharge values that reflect the increasing duration of drainage and perched water table status in the toposequence from ridge top and side slope to bottom slopes and stream channels (Sect. 4.3.1.1).

\subsubsection{Assumptions in Surface Water Analyses}

The most significant assumptions made in calculating the concentrations of radionuclides in surface water concern the dilution of transported radionuclides in WOL. Since the PA analyses are performed on an annual time step, a steady-state annual average inflow, derived from measured daily average values, is used in surface water calculations. WOL and WOD are assumed to persist in their present conditions into the future.

\subsubsection{Assumptions in Groundwater Analyses}

The groundwater flow and transport model constructed for PA groundwater analy sis assumes that movement of contaminants through the subsurface of SWSA 6 can be adequately modeled by solving the advection-dispersion equation (see Appendix E) in a two-dimensional saturated porous medium under steady-state conditions. Physical properties of this medium and the transported constituents follow:

- Saturated thickness. The thickness of the saturated zone is constant at $9 \mathrm{ft}$.

- Bulk density. The bulk density of all geologic materials is set at $1.35 \mathrm{~g} / \mathrm{mL}$, consistent with the shallow subsurface modeling.

- Porosity. A value of $0.05(5 \%)$ effective porosity was used. This value is obtained from aquifer tests performed at the Engineered Test Facility, located in SWSA 6 (Davis et al. 1984).

- Hydraulic conductivity. The uniform saturated hydraulic conductivity $(K)$ field is based on point hydraulic conductivity data derived from hydraulic tests performed at wells in the modeling area. The average estimated value of $K$ was adjusted to calibrate the groundwater flow model to average measurements of the local water table. The hydraulic conductivity tensor is assigned a constant anisotropy of $K_{x}: K_{y}:: 3: 1$, based on results at the Engineered Test Facility site (Davis et al. 1984).

- Dispersivity. The following fixed values of dispersivity are used: $\alpha_{L}=0.15 \mathrm{~m}(0.5 \mathrm{ft}), \alpha_{T}=0.08 \mathrm{~m}$ $(0.25 \mathrm{ft})$, and $\alpha_{V}=0.08 \mathrm{~m}$. These values are consistent with those reported by Lee et al. (1989).

It is further assumed that all groundwaters in the SWSA 6 modeling area eventually discharge to WOC and WOL. The exit point for all surface and groundwaters is WOL and, in turn, WOD. 


\subsubsection{Retardation in the Subsurface}

Values for chemical adsorption $\left(K_{-d}\right)$ of radionuclides to the subsoil materials at the SWSA 6 site are presented in Table 2.3. The nuclides fall into three broad groups of $K_{d}$ values:

$\begin{array}{lll}\text { Low } & K_{d}=0 \text { to } 30 & \mathrm{H}, \mathrm{C}, \mathrm{Cl}, \mathrm{K}, \mathrm{Ca}, \mathrm{Se}, \mathrm{Rb}, \mathrm{Sr}, \mathrm{Tc}, \mathrm{I} \\ \text { Medium } & K_{d}=40 \text { to } 300 & \mathrm{Zr}, \mathrm{Nb}, \mathrm{Cd}, \mathrm{Sn}, \mathrm{Eu}, \mathrm{Pb}, \mathrm{Ac}, \mathrm{U}, \mathrm{Np}, \mathrm{Pu}, \mathrm{Am}, \mathrm{Cm}, \mathrm{Cf} \\ \text { High } & K_{d}=400 \text { to } 3000 & \mathrm{Be}, \mathrm{Al}, \mathrm{Co}, \mathrm{Ni}, \mathrm{Pd}, \mathrm{Cs}, \mathrm{Sm}, \mathrm{Os}, \mathrm{Bi}, \mathrm{Ra}, \mathrm{Th}, \mathrm{Pa}\end{array}$

The $K_{d}$ value of zero is selected for $\mathrm{H}, \mathrm{C}, \mathrm{Cl}, \mathrm{Se}, \mathrm{Tc}$, and I because the soluble anion forms of these nuclides are not expected to adsorb significantly onto soil. Larger values of $K_{d}$ effectively slowed the advective transport so that diffusion became an important factor for very large values for time. The $K_{d}$ for cadmium is obtained from Turner and Steele (1988), and the value for nickel is from the investigation of Swanson (1983). The $K_{d} s$ for the remainder of the nuclides are based on the recommendations from several sources, including Friedman and Kelmers (1990). In all cases the $K_{d}$ values are obtained with equilibrium methods using soil material from the waste site or soil values that are available from published sources. Jardine, Jacobs, and Wilson (1993) have shown that $K_{d} s$ obtained by equilibrium methods are suitable for representing adsorption during unsaturated flow, even at high flow rates close to saturation.

The $K_{d}$ values are used in transport calculations through the shallow subsurface zone to surface water and in the transport of nuclides into the groundwater through the vadose zone. The $K_{d}$ values are applied to a soil volume estimated to occur between the waste units and the nearest surface drainage channel or water table as appropriate for lateral flow and recharge calculations. The specific $K_{d}$ values for soil (Table 2.3) are estimated or obtained from the following sources: Baes and Sharp (1981); Baes et al. (1984); Davis et al. (1984); Friedman and Kelmers (1990); Ketelle et al. (1995); Johnston and Gillham (1980); Rothschild et al. (1984); Sheppard et al. (1984); Sheppard and Thibault (1990); Solomon et al. (1992); Swanson (1983); and Turner and Steele (1988).

\subsubsection{Credit for Engineered Features}

In addition to the engineered barriers discussed in Sect. 2.6.2.2, a few geotechnical designs were installed at SWSA 6 to enhance the performance of the site. In August 1983 construction of a passive French drain system was initiated in the 49-trench area of SWSA 6 (Davis and Stansfield 1984). The purpose of the drain was to hydrologically isolate a 0.44 -ha area of SWSA 6 containing a group of $49 \mathrm{LLW}$ trenches by separating it from upgradient groundwater recharge. The drain is $252 \mathrm{~m}$ in length with a maximum depth of $9 \mathrm{~m}$. While initial measurements at nearby monitoring wells shortly after construction of the drain indicated drops in water level of as much as $2.24 \mathrm{~m}$, the longterm benefit of the French drain is modest due to rapid clogging of flow paths by sediments. There is little influence of the French drain on calibration of the groundwater model. 
Table 2.3. Element-specific soil/water partition coefficients used for environmental transport analyses

\begin{tabular}{cc|cc}
\hline Element & $\begin{array}{c}\text { Soil/water } K_{d} \\
(\mathrm{~mL} / \mathrm{g})\end{array}$ & Element & $\begin{array}{c}\text { Soil/water } K_{d} \\
(\mathrm{~mL} / \mathrm{g})\end{array}$ \\
\hline $\mathrm{H}$ & 0 & $\mathrm{I}$ & 0 \\
$\mathrm{Be}$ & 1000 & $\mathrm{Cs}$ & 3000 \\
$\mathrm{C}$ & 0 & $\mathrm{Sm}$ & 1000 \\
$\mathrm{Al}$ & 3000 & $\mathrm{Eu}$ & 40 \\
$\mathrm{Cl}$ & 0 & $\mathrm{Os}$ & 1000 \\
$\mathrm{~K}$ & 30 & $\mathrm{Bi}$ & 500 \\
$\mathrm{Ca}$ & 30 & $\mathrm{~Pb}$ & 100 \\
$\mathrm{Co}$ & 800 & $\mathrm{Ra}$ & 3000 \\
$\mathrm{Ni}$ & 2000 & $\mathrm{Ac}$ & 40 \\
$\mathrm{Se}$ & 0 & $\mathrm{Th}$ & 3000 \\
$\mathrm{Rb}$ & 30 & $\mathrm{~Pa}$ & 400 \\
$\mathrm{Sr}$ & 30 & $\mathrm{U}$ & 40 \\
$\mathrm{Zr}$ & 50 & $\mathrm{~Np}$ & 40 \\
$\mathrm{Nb}$ & 100 & $\mathrm{Pu}$ & 40 \\
$\mathrm{Tc}$ & 0 & $\mathrm{Am}$ & 40 \\
$\mathrm{Pd}$ & 2000 & $\mathrm{Cm}$ & 40 \\
$\mathrm{Cd}$ & 200 & $\mathrm{Cf}$ & 40 \\
$\mathrm{Sn}$ & 100 & & \\
\hline
\end{tabular}

The SWSA 6 remediation project addressed in DOE's Accelerated Cleanup Plan includes the construction of a slurry cutoff wall near the high-range wells, along the southwestern edge of cap 3 shown in Fig. 3.23 (Kaiser 1996). The slurry wall is expected to provide a long-term barrier to subsurface flow, and was considered during the development of the SWSA 6 groundwater flow model. This barrier does have a positive impact on slowing the releases of radionuclides from the high-range wells, which contain the site's largest inventory of ${ }^{90} \mathrm{Sr}$ and ${ }^{137} \mathrm{Cs}$ (see Table 4.6). This revised PA assumes that the slurry wall is in place, resulting in a modified flow field in its vicinity and impeded flow from the high-range wells. If this slurry wall is not constructed, the environmental transport of radionuclides from the high-range wells will proceed faster than the PA has estimated, producing higher concentrations in the surface water integration point (WOD), with potential negative impacts on the allowable radionuclide inventories of ${ }^{90} \mathrm{Sr}$ and ${ }^{137} \mathrm{Cs}$.

The remediation project also includes plans for the construction of additional and expanded caps over some facilities, consisting of "a 12-oz. non-woven geotextile covered with 12 inches of native soil and vegetation" (Kaiser 1996). Such a cap, with no clay or drainage layers, is unlikely to afford any significant long-term hydrologic protection, and so is not given credit in this PA.

The attributes of the engineered cover for the IWMF following closure are based on the capping plan developed and implemented for Tumulus I and II at SWSA 6 (Map C3E020016A046), with the following layers: 
- $45 \mathrm{~cm}$ (minimum) of topsoil with grass vegetation,

- composite drainage net,

- flexible membrane liner,

- $60 \mathrm{~cm}$ (minimum) of compacted subsoil,

- geomembrane,

- $15 \mathrm{~cm}$ (minimum) of variable fill layer, and

- composite drainage net.

These layers are placed over each tumulus pad loaded with vaults. The soil hydraulic properties selected to represent the cap (Appendix D) did not have the same features as the engineered cover; however, these properties significantly restricted seepage to the vaults. The annual water flux into the vault stack is assumed to equal the annual water flux out of the stack in water budget calculations. The cap is assigned an effective life of 10 years with a very low drainage rate. During the following 10 years, percolation through the cap is linearly ramped up to values calculated for a leaking cap with macropores. The integrity of the geomembrane is expected to diminish during this period, and roots are also expected to penetrate the compacted soil layer. These changes lead to shrinkage and swelling of clay materials and the gradual formation of cracks and channels that allow drainage to bypass through the compacted clay/soil matrix (Bass, Lyman, and Trantnyek 1985; Goldman et al. 1988). For the remaining 80 years of the 100 -year institutional control period, the burial site is assumed to have a mown grass cover and a leaking cap. Seepage resulting from cap failure is collected and treated during the institutional control period (see Sect. 3.2.2.).

The site is considered to revert to forest vegetation through species succession after the grass cover is no longer actively maintained. Natural succession proceeds by invasion of early succession tree species such as eastern red cedar, shortleaf pine, and sweetgum; and these are followed by oakhickory forest species at a later stage (Suter, Luxmoore, and Smith 1993). The successional process takes about 30 years. The hydrologic consequence of these temporal changes in vegetation is not considered significant for purposes of the revised PA, and one set of soil hydraulic properties (Appendix D, Sect. D.2, Table D.2) is used for water budget simulations following termination of institutional control.

\subsection{METHODOLOGICAL MODIFICATIONS AND CORRECTIONS TO THE REVISED PERFORMANCE ASSESSMENT}

The initial version of this PA was published in February 1994. That analysis determined that some radionuclides (notably ${ }^{14} \mathrm{C},{ }^{36} \mathrm{Cl}$, and ${ }^{239} \mathrm{Pu}$ ) in the reported inventory of IWMF exceeded the performance objective for groundwater resource protection. This situation was alleviated by removal of several waste vaults from the IWMF. Since that time, the facility has continued disposal operations with limits on the radionuclide content of waste, and the inventory has changed as a result. Several 
other changes and improvements were made to the various segments of the PA modeling tools and parameters. These are outlined below.

In addition to changes in disposed inventory, several methodological improvements in this PA analysis have been developed, and are reflected in this revision. The most fundamental change has been in the basic approach of determining disposal limits. The initial PA evaluated the performance of the IWMF and other facilities in SWSA 6 by working only with the currently disposed inventory, extrapolating the disposed inventory, and determining whether it met the performance objectives. Since the publication of the initial PA, all disposal units in SWSA 6 have become inactive except for the IWMF, and their inventories are now fixed. The inventory at the IWMF grows with continuing operations. Rather than having the PA evaluate whether some assumed inventory is capable of meeting the performance objectives, a much more useful and generalized analysis is to determine the maximum allowable inventory which meets the performance objectives. This revised PA does just that: It determines the maximum allowable inventories corresponding to a variety of exposure scenarios and resolves these to the most limiting case for each radionuclide. The result (Table 7.1) is a table of the maximum allowable activity inventory for each radionuclide assessed and the pathway which corresponds to the limitation. The IWMF operator is then obligated to compare the IWMF inventory to the allowable maxima in the table and, furthermore, to make allowances for overlapping contributions to dose from the various radionuclides.

\subsubsection{Changes in Radionuclides Considered}

This revised PA, which includes the IWMF, considers an expanded set of radionuclides compared with the initial version of the PA. Since one purpose of the revised PA is to establish WAC in the form of limits on activities of different radionuclides for disposal, consideration of a wide variety of radionuclides that could be included in future disposals is important. This revised PA considers all radionuclides with half-lives greater than about 5 years that reasonably could be found in significant quantities in LLW generated at ORNL. Selection of these radionuclides was based on records of past disposals of LLW at ORNL and an assumption that fission and neutron activation would be the primary processes producing LLW for future disposal. The number of radionuclides considered for IWMF disposal is 63 , compared with a total of 35 radionuclides considered previously. Additional radionuclides could be included in future revisions of the PA, should they be reported in significant quantities in future disposals.

For all disposal units other than the IWMF, the radionuclides considered in this revised PA are the same as those considered previously. Since all of the other units are closed to further disposals, the purpose of the assessment is to evaluate doses for the reported disposals, rather than to establish WAC for future disposals, and the assessment is based on the same reported disposals of radionuclides as in the previous assessment. 


\subsubsection{Changes in the Inventory}

For this revision of the PA, the inventory reported in the Waste Management and Remedial Action Division Waste Tracking System (WMRAD-WTS) database was used while the data from these records are imperfect, they represent the best source of information on waste disposals. In the initial PA, the inventory for some operating units was linearly extrapolated to estimate the inventory at closure. However, all of the disposal units except for the IWMF have since closed, and a final inventory is now available. With the establishment of this final inventory for the closed units, the total number of some types of units changed. Additionally, the Quadrex trenches, which were not analyzed for the initial PA, were added to the inventory to be analyzed.

In the initial PA, a most probable value was estimated on the basis of an uncertainty analysis of the inventory, and this value was then used in the calculations. However, in this revised PA the reported values were used, and any uncertainty in the reported inventory was evaluated as part of the uncertainty analysis (as described in Appendices A and I).

\subsubsection{Changes in Source Term Modeling}

For the initial PA, the SOURCE1 and SOURCE2 computer codes were developed to calculate releases of radionuclides from the different types of disposal technologies used in SWSA 6. Since the publication of the initial PA, a detailed verification plan has been implemented and completed for each of these codes. The intent of this plan was to verify that the codes were implementing algorithms as designed. These codes combine a number of mechanisms in order to simulate radionuclide releases. Although individual mechanisms have been validated (over relatively short periods of time as compared to the length of simulations), validation of these codes as a whole is not possible because such data are not and will not be available.

In the current version of the codes, a first-order advection model has replaced the simple model in the original version of the codes. This model eliminates some of the simplifying assumptions made to implement the original model and, as a result, should more closely simulate advective transport from the waste.

For SOURCE1 a new model that calculates the degradation and failure of a tumulus-type pad and leachate collection system was added. In the initial PA, no credit was taken for the pad and leachate collection system. In this revised PA, some credit is allowed for these systems during the institutional control period. However, these systems are assumed to have failed at the end of the institutional control period.

The radionuclide transport parameters (i.e., diffusion coefficients, distribution coefficients, and solubilities) have been reviewed and revised. Where possible, these parameters are based on appropriate values reported in the literature. However, specific data are not available for many of the radionuclides evaluated in this revised PA. Therefore, a consistent approach for the estimation of transport parameters was developed and implemented. This approach is outlined in Appendix C. For the actinides, better estimates were obtained for distribution coefficients and solubilities in basic $\mathrm{pH}$ 
systems. Consequently, for disposal units containing cement and grout, higher distribution coefficients and lower solubilities were used for the actinides than were used in the initial PA.

In the evaluation of intruder scenarios for the initial PA, no credit was taken for inventory reduction as a result of mobilization and transport of radionuclides from a disposal unit. However, for this revised PA, conservative assumptions were made to give some credit to mobilization and transport. These assumptions included $(a)$ delayed failure of a given disposal unit (as compared to the failure times used for water-pathway calculations), $(b)$ transport by advection only, and $(c)$ transport not solubility-limited. For the advective calculation, a distribution coefficient at the high end of the expected range for a given radionuclide was selected. The combined effect of all of these assumptions was a calculated radionuclide release that was significantly lower than that used in the water-pathway calculations. For the water pathway calculations, assumptions were selected that result in a conservatively high release rate, which would not be conservative for intruder calculations (Sect. 4.1). Because the calculated release for the intruder scenarios was, by design, conservatively low, some credit can be taken for inventory reduction in the intruder dose assessment.

\subsubsection{Changes in Water Budget Modeling}

Terrain analysis of the SWSA 6 landscape is included in this revised PA. This analysis uses topographical information to determine convergent flow areas within a watershed. Application of the procedure to SWSA 6 enables estimation of spatially varying recharge to groundwater and the determination of the site-specific upslope area contributing water flow into each of the waste zones (see Sect. 4.3.1.1).

\subsubsection{Changes in Shallow Subsurface Transport Modeling}

The modeling of subsurface transport in the initial PA utilized the TUMSIM and WELSIM codes, which applied algorithms for chemical adsorption and half-life decay. These codes have been revised to include algorithms for preferential flow and time-varying soil matrix volumes (analogous to chromatography) involved with chemical adsorption. The revised models have been given the new names PADSIM and HOLSIM for the applications to tumulus and below-ground (silos, wells, trenches) waste zones, respectively (see Sect. 4.3.1.2 and Appendix D). The PADSIM code has been applied in the PA for the proposed Class II Waste Disposal Facility (ORNL 1997c).

\subsubsection{Changes in Groundwater Transport Modeling}

Changes to the modeling of groundwater transport involve minor changes to modeling parameters based on more extensive data, the selection of a single steady-state flow field, and the addition of a proposed slurry wall intended to reduce groundwater fluxes from the high-range wells. Better data sets of hydraulic conductivity estimates and water table elevation measurements throughout SWSA 6 provided an improved basis for calibration of the groundwater flow model. The base modeling grid was slightly refined and extended to allow for better modeling of the area to the west of 
the IWMF during the time that additional IWMF pads were proposed. The groundwater modeling program, USGS MOC, was not changed between versions.

The groundwater recharge and flow field for the initial PA changed over time, in order to reflect short-term changes in water infiltration behavior at the ground surface. Calculations for the revised PA used a single steady-state flow field representative of long-term conditions of the site. This simplification was necessary to reduce the amount of time required by the computer to make calculations, since the number of radionuclides analyzed in this revised PA was increased from 35 to 63. The effect of this change is to allow somewhat faster transport of radionuclides in the first hundred years or so, resulting in lower disposal limits for short-lived mobile species such as tritium. This conservative adjustment was necessary to accomplish the modeling of many more species than was done in the initial PA.

A correction was made to resolve discrepancies found in the initial PA analyses with respect to flux of water from the shallow subsurface model to the groundwater as recharge. For the current revision, these values are consistent with one another.

Calculations for the transport of ${ }^{238} \mathrm{U}$ in the initial PA were performed as a special case of onedimensional analytical modeling, since the MOC model, used for everything else, would not converge to a satisfactory result. With improvements in the modeling process this special case was no longer necessary.

\subsubsection{Changes in Exposure Scenarios for Off-Site Individuals}

This revised PA for the SWSA 6 disposal facility includes two important changes in assumptions about exposure scenarios for off-site individuals compared with the initial PA.

First, although the revised PA assumes, as did the initial PA, that releases of radionuclides to groundwater and surface water are the most important in determining potential doses to off-site individuals, this revised PA also evaluates doses to off-site individuals from atmospheric releases of the volatile radionuclides ${ }^{3} \mathrm{H}$ and ${ }^{14} \mathrm{C}$, based on modeling of releases to air, atmospheric transport, and exposure pathways. In the previous assessment, the atmospheric transport pathway was assumed to be unimportant based solely on historical air monitoring data for the ORR, and this pathway was not evaluated further. An evaluation of the atmospheric transport pathway based on modeling is particularly important for the IWMF because the results are used, in conjunction with the modeling results for releases to water, in establishing WAC for the volatile radionuclides of concern.

Second, in evaluating doses to off-site individuals from releases of radionuclides to surface water, this revised PA considers doses due to consumption of contaminated fish. This potentially important exposure pathway was not considered in the initial PA. The other exposure pathways resulting from releases to groundwater or surface water-including the drinking water, milk, and meat pathways and swimming in contaminated surface water-essentially are unchanged from the initial PA.

In addition, the results of the dose analysis for off-site individuals due to releases of radionuclides to groundwater or surface water in the form of annual doses per unit concentration of radionuclides in water are presented somewhat differently than in the initial PA. 
First, in the analyses of dose from all exposure pathways combined, the annual doses per unit concentration for exposure to contaminated groundwater are presented separately from the results for contaminated surface water. This separation is useful because only the drinking water, milk, and meat pathways apply to groundwater, whereas all of the assumed exposure pathways apply to surface water.

Second, in the analyses of dose from all exposure pathways combined for contaminated surface water, the annual doses per unit concentration for exposure to water in WOC are presented separately from the results for exposure to water in the Clinch River. This separation takes into account that the fish pathway is assumed to apply only in the Clinch River, but not in WOC, and that the average concentrations of radionuclides in the Clinch River would be considerably less than in WOC, due to the dilution of contaminants from the creek when mixed with the much larger volume of water in the Clinch River.

\subsubsection{Changes in Exposure Scenarios for Inadvertent Intruders}

This revised PA for the SWSA 6 disposal facility includes two important changes in assumptions about exposure scenarios for inadvertent intruders compared with the initial PA.

First, the scenario for exposure of inadvertent intruders to contaminated groundwater or surface water on the disposal site included in the initial PA has been deleted from this revised PA. The exclusion of scenarios for exposure of inadvertent intruders to contaminated water on the disposal site is based on the recent DOE policy statement that the relevant exposure scenarios for inadvertent intruders to be considered in PAs are only those that involve exposure to solid waste remaining in the disposal units (DOE 1996c). The justification for excluding exposures to contaminated water on the disposal site from the dose analysis for inadvertent intruders is discussed in more detail in Sect. 2.5.2.

Second, in evaluating the post-drilling scenario for inadvertent intruders, the volume of waste that is assumed to be exhumed by drilling has been reduced by a factor of 10 in this revised PA compared with the initial PA. This change was based on consideration of the thickness of waste in the various disposal units in the SWSA 6 facility and the recognition that the volume of drilling waste assumed previously was unreasonably large for this facility. Since the dose for the post-drilling scenario is proportional to the volume of waste exhumed by drilling, the results obtained in this revised PA are a factor of 10 less than the results obtained in the initial PA. The other exposure scenarios for inadvertent intruders considered in this PA, including the agriculture, resident, and discovery scenarios, are essentially unchanged from the initial PA except, as noted above, exposures to contaminated water on the disposal site have been excluded.

In addition, the results of the dose analysis for the agriculture scenario, in the form of annual doses per unit concentration of radionuclides in waste prior to disposal, are presented somewhat differently than in the initial PA. The agriculture scenario involves exposure to waste remaining in the disposal units and to waste that has been exhumed from the units and mixed with native soil in a vegetable garden. In the dose analysis for the agriculture scenario presented in this revised PA, the annual doses per unit concentration are presented separately for exposure to waste in the disposal units and to waste in the vegetable garden. This separation is useful because, for a given concentration in waste prior to disposal, the average concentration of waste within the disposal units is different from 
the average concentration in material exhumed from the units when the thickness of uncontaminated cover material that would be exhumed along with the waste is taken into account.

\subsubsection{Changes in Parameter Values for Exposure Pathway Models}

For evaluation of doses for the assumed exposure pathways for off-site individuals and inadvertent intruders, some of the parameter values assumed in this revised PA are different from the values assumed in the initial PA. In particular, changes have been made in the internal and external dosimetry data used in the revised PA.

For ingestion and inhalation of radionuclides, the internal dose conversion factors (i.e., the doses per unit activity intake) used in the revised PA were obtained from Federal Guidance Report No. 11 (Eckerman, Wolbarst, and Richardson 1988). These data replace the internal dose conversion factors from the DOE compilation (DOE 1988b) used in the initial PA. For all radionuclides considered in this assessment, the change in internal dose conversion factors results in changes in calculated doses of less than $20 \%$.

For external exposure to radionuclides, many of the external dose-rate conversion factors (i.e., the dose rates per unit activity concentration in the source region) used in the revised PA were obtained from Federal Guidance Report No. 12 (Eckerman and Ryman 1993). In particular, these data were used in evaluating external dose from immersion in contaminated water, exposure to radionuclides in surface soil, and exposure to radionuclides in uncovered waste in disposal units. The newer data for these exposure pathways replace the external dose-rate conversion factors from the DOE compilation (DOE 1988a) used in the initial PA. For all radionuclides considered in this revised $\mathrm{PA}$, the change in external dose-rate conversion factors for these exposure pathways results in changes in calculated doses of about $20 \%$ or less.

In evaluating external dose from exposure to waste in disposal units which are shielded by a layer of uncontaminated material, the external dose-rate conversion factors used in the revised PA are unchanged from the values used in the initial PA, because the appropriate data are not provided in the Federal Guidance report. The external dose-rate conversion factors for these pathways used in this assessment are known to be in error, but probably by no more than about $20 \%$.

All other parameter values used in the exposure pathway models in the revised PA, including the transfer coefficients through food chain pathways and the usage factors for internal and external exposure pathways, are the same as in the initial PA.

\subsubsection{Changes in the Uncertainty Analysis}

The objective (input variable) uncertainty analysis method used in the initial PA was based on the forward propagation of parametric uncertainty through the assessment computer models. This method of uncertainty analysis has been retained for the revised PA of the non-IWMF part of SWSA 6 . For the IWMF, the revised PA was performed by back-calculating the maximum allowable radionuclide inventory based on the regulatory limits. The uncertainty analysis for the IWMF was 
performed with the IWMF inventory fixed at the evaluated disposal limits. The effects of the uncertainty in the disposed inventory on disposal operations is addressed in Sect. 7.1.

Since the initial PA, several changes to the non-IWMF part of SWSA 6 have occurred: (1) the number of disposal units under each disposal unit type accounted for in the initial PA has changed, (2) new disposal units have been added, and (3) the radionuclide inventory, which was based on the final reported inventory, has changed in some cases. To account for these changes, the uncertainties associated with the non-IWMF radionuclide inventories were updated in the following manner:

- The uncertainties in the radionuclide inventory were applied to the reported inventories instead of to the most probable activity (MPA). The initial PA modeling was based on the MPA values and the associated uncertainties.

- The same magnitude of uncertainty used in the initial PA was used for cases where the inventory had not changed appreciably (within approximately $\pm 20 \%$ ).

- The largest (most conservative) magnitude of uncertainty was used for the radionuclides from the initial PA for cases where the inventories had changed appreciably or where the radionuclides were not considered or did not exist in the inventories of the initial PA. [Changes to the inventories, from the standpoint of the PA, could be due to several reasons. including the addition or removal of waste packages in certain disposal units and the addition of neu disposal units. Also, the use of "zones" has resulted in a redistribution of the inventories for calculation purposes. Review of inventory records resulted in an update of the (WMRAD-WTS) database.]

The changes to the uncertainty estimates for the non-IWMF radionuclide inventory are described in more detail in Appendix A. 


\section{DISPOSAL FACILITY DESCRIPTION}

This section presents a brief review of the known characteristics of SWSA 6 , including the IWMF; the characteristics of the wastes disposed in SWSA 6 (after September 26, 1988) and anticipated to be disposed of in IWMF; and a summary of disposal unit designs. The descriptions presented are intended to provide the essential background for understanding the analysis of the facility performance and to summarize the work that has been performed in site characterization and facility design.

\subsection{SITE CHARACTERISTICS}

SWSA 6 has been used as a LLW disposal facility since 1969 and continuously since 1974 . The site has been investigated extensively, and much of the site description is based on these investigations. A summary of the detailed investigations of the site is available in Bechtel (1991a).

\subsubsection{Geography and Demography}

The geography surrounding SWSA 6 and DOE's ORR is typical of the Tennessee Valley, with lineaments of rolling wooded hills and ridges trending northeast, dissected by networks of streams which drain the regionally copious rainfall. In general, ridges are sparsely populated, with farms, towns, and cities spread out in valleys. The ORR is an uninhabited tract of government-owned land containing three principal industrial sites [the Y-12 Plant, ORNL, and the ETTP (formerly the K-25 Site)] established in the early 1940s as part of the Manhattan Project. The nearest center of population is the residential section of Oak Ridge, which borders the ORR to the north and east. The ORR is substantially bordered to the south and west by the Clinch River.

\subsubsection{Disposal Site Location}

The SWSA 6 site is located about $3 \mathrm{~km}$ (1.9 miles) south of ORNL on the ORR, as shown in Fig. 3.1. The site lies in Melton Valley near the southwestern boundary of the ORR and is completely contained within the WOC watershed (Fig. 3.2). Significant local features include WOL south of SWSA 6, and the Clinch River, located about $1 \mathrm{~km}(0.6 \mathrm{mile})$ southwest of the site.

SWSA 6 has been used by ORNL for disposal of on-site-generated solid LLW (SLLW) for approximately 25 years. Development of the 28 -ha (68-acre) site began in 1959, and the operational life is estimated to continue through 2003 . Fewer than 12 ha ( 30 acres) of the total site are usable for LLW disposal because of land use constraints imposed by steep slopes, a shallow water table, or proximity to streams. 


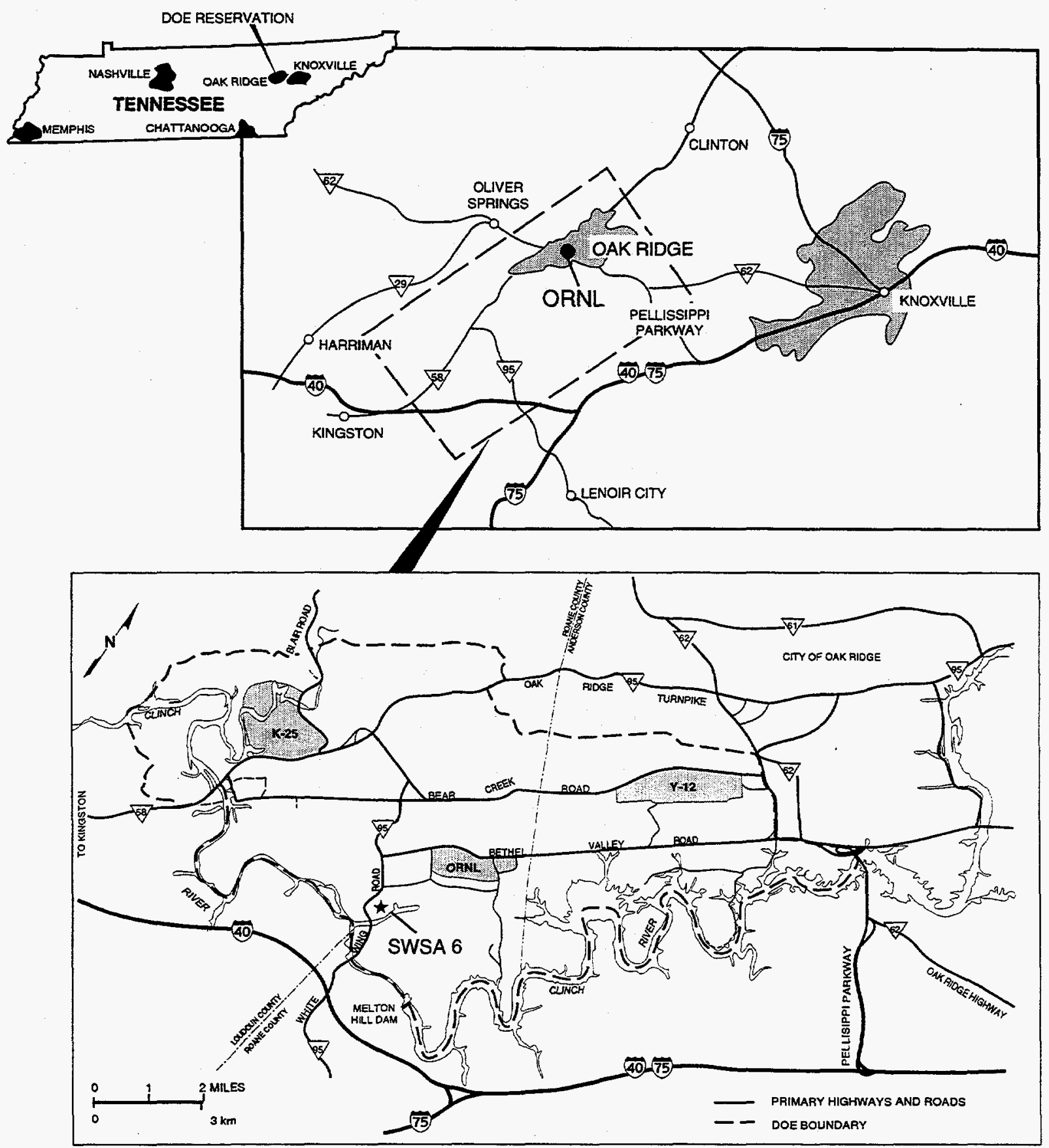

Fig. 3.1. General location map for Oak Ridge Reservation, Oak Ridge National Laboratory, and Solid Waste Storage Area 6. 


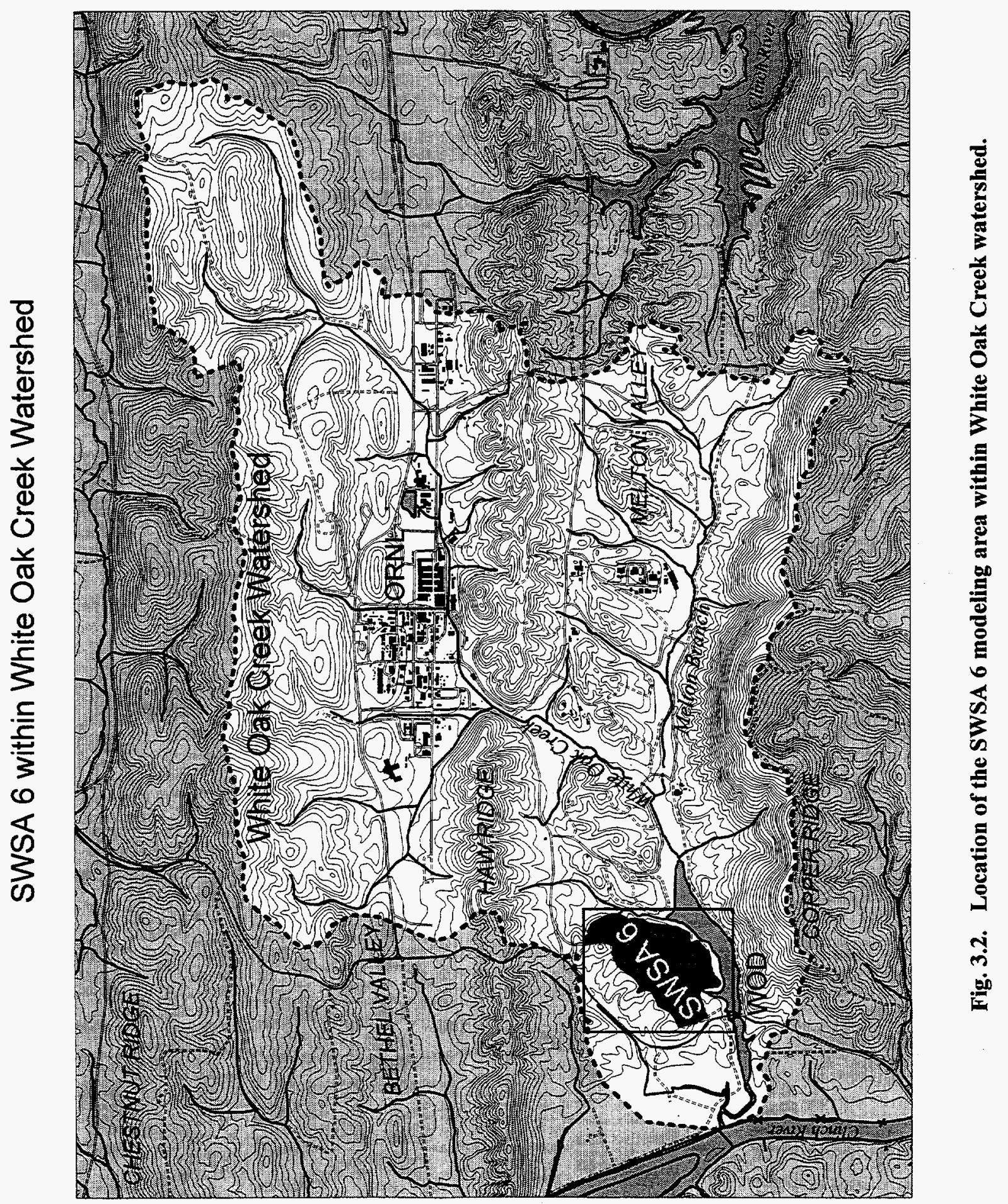




\subsubsection{Disposal Site Description}

The relatively remote location of SWSA 6 within the ORR limits the potential for interaction between waste disposal operations and the public. Population distribution and use of adjacent land are discussed in detail in Sects. 3.1.1.3 and 3.1.1.4. Access to SWSA 6 is gained only from within the security boundary for ORNL, with SWSA 6 having an additional security perimeter. The site's natural resources are common to the Valley and Ridge Province, and no unique geologic or hydrologic resources are associated with the disposal facility. The natural resources of the site are discussed in detail in Sect. 3.1.7.

SWSA 6 is bordered on the south by WOL, an impoundment of WOC. This lake is formed by WOD, an earthen dam located where State Highway 95 crosses the WOC Embayment, as seen in the foreground of the aerial photograph in Fig. 3.3. Surface runoff from SWSA 6 drains to three small ephemeral creeks which discharge to WOL.

SWSA 6 began accepting waste in 1969 and has been used for the disposal of radioactive waste continuously since 1974 . Most of the 28-ha (68-acre) area within SWSA 6 that is suitable for disposal had been utilized prior to September 26,1988 . The overall facility was the subject of RCRA remediation as of September 26, 1988, and is now a subject of CERCLA remediation. Fig. 3.4 shows the location of the individual disposal units within SWSA 6 that have accepted waste since September 26,1988 , and are considered in this revised PA. A map of SWSA 6 identifying local surface waters, State Highway 95, WOD, and the disposal unit groups in SWSA 6, including the interim closure caps over disposal areas used prior to September 26, 1988, is shown in Fig. 3.5. Disposal operations subject to this revised PA are a combination of shallow land burial trenches, wells, silos, and tumulus disposal units. The detailed description of these disposal units is presented in Sect. 3.2. Disposal units used prior to September 26, 1988, and neighboring disposal units (all those in the WOC watershed) that could contribute to the impacts of disposal units considered in this revised PA are considered in the Composite Analysis for SWSA 6 (ORNL 1997b), which is a companion document to this PA.

\subsubsection{Population Distribution}

The population of the ten counties nearest the ORR is 717,880 , based on the 1990 census (Fig. 3.6). Towns in the vicinity of the ORR include Oak Ridge, Oliver Springs, Clinton, Lenoir City, Farragut, Kingston, and Harriman (Fig. 3.7). Knoxville, the major metropolitan area nearest Oak Ridge, is about $40 \mathrm{~km}$ ( 25 miles) to the east and has a population of about 165,000 (1990 census).

\subsubsection{Uses of Adjacent Lands}

The ORR consists of approximately 14,000 ha (34,500 acres), located mostly within the corporate limits of the city of Oak Ridge, approximately $20 \mathrm{~km}$ (12 miles) west of Knoxville, Tennessee. All the land within the ORR is owned by the federal government and is administered, managed, and controlled by DOE. 


\section{View of SWSA 6 to the North Over White Oak Dam}

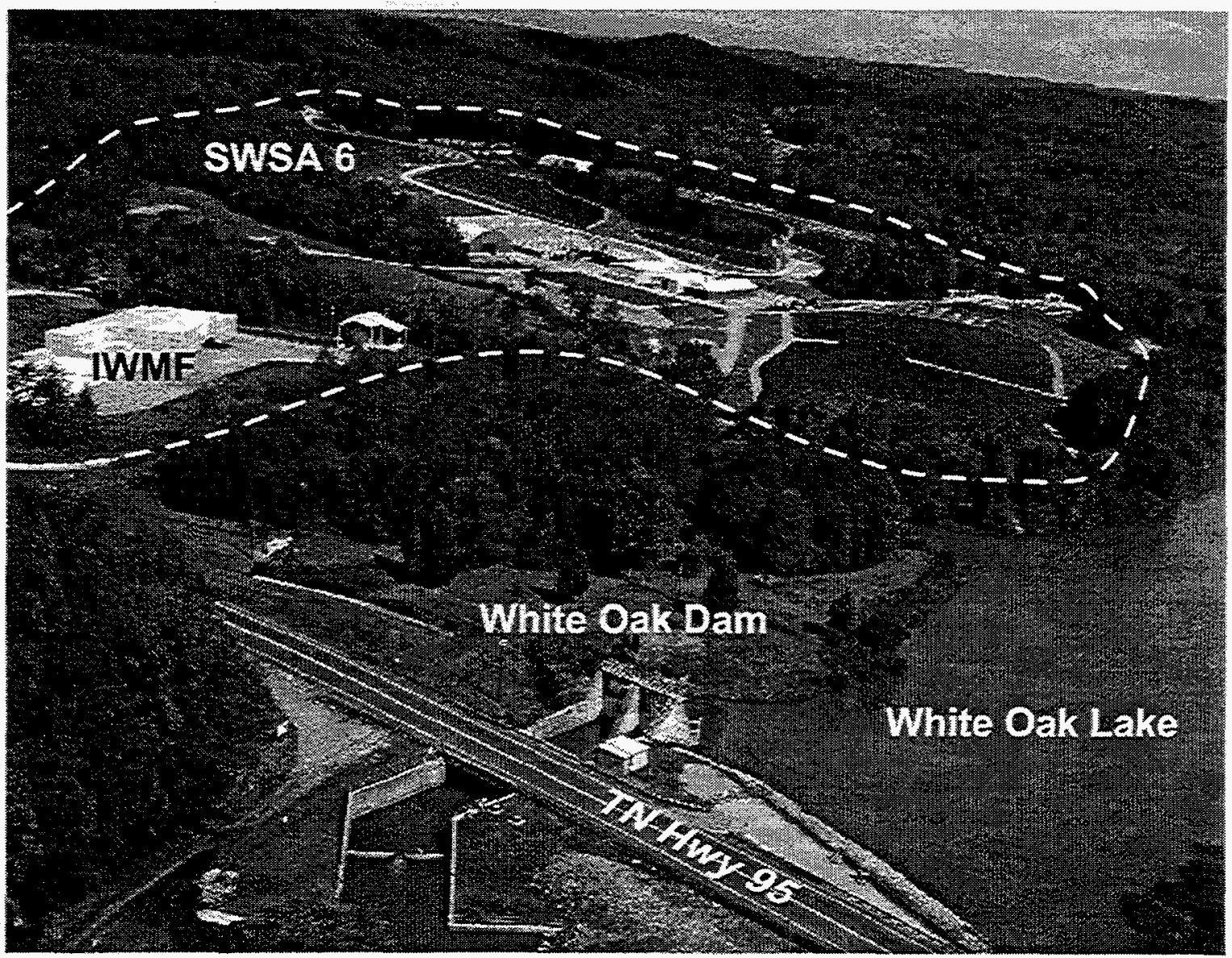

Fig. 3.3. Aerial photograph of SWSA 6 and White Oak Dam. 
Disposals Within SWSA 6 After September, 1988

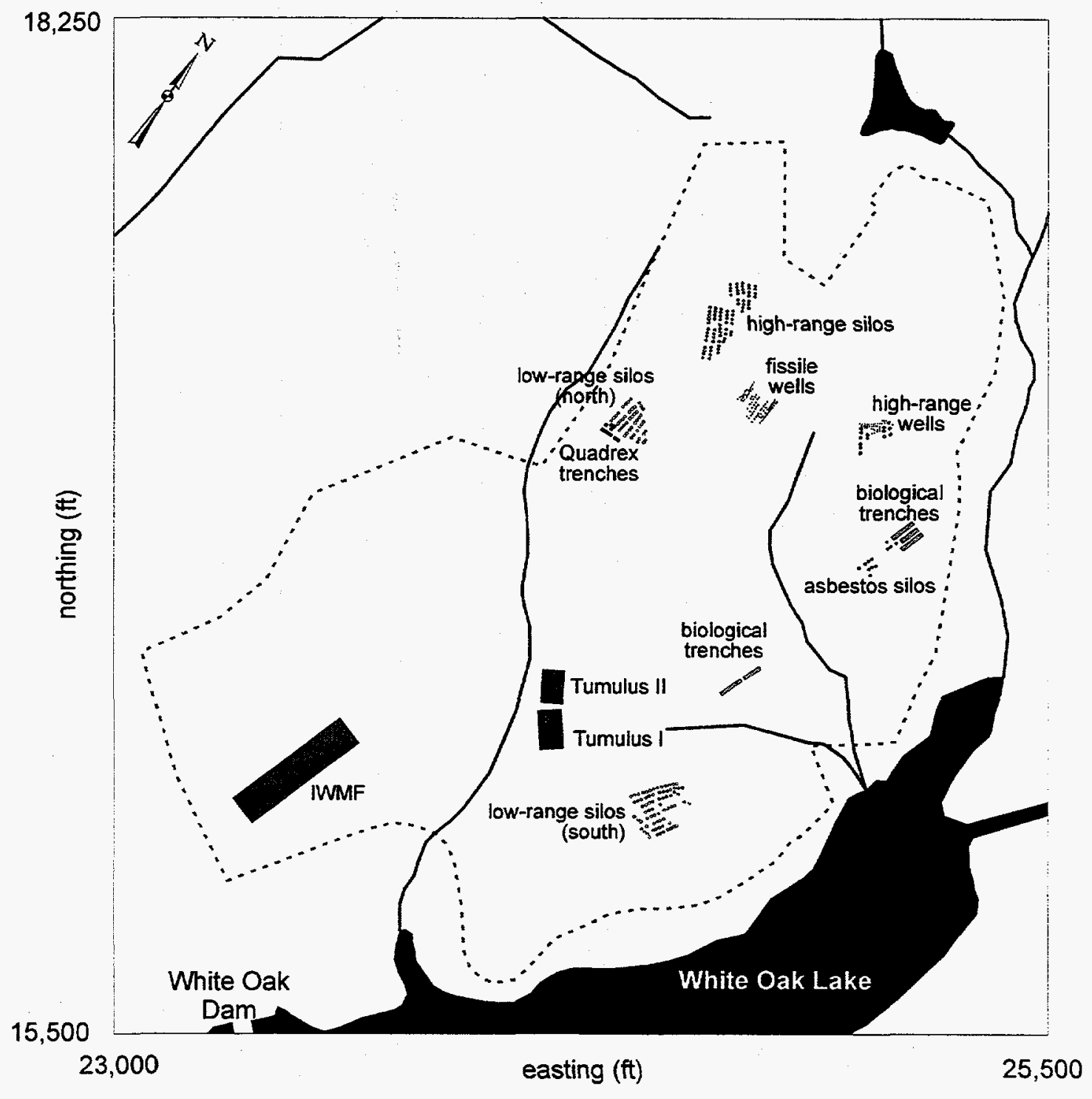

Fig. 3.4. Location of individual disposal units in SWSA 6 made after September 26, 1988. 


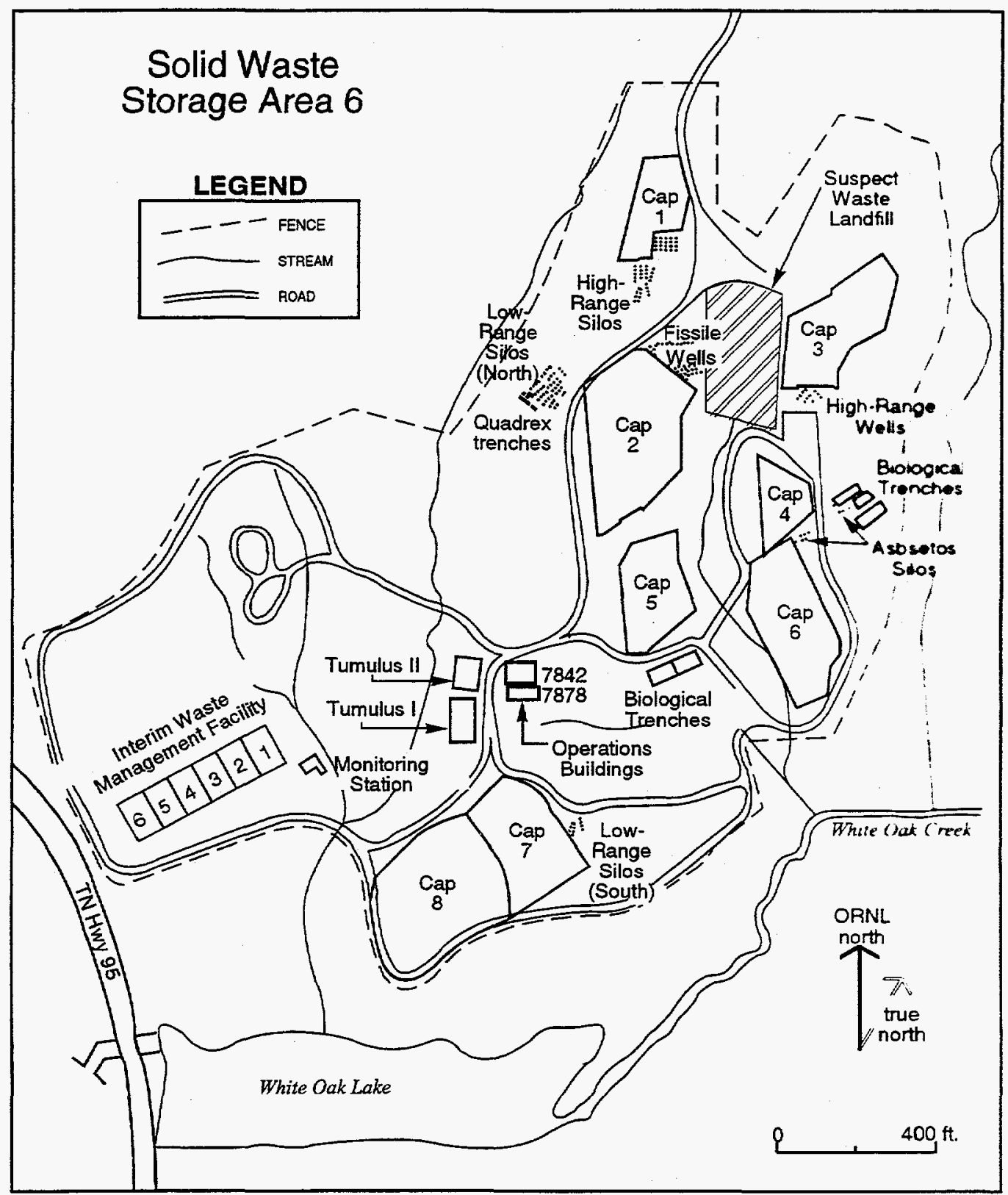

Fig. 3.5. Location of SWSA 6 waste disposal facility groups and caps. 


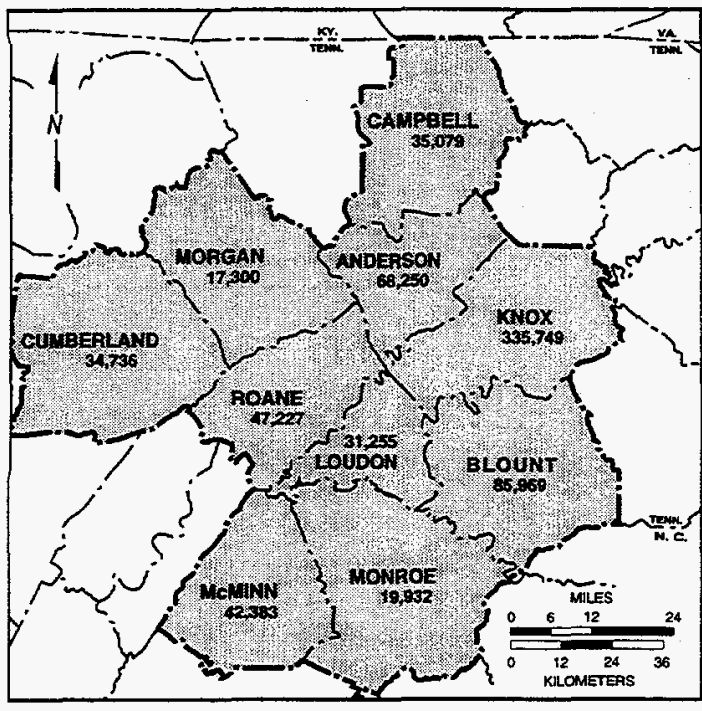

Fig. 3.6. Locations and populations of counties near Oak Ridge Reservation.

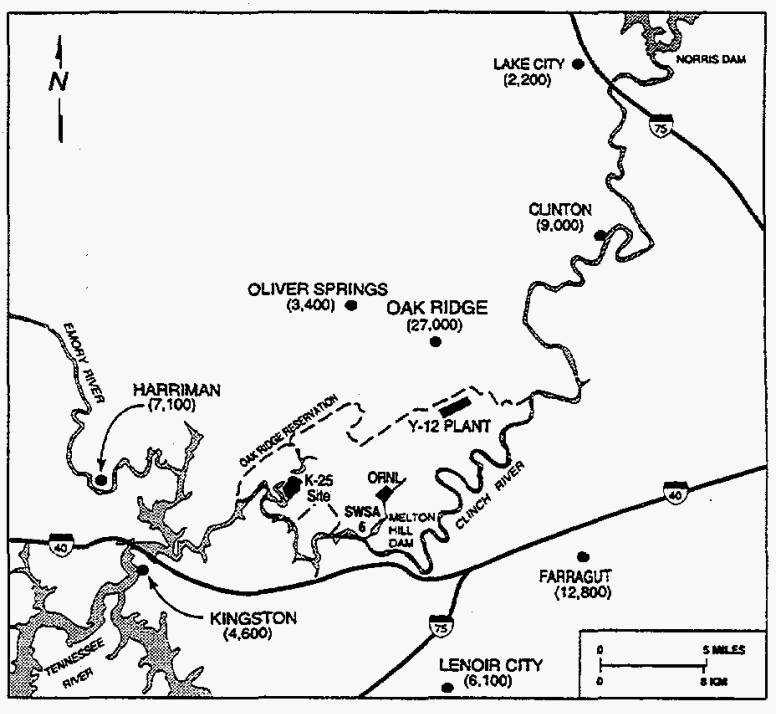

Fig. 3.7. Locations and populations of towns near Oak Ridge Reservation.

Land uses within ORR can be grouped into four classifications: industrial, forested/ undeveloped, public/quasi-public, and water. The industrial areas account for approximately 4700 ha (11,600 acres) of the total site acreage. About 500 ha (1,240 acres) are used for a security buffer zone around various facilities. About 300 ha (740 acres) of ORR's land is classified as public land and consists mainly of the 36-ha (89-acre) Clark Center Recreational Park, numerous small public cemeteries, and an on-site public road. The remaining area, about 8,500 ha (21,000 acres), consists of forest and undeveloped land, some of which is managed as pine plantations for production of pulpwood and saw timber. The DOE water treatment facility, which provides water to many ORR facilities and the city of Oak Ridge, is located just north of Y-12. There are no prime farmlands on the ORR.

Land bordering the ORR is predominantly rural and used largely for residences, small farms, forest land, and pasture land. The city of Oak Ridge, adjacent to the northeast portion of ORR, has a typical urban mix of residential, public, commercial, and industrial land uses. There are four residential areas along the northern boundary of ORR, and each has several residences within $30 \mathrm{~m}$ (100 ft) of the site boundary.

The shortest distance from the SWSA 6 disposal facility to the ORR boundary, at the point at which WOC discharges to the Clinch River, is approximately $1 \mathrm{~km}(0.6 \mathrm{mile})$. The location of SWSA 6 in the Melton Valley area is consistent with and adjacent to the historical sites for radioactive waste disposal at ORNL, since Melton Valley has been used for disposal of solid and liquid wastes (at SWSA 4, SWSA 5, Pits and Trenches, and the hydrofracture facilities) since the early 1950s. Much of the land in Melton Valley, including SWSA 6 and the adjacent WOL, is currently subject to remediation under CERCLA. WOL receives all the liquid discharges from the 
ORNL main plant area located in Bethel Valley, all of the liquid discharges from active facilities located in Melton Valley (e.g. the High-Flux Isotope Reactor and the Radiochemical Engineering Development Center), and any contaminated discharges from ORNL facilities that are included in the decontamination and decommissioning (D\&D) program or are part of the CERLCA process on the ORR. The portion of SWSA 6 being considered in this PA is the last facility on the ORR that can contribute contamination to the WOL prior to its discharge to the WOC embayment and subsequently to the Clinch River. Since SWSA 6 will ultimately be closed under the CERCLA process, potential discharges from the portion of SWSA 6 considered in this PA are not anticipated to adversely affect any other facility or existing land use in the vicinity of SWSA 6.

Land use planning on the ORR is an ongoing activity and is directed toward the long-term reduction of the DOE footprint in the Oak Ridge area. While current planning for the footprint reduction effort is incomplete, there are no existing plans or discussions of any plans to release the land associated with SWSA 6, or any of the land potentially contaminated from historical operations on the ORR, to the public at any time in the future. Access to land potentially contaminated from historical operations is controlled by fences, security patrols, and gates to prevent potential exposure of the public to radioactive materials. There are no plans to reduce the present level of access controls in the vicinity of SWSA 6.

\subsubsection{Meteorology and Climatology}

The climate of the ORR is moderated by the influence of the Cumberland Mountains to the west and the Great Smoky Mountains to the east. They divert the hot winds emanating from the Atlantic coast to produce warm, humid summers and cool winters. Extremes in precipitation, temperature, and winds are uncommon.

The mean annual temperature in Oak Ridge is $14.4^{\circ} \mathrm{C}\left(58^{\circ} \mathrm{F}\right)$. The coldest month is usually January, with temperatures averaging $3.3^{\circ} \mathrm{C}\left(38^{\circ} \mathrm{F}\right)$ and lows occasionally reaching $-17^{\circ} \mathrm{C}\left(0^{\circ} \mathrm{F}\right)$. The warmest month is usually July, with temperatures averaging $25^{\circ} \mathrm{C}\left(77^{\circ} \mathrm{F}\right)$ and highs occasionally reaching $38^{\circ} \mathrm{C}\left(100^{\circ} \mathrm{F}\right)$. Daily temperature fluctuations are typically $12^{\circ} \mathrm{C}\left(20^{\circ} \mathrm{F}\right)$.

Prevailing winds are influenced by the topography and are either up-valley (from the southwest) or down-valley (from the northeast). Daytime winds are typically up-valley, and nighttime winds are typically down-valley. Tornadoes and high winds are rare.

Precipitation is highly variable within and between years. The 40 -year annual average precipitation is $1.4 \mathrm{~m}$ (54 in.) with approximately $0.26 \mathrm{~m}$ (10.4 in.) of snowfall. Monthly precipitation is typically highest in January and February, with storms of low intensity and long duration. Thunderstorms are common during the summer. October is typically lowest in precipitation.

\subsubsection{Ecology of the ORR}

A large portion of the ORR is forested. The dominant plant association on the ORR is oakhickory forest, which is most widely distributed on ridges and dry slopes (Kitchings and Mann 1976; 
Mann et al. 1996). Southern yellow pines are also common, especially in areas that were cleared and farmed before 1942. The most common understory trees are red maple, blackgum, and sourwood.

The ORR provides habitat for a large number of animal species, including about 60 reptilian and amphibian species, more than 152 species of birds (including 32 species of waterfowl, wading birds, and shorebirds), and about 40 mammalian species (Mann et al. 1996). Habitats supporting the greatest number of species are those dominated by hardwood forests and wetlands.

Suitable habitat for the federally listed threatened bald eagle exists on Melton Hill Lake, which borders the ORR on the south, and eagles have recently been observed there. In addition, a dead endangered gray bat was recently found at the $\mathrm{Y}-12$ plant. No other federally listed threatened or endangered plant or animal species are known to occur on the ORR except for threatened peregrine falcons, which are uncommon visitors.

Of the animals listed by the state of Tennessee as endangered or threatened (Hatcher 1994a), only the threatened osprey is known to occur regularly on the ORR. Other state endangered or threatened species of wildlife may occasionally visit the ORR, but suitable breeding habitat is not present (Kroodsma 1987). Wildlife species designated by the state as in need of management on the ORR have been reported by Hatcher (1994b).

A number of plant species that are found on the ORR are candidates for federal listing or are listed by the state of Tennessee as endangered, threatened, or of special concem (Mann et al. 1996).

\subsubsection{Aquatic Ecology of Melton Valley}

Extensive studies of Melton Branch and WOC conducted under the ORNL Biological Monitoring and Abatement Program included in-stream ecological monitoring. studies of the periphyton communities, toxicity testing, radioecological studies, and studies of bioaccumulation of nonradiological contaminants. Results of studies from 1986 through 1990 have been reported in a series of annual reports covering this period (Loar et al. 1987-92). Except during drier than normal months, there is sufficient flow in Melton Branch to allow the maintenance of a relatively diverse benthic macroinvertebrate community and a small fish community (Ryon 1988; Smith 1988a, 1992). Beaver dams have been found at several places in the WOC watershed (Rosensteel 1995).

Fish surveys in lower Melton Branch $0.6 \mathrm{~km}$ ( 0.4 mile) above its confluence with WOC found creek chubs, blacknose dace, and redbreast sunfish (Loar et al. 1991). The densities and standing crops of fish found in lower Melton Branch are comparable with values from other small headwater streams in the area. Samples in uppermost Melton Branch [Melton Branch km 1.4 and 2.1 (miles 0.86 and 1.3)] found only creek chubs and blacknose dace. A weir on Melton Branch upstream of $\mathrm{km} 2.1$ (mile 1.3) serves as a barrier to movement of fish further upstream.

Most of the benthic macroinvertebrate taxa sampled in Melton Branch are typical of either moderately disturbed or relatively undisturbed streams on ORR (Smith 1988a, 1988b; Smith and Ryon 1989). The relative abundance and biomass of disturbance-intolerant species of benthic insects [Plecoptera (stoneflies) and Ephemetoptera (mayflies)] in upper Melton Branch km 2.1 (mile 1.3) 
were greater than the composition of the downstream sampling sites at $\mathrm{km} 1.2$ and 0.6 (miles 0.75 and 0.37 ), indicating that the upstream reaches are relatively undisturbed (Smith 1992).

\subsubsection{Terrestrial Ecology of Melton Valley}

Melton Valley contains a variety of ecosystems, from those that are greatly disturbed to some that are relatively undisturbed. Where the valley has been heavily disturbed, the current vegetation cover is primarily grass and herbaceous plants. The vegetation in the rest of the valley is typical of forests found throughout the ORR (Cunningham, Pounds, and Parr 1988). Relatively undisturbed second-growth forests of mixed oak-hickory occur on the ridges and dry slopes, while pine and pinehardwood on the lower slopes and valleys are typical of abandoned, eroded farmland on the ORR.

Wildlife in Melton Valley is also typical of that on the ORR as a whole (Kroodsma 1985) and includes rat snakes, black racers, red-eyed vireos, scarlet tanagers, red-tailed and red-shouldered hawks, yellow-billed cuckoos, coyotes, deer mice, gray squirrels, flying squirrels, and white-tailed deer.

No federally listed or proposed endangered or threatened plant or animal species or designated or proposed critical habitats are known to regularly occur in Melton Valley, but the threatened bald eagle and peregrine falcon are uncommon visitors to the vicinity.

While some state-listed endangered or threatened species of wildlife (Hatcher 1994a) may occasionally visit the vicinity, no suitable breeding habitat is present, and no such animal species are known to regularly occur (Kroodsma 1987). Of species listed by the state as in need of management (Hatcher 1994b), the southeastern shrew, Cooper's hawk, the sharp-shinned hawk, and the yellowbellied sapsucker are known to be present in Melton Valley. Other animal species listed by the state as in need of management that may be found in wetlands in Melton Valley are the northern harrier, the little blue heron, and the great egret (Mitchell 1995).

Some plants listed by the state as threatened or endangered are known to occur in Melton Valley. Pink lady's slipper, a species endangered in Tennessee due to commercial exploitation, and ginseng, a species listed by the state as threatened, grow in the valley. A small population of the statelisted threatened Canada lily grows in one wetland area. River bulrush and lesser lady's tresses, species listed by the state as of special concern, have also been reported from Melton Valley (Awl 1995).

\subsubsection{Geology, Seismology, and Volcanology}

This section discusses the regional geologic setting within the Valley and Ridge Province in East Tennessee, as well as the local geology and soils in the vicinity of Melton Valley and SWSA 6. 


\subsubsection{Regional and Site-Specific Geology and Topography}

The topography of the ORR (Fig. 3.8) and SWSA 6 (Fig. 3.9) is typical of that in the western portion of the Valley and Ridge Province of eastern Tennessee. The valley is about $2 \mathrm{~km}$ (1.2 miles) wide and trends northeast-southwest. Haw Ridge lies about $1 \mathrm{~km}(0.6$ mile) northwest of Melton Valley with crest elevations of approximately $300 \mathrm{~m}(1000 \mathrm{ft})$. Melton Hill, with a high crest of $413 \mathrm{~m}$ (1356 ft) on Copper Ridge, lies about $1 \mathrm{~km}(0.6 \mathrm{mile})$ southeast of the axis of Melton Valley. A line of low knobs with crest elevations of about $260 \mathrm{~m}(850 \mathrm{ft}$ ) occurs near the center of Melton Valley. SWSA 6 is located on the southeast slope of such a knob. The lowest topography in the vicinity of SWSA 6 is at WOL [ $227 \mathrm{~m} \mathrm{(745} \mathrm{ft)],} \mathrm{giving} \mathrm{a} \mathrm{total} \mathrm{topographic} \mathrm{relief} \mathrm{in} \mathrm{the} \mathrm{site} \mathrm{of} \mathrm{about}$ $30 \mathrm{~m}$ (100 ft). Slopes within SWSA 6 range from less than $5 \%$ to greater than $25 \%$.

The ORR is underlain by sedimentary bedrock of the Paleozoic era that generally dips to the southeast in an imbricate pattern due to the regional geologic structure that formed during the Appalachian Orogeny some 300 million years ago. The stratigraphic column in Table 3.1 includes descriptions and local thicknesses of bedrock formations recognized on the ORR (Lee and Ketelle 1989). A geologic map of the ORR is shown in Fig. 3.10. Geologic structures present on the ORR include regional-scale thrust faults, local faults having various orientations, local folds, and numerous sets of local joints and fractures. Bedrock fracturing is ubiquitous on the ORR, with variations in the degree of fracturing based on local bedrock type and proximity to local or regional-scale folds and faults. Two regionally important thrust faults cross the ORR in a northeast-southwest direction: the White Oak Mountain Fault Zone, which is several kilometers northwest of the SWSA 6 site, and the Copper Creek Fault, which outcrops on the northwest slope of Haw Ridge about $1 \mathrm{~km}$ northwest of SWSA 6.

The Copper Creek Fault underlies SWSA 6 at a depth of about $300 \mathrm{~m}(1000 \mathrm{ft})$ below the land surface. Motion of bedrock above the Copper Creek Fault during the Appalachian Orogeny carried the Upper Rome Formation, the Conasauga Group, and the overlying Knox Group strata to their present orientation. At the end of the Paleozoic, the rocks that outcrop at the land surface were buried deeply beneath a mountainous deformation belt. The present regional terrain is the result of weathering and erosion of bedrock and soils over the millennia since the Appalachian Orogeny.

Variable resistance to weathering and erosion of the dipping strata causes the parallel alignment of ridges and valleys characteristic of the region. Locally, ridges are underlain by weathering- or erosion-resistant rock types, while valleys are underlain by the easily weathered or erodible rock types. Haw Ridge, northwest of SWSA 6, is underlain by the hard sandstones of the Upper Rome Formation. Melton Valley is underlain by interbedded shale, calcareous siltstone, and limestone bedrock of the Conasauga Group. The Conasauga Group is divided into six geologic formations on the ORR (Table 3.1). Conasauga bedrock is fairly weatherable because of the dominance of calcium-carbonate-cemented rock and the high silt content. Variations in the weathering and erosion patterns of the Conasauga formations result in the presence of a line of knobs underlain by the Maryville Limestone near the axis of Melton Valley. 


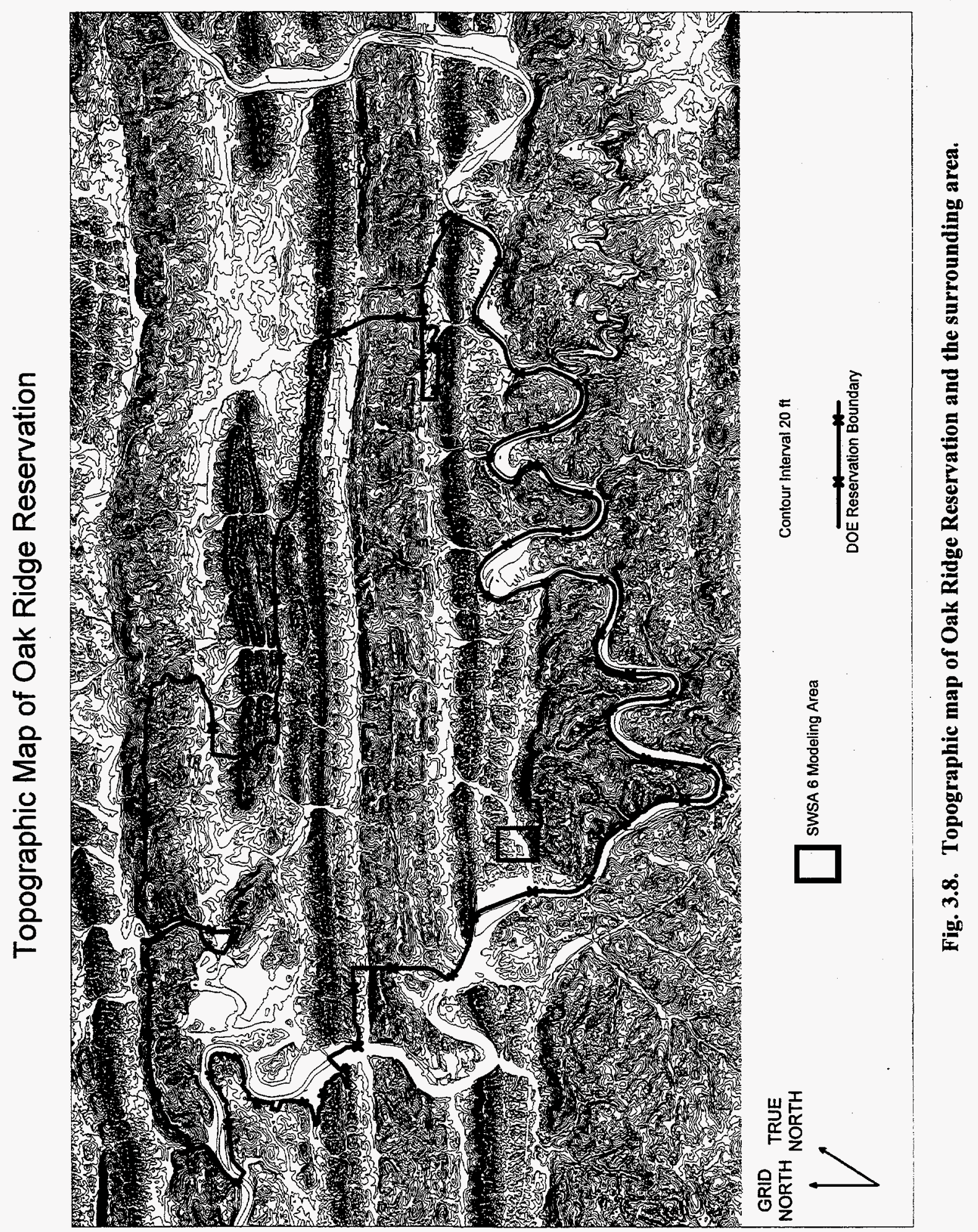




\section{SWSA 6 Topography (ft)}
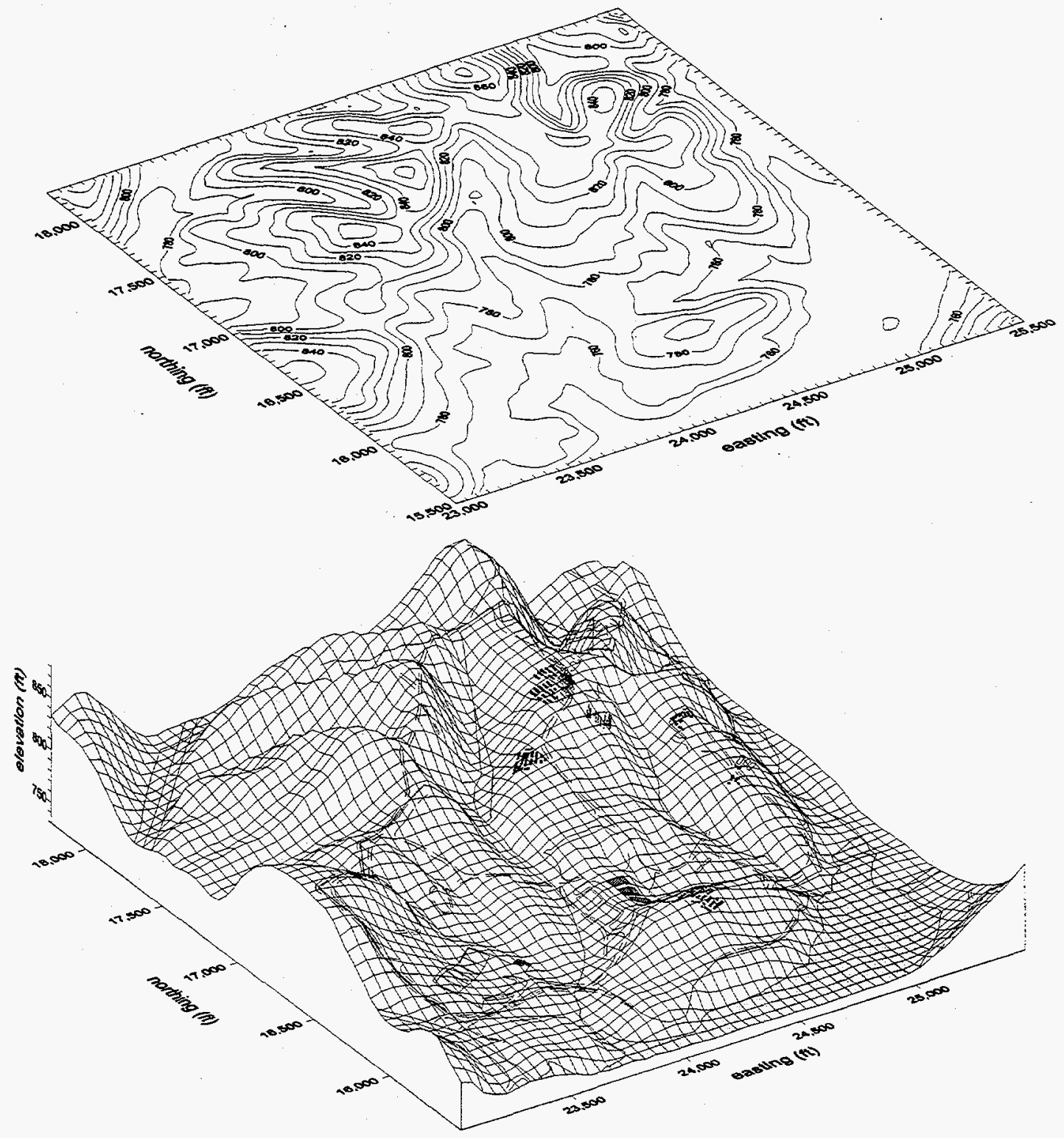

Fig. 3.9. Topography of the SWSA 6 area. 
Table 3.1. Stratigraphic column of Cambro-Ordovician Rocks, White Oak Mountain thrust block, Oak Ridge, Tennessee

\begin{tabular}{|c|c|c|c|c|}
\hline Age & Group $^{\alpha}$ & Formation/unit & Description & $\begin{array}{l}\text { Thickness } \\
(\mathrm{m})\end{array}$ \\
\hline \multirow{8}{*}{ 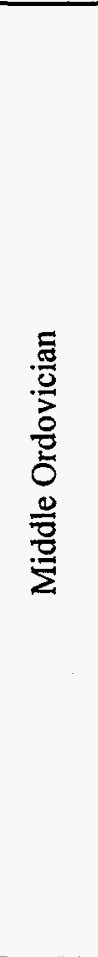 } & \multirow{8}{*}{ 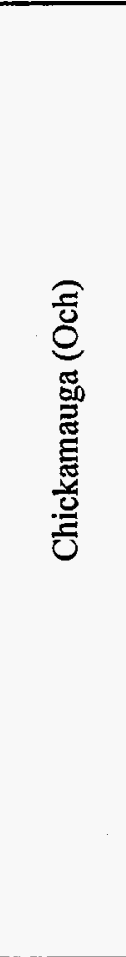 } & Unit $\mathrm{H}^{b}$ & $\begin{array}{l}\text { Thin interbedded limestone and calcareous siltstone. Gray, } \\
\text { olive, buff, and maroon. [Moccasin Fm] }]^{c}\end{array}$ & $>82$ \\
\hline & & Unit G & $\begin{array}{l}\text { Limestone and siltstone in thick beds. Limestone fine to } \\
\text { medium grained, nodular. [Witten Fm] }\end{array}$ & 88 \\
\hline & & Unit $F$ & $\begin{array}{l}\text { Laminated to thin-bedded calcareous and shaly siltstone. } \\
\text { Maroon and olive gray. [Bowen } \mathrm{Fm} \text { ] }\end{array}$ & 6 \\
\hline & & Unit $\mathrm{E}$ & $\begin{array}{l}\text { Limestone and siltstone in thick beds. Limestone fine to } \\
\text { medium grained, nodular, and amorphous. Siltstone dark } \\
\text { gray with limestone laminae. [Benbolt/Wardell Fm] }\end{array}$ & 91 \\
\hline & & Unit D & $\begin{array}{l}\text { Limestone. Medium grained and stylolitic. Nodular chert. } \\
\text { [Rockdell Fm] }\end{array}$ & 43 \\
\hline & & Unit C & $\begin{array}{l}\text { Limestone and siltstone in thick beds. Limestone nodular } \\
\text { and micritic. Siltstone calcareous and dark gray. Nodular } \\
\text { chert. [Fleanor Shale Member, Lincolnshire Fm] }\end{array}$ & 29 \\
\hline & & Unit B & $\begin{array}{l}\text { Siltstone. Massive maroon and gray with limestone in thin, } \\
\text { even beds. [Eidson Member, Lincolnshire Fm] }\end{array}$ & 76 \\
\hline & & Unit $A$ & $\begin{array}{l}\text { Limestone and siltstone in thick beds. Dark to light gray, } \\
\text { purplish to maroon. Nodular and bedded chert. [Blackford } \\
\text { Fm] }\end{array}$ & 91 \\
\hline \multirow{3}{*}{$\frac{\frac{5}{0}}{\frac{0}{2}}$} & \multirow{4}{*}{ 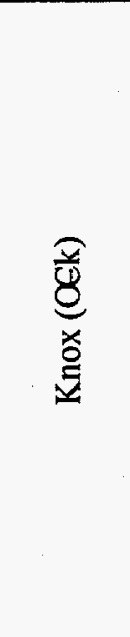 } & Newala & $\begin{array}{l}\text { Medium-bedded dolostones and limestones with variable } \\
\text { chert content, scattered chert matrix limestones. Abundant } \\
\text { maroon mottling. [Mascot Dolomite / Kingsport Fm] }\end{array}$ & $274^{d}$ \\
\hline & & Longview & $\begin{array}{l}\text { Dense, massive chert, bedded chert, and dolomoldic chert } \\
\text { observed in residuum. }\end{array}$ & $15-30^{d}$ \\
\hline & & Chepultepec & $\begin{array}{l}\text { Dolostone, fine to medium grained, light to medium gray, } \\
\text { medium to thick bedded, sandy near base. }\end{array}$ & $150-300^{d}$ \\
\hline 离 & & $\begin{array}{l}\text { Copper } \\
\text { Ridge }\end{array}$ & $\begin{array}{l}\text { Dolostone, medium to thick bedded, fine to coarse } \\
\text { crystalline, medium to dark gray. Chert varieties include } \\
\text { massive, cryptopoan, and oolitic. }\end{array}$ & $274-396^{d}$ \\
\hline
\end{tabular}


Table 3.1 (continued)

\begin{tabular}{|c|c|c|c|c|}
\hline Age & Group $^{\alpha}$ & Formation/unit & Description & $\begin{array}{l}\text { Thickness } \\
\text { (m) }\end{array}$ \\
\hline \multirow{6}{*}{ 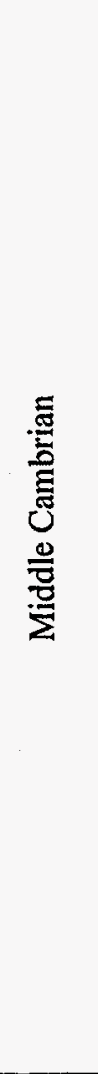 } & \multirow{6}{*}{ 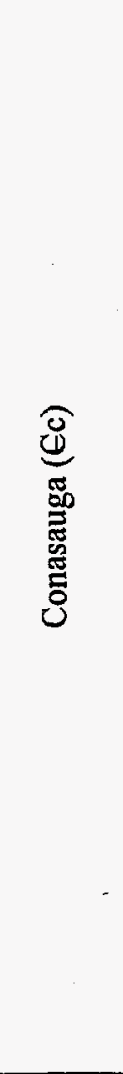 } & $\begin{array}{l}\text { Maynardville } \\
\text { (€mn) }\end{array}$ & $\begin{array}{l}\text { Upper (Chances Branch Mbr.)-limestone and dolomitic } \\
\text { limestone in thick massive beds. } \\
\text { Lower (Low Hollow Mbr.)-dolomotic limestone in thick } \\
\text { massive beds. Light gray to buff. }\end{array}$ & 43 \\
\hline & & $\begin{array}{l}\text { Nolichucky } \\
(\in n)\end{array}$ & $\begin{array}{l}\text { Upper-shale and limestone in thin to thick beds. Shale } \\
\text { dark gray or maroon. Limestone light gray, oolitic, wavy } \\
\text { bedded, or massive. } \\
\text { Lower-shale and limestone in medium to thick beds. } \\
\text { Shale dark gray, olive gray, or maroon. Limestone light } \\
\text { gray, oolitic, glauconitic, wavy bedded, and intraclastic. }\end{array}$ & $131-137$ \\
\hline & & $\begin{array}{l}\text { Maryville } \\
(€ \mathrm{~m})\end{array}$ & $\begin{array}{l}\text { Limestone and shale or siltstone in medium beds. } \\
\text { Limestone light gray, intraclastic, or wavy bedded. Shale } \\
\text { or siltstone dark gray. [Dismal Gap Fm] }\end{array}$ & $98-125$ \\
\hline & & $\begin{array}{l}\text { Rogersville } \\
\text { (Grg) }\end{array}$ & $\begin{array}{l}\text { Shale and argillaceous limestone. Laminated to thin } \\
\text { bedded, maroon, dark gray, and light gray. }\end{array}$ & $24-34$ \\
\hline & & $\begin{array}{l}\text { Rutledge } \\
\text { (Grt) }\end{array}$ & $\begin{array}{l}\text { Limestone and shale in thin beds. Limestone light to olive } \\
\text { gray. Shale gray or maroon. [Friendship Fm] }\end{array}$ & $30-37$ \\
\hline & & $\begin{array}{l}\text { Pumpkin } \\
\text { Valley } \\
\text { (Gpv) }\end{array}$ & $\begin{array}{l}\text { Upper-shale and calcareous siltstone. Laminated to very } \\
\text { thin bedded. Shale reddish brown, reddish gray, or gray. } \\
\text { Calcareous siltstone light gray or glauconitic. } \\
\text { Lower-shale and siltstone or silty sandstone. Thin } \\
\text { bedded. Shale reddish brown or gray to greenish gray. } \\
\text { Siltstone and silty sandstone light gray. }\end{array}$ & $40-46$ \\
\hline 总 & & $\begin{array}{l}\text { Rome } \\
(\in r)\end{array}$ & $\begin{array}{l}\text { Sandstone and thin shale interbeds. Sandstone fine } \\
\text { grained, light gray or pale maroon. Shale maroon or olive } \\
\text { gray. }\end{array}$ & Unknown \\
\hline
\end{tabular}

${ }^{a}$ Group name abbreviations are those commonly used on geologic maps and cross sections in the region.

${ }^{b}$ Chickamauga Group stratigraphic subdivisions reflect those identified at the ORNL site, since a standardized nomenclature for these units has not been published. Other formation names are consistent with regional stratigraphic nomenclature, though some more recent workers have introduced new names.

${ }^{c}$ Nonstandard formation names which may be found in some documents are indicated in square brackets.

${ }^{d}$ Estimated value.

Source: After Lee and Ketelle 1989. 


\section{GEOLOGIC MAP OF THE DOE OAK RIDGE RESERVATION}

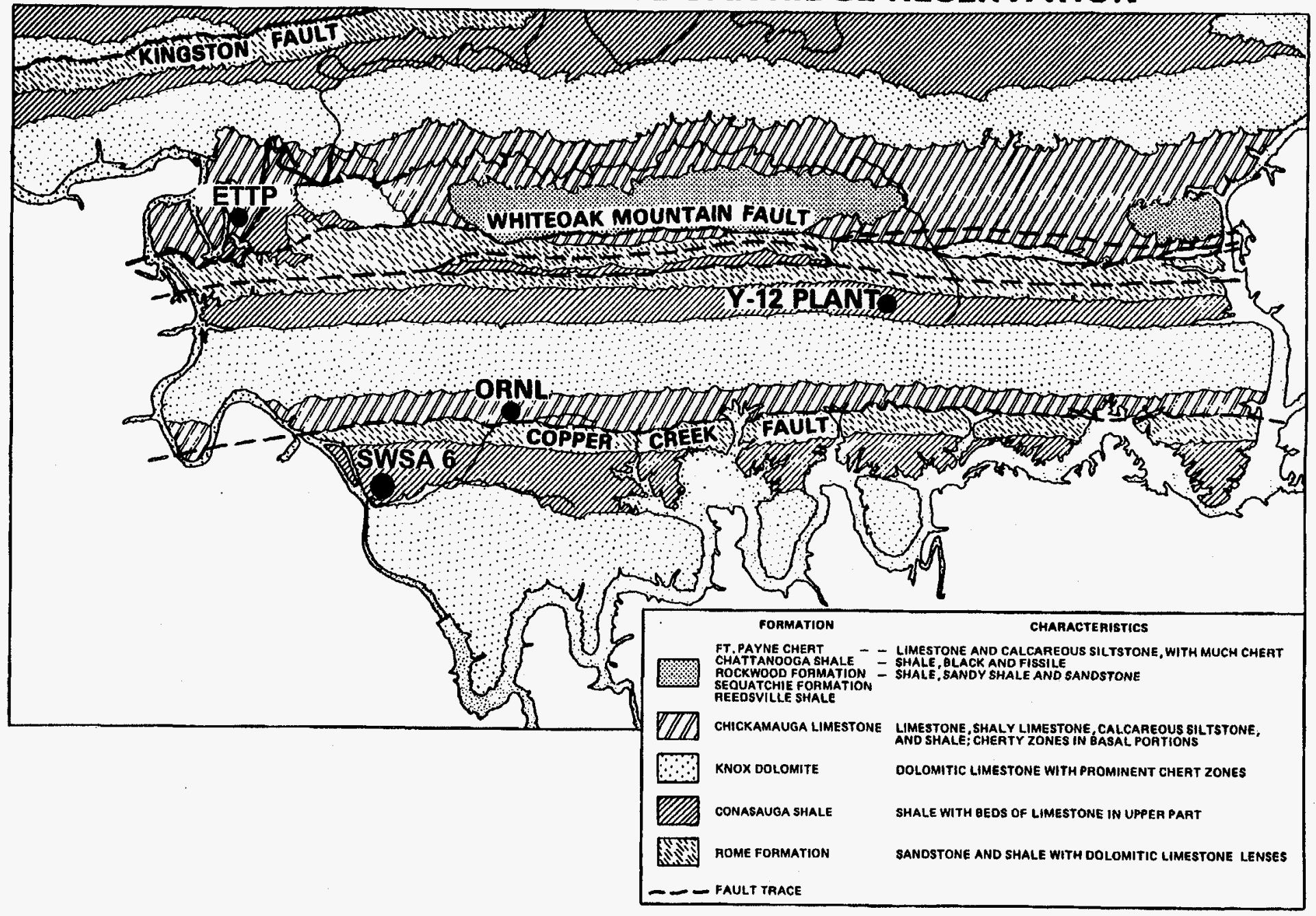


SWSA 6 is underlain by two of the Conasauga Group formations. The Maryville Limestone underlies the northern half of the site, and the Nolichucky Shale underlies the southern half. The SWSA 6 geologic map (Fig. 3.11) and cross section (Fig. 3.12) show the location of the stratigraphic contact between the Maryville Limestone and the Nolichucky Shale as well as other data related to geologic structure of SWSA 6. Overall, the bedrock in SWSA 6 dips to the southeast at an attitude of about 10 to $15^{\circ}$. However, at any specific location within the site, strike and dip of bedding are variable and are affected by local tight, plunging folds that are typically several meters wide and of undetermined length. In addition, there is apparently a general rotation in geologic strike near the middle portion of the site, and localized faulting typical of the upper Maryville and lower Nolichucky occurs within the site.

Soils in most of the SWSA 6 area are residual products derived from weathering and leaching of the underlying bedrock. Soils, as discussed here, include the total thickness of weathered earth materials from the land surface to competent bedrock. The soil mass is an irregularly shaped volume, thinnest at creeks and thickest beneath upland terrain and topographic divides. This characteristic develops because streams have removed most weathered material beneath their beds, and erosion carries soil to the site streams, where it is carried to WOC as sediment.

Soils in SWSA 6 were investigated by Lee and Lietzke (1987). In most areas a relatively thin $(<0.5 \mathrm{~m})$ soil column of residuum and/or colluvium overlies saprolitic regolith of weathered bedrock. Fig. 3.13 shows typical soil profiles in hilltop, sideslope, and toeslope locations. The upper portion of the regolith (to depths of several meters) is typically leached by chemical weathering processes, is depleted of calcium carbonate, and has an acidic $\mathrm{pH}$. Deeper zones typically have neutral $\mathrm{pH}$, indicating the presence of free calcium carbonate. Below-grade waste disposal units in SWSA 6 are constructed in the regolith.

Surficial soils and saprolitic regolith have been mapped in SWSA 6 as shown in Fig. 3.14. Residuum and saprolite derived from weathering of the major bedrock formations (Maryville Limestone and Nolichucky Shale) have been identified in the mapped soil units for the site. Several alluvial soils that mantle the underlying residuum have also been discriminated. Modern alluvium occurs along the site stream drainages, while old alluvial soils occur in the western portion of the site and are thought to have been deposited by the Clinch River during the Pleistocene epoch.

Soils of the Maryville Limestone and Nolichucky Shale are discriminated in site mapping based on colorimetric and textural characteristics. Based on a review of soil test data (Lee and Lietzke 1987), the most obvious difference between the Maryville and Nolichucky soils is that the Maryville soils have soil-water retentions (i.e., differences in water content between field capacity and wilting point) of 10 to $20 \%$ while the Nolichucky soils tested have soil-water retentions of less than about 5\%. Other physical and chemical properties of the Maryville and Nolichucky soils are quite similar. The soil hydraulic properties used for the analysis of SWSA 6 are given in Appendices $\mathrm{D}$ and $\mathrm{E}$. 


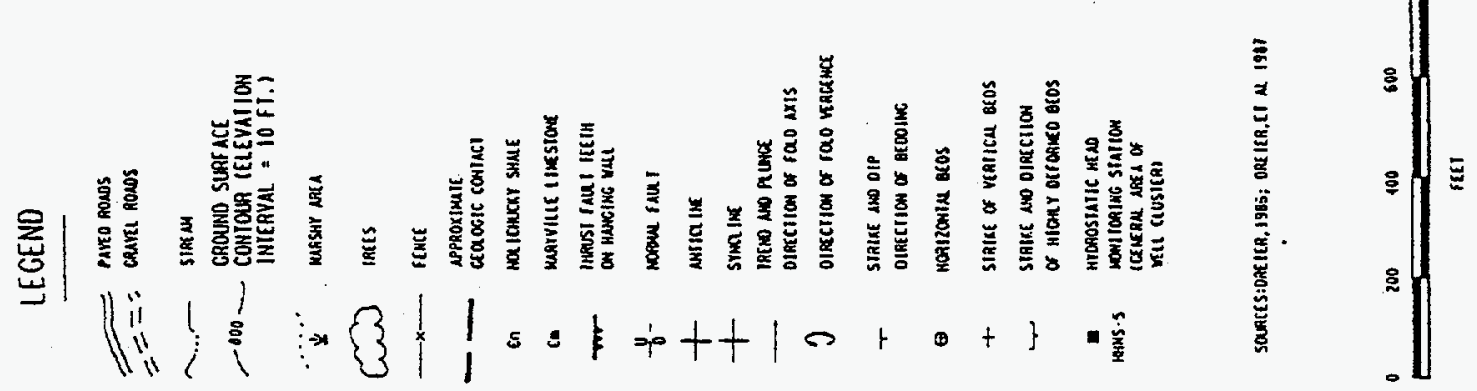

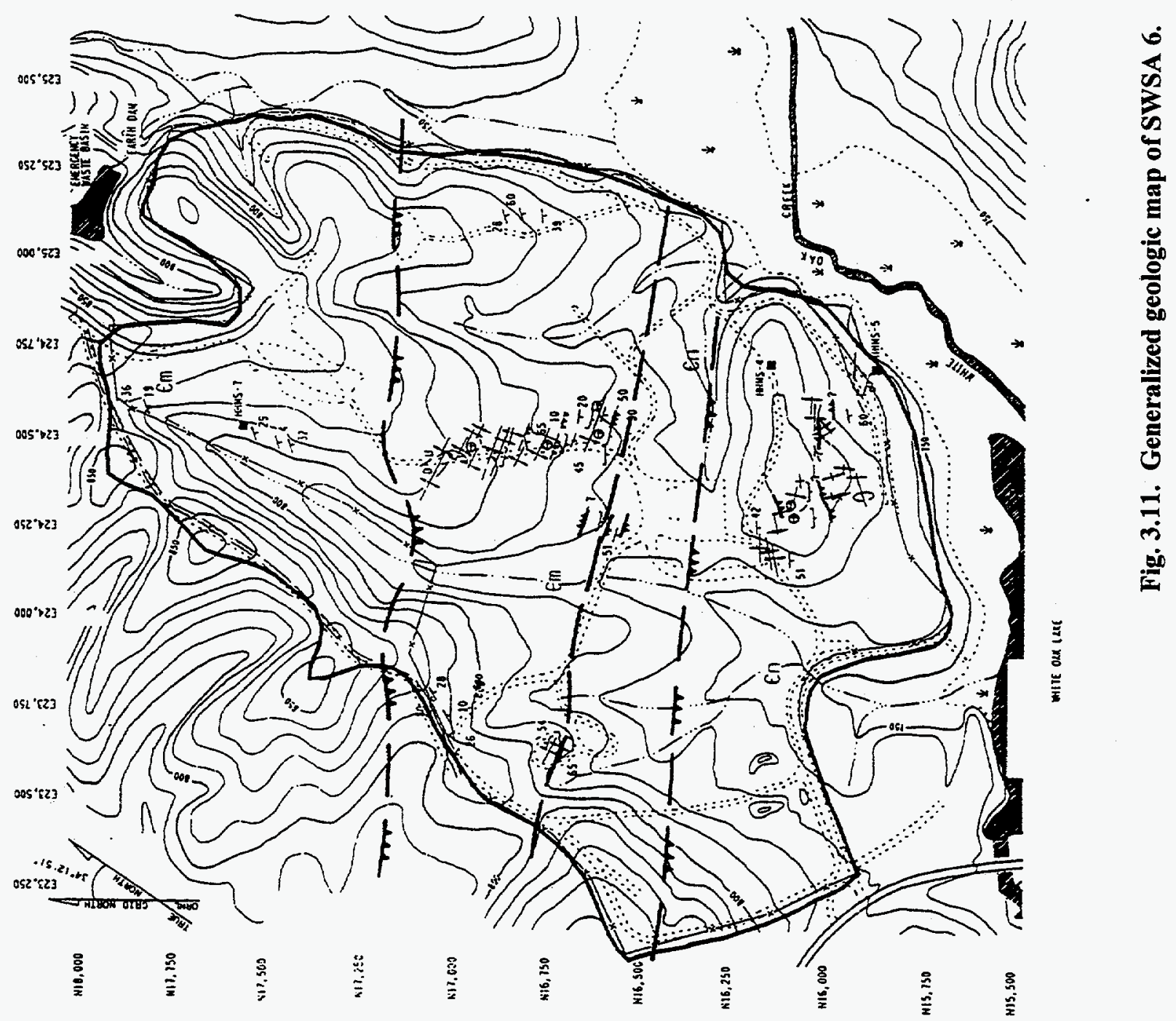




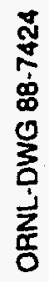

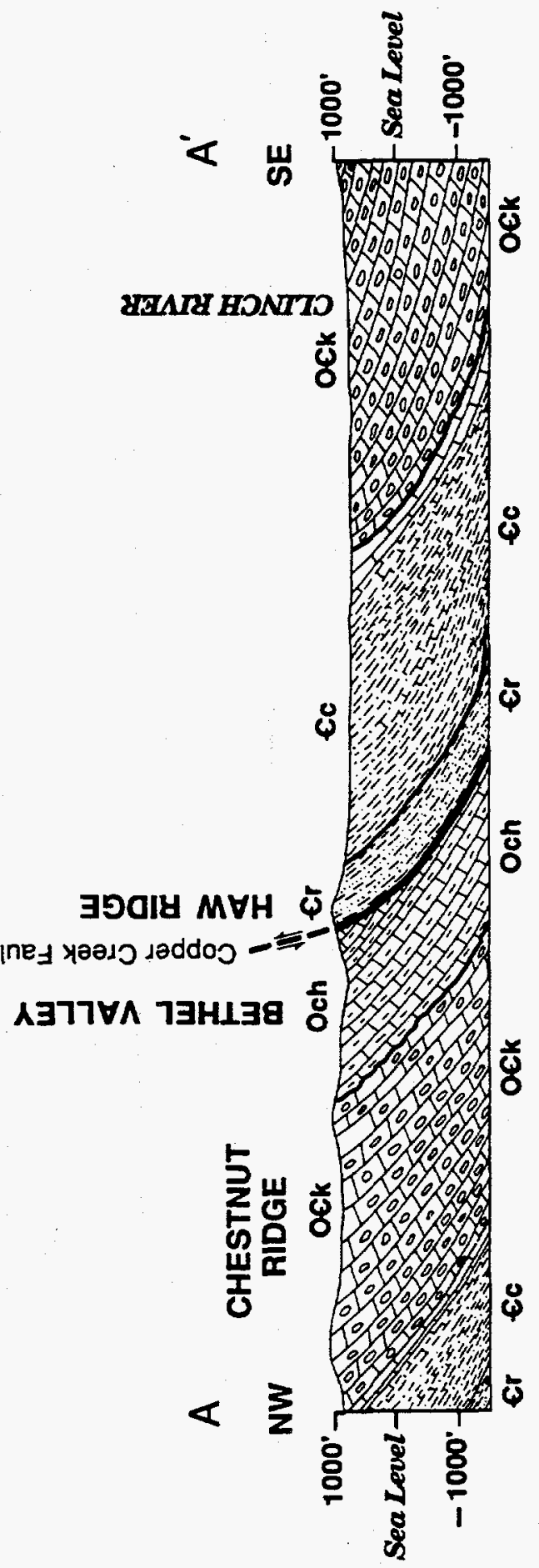

它 
Hilltop

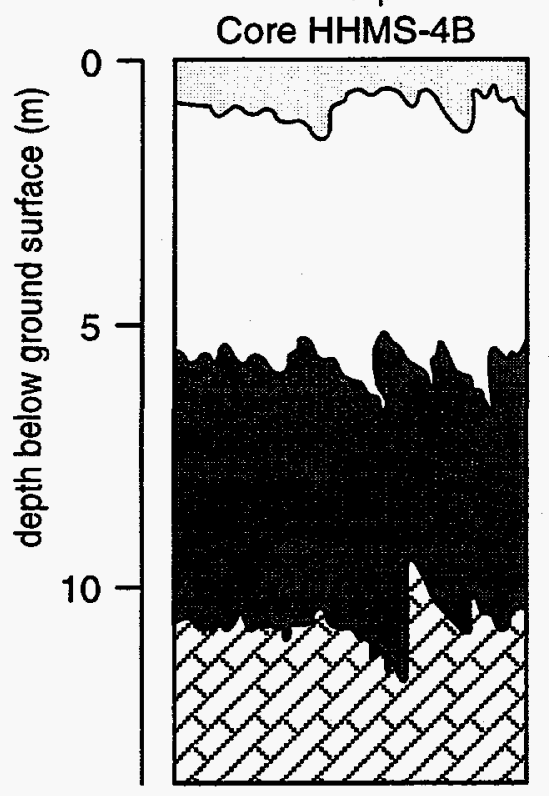

Sideslope

Core HHMS-5A

soil solum

(residuum)

oxidized and leached regolith

unoxidized and unleached rock

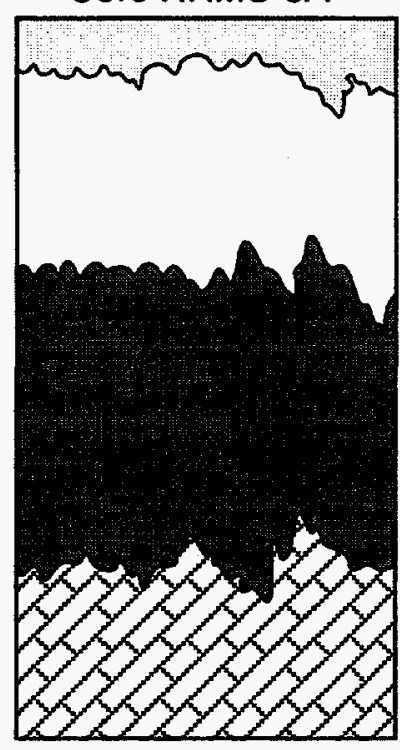

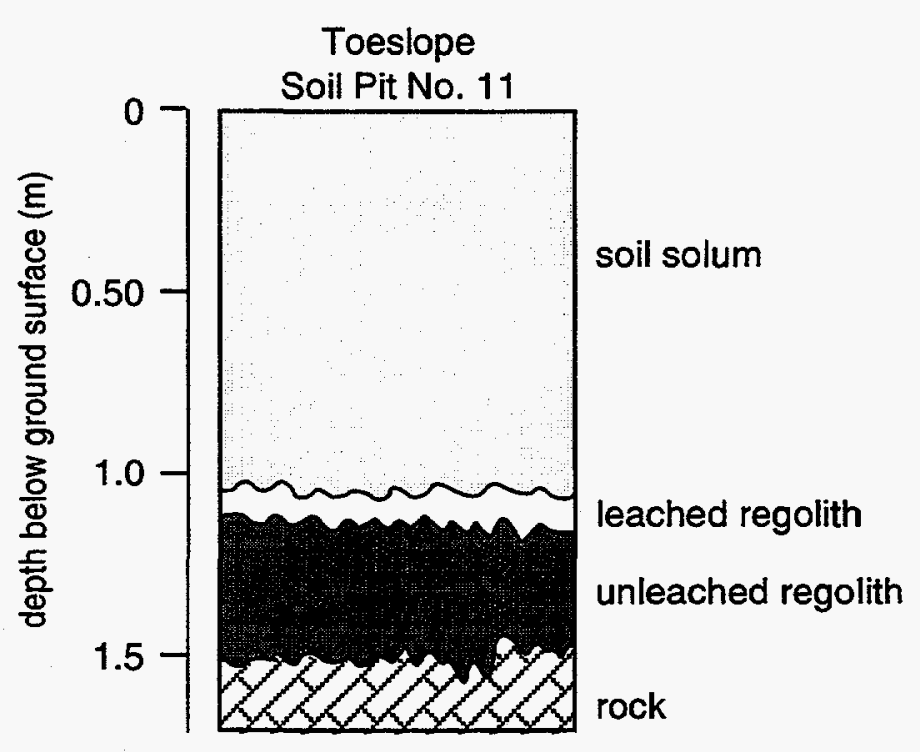

Fig. 3.13. Typical soil profiles observed at SWSA 6. 


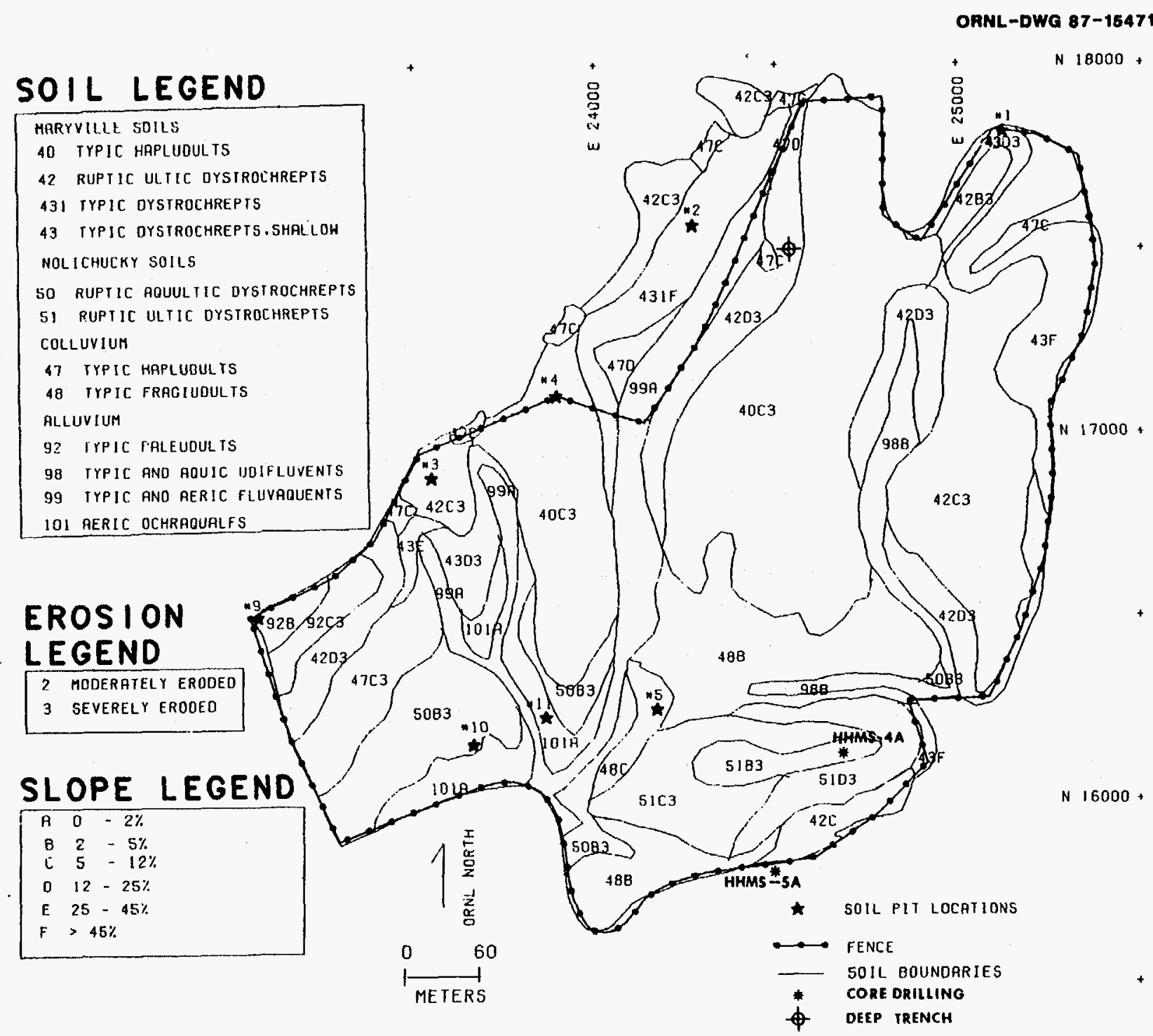

Fig. 3.14. Soil map of SWSA 6. 
The surface soil has been subjected to a considerable amount of disturbance associated with waste management operations. These impacts have included road construction, surface gravel placement, compaction from vehicular traffic and hydraulic equipment, and maintenance of grass cover.

\subsubsection{Seismology}

The seismology of the ORR is fully discussed in Boyle et al. (1982). The discussion in this section is largely drawn from this reference.

Regional tectonics. Tectonic forces, directed toward the northwest, deformed the rocks of the Appalachian geosyncline late in the Paleozoic era. In the Piedmont and Blue Ridge provinces, deformation was the largest, and rocks were metamorphosed and injected with magma. This area was thrust to the northwest along boundary faults such as the Great Smoky Fault. The result of this thrusting was the shingling of the Valley and Ridge boundary into a series of thrust sheets. It is generally accepted that these thrust sheets do not extend into the basement but are bounded at depth by a lateral sole fault. This sole fault is assumed to be in some readily deformable formation above the crystalline basement, and is expected to be at a depth of $2,700 \mathrm{~m}(9,000 \mathrm{ft})$, with crystalline basement at $4000 \mathrm{~m}$ (13,000 ft) (Stockdale 1951).

Because the youngest stratigraphic units mapped in the Valley and Ridge Province of southern Appalachia are of Pennsylvanian age, geologists believe that all the structural features of the primary Appalachian system were formed by the end of the Paleozoic era during what is now called the Appalachian Revolution. Although numerous faults exist within the area, they all originated during that orogenic period; apparently, major tectonic activity ceased completely thereafter. No physiographic evidence indicating tectonic activity, such as stream offsets, displacement of alluvial deposits, or dislocations of Plio-Pleistocene terrace materials, has been observed along any of these thrust-fault areas. Consequently, there is no reason to expect current or future translocations of these tectonic relics (McMaster 1963; Clark and Stearn 1968; 10 CFR 100, Appendix A).

Seismic History. Recent seismic events capable of producing a shock in the Oak Ridge area and recorded in the literature since 1800 are listed in Table 3.2. Data for the older earthquake incidents are largely estimates extrapolated from nonspecific newspaper reports. In addition, these nineteenth-century records generally show a definite bias toward earthquakes of high intensity, an attitude that reflects the inherent limitations of intensity measurements during that period. The inability to record low-intensity earthquakes (no instrumentally recorded earthquakes) also explains the fewer tectonic incidences recorded in the earlier time interval. Some moderate-intensity earthquakes of the nineteenth century almost certainly went unreported because the region was sparsely populated at that time.

The seismic events closest to the ORR were both about $8 \mathrm{~km}$ away. Both were Modified Mercalli Intensity (MMI) V events, one in 1930 in Kingston and one in 1957 in Knox County. The 
Table 3.2. Annotated list of earthquakes that have affected the Oak Ridge Reservation or the eastern Tennessee vicinity (Boyle et al. 1982)

\begin{tabular}{|c|c|c|c|c|c|c|}
\hline Date & $\begin{array}{l}\text { Geoc } \\
\text { coord } \\
{ }^{\circ} \mathrm{N}\end{array}$ & $\begin{array}{l}\text { detic } \\
\text { linates } \\
{ }^{\circ} \mathrm{W}\end{array}$ & Epicenter area & $\begin{array}{l}\text { Max. } \\
\text { MMI at } \\
\text { epicenter }\end{array}$ & $\begin{array}{l}\text { Estimated } \\
\text { MMI at } \\
\text { Oak Ridge }\end{array}$ & Notes \\
\hline $\begin{array}{l}1811, \text { Dec. } 16 \\
1812, \text { Jan. } 23 \\
\text { Feb. } 7\end{array}$ & 36.6 & 89.6 & New Madrid, Mo. & $\mathrm{XII}$ & $\mathrm{V}-\mathrm{VI}$ & $\begin{array}{l}\text { Strongest shocks of a great series collectively } \\
\text { known as the New Madrid Earthquake. } \\
\text { Topographic changes effected over an area of } \\
3000 \text { to } 5000 \text { sq mile in Mississippi Valley }\end{array}$ \\
\hline 1843, Jan. 4 & 35.2 & 90.0 & Western Tennessee & VIII & III-IV & $\begin{array}{l}\text { Shock felt over } 12 \text { states, including the entire } \\
\text { Tennessee Valley }\end{array}$ \\
\hline 1844, Nov. 28 & 36.0 & 84.0 & Knoxville, Tenn. & VI & $\mathrm{V}$ & $25 \mathrm{mi}$ from Oak Ridge area \\
\hline 1861, Aug. 31 & 36.6 & 78.5 & Virginia & VI & III-IV & $\begin{array}{l}\text { Described as "heavy shock" in the Oak Ridge } \\
\text { area }\end{array}$ \\
\hline 1886, Aug. 31 & 32.9 & 80.0 & Charleston, S.C. & $\mathrm{IX}-\mathrm{X}$ & V-VI & $\begin{array}{l}\text { The Great Charleston Earthquake, felt over the } \\
\text { entire eastern U.S. }\end{array}$ \\
\hline 1895, Oct. 31 & 37.0 & 89.4 & Charleston, Mo. & $\mathrm{XI}$ & III-IV & $\begin{array}{l}\text { Shock felt over } 23 \text { states, including the entire } \\
\text { Tennessee Valley }\end{array}$ \\
\hline 1895, May 31 & 37.3 & 80.7 & Giles County, Va. & VII & III-IV & $\begin{array}{l}\text { Shock felt throughout East Tennessee. Heaviest } \\
\text { shock in historic time in southern Appalachia }\end{array}$ \\
\hline 1902 , May 29 & 35.1 & 85.3 & Chattanooga, Tenn. & $\mathrm{v}$ & $?$ & $\begin{array}{l}\text { Not reported to have been felt in the Oak Ridge } \\
\text { area }\end{array}$ \\
\hline 1902, Oct. 18 & 35.0 & 85.3 & Chattanooga, Tenn. & $\mathrm{V}$ & ? & $\begin{array}{l}\text { Not reported to have been felt in the Oak Ridge } \\
\text { area }\end{array}$ \\
\hline 1904, Mar. 4 & 35.7 & 83.5 & Maryville, Tenn. & V & II-III & Low intensity except at epicenter \\
\hline 1905 , Jan. 27 & 34.0 & 86.0 & Gadsden, Ala. & VII & II & $\begin{array}{l}\text { Large "felt" area, but probably very-low-intensity } \\
\text { shock }\end{array}$ \\
\hline 1913, Mar. 28 & 36.2 & 83.7 & $\begin{array}{l}\text { Strawberry Plains, } \\
\text { Tenn. }\end{array}$ & VII & V-VI & $\begin{array}{l}\text { One of the strongest shocks in southern } \\
\text { Appalachia }\end{array}$ \\
\hline 1913, Apr. 17 & 35.3 & 84.2 & Ducktown, Tenn & V & $?$ & $\begin{array}{l}\text { Not reported to have been felt in the Oak Ridge } \\
\text { area }\end{array}$ \\
\hline 1914, Jan. 23 & 35.3 & 84.2 & $\begin{array}{l}\text { Southeastern } \\
\text { Tennessee }\end{array}$ & $\mathrm{V}$ & $?$ & $\begin{array}{l}\text { Only felt reports are from the epicenter, so } \\
\text { probably local }\end{array}$ \\
\hline 1916, Feb. 21 & 35.5 & 82.5 & Asheville, N.C. & VI & III-IV & $\begin{array}{l}\text { Felt over whole state of Tennessee, especially } \\
\text { mountains of east Tennessee }\end{array}$ \\
\hline 1916 , Oct. 18 & 33.5 & 86.2 & Easonville, Ala & VII & III & $\begin{array}{l}\text { Felt over seven-state area, but only light shock in } \\
\text { Oak Ridge }\end{array}$ \\
\hline 1918 , June 21 & 36.0 & 84.1 & Lenoir City, Tenn. & $\mathrm{V}$ & IV & $15 \mathrm{mi}$ from Oak Ridge area \\
\hline 1920 , Dec. 14 & 36.9 & 85.0 & Rockwood, Tenn & $\mathrm{V}$ & III & $35 \mathrm{mi}$ from Oak Ridge area \\
\hline 1921, Dec. 15 & 35.8 & 84.6 & Kingston, Tenn & $\mathrm{V}$ & III-IV & $\begin{array}{l}\text { Shock of "considerable intensity" only } 15 \mathrm{mi} \\
\text { from Oak Ridge area }\end{array}$ \\
\hline 1924 , Oct. 20 & 35.0 & 82.6 & $\begin{array}{l}\text { Pickens County, } \\
\text { S.C. }\end{array}$ & $\mathrm{V}$ & II & $\begin{array}{l}\text { Large felt area, but little effect in eastern } \\
\text { Tennessee }\end{array}$ \\
\hline 1927, Oct. 8 & 35.0 & 85.3 & Chattanooga, Tenn. & IV-V & II & $\begin{array}{l}\text { Not reported to have been felt in the Oak Ridge } \\
\text { area }\end{array}$ \\
\hline 1928, Nov. 2 & 35.8 & 82.8 & $\begin{array}{l}\text { Madison County, } \\
\text { N.C. }\end{array}$ & VII & III & Large felt area, including all of eastern Tennessee \\
\hline 1930, Aug. 30 & 35.9 & 84.4 & Kingston, Tenn. & $\mathrm{V}$ & V & 5 mi northwest of Oak Ridge Reservation \\
\hline 1938, Mar. 31 & 35.6 & 83.6 & $\begin{array}{l}\text { Little Tennessee } \\
\text { River Basin }\end{array}$ & III & I-III & $\begin{array}{l}\text { Centered in mountains and felt widely in eastern } \\
\text { Tennessee }\end{array}$ \\
\hline
\end{tabular}


Table 3.2. (continued)

\begin{tabular}{|c|c|c|c|c|c|c|}
\hline Date & $\begin{array}{l}\text { Geo } \\
\text { coord } \\
{ }^{\circ} \mathrm{N}\end{array}$ & $\begin{array}{l}\text { detic } \\
\text { dinates } \\
{ }^{\circ} \mathrm{W}\end{array}$ & Epicenter area & $\begin{array}{l}\text { Max. } \\
\text { MMI at } \\
\text { epicenter }\end{array}$ & $\begin{array}{l}\text { Estimated } \\
\text { MMI at } \\
\text { Oak Ridge }\end{array}$ & Notes \\
\hline 1940, Oct. 19 & 35.0 & 85.0 & Chattanooga, Tenn & $\mathrm{V}$ & $?$ & $\begin{array}{l}\text { Not reported to have been felt in the Oak Ridge } \\
\text { area }\end{array}$ \\
\hline 1941, Sept. 8 & 35.0 & 85.3 & Chattanooga, Tenn. & IV-V & ? & $\begin{array}{l}\text { Not reported to have been felt in the Oak Ridge } \\
\text { area }\end{array}$ \\
\hline 1945, June 14 & 35.0 & 84.5 & Cleveland, Tenn. & $\mathrm{V}$ & II & $\begin{array}{l}\text { Felt area over southeast Tennessee and northwest } \\
\text { Georgia }\end{array}$ \\
\hline 1946, Apr. 6 & 35.2 & 84.9 & Cleveland, Tenn. & III & $?$ & No reports of shock outside of the city \\
\hline 1947, Dec. 27 & 35.0 & 85.3 & Chattanooga, Tenn. & IV & $?$ & $\begin{array}{l}\text { Not reported to have been felt in the Oak Ridge } \\
\text { area }\end{array}$ \\
\hline 1954 , Jan. 1 & 36.6 & 83.7 & Knoxville, Tenn. & V-VI & IV-V & $\begin{array}{l}\text { Large shock area, including all of eastern } \\
\text { Tennessee; no damage at Oak Ridge }\end{array}$ \\
\hline 1954, Jan. 22 & 35.4 & 84.4 & $\begin{array}{l}\text { McMinn County, } \\
\text { Tenn }\end{array}$ & $\mathrm{V}$ & ? & No reports of shock outside of the county \\
\hline 1956, Sept. 7 & 35.5 & 84.0 & Corbin, $\mathrm{Ky}$. & VI & IV-V & $\begin{array}{l}\text { Two shocks, } 14 \text { min apart, felt over most of } \\
\text { southern Appalachia }\end{array}$ \\
\hline 1957, June 23 & 35.9 & 84.3 & $\begin{array}{l}\text { Knox County, } \\
\text { Tenn. }\end{array}$ & $\mathrm{V}$ & IV & $5 \mathrm{mi}$ from Oak Ridge area \\
\hline 1959, June 12 & 35.3 & 84.3 & $\begin{array}{l}\text { Tellico Plains, } \\
\text { Tenn. }\end{array}$ & IV & II-III & $\begin{array}{l}\text { Widely felt over eastern Tennessee and western } \\
\text { North Carolina }\end{array}$ \\
\hline 1960, Apr. 15 & 35.8 & 83.9 & Knoxville, Tenn. & $\mathrm{V}$ & IV & $20 \mathrm{mi}$ from Oak Ridge area \\
\hline 1968, Nov. 9 & 38.0 & 88.5 & Southern Illinois & VII & II-III & $\begin{array}{l}\text { Felt over } 400,000 \text {-sq. Mile area including } 23 \\
\text { states and areas of Canada. }\end{array}$ \\
\hline 1969 , July 3 & 36.1 & 83.7 & Knoxville, Tenn. & V & III-IV & $30 \mathrm{mi}$ from Oak Ridge area \\
\hline 1969, Nov. 19 & 37.4 & 81.0 & $\begin{array}{l}\text { Southern West } \\
\text { Virginia }\end{array}$ & VI & II-III & Large felt area but small intensity \\
\hline 1971, July 12 & 35.9 & 84.3 & $\begin{array}{l}\text { Knoxville-Oak } \\
\text { Ridge, Tenn. }\end{array}$ & III-IV & III-IV & $\begin{array}{l}\text { Shock felt with full intensity in Oak Ridge area; } \\
\text { no personal injuries or property damage reported }\end{array}$ \\
\hline 1973 , Oct. 5 & 35.5 & 83.7 & Maryville, Tenn. & IV-V & III-IV & $25 \mathrm{mi}$ from Oak Ridge area \\
\hline 1973, Nov. 3 & 35.5 & 83.7 & Maryville, Tenn. & V-VI & IV-V & $25 \mathrm{mi}$ from Oak Ridge area \\
\hline 1975, Feb. 10 & 36.1 & 83.6 & Knoxville, Tenn. & $?$ & $?$ & $\begin{array}{l}\text { Not reported to be felt in Oak Ridge, } 60 \mathrm{mi} \text { from } \\
\text { Oak Ridge }\end{array}$ \\
\hline 1975, May 2 & 36.1 & 84.4 & Roane Co., Tenn. & $?$ & III & $10 \mathrm{mi}$ from Oak Ridge area \\
\hline
\end{tabular}

Sources:

1. B. C. Moneymaker, "Earthquakes of Tennessee and Nearby Sections of Neighboring States."

"Part I (1699-1850)," J. Tenn. Acad. Sci. 29(3): 224-233 (1954).

"Part II (1851-1900)," J. Tenn. Acad. Sci. 30(3): 222-223 (1955).

"Part III (1901-1925)," J. Tenn. Acad. Sci. 32(2): 91-105 (1957).

"Part IV (1926-1950)," J. Tenn. Acad. Sci. 33(3): 224-239 (1958).

2. Project Management Corporation, Preliminary Information Clinch River Site for LMFBR Demonstration Plant, Aug. 23, 1972, pp. 73-82.

3. The following publications of the U.S. Department of Commerce, National Oceanic and Atmospheric Administration, Environmental Data Service.

a. United States Earthquakes, 1928-1935 (collected annual reports), No. COM-73-11456 (reprint).

b. Unites States Earthquakes, 1936-1940 (collected annual reports), No. COM-73-11457 (reprint).

c. Unites States Earthquakes, $1941-1945$ (collected annual reports), No. COM-73-11447 (reprint).

d. United States Earthquakes, 1946-1972 (individual annual reports).

e. Preliminary Determination of Epicenters, 1972 (monthly listing).

f. Earthquake History of the United States, Publication 41-1 (Rev. ed.through 1970), Washington, D.C., 1973, pp. 21-58. 
most recent significant event occurred on November 30, 1973, in Maryville, about $35 \mathrm{~km}$ to the southeast, with a local MMI of IV-V.

The more recent seismic records indicate that the Appalachian region extending from Chattanooga to southwestern Virginia averages one to two earthquakes per year. This seismic activity is not uniform but consists of extended periods with no shocks followed by a burst of earthquakes. The maximum shock experience in the Oak Ridge area was an MMI of VI, recorded on March 28, 1913 (10 CFR 100, Appendix A). Great distant earthquakes, such as the New Madrid series of 1811 and 1812 and the Great Charleston Earthquake of 1886 , have affected the site with intensities greater than or equal to the maximum intensity of shocks involving regions that surround the site (Clark and Stearn 1968). The following are the four areas of major current tectonic mobility that have affected the Oak Ridge area:

1. The Mississippi Valley, encompassing the New Madrid region of Arkansas, Kentucky, Missouri, and Tennessee. This seismic province includes the epicenter of the great series of New Madrid earthquakes, which repeatedly attained an MMI of XII. This area lies more than $400 \mathrm{~km}$ (250 miles) northwest of ORNL. The New Madrid quakes attained an intensity of V to VI in the Oak Ridge area.

2. The Lower Wabash Valley, located in the southern regions of Illinois and Indiana. A southern Illinois earthquake of MMI VII in 1968 was felt over a $1,000,000-\mathrm{km}^{2}\left(400,000-\mathrm{mile}^{2}\right)$ area, including a mild shock of intensity II to III in the Oak Ridge vicinity. ORNL lies more than 370 $\mathrm{km}$ (230 miles) southeast of this region of active seismicity.

3. Charleston, South Carolina, site of one of the greatest historic earthquakes experienced in the eastern United States. The August 31, 1886, shock of MMI IX was felt over the entire eastern coast and registered an intensity of V to VI in the Oak Ridge region. Recurrent seismic activity continues in this area, which is $520 \mathrm{~km}$ ( 325 miles) southeast of ORNL.

4. The Appalachian Mountains of eastern Tennessee and western North Carolina, centers that exhibit moderate seismic activity at the frequency of one to two shocks per year. Part of this seismic area lies only $80 \mathrm{~km}$ ( 50 miles) east of the ORNL site and accounts for most of the seismicity native to the eastern Tennessee region.

As discussed previously, no correlation has been observed between recorded earthquakes on the ORR and superficial tectonic structures of the Valley and Ridge Province. During historic times, the zone of relatively high seismicity in the adjacent Blue Ridge Province has involved movements of only low intensity that probably represent minor adjustments of highly disturbed rock formations (Algermissen 1969).

Algermissen assessed seismic risk for the United States to assist in establishing design requirements for buildings in various regions of the country (Algermissen 1969). Seismicity ratings were based either on a historical earthquake of considerable intensity or on frequency of seismic incidences regardless of intensity. The ORR lies in what Algermissen designated as seismic zone 2, which is an area of moderate activity. 
Algermissen and Perkins (1976) provide probabilistic estimates for the frequency of earthquakes of a given horizontal acceleration. It must be emphasized that their estimates apply only to foundations that are coupled to bedrock. For foundations coupled to bedrock at any location within the southern Appalachian region (e.g., ORNL), there is a 10\% probability that the horizontal acceleration will exceed $7 \%$ of gravity (equivalent to an MMI of VII) in a 50-year period. The equation $\log (a)=(I / 3)-(1 / 2)$ is a universally recognized empirical relationship between horizontal acceleration (a) and MMI ( $I$ (Richter 1958). Accordingly, a horizontal acceleration of $70 \mathrm{~cm} / \mathrm{s}^{2}(27.6$ in. $\left./ \mathrm{s}^{2}\right)$ ( $7 \%$ of gravity) is equivalent to an MMI of VII.

Algermissen and Perkins' probabilistic estimate agrees reasonably well with the seismic history of the ORNL site. Table 3.2 lists five earthquakes in the last 165 years that produced a MMI of V to VI within the vicinity of Oak Ridge. During the same time interval, no earthquakes of MMI VII or higher were reported. Intensity VII earthquakes occur approximately one order of magnitude less frequently than intensity V to VI earthquakes. This suggests a recurrence interval on the order of 300 to 1000 years for intensity VII earthquakes, an estimate that is consistent with Algermissen and Perkins' probabilistic estimate (a $10 \%$ probability of occurrence in a 50 -year period is equivalent to a 500-year recurrence interval).

Damage caused by intensity VII earthquakes is not severe. Examples of damage to be expected are (1) weak chimneys broken off at the roof line; (2) damage to weak masonry of low standards of workmanship; (3) some cracks in masonry of ordinary workmanship; (4) fall of plaster, loose bricks, and stones; and (5) damage to concrete irrigation ditches (Richter 1958).

Although the Oak Ridge area experiences a moderate level of seismic activity, no incidence of surface deformation has been documented. Earthquakes of the types that occur within the region are common throughout the world. The shocks are of normal focus- 40 to $50 \mathrm{~km}$ ( 25 to $30 \mathrm{miles}$ ) deep. It is highly improbable that a shock of major intensity will occur in the Oak Ridge area for several thousand years. Forces from more seismically active areas will probably be dissipated by distance.

\subsubsection{Volcanology}

There is no volcanic activity in the Oak Ridge area. The nearest volcanic activity of recent time would be in either the Carribean archipelago, the Mexican Cordillera, or the Colorado Plateau, all of which are over $2000 \mathrm{~km}$ (1200 miles) distant. The only effects on ORR from volcanic activity would be secondary, as in climatic changes wrought by eruptions associated with large amounts of material discharged into the atmosphere.

\subsubsection{Hydrology}

Precipitation records for the Oak Ridge area show the 40-year mean annual precipitation for $1950-90$ to be $1370 \mathrm{~mm} /$ year (54 in./year) (Kornegay et al. 1993). This input of water to the landscape is partitioned into two main components on an annual basis. The evapotranspiration 
process returns an average of $730 \mathrm{~mm}$ ( $29 \mathrm{in}$.) of water to the atmosphere as vapor (Luxmoore and Huff 1989). The difference of $640 \mathrm{~mm} /$ year ( $25 \mathrm{in}$./year) between precipitation and evapotranspiration $(1370 \mathrm{~mm}-730 \mathrm{~mm}$ ) drains through the root zone and vadose zone to produce stream flow and groundwater recharge. On an annual basis there is little or no significant change in soil water storage. The annual water budget is composed of many storm events and diurnal changes in weather that contribute to dynamic changes in water status and water flow in the landscape. On average, somewhat less than $50 \%$ of annual precipitation drains through soil as lateral flow to streams and recharge to groundwater.

On a monthly basis, precipitation is received more or less uniformly through the year. In contrast, evapotranspiration is highly seasonal, increasing with leaf-out of vegetation in spring to a maximum in summer, then declining in autumn with leaf fall. The combination of rather uniform monthly precipitation and seasonal evapotranspiration results in soil water drainage being dominant during winter and early spring. In autumn, precipitation preferentially recharges soil water to field capacity before significant drainage occurs. The seasonal pattern of soil water drainage has an important influence on chemical transport in the landscape.

The hydrologic framework for the ORR has been described by Solomon et al. (1992) in terms of the following four zones (see Fig. 3.15):

1. A storm flow zone constitutes the upper $1-2 \mathrm{~m}(3-6 \mathrm{ft})$ of the soil profile, in which precipitation-driven lateral flow generates up to $90 \%$ of stream flow. This zone is a major pathway for laterally transporting contaminants from the subsurface to surface waters.

2. A vadose zone is predominantly unsaturated and consists of weathered regolith $1-15 \mathrm{~m}$ (3-50 $\mathrm{ft}$ ) thick, with a fluctuating water table as the lower boundary. This zone has (exponentially) decreasing hydraulic conductivity with depth.

3. A groundwater zone contributes the remaining $10 \%$ or more of stream flow, and this occurs through a permeable layer called the water table interval. This flow zone has a thickness of 1-5 m (3-15 ft) (Clapp 1992, pp. 123-126). Intermediate and deep intervals of the aquifer

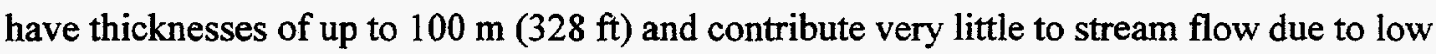
hydraulic conductivity and disconnected fractures.

4. An aquiclude beyond a depth of $200 \mathrm{~m}(650 \mathrm{ft})$ has extremely slow water flow rates that are estimated to change on geological time scales.

The hydrologically active features of the upper three zones are responsible for essentially all radionuclide transport from waste sites. Solomon et al. (1992) conclude that groundwater flow volumes decrease and solute residence times increase sharply with depth. They further estimate that the chemical transport rate in the storm flow zone is on the order of meters per hour, decreasing exponentially with depth to flow rates of a few centimeters per year. Their review showed no evidence for contaminant migration along deep subsurface flow paths of the intermediate and deep intervals of the groundwater. The residence times for solutes in the water table interval are in the range from a few days to a few years. Flow rates for deeper solutes have been estimated from ${ }^{14} \mathrm{C}$ 


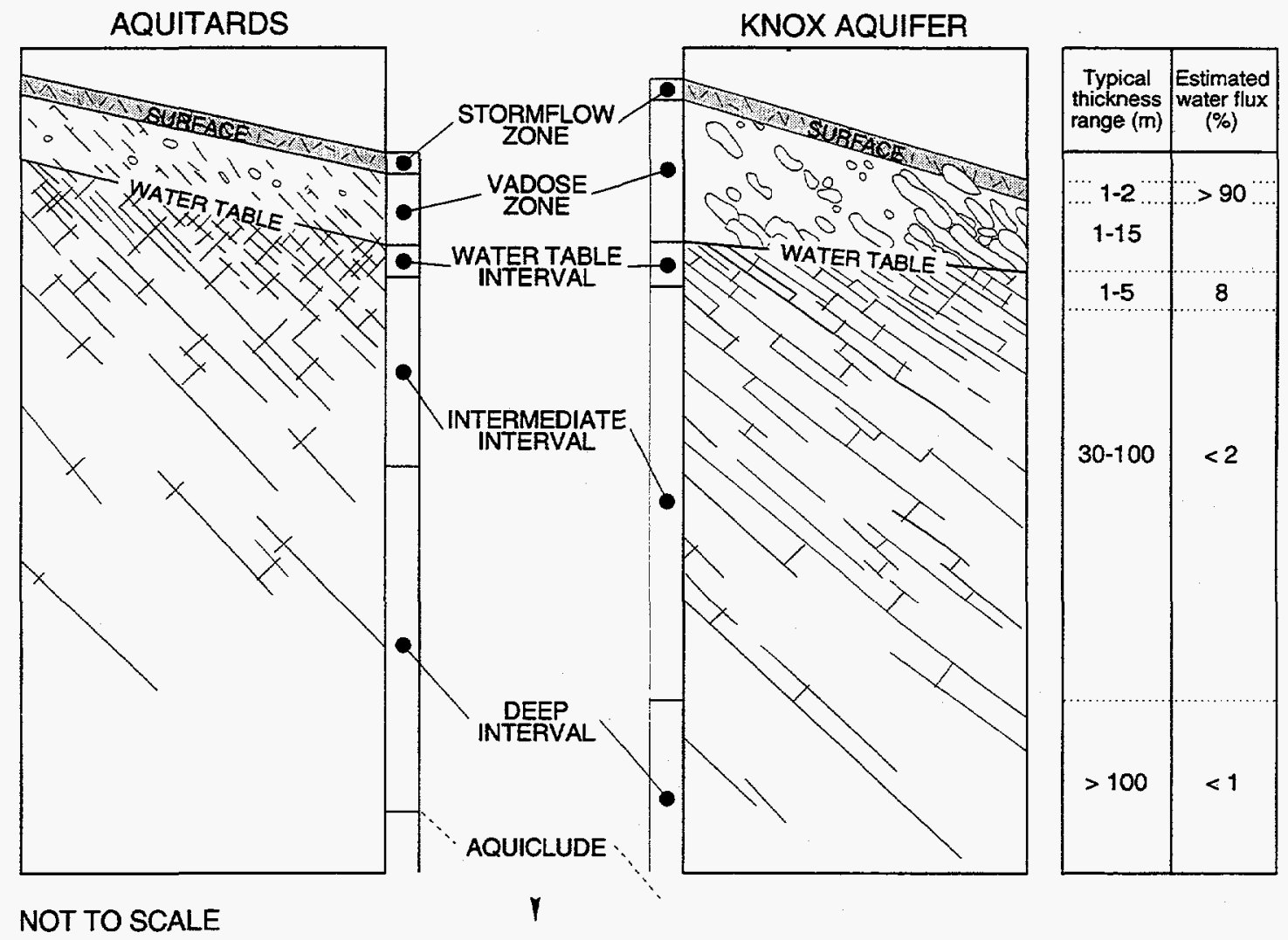

Fig. 3.15. Schematic profile showing subsurface flow zones and intervals, general thickness ranges, estimated relative water flux, and change in water type with depth for the aquitard of SWSA 6 in comparison to the aquifer of the Knox geological formation. Source: After Solomon et al. 1992. 
measurements to be in the order of hundreds to tens of thousands of years (Solomon et al. 1992). Chemical adsorption and matrix diffusion have been identified as important geochemical processes that retard chemical transport in local soils, creating secondary contaminant sources that may persist for many decades. Therefore, the model for transport of radionuclides in the saturated zone assumes contaminant migration is confined to the groundwater zone.

\subsubsection{Surface Water}

The WOC watershed (Fig. 3.2$)$ is $16.8 \mathrm{~km}^{2}$ (6.5 miles ${ }^{2}$ ) in area, and headwater flows originate on the southeast flank of Chestnut Ridge. Precipitation has been measured at SWSA 6 using a continuous-recording rain gauge since 1980. Data are maintained in the ORNL Environmental Restoration and Waste Management (ERWM) database. WOC receives runoff and permitted wastewater discharges from ORNL and associated facilities in both Bethel and Melton valleys. The creek also receives discharges of contaminated groundwater from several former waste disposal sites associated with historic activities at ORNL. The average discharge of WOC at WOD is $3.7 \times 10^{4} \mathrm{~m}^{3} / \mathrm{d}$ (15 cfs), according to records for the U.S. Geological Survey (USGS) gauge 03538000, presented in Fig. 3.16. Smaller streams are often intermittent, flowing only when fed by lateral inflow or by runoff from heavy rains. In effect, they act as surface drains, providing an outlet for discharging subsurface waters but, unlike perennial streams, not contributing enough recharge to maintain a constant water table elevation.

Surface runoff and groundwater discharges at SWSA 6 flow to three ephemeral tributaries of WOC, all of which discharge directly to WOL. Discharges from some areas of SWSA 6 run off directly into WOL without convergence to a stream. Flows in the main channel of WOC and Melton Branch, its major upstream tributary, are gauged continuously at several flumes. Two small streams originate within SWSA 6, receiving surface runoff, stormflow discharges, and groundwater discharges. The third stream, which receives discharge from SWSA 6, lies east of the site and also receives runoff and groundwater discharges from a watershed of $0.65 \mathrm{~km}^{2}\left(0.25 \mathrm{mile}^{2}\right)$, which encompasses the southeast flank of Haw Ridge and a portion of the pits and trenches (WAG 7). Long-term, continuous stream gauging has not been performed on the ephemeral tributaries originating in SWSA 6.

A limited data record for the ephemeral streams in SWSA 6 has been collected (Davis et al. 1987). These records indicate that site streams respond to rainfall events and generally go dry during summer and autumn. Discharge and water quality data for the ephemeral streams in SWSA 6 have been recorded to supplement an earlier data record (R. B. Clapp, ORNL, personal communication to D. W. Lee, ORNL, Oak Ridge, Tenn., June 29, 1993). These data have been collected using storm and grab samples from March 1992 to February 1993. Analysis of these data indicates that for over $90 \%$ of the time the discharge in the creeks is less than $1 \mathrm{~L} / \mathrm{s}(0.04 \mathrm{cfs})$. Discharge events occur in response to major precipitation events that occur infrequently throughout the year. Consequently, these ephemeral streams do not have sufficient discharge to support a drinking water supply for an individual and are not considered as possible drinking water resources in this revised PA. Water 


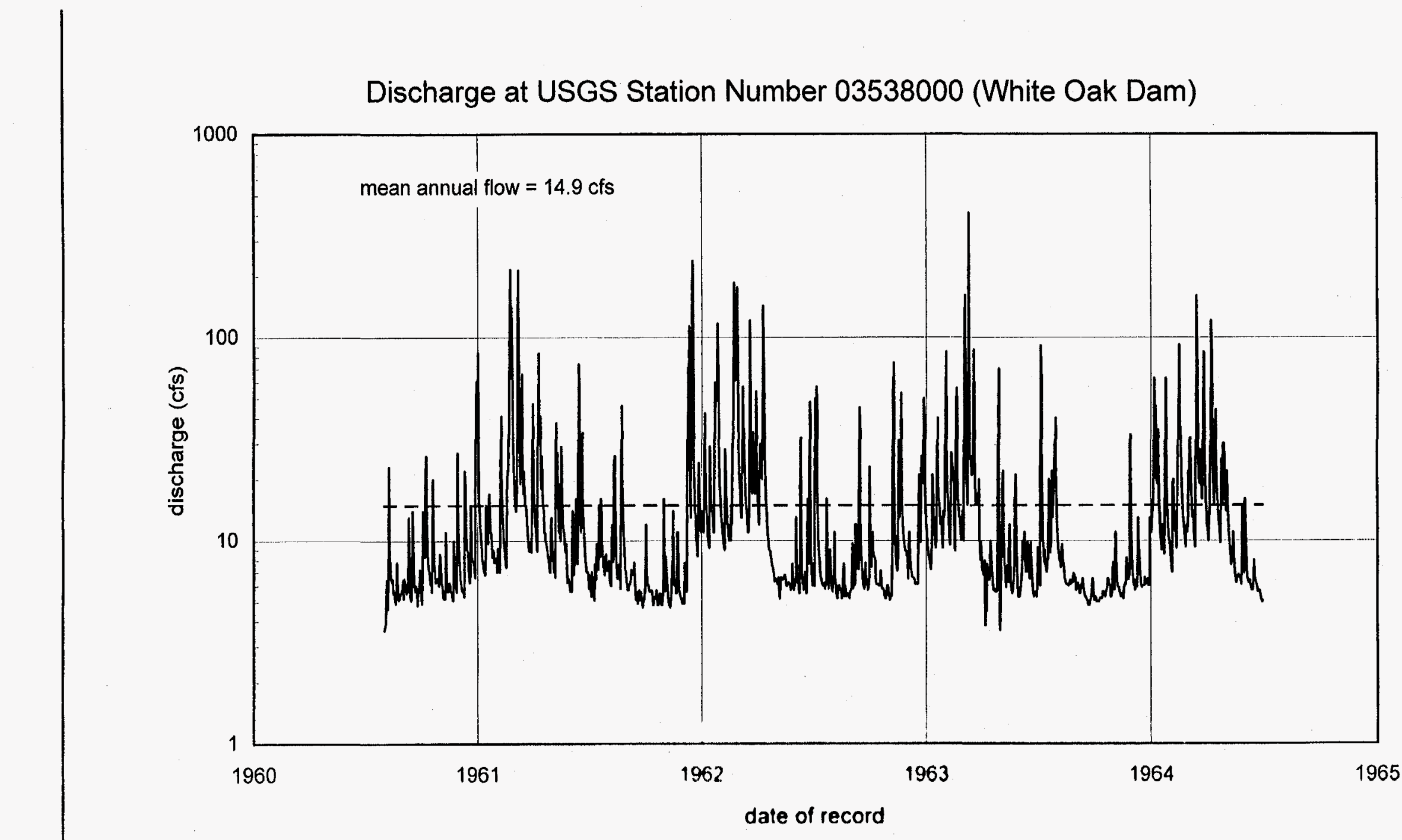


quality data collected during this sampling period indicate that ${ }^{3} \mathrm{H}$ is being released to surface water during storm events. Concentrations of $1-5 \mu \mathrm{Ci} / \mathrm{L}$ are commonly reported in the surface water during and following a storm event. These releases of contamination are associated with historical disposal operations performed in SWSA 6 prior to September 26, 1988, and are investigated by the Active Sites Environmental Monitoring Program (Ashwood et al. 1990, Ashwood, Hicks, and Morrissey 1992). Infrequent and low concentrations of ${ }^{90} \mathrm{Sr}$ and ${ }^{137} \mathrm{Cs}(<30 \mathrm{pCi} / \mathrm{L})$ in surface water have also been reported in response to precipitation events (R. B. Clapp, ORNL, personal communication to D. W. Lee, ORNL, Oak Ridge, Tenn., June 29, 1993).

\subsubsection{Groundwater}

Subsurface waters occur in two distinct regions: in deep, fully saturated unweathered bedrock, and in the vadose zone in the overlying regolith. While there is hydraulic connection between the two, the behavior is sufficiently different that they should be discussed separately.

In areas underlain by the shales and silty limestones of the Conasauga Group, groundwater occurs in a continuous, unconfined saturated zone. Unweathered bedrock at Oak Ridge is of low primary porosity, and groundwater occurs and flows in fractures and weathered zones. The most prominent fracture orientations are parallel to local geologic strike and include bedding planes and strike-parallel fractures and joints. Less prominent and less penetrative fractures are perpendicular and oblique to local strike. The porosity of weathered and unweathered bedrock in the Conasauga Group is quite low $(<5 \%)$, resulting in low groundwater storage capacity. Most wells in the area cannot sustain pumping at rates greater than a few liters per minute. Groundwater flow is rapid through the fracture network, however, with velocities over $0.1 \mathrm{~m} / \mathrm{d}$ (4 in./d) documented (Moore 1989). The combined influences of bedrock dip and fracture control of groundwater flow result in anisotropy of the aquifer hydraulic conductivity. Maximum hydraulic conductivity in this regime normally occurs parallel to local geologic strike.

Saturated hydraulic conductivity at the SWSA 6 site, as elsewhere in Conasauga terrain, generally decreases with depth, and at any discrete depth the conductivity may vary within two to three orders of magnitude. (See Appendix $E$ for a more detailed discussion of hydraulic conductivity.) Anisotropy of the hydraulic conductivity tensor, $K_{x x}: K_{y y}$, was estimated from Conasauga Group aquifer pump tests on the ORR. Estimates range from 3:1 to $>30: 1$, with maximum conductivity parallel to strike $\left(K_{x x}\right)$ (Davis et al. 1984; Lozier, Spiers, and Pearson 1986; Lee et al. 1989). No variation in the hydraulic conductivity values over the modeled area is justified, because no directional variation in spatial correlation over the site could be discerned. Therefore, spatially invariant values for hydraulic conductivity and tensor anisotropy were used in the groundwater analysis.

Solute transport in fractured systems can be quite rapid, depending on the ion exchange and adsorption characteristics of the soil or rock through which the solute migrates. Laboratory adsorption tests for various radionuclides have been performed on some soil and bedrock materials typical of those present at SWSA 6 (Friedman and Kelmers 1990). Most of these tests were 
performed with batch-type test conditions using materials with much higher surface-area-to-volume ratios than are actually present along groundwater flow paths. For some radionuclides, the resulting distribution coefficients are substantially higher than field measurements of contaminant movement at waste disposal facilities.

The estimated water table elevation at SWSA 6 is interpolated from field measurements. Data collection of historic water levels was performed by numerous investigators at different times and for different purposes. While such historic data are plentiful, rarely were a large number of wells measured in a short time interval. For this reason the water table configuration in this analysis uses the annual average elevation derived from all water table measurements in individual wells. Appendix E contains a listing of water table elevations from wells in SWSA 6.

The presence of over 1000 previously constructed waste burial trenches and auger holes has undoubtedly affected the site hydrogeology by increasing recharge to groundwater when disposal units were open to interception of shallow lateral groundwater flow. While capping of several disposal areas has temporarily reduced drainage through previously constructed disposal units and reduced total aquifer recharge in SWSA 6, the longevity of the caps and their effectiveness in reducing drainage is uncertain. The effect of existing groundwater contaminants on reducing the aquifer retardation characteristics through occupation of available ion exchange sites or introduction of chelating agents into the aquifer is unknown.

Traditionally accepted contributions to stream flow by shallow lateral flow and groundwater of $90 \%$ and $10 \%$, respectively (Fig. 3.15), were not supported by a recent hydrologic analysis of Clapp, Scanlon, and Timmins (n.d.). They used topographic indices of convergent flow to model the hydrologic responses of Center Seven Creek in Melton Valley, an area with soils and subsoils similar to those of SWSA 6 . These investigators estimated the proportions of shallow flow and groundwater contributing to stream flow to be $53 \%$ and $47 \%$, respectively, for seven annual simulations. The shallow flow proportion is likely to be a lower bound, since the study was conducted for a 7-year period during which mean annual precipitation was $25 \%$ lower than average for the area. The shallow flow contribution to stream flow is estimated to rise to $70 \%$ in an average year, on the assumption that most of the added flow generated with additional rainfall would be contributed by shallow flow rather than by groundwater flow. It is more conservative for PA analyses to favor the recharge path than the shallow flow path for the analysis of water quality at $100 \mathrm{~m}$ from the disposal site, and an approximate 70:30 ratio for the shallow flow and groundwater contributions to stream flow was adopted (Appendix D). The hydrologic modeling of Clapp, Scanlon, and Timmins (n.d.) also suggested, from comparisons of simulation results with groundwater elevation data, that recharge is not spatially uniform across the landscape.

Low-level releases of ${ }^{3} \mathrm{H}$ have been associated with the underpad drainage layer of Tumulus I, and a singular incident of a release of ${ }^{3} \mathrm{H}$ from Tumulus II has been recorded. Corrective action was taken to reduce future releases from Tumulus II. The cause for the low-level releases of ${ }^{3} \mathrm{H}$ in the underpad drainage layer of Tumulus I is currently under investigation, and corrective actions will be initiated once the cause is identified. Groundwater quality has been investigated extensively as part of the environmental surveillance activities for SWSA 6 (ORNL 1993b). 
Groundwater quality has been adversely impacted from historical disposal operations. Volatile organic compounds (VOCs) and radionuclides have been identified in wells throughout the facility. VOC contamination occurs primarily along the eastern site boundary, where data suggest that the VOCs are migrating towards the perennial creek to the east of the facility and concentrations are decreasing within the site. Extensive subsurface investigations have been performed as part of the CERCLA remediation activities for SWSA 6 (Bechtel 1991b). Additional monitoring activities are performed as part of the ERWM Program to better define the extent of contamination within SWSA 6 and the effects of corrective measures (Clapp and Marshall 1992; Clapp 1992). Contamination of groundwater due to migration of plumes from previously used areas has occurred at the sites analyzed in this PA, complicating the monitoring of the units analyzed in this assessment for performance verification or nonperformance detection. Moreover, because of existing contaminant plumes, the potential adsorption capacity of the site soils is unclear.

\subsubsection{Geochemistry}

Parent materials of the Conasauga Group contain carbonate that is slowly weathered and leached to varying degrees. As carbonate leaching increases, the soil $\mathrm{pH}$ decreases: thus. soil $\mathrm{pH}$ is a good index of weathering. A soil with a $\mathrm{pH}$ over 6.5 generally contains carbonate, and as the soil $\mathrm{pH}$ declines, the exchangeable calcium and magnesium in the soil also decline (Rothschild et al. 1984). After carbonate is removed, other less soluble minerals such as quartz, feldspars, and phyllosilicates control groundwater quality and result in groundwater with lower ionic strength than carbonatecontrolled groundwater. The subsoils of SWSA 6 usually contain carbonates, and these control groundwater geochemistry. Thus, the water quality of the upper subsurface is dominated by mixed cations and bicarbonate anions (Solomon et al. 1992). Water quality in the subsurface adjacent to the LLW silos, high-range wells, asbestos silos, and fissile wells is routinely determined as part of the Active Sites Environmental Monitoring Program (Wickliff, Morrissey, and Ashwood 1991; Ashwood, Wickliff, and Morrissey 1991; Ashwood, Hicks, and Morrissey 1992). Water quality in the drainage layers and in the subsurface of Tumulus I, Tumulus II, and the IWMF is also routinely monitored.

\subsubsection{Natural Resources}

Natural resources on the ORR include water in creeks and impoundments, timber and other forest products, fish and wildlife, and minerals mined from geologic formations.

\subsubsection{Geologic Resources}

Exploitation of geologic resources in the Oak Ridge area has been limited to the mining of limestones and dolomites. The Maynardville limestone in the Conasauga Group is being actively mined by the Rogers Group in Union Valley. Several abandoned quarries are located on the ORR, 
including (1) Kerr Hollow Quarry, near the intersection of Scarboro Road and Bethel Valley Road, in the Five Oaks Member at the bottom of the of the Chickamauga Group in Bethel Valley; (2) the nearby old Rogers Quarry north of Bethel Valley Road, in the Rockdell Formation (Unit D) above the Five Oaks; (3) the quarry near East Fork Poplar Creek and Gallaher Cemetery, in the Pond Spring Formation at the bottom of the Chickamauga Group in East Fork Valley; (4) a quarry in Knoxville dolomites on the western tip of McKinney Ridge $1 \mathrm{~km}$ northeast of ETTP; and (5) a small quarry in the Knox Group on the north side of the water gap for Poplar Creek through Black Oak Ridge, due north of ETTP.

Radionuclides from SWSA 6 that find their way into the groundwater would not put these quarries at risk of contamination, since the groundwater beneath western Melton Valley ultimately discharges to the Clinch River.

\subsubsection{Water Resources}

Eastern Tennessee is rich with water in the form of naturally occurring streams, rivers, springs, and groundwater, as well as reservoirs used for power generation, flood control, water supply, and recreation. SWSA 6 lies near the outlet of WOC watershed (Fig. 3.2), which drains most of the ORNL main plant area in Bethel Valley and most of Melton Valley as well. WOC and Melton Branch both feed WOL, an impoundment created by WOD. Below the dam is the WOC embayment of the Clinch River, which was dammed in 1939 to form Watts Bar Lake, a major navigable reservoir. Neither Melton Branch nor WOC is used as a drinking water supply. These watercourses are completely within the ORR fenced boundary and are not accessible to the public, though for the purposes of this PA access is assumed. Of the surface waters in WOC watershed, only WOL contains sufficient water to be considered a year-round source of drinking water. The average discharge of WOL to the Clinch River is about $0.42 \mathrm{~m}^{3} / \mathrm{s}$ (15 cfs).

The Clinch River serves as a drinking water supply for parts of the ORR and for several surrounding communities, the closest of which are Oak Ridge [30 km (19 miles) upstream of the WOC embayment], and Kingston ( $30 \mathrm{~km}$ downstream). The nearest water intake is about $10 \mathrm{~km}$ (6 miles) downstream at the ETTP. The Clinch River should be expected to be used as a primary drinking water source for any future community established nearby. The average discharge of the Clinch River near WOD is about $140 \mathrm{~m}^{3} / \mathrm{s}$ (4900 cfs).

While industrial and drinking water supplies in the area are primarily taken from surface water sources, single-family groundwater wells are common in adjacent rural areas not served by the public water supply system. Most of the residential water supply wells in the immediate area of ORR are on the opposite side of the Clinch River. Most wells used for potable water are in the deeper principal carbonate aquifers [up to $300 \mathrm{~m}(1000 \mathrm{ft})$ depth.]. 


\subsubsection{Natural Background Radiation}

This section discusses exposures of the public to natural background radiation. These exposures, which are largely unavoidable, provide a context for judging the significance of projected doses to the public due to releases of radionuclides from the SWSA 6 facility.

The discussion in this section is divided into two parts. Sect. 3.1.8.1 reviews the available information on average doses in the U.S. population from various sources of exposure, including natural background. Sect. 3.1.8.2 presents data specific to the ORR on external gamma radiation exposure and concentrations of naturally occurring radionuclides in air, water, and soil.

\subsubsection{Average Radiation Doses in U.S. Population}

Available data on average radiation doses in the U.S. population from various sources of exposure have been summarized by the National Council on Radiation Protection and Measurements (NCRP 1987). The information developed by NCRP is summarized in Table 3.3 and described as follows.

Taking into account all sources of exposure except tobacco, the average annual EDE in the U.S. population is about $360 \mathrm{mrem}(3.6 \mathrm{mSv})$. About $300 \mathrm{mrem}(3.0 \mathrm{mSv})$, or about $82 \%$, of the total dose is due to natural sources.

The most important natural source of radiation exposure is indoor radon. This source contributes about $67 \%$ of the dose from all natural sources and about $55 \%$ of the dose from all sources. The remaining natural sources-including cosmic rays, cosmogenic and terrestrial radionuclides, and radionuclides occurring naturally in the body $\left(\right.$ e.g. ${ }^{40} \mathrm{~K}$ ) - contribute about $33 \%$ of the dose from all natural sources and about $27 \%$ of the dose from all sources.

The average annual EDE from all man-made sources is about $60 \mathrm{mrem}(0.6 \mathrm{mSv})$, or about $18 \%$ of the dose from all sources. Medical exposures contribute about $84 \%$ of the dose from all manmade sources and about $15 \%$ of the dose from all sources. Consumer products contribute about $14 \%$ of the dose from all man-made sources and about $3 \%$ of the dose from all sources. Other man-made sources-including occupational exposures, releases from nuclear fuel cycle facilities, and other miscellaneous environmental sources-contribute only about $2 \%$ of the dose from all man-made sources and less than $1 \%$ of the dose from all sources.

\subsubsection{Natural Radiation Environment on the Oak Ridge Reservation}

A variety of data can be used to characterize the natural radiation environment on or near the ORR. As discussed in the following paragraphs, the available data include measurements of external gamma radiation exposure and concentrations of radionuclides in air, water, and soil. 
Table 3.3 Average annual effective dose equivalents in U.S. population from exposure to various sources ${ }^{a}$

\begin{tabular}{lcc}
\hline \multicolumn{1}{c}{ Source of radiation exposure } & $\begin{array}{c}\text { Annual effective dose } \\
\text { equivalent (mrem) }\end{array}$ & $\begin{array}{c}\text { Percent of } \\
\text { total dose }\end{array}$ \\
\hline Natural sources & 200 & 55 \\
$\quad$ Radon & 100 & 27 \\
$\quad$ Other $^{b}$ & 0.9 & 0.3 \\
Occupational $^{d}$ & 0.05 & 0.01 \\
Nuclear fuel cycle $^{e}$ & & \\
Consumer products $^{\text {Tobaccof }}$ & & 3 \\
$\quad$ Other & & \\
Miscellaneous environmental sources & & \\
Medical & 9 & 0.02 \\
$\quad$ Diagnostic X rays & 0.06 & 11 \\
$\quad$ Nuclear medicine & 39 & 4 \\
Rounded total & 14 & \\
\hline
\end{tabular}

${ }^{\circ}$ Data obtained from Table 8.1 of NCRP Report No. 93 (NCRP 1987).

${ }^{b} 1 \mathrm{mrem}=0.01 \mathrm{mSv}$.

'Other natural sources include cosmic rays, cosmogenic and terrestrial radionuclides, and radionuclides occurring naturally in the body. These sources contribute average annual EDEs of about 30, 30, and $40 \mathrm{mrem}$, respectively.

${ }^{d}$ About one million individuals receive occupational exposure; average annual EDE in this population is about 230 mrem.

'Estimate-based collective dose to populations within $80 \mathrm{~km}$ ( 50 miles) of operating facilities.

$f_{E D E}$ was not estimated; estimated average annual dose equivalent to segment of bronchial epithelium of smokers is $16 \mathrm{rem}$.

sVariety of consumer products (e.g., smoke detectors, radioluminous products, gas mantles) containing radioactive materials.

${ }^{h}$ Sources include airborne emissions not accounted for under nuclear fuel cycle facilities, mineral extraction industry facilities, transportation of radioactive materials, and global fallout of man-made radionuclides from the atmospheric (e.g., from testing of nuclear weapons).

\subsection{Background External Gamma Exposure}

External gamma radiation exposures are measured at a number of locations on or near the ORR (LMES 1995). Measurements at Norris Dam should provide data which are largely unaffected by any operations on the ORR and thus should be representative of background exposures. 
During 1994, the mean exposure rate at Norris Dam was $7.5 \mu \mathrm{R} / \mathrm{h}$ (LMES 1995). This exposure rate includes contributions from cosmic rays and from cosmogenic and terrestrial radionuclides. The measured exposure rate can be converted to an estimate of annual EDE as follows. An exposure of $1 \mathrm{R}$ corresponds to an EDE of approximately $0.8 \mathrm{rem}$ (ICRP 1987). Therefore, the mean exposure rate corresponds to an $\mathrm{EDE}$ rate of about $6.0 \mu \mathrm{rem} / \mathrm{h}$, and for continuous exposure outdoors, the annual EDE would be about 53 mrem. Taking into account that exposure during indoor residence should reduce the average external dose by about 10\% (NCRP 1987), the estimated annual EDE from external exposure to all natural sources at this location would be about 48 mrem.

The estimated external dose from cosmic rays and cosmogenic and terrestrial radionuclides obtained above is somewhat less than the average value in the U.S. population of about 60 mrem (see footnote $c$ in Table 3.3). The somewhat lower exposure near the ORR is consistent with other measurements throughout the southeastern United States (EPA 1990) and is due mainly to the low elevation at the site and thus the relatively low contribution from cosmic rays.

\subsection{Background Levels of Radionuclides in Air}

Measured concentrations of radionuclides in air at Norris Dam and Fort Loudoun Dam obtained during 1994 (LMES 1995) are summarized in Table 3.4. These measurement locations are sufficiently far from the ORR that the data should be largely unaffected by releases from the Reservation. In addition to naturally occurring radionuclides (i.e., ${ }^{3} \mathrm{H},{ }^{7} \mathrm{Be}$, and isotopes of thorium and uranium), some man-made radionuclides (i.e., ${ }^{60} \mathrm{Co}, \mathrm{Sr},{ }^{137} \mathrm{Cs},{ }^{238,239} \mathrm{Pu},{ }^{241} \mathrm{Am}$, and ${ }^{244} \mathrm{Cm}$ ) were detected. However, the man-made radionuclides usually were detected in relatively few samples, and some of these radionuclides are part of the background due to global fallout from the atmosphere.

The measured concentrations of radionuclides in air can be converted to an estimate of annual EDE from inhalation using the dose conversion factors for inhalation given in Appendix G, Table G.3, for an annual air intake of $8,000 \mathrm{~m}^{3}$ (see Appendix G, Sect. G.5.2.1). The estimated annual EDE from inhalation is about $7 \mathrm{mrem}$, and about $63 \%$ of this dose is due to exposure to ${ }^{232} \mathrm{Th}$ and ${ }^{234} \mathrm{U}$.

\subsection{Background Levels of Radionuclides in Surface Water}

Measured concentrations of radionuclides at the Oak Ridge Marina and the Anderson County Filtration Plant on Melton Hill Reservoir obtained during 1994 (LMES 1995) are summarized in Table 3.5. These measurements should be largely unaffected by any releases from the ORR, and they should be representative of background concentrations of radionuclides in surface waters near the Reservation that might be used as a public drinking water supply. In addition to uranium, some manmade radionuclides (i.e., ${ }^{60} \mathrm{Co}, \mathrm{Sr},{ }^{99} \mathrm{Tc}$, and ${ }^{137} \mathrm{Cs}$ ) were detected at these locations. However, the man-made radionuclides usually were detected in relatively few samples, and some of these radionuclides are part of the background due to global fallout from the atmosphere. 
Table 3.4 Measured concentrations of radionuclides in air near the Oak Ridge Reservation ${ }^{a}$

\begin{tabular}{lc|lc}
\hline Radionuclide & $\begin{array}{l}\text { Concentration } \\
\left(10^{-9} \mu \mathrm{Ci} / \mathrm{m}^{3}\right)\end{array}$ & Radionuclide & $\begin{array}{l}\text { Concentration } \\
\left(10^{-9} \mu \mathrm{Ci} / \mathrm{m}^{3}\right)\end{array}$ \\
\hline${ }^{3} \mathrm{H}$ & $6.9 \times 10^{3}$ & ${ }^{234} \mathrm{U}$ & $1.3 \times 10^{-2}$ \\
${ }^{7} \mathrm{Be}$ & $8.3 \times 10^{1}$ & ${ }^{235} \mathrm{U}$ & $2.0 \times 10^{-3}$ \\
${ }^{60} \mathrm{Co}$ & $2.1 \times 10^{-2}$ & ${ }^{238} \mathrm{U}$ & $6.1 \times 10^{-3}$ \\
$\mathrm{Total} \mathrm{Sr}$ & $2.3 \times 10^{-2}$ & ${ }^{238} \mathrm{Pu}$ & $2.9 \times 10^{-4}$ \\
${ }^{137} \mathrm{Cs}$ & $1.7 \times 10^{-2}$ & ${ }^{239} \mathrm{Pu}$ & $4.2 \times 10^{-5}$ \\
${ }^{228} \mathrm{Th}$ & $2.0 \times 10^{-3}$ & ${ }^{241} \mathrm{Am}$ & $6.9 \times 10^{-4}$ \\
${ }^{230} \mathrm{Th}$ & $2.2 \times 10^{-3}$ & ${ }^{244} \mathrm{Cm}$ & $1.9 \times 10^{-4}$ \\
${ }^{232} \mathrm{Th}$ & $2.1 \times 10^{-3}$ & & \\
\hline
\end{tabular}

${ }^{\circ}$ Average concentrations at Norris Dam and Fort Loudoun Dam during 1994 from Table 5.2 of LMES (1995).

Table 3.5 Measured concentrations of radionuclides in surface water near the Oak Ridge Reservation ${ }^{a}$

\begin{tabular}{|c|c|c|}
\hline Measurement location & Radionuclide & $\begin{array}{l}\text { Concentration } \\
(\mathrm{pCi} / \mathrm{L})\end{array}$ \\
\hline \multirow[t]{6}{*}{ Melton Hill Reservoir - Oak Ridge Marina } & ${ }^{60} \mathrm{Co}$ & 3.5 \\
\hline & Total Sr & 1.2 \\
\hline & ${ }^{137} \mathrm{Cs}$ & 1.0 \\
\hline & Gross beta & 2.7 \\
\hline & Gross alpha & 1.2 \\
\hline & Total U & 0.48 \\
\hline Melton Hill Reservoir - Anderson County & ${ }^{60} \mathrm{Co}$ & 2.3 \\
\hline \multirow[t]{5}{*}{ Filtration Plant } & Total Sr & 1.4 \\
\hline & ${ }^{99} \mathrm{Tc}$ & 0.86 \\
\hline & Gross beta & 2.2 \\
\hline & Gross alpha & 0.66 \\
\hline & Total U & 0.62 \\
\hline
\end{tabular}

${ }^{a}$ Average concentrations during 1994 from Table 5.35 of LMES (1995). Measurement is given only when average value is greater than zero.

The measured concentrations of radionuclides in surface water can be converted to estimates of annual EDE from the drinking water pathway using the dose per unit concentration given in Appendix G, Table G.7. At the Oak Ridge Marina, the annual EDE from ${ }^{60} \mathrm{Co}$, ${ }^{137} \mathrm{Cs}$, and total 
uranium would be about $0.2 \mathrm{mrem}$. If the total strontium measurement is attributed to ${ }^{90} \mathrm{Sr}$ and the gross alpha measurement less the contribution from total uranium is attributed to ${ }^{232} \mathrm{Th}$, which should be conservative assumptions, the annual EDE from all radionuclides would be about 2 mrem. Similarly, at the Anderson Country Filtration Plant, the annual EDE from ${ }^{60} \mathrm{Co},{ }^{99} \mathrm{Tc}$, and total uranium would be about $0.2 \mathrm{mrem}$, and the annual EDE from all radionuclides would be about $0.4 \mathrm{mrem}$.

\subsection{Background Levels of Radionuclides in Groundwater}

Measured concentrations of radionuclides in groundwater from a number of residential wells near the ORR obtained during 1994 (LMES 1995) are summarized in Table 3.6. The wells are located in different geological formations. In many cases, the wells could be affected by releases from the ORR because of their proximity to the boundary.

Based on these data, it is difficult to estimate the dose that might result from the drinking water pathway. If the gross beta measurement is attributed to ${ }^{90} \mathrm{Sr}$ and the gross alpha measurement is attributed to ${ }^{226} \mathrm{Ra}$, which should be conservative assumptions, the annual EDE from all radionuclides would be about 2 mrem.

Table 3.6 Measured concentrations of radionuclides in groundwater near the Oak Ridge Reservation ${ }^{a}$

\begin{tabular}{lc}
\hline Radionuclide & $\begin{array}{c}\text { Concentration } \\
(\mathrm{pCi} / \mathrm{L})\end{array}$ \\
\hline Total strontium & 3.1 \\
Gross beta & 3.6 \\
Gross alpha & 1.5 \\
\hline \multicolumn{2}{c}{${ }^{a}$ Average concentrations in all wells during 1994 from Table 5.46} \\
of LMES (1995).
\end{tabular}

\subsection{Background Levels of Radionuclides in Soil}

Concentrations of radionuclides in soil have been measured at many locations on or near the ORR (ORNL 1993a). Measurements were made in the three major geologic strata on the Reservation (the Conasauga, Chickamauga, and Knox groups) and at different depths below the surface (the A, B, and $\mathrm{C}$ horizons). The extensive set of measurements to characterize background levels of radionuclides in soil are summarized in Table 3.7. 
Table 3.7 Measured concentrations of radionuclides in soils on or near the Oak Ridge Reservation ${ }^{a}$

\begin{tabular}{|c|c|c|c|}
\hline Radionuclide & Horizon $^{b}$ & Group & $\begin{array}{l}\text { Concentration } \\
\qquad(\mathrm{pCi} / \mathrm{g})\end{array}$ \\
\hline${ }^{3} \mathrm{H}$ & A & $\begin{array}{l}\text { Conasauga } \\
\text { Chickamauga } \\
\text { Knox }\end{array}$ & $\begin{array}{l}0.032 \\
0.056 \\
0.017\end{array}$ \\
\hline${ }^{40} \mathrm{~K}$ & A & $\begin{array}{l}\text { Conasauga } \\
\text { Chickamauga } \\
\text { Knox } \\
\text { Conasauga } \\
\text { Chickamauga } \\
\text { Knox } \\
\text { Conasauga } \\
\text { Chickamauga } \\
\text { Knox }\end{array}$ & $\begin{array}{l}16 \\
12 \\
3.6 \\
18 \\
23 \\
7.9 \\
23 \\
21 \\
8.0\end{array}$ \\
\hline${ }^{90} \mathrm{Sr}$ & A & Conasauga & 0.39 \\
\hline${ }^{99} \mathrm{Tc}$ & A & $\begin{array}{l}\text { Conasauga } \\
\text { Chickamauga }\end{array}$ & $\begin{array}{l}0.96 \\
1.2\end{array}$ \\
\hline${ }^{137} \mathrm{Cs}$ & $\begin{array}{l}\mathrm{B} \\
\mathrm{C}\end{array}$ & $\begin{array}{l}\text { Conasauga } \\
\text { Chickamauga } \\
\text { Knox } \\
\text { Conasauga } \\
\text { Knox } \\
\text { Conasauga }\end{array}$ & $\begin{array}{l}0.56 \\
1.1 \\
0.92 \\
0.015 \\
0.0036 \\
0.0008\end{array}$ \\
\hline${ }^{226} \mathrm{Ra}^{c}$ & A & $\begin{array}{l}\text { Conasauga } \\
\text { Chickamauga } \\
\text { Knox } \\
\text { Conasauga } \\
\text { Chickamauga } \\
\text { Knox } \\
\text { Conasauga } \\
\text { Chickamauga } \\
\text { Knox }\end{array}$ & $\begin{array}{l}0.76 \\
1.0 \\
1.0 \\
0.81 \\
1.0 \\
1.5 \\
0.86 \\
1.2 \\
1.4\end{array}$ \\
\hline${ }^{228} \mathrm{Th}^{d}$ & A & $\begin{array}{l}\text { Conasauga } \\
\text { Chickamauga } \\
\text { Knox } \\
\text { Conasauga } \\
\text { Chickamauga } \\
\text { Knox } \\
\text { Conasauga } \\
\text { Chickamauga } \\
\text { Knox }\end{array}$ & $\begin{array}{l}1.0 \\
1.2 \\
0.45 \\
1.3 \\
1.5 \\
1.1 \\
0.99 \\
1.7 \\
1.2\end{array}$ \\
\hline
\end{tabular}


Table 3.7. (continued)

\begin{tabular}{|c|c|c|c|}
\hline Radionuclide & Horizon $^{b}$ & Group & $\begin{array}{c}\text { Concentration } \\
(\mathrm{pCi} / \mathrm{g})\end{array}$ \\
\hline \multirow[t]{9}{*}{${ }^{230} \mathrm{Th}^{c}$} & $\mathrm{~A}$ & Conasauga & 0.74 \\
\hline & & Chickamauga & 1.1 \\
\hline & & Knox & 0.93 \\
\hline & B & Conasauga & 0.85 \\
\hline & & Chickamauga & 1.1 \\
\hline & & Knox & 1.4 \\
\hline & C & Conasauga & 0.71 \\
\hline & & Chickamauga & 1.2 \\
\hline & & Knox & 1.5 \\
\hline \multirow[t]{9}{*}{${ }^{232} \mathrm{Th}$} & $A$ & Conasauga & 1.0 \\
\hline & & Chickamauga & 1.2 \\
\hline & & Knox & 0.65 \\
\hline & B & Conasauga & 1.2 \\
\hline & & Chickamauga & 1.6 \\
\hline & & Knox & 1.2 \\
\hline & $\mathrm{C}$ & Conasauga & 1.1 \\
\hline & & Chickamauga & 1.5 \\
\hline & & Knox & 1.2 \\
\hline \multirow[t]{9}{*}{${ }^{234} \mathrm{Th}^{e}$} & A & Conasauga & 1.5 \\
\hline & & Chickamauga & 0.70 \\
\hline & & Knox & 0.92 \\
\hline & B & Conasauga & 0.91 \\
\hline & & Chickamauga & $0.74^{f}$ \\
\hline & & Knox & 0.99 \\
\hline & $\mathrm{C}$ & Conasauga & 1.1 \\
\hline & & Chickamauga & 1.0 \\
\hline & & Knox & 0.89 \\
\hline \multirow[t]{9}{*}{${ }^{234} U^{c \cdot g}$} & $A$ & Conasauga & 1.1 \\
\hline & & Chickamauga & 1.1 \\
\hline & & Knox & 1.3 \\
\hline & B & Conasauga & 1.1 \\
\hline & & Chickamauga & 1.0 \\
\hline & & Knox & 1.5 \\
\hline & C & Conasauga & 0.86 \\
\hline & & Chickamauga & 1.1 \\
\hline & & Knox & 1.6 \\
\hline \multirow[t]{9}{*}{${ }^{235} \mathrm{U}^{h}$} & A & Conasauga & 0.054 \\
\hline & & Chickamauga & 0.074 \\
\hline & & Knox & 0.096 \\
\hline & B & Conasauga & 0.054 \\
\hline & & Chickamauga & 0.095 \\
\hline & & Knox & 0.22 \\
\hline & $\mathrm{C}$ & Conasauga & 0.039 \\
\hline & & Chickamauga & 0.096 \\
\hline & & Knox & 0.12 \\
\hline
\end{tabular}


Table 3.7. (continued)

\begin{tabular}{|c|c|c|c|}
\hline Radionuclide & Horizon $^{b}$ & Group & $\begin{array}{l}\text { Concentration } \\
\qquad(\mathrm{pCi} / \mathrm{g})\end{array}$ \\
\hline \multirow[t]{4}{*}{${ }^{236} \mathrm{U}$} & A & Conasauga & 0.0098 \\
\hline & & Chickamauga & 0.0063 \\
\hline & & Knox & 0.0093 \\
\hline & B & Conasauga & 0.0006 \\
\hline \multirow[t]{9}{*}{${ }^{238} \mathrm{U}$} & A & Conasauga & 1.2 \\
\hline & & Chickamauga & 1.1 \\
\hline & & Knox & 1.3 \\
\hline & B & Conasauga & 1.1 \\
\hline & & Chickamauga & 1.1 \\
\hline & & Knox & 1.7 \\
\hline & $\mathrm{C}$ & Conasauga & 0.86 \\
\hline & & Chickamauga & 1.1 \\
\hline & & Knox & 1.7 \\
\hline \multirow[t]{3}{*}{${ }^{237} \mathrm{~Np}$} & $\mathrm{~A}$ & Conasauga & 0.13 \\
\hline & & Chickamauga & 0.093 \\
\hline & & Knox & 0.076 \\
\hline \multirow[t]{4}{*}{${ }^{238} \mathrm{Pu}$} & A & Conasauga & 0.014 \\
\hline & & Chickamauga & 0.029 \\
\hline & & Knox & 0.020 \\
\hline & B & Conasauga & 0.085 \\
\hline \multirow[t]{3}{*}{${ }^{239 / 240} \mathrm{Pu}$} & A & Conasauga & 0.014 \\
\hline & & Chickamauga & 0.028 \\
\hline & & Knox & 0.020 \\
\hline${ }^{247} \mathrm{Cm}$ & A & Conasauga & 0.0055 \\
\hline
\end{tabular}

${ }^{9}$ Median concentrations from Table 6.1b of ORNL (1993).

${ }^{b}$ The A, B, and C horizons are successive layers of soil extending downward. The A horizon is the uppermost layer of surface soil, containing the most organic carbon and the highest biotic activity, and usually is less than $10 \mathrm{~cm}$ thick. The $\mathrm{B}$ horizon, containing a net accumulation of soil clay minerals and iron oxides, extends to depths of $50 \mathrm{~cm}$ or more. In the $C$ horizon, the layer below the $\mathrm{B}$ horizon, soil processes are minimal.

${ }^{c}$ Radionuclide is long-lived decay product of ${ }^{238} \mathrm{U}$.

${ }^{d}$ Radionuclide is short-lived decay product of ${ }^{232} \mathrm{Th}$.

${ }^{e}$ Radionuclide is short-lived decay product of ${ }^{238} \mathrm{U}$; concentrations are based on measurements of beta emissions, except as noted.

Concentration is based on measurements of gamma emissions.

${ }^{8}$ Measured concentrations include possible contributions from ${ }^{233} \mathrm{U}$, but comparison of values with corresponding concentrations for parent radionuclide ${ }^{238} \mathrm{U}$ suggests that contributions from ${ }^{233} \mathrm{U}$ are relatively unimportant.

${ }^{h}$ Concentrations are based on measurements of alpha emissions, and do not take into account limited measurements of gamma emissions. 
Both naturally occurring and man-made radionuclides were detected in the various soil samples. The most important naturally occurring radionuclides are ${ }^{40} \mathrm{~K},{ }^{226} \mathrm{Ra},{ }^{232} \mathrm{Th}$ and its decay products, and ${ }^{234,235,238} \mathrm{U}$ and their decay products. The various man-made radionuclides in soil could have resulted either from global fallout from the atmosphere or from operations on the ORR.

The SWSA 6 site is underlain by two formations of the Conasauga Group. The data in Table 3.7 indicate that the concentrations of ${ }^{40} \mathrm{~K}$ in the Conasauga Group are comparable to those in the Chickamauga Group but are substantially higher than those in the Knox Group. For the naturally occurring alpha-emitting isotopes of radium, thorium, and uranium, the concentrations tend to be the lowest in the Conasauga Group, especially in the $\mathrm{B}$ and $\mathrm{C}$ horizons, and the highest in the Knox Group. However, the variation in concentrations among the different groups generally is less than a factor of 2 .

Conversion of the measured concentrations of radionuclides in soil to an estimate of dose requires an assumption about the exposure scenario, because several exposure pathways generally would be involved. However, the dose from external exposure would be represented by the measurements of external gamma radiation exposure described earlier in this section, less an assumed contribution from cosmic rays; and the dose from inhalation exposure following suspension of radionuclides into the air would be represented by the measured concentrations in air, as also described earlier in this section.

The one important exposure pathway for radionuclides in surface soil not accounted for by the measurements of gamma exposure and airborne concentrations of radionuclides is exposure to indoor radon. As described in Appendix G, Sect. G.5.2.1, the annual EDE from exposure to ${ }^{222} \mathrm{Rn}$ per unit concentration of ${ }^{226} \mathrm{Ra}$ in soil is estimated to be $0.12 \mathrm{rem}$ per $\mu \mathrm{Cj} / \mathrm{m}^{3}$, and the annual dose from exposure to ${ }^{220} \mathrm{Rn}$ per unit concentration of ${ }^{232} \mathrm{Th}$ in soil is estimated to be $0.010 \mathrm{rem}$ per $\mu \mathrm{Ci} / \mathrm{m}^{3}$. These dose estimates assume residence in a home for $50 \%$ of the time during a year. Based on the data in Table 3.7, the average concentrations of ${ }^{226} \mathrm{Ra}$ and ${ }^{232} \mathrm{Th}$ in soil below the A horizon are about 1.1 and $1.3 \mathrm{pCi} / \mathrm{g}$, respectively. The data for the $\mathrm{A}$ horizon (the top $10 \mathrm{~cm}$ ) are neglected because the assumption is that the top layer of soil normally would be removed in constructing a home. Assuming a density of soil of $1.4 \mathrm{~g} / \mathrm{cm}^{3}$ gives concentrations of 1.5 and $1.8 \mu \mathrm{Ci} / \mathrm{m}^{3}$, respectively. Therefore, the estimated annual EDEs from exposure to indoor ${ }^{222} \mathrm{Rn}$ and ${ }^{220} \mathrm{Rn}$ are 180 and $20 \mathrm{mrem}$, respectively, giving a total annual EDE from indoor radon of about $200 \mathrm{mrem}$. This estimate is consistent with the average dose in the U.S. population from indoor radon given in Table 3.3. 


\subsection{PRINCIPAL FACILITY DESIGN FEATURES}

This section presents the design features of the several different disposal unit types considered by this revised PA. While a variety of types are discussed, the only disposal unit still operating is the IWMF. The SWSA 6 facility includes additional disposal units, which were used for disposal prior to September 26, 1988, and are not considered in this revised PA. The principal design features are discussed with respect to the time periods of importance to the PA.

\subsubsection{Period of Operations}

SWSA 6 is the only active LLW disposal area on the ORR. Until 1986 all LLW generated at ORNL, including low-level mixed waste, was disposed of by shallow land burial, generally in unlined trenches and auger holes. In 1984 the practice of shallow land disposal on the ORR came under closer scrutiny by federal and state regulators and DOE officials. As a result, major changes in the operation of SWSA 6 were initiated in 1986, including (1) the exclusion of all mixed waste from disposal in SWSA 6; (2) the use of greater confinement disposal (GCD) techniques, such as concrete silos and pipe-lined auger holes, for below-grade disposal; and (3) the storage of some low-activity LLW at ETTP and all mixed waste at ORNL. In addition to the GCD techniques for below-grade disposal, ORNL also developed plans in 1986 for demonstrating the above-grade tumulus disposal technology, which was originally developed in France.

Because of the disposal practices prior to 1986 , some areas in SWSA 6 were remediated under a RCRA interim status closure agreement with TDEC. The remediation activities were coordinated with ongoing GCD waste disposal operations. SWSA 6 is being remediated under CERCLA. A public meeting was held February 9, 1993, to discuss the proposed plan for remediation of SWSA 6. Comments from the public clearly indicated that the preferred alternative of the Interim Proposed Plan for immediate and substantial remedial actions was not supported, and new information indicated that CERCLA site priorities should be reordered. The deferred action plan that has been developed emphasizes site monitoring and technology development and demonstration. Remediation under CERCLA will occur when risks from SWSA 6 warrant action. Subsequently, all below-grade disposal operations were discontinued in January 1994. IWMF disposal operations have filled the disposal unit to $50 \%$ capacity. The projected date for filling the IWMF to full capacity is 2003.

The disposal methods used for each type of waste disposed of in SWSA 6 since issuance of DOE O 5820.2A on September 26, 1988, and the details on the design, waste handling, and waste disposal operations for each disposal unit are discussed in the text that follows. These descriptions of waste disposal operations do not address the cover system to be placed on the disposal units because 
the ultimate closure of SWSA 6 will be a result of the CERCLA process. A scenario for the cover system, which is considered to be a conservative scenario, is provided in Sect. 3.2.3, but this scenario may change significantly in the following years. Final remediation of SWSA 6 will include the consideration of long-term land use, institutional control, and the benefit-cost ratio of remediation alternatives.

Fig. 3.5 shows the location of the SWSA 6 disposal units, roads, and ephemeral streams. Disposals of radionuclides addressed in this PA are grouped into zones, based on proximity and disposal type. These zones, referenced throughout this revised PA, are identified in Fig. 3.17 and Table 3.8. Best estimates of disposed inventories for each of the facilities examined in the PA are given in Tables 4.5-4.7.

\subsubsection{Below-Grade Disposal Units}

Below-grade disposal methods that were used in SWSA 6 include concrete silos, wells in concrete silos, pipe-lined auger hole wells, unlined trenches, and landfills. ORNL began phasing out some below-grade disposal operations in SWSA 6 in December 1992 at the request of TDEC because of concerns about shallow land disposal in the trenches and landfill and concerns that the belowgrade wells would not meet the long-term performance objectives of DOE O 5820.2A. Lise of the wells in concrete silos and piped-lined auger hole wells for disposal was phased out in 1992. The suspect waste landfill was also closed in 1992 for disposal of waste. The unlined trenches were phased out for animal wastes in 1992 and for other biological wastes in early 1993. Use of the beowgrade disposal units was discontinued on January 1, 1994.

Water entry into below grade disposal units may occur by infiltration through the surface or by subsurface flow through side walls and/or the base of disposal units. Water may be largely excluded from disposal units constructed of concrete and/or steel until these units degrade through cracking of concrete and corrorsion of steel. However, obtaining a hydrologic seal between two materials with differing properties such as concrete and steel is difficult. Water entry into trenches and landfills is unrestricted since no preventative measures are taken. Surface infiltration can readily occur and the disturbance from trench construction may enhance lateral subsurface flow through the storm flow zone.

\subsection{Low-Range and High-Range Silos}

Concrete silos were used for disposal of low-range (CH LLW) and high-range (RH LLW $<1 \mathrm{rem} / \mathrm{h}$ ) waste until January 1994. These concrete silos are located in separate areas of SWSA 6 but are identical in construction. Silos were constructed of two 14-gauge, 16-ft long, corrugated steel 


\section{Discretization of Post-9/88 SWSA 6 Disposal Facility Zones}

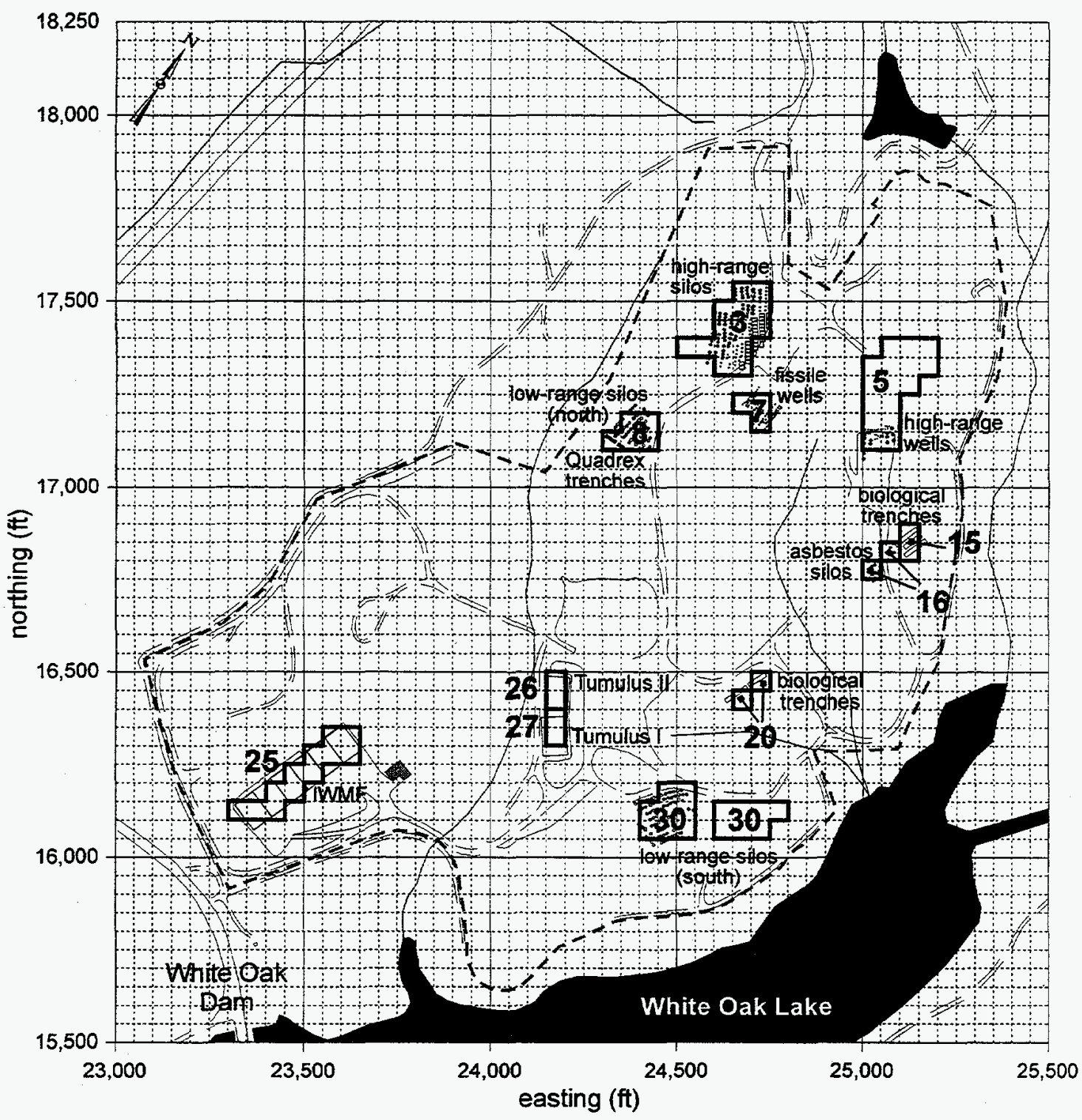

Fig. 3.17. Assignment of waste disposal zones used in the performance assessment. 
Table 3.8 Zone, disposal unit type, number of units, and volume of waste for SWSA 6 disposal units

\begin{tabular}{cccc}
\hline Zone & Disposal Unit & $\begin{array}{c}\text { Number of } \\
\text { units }\end{array}$ & $\begin{array}{c}\text { Volume of waste } \\
\left(\mathrm{m}^{3}\right)\end{array}$ \\
\hline 3 & High-range silos & 37 & 440 \\
5 & High-range silos & 9 & 6 \\
5 & High-range wells-in-silos & 53 & 13 \\
7 & Fissile wells & 2 & 0.3 \\
8 & Quadrex Trenches & 5 & 70 \\
8 & Low-range silos & 24 & 280 \\
15 & Biological trenches & 4 & 330 \\
16 & Asbestos silos & 11 & 150 \\
20 & Biological tenches & 2 & 110 \\
25 & IWMF & 1 & $5400^{b}$ \\
26 & Tumulus II & 1 & 600 \\
27 & Tumulus I & 1 & 740 \\
30 & Low-range silos & 105 & 1100 \\
\hline
\end{tabular}

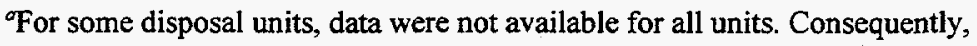
disposed volumes were estimated (by linear extrapolation) for those units.

${ }^{b}$ Estimated disposed volume for 6 pads at closure. IWMF is the only operating disposal unit in SWSA 6 and it has been filled to about 50\% of capacity as of September 1997.

pipes of 8- and 9-ft diameters. A trench was dug approximately $12 \mathrm{~m}(40 \mathrm{ft})$ long by $5 \mathrm{~m}(15 \mathrm{ft})$ deep. The depth of the trench was located and excavated with its lowest point a minimum of $0.6 \mathrm{~m}$ ( $2 \mathrm{ft}$ ) above the maximum water table elevation. Generally three or four silos were placed in the trench. The larger pipe was placed vertically in the trench with minimal space between the pipes and with the top of the pipe $15-30 \mathrm{~cm}(6-12 \mathrm{in}$.) above ground level. The smaller pipe was centered inside the larger pipe and extends approximately $15 \mathrm{~cm}(6 \mathrm{in}$.) above the top of the outer pipe.

A 20-ft section of 3-in. diameter polyvinylchloride (PVC) pipe with slots cut in the bottom 2-3 $\mathrm{ft}$ was used as a monitoring well in some of the silos. Another PVC pipe was placed outside the silos at the low point of the trench. The space around the silos was backfilled with dirt, leaving the tops of the outer pipes approximately $15 \mathrm{~cm}$ (6 in.) above finish grade. As the fill settled, more fill was added to route surface water runoff away from the silo. A 1-ft thick, steel-rod-reinforced concrete pad was poured in the bottom of each silo. The annular space between the two pipes was filled with concrete. Each silo was painted with a unique number [TL-XXX (trench/low-range) or TH-XXX (trench/high-range)] on the outside of the 8-ft pipe that extends above the ground. A 
temporary cover was placed over the open silo when the silo was not being filled. A section view of a typical silo used for $\mathrm{CH}$ and RH LLW is shown in Fig. 3.18. Fig. 3.19 and Fig. 3.20 show the locations of the low-range and high-range silos in proximity to other SWSA 6 disposal units, buildings, roads, ephemeral streams, and foliage. The shaded silos were evaluated for this performance assessment. The remaining silos were filled prior to September 26, 1988.

Generally, noncompactible bulky items, small boxes, 55-gal drums, or soil were disposed of in the low-range concrete silos. Waste packaged in 20 -mil plastic bags containing doubled bagged waste or 1-, 2-, 5-, 10-, or 20-gal metal cans or 30- or 55-gal metal drums were disposed of in the high-range silos. The packaged (drums only) $\mathrm{CH}$ LLW was loaded on a transport vehicle and transported from the waste generator to the Waste Examination and Assay Facility (WEAF) for inspection by real-time radioagraphy. After successful inspection at the WEAF, the waste was transported to a temporary storage facility or a staging area at the disposal site. RH LLW was transported directly to the disposal site. A crane was used to remove the cover from the top of the silo and to lower the waste packages into the silo to prevent the packages from opening. Waste packages were placed as close to one another as practical to minimize the void space between containers. Waste was placed into the silo as long as the maximum radiation reading at the top of the silo did not exceed $200 \mathrm{mrem} / \mathrm{h}$ with the cap removed. If the dose rate was $>200 \mathrm{mrem} / \mathrm{h}$ at the surface after waste was placed in an $\mathrm{RH}$ silo, the silo was roped off, and no additional waste was placed in the silo. The silo was then grouted until the dose rate at the surface was $<200 \mathrm{mrem} / \mathrm{h}$. After the silo was filled with waste, grout was poured between the waste packages to stabilize the waste. Waste placement and grouting was continued until the grout was within $0.3 \mathrm{~m}(1 \mathrm{ft})$ of the top of the silo. After the grout hardened, the silo was covered with a minimum $0.3 \mathrm{~m}(1 \mathrm{ft})$ thick, steel-rod-reinforced concrete cap. Prior to the concrete cap hardening, a stenciled bolt with the silo identification number was placed in the soft concrete cap. After closure and capping of the silo, the radiation reading over the top of the silo was $<2.5 \mathrm{mrem} / \mathrm{h}$.

Disposal of CH LLW and RH LLW in silos was discontinued on January 1, 1994. Since then, the waste has been disposed of in the IWMF or stored on-site in above-grade concrete storage containers awaiting access to an off-site DOE disposal facility.

Silos are expected to allow significant water entry after the concrete develops cracks and later degrades to rubble. The galvanized pipes used as concrete forms are expected to disintegrate in the acid subsoil environment of SWSA 6. Initially, however, the pipes should prevent lateral flow. Nevertheless, monitoring results have shown that the construction of impermeable silos is difficult. Davis et al. (1989) observed water in 34 of 44 silos that were monitored at SWSA 6 . Water levels were shown to be either static, accumulate over time or to oscillate in response to rainfall. Grouting of waste within a silo was introduced to help exclude water interaction with radioactive waste. 


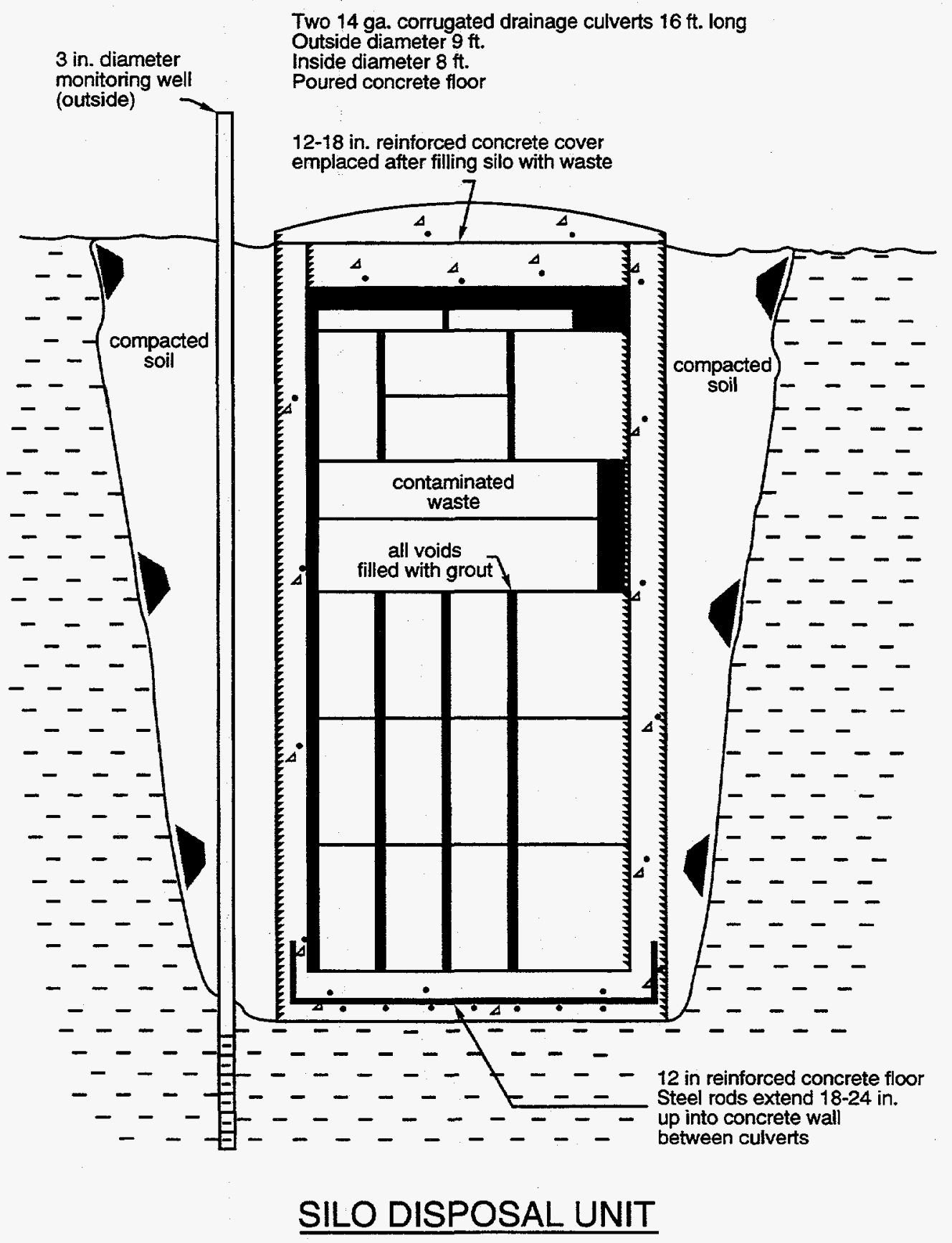

Fig. 3.18. Cross section of a concrete silo. 


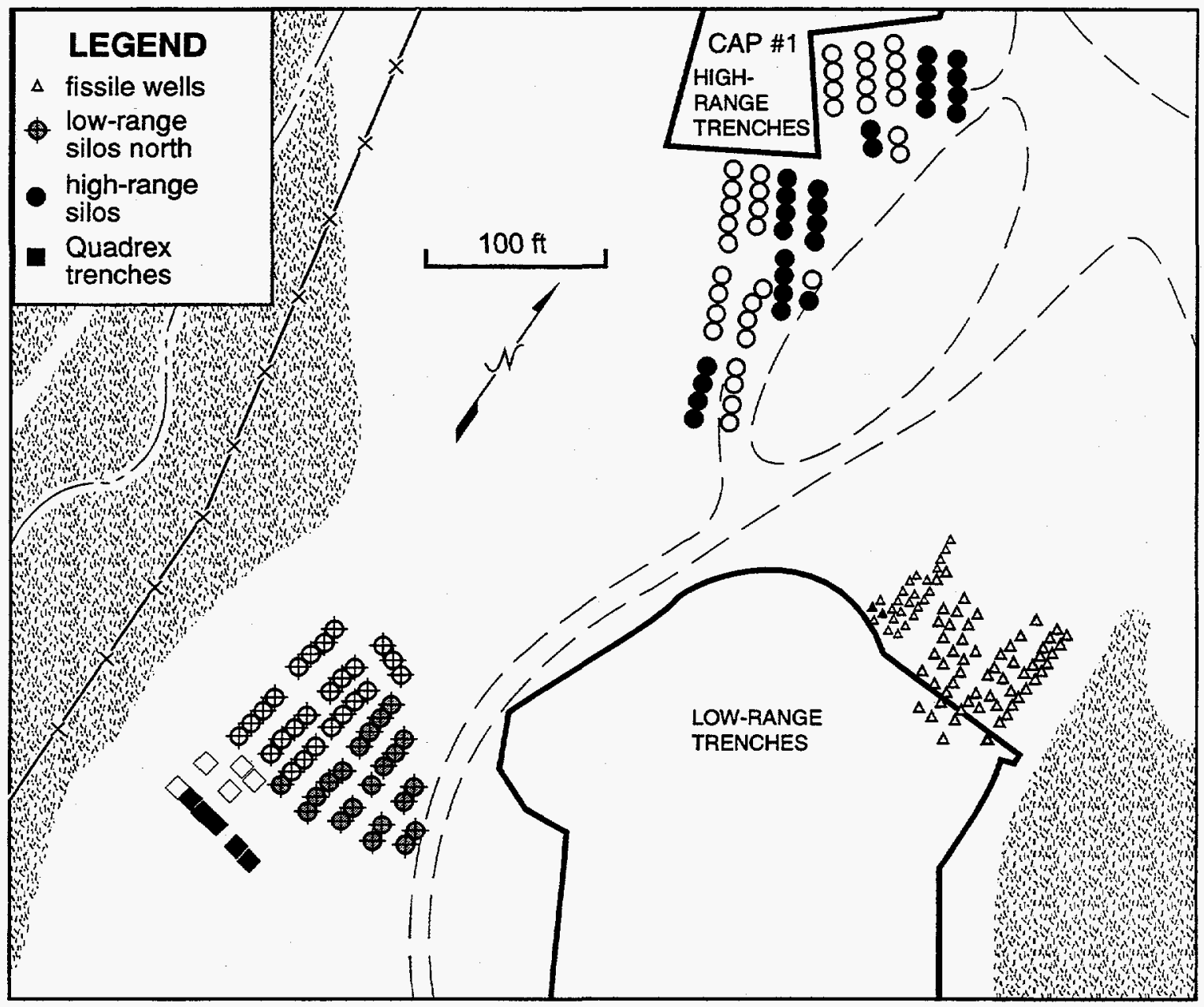

Fig. 3.19. Location of low-range silos, high-range silos, fissile wells, and Quadrex trenches in SWSA 6. 


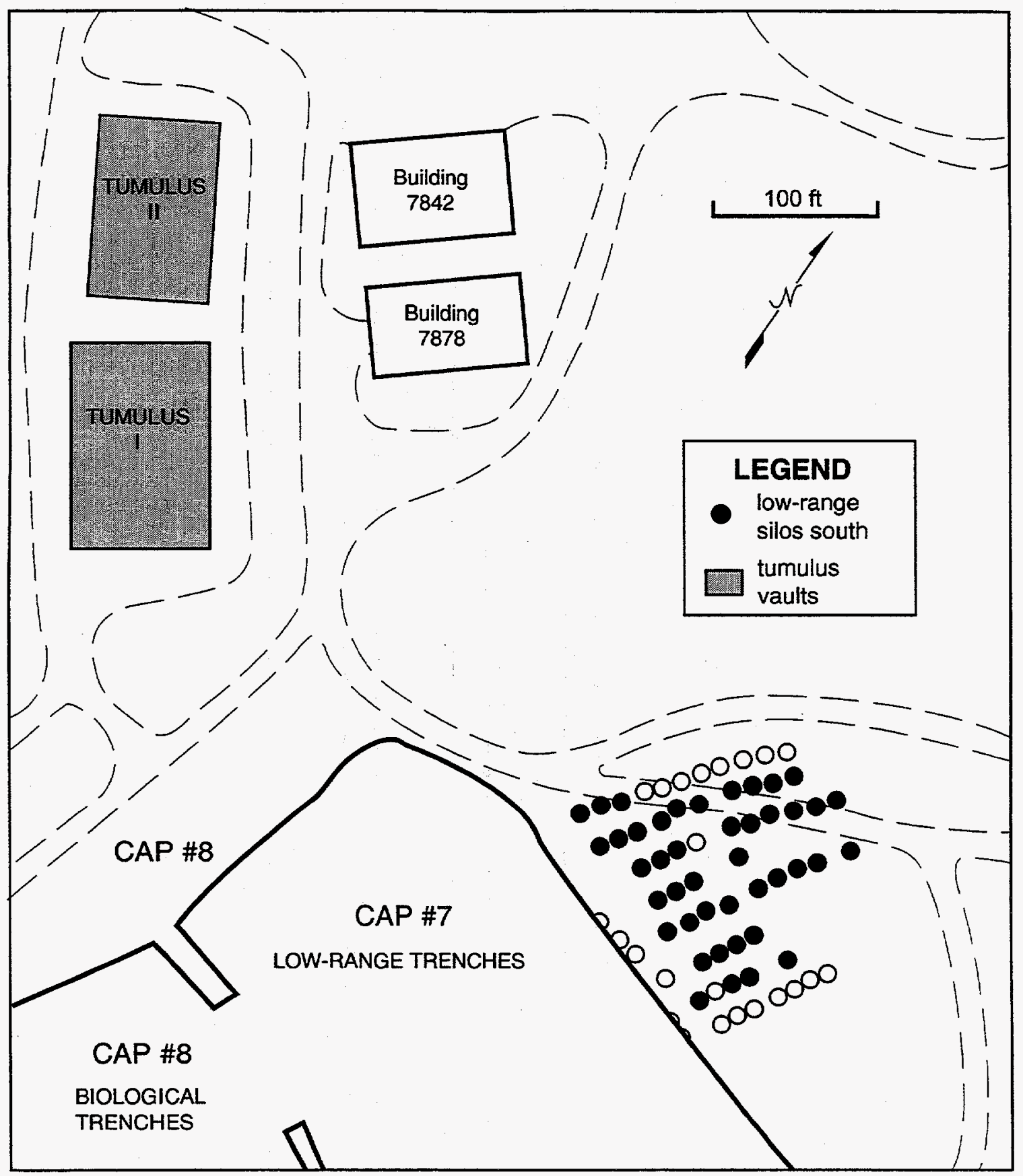

Fig. 3.20. Location of low-range silos and tumuli in SWSA 6. 


\subsection{Asbestos Silos}

Contaminated asbestos waste was disposed of in dedicated concrete silos. The asbestos concrete silos are located in separate areas of SWSA 6 but are identical in construction to the concrete silos described previously in Sect. 3.2.1.1.1. Fig. 3.21 shows the location of the asbestos silos in proximity to other SWSA 6 disposal units, roads, ephemeral streams, and foliage. The legend indicates the silos evaluated in this performance assessment. The other silos were filled prior to September 26, 1988. Generally, asbestos waste was packaged in special, asbestos-labeled, 6-mil polyethylene bags, sealed with tape, and placed in a second asbestos-labeled polyethylene bag. Asbestos waste was transported from the generator's facility directly to the disposal site in dumpsters in a closed transport vehicle. Waste disposal and silo closure was implemented in the same manner as is described in Sect. 3.2.1.1.1.

Disposal of asbestos waste in silos was discontinued on January 1, 1994. Since then waste has been disposed of in the IWMF vaults or stored on-site in above-grade concrete storage containers awaiting access to an off-site disposal facility.

Water entry into asbestos silos is expected to be similar as for the silos discussed in the previous section because of the identical silo construction method used.

\subsection{High-Range Wells-in-Silos}

A modified version of the previously described concrete silo was used for the disposal of

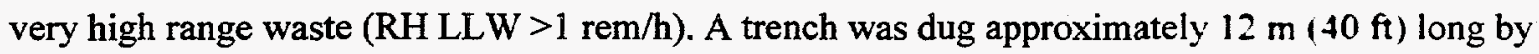
$5 \mathrm{~m}$ ( $15 \mathrm{ft}$ ) deep. The depth of the trench was always located and excavated with its lowest point a minimum of $0.6 \mathrm{~m} \mathrm{(} 2 \mathrm{ft}$ ) above the maximum water table elevation. Three or four concrete silos constructed of one 16-gauge, 16-ft long, $9 \mathrm{ft}$ diameter, corrugated steel pipe were placed in each trench with minimal space between the silos and with the top of the silo 15.2 to $30.5 \mathrm{~cm}$ (6 to $12 \mathrm{in}$.) above ground level. The space around the silos was backfilled with dirt leaving the top of the silo approximately $15 \mathrm{~cm}$ ( 6 in.) above finish grade. As the fill settled, more fill was added as required to provide surface water runoff away from the silo. A 1-ft thick, steel-rod-reinforced concrete pad was poured in the bottom of each silo. A 20-ft section of 3-in. diameter PVC pipe with slots cut in the bottom 2-3 $\mathrm{ft}$ was used as a monitoring well. The PVC pipe was placed inside each silo with the bottom resting on the concrete pad.

Seven wells were placed in a geometric array inside each silo. The wells were constructed of 0.75-in. thick steel pipes, 16 - $\mathrm{ft}$ long with an inside diameter of $20 \mathrm{in}$. The annular space between the outside surface of the pipes and the inside surface of the silo was filled with concrete to approximately $1 \mathrm{~cm}(0.5$ in.) below the top of the pipes. A bolt stenciled with the well identification 


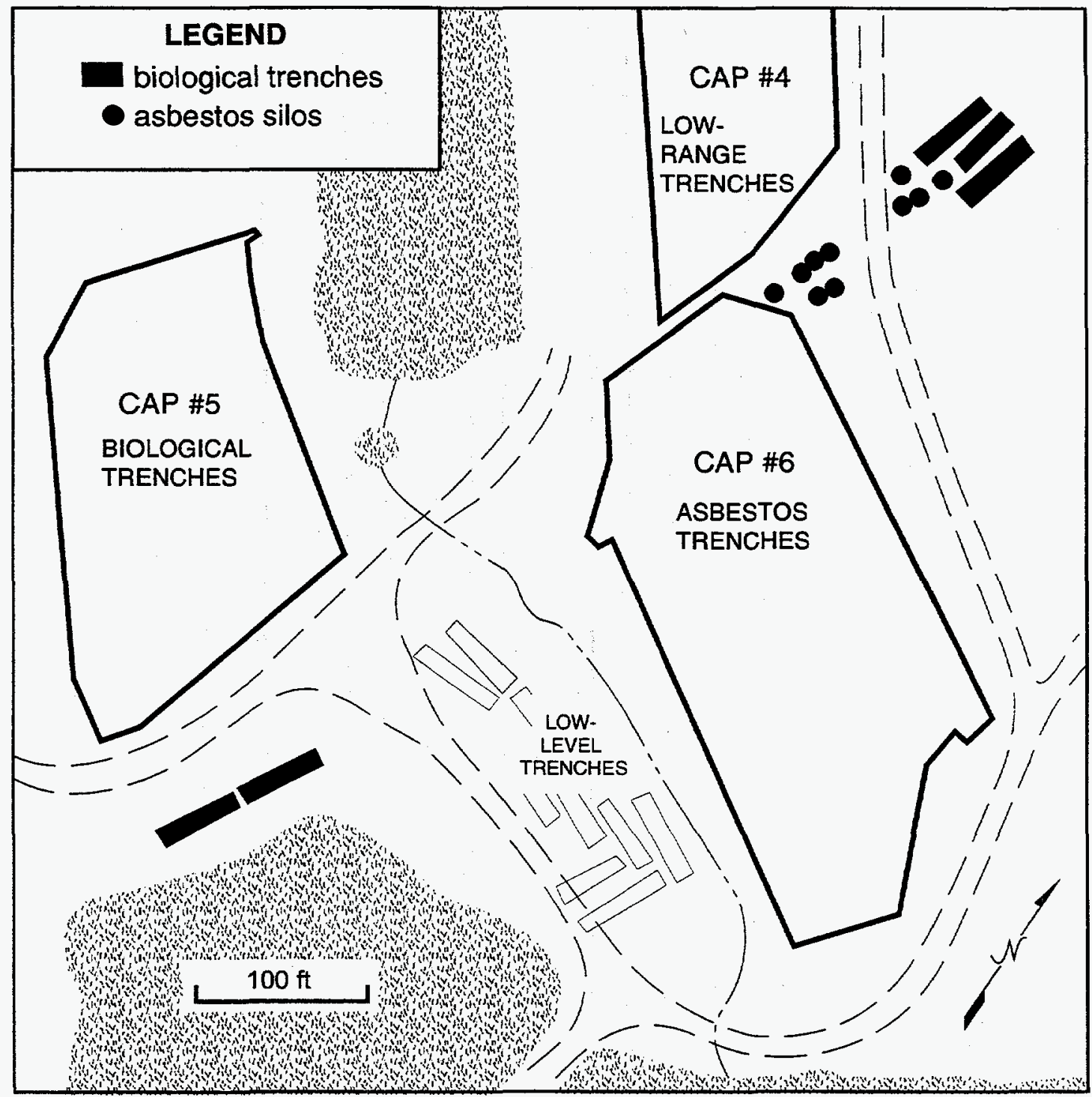

Fig. 3.21. Location of asbestos silos and biological trenches in SWSA 6. 
number was placed in the concrete at the top of each of the seven wells. Each well was identified by a unique number [WH-XXX (well/high-range)]. A temporary cover was placed over the open wells when they were not being filled. A typical section view of a concrete silo with high-range wells used for waste with an unshielded container dose rate $>1 \mathrm{rem} / \mathrm{h}$ is shown in Fig. 3.22. Fig. 3.23 shows the location of the high-range wells-in-silos in proximity to other SWSA 6 disposal units, roads, ephemeral streams, and foliage. The legend indicates the high-range wells-in-silos evaluated in this performance assessment. The remaining units were filled prior to September 26, 1988.

The waste disposed of in concrete silos with high-range wells was packaged in 1-, 2-, 5-, 10-, or 20-gal metal cans or 30-gal metal drums and transported to the disposal site in a lead-shielded, bottom-discharge carrier. Using a crane, the carrier was placed over the well, the bottom carrier drawer was opened, and the waste was lowered into the well. Prefabricated concrete plugs were placed in the well on top of the waste to reduce the radiation reading at the top of the well to $<200 \mathrm{mrem} / \mathrm{h}$. When a well in the silo was filled, the well was capped with a minimum 1 - $\mathrm{ft}$ steel-rodreinforced concrete cap. Prior to the concrete cap hardening, a stenciled bolt with the well identification number was placed in the soft concrete cap. The radiation reading over the top of a closed well was $<2.5 \mathrm{mrem} / \mathrm{h}$.

Very high range wastes are no longer disposed of in high-range wells in concrete silos. This waste is managed as a special-case waste and is transported to ORNL retrievable storage wells in shielded waste carriers. The current waste management plan for very high range LLW is to store the waste on-site until access to an off-site disposal facility is available. High-range wells built within silos have 0.75 in. thick steel walls and the wells are grouted in concrete within a silo. This is a formidable barrier to lateral flow. Seepage into these wells may eventually occur through the concrete base or the cap of each well.

\subsection{High-Range Wells}

Heavy-wall steel pipe wells were also used to dispose of very high range waste (RH LLW $>1 \mathrm{rem} / \mathrm{h}$ ). These wells were constructed of 0.75 -in. thick steel pipe vertically centered in a drilled auger hole with the top of the well approximately $15 \mathrm{~cm}(6 \mathrm{in}$.) above ground level. The surrounding space was backfilled with dirt. The pipes were generally $16 \mathrm{ft}$ long with an inside diameter of $30 \mathrm{in}$. A $0.3 \mathrm{~m}$ (1-ft) thick concrete plug was poured in the bottom of the well.

A monitoring well, made from a 3-in. diameter PVC pipe with a bottom cap and slotted $1 \mathrm{ft}$ from the bottom, was placed outside the well to allow collection of liquids for sampling and quarterly monitoring of the hydrological isolation of the well. The top of each well was painted with a unique identification number [WH-XXX (well/high-range)]. A typical section view of a high-range well used for RH LLW with an unshielded container dose rate $>1 \mathrm{rem} / \mathrm{h}$ is shown in Fig. 3.24. Fig. 3.23 


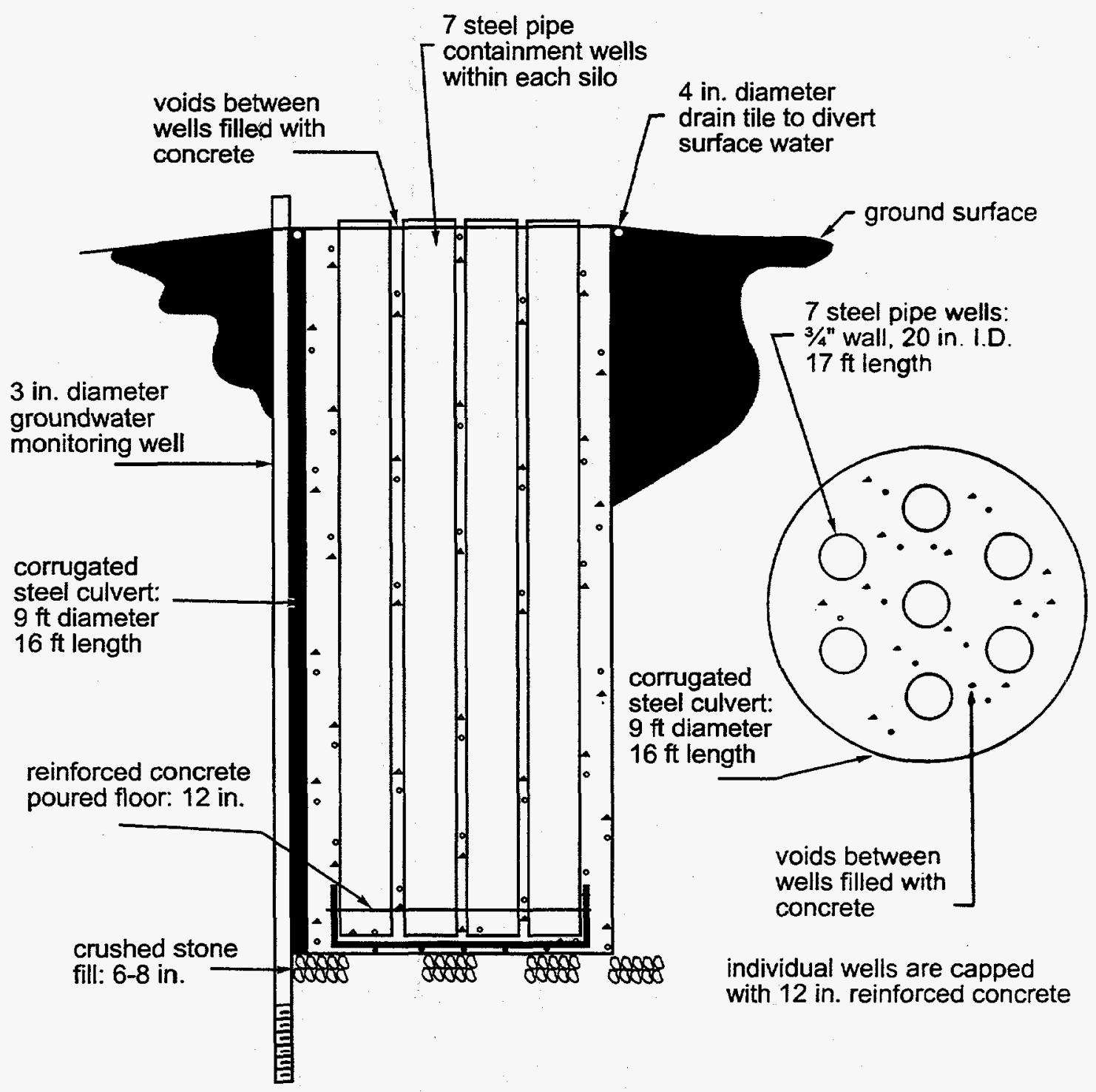

MULTIPLE WELL DISPOSAL UNIT

Fig. 3.22. Cross section of a concrete silo with high-range wells. 


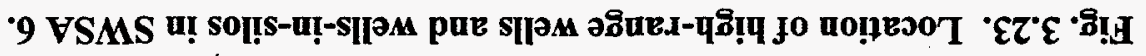

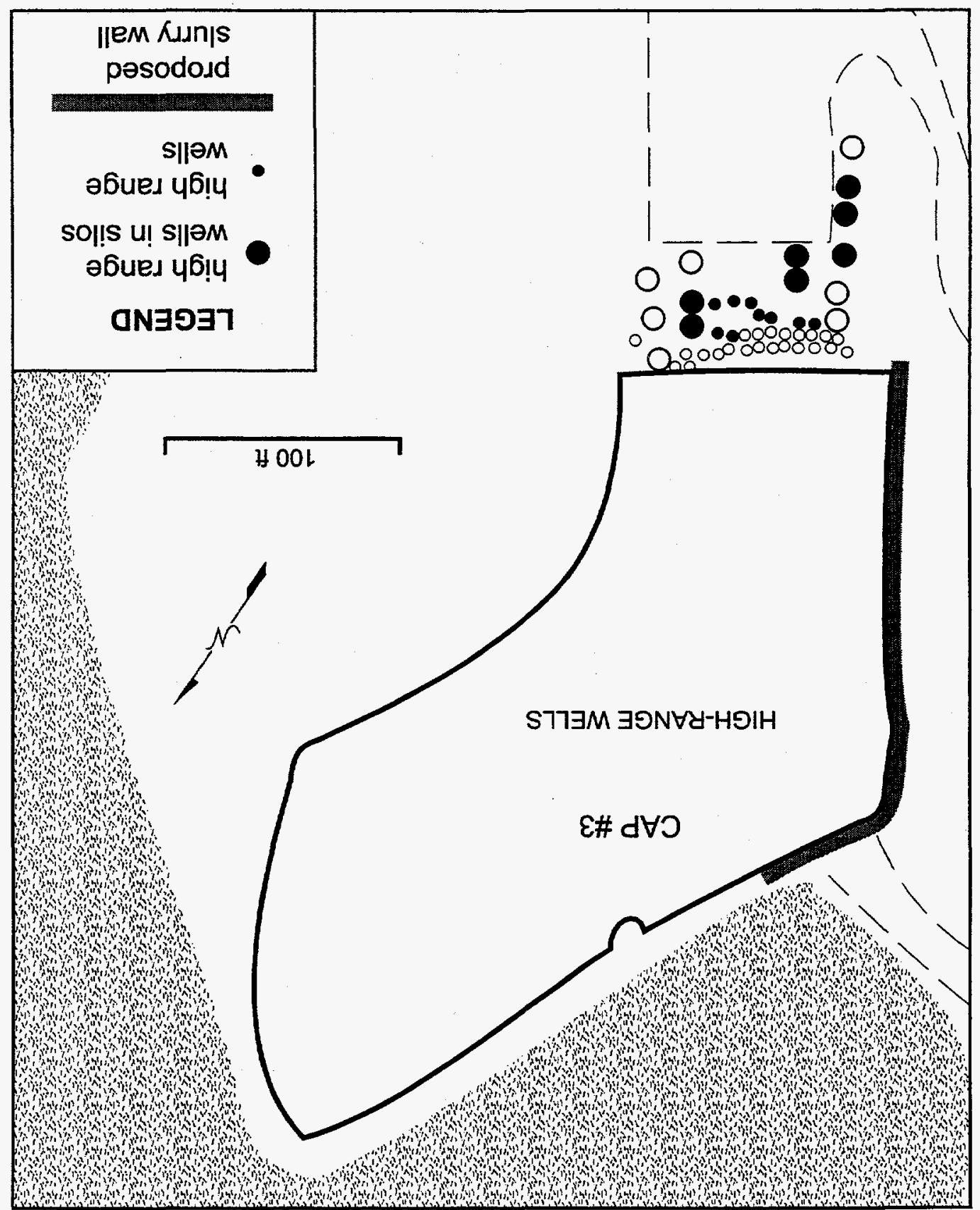


well is capped with 12 in

reinforced concrete cap

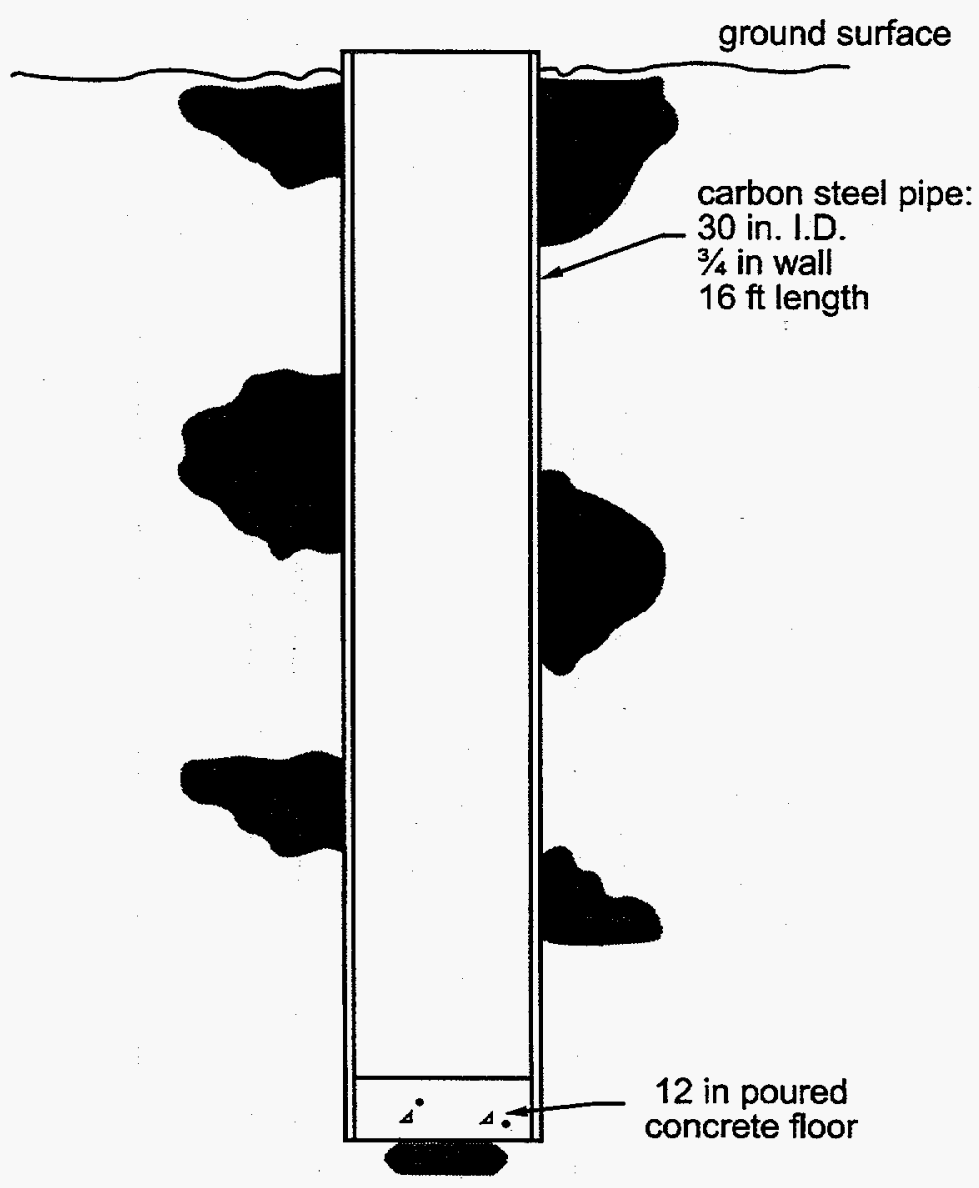

SINGLE WELL DISPOSAL UNIT

Fig. 3.24. Cross section of a high-range well. 
shows the location of the high-range wells in proximity to other SWSA 6 disposal units, roads, ephemeral streams, and foliage. The legend indicates which high-range wells are evaluated in this performance assessment. The remaining wells were filled prior to September 26, 1988.

Generally, only waste packaged in 55-gal metal drums was disposed of in high-range wells. The waste was transported to the burial site and disposed of in the same manner as the high-range wells-in-silos. After the well was filled, the well was capped with a minimum 1-ft thick, steel-rodreinforced concrete cap. Prior to the concrete cap hardening, a stenciled bolt with the well identification number was placed in the soft concrete cap. After well closure and capping, the radiation reading over the top of the well was $<2.5 \mathrm{mrem} / \mathrm{h}$.

Very high range wastes are no longer disposed of in high-range wells. This waste is managed as a special-case waste and is transported to ORNL retrievable storage wells in shielded waste carriers. The current waste management plan for very high range LLW is to store the waste on-site until access to an off-site disposal facility is available.

High range wells have 2-cm thick walls and concrete plugs at each end to seal in waste. Cracks between the concrete and the steel wall may eventually develop due to differential expansion and corrosion. The walls of the wells will eventually corrode and allow entry of lateral subsurface flow.

\subsection{Fissile Wells}

Fissile waste was disposed of in dedicated fissile wells. The fissile wells were constructed in the same manner as the high-range wells described above. Fissile wells were spaced so that a minimum of $1 \mathrm{~m} \mathrm{(} 3 \mathrm{ft}$ ) of earth separates the sides of adjacent wells. Fissile wells are numbered WF-XXX (well/fissile). Fissile waste was packaged in 1-, 2-, 5-, 10-, or 20-gal cans or 30- or 55-gal drums, transported to the burial site in a shielded waste carrier, and disposed of in the same manner as waste in the high-range wells (Sect. 3.2.1.1.4). The well was capped in the same manner as the high-range wells. Fig. 3.19 shows the location of the fissile wells in proximity to other SWSA 6 disposal units, roads, ephemeral streams, and foliage. The legend indicates the fissile wells evaluated in this performance assessment. The remaining wells were filled prior to September 26, 1988.

Fissile waste is no longer disposed of in fissile wells. This waste is also managed as a specialcase waste and is transported to ORNL retrievable storage wells in shielded waste carriers. The current waste management plan for fissile waste is to store the waste on-site until access to an off-site disposal facility is available.

These disposal units have similar seepage potential as the high range wells. 


\subsection{Biological Trenches}

Biological waste was disposed of in trenches that were approximately 3-15 m (10-50 ft) long

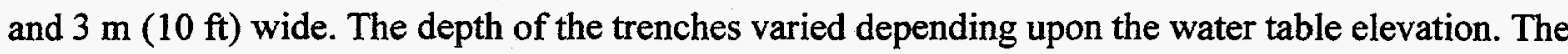

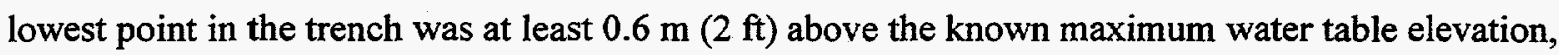
and spacing between adjacent trenches is at least $1.5 \mathrm{~m}(5 \mathrm{ft})$. The trench was graded to slope to one end at a rate of approximately $4 \mathrm{~cm} / \mathrm{m}(0.5 \mathrm{in} . / \mathrm{ft})$. Trenches were separately located from other waste disposal sites. Each trench is identified by a unique number [TB-XXX (trench/biological)]. Surface water drainage is controlled by separate ditching around the trench that conforms to existing topographic conditions. The ditching is compatible with the overall drainage network of the waste area regardless of whether the trench is on standby, in use, or closed.

The trenches were located and oriented for the most efficient and practical land usage. The trenches were sized and sectioned by removable steel plates to improve efficiency of land usage and prevent trench sidewall collapse. In the event that unforeseen fluctuations in the water table caused the excavation to fall below the water table, the trench was backfilled with Conasauga shale to a

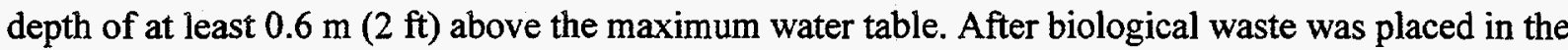
trench, it was covered with at least $1 \mathrm{~m}(3 \mathrm{ft})$ of dirt. When the trench was filled, the surface of the closed trench was planted with grass, mowed, and kept free of trees.

Fig. 3.21 shows the location of the biological trenches in proximity to other SWSA 6 disposal units, roads, ephemeral streams, and foliage. The legend indicates which biological trenches were evaluated for the performance assessment. The remaining trenches were filled prior to September 26 , 1988.

Biological waste is no longer disposed of in the SWSA 6 biological trenches. The current waste management plan is to incinerate the waste at an off-site commercial treatment facility. The treated waste is returned to ORNL for storage or disposal at the IWMF.

Biological trenches are unlined and do not prevent infiltration or the lateral subsurface flow from upslope areas.

\subsection{Suspect Waste Landfill}

Suspect waste was disposed of in an open landfill in the northeast area of SWSA 6 until December 1992. The landfill covered less than 0.4 ha (1 acre). After disposal the waste was covered with at least $0.3 \mathrm{~m}(1 \mathrm{ft})$ of soil. Suspect waste is no longer disposed of in the landfill. Waste previously classified as suspect waste is now classified as LLW.

The landfill, like the biological trenches, does not exclude any hydrologic interaction with the suspect waste. 


\subsection{Quadrex Trenches}

The Quadrex trenches were operated from January 1987 unitl September 1989. About $70 \mathrm{~m}^{3}$ of LLW was disposed of in the 5 trenches that were operated after September 1988. The LLW was packaged in large metal boxes (manufactured by the Quadrex Corporation) measuring $8 \times 8 \times 20 \mathrm{ft}$. These boxes were placed in unlined trenches, the void space in the box was filled with grout, and the box was then covered with soil. The depth of the trenches varied depending upon the water table

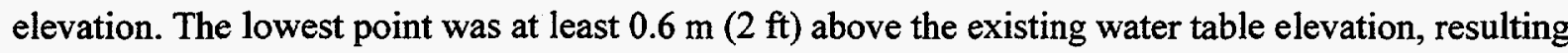
in trench depths of 4.6 to $6 \mathrm{~m}$ (15 to $20 \mathrm{ft}$ ).

Although the Quadrex trenches do not have a steel-reinforeced concrete cap (similar to the silos, wells, and wells-in-silos), it has been assumed that there is at least a $0.3 \mathrm{~m}(1 \mathrm{ft})$ cap of uncontaminated grout on top of the waste. This assumpiton is reasonable when one considers that (a) the LLW disposed of in these trenches was likely to be highly compactible, (b) the boxes have a large void volume (estimated to be at least 60 percent by volume based on the reported disposed volume and the dimensions of the boxes), and (c) the additon of the grout would compress the waste as it filled the box from above.

The hydrologic charcteristics of the grout monoliths formed in the Quadrex trenches are not known and, therefore, these monoliths may not provide the same degree of hydrologic isolation of wastes as do engineered units such as tumulus- or silo-type units. To be conservative, for the environmental transport calculations, the Quadrex trenches were treated as mixtures of wastes and soils, and no credit was taken for hydrologic isolation by engineered barriers. However, the monolith should serve as an intruder barrier and appropriate credit may be taken for such a barrier in the intruder calculations.

Fig. 3.19 shows the location of the Quadrex trenches in proximity to other SWSA 6 disposal units, roads, ephemeral streams, and foliage.

\subsubsection{Above Grade Tumulus Disposal Units}

Above-grade tumulus is the preferred method for disposal of CH LLW on the ORR. Tumulus I and Tumulus II were used for the disposal of CH LLW from April 1988 through March 1992. The IWMF began operation in December 1991.

Seepage into above grade units is potentially restricted by two hydrologic barriers. The reinforced concrete vaults are a significant barrier to water entry until cracks develop in the vault walls. Each above grade unit is expected to be enclosed by a RCRA-type cap composed of compacted subsoil material, a geomembrane, and a drainage layer for lateral transfer of soil water drainage restricted by the geomembrane. These layers are covered with top soil and vegetated with grass 
which is periodically mown during the active institutional control period. Water is expected to enter the tumulus vaults as these two protective measures fail. The main path of water entry is from infiltration through the cap. Lateral subsurface flow is not expected from outside the units due to the domed structure of the cap that favors lateral flow away from the disposal unit rather than into the disposal unit. Evidence of hydrologic failure of Tumulus I and II was obtained from tritium monitoring data from the sites (SAIC 1995). Elevated tritium levels were found in monitoring samples taken from the pad and underpad drains during cap construction. Precipitation mobilized tritium from leaking vaults, particularly from Tumulus II. Tritium releases have declined following completion of the cap. The corrective actions in response to these discharges are being addressed as part of the Environmental Restoration Program.

\subsection{Low-Level Waste Disposal Development and Demonstration Program}

In July 1987, Energy Systems issued the Low-Level Waste Disposal Development and Demonstration (LLWDDD) Program strategy for managing LLW on the ORR. The LLWDDD strategy established four classes of LLW based on the specific types and quantities of radionuclides in the waste. Class L-I was low activity waste suitable for disposal in an industrial type landfill. Class L-II was waste primarily containing radionuclides with half lives $<30$ years that required disposal in engineered facilities designed to isolate the waste from the environment for several hundred years. During this period, the short-lived radionuclides would decay to acceptable levels. Class L-II waste may also contain low concentrations of long-lived radionuclides. Class L-III was waste with half-lives $>30$ years that was to be disposed of in facilities that provide intruder protection and groundwater protection by treatment of wastes prior to disposal. Class L-IV was high activity waste not suitable for disposal on the ORR. In implementing the LLWDDD strategy, a site-specific pathways analysis would establish the specific waste concentration limits for the various waste disposal technologies.

\subsection{Tumulus I Disposal}

Tumulus I was originally referred to as the Tumulus Disposal Demonstration Project (TDDP), which was developed and implemented as part of the LLWDDD Program. The purpose of the TDDP was to demonstrate the ability of an above-grade disposal unit to contain the release of LLW to the environment. Tumulus disposal involves packaging LLW in steel boxes, placing the steel boxes inside concrete vaults (Fig. 3.25), stacking the vaults on a curbed concrete pad, and capping with natural materials. Fig. 3.20 shows the location of Tumulus I in proximity to other SWSA 6 disposal units, buildings, and roads. 


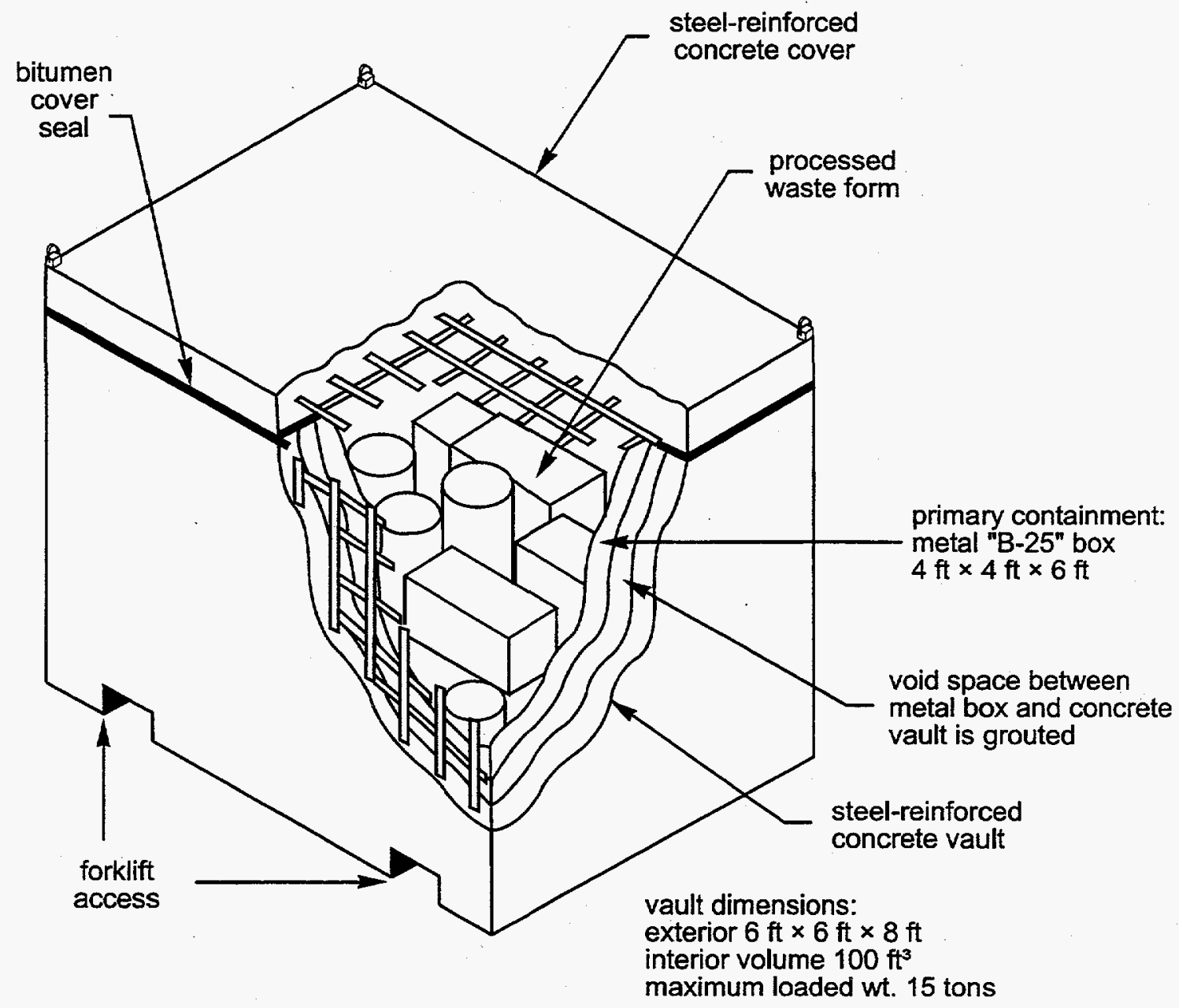

TUMULUS VAULT

Fig. 3.25. Generic concrete vault for tumulus disposal operations. 
The first tumulus pad (Tumulus I) was constructed in SWSA 6 during early 1987. Actual loading of concrete vaults onto the pad began in April 1988. The Tumulus I pad was filled to capacity in June 1990, and a tent was installed over the entire unit after Tumulus II was filled to capacity. A total of 291 vaults [approximately $788 \mathrm{~m}^{3}\left(27,840 \mathrm{ft}^{3}\right)$ ] were placed on the Tumulus I pad.

The Tumulus I pad is located on an approximately 0.60 -ha (1.5-acre) site in the south area of SWSA 6 (Fig. 3.20). The Tumulus I pad is approximately $20 \times 32 \mathrm{~m}(65 \times 105 \mathrm{ft})$. The pad was constructed using high-strength (6000 psi) concrete and reinforced using epoxy-coated rebar. The concrete pad varies in thickness from $20 \mathrm{~cm}$ ( 8 in.) at the center to $40 \mathrm{~cm}$ (16 in.) along the perimeter of the pad. The pad has a concrete curb $15 \mathrm{~cm}$ ( $6 \mathrm{in}$.) high along the entire perimeter. The concrete pad was designed to serve as the primary leachate collection system for any leachate generated during operations and after closure. Surface drainage channels were constructed north, east, and south of the pad to divert surface runoff away from the pad.

The concrete vaults that were loaded and doubled stacked on the concrete pad are designed to be used as structurally stable overpacks for containerized LLW. The concrete vaults are approximately $0.2 \mathrm{~m}(8 \mathrm{in}$.) thick and are $1.6 \mathrm{~m}(5.4 \mathrm{ft})$ high, $1.7 \mathrm{~m}(5.6 \mathrm{ft})$ wide, and $2.4 \mathrm{~m}(7.8 \mathrm{ft})$ long. An inner cavity is sized to receive a $1.2 \times 1.2 \times 1.8-\mathrm{m}(4 \times 4 \times 6$-ft) metal box with a 10 -cm (4-in.) annular space. After the containerized SLLW is placed in the vault, the annular space is filled with concrete, and a $0.2-\mathrm{m}(8$-in.) thick precast concrete lid is placed on the vault and sealed with bitumen.

\subsection{Tumulus II Disposal}

The Tumulus II unit was operated after the Tumulus I pad was filled and preceded the operation of the IWMF. The Tumulus II pad began operation in October 1990 and was filled to capacity in March 1992 using vaults identical to those used for Tumulus I. A tent was installed over the entire unit. A total of 220 vaults [approximately $600 \mathrm{~m}^{3}\left(21,120 \mathrm{ft}^{3}\right)$ ] were placed on the Tumulus II pad.

The Tumulus II pad is located on an approximately 0.40 -ha (1-acre) site just north of the Tumulus I pad (Fig. 3.20). The tumulus pad is approximately $18 \times 27 \mathrm{~m}(60 \times 90 \mathrm{ft})$ and $30 \mathrm{~cm}$ (12 in.) thick. The pad was constructed of high-density concrete and reinforced with epoxy-coated steel. The pad has concrete curbs $0.30 \mathrm{~m}$ ( $1 \mathrm{ft}$ ) high on the south, east, and west sides. The north side does not have a curb and was used for vehicle access during vault loading operations. The loading area was adjacent to the north side of the pad and was constructed of crushed stone. Surface drainage channels are constructed north and east of the pad. These channels are connected to the existing surface drainage channels for Tumulus I. 
One of the principal features of tumulus disposal is the inherent capability for monitoring groundwater and surface water for contamination. The sealed concrete pad is the primary barrier from the groundwater. The pad is sloped $1 \%$ to one side where a curb and gutter collects all surface pad runoff and drains the water to a monitoring station. A liner below the pad provides a secondary barrier from the groundwater and collects any water that may have penetrated the pad. Any water collected in the secondary barrier is also diverted to the monitoring station. The monitoring station is equipped for receiving, monitoring, and collecting samples from flows received from both the surface pad drain and underpad liner drain systems.

\subsubsection{The Interim Waste Management Facility}

The IWMF (an above-grade tumulus unit) is the only active disposal unit in SWSA 6. The IWMF occupies an area of approximately $3.8 \mathrm{ha}(9.5 \mathrm{acres})$ in the southwest portion of SWSA 6 (Fig. 3.5). Each tumulus pad is approximately $18 \times 27 \mathrm{~m}(60 \times 90 \mathrm{ft})$ and $38 \mathrm{~cm}(15 \mathrm{in}$.$) thick. The$ pads are constructed using high-density concrete and reinforced with epoxy-coated steel. The pad has concrete curbs $0.30 \mathrm{~m}(1 \mathrm{ft})$ high on the north, south, and west sides. The east side does not have a curb and is used for vehicle access during vault loading operations. Each pad provides disposal for 330 vaults [approximately $900 \mathrm{~m}^{3}\left(32,000 \mathrm{ft}^{3}\right)$ ] stacked three high. IWMF uses vaults similar to those used for Tumulus I and Tumulus II.

The IWMF has been designed to divert water into three sumps. The sumps are located in a monitoring station adjacent to the tumulus pads. The monitoring station is equipped for receiving, monitoring, and collecting samples from flows received from the storm water, underpad, and infiltration drain systems. The underpad sump is designed to allow monitoring of any groundwater that may accumulate under the pads. The storm-water sump collects water from the pad that is in operation and the empty pads. The infiltration sump is used to collect water from the pads that have been filled with vaults. An illustration showing vaults stacked on the curbed concrete pad, drain lines, and the proposed tumulus cap is shown in Fig. 3.26.

The unit was designed for six tumulus pads. The disposal capacity of the six IWMF pads is anticipated to be filled in 2003. Fig. 3.27 shows the IWMF in proximity to the monitoring station, roads, ephemeral streams, and foliage.

Construction of the first IWMF pad was completed in December 1990. The second pad was completed in May 1992, and pads 3 and 4 were completed in May 1994. The final two pads, pads 5 and 6 were completed in April 1995.

The operating history of the IWMF began with the first pad being loaded on December 21, 1991, and filled on March 6, 1993. The second pad was put into operation on April 7, 1993, and was filled to capacity on December 20, 1994. The third IWMF pad began accepting waste on December 
ORNL DWG 93M-8591

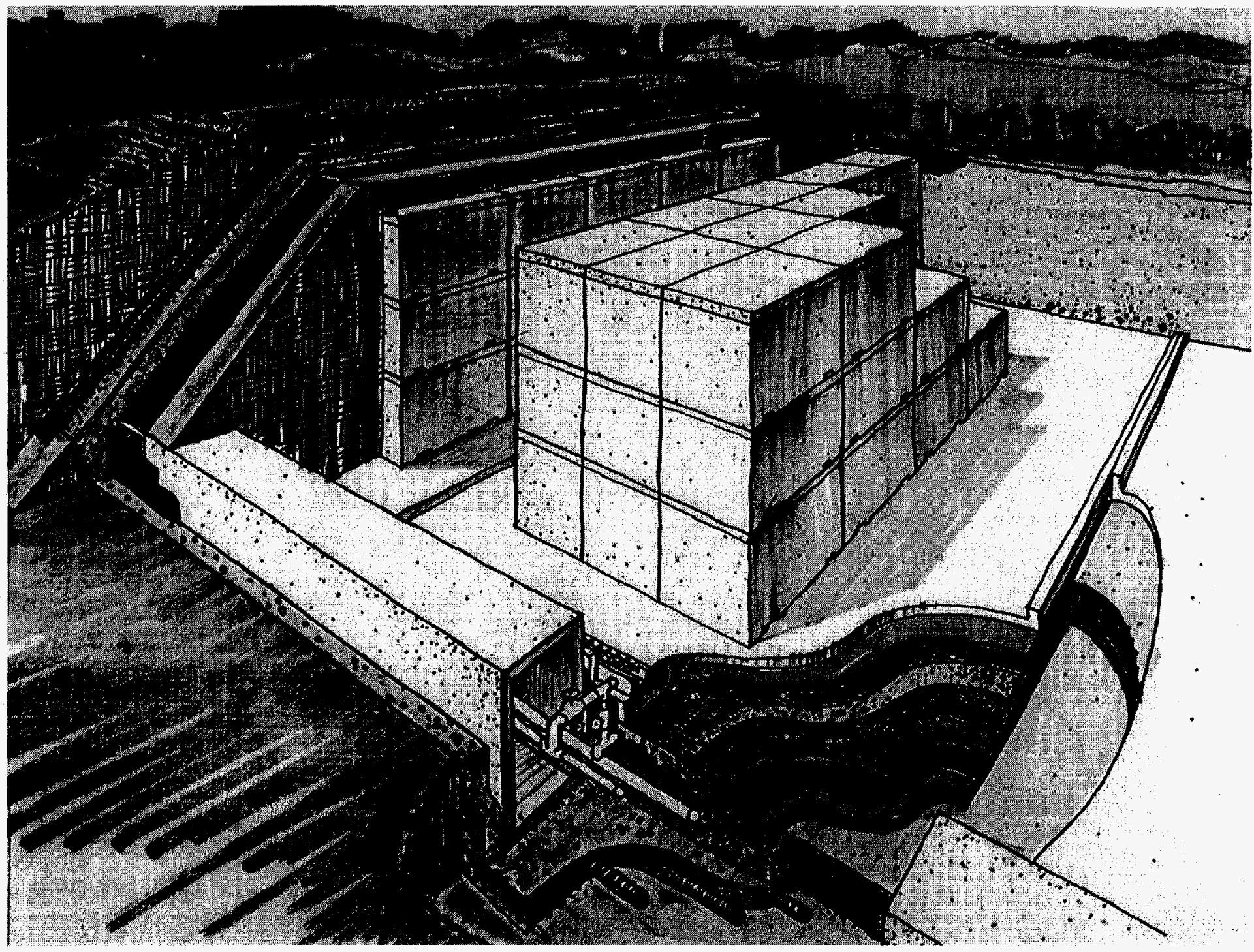

Fig. 3.26. Interim Waste Management Facility showing vaults of low-level waste, drain lines, and final cover. 


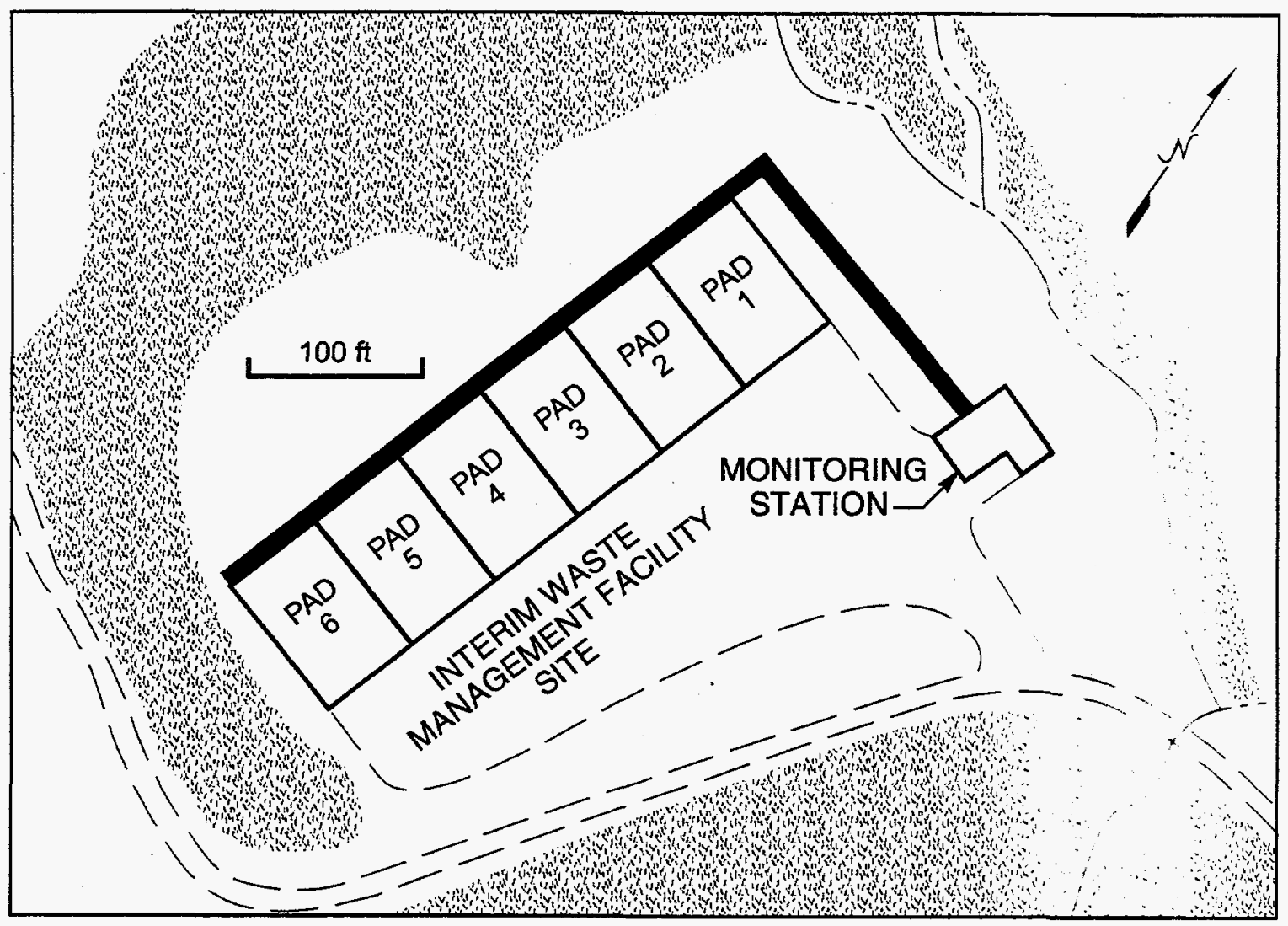

Fig. 3.27. The Interim Waste Management Facility site in SWSA 6. 
20, 1994, and was filled on April 4, 1997. As operating experience has been gained at the IWMF, and waste treatement has been incorporated into IWMF operations, the operating life of the IWMF has been extended. The IWMF is projected to continue to operate through 2003.

Generally, compactible and noncompactible CH LLW packaged in metal boxes or drums is disposed of on the tumulus pads. The packaged waste is loaded on a transfer vehicle and transported from the waste generator or compactor to a staging area at the disposal site. A crane is used to remove the lid from the concrete vault and place the packaged waste into the vault. The vault is filled with grout and the lid is sealed with bitumen. A unique LLW number (LL-XXXX) is stenciled on all four sides of the vault. A crane is used to load the vault onto a transfer vehicle to transport the waste to the pad. The vault is placed on the pad so that the side having the highest surface dose rate is facing inward. Vaults are placed and stacked on the pad in rows abutting each other with minimal space between each vault. The maximum surface dose rate of a vault is not to exceed $200 \mathrm{mrem} / \mathrm{h}$.

The current waste management plan is to continue disposal of $\mathrm{CH} \mathrm{LLW} \mathrm{that} \mathrm{meets} \mathrm{the}$ IWMF WAC until the IWMF capacity is reached.

\subsubsection{Interim Closure Period}

The interim closure period begins at the end of unit operations, which is coincident with the time that the IWMF is filled to capacity, and continues until the SWSA 6 facility is closed. During this interval of time decisions on the final closure of the facility are made, and the remedial actions derived from the CERCLA process are implemented. Specific and detailed plans for this time period are not finalized and are to be addressed by the CERCLA process. The design features outlined in this section are those which are a minimum set of design elements that are expected to be incorporated into the facility. Additional actions may be taken that would improve the performance of the facility during this time period.

During this period of time, specific actions to minimize infiltration are not planned. The existing interim closure actions at SWSA 6 for disposal units closed prior to September 26, 1988, which included the installation of 10 acres of hypalon covers for the minimization of infiltration, are expected to degrade and are not to be replaced. Monitoring of the groundwaters beneath the facility is expected to continue to identify any releases of contamination that might warrant immediate corrective actions. Maintenance of the vegetative cover is planned which will minimize erosion and reduce drainage to the extent that evapotranspiration reduces the available water from penetrating disposal units. Collection and treatment of water from the seepage collection galleries of IWMF will continue, which will essentially eliminate the potential for the release of contaminated water to the environment from the IWMF. 
During the period of interim closure, the disposal unit covers installed prior to the end of operations will be maintained for all disposal units. The IWMF is presumed to remain uncovered during the interim closure period. Any subsidence of biological trench or suspect landfill covers will be filled and revegetated to reestablish the disposal unit cover. The facility is to continue to have a grass vegetative cover, which will minimize erosion.

The structural stability of the disposal unit will be maintained throughout the interim closure period for all of the engineered disposal units in SWSA 6. The structural analysis incorporated into the analysis of performance indicates all of the disposal units, with the exception of the biological trenches and suspect landfill, have sufficient engineered strength to be stable throughout the interim closure period. The biological trenches and the suspect landfill have the potential to lose structural stability during the interim closure period from subsidence of the trench cover. Prompt corrective action will restore structural stability of these disposal units.

Provision for inadvertent intruder protection during the interim closure period is not needed, because active institutional control will be maintained. Fences and access controls in place during the operations period will continue to function, such that inadvertent access to the disposal unit will be denied.

\subsubsection{Closure}

The closure of the SWSA 6 facility will be performed after a ROD for SWSA 6 is prepared under the CERCLA process. The details for this closure have not been defined and cannot be defined until the ROD has been issued. For the purposes of this revised PA, assumptions have been used to evaluate the long-term performance of the SWSA 6 facility. The closure period is considered to begin

after closure has been completed and continue until the termination of active institutional control, 100 years after closure. During this 100 -year period, maintenance of the unit is assumed to continue. Leachate collection and treatment from the IWMF is also assumed to continue and any unexpected releases from the IWMF are expected to result in corrective actions. Public access to the facility is to be denied by the maintenance of fences and access controls. The closure of the facility, for the purposes of this revised PA, is assumed to include minimal improvements to the disposal unit covers, as discussed below. Maintenance, during the closure period, is expected to repair any failures in disposal unit covers, and address any releases of contamination.

Water infiltration is expected to remain essentially the same as during the interim closure period, with the exception of the high-range wells, which are expected to have an additional one-foot of soil added to the disposal unit cover. A slurry wall is also expected to be installed on the eastern edge of the high-range wells to reduce the transport of contamination to the creek west of the SWSA 6 facility. Drainage will be reduced during the closure period by the effect of 
evapotranspiration from the maintained vegetative cover. The IWMF is presumed to be covered with a earthen cover of three foot of soil and drainage materials. The drainage layer, to be included in the cover for the IWMF, is presumed to be a one foot thick layer of rock, separated by geotextiles, which will enhance lateral drainage and reduce seepage into the IWMF vaults.

Disposal cover integrity is expected to decline throughout the closure period as a result of subsurface degradation processes (Sect. 2.6.3.6). Should subsidence events or releases of contamination occur, corrective actions are expected to occur which will reestablish the integrity of the surface of the unit covers.

The structural stability of the engineered disposal units at the SWSA 6 facility is expected to be maintained throughout the closure period as result of the structural integrity of the disposal units. Structural failures are expected to be addressed by corrective actions taken during the period of active institutional control.

Inadvertent intrusion during the closure period is not expected. Fences and access controls are expected to be maintained throughout the closure period. Consequently, inadvertent access to the facility will be denied.

\subsubsection{Post-Closure Period}

The site is considered to revert to forest vegetation through species succession after the grass cover is no longer actively maintained. Natural succession proceeds by invasion of early succession tree species such as eastern red cedar, short-leaf pine, and sweetgum; these are followed by oakhickory forest species at a later stage (Suter et al. 1993). The hydrologic consequence of these temporal changes in species was not considered significant, and one set of hydrologic simulation results was used for the period following termination of institutional control.

\subsection{WASTE CHARACTERISTICS}

LLW is radioactive waste not classified as high-level waste, transuranic (TRU) waste, spent nuclear fuel, or by-product material specified as uranium or thorium mill tailings and waste, as defined by DOE O 5820.2A. Test specimens of fissionable material, irradiated for research and development only, may be classified as LLW, provided the concentration of TRU radionuclides is $<100 \mathrm{nCi} / \mathrm{g}$. Small volumes of waste containing naturally occurring and accelerator-produced radioactive material may also be managed as LLW in accordance with DOE O 5820.2A, Chapter IV.

LLW is classified as either $\mathrm{CH}$ or RH based on the radiation dose rate at the surface of the 
waste package. Approximately $1,700 \mathrm{~m}^{3} /$ year $\left(60,000 \mathrm{ft}^{3} /\right.$ year) of LLW is routinely handled at ORNL. CH LLW accounts for $93 \%$ of the volume but only $1.5 \%$ of the activity.

Prior to the initial PA, ORNL managed some special categories of LLW-such as fissile, radioactively contaminated asbestos, and biological-in below-grade disposal units. This practice of segregating waste has been discontinued. Wastes are now disposed in the IWMF (currently the only operating disposal unit in SWSA 6) if the ORNL SLLW Waste Acceptance Criteria is met. Otherwise, the waste is stored in storage facilities. The waste segregation categories used before 1994 are described in Sect. 3.3.1. Below-grade disposal ceased in SWSA 6 on January 1, 1994. Based on operational projections, the IWMF is expected to be at capacity by 2003. A generic listing of LLW typically generated at ORNL is presented in Table 3.9 .

\subsubsection{Segregated Waste}

Waste disposed in the below-grade disposal units in SWSA 6 were segregated before disposal. The two main segregation categories used were CH LLW and RH LLW. CH LLW is waste that has a radiation dose rate at the package surface of $\leq 200 \mathrm{mrem} / \mathrm{h}$. CH LLW consists of various contaminated items such as laboratory equipment, facility refurbishment waste, decontamination and decommissioning waste, personnel protective clothing, air filters, and bulk materials such as soil, sludge, and construction debris. RH LLW is waste that has a surface dose rate of $>200 \mathrm{mrem} / \mathrm{h}$ and consists of debris from reactors and hot cell operations, ion exchange resins, and solidified supernatants from liquid LLW (LLLW) evaporation. The other waste segregation categories used were fissile, biological, and asbestos. The characteristics of the waste, based on the waste segregation categories, are described below.

\subsubsection{Contact-Handled LLW}

The physical form of the waste is the primary factor controlling the selection of treatment methods. ORNL segregated CH LLW into two categories, compactible and noncompactible, based on its physical characteristics.

Compactible waste consisted of dry materials such as plastic bags, paper, personnel protective clothing, light-gauge metal, and glassware that can be compacted by conventional compaction equipment. Compactible waste was segregated from other LLW streams, double bagged in 4-mil-thick plastic bags, and stored in steel, double-door yellow dumpsters at the generator's facility. Compactible waste was compacted at an on-site commercial treatment facility. The maximum unshielded surface dose rate of a bag of compactible waste was limited to $\leq 200 \mathrm{mrem} / \mathrm{h}$. Most compactible waste packages had a surface dose rate of $<10 \mathrm{mrem} / \mathrm{h}$. 
Table 3.9 Waste descriptions

\begin{tabular}{|c|c|c|}
\hline \multicolumn{3}{|c|}{ Laboratory equipment } \\
\hline \multicolumn{3}{|l|}{ Bench Equipment } \\
\hline Glassware & Evaporating dishes & Gauges \\
\hline Plastic bottles, tubing & Blotter paper & Clamps \\
\hline sheeting & Electrodes & Ring stands \\
\hline Wipes & Combustion boats & Wire \\
\hline Crucibles & Mortars and pesties & Tongs \\
\hline \multicolumn{3}{|l|}{ Processing equipment } \\
\hline Bottles racks & Balances & Ultrasonic cleaners \\
\hline Small furnaces & Band saws & Metal rods \\
\hline Hydraulic presses & Glove boxes & Vacuum pumps \\
\hline Welding equipment & Heat lamps & Sanders \\
\hline Vacuum chambers & Grinders & Drill presses \\
\hline Heat lamps & Small tanks & \\
\hline \multicolumn{3}{|c|}{ Personnel protective clothing and equipment } \\
\hline Lab coats & Face masks & Rags \\
\hline Coveralls & Paper suits & Buckets \\
\hline Shoe covers & Mops & Tape \\
\hline Rubber gloves & Brooms & Plastic bags \\
\hline $\begin{array}{l}\text { Reservation trees, shrubs, } \\
\text { grass, etc. }\end{array}$ & $\begin{array}{l}\text { Reservation deer, geese, ducks, } \\
\text { fish, etc. }\end{array}$ & $\begin{array}{l}\text { Research animal carcasses, } \\
\text { tissues, etc. }\end{array}$ \\
\hline Ovens & Floor tile & Insulation \\
\hline Furnaces & Transite pipe & Gloves \\
\hline Chemical hoods & Insulation & Wood \\
\hline Choker Cables & Metal grating & Paper \\
\hline Conduit & Miscellaneous furniture & Plastic \\
\hline Cylinders & Sheet metal duct & Fans \\
\hline Dry wall & Large tanks and vessels & Pumps \\
\hline Tools & Vessels & Motors \\
\hline Metal piping & Air filters & Valves \\
\hline Asphalt & Gravel & Sediment \\
\hline Concrete & Plaster & Tar \\
\hline Charcoal & Roofing & Sludge \\
\hline Dirt & Sand & Resin \\
\hline
\end{tabular}


Noncompactible waste consisted of large, heavy, or bulky items such as piping, equipment, instrumentation, heavy glass containers, wood, soil, concrete, and other debris. Noncompactible waste was segregated from other waste streams, packaged in 4-mil-thick plastic bags, and placed in a 55-gal metal drum or $4 \times 4 \times 6$-ft metal box. Bulk waste such as soil, gravel, concrete, asphalt, and other construction and demolition debris was generally packaged in plastic lined $4 \times 4 \times 6$ - $\mathrm{ft}$ metal boxes. Large items of noncompactible waste that would not fit in a drum or box, such as large tanks or vessels, were accepted on a case-by-case basis. Some noncompactible waste was transported to an off-site commercial treatment facility for incineration or supercompaction. The maximum surface dose rate of the outer container was limited to $\leq 200 \mathrm{mrem} / \mathrm{h}$. Most noncompactible waste packages had a surface dose rate of $<10 \mathrm{mrem} / \mathrm{h}$.

\subsubsection{Remote-Handled LLW}

Remote-handled LLW was subdivided into two categories for handling and long-term management: high range and very high range. High-range waste is RH LLW with a maximum contact reading $\leq 1 \mathrm{rem} / \mathrm{h}$. Very high range waste is $R H$ LLW with a contact intensity $>1 \mathrm{rem} / \mathrm{h}$.

High-range waste $>200 \mathrm{mrem} / \mathrm{h}$ and $<1 \mathrm{rem} / \mathrm{h}$ consisted of the same types of compactible and noncompactible materials described in Sect. 3.3.1.1. High-range waste was generally double bagged in 4-mil plastic bags and placed inside an outer container. Large items that would not fit in a plastic bag was either double wrapped in plastic or placed in alternate containers. Approved outer containers were either 20-mil plastic bags, 1-20-gal metal cans, or 30- or 55-gal metal drums. High-range waste was not treated because a treatment facility for RH waste was not available.

Very high range waste consisted primarily of obsolete equipment and materials contaminated with activation or fission products from reactors and from isotope production hot cells. Very high range wastes were packaged in an inner container, sealed, and placed in an outer container. The outer container was typically a 1-20-gal metal can or a 30- or 55-gal metal drum. This type of waste had surface dose rates that ranged up to thousands of rem per hour and was handled as a special-case waste. Because of its very high radiation level, this waste was transported in shielded waste carriers or shielded transport casks. Very high range wastes were not treated because a treatment facility for RH waste was not available.

Very high range wet solid wastes were also generated during treatment of LLLW. Dewatered ion exchange resins from reactor facilities and solidified supernatants from the LLLW evaporator concentrate storage tanks produced a RH LLW $>1 \mathrm{rem} / \mathrm{h}$. These waste streams were packaged in large steel or high-density polyethylene containers. 


\subsubsection{Fissile Waste}

Waste that contained ${ }^{233} \mathrm{U},{ }^{235} \mathrm{U},{ }^{238} \mathrm{Pu},{ }^{239} \mathrm{Pu},{ }^{241} \mathrm{Pu}$ or the isotopes of neptunium, americium, curium, berkelium, and californium was managed as fissile waste, provided the concentration of the TRU radionuclides with half lives $>20$ years was $<100 \mathrm{nCi} / \mathrm{g}$. For criticality and security reasons, waste containing $\geq 1 \mathrm{~g}$ or $\geq 1 \mathrm{~g} / \mathrm{ft}^{3}$ of ${ }^{235} \mathrm{U}$ or its fissile mass equivalent was handled separately. All fissile wastes were packaged in containers that provide at least two containment barriers to prevent the inadvertent release of radioactive material during handling. The dose rate of fissile waste packages ranged to $>1 \mathrm{rem} / \mathrm{h}$. Fissile wastes were not treated because a treatment facility was not available for fissile waste and existing treatment facilities were not suitable for fissile wastes.

\subsubsection{Biological Waste}

Biological LLW consisted of animal carcasses, tissues, excrements, and bedding that were generated when radionuclides were used in biological research. Also included were contaminated plants and animals from the ORR, including deer, ducks, geese, trees, grass, and plants. Sewage sludge from the Sanitary Wastewater Treatment Facility was also managed as biological LLW.

Radioactive animal carcasses and tissues were frozen and stored by the waste generator. Contaminated vegetation and sewage sludge was temporarily stored at an ORNL waste storage facility. When sufficient quantities of contaminated biological waste were accumulated, it was transported and disposed in the biological trenches. The dose rate of biological LLW packages was usually much less than $10 \mathrm{mrem} / \mathrm{h}$.

\subsubsection{Asbestos Waste}

Until the late 1970s, asbestos was used extensively at ORNL for the insulation of pipes. Asbestos waste can also be found in floor tiles, ovens, and furnaces. Radioactively contaminated asbestos waste was generated during maintenance or demolition of contaminated facilities. Generally, asbestos waste was packaged in special, asbestos-labeled, 6-mil polyethylene bags, sealed with tape, and placed in a second asbestos-labeled polyethylene bag. Heavy materials such as asbestos tiles or bench tops were placed in fiber board drums. Asbestos waste was not treated because treatment facilities for asbestos waste were not available. The maximum dose rate of packaged asbestos waste was limited to $\leq 1 \mathrm{rem} / \mathrm{h}$. The typical dose rate of packaged asbestos waste was much less than 10 $\mathrm{mrem} / \mathrm{h}$. Asbestos waste was disposed of in the asbestos silos. 


\subsubsection{Suspect Waste}

Suspect waste consisted of debris that was generated during the decontamination and decommissioning or construction of facilities and other waste such as soil, air filters, wood, empty drums, laboratory equipment, and personal protective clothing. Suspect waste was waste that had no measurable contamination but could not be certified by routine health physics surveys as free of internal contamination. Facilities that generate only alpha-emitting or beta-emitting radionuclides did not generate suspect waste. Facilities that generate beta- or gamma-emitting waste only generated suspect waste materials that had been individually surveyed, thus reducing the possibility that high concentrations of beta or gamma emitters were well shielded by uncontaminated material towards the outside of a waste package. Because of the history and locatoin of these facilities, the waste was disposed of in a landfill in SWSA 6. Because (a) there was no reported readioactive inventory for this waste and (b) there is liekly to be little radioactivity present, the suspect waste landfill was not considered in this PA.

\subsubsection{IWMF Waste}

In 1994, a WAC specifically applicable to the IWMF was established that was revised in 1996. In addition to specifying waste container and labeling requirements, the WAC defines the characteristics of waste that is acceptable for disposal at the IWMF and establishes a screening value for each waste container. By summing the screening values results for each container the radionuclide inventory can be determined so that the total of all disposed waste on each pad does not exceed the per pad radionuclide limit developed in this PA. The disposal WAC restricts activity concentrations that exceed Class $C$ levels as defined in 10 CFR 61.55. Greater than Class $C$ waste is treated as special case waste and is stored.

WAC are also defined for (a) asbestos waste, (b) soil, concrete, and other wastes for which practical treatment alternatives do not exist, and (c) resin, sludge, and solidified LLLW.

Contaminated asbestos waste is any waste that contains commercial asbestos or asbestos material that is contaminated or suspected to be contaminated with low-level radioactive material. The wastes falling under the "soil, concrete, or other wastes" category are waste items not conducive to volume reduction by compaction. The wastes categorized as "resin, sludge, and solidified Liquid Low-Level Waste (LLLW)" consists of a wide variety of resins and sludges, such as bead resins, powder resins, aqueous sludges, sewage treatment plant sludge, and Process Waste Treatment Plant (PWTP) filter cake. Note that asbestos waste, soil, concrete, and other wastes, and resins, sludges, and solidified LLLW not meeting the radionuclide limits for IWMF or that cannot be packaged properly for disposal constitutes special case waste and is stored. 


\section{ANALYSIS OF PERFORMANCE}

This section describes the methods used to analyze the performance of the various disposal units in the SWSA 6 facility and provides an overview of the data used in the analysis. Except as noted in Sect. 4.1.4, the discussions in this section are concerned with the methods for estimating releases of radionuclides to off-site locations and resulting doses to members of the public. The analysis of performing of the various disposal units with respect to potential exposures of inadvertent intruders is discussed in detail in Sect. 6.

Wastes previously disposed of in SWSA 6 and wastes to be disposed in the IWMF in the future include many radionuclides. This revised PA for the closed disposal units (i.e., all units other than the IWMF) is based on the reported disposals of individual radionuclides in each of these units. However, the radionuclides that will be disposed of in the IWMF in the future are not entirely known. Therefore, development of the comprehensive list of radionuclides to be considered in this revised PA was based on the radionuclides that were reported in past disposals in the closed disposal units and the IWMF (ORNL 1994) and additional radionuclides that were included in a recent PA for another disposal facility on the ORR (ORNL 1997d). The additional radionuclides that were not reported in past disposals at SWSA 6 were selected primarily on the assumption that nuclear fission and neutron activation are the most important processes producing waste to be disposed of in the IWMF. The radionuclides initially considered for inclusion in this revised PA are listed in Table 4.1.

However, many of the radionuclides listed in Table 4.1 would not be significant in regard to potential future exposures of off-site members of the public or inadvertent intruders onto the disposal site, either for the IWMF or for the closed disposal units. In particular, radionuclides with half-lives substantially less than 5 years can be eliminated from further consideration. Such factors as the expected performance of engineered barriers, the expected travel times of radionuclides in the environment to the assumed locations of off-site individuals, and the maintenance of active institutional controls over the disposal site for at least 100 years after disposal ensure that all shortlived radionuclides will decay to innocuous levels before exposures of off-site individuals or inadvertent intruders could occur. The elimination of short-lived radionuclides from further consideration in this revised PA can be justified after the fact by noting that the disposal limits for the IWMF obtained in this analysis for radionuclides with half-lives of about 5 years (e.g., ${ }^{60} \mathrm{Co},{ }^{154} \mathrm{Eu}$, ${ }^{228} \mathrm{Ra}$ ) are very high and are considerably higher than the past disposals of the shorter-lived radionuclides listed in Table 4.1 .

Several radionuclides listed in Table 4.1 with half-lives greater than 5 years also were not included in this revised PA. The longer-lived radionuclides not considered further are ${ }^{85} \mathrm{Kr},{ }^{108 \mathrm{~m}} \mathrm{Ag}$, ${ }^{133} \mathrm{Ba},{ }^{144} \mathrm{Nd},{ }^{146} \mathrm{Pm},{ }^{166 m} \mathrm{Ho},{ }^{182} \mathrm{Hf},{ }^{194} \mathrm{Hg},{ }^{209} \mathrm{Po},{ }^{236} \mathrm{~Np}$, and ${ }^{247} \mathrm{Bk}$. The elimination of these radionuclides was based on such considerations as their very long half-life (i.e., very low specific activity), very low production in nuclear fission or neutron activation, occurrence only in gaseous form, and the low reported disposals in SWSA 6 and at other DOE sites. In general, the activities of these radionuclides 
Table 4.1. Complete list of radionuclides which have been or could be disposed of at the Interim Waste Management Facility

\begin{tabular}{|c|c|c|c|c|c|c|c|}
\hline Nuclide & $\begin{array}{l}\text { Half-life }^{\alpha} \\
\text { (years) }\end{array}$ & Nuclide & $\begin{array}{c}\text { Half-life }^{a} \\
\text { (years) }\end{array}$ & Nuclide & $\begin{array}{l}\text { Half-life }^{a} \\
\text { (years) }\end{array}$ & Nuclide & $\begin{array}{l}\text { Half-life }^{a} \\
\text { (years) }\end{array}$ \\
\hline${ }^{225} \mathrm{AC}$ & $2.74 \times 10^{-2}$ & ${ }^{51} \mathrm{Cr}$ & $7.59 \times 10^{-2}$ & ${ }^{93 \mathrm{~m}} \mathrm{Nb}$ & $1.36 \times 10^{1}$ & ${ }^{125} \mathrm{Sb}$ & $2.73 \times 10^{0}$ \\
\hline${ }^{227} \mathrm{Ac}$ & $2.18 \times 10^{1}$ & ${ }^{129} \mathrm{Cs}$ & $3.66 \times 10^{-3}$ & ${ }^{94} \mathrm{Nb}$ & $2.03 \times 10^{4}$ & ${ }^{46} \mathrm{Sc}$ & $2.30 \times 10^{-1}$ \\
\hline${ }^{108 \mathrm{~m}} \mathrm{Ag}$ & $1.30 \times 10^{2}$ & ${ }^{134} \mathrm{Cs}$ & $2.06 \times 10^{0}$ & ${ }^{95} \mathrm{Nb}$ & $9.59 \times 10^{-2}$ & ${ }^{75} \mathrm{Se}$ & $3.28 \times 10^{-1}$ \\
\hline${ }^{110 \mathrm{~m}} \mathrm{Ag}$ & $6.84 \times 10^{-1}$ & ${ }^{135} \mathrm{Cs}$ & $3.00 \times 10^{6}$ & ${ }^{144} \mathrm{Nd}$ & $2.38 \times 10^{15}$ & ${ }^{79} \mathrm{Se}$ & $6.50 \times 10^{4}$ \\
\hline${ }^{111} \mathrm{Ag}$ & $2.05 \times 10^{-2}$ & ${ }^{136} \mathrm{Cs}$ & $3.61 \times 10^{-2}$ & ${ }^{59} \mathrm{Ni}$ & $7.50 \times 10^{4}$ & ${ }^{151} \mathrm{Sm}$ & $9.00 \times 10^{1}$ \\
\hline${ }^{26} \mathrm{Al}$ & $7.20 \times 10^{5}$ & ${ }^{137} \mathrm{Cs}$ & $3.02 \times 10^{1}$ & ${ }^{63} \mathrm{Ni}$ & $1.00 \times 10^{2}$ & ${ }^{113} \mathrm{Sn}$ & $3.15 \times 10^{-1}$ \\
\hline${ }^{241} \mathrm{Am}$ & $4.33 \times 10^{2}$ & ${ }^{64} \mathrm{Cu}$ & $1.45 \times 10^{-3}$ & ${ }^{236} \mathrm{~Np}$ & $1.55 \times 10^{5}$ & ${ }^{117 \mathrm{~m}} \mathrm{Sn}$ & $3.73 \times 10^{-2}$ \\
\hline${ }^{242 \mathrm{~m}} \mathrm{Am}$ & $1.41 \times 10^{2}$ & ${ }^{166} \mathrm{Dy}$ & $9.32 \times 10^{-3}$ & ${ }^{237} \mathrm{~Np}$ & $2.14 \times 10^{6}$ & ${ }^{119 m} \mathrm{Sn}$ & $8.03 \times 10^{-1}$ \\
\hline${ }^{243} \mathrm{Am}$ & $7.37 \times 10^{3}$ & ${ }^{253} \mathrm{Es}$ & $5.61 \times 10^{-2}$ & ${ }^{239} \mathrm{~Np}$ & $6.45 \times 10^{-3}$ & ${ }^{121 \mathrm{~m}} \mathrm{Sn}$ & $5.50 \times 10^{1}$ \\
\hline${ }^{195} \mathrm{Au}$ & $5.10 \times 10^{-1}$ & ${ }^{254 \mathrm{~m}} \mathrm{Es}$ & $4.49 \times 10^{-3}$ & ${ }^{199} \mathrm{Os}$ & $4.22 \times 10^{-2}$ & ${ }^{126} \mathrm{Sn}$ & $1.00 \times 10^{5}$ \\
\hline${ }^{199} \mathrm{Au}$ & $8.60 \times 10^{-3}$ & ${ }^{152} \mathrm{Eu}$ & $1.33 \times 10^{1}$ & ${ }^{194} \mathrm{Os}$ & $6.00 \times 10^{0}$ & ${ }^{85} \mathrm{Sr}$ & $1.78 \times 10^{-1}$ \\
\hline${ }^{133} \mathrm{Ba}$ & $1.05 \times 10^{1}$ & ${ }^{154} \mathrm{Eu}$ & $8.80 \times 10^{\circ}$ & ${ }^{32} \mathrm{P}$ & $3.91 \times 10^{-2}$ & ${ }^{89} \mathrm{Sr}$ & $1.38 \times 10^{-1}$ \\
\hline${ }^{137 m} \mathrm{Ba}$ & $4.86 \times 10^{-6}$ & ${ }^{155} \mathrm{Eu}$ & $4.96 \times 10^{0}$ & ${ }^{33} \mathrm{P}$ & $6.93 \times 10^{-2}$ & ${ }^{90} \mathrm{Sr}$ & $2.85 \times 10^{1}$ \\
\hline${ }^{140} \mathrm{Ba}$ & $3.49 \times 10^{-2}$ & ${ }^{156} \mathrm{Eu}$ & $4.16 \times 10^{-2}$ & ${ }^{231} \mathrm{~Pa}$ & $3.28 \times 10^{4}$ & ${ }^{179} \mathrm{Ta}$ & $1.82 \times 10^{\circ}$ \\
\hline${ }^{7} \mathrm{Be}$ & $1.46 \times 10^{-1}$ & ${ }^{55} \mathrm{Fe}$ & $2.73 \times 10^{0}$ & ${ }^{233} \mathrm{~Pa}$ & $7.40 \times 10^{-2}$ & ${ }^{182} \mathrm{Ta}$ & $3.16 \times 10^{-1}$ \\
\hline${ }^{10} \mathrm{Be}$ & $1.60 \times 10^{6}$ & ${ }^{59} \mathrm{Fe}$ & $1.22 \times 10^{-1}$ & ${ }^{210} \mathrm{~Pb}$ & $2.23 \times 10^{1}$ & ${ }^{160} \mathrm{~Tb}$ & $1.98 \times 10^{-1}$ \\
\hline${ }^{207} \mathrm{Bi}$ & $3.20 \times 10^{1}$ & ${ }^{153} \mathrm{Gd}$ & $6.62 \times 10^{-1}$ & ${ }^{212} \mathrm{~Pb}$ & $1.22 \times 10^{-3}$ & ${ }^{95 \mathrm{~m}} \mathrm{Tc}$ & $1.67 \times 10^{-1}$ \\
\hline${ }^{247} \mathrm{Bk}$ & $1.40 \times 10^{3}$ & ${ }^{68} \mathrm{Ge}$ & $7.43 \times 10^{-1}$ & ${ }^{107} \mathrm{Pd}$ & $6.50 \times 10^{6}$ & ${ }^{99} \mathrm{Tc}$ & $2.13 \times 10^{5}$ \\
\hline${ }^{249} \mathrm{Bk}$ & $8.77 \times 10^{-1}$ & ${ }^{3} \mathrm{H}$ & $1.23 \times 10^{1}$ & ${ }^{109} \mathrm{Pd}$ & $1.54 \times 10^{-3}$ & ${ }^{123 \mathrm{~m}} \mathrm{Te}$ & $3.23 \times 10^{-1}$ \\
\hline${ }^{82} \mathrm{Br}$ & $4.03 \times 10^{-3}$ & ${ }^{181} \mathrm{Hf}$ & $1.16 \times 10^{-1}$ & ${ }^{146} \mathrm{Pm}$ & $5.53 \times 10^{0}$ & ${ }^{228} \mathrm{Th}$ & $1.91 \times 10^{\circ}$ \\
\hline${ }^{14} \mathrm{C}$ & $5.73 \times 10^{3}$ & ${ }^{182} \mathrm{Hf}$ & $9.00 \times 10^{6}$ & ${ }^{147} \mathrm{Pm}$ & $2.62 \times 10^{0}$ & ${ }^{229} \mathrm{Th}$ & $7.34 \times 10^{3}$ \\
\hline${ }^{41} \mathrm{Ca}$ & $1.03 \times 10^{5}$ & ${ }^{194} \mathrm{Hg}$ & $5.20 \times 10^{2}$ & ${ }^{209} \mathrm{Po}$ & $1.02 \times 10^{2}$ & ${ }^{230} \mathrm{Th}$ & $7.54 \times 10^{4}$ \\
\hline${ }^{109} \mathrm{Cd}$ & $1.27 \times 10^{0}$ & ${ }^{203} \mathrm{Hg}$ & $1.28 \times 10^{-1}$ & ${ }^{195 \mathrm{~m}} \mathrm{Pt}$ & $1.10 \times 10^{-2}$ & ${ }^{232} \mathrm{Th}$ & $1.41 \times 10^{10}$ \\
\hline${ }^{113 \mathrm{~m}} \mathrm{Cd}$ & $1.37 \times 10^{1}$ & ${ }^{166 m} \mathrm{Ho}$ & $1.20 \times 10^{3}$ & ${ }^{236} \mathrm{Pu}$ & $2.85 \times 10^{0}$ & ${ }^{234} \mathrm{Th}$ & $6.60 \times 10^{-2}$ \\
\hline${ }^{139} \mathrm{Ce}$ & $3.77 \times 10^{-1}$ & ${ }^{122} \mathrm{I}$ & $6.85 \times 10^{-6}$ & ${ }^{238} \mathrm{Pu}$ & $8.77 \times 10^{1}$ & ${ }^{204} \mathrm{Tl}$ & $3.78 \times 10^{0}$ \\
\hline${ }^{141} \mathrm{Ce}$ & $8.90 \times 10^{-2}$ & ${ }^{123} \mathrm{I}$ & $1.51 \times 10^{-3}$ & ${ }^{239} \mathrm{Pu}$ & $2.41 \times 10^{4}$ & ${ }^{232} \mathrm{U}$ & $6.89 \times 10^{1}$ \\
\hline${ }^{144} \mathrm{Ce}$ & $7.81 \times 10^{-1}$ & ${ }^{124} I$ & $1.14 \times 10^{-2}$ & ${ }^{240} \mathrm{Pu}$ & $6.56 \times 10^{3}$ & ${ }^{233} \mathrm{U}$ & $1.59 \times 10^{5}$ \\
\hline${ }^{249} \mathrm{Cf}$ & $3.51 \times 10^{2}$ & ${ }^{125} \mathrm{I}$ & $1.65 \times 10^{-1}$ & ${ }^{241} \mathrm{Pu}$ & $1.44 \times 10^{l}$ & ${ }^{234} \mathrm{U}$ & $2.45 \times 10^{5}$ \\
\hline${ }^{250} \mathrm{Cf}$ & $1.31 \times 10^{1}$ & ${ }^{129} \mathrm{I}$ & $1.57 \times 10^{7}$ & ${ }^{242} \mathrm{Pu}$ & $3.76 \times 10^{5}$ & ${ }^{235} \mathrm{U}$ & $7.04 \times 10^{8}$ \\
\hline${ }^{251} \mathrm{Cf}$ & $9.00 \times 10^{2}$ & 131 & $2.20 \times 10^{-2}$ & ${ }^{244} \mathrm{Pu}$ & $8.26 \times 10^{7}$ & ${ }^{236} \mathrm{U}$ & $2.34 \times 10^{7}$ \\
\hline${ }^{252} \mathrm{Cf}$ & $2.65 \times 10^{0}$ & ${ }^{133} I$ & $2.37 \times 10^{-3}$ & ${ }^{223} \mathrm{Ra}$ & $3.13 \times 10^{-2}$ & ${ }^{238} \mathrm{U}$ & $4.47 \times 10^{9}$ \\
\hline${ }^{36} \mathrm{Cl}$ & $3.01 \times 10^{5}$ & ${ }^{135} I$ & $7.50 \times 10^{-4}$ & ${ }^{224} \mathrm{Ra}$ & $9.86 \times 10^{-3}$ & ${ }^{187} \mathrm{~W}$ & $2.74 \times 10^{-3}$ \\
\hline${ }^{240} \mathrm{Cm}$ & $7.40 \times 10^{-2}$ & ${ }^{111}$ In & $7.69 \times 10^{-3}$ & ${ }^{226} \mathrm{Ra}$ & $1.60 \times 10^{3}$ & ${ }^{188} \mathrm{~W}$ & $1.90 \times 10^{-1}$ \\
\hline${ }^{242} \mathrm{Cm}$ & $4.47 \times 10^{-1}$ & ${ }^{114 m} \mathrm{In}$ & $1.36 \times 10^{-1}$ & ${ }^{228} \mathrm{Ra}$ & $5.75 \times 10^{0}$ & ${ }^{135} \mathrm{Xe}$ & $1.04 \times 10^{-3}$ \\
\hline${ }^{243} \mathrm{Cm}$ & $2.85 \times 10^{1}$ & ${ }^{192} \mathrm{Ir}$ & $2.02 \times 10^{-1}$ & ${ }^{87} \mathrm{Rb}$ & $4.80 \times 10^{10}$ & ${ }^{88} Y$ & $2.92 \times 10^{-1}$ \\
\hline${ }^{244} \mathrm{Cm}$ & $1.81 \times 10^{1}$ & ${ }^{40} \mathrm{~K}$ & $1.28 \times 10^{9}$ & ${ }^{186} \mathrm{Re}$ & $1.04 \times 10^{-2}$ & ${ }^{90} \mathrm{Y}$ & $7.32 \times 10^{-3}$ \\
\hline${ }^{245} \mathrm{Cm}$ & $8.50 \times 10^{3}$ & ${ }^{85} \mathrm{Kr}$ & $1.07 \times 10^{1}$ & ${ }^{188} \mathrm{Re}$ & $1.94 \times 10^{-3}$ & ${ }^{169} \mathrm{Yb}$ & $8.77 \times 10^{-2}$ \\
\hline${ }^{246} \mathrm{Cm}$ & $4.73 \times 10^{3}$ & ${ }^{140} \mathrm{La}$ & $4.60 \times 10^{-3}$ & ${ }^{101} \mathrm{Rh}$ & $3.30 \times 10^{0}$ & ${ }^{65} \mathrm{Zn}$ & $6.69 \times 10^{-1}$ \\
\hline${ }^{247} \mathrm{Cm}$ & $1.56 \times 10^{7}$ & ${ }^{173} \mathrm{Lu}$ & $1.37 \times 10^{0}$ & ${ }^{222} \mathrm{Rn}$ & $1.05 \times 10^{-2}$ & ${ }^{93} \mathrm{Zr}$ & $1.53 \times 10^{6}$ \\
\hline${ }^{248} \mathrm{Cm}$ & $3.40 \times 10^{5}$ & ${ }^{54} \mathrm{Mn}$ & $8.55 \times 10^{-1}$ & ${ }^{103} \mathrm{Ru}$ & $1.08 \times 10^{-1}$ & ${ }^{95} \mathrm{Zr}$ & $1.75 \times 10^{-1}$ \\
\hline${ }^{57} \mathrm{Co}$ & $7.45 \times 10^{-1}$ & ${ }^{99} \mathrm{Mo}$ & $7.53 \times 10^{-3}$ & ${ }^{105} \mathrm{Ru}$ & $1.02 \times 10^{0}$ & & \\
\hline${ }^{58} \mathrm{Co}$ & $1.94 \times 10^{-1}$ & ${ }^{22} \mathrm{Na}$ & $2.60 \times 10^{0}$ & ${ }^{35} \mathrm{~S}$ & $2.40 \times 10^{-1}$ & & \\
\hline${ }^{60} \mathrm{Co}$ & $5.27 \times 10^{0}$ & ${ }^{24} \mathrm{Na}$ & $1.71 \times 10^{-3}$ & ${ }^{124} \mathrm{Sb}$ & $1.65 \times 10^{-1}$ & & \\
\hline
\end{tabular}


in waste for disposal in the IWMF would be expected to be much less than the activities of the more common radionuclides in low-level waste, and thus, these radionuclides could not contribute significantly to doses to off-site individuals or inadvertent intruders.

Based on these considerations, the 63 radionuclides listed in Table 4.2 were selected for inclusion in this revised PA, as well as the closed disposal units. This list is expected to include all radionuclides that could contribute significantly to doses to off-site individuals or inadvertent intruders. This assumption can be justified after the fact by noting that, for the closed disposal units, the results of this revised PA show that only a very few of the radionuclides listed in Table 4.2 contributed significantly to the estimated doses.

Additional radionuclides, particularly those with half-lives greater than 5 years, could be included in this PA if their reported inventories in future disposals warrant further consideration. A simple methodology for screening of additional radionuclides is presented in Sect. 7.2.2 to facilitate decisions by waste management personnel about the need to include radionuclides not listed in Table 4.2.

For the IWMF, which is the only currently operating disposal unit, the analysis in this revised PA determines limits on average concentrations in waste, and the corresponding inventory of each radionuclide for disposal, that would satisfy each performance objective of DOE O 5820.2A. The approach used to calculate the limiting average concentrations and inventories is to identify scenarios for analysis that bound the performance of the facility. With these bounding scenarios (c.g., exposures from consumption of drinking water at WOD or from groundwater beyond the expanded buffer zone), the dose-based performance objectives in DOE O 5820.2A are converted to IWMIF inventories for each scenario selected for analysis. The models used for analyzing the scenarios are then used to calculate the limiting average concentrations in waste that correspond to the allowable doses, given an existing contribution to dose from post-1988 disposals in SWSA 6. For potential exposures associated with environmental transport, iterative calculations are performed to determine the limiting average concentrations which are converted to limiting inventories. The limiting inventories for each radionuclide and scenario are examined to determine the most restrictive inventory, termed the "allowable concentration and inventory," for each radionuclide in waste that satisfies the performance objectives in DOE O 5820.2A. The limiting average concentrations are averages of all disposal units and are not intended to be applied to individual waste packages. Fig. 4.1 illustrates the iterative analysis method used for analyzing the release and transport of contamination, as described in this section.

This section provides the justification for selecting the bounding scenarios considered in detail in this revised PA. The data used in the analysis are identified and the sources documented. Any interpretation of these data is also presented. The assumptions used for analyzing the scenarios are explicitly identified. Following the discussion of scenarios, data, and assumptions, the conceptual models for analyzing the scenarios are described in detail. The verification and validation of the models used in the analysis are also discussed. 
Table 4.2. Radionuclide-specific physical data used throughout the SWSA 6 performance assessment

\begin{tabular}{|c|c|c|c|c|c|}
\hline Nuclide & Element name & $\begin{array}{c}\text { Half-life }^{a} \\
\text { (year) }\end{array}$ & $\begin{array}{l}\text { Decay } \\
\text { coefficient } \\
\text { (1/year) }\end{array}$ & $\begin{array}{c}\text { Specific } \\
\text { activity }^{\prime \prime} \\
\text { (Ci/g) }\end{array}$ & $\begin{array}{l}\text { Theoretical } \\
\text { maximum } \\
\text { disposal limit } \\
\text { (Ci/pad) }\end{array}$ \\
\hline${ }^{3} \mathrm{H}$ & hydrogen (tritium) & $1.23 \times 10^{1}$ & $5.64 \times 10^{-2}$ & $9.65 \times 10^{3}$ & $5.4 \times 10^{12}$ \\
\hline${ }^{10} \mathrm{Be}$ & beryllium & $1.60 \times 10^{6}$ & $4.33 \times 10^{-7}$ & $2.23 \times 10^{2}$ & $3.5 \times 10^{7}$ \\
\hline${ }^{14} \mathrm{C}$ & carbon & $5.73 \times 10^{3}$ & $1.21 \times 10^{-4}$ & $4.46 \times 10^{0}$ & $4.6 \times 10^{10}$ \\
\hline${ }^{26} \mathrm{Al}$ & aluminum & $7.20 \times 10^{5}$ & $9.63 \times 10^{-7}$ & $1.91 \times 10^{-2}$ & $4.4 \times 10^{7}$ \\
\hline${ }^{36} \mathrm{Cl}$ & chlorine & $3.01 \times 10^{5}$ & $2.30 \times 10^{-6}$ & $3.30 \times 10^{-2}$ & $5.6 \times 10^{7}$ \\
\hline${ }^{40} \mathrm{~K}$ & potassium & $1.28 \times 10^{9}$ & $5.42 \times 10^{-10}$ & $6.98 \times 10^{-6}$ & $5.1 \times 10^{3}$ \\
\hline${ }^{41} \mathrm{Ca}$ & calcium & $1.03 \times 10^{5}$ & $6.73 \times 10^{-6}$ & $8.46 \times 10^{-2}$ & $1.1 \times 10^{8}$ \\
\hline${ }^{60} \mathrm{Co}$ & cobalt & $5.27 \times 10^{0}$ & $1.32 \times 10^{-1}$ & $1.13 \times 10^{3}$ & $7.5 \times 10^{12}$ \\
\hline${ }^{59} \mathrm{Ni}$ & nickel & $7.50 \times 10^{4}$ & $9.24 \times 10^{-6}$ & $8.08 \times 10^{-2}$ & $6.1 \times 10^{8}$ \\
\hline${ }^{63} \mathrm{Ni}$ & & $1.00 \times 10^{2}$ & $6.93 \times 10^{-3}$ & $6.17 \times 10^{\mathrm{l}}$ & $4.7 \times 10^{11}$ \\
\hline${ }^{79} \mathrm{Se}$ & selenium & $6.50 \times 10^{4}$ & $1.07 \times 10^{-5}$ & $6.97 \times 10^{-2}$ & $2.8 \times 10^{8}$ \\
\hline${ }^{87} \mathrm{Rb}$ & rubidium & $4.80 \times 10^{10}$ & $1.44 \times 10^{-11}$ & $8.59 \times 10^{-8}$ & $1.1 \times 10^{2}$ \\
\hline${ }^{90} \mathrm{Sr}$ & strontium & $2.85 \times 10^{1}$ & $2.43 \times 10^{-2}$ & $1.36 \times 10^{2}$ & $3.0 \times 10^{11}$ \\
\hline${ }^{93} \mathrm{Zr}$ & zirconium & $1.53 \times 10^{6}$ & $4.53 \times 10^{-7}$ & $2.51 \times 10^{-3}$ & $1.4 \times 10^{7}$ \\
\hline${ }^{93 \mathrm{~m}} \mathrm{Nb}$ & niobium & $1.36 \times 10^{1}$ & $5.10 \times 10^{-2}$ & $2.83 \times 10^{2}$ & $2.1 \times 10^{12}$ \\
\hline${ }^{94} \mathrm{Nb}$ & & $2.03 \times 10^{4}$ & $3.41 \times 10^{-5}$ & $1.87 \times 10^{-1}$ & $1.4 \times 10^{9}$ \\
\hline${ }^{99} \mathrm{Tc}$ & technetium & $2.13 \times 10^{5}$ & $3.25 \times 10^{-6}$ & $1.70 \times 10^{-2}$ & $1.7 \times 10^{8}$ \\
\hline${ }^{107} \mathrm{Pd}$ & palladium & $6.50 \times 10^{6}$ & $1.07 \times 10^{-7}$ & $5.14 \times 10^{-4}$ & $4.0 \times 10^{5}$ \\
\hline${ }^{113 \mathrm{~m}} \mathrm{Cd}$ & cadmium & $1.37 \times 10^{1}$ & $5.06 \times 10^{-2}$ & $2.17 \times 10^{2}$ & $1.6 \times 10^{12}$ \\
\hline${ }^{121 \mathrm{~m}} \mathrm{Sn}$ & $\operatorname{tin}$ & $5.50 \times 10^{1}$ & $1.26 \times 10^{-2}$ & $5.91 \times 10^{1}$ & $3.3 \times 10^{11}$ \\
\hline${ }^{126} \mathrm{Sn}$ & & $1.00 \times 10^{5}$ & $6.93 \times 10^{-6}$ & $2.84 \times 10^{-2}$ & $1.6 \times 10^{8}$ \\
\hline${ }^{129} \mathrm{I}$ & iodine & $1.57 \times 10^{7}$ & $4.41 \times 10^{-8}$ & $1.77 \times 10^{-4}$ & $7.6 \times 10^{5}$ \\
\hline${ }^{135} \mathrm{Cs}$ & cesium & $3.00 \times 10^{6}$ & $2.31 \times 10^{-7}$ & $1.15 \times 10^{-3}$ & $1.9 \times 10^{6}$ \\
\hline${ }^{137} \mathrm{Cs}$ & & $3.00 \times 10^{1}$ & $2.31 \times 10^{-2}$ & $8.70 \times 10^{1}$ & $1.4 \times 10^{11}$ \\
\hline${ }^{151} \mathrm{Sm}$ & samarium & $9.00 \times 10^{1}$ & $7.70 \times 10^{-3}$ & $2.63 \times 10^{1}$ & $1.7 \times 10^{11}$ \\
\hline${ }^{152} \mathrm{Eu}$ & europium & $1.33 \times 10^{1}$ & $5.21 \times 10^{-2}$ & $1.73 \times 10^{2}$ & $8.0 \times 10^{11}$ \\
\hline${ }^{154} \mathrm{Eu}$ & & $8.80 \times 10^{0}$ & $7.88 \times 10^{-2}$ & $2.70 \times 10^{2}$ & $1.2 \times 10^{12}$ \\
\hline${ }^{155} \mathrm{Eu}$ & & $4.96 \times 10^{\circ}$ & $1.40 \times 10^{-1}$ & $4.65 \times 10^{2}$ & $2.1 \times 10^{12}$ \\
\hline${ }^{194} \mathrm{Os}$ & osmium & $6.00 \times 10^{0}$ & $1.16 \times 10^{-1}$ & $3.11 \times 10^{2}$ & $6.0 \times 10^{12}$ \\
\hline${ }^{207} \mathrm{Bi}$ & bismuth & $3.22 \times 10^{1}$ & $2.15 \times 10^{-2}$ & $5.36 \times 10^{1}$ & $4.4 \times 10^{11}$ \\
\hline${ }^{210} \mathrm{~Pb}$ & lead & $2.23 \times 10^{1}$ & $3.11 \times 10^{-2}$ & $7.63 \times 10^{1}$ & $7.3 \times 10^{11}$ \\
\hline${ }^{226} \mathrm{Ra}$ & radium & $1.60 \times 10^{3}$ & $4.33 \times 10^{-4}$ & $9.89 \times 10^{-1}$ & $4.2 \times 10^{9}$ \\
\hline${ }^{228} \mathrm{Ra}$ & & $5.75 \times 10^{0}$ & $1.21 \times 10^{-1}$ & $2.73 \times 10^{2}$ & $1.2 \times 10^{12}$ \\
\hline${ }^{227} \mathrm{Ac}$ & actinium & $2.18 \times 10^{1}$ & $3.18 \times 10^{-2}$ & $7.23 \times 10^{1}$ & $6.2 \times 10^{11}$ \\
\hline${ }^{229} \mathrm{Th}$ & thorium & $7.34 \times 10^{3}$ & $9.44 \times 10^{-5}$ & $2.13 \times 10^{-1}$ & $1.5 \times 10^{9}$ \\
\hline${ }^{230} \mathrm{Th}$ & & $7.54 \times 10^{4}$ & $9.19 \times 10^{-6}$ & $2.11 \times 10^{-2}$ & $1.5 \times 10^{8}$ \\
\hline
\end{tabular}


Table 4.2 (continued)

\begin{tabular}{|c|c|c|c|c|c|}
\hline Nuclide & Element name & $\begin{array}{l}\text { Half-life }^{a} \\
\text { (year) }\end{array}$ & $\begin{array}{c}\text { Decay } \\
\text { coefficient } \\
\text { (1/year) }\end{array}$ & $\begin{array}{l}\text { Specific } \\
\text { activity }^{a} \\
(\mathrm{Ci} / \mathrm{g})\end{array}$ & $\begin{array}{l}\text { Theoretical } \\
\text { maximum } \\
\text { disposal limit } \\
\text { (Ci/pad) }\end{array}$ \\
\hline${ }^{232} \mathrm{Th}$ & & $1.41 \times 10^{10}$ & $4.92 \times 10^{-11}$ & $1.10 \times 10^{-7}$ & $8.0 \times 10^{2}$ \\
\hline${ }^{231} \mathrm{~Pa}$ & protactinium & $3.28 \times 10^{4}$ & $2.11 \times 10^{-5}$ & $4.72 \times 10^{-2}$ & $6.2 \times 10^{8}$ \\
\hline${ }^{232} \mathrm{U}$ & uranium & $6.89 \times 10^{1}$ & $1.01 \times 10^{-2}$ & $2.14 \times 10^{1}$ & $1.8 \times 10^{11}$ \\
\hline${ }^{233} \mathrm{U}$ & & $1.59 \times 10^{5}$ & $4.36 \times 10^{-6}$ & $9.68 \times 10^{-3}$ & $8.0 \times 10^{7}$ \\
\hline${ }^{234} \mathrm{U}$ & & $2.45 \times 10^{5}$ & $2.83 \times 10^{-6}$ & $6.25 \times 10^{-3}$ & $5.2 \times 10^{7}$ \\
\hline${ }^{235} \mathrm{U}$ & & $7.04 \times 10^{8}$ & $9.85 \times 10^{-10}$ & $2.16 \times 10^{-6}$ & $1.8 \times 10^{4}$ \\
\hline${ }^{236} \mathrm{U}$ & & $2.34 \times 10^{7}$ & $2.96 \times 10^{-8}$ & $6.47 \times 10^{-5}$ & $5.3 \times 10^{5}$ \\
\hline${ }^{238} \mathrm{U}$ & & $4.47 \times 10^{9}$ & $1.55 \times 10^{-10}$ & $3.36 \times 10^{-7}$ & $2.8 \times 10^{3}$ \\
\hline${ }^{237} \mathrm{~Np}$ & neptunium & $2.14 \times 10^{6}$ & $3.24 \times 10^{-7}$ & $7.05 \times 10^{-4}$ & $1.2 \times 10^{7}$ \\
\hline${ }^{238} \mathrm{Pu}$ & plutonium & $8.77 \times 10^{3}$ & $7.90 \times 10^{-3}$ & $1.71 \times 10^{1}$ & $2.9 \times 10^{11}$ \\
\hline${ }^{239} \mathrm{Pu}$ & & $2.41 \times 10^{4}$ & $2.88 \times 10^{-5}$ & $6.22 \times 10^{-2}$ & $1.0 \times 10^{9}$ \\
\hline${ }^{240} \mathrm{Pu}$ & & $6.56 \times 10^{3}$ & $1.06 \times 10^{-4}$ & $2.28 \times 10^{-1}$ & $3.8 \times 10^{9}$ \\
\hline${ }^{24} \mathrm{Pu}$ & & $1.44 \times 10^{1}$ & $4.81 \times 10^{-2}$ & $1.03 \times 10^{2}$ & $1.7 \times 10^{12}$ \\
\hline${ }^{242} \mathrm{Pu}$ & & $3.76 \times 10^{5}$ & $1.84 \times 10^{-6}$ & $3.82 \times 10^{-3}$ & $6.4 \times 10^{7}$ \\
\hline${ }^{244} \mathrm{Pu}$ & & $8.26 \times 10^{7}$ & $8.39 \times 10^{-9}$ & $1.77 \times 10^{-5}$ & $3.0 \times 10^{5}$ \\
\hline${ }^{241} \mathrm{Am}$ & americium & $4.33 \times 10^{2}$ & $1.60 \times 10^{-3}$ & $3.43 \times 10^{0}$ & $4.0 \times 10^{10}$ \\
\hline${ }^{242 m} \mathrm{Am}$ & & $1.41 \times 10^{2}$ & $4.92 \times 10^{-3}$ & $9.72 \times 10^{0}$ & $1.1 \times 10^{11}$ \\
\hline${ }^{243} \mathrm{Am}$ & & $7.37 \times 10^{3}$ & $9.40 \times 10^{-5}$ & $1.99 \times 10^{-1}$ & $2.3 \times 10^{9}$ \\
\hline${ }^{243} \mathrm{Cm}$ & curium & $2.85 \times 10^{1}$ & $2.43 \times 10^{-2}$ & $5.16 \times 10^{1}$ & $6.0 \times 10^{11}$ \\
\hline${ }^{244} \mathrm{Cm}$ & & $1.81 \times 10^{3}$ & $3.83 \times 10^{-2}$ & $8.09 \times 10^{1}$ & $9.3 \times 10^{11}$ \\
\hline${ }^{245} \mathrm{Cm}$ & & $8.50 \times 10^{3}$ & $8.15 \times 10^{-5}$ & $1.72 \times 10^{-1}$ & $2.0 \times 10^{9}$ \\
\hline${ }^{245} \mathrm{Cm}$ & & $4.73 \times 10^{3}$ & $1.47 \times 10^{-4}$ & $3.97 \times 10^{-1}$ & $4.6 \times 10^{9}$ \\
\hline${ }^{247} \mathrm{Cm}$ & & $1.56 \times 10^{7}$ & $4.44 \times 10^{-8}$ & $9.28 \times 10^{-5}$ & $1.1 \times 10^{6}$ \\
\hline${ }^{248} \mathrm{Cm}$ & & $3.40 \times 10^{5}$ & $2.04 \times 10^{-6}$ & $4.25 \times 10^{-3}$ & $4.9 \times 10^{7}$ \\
\hline${ }^{249} \mathrm{Cf}$ & californium & $3.51 \times 10^{2}$ & $1.97 \times 10^{-3}$ & $4.09 \times 10^{0}$ & $1.3 \times 10^{10}$ \\
\hline${ }^{250} \mathrm{Cf}$ & & $1.31 \times 10^{1}$ & $5.29 \times 10^{-2}$ & $1.09 \times 10^{2}$ & $3.6 \times 10^{11}$ \\
\hline${ }^{251} \mathrm{Cf}$ & & $9.00 \times 10^{2}$ & $7.70 \times 10^{-4}$ & $1.58 \times 10^{0}$ & $5.0 \times 10^{9}$ \\
\hline
\end{tabular}

${ }^{a}$ Source: Brown and Firestone 1986.

${ }^{b}$ Theoretical maximum disposal limit per disposal pad in IWMF is based on specific activity and density of each radionuclide and assumption that each disposal pad contains 330 disposal vaults with waste volume per vault of $2.6 \mathrm{~m}^{3}$. 
Identify dose objectives, exposure scenarios, and radionuclides

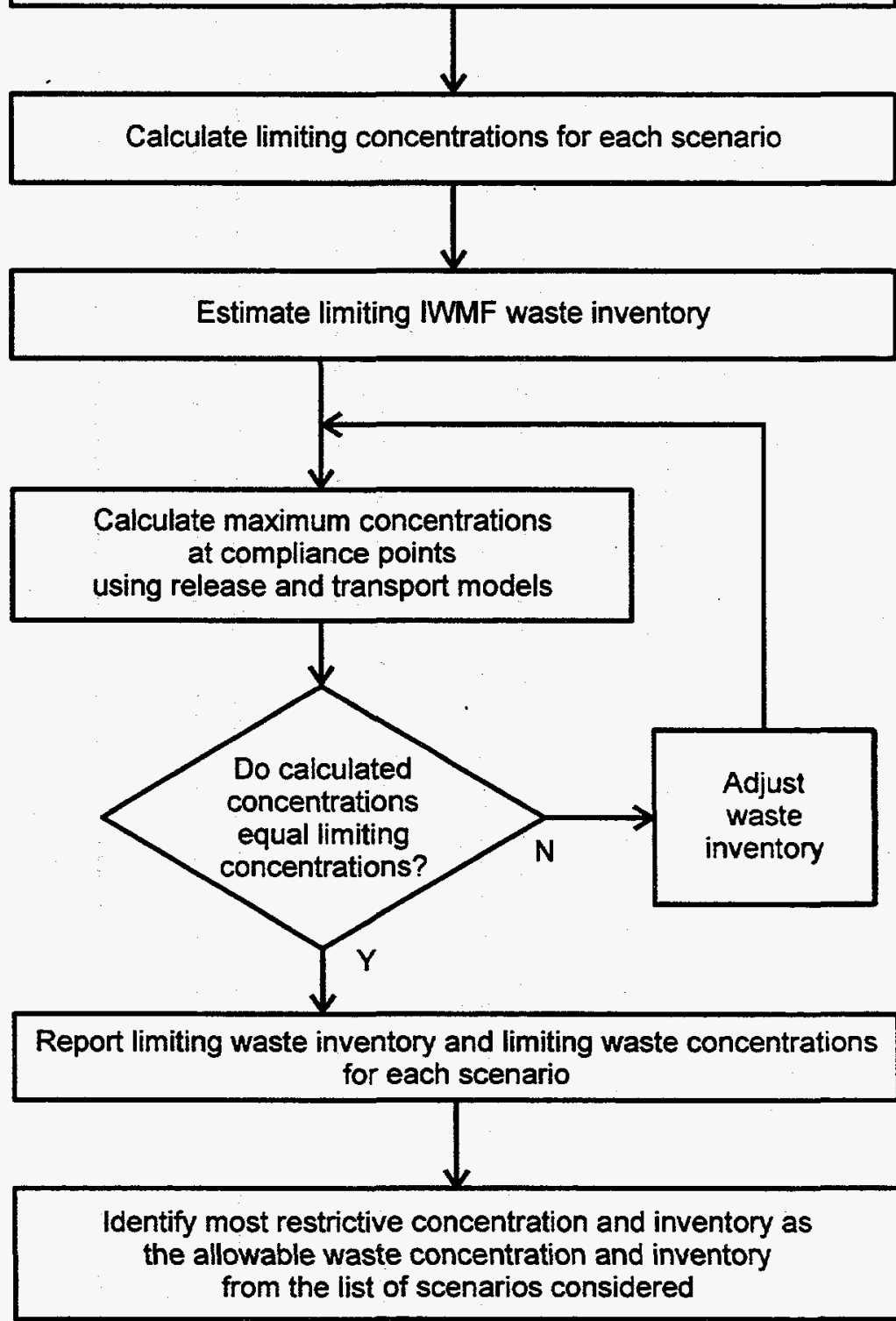

Fig. 4.1. Iterative analysis method for releases to the environment for the SWSA 6 performance assessment. 


\subsection{SOURCE TERMS}

Two different types of source terms have been developed for this revised PA. The source term for all pathways, air pathways, and water resources protection analyses is the release rate of a radionuclide to the environment as a function of time. The source term for direct intrusion is the remaining radionuclide inventory at a specific time. These two source terms cannot both be conservatively evaluated by a single calculational method. For example, consider a conservative source term calculation of releases to the environment. In this sense, "conservative" means that the calculated source term is believed to be a reasonable upper-bound release rate. Hence, a conservative calculated release rate will result in a rapid depletion of the radionuclide inventory. However, from the standpoint of direct intrusion, the remaining inventory at a specific time could not be considered conservative. For direct intrusion, "conservative" means that the remaining inventory is believed to be a reasonable upper-bound estimate. Therefore, to evaluate conservative source terms for releases to the environment and for direct intrusion, different approaches are used. The descriptions of the approaches to calculate source terms for all pathways, air pathways, and water resource protection are provided in Sects. 4.1.1 through 4.1.3. The development of the source term for direct intrusion is presented in Sect. 4.1.4.

\subsubsection{Source Terms for All-Pathways Analysis}

The all-pathways analysis estimates the potential dose to a member of the public from the disposal of radioactive waste in SWSA 6, where the member of the public is located outside the facility boundary of SWSA 6 . The exposure of a member of the public to disposed waste requires the transport of radionuclides from the disposed waste to the point of compliance. Before radionuclides can be transported, they must be removed from the waste material to a transport medium, such as air or water.

This section presents the analytical methods used in this revised PA to evaluate the source term for the transport of radionuclides in water. The latest version (2.0) of the SOURCE1 and SOURCE2 computer programs (collectively called the SOURCE programs) were used to calculate the rate of release of radionuclides to the environment (i.e., release to water) from SWSA 6 waste disposal units (Icenhour and Tharp 1996). SOURCE1 is used to simulate releases from tumulus-type disposal units (i.e., IWMF, Tumulus I, and Tumulus II). SOURCE2 is used to simulate releases from silo, well, well-in-silo, and trench-type disposal units. The following sections provide an overview of the SOURCE programs and the input parameters used in these computer programs.

\subsubsection{SOURCE Computer Programs}

The SOURCE programs simulate the degradation and failure of engineered barriers (e.g., concrete and metal) used in waste disposal units and calculate releases of radionuclides as a result of advection and diffusion. The following two sections provide an overview of the conceptual model and a brief description of major revisions that were incorporated into Version 2.0 of the SOURCE 
programs. Appendix B describes the SOURCE1 and SOURCE2 conceptual models. A detailed description of the SOURCE programs-including algorithms, input requirements, and output options-can be found in the user's manual (Icenhour and Tharp 1996).

\subsection{Overview of the Conceptual Model}

The routines of the SOURCE programs have four primary functions: structural analysis, simulation of concrete- and metal-barrier degradation, cracking analysis, and nuclide-leaching calculations. The structural analysis routine establishes initial bending moments and shear forces. The concrete- and metal-barrier degradation routines simulate the deterioration of engineered barriers with time. The cracking analysis routines calculate moments and shears required for concrete cracking and compare these values with the moments and shears evaluated in the structural analysis. Moments and shears required for cracking vary as the engineered facility degrades. The leaching routines calculate the release rate of nuclides to the environment. A detailed illustration of the logic flow used in the SOURCE computer programs to model these processes is provided in Fig. 4.2. The structural analysis is performed once at the beginning of a simulation. The concrete- and metal-barrier degradation and cracking analyses are performed using annual time steps. Nuclide release rates are calculated using monthly time steps.

Before the annual simulation begins, structural analyses of the disposal unit are conducted to establish the moments and forces placed on the various structural components. For the roof, walls, and floor, the SOURCE programs calculate the uniform load, bending moments resulting from uniform loading, and shear and compressive forces. The walls are also subjected to hydrostatic pressures caused by the backfill and waste. Calculations of bending moments and shear forces for the walls are based on these hydrostatic pressures. The bending moments and shear forces attributed to hydrostatic pressures are added to the bending moments and shear forces for the uniform load to give the total bending moments and shear forces for the walls.

Following the structural analysis, the computer programs enter an annual loop in which chemical and physical deterioration of the concrete and steel barriers used in the disposal unit is modeled. Properties of the structural members of the facility are updated to reflect degradation, and the updated properties are used in cracking analyses of the roof, walls, and floor of the disposal unit to assess the ability of the structure to bear the loads placed upon it. The deterioration of the concrete barriers is simulated with respect to the removal of calcium hydroxide from the cement matrix, sulfate attack of the concrete, and corrosion of steel reinforcement. The properties of the concrete components (e.g., strength, thickness, and $\mathrm{pH}$ ) are updated for each year of the simulation to reflect projected rates of deterioration. Failure rates of steel containers and the epoxy coating on reinforcing steel are determined by using a linear failure model.

As an engineered structure is weakened by chemical and physical attack, a point is reached at which the structure can no longer bear the loads placed upon it. Under these conditions, the engineered barriers will crack or otherwise fail. Failure is judged in terms of the capability of the disposal unit to 
ORNL DWG 93A-738

\section{LOGIC FLOW IN THE SOURCE COMPUTER CODES}

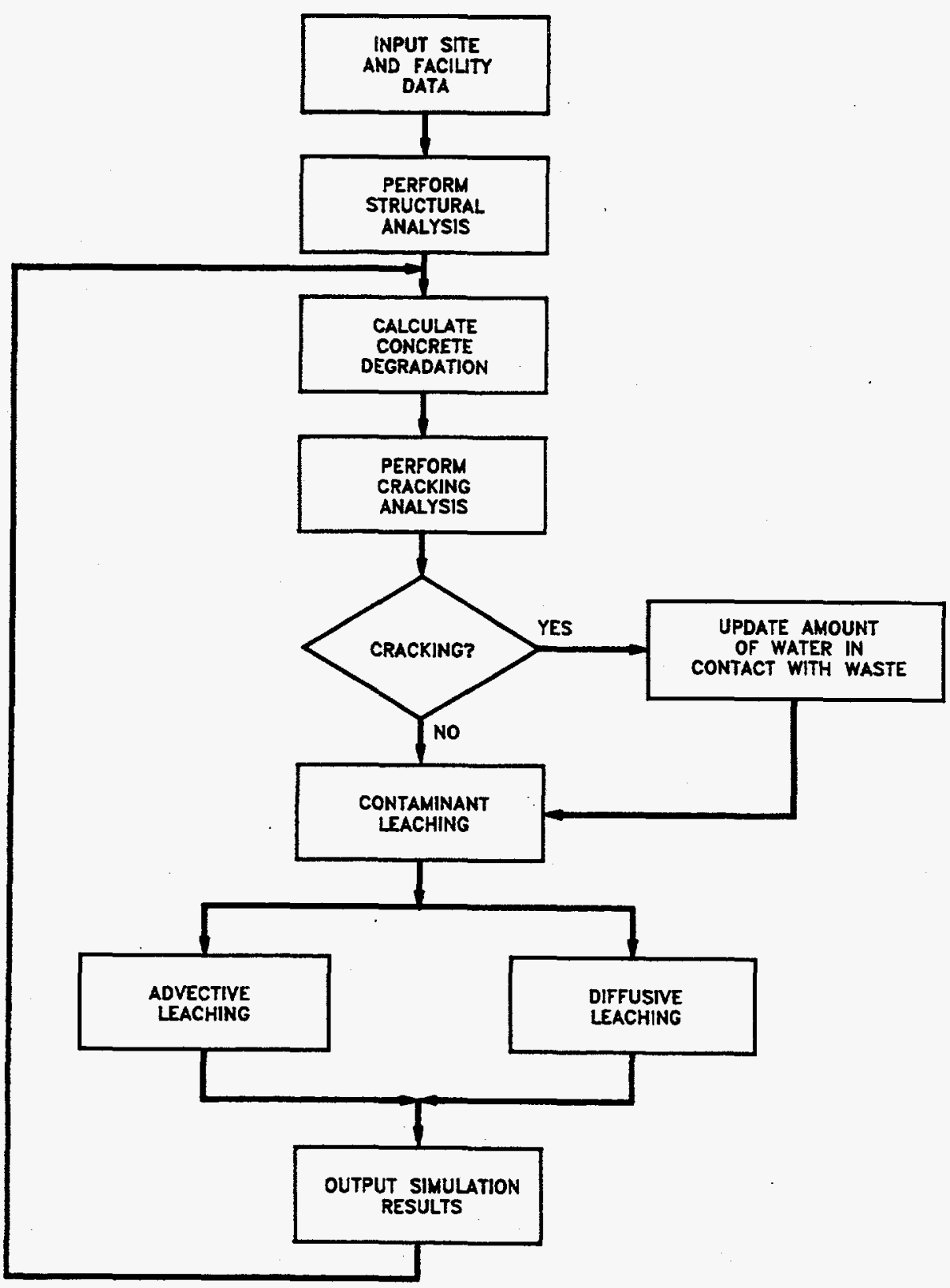

Fig. 4.2. Logic flow of the SOURCE1 and SOURCE2 computer programs. 
isolate the waste from water percolating through the disposal site. When the disposal unit is no longer hydraulically intact, the engineered barriers are assumed to offer no benefit. The cracking analysis is performed if hydraulic failure of the disposal unit has not occurred. The cracking moment, cracking shear, and ultimate strength are each calculated for the roof, walls, and floor and compared to the moments and forces calculated in the structural analysis. If the calculated moments or shears exceed the cracking moments or shear forces, the structural member is projected to crack. Fracture characteristics (depth, spacing, and width) are calculated following the onset of cracking. Cracking or spalling of concrete members of the disposal unit may result from corrosion of the steel reinforcement. In the event of cracking, fracture characteristics are calculated. In the event of spalling, the thicknesses of the concrete members are updated. Figure 4.3 demonstrates the logic flow of the structural and cracking analyses that are performed to estimate the time of failure of the disposal unit.

Radionuclide release rates from waste disposal units are a function of the integrity of the waste (or waste form) and the engineered barriers used in construction of the unit (e.g., concrete and metal containers). Intact barriers minimize the contact of water with the waste, thereby minimizing releases of radionuclides. As barriers deteriorate over time, water more readily contacts the waste and mobilizes radionuclides, thus accelerating releases to the environment. The SOURCE programs consider two mechanisms through which waste radionuclides are released into the environment: advection (bulk flow driven by hydraulic pressure differences) and diffusion (nuclide movement driven by concentration differences). The calculated total release rate resulting from advection and diffusion is compared with the rate of release dictated by the solubility limit of the nuclide in water. If the solubility limit is exceeded, the release rate is adjusted to the solubility-limited rate. As a disposal unit degrades, the percolation rate of water through the waste increases. Thus, except for cases constrained by solubility, advective releases will increase with degradation and, in general, dominate the total release. The total release is divided into two components: one that flows vertically for recharge to groundwater and a second that flows laterally in the shallow-subsurface flow region of the site.

The IWMF design includes a steel-reinforced concrete pad under the disposal vaults and a leachate collection system. The Tumulus I and Tumulus II disposal units also have a concrete pad under the disposal vaults. Although their leachate collection systems are not as elaborate as that for the IWMF, these units also have the capability to collect and monitor leachate. The SOURCE1 program simulates the degradation and failure of the pad and the collection system. As long as the pad and the collection system are functional, releases to the environment are attenuated. Increased degradation results in increased releases to the environment until the pad and collection system are no longer functional. At this point, calculated releases from the disposal vaults are no longer attenuated.

\subsection{Revisions to SOURCE1 and SOURCE2}

Version 1.0 of the SOURCE programs (Shuman, Chau, and Jennrich 1992) was used for the source term calculations for the initial PA. Several revisions have been incorporated into Version 2.0 of the SOURCE programs. These revisions include the incorporation of a new advective transport 


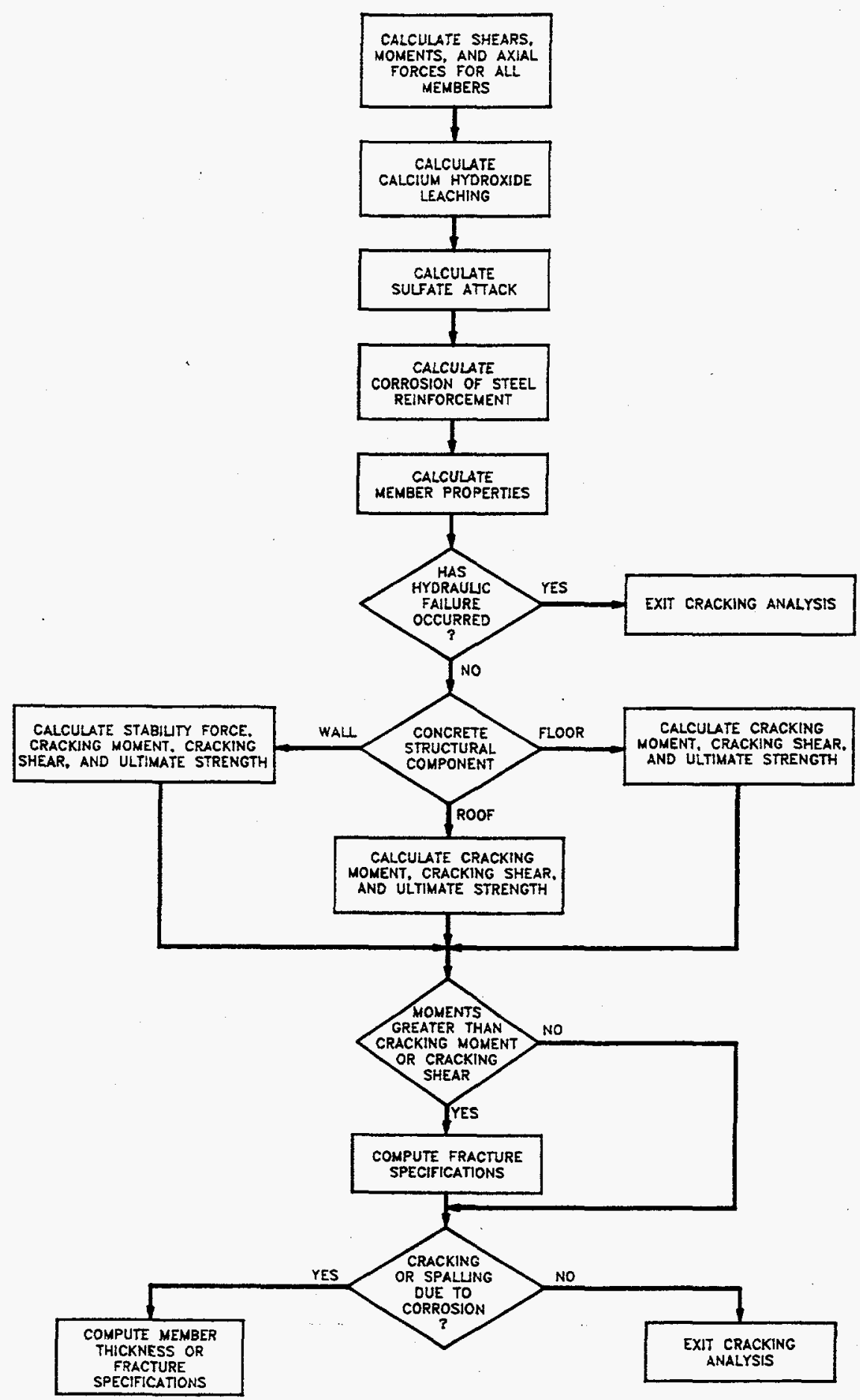

Fig. 4.3. Logic flow of the concrete-degradation and -cracking subroutines for the SOURCE1 and SOURCE2 computer programs. 
model, development of a new model that calculates the degradation and failure of a tumulus-type pad and leachate collection system (for SOURCE1), improvement of routines for controlling water seepage and radionuclide inventory inputs, and expansion of options for obtaining output summaries. A detailed description of each of these changes can be found in the SOURCE1 and SOURCE2 user's manual (Icenhour and Tharp 1996).

\subsubsection{Input Parameters for the SOURCE1 and SOURCE2 Computer Programs}

The SOURCE program input parameters can be divided into four general categories: (1) disposal unit physicochemical parameters, (2) radionuclide transport parameters, (3) radionuclide inventory, and (4) water-seepage rates.

\subsection{Physicochemical Parameters}

The disposal unit physicochemical parameters describe the dimensions and construction of the unit and the chemical composition of the media interacting with the unit. Table 4.3 provides the physicochemical parameters used for the simulations of the different disposal technologies used in SWSA 6 (i.e., tumulus, silo, well, well-in-silo, and trench-type disposal units). Note that SOURCE2 is used for simulations of trench-type disposal units. At ORNL, these types of units have no engineered barriers other than potentially a cover. The trenches are modeled as silos (i.e., with equivalent volume and surface area) and input parameters are selected such that these "silos" will fail hydraulically at the beginning of the simulation. Hence, any water that penetrates the cover is immediately available to flow through the waste in the trench and to transport radionuclides away from the waste. The amount and timing of the water penetrating the cover are provided as an input to the SOURCE2 computer program. For other units modeled by SOURCE2 (i.e., silos, wells, wells-in-silos) hydraulic failure occurs later in the calculation as engineered barriers degrade.

\subsection{Radionuclide Transport Parameters}

Radionuclide transport parameters (e.g., distribution coefficient, diffusion coefficients, and solubility) are used in the calculation of the release rates of the radionuclides from the waste. Radionuclide-specific transport parameters for the all-pathways source term calculations are summarized in Table 4.4. Appendix $\mathrm{C}$ outlines the methodology used in developing the radionuclidespecific input parameters.

\subsection{Radionuclide Inventory}

Table 4.5 presents the radionuclide inventory used in the calculations for this revised PA by disposal unit type and zone. The inventory is given in units of mass per disposal unit. The inventory presented in the table is based on the WMRAD-WTS database and reflects only those wastes 
Table 4.3. Physicochemical parameters used in the SOURCE1 and SOURCE2 simulations of the SWSA 6 disposal units ${ }^{a}$

\begin{tabular}{l} 
Parameter \\
\hline Zone \\
Disposal unit area, $\mathrm{m}^{2}$ \\
Total dissolved solids, ppm \\
Groundwater temperature, ${ }^{\circ} \mathrm{C}$ \\
Groundwater pH \\
Soil and waste properties \\
Earthen cover thickness, $\mathrm{m}$ \\
Earthen cover density, g/cm ${ }^{3}$ \\
Friction angle of waste backfill, \\
degrees \\
Friction angle of soil backfill, degrees \\
Density of soil backfill, $\mathrm{g} / \mathrm{cm}^{3}$ \\
Waste density, $\mathrm{g} / \mathrm{cm}^{3}$ \\
Relative saturation of waste \\
Saturated hydraulic conductivity, $\mathrm{cm} / \mathrm{s}$ \\
Recharge \\
Soil backfill \\
Concrete
\end{tabular}

Groundwater constituent concentrations, $\mathrm{mol} / \mathrm{L}$

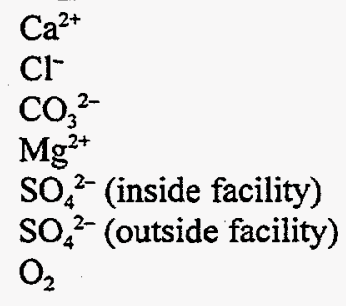

$\begin{array}{lllll}2.10 \times 10^{-3} & 2.10 \times 10^{-3} & 2.10 \times 10^{-3} & 2.10 \times 10^{-3} & 2.10 \times 10^{-3} \\ 2.04 \times 10^{-4} & 2.04 \times 10^{-4} & 2.04 \times 10^{-4} & 2.04 \times 10^{-4} & 2.04 \times 10^{-4} \\ 1.00 \times 10^{-3} & 1.00 \times 10^{-3} & 1.00 \times 10^{-3} & 1.00 \times 10^{-3} & 1.00 \times 10^{-3} \\ 5.21 \times 10^{-4} & 5.21 \times 10^{-4} & 5.21 \times 10^{-4} & 5.21 \times 10^{-4} & 5.21 \times 10^{-4} \\ 2.62 \times 10^{-4} & 2.62 \times 10^{-4} & 2.62 \times 10^{-4} & 2.62 \times 10^{-4} & 2.62 \times 10^{-4} \\ 2.62 \times 10^{-4} & 2.62 \times 10^{-4} & 2.62 \times 10^{-4} & 2.62 \times 10^{-4} & 2.62 \times 10^{-4} \\ 3.44 \times 10^{-4} & 3.44 \times 10^{-4} & 3.44 \times 10^{-4} & 3.44 \times 10^{-4} & 3.44 \times 10^{-4}\end{array}$

Constituent solubilities, $\mathrm{mol} / \mathrm{L}$

$\begin{array}{llllll}\mathrm{Ca}(\mathrm{OH})_{2} & 2.00 \times 10^{-2} & 2.00 \times 10^{-2} & 2.00 \times 10^{-2} & 2.00 \times 10^{-2} & 2.00 \times 10^{-2} \\ \mathrm{CO}_{3}^{2-} & 1.20 \times 10^{-3} & 1.20 \times 10^{-3} & 1.20 \times 10^{-3} & 1.20 \times 10^{-3} & 1.20 \times 10^{-3} \\ \mathrm{Mg}^{2+} & 1.20 \times 10^{-3} & 1.20 \times 10^{-3} & 1.20 \times 10^{-3} & 1.20 \times 10^{-3} & 1.20 \times 10^{-3}\end{array}$

Concrete constituent concentrations, $\mathrm{mol} / \mathrm{L}$

Calcium concentration in $\mathrm{C}-\mathrm{S}-\mathrm{H}$ system ${ }^{h}$
$1.75 \times 10^{0}$
$1.75 \times 10^{0}$
$1.75 \times 10^{\circ}$
$1.75 \times 10^{0}$
$1.75 \times 10^{0}$
$2.00 \times 10^{-2}$
$2.00 \times 10^{-2}$
$2.00 \times 10^{-2}$
$2.00 \times 10^{-2}$
$2.00 \times 10^{-2}$
$2.11 \times 10^{0}$
$2.11 \times 10^{0}$
$2.11 \times 10^{0}$
$2.11 \times 10^{0}$
$2.11 \times 10^{0}$
$1.00 \times 10^{-2}$
$1.00 \times 10^{-2}$
$1.00 \times 10^{-2}$
$1.00 \times 10^{-2}$
$1.00 \times 10^{-2}$
$7.10 \times 10^{-1}$
$7.10 \times 10^{-1}$
$7.10 \times 10^{-1}$
$7.10 \times 10^{-1}$
$7.10 \times 10^{-1}$

Calcium concentration in pore fluid

$\mathrm{CaO}$ content in cement

Silica concentration in C-S-H system 
Table 4.3. (continued)

\begin{tabular}{|c|c|c|c|c|c|}
\hline \multirow[b]{2}{*}{ Parameter } & \multicolumn{5}{|c|}{ Disposal technology } \\
\hline & Silo $^{b}$ & Well ${ }^{c}$ & Well-in- silo ${ }^{d}$ & Trench ${ }^{e, f}$ & Tumulus ${ }^{g}$ \\
\hline \multicolumn{6}{|l|}{ Concrete design specifications } \\
\hline Compressive strength at 28 days, $\mathrm{Pa}$ & $3.45 \times 10^{7}$ & $3.45 \times 10^{7}$ & $3.45 \times 10^{7}$ & $3.45 \times 10^{7}$ & $3.45 \times 10^{7}$ \\
\hline Poisson's ratio of concrete & $1.50 \times 10^{-1}$ & $1.50 \times 10^{-1}$ & $1.50 \times 10^{-1}$ & $1.50 \times 10^{-1}$ & $1.50 \times 10^{-1}$ \\
\hline Modulus of elasticity of steel, $\mathrm{Pa}$ & $2.00 \times 10^{11}$ & $2.00 \times 10^{11}$ & $2.00 \times 10^{11}$ & $0.00 \times 10^{0}$ & $2.00 \times 10^{11}$ \\
\hline Yield strength of steel, $\mathrm{Pa}$ & $4.14 \times 10^{8}$ & $4.14 \times 10^{8}$ & $4.14 \times 10^{8}$ & $0.00 \times 10^{0}$ & $4.14 \times 10^{8}$ \\
\hline Modulus of subgrade reaction, $\mathrm{Pa}$ & $2.07 \times 10^{6}$ & $2.07 \times 10^{6}$ & $2.07 \times 10^{6}$ & $2.07 \times 10^{6}$ & $1.38 \times 10^{7}$ \\
\hline $\begin{array}{l}\text { Young's modulus of elasticity } \\
\text { (concrete), } \mathrm{Pa}\end{array}$ & $2.00 \times 10^{10}$ & $2.00 \times 10^{10}$ & $2.00 \times 10^{10}$ & $0.00 \times 10^{0}$ & $2.00 \times 10^{10}$ \\
\hline Concrete water-to-cement ratio & $4.00 \times 10^{-1}$ & $4.00 \times 10^{-1}$ & $4.00 \times 10^{-1}$ & $4.00 \times 10^{-1}$ & $4.00 \times 10^{-1}$ \\
\hline Concrete density, $\mathrm{g} / \mathrm{cm}^{3}$ & $2.40 \times 10^{\circ}$ & $2.40 \times 10^{\circ}$ & $2.40 \times 10^{0}$ & $2.40 \times 10^{\circ}$ & $2.40 \times 10^{0}$ \\
\hline Concrete porosity & $1.50 \times 10^{-1}$ & $1.50 \times 10^{-1}$ & $1.50 \times 10^{-1}$ & $1.50 \times 10^{-1}$ & $1.50 \times 10^{-1}$ \\
\hline Cement content, $\mathrm{kg} / \mathrm{m}^{3}$ & $3.85 \times 10^{2}$ & $3.85 \times 10^{2}$ & $3.85 \times 10^{2}$ & $3.85 \times 10^{2}$ & $4.03 \times 10^{2}$ \\
\hline Initial pH & $1.25 \times 10^{1}$ & $1.25 \times 10^{\prime}$ & $1.25 \times 10^{1}$ & $1.25 \times 10^{1}$ & $1.25 \times 10^{1}$ \\
\hline \multicolumn{6}{|l|}{ Diffusion coefficients in concrete, $\mathrm{m}^{2} / \mathrm{s}$} \\
\hline $\mathrm{NaOH}, \mathrm{KOH}$ & $2.12 \times 10^{-11}$ & $2.12 \times 10^{-11}$ & $2.12 \times 10^{-11}$ & $2.12 \times 10^{-11}$ & $2.12 \times 10^{-11}$ \\
\hline $\mathrm{Ca}(\mathrm{OH})_{2}$ & $1.82 \times 10^{-11}$ & $1.82 \times 10^{-11}$ & $1.82 \times 10^{-11}$ & $1.82 \times 10^{-11}$ & $1.82 \times 10^{-11}$ \\
\hline $\mathrm{Cl}^{-}$ & $5.08 \times 10^{-11}$ & $5.08 \times 10^{-11}$ & $5.08 \times 10^{-11}$ & $5.08 \times 10^{-11}$ & $5.08 \times 10^{-11}$ \\
\hline $\mathrm{CO}_{2}$ & $1.92 \times 10^{-10}$ & $1.92 \times 10^{-10}$ & $1.92 \times 10^{-10}$ & $1.92 \times 10^{-10}$ & $1.92 \times 10^{-10}$ \\
\hline $\mathrm{O}_{2}$ & $2.10 \times 10^{-10}$ & $2.10 \times 10^{-10}$ & $2.10 \times 10^{-10}$ & $2.10 \times 10^{-10}$ & $2.10 \times 10^{-10}$ \\
\hline $\mathrm{SO}_{4}{ }^{2-}$ & $1.06 \times 10^{-11}$ & $1.06 \times 10^{-11}$ & $1.06 \times 10^{-11}$ & $1.06 \times 10^{-11}$ & $1.06 \times 10^{-11}$ \\
\hline \multicolumn{6}{|l|}{ Well-steel properties } \\
\hline Steel density, $\mathrm{g} / \mathrm{cm}^{3}$ & & $7.80 \times 10^{\circ}$ & $7.80 \times 10^{\circ}$ & & \\
\hline Poisson's ratio of steel & & $3.00 \times 10^{-1}$ & $3.00 \times 10^{-1}$ & & \\
\hline Yield strength of steel wall, $\mathrm{Pa}$ & & $2.48 \times 10^{8}$ & $2.48 \times 10^{8}$ & & \\
\hline \multicolumn{6}{|c|}{ Epoxy coating and steel failure times, years } \\
\hline \multicolumn{6}{|l|}{ Epoxy coating } \\
\hline Start of failure & $0.00 \times 10^{0}$ & & $0.00 \times 10^{0}$ & $0.00 \times 10^{0}$ & $0.00 \times 10^{\circ}$ \\
\hline Time to complete failure & $2.00 \times 10^{1}$ & & $2.00 \times 10^{1}$ & $2.00 \times 10^{1}$ & $2.00 \times 10^{1}$ \\
\hline \multicolumn{6}{|l|}{ Steel liner or container } \\
\hline Start of failure & $0.00 \times 10^{0}$ & & $0.00 \times 10^{0}$ & $0.00 \times 10^{0}$ & $0.00 \times 10^{0}$ \\
\hline Time to complete failure & $6.00 \times 10^{1}$ & & $6.00 \times 10^{1}$ & $0.00 \times 10^{0}$ & $6.00 \times 10^{1}$ \\
\hline \multicolumn{6}{|l|}{ Well wall } \\
\hline Start of failure & & $0.00 \times 10^{0}$ & $0.00 \times 10^{0}$ & & \\
\hline Time to complete failure & & $7.50 \times 10^{1}$ & $7.50 \times 10^{1}$ & & \\
\hline
\end{tabular}

\section{Well design specifications}

Well dimensions, $\mathrm{cm}$

Radius

$3.91 \times 10^{1} \quad 2.64 \times 10^{1}$

Height

$4.57 \times 10^{2} \quad 4.57 \times 10^{2}$

Structural member thickness, $\mathrm{cm}$

Roof

$3.05 \times 10^{1} \quad 3.05 \times 10^{1}$

Wall

$1.90 \times 10^{0} \quad 1.90 \times 10^{0}$

Floor

$3.05 \times 10^{1} \quad 3.05 \times 10^{1}$ 
Table 4.3. (continued)

\begin{tabular}{llll}
\hline & \multicolumn{3}{c}{ Disposal technology } \\
\cline { 2 - 4 } Parameter & Silo $^{b}$ & Well $^{c}$ & Well-in- silo \\
\hline Concrete-cover thickness on tension face, $\mathrm{cm}$ & & & \\
Roof & & & Tumulus $^{g}$ \\
X-direction & $1.48 \times 10^{1}$ & $1.48 \times 10^{1}$ & \\
Y-direction & $1.48 \times 10^{1}$ & $1.48 \times 10^{1}$ & \\
Floor & & & \\
X-direction & $0.00 \times 10^{\circ}$ & $0.00 \times 10^{\circ}$ & \\
Y-direction & $0.00 \times 10^{\circ}$ & $0.00 \times 10^{\circ}$ &
\end{tabular}

\section{Silo design specifications}

Silo dimensions, $m$

Radius

Height

Concrete-member thickness, $\mathrm{cm}$

Roof

Wall

Floor

Steel-reinforcement radius, $\mathrm{cm}$

Roof

Wall

Floor

Spacing of steel reinforcement, $\mathrm{cm}$

Roof

Wall

Floor

Corrugated-steel thickness, $\mathrm{cm}$

Compression face

Tension face

$$
1.30 \times 10^{0}
$$$$
4.57 \times 10^{\circ}
$$

$3.05 \times 10^{1}$

$1.52 \times 10^{1}$

$3.05 \times 10^{1}$

$4.76 \times 10^{-1}$
$0.00 \times 10^{0}$
$4.76 \times 10^{-1}$

$1.52 \times 10^{1}$

$0.00 \times 10^{0}$

$1.52 \times 10^{1}$
$1.37 \times 10^{0}$

$4.57 \times 10^{0}$

$3.20 \times 10^{0}$

$1.75 \times 10^{\circ}$

$0.00 \times 10^{0}$

$2.76 \times 10^{1}$

$3.05 \times 10^{1}$

$3.05 \times 10^{1}$

$1.52 \times 10^{1}$

$3.05 \times 10^{1}$

$4.76 \times 10^{-1} \quad 0.00 \times 10^{0}$

$0.00 \times 10^{0} \quad 0.00 \times 10^{0}$

$4.76 \times 10^{-1} \quad 0.00 \times 10^{0}$

$1.52 \times 10^{1}$

$0.00 \times 10^{0}$

$1.52 \times 10^{1}$

$0.00 \times 10^{0}$

$0.00 \times 10^{0}$

$0.00 \times 10^{0}$

Concrete cover thickness on tension face, $\mathrm{cm}$

Roof

$\mathrm{X}$-direction

$1.48 \times 10^{1}$

$1.48 \times 10^{3}$

$1.48 \times 10^{1}$

Y-direction

$1.48 \times 10^{1}$

$1.48 \times 10^{1}$

$1.48 \times 10^{1}$

Wall

Horizontal direction

$0.00 \times 10^{0}$

Vertical direction

$0.00 \times 10^{0}$

$0.00 \times 10^{\circ} \quad 0.00 \times 10^{0}$

$0.00 \times 10^{0} \quad 0.00 \times 10^{0}$

Floor

$X$-direction

$1.48 \times 10^{1}$

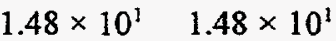

Y-direction

$1.48 \times 10^{1}$

$1.48 \times 10^{1}$
$1.48 \times 10^{1}$

Tumulus-design specifications

Layers of vaults 3

Number of vaults wide 10

Number of vaults long 
Table 4.3. (continued)

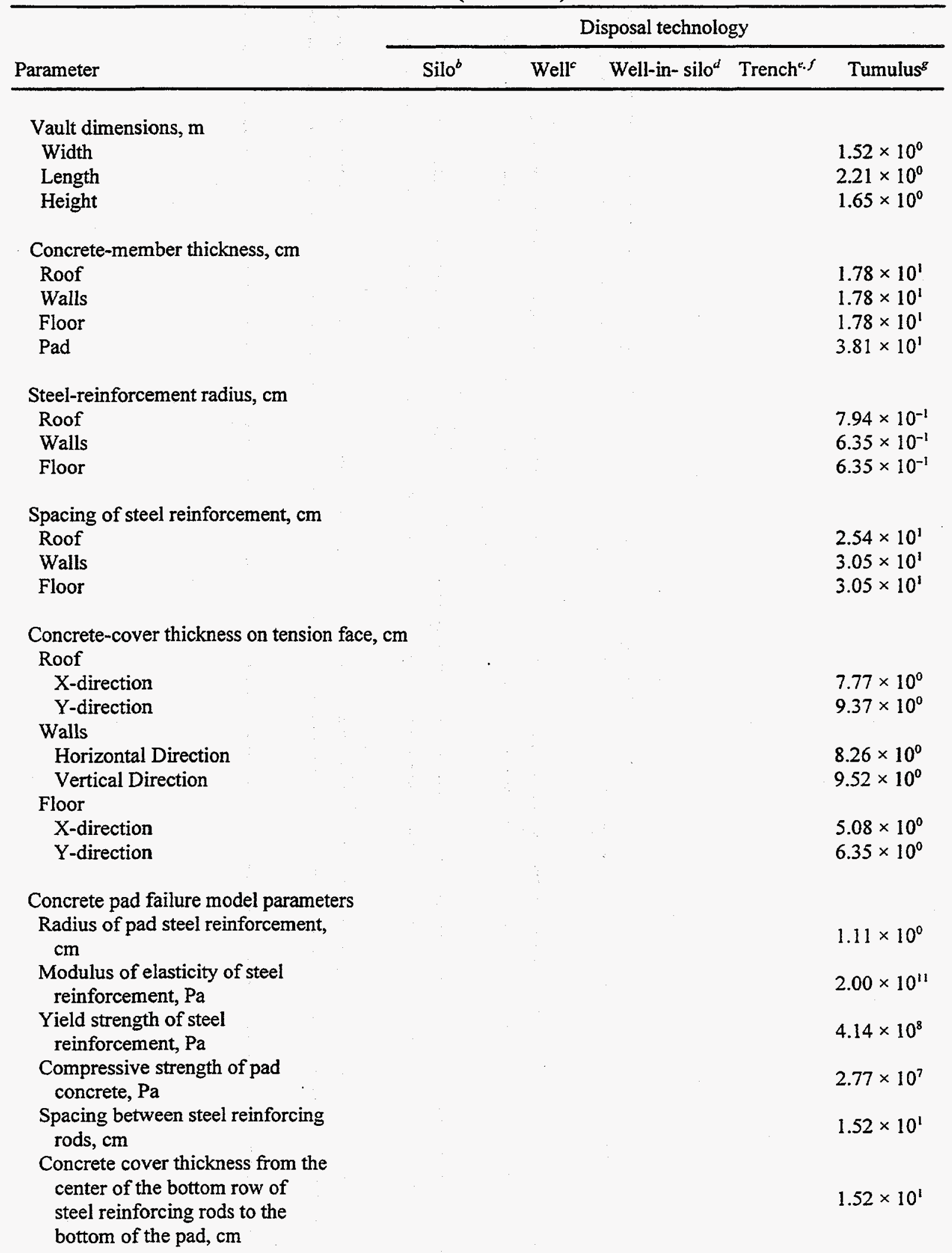


Table 4.3. (continued)

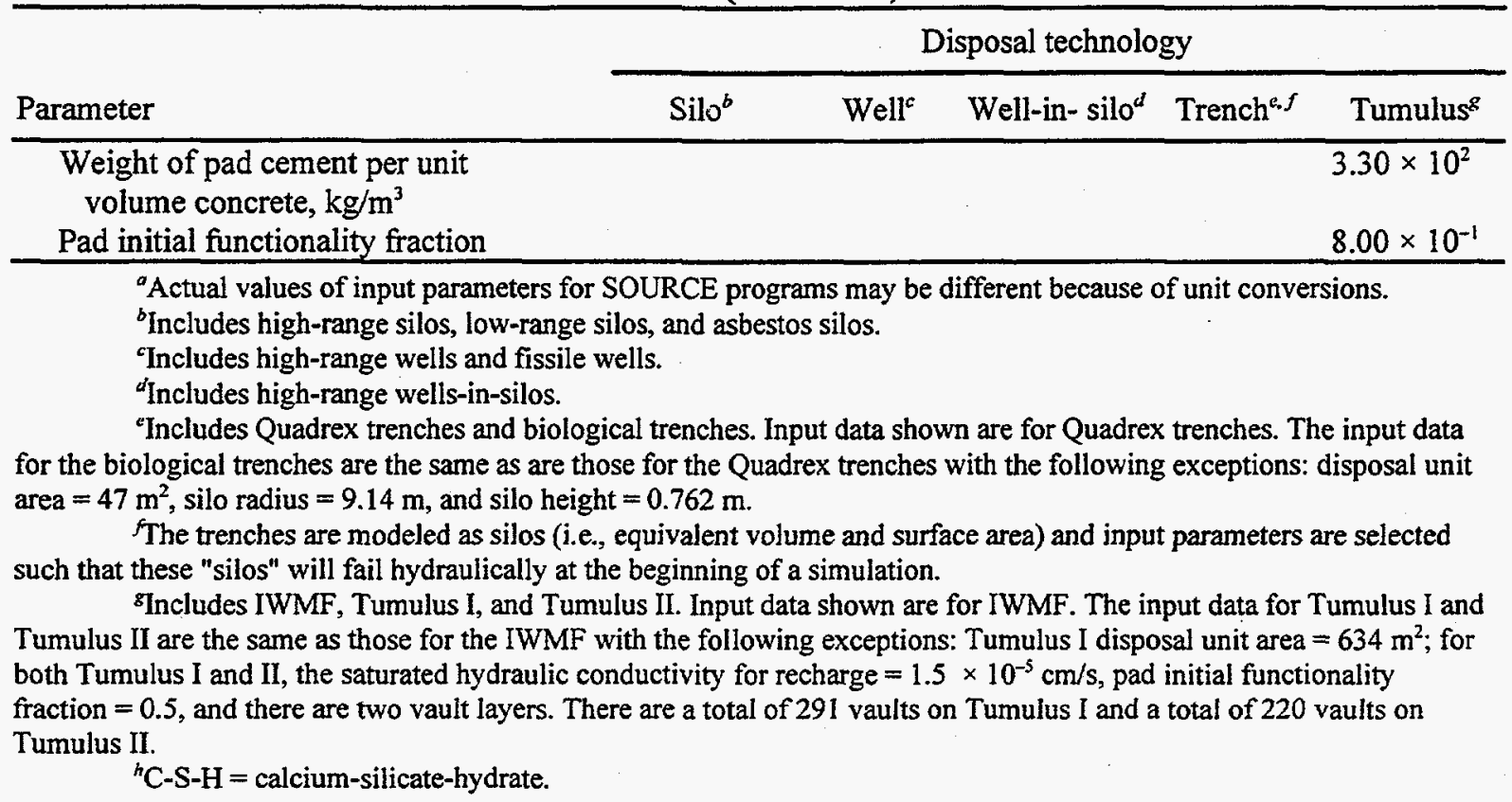

disposed of after September 1988. In addition, this inventory has been screened by both half-life and waste $K_{d}$. Radionuclides with a half-life of less than 5 years were not considered. The maximum concentration in solution for a given radionuclide in a disposal unit was estimated from the concentration in solid waste and the waste $K_{d}$. This concentration was compared with a waterconcentration limit (Table 4.19), and those radionuclides that had concentrations less than the limit were eliminated from further consideration for the all-pathways analysis. The screening methodology and its basis are described in further detail in Appendix A. The same radionuclide inventory, in terms of radioactivity and concentration in solid waste, is presented in Table 4.6 and Table 4.7, respectively.

No inventory is given for the IWMF because the results of the calculations were used to determine the inventory limits for radionuclides disposed of in this disposal unit. For the IWMF, the calculations were performed iteratively to determine the initial radionuclide inventory (i.e., gram per vault) that would result in a surface-water or groundwater concentration equal to the limit established by the performance criteria. The limiting inventories for the IWMF were then compared with the existing IWMF inventories to demonstrate compliance. The limiting inventories used in the allpathways calculations are presented in Sect. 5.1.2, and compliance of existing IWMF disposal with the performance criteria is presented in Sect. 7.1.

\subsection{Water Seepage Rates}

The rates of water seepage into the disposal units are calculated using the UTM model, as described in Sect. 4.3.1.1. The results of these calculations, which are an input for the SOURCE1 and SOURCE2 programs, are presented in Table 4.8 and Table 4.9. 
Table 4.4 Radionuclide-specific input data to SOURCE1 and SOURCE2 for the SWSA 6 performance assessment ${ }^{n}$

\begin{tabular}{|c|c|c|c|c|c|}
\hline \multirow{2}{*}{ Nuclide } & \multirow{2}{*}{$\begin{array}{l}\text { Half-life } \\
\text { (years) }\end{array}$} & \multirow{2}{*}{$\begin{array}{l}\text { Solubility } \\
(\mathrm{mol} / \mathrm{L})\end{array}$} & \multirow{2}{*}{$\begin{array}{l}\text { Waste } K_{d} \\
(\mathrm{~mL} / \mathrm{g})\end{array}$} & \multicolumn{2}{|c|}{$\begin{array}{l}\text { Diffusion coefficient } \\
\left(\mathrm{m}^{2} / \mathrm{s}\right)\end{array}$} \\
\hline & & & & Waste & Concrete \\
\hline${ }^{3} \mathrm{H}$ & $1.23 \times 10^{1}$ & $1.11 \times 10^{2}$ & $1.99 \times 10^{-1}$ & $3.88 \times 10^{-9}$ & $4.73 \times 10^{-10}$ \\
\hline${ }^{10} \mathrm{Be}$ & $1.60 \times 10^{6}$ & $8.00 \times 10^{-6}$ & $3.12 \times 10^{6}$ & $3.63 \times 10^{-17}$ & $1.14 \times 10^{-11}$ \\
\hline${ }^{14} \mathrm{C}$ & $5.73 \times 10^{3}$ & $1.11 \times 10^{-4}$ & $1.09 \times 10^{0}$ & $1.55 \times 10^{-11}$ & $1.73 \times 10^{-12}$ \\
\hline${ }^{26} \mathrm{Al}$ & $7.20 \times 10^{5}$ & $5.24 \times 10^{0}$ & $1.68 \times 10^{5}$ & $1.28 \times 10^{-16}$ & $5.84 \times 10^{-13}$ \\
\hline${ }^{36} \mathrm{Cl}$ & $3.01 \times 10^{5}$ & $4.61 \times 10^{0}$ & $1.77 \times 10^{-1}$ & $7.28 \times 10^{-11}$ & $8.98 \times 10^{-12}$ \\
\hline${ }^{40} \mathrm{~K}$ & $1.28 \times 10^{9}$ & $4.61 \times 10^{\circ}$ & $7.14 \times 10^{0}$ & $2.90 \times 10^{-11}$ & $2.15 \times 10^{-12}$ \\
\hline${ }^{4 i} \mathrm{Ca}$ & $1.03 \times 10^{5}$ & $1.53 \times 10^{-4}$ & $4.61 \times 10^{0}$ & $3.12 \times 10^{-12}$ & $3.49 \times 10^{-13}$ \\
\hline${ }^{60} \mathrm{Co}$ & $5.27 \times 10^{0}$ & $3.46 \times 10^{0}$ & $2.07 \times 10^{6}$ & $3.21 \times 10^{-17}$ & $1.12 \times 10^{-12}$ \\
\hline${ }^{59} \mathrm{Ni}$ & $7.50 \times 10^{4}$ & $7.83 \times 10^{-4}$ & $6.38 \times 10^{0}$ & $1.00 \times 10^{-11}$ & $1.08 \times 10^{-12}$ \\
\hline${ }^{63} \mathrm{Ni}$ & $1.00 \times 10^{2}$ & $7.83 \times 10^{-4}$ & $6.38 \times 10^{0}$ & $1.00 \times 10^{-11}$ & $1.08 \times 10^{-12}$ \\
\hline${ }^{79} \mathrm{Se}$ & $6.50 \times 10^{4}$ & $4.45 \times 10^{0}$ & $2.21 \times 10^{1}$ & $1.34 \times 10^{-11}$ & $1.46 \times 10^{-12}$ \\
\hline${ }^{87} \mathrm{Rb}$ & $4.80 \times 10^{10}$ & $1.95 \times 10^{1}$ & $1.40 \times 10^{1}$ & $1.27 \times 10^{-11}$ & $9.32 \times 10^{-13}$ \\
\hline${ }^{90} \mathrm{Sr}$ & $2.85 \times 10^{1}$ & $7.45 \times 10^{-5}$ & $8.75 \times 10^{0}$ & $1.19 \times 10^{-12}$ & $1.29 \times 10^{-13}$ \\
\hline${ }^{93} \mathrm{Zr}$ & $1.53 \times 10^{6}$ & $2.19 \times 10^{-3}$ & $4.97 \times 10^{1}$ & $4.00 \times 10^{-13}$ & $4.30 \times 10^{-14}$ \\
\hline${ }^{93 \mathrm{~m}} \mathrm{Nb}$ & $1.36 \times 10^{1}$ & $2.60 \times 10^{-1}$ & $5.90 \times 10^{1}$ & $3.78 \times 10^{-13}$ & $4.07 \times 10^{-14}$ \\
\hline${ }^{94} \mathrm{Nb}$ & $2.03 \times 10^{4}$ & $2.60 \times 10^{-1}$ & $5.90 \times 10^{1}$ & $3.78 \times 10^{-13}$ & $4.07 \times 10^{-14}$ \\
\hline${ }^{99} \mathrm{Tc}$ & $2.13 \times 10^{5}$ & $9.12 \times 10^{-2}$ & $3.18 \times 10^{0}$ & $2.52 \times 10^{-12}$ & $2.75 \times 10^{-13}$ \\
\hline${ }^{107} \mathrm{Pd}$ & $6.50 \times 10^{6}$ & $3.76 \times 10^{-9}$ & $1.39 \times 10^{6}$ & $4.44 \times 10^{-17}$ & $6.25 \times 10^{-13}$ \\
\hline${ }^{113 \mathrm{~m}} \mathrm{Cd}$ & $1.37 \times 10^{1}$ & $7.64 \times 10^{0}$ & $1.42 \times 10^{5}$ & $2.89 \times 10^{-16}$ & $3.99 \times 10^{-13}$ \\
\hline${ }^{121 \mathrm{~m}} \mathrm{Sn}$ & $5.50 \times 10^{1}$ & $1.37 \times 10^{1}$ & $3.02 \times 10^{1}$ & $2.25 \times 10^{-13}$ & $2.41 \times 10^{-14}$ \\
\hline${ }^{126} \mathrm{Sn}$ & $1.00 \times 10^{5}$ & $1.37 \times 10^{1}$ & $3.02 \times 10^{1}$ & $2.25 \times 10^{-13}$ & $2.41 \times 10^{-14}$ \\
\hline${ }^{129} \mathrm{I}$ & $1.57 \times 10^{7}$ & $7.68 \times 10^{0}$ & $5.51 \times 10^{-1}$ & $2.49 \times 10^{-11}$ & $2.86 \times 10^{-12}$ \\
\hline${ }^{135} \mathrm{Cs}$ & $3.00 \times 10^{6}$ & $1.60 \times 10^{1}$ & $1.99 \times 10^{1}$ & $7.26 \times 10^{-12}$ & $5.12 \times 10^{-13}$ \\
\hline${ }^{137} \mathrm{Cs}$ & $3.00 \times 10^{1}$ & $1.60 \times 10^{1}$ & $1.99 \times 10^{1}$ & $7.26 \times 10^{-12}$ & $5.12 \times 10^{-13}$ \\
\hline${ }^{151} \mathrm{Sm}$ & $9.00 \times 10^{1}$ & $3.60 \times 10^{0}$ & $6.20 \times 10^{1}$ & $4.98 \times 10^{-14}$ & $5.33 \times 10^{-15}$ \\
\hline${ }^{152} \mathrm{Eu}$ & $1.33 \times 10^{1}$ & $2.84 \times 10^{-6}$ & $6.30 \times 10^{1}$ & $5.06 \times 10^{-14}$ & $5.38 \times 10^{-15}$ \\
\hline${ }^{154} \mathrm{Eu}$ & $8.80 \times 10^{0}$ & $2.84 \times 10^{-6}$ & $6.30 \times 10^{1}$ & $5.06 \times 10^{-14}$ & $5.38 \times 10^{-15}$ \\
\hline${ }^{155} \mathrm{Eu}$ & $4.96 \times 10^{0}$ & $2.84 \times 10^{-6}$ & $6.30 \times 10^{1}$ & $5.06 \times 10^{-14}$ & $5.38 \times 10^{-15}$ \\
\hline${ }^{194} \mathrm{Os}$ & $6.00 \times 10^{0}$ & $2.24 \times 10^{-1}$ & $3.44 \times 10^{1}$ & $3.46 \times 10^{-13}$ & $6.85 \times 10^{-15}$ \\
\hline${ }^{210} \mathrm{~Pb}$ & $2.23 \times 10^{\prime}$ & $5.16 \times 10^{-5}$ & $4.95 \times 10^{1}$ & $9.17 \times 10^{-14}$ & $9.86 \times 10^{-15}$ \\
\hline${ }^{207} \mathrm{Bi}$ & $3.22 \times 10^{1}$ & $5.40 \times 10^{-6}$ & $4.79 \times 10^{0}$ & $2.11 \times 10^{-12}$ & $2.29 \times 10^{-13}$ \\
\hline${ }^{226} \mathrm{Ra}$ & $1.60 \times 10^{3}$ & $6.21 \times 10^{-8}$ & $2.03 \times 10^{3}$ & $4.12 \times 10^{-13}$ & $4.42 \times 10^{-14}$ \\
\hline${ }^{228} \mathrm{Ra}$ & $5.75 \times 10^{0}$ & $6.21 \times 10^{-8}$ & $2.03 \times 10^{1}$ & $4.12 \times 10^{-13}$ & $4.42 \times 10^{-14}$ \\
\hline${ }^{227} \mathrm{Ac}$ & $2.18 \times 10^{1}$ & $1.55 \times 10^{-5}$ & $3.69 \times 10^{3}$ & $3.01 \times 10^{-16}$ & $3.23 \times 10^{-17}$ \\
\hline${ }^{229} \mathrm{Th}$ & $7.34 \times 10^{3}$ & $3.00 \times 10^{-9}$ & $3.73 \times 10^{3}$ & $4.70 \times 10^{-16}$ & $5.04 \times 10^{-17}$ \\
\hline${ }^{230} \mathrm{Th}$ & $7.54 \times 10^{4}$ & $3.00 \times 10^{-9}$ & $3.73 \times 10^{3}$ & $4.70 \times 10^{-16}$ & $5.04 \times 10^{-17}$ \\
\hline
\end{tabular}


Table 4.4. (continued)

\begin{tabular}{|c|c|c|c|c|c|}
\hline \multirow{2}{*}{ Nuclide } & \multirow{2}{*}{$\begin{array}{l}\text { Half-life } \\
\text { (years) }\end{array}$} & \multirow{2}{*}{$\begin{array}{l}\text { Solubility } \\
(\mathrm{mol} / \mathrm{L})\end{array}$} & \multirow{2}{*}{$\begin{array}{l}\text { Waste } K_{d} \\
(\mathrm{~mL} / \mathrm{g})\end{array}$} & \multicolumn{2}{|c|}{$\begin{array}{l}\text { Diffusion coefficient } \\
\qquad\left(\mathrm{m}^{2} / \mathrm{s}\right)\end{array}$} \\
\hline & & & & Waste & Concrete \\
\hline${ }^{230} \mathrm{Th}^{b}$ & $7.54 \times 10^{4}$ & $7.57 \times 10^{-8}$ & $5.37 \times 10^{1}$ & $3.25 \times 10^{-14}$ & $c$ \\
\hline${ }^{232} \mathrm{Th}$ & $1.41 \times 10^{10}$ & $3.00 \times 10^{-9}$ & $3.73 \times 10^{3}$ & $4.70 \times 10^{-16}$ & $5.04 \times 10^{-17}$ \\
\hline${ }^{232} \mathrm{Th}^{b}$ & $1.41 \times 10^{10}$ & $7.57 \times 10^{-8}$ & $5.37 \times 10^{1}$ & $3.25 \times 10^{-14}$ & $c$ \\
\hline${ }^{231} \mathrm{~Pa}$ & $3.28 \times 10^{4}$ & $5.71 \times 10^{-4}$ & $3.77 \times 10^{3}$ & $4.88 \times 10^{-16}$ & $5.23 \times 10^{-17}$ \\
\hline${ }^{232} \mathrm{U}$ & $6.89 \times 10^{1}$ & $3.00 \times 10^{-10}$ & $3.82 \times 10^{3}$ & $5.25 \times 10^{-16}$ & $5.63 \times 10^{-17}$ \\
\hline${ }^{233} \mathrm{U}$ & $1.59 \times 10^{5}$ & $3.00 \times 10^{-10}$ & $3.82 \times 10^{3}$ & $5.25 \times 10^{-16}$ & $5.63 \times 10^{-17}$ \\
\hline${ }^{234} \mathrm{U}$ & $2.45 \times 10^{5}$ & $3.00 \times 10^{-10}$ & $3.82 \times 10^{3}$ & $5.25 \times 10^{-16}$ & $5.63 \times 10^{-17}$ \\
\hline${ }^{235} \mathrm{U}$ & $7.04 \times 10^{8}$ & $3.00 \times 10^{-10}$ & $3.82 \times 10^{3}$ & $5.25 \times 10^{-16}$ & $5.63 \times 10^{-17}$ \\
\hline${ }^{235} \mathrm{U}^{b}$ & $7.04 \times 10^{8}$ & $1.46 \times 10^{-6}$ & $5.49 \times 10^{1}$ & $3.64 \times 10^{-14}$ & $c$ \\
\hline${ }^{236} U$ & $2.34 \times 10^{7}$ & $3.00 \times 10^{-10}$ & $3.82 \times 10^{3}$ & $5.25 \times 10^{-16}$ & $5.63 \times 10^{-17}$ \\
\hline${ }^{238} \mathrm{U}$ & $4.47 \times 10^{9}$ & $3.00 \times 10^{-10}$ & $3.82 \times 10^{3}$ & $5.25 \times 10^{-16}$ & $5.63 \times 10^{-17}$ \\
\hline${ }^{238} \mathrm{U}^{b}$ & $4.47 \times 10^{9}$ & $1.46 \times 10^{-6}$ & $5.49 \times 10^{1}$ & $3.64 \times 10^{-14}$ & $c$ \\
\hline${ }^{237} \mathrm{~Np}$ & $2.14 \times 10^{6}$ & $3.00 \times 10^{-9}$ & $3.85 \times 10^{3}$ & $4.04 \times 10^{-16}$ & $4.35 \times 10^{-17}$ \\
\hline${ }^{238} \mathrm{Pu}$ & $8.77 \times 10^{1}$ & $1.00 \times 10^{-10}$ & $3.90 \times 10^{3}$ & $5.59 \times 10^{-16}$ & $6.00 \times 10^{-17}$ \\
\hline${ }^{238} \mathrm{Pu}^{b}$ & $8.77 \times 10^{1}$ & $1.71 \times 10^{-8}$ & $5.61 \times 10^{1}$ & $3.87 \times 10^{-14}$ & $c$ \\
\hline${ }^{239} \mathrm{Pu}$ & $2.41 \times 10^{4}$ & $1.00 \times 10^{-10}$ & $3.90 \times 10^{3}$ & $5.59 \times 10^{-16}$ & $6.00 \times 10^{-17}$ \\
\hline${ }^{240} \mathrm{Pu}$ & $6.56 \times 10^{3}$ & $1.00 \times 10^{-10}$ & $3.90 \times 10^{3}$ & $5.59 \times 10^{-16}$ & $6.00 \times 10^{-17}$ \\
\hline${ }^{241} \mathrm{Pu}$ & $1.44 \times 10^{1}$ & $1.00 \times 10^{-10}$ & $3.90 \times 10^{3}$ & $5.59 \times 10^{-16}$ & $6.00 \times 10^{-17}$ \\
\hline${ }^{242} \mathrm{Pu}$ & $3.76 \times 10^{5}$ & $1.00 \times 10^{-10}$ & $3.90 \times 10^{3}$ & $5.59 \times 10^{-16}$ & $6.00 \times 10^{-17}$ \\
\hline${ }^{244} \mathrm{Pu}$ & $8.26 \times 10^{7}$ & $1.00 \times 10^{-10}$ & $3.90 \times 10^{3}$ & $5.59 \times 10^{-16}$ & $6.00 \times 10^{-17}$ \\
\hline${ }^{241} \mathrm{Am}$ & $4.33 \times 10^{2}$ & $4.00 \times 10^{-10}$ & $3.93 \times 10^{3}$ & $3.80 \times 10^{-16}$ & $4.08 \times 10^{-17}$ \\
\hline${ }^{242 \mathrm{~m}} \mathrm{Am}$ & $1.41 \times 10^{2}$ & $4.00 \times 10^{-10}$ & $3.93 \times 10^{3}$ & $3.80 \times 10^{-16}$ & $4.08 \times 10^{-17}$ \\
\hline${ }^{243} \mathrm{Am}$ & $7.38 \times 10^{3}$ & $4.00 \times 10^{-10}$ & $3.93 \times 10^{3}$ & $3.80 \times 10^{-16}$ & $4.08 \times 10^{-17}$ \\
\hline${ }^{243} \mathrm{Cm}$ & $2.85 \times 10^{1}$ & $1.00 \times 10^{-10}$ & $3.98 \times 10^{3}$ & $4.40 \times 10^{-16}$ & $5.18 \times 10^{-17}$ \\
\hline${ }^{244} \mathrm{Cm}$ & $1.81 \times 10^{1}$ & $1.00 \times 10^{-10}$ & $3.98 \times 10^{3}$ & $4.40 \times 10^{-16}$ & $5.18 \times 10^{-17}$ \\
\hline${ }^{245} \mathrm{Cm}$ & $8.50 \times 10^{3}$ & $1.00 \times 10^{-10}$ & $3.98 \times 10^{3}$ & $4.40 \times 10^{-16}$ & $5.18 \times 10^{-17}$ \\
\hline${ }^{246} \mathrm{Cm}$ & $4.73 \times 10^{3}$ & $1.00 \times 10^{-10}$ & $3.98 \times 10^{3}$ & $4.40 \times 10^{-16}$ & $5.18 \times 10^{-17}$ \\
\hline${ }^{247} \mathrm{Cm}$ & $1.56 \times 10^{7}$ & $1.00 \times 10^{-10}$ & $3.98 \times 10^{3}$ & $4.40 \times 10^{-16}$ & $5.18 \times 10^{-17}$ \\
\hline${ }^{248} \mathrm{Cm}$ & $3.40 \times 10^{5}$ & $1.00 \times 10^{-10}$ & $3.98 \times 10^{3}$ & $4.40 \times 10^{-16}$ & $5.18 \times 10^{-17}$ \\
\hline${ }^{249} \mathrm{Cf}$ & $3.51 \times 10^{2}$ & $3.49 \times 10^{0}$ & $4.06 \times 10^{3}$ & $4.40 \times 10^{-16}$ & $5.01 \times 10^{-17}$ \\
\hline${ }^{250} \mathrm{Cf}$ & $1.31 \times 10^{1}$ & $3.49 \times 10^{\circ}$ & $4.06 \times 10^{3}$ & $4.40 \times 10^{-16}$ & $5.01 \times 10^{-17}$ \\
\hline${ }^{251} \mathrm{Cf}$ & $9.00 \times 10^{2}$ & $3.49 \times 10^{0}$ & $4.06 \times 10^{3}$ & $4.40 \times 10^{-16}$ & $5.01 \times 10^{-17}$ \\
\hline
\end{tabular}

${ }^{\circ}$ The methodology for estimation of the values in this table and sources is presented in Appendix $C$. ${ }^{b}$ Values used for Quadrex trench calculations.

Not applicable for Quadrex trenches. 
Table 4.5. Radionuclide inventory by zone and disposal unit for radionuclides disposed of in SWSA 6 after September 1988

\begin{tabular}{|c|c|c|c|c|c|c|}
\hline Nuclide & $\begin{array}{c}3 \\
\text { High-range } \\
\text { silos }^{a} \\
(\mathrm{~g} / \text { silo })\end{array}$ & $\begin{array}{c}\mathbf{5} \\
\text { High-range } \\
\text { wells }^{b} \\
\text { (g/well) }\end{array}$ & $\begin{array}{c}5 \\
\text { High-range } \\
\text { wells-in-silos } \\
(\mathrm{g} / \text { well })\end{array}$ & $\begin{array}{c}7 \\
\text { Fissile } \\
\text { wells } \\
\text { (g/well) }\end{array}$ & $\begin{array}{c}8 \\
\text { Quadrex } \\
\text { trenches } \\
\text { (g/trench) }\end{array}$ & $\begin{array}{c}8 \\
\text { Low-range } \\
\text { silosf } \\
(\mathrm{g} / \mathrm{silo})\end{array}$ \\
\hline${ }^{3} \mathrm{H}$ & $2.88 \times 10^{-5}$ & & & & & $7.30 \times 10^{-5}$ \\
\hline${ }^{14} \mathrm{C}$ & $2.56 \times 10^{-4}$ & & & & & $5.80 \times 10^{-5}$ \\
\hline${ }^{41} \mathrm{Ca}$ & & & $1.57 \times 10^{-1}$ & & & \\
\hline${ }^{40} \mathrm{~K}$ & $6.81 \times 10^{0}$ & & & & & \\
\hline${ }^{60} \mathrm{Co}$ & & & $4.19 \times 10^{-2}$ & & & \\
\hline${ }^{63} \mathrm{Ni}$ & $6.35 \times 10^{-5}$ & & & & & $6.75 \times 10^{-5}$ \\
\hline${ }^{90} \mathrm{Sr}$ & $2.76 \times 10^{-3}$ & $1.09 \times 10^{0}$ & $3.12 \times 10^{-2}$ & & $7.81 \times 10^{-7}$ & $5.76 \times 10^{-3}$ \\
\hline${ }^{99} \mathrm{Tc}$ & & & $4.80 \times 10^{-1}$ & & & $1.41 \times 10^{-1}$ \\
\hline${ }^{137} \mathrm{Cs}$ & $5.16 \times 10^{-3}$ & $1.70 \times 10^{0}$ & $2.58 \times 10^{-1}$ & $2.44 \times 10^{-1}$ & $1.87 \times 10^{-3}$ & $7.04 \times 10^{-3}$ \\
\hline${ }^{152} \mathrm{Eu}$ & $4.87 \times 10^{-4}$ & & $1.58 \times 10^{-1}$ & & & $1.12 \times 10^{-3}$ \\
\hline${ }^{154} \mathrm{Eu}$ & $1.30 \times 10^{-4}$ & & $4.38 \times 10^{-2}$ & & & $4.12 \times 10^{-4}$ \\
\hline${ }^{155} \mathrm{Eu}$ & $1.73 \times 10^{-6}$ & & & & & \\
\hline \multicolumn{7}{|l|}{${ }^{194} \mathrm{Os}$} \\
\hline \multicolumn{7}{|l|}{${ }^{210} \mathrm{~Pb}$} \\
\hline${ }^{226} \mathrm{Ra}$ & & & & & & $2.70 \times 10^{-4}$ \\
\hline${ }^{229} \mathrm{Th}$ & & & $7.19 \times 10^{-4}$ & & & \\
\hline${ }^{230} \mathrm{Th}$ & & & & & $2.31 \times 10^{-2}$ & \\
\hline${ }^{232} \mathrm{Th}$ & $3.43 \times 10^{1}$ & & $6.92 \times 10^{0}$ & $5.50 \times 10^{0}$ & $2.84 \times 10^{3}$ & $2.63 \times 10^{3}$ \\
\hline${ }^{232} U$ & & & & & & $1.93 \times 10^{-7}$ \\
\hline${ }^{233} \mathrm{U}$ & & & & & & $4.18 \times 10^{-2}$ \\
\hline${ }^{235} \mathrm{U}$ & & & & $1.36 \times 10^{2}$ & $1.97 \times 10^{1}$ & $1.60 \times 10^{1}$ \\
\hline${ }^{238} \mathrm{U}$ & $8.24 \times 10^{2}$ & & & $7.28 \times 10^{3}$ & $9.30 \times 10^{2}$ & $2.00 \times 10^{3}$ \\
\hline \multicolumn{7}{|l|}{${ }^{237} \mathrm{~Np}$} \\
\hline${ }^{238} \mathrm{Pu}$ & & & & & $2.49 \times 10^{-5}$ & $1.66 \times 10^{-6}$ \\
\hline${ }^{239} \mathrm{Pu}$ & $4.60 \times 10^{-4}$ & & & & & $7.30 \times 10^{-2}$ \\
\hline \multicolumn{7}{|l|}{${ }^{240} \mathrm{Pu}$} \\
\hline \multicolumn{7}{|l|}{${ }^{242} \mathrm{Pu}$} \\
\hline${ }^{241} \mathrm{Am}$ & & & & & & $1.19 \times 10^{-3}$ \\
\hline${ }^{243} \mathrm{Am}$ & & & & & & $5.68 \times 10^{-5}$ \\
\hline${ }^{244} \mathrm{Cm}$ & $1.75 \times 10^{-4}$ & & & & $3.71 \times 10^{-6}$ & $1.65 \times 10^{-5}$ \\
\hline${ }^{249} \mathrm{Cf}$ & & & & & & $1.15 \times 10^{-5}$ \\
\hline
\end{tabular}

${ }^{a}$ Inventory for 37 silos.

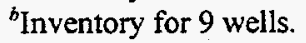

'Inventory for 53 wells-in-silos.
${ }^{d}$ Inventory for 2 wells.

'Inventory for 5 trenches.

Inventory for 24 silos. 
(Table 4.5 continued)

\begin{tabular}{|c|c|c|c|c|c|c|}
\hline Nuclide & $\begin{array}{c}15 \\
\text { Biological } \\
\text { trenches } \\
\text { (g/trench) } \\
\end{array}$ & $\begin{array}{c}16 \\
\text { Asbestos } \\
\text { silos }^{h} \\
\left(\mathrm{~g} / \text { silo }^{\prime}\right) \\
\end{array}$ & $\begin{array}{c}20 \\
\text { Biological }^{2} \\
\text { trenches } \\
\text { (g/trench) } \\
\end{array}$ & $\begin{array}{c}26 \\
\text { Tumulus If } \\
\text { (g/vault) } \\
\end{array}$ & $\begin{array}{c}27 \\
\text { Tumulus } \mathrm{I}^{k} \\
\text { (g/vault) }\end{array}$ & $\begin{array}{c}30 \\
\text { Low-range } \\
\text { silos' }^{\prime} \\
\text { (g/silo) }\end{array}$ \\
\hline${ }^{3} \mathrm{H}$ & & & & $7.15 \times 10^{-7}$ & $9.61 \times 10^{-7}$ & $9.52 \times 10^{-6}$ \\
\hline${ }^{14} \mathrm{C}$ & & $3.45 \times 10^{-5}$ & & $4.34 \times 10^{-6}$ & $2.95 \times 10^{-5}$ & $1.48 \times 10^{-4}$ \\
\hline \multicolumn{7}{|l|}{${ }^{4 i} \mathrm{Ca}$} \\
\hline \multicolumn{7}{|l|}{${ }^{40} \mathrm{~K}$} \\
\hline \multicolumn{7}{|l|}{${ }^{60} \mathrm{Co}$} \\
\hline${ }^{63} \mathrm{Ni}$ & & & & & $1.13 \times 10^{-5}$ & \\
\hline${ }^{90} \mathrm{Sr}$ & $2.23 \times 10^{-5}$ & $1.86 \times 10^{-5}$ & $2.16 \times 10^{-5}$ & $9.43 \times 10^{-5}$ & $3.03 \times 10^{-4}$ & $6.49 \times 10^{-4}$ \\
\hline${ }^{99} \mathrm{Tc}$ & & $7.33 \times 10^{-3}$ & & & $1.48 \times 10^{-2}$ & \\
\hline${ }^{137} \mathrm{Cs}$ & $8.23 \times 10^{-6}$ & $8.75 \times 10^{-5}$ & & $4.02 \times 10^{-4}$ & $9.76 \times 10^{-4}$ & $1.36 \times 10^{-3}$ \\
\hline${ }^{152} \mathrm{Eu}$ & & $5.25 \times 10^{-7}$ & & $2.85 \times 10^{-6}$ & $1.70 \times 10^{-5}$ & $2.75 \times 10^{-4}$ \\
\hline${ }^{154} \mathrm{Eu}$ & & & & $1.83 \times 10^{-6}$ & $1.44 \times 10^{-5}$ & $1.61 \times 10^{-4}$ \\
\hline${ }^{155} \mathrm{Eu}$ & & & & & & $5.76 \times 10^{-6}$ \\
\hline${ }^{194} \mathrm{Os}$ & & & & $1.40 \times 10^{-6}$ & & \\
\hline${ }^{210} \mathrm{~Pb}$ & & & & & $7.68 \times 10^{-3}$ & \\
\hline${ }^{226} \mathrm{Ra}$ & & & & & $5.91 \times 10^{-6}$ & $5.30 \times 10^{-6}$ \\
\hline${ }^{229} \mathrm{Th}$ & & & & & & $7.60 \times 10^{-6}$ \\
\hline${ }^{230} \mathrm{Th}$ & & & & & & $5.28 \times 10^{-4}$ \\
\hline${ }^{232} \mathrm{Th}$ & & $6.95 \times 10^{1}$ & & $2.08 \times 10^{1}$ & $1.94 \times 10^{1}$ & $3.28 \times 10^{2}$ \\
\hline \multicolumn{7}{|l|}{${ }^{232} \mathrm{U}$} \\
\hline${ }^{233} \mathrm{U}$ & & & & $1.97 \times 10^{-2}$ & $1.73 \times 10^{-2}$ & $6.05 \times 10^{-2}$ \\
\hline \multicolumn{7}{|l|}{${ }^{235} \mathrm{U}$} \\
\hline${ }^{238} \mathrm{U}$ & & $1.30 \times 10^{2}$ & & $4.74 \times 10^{1}$ & $7.80 \times 10^{i}$ & $8.16 \times 10^{2}$ \\
\hline${ }^{237} \mathrm{~Np}$ & & & & & $3.90 \times 10^{-2}$ & $1.58 \times 10^{-2}$ \\
\hline${ }^{238} \mathrm{Pu}$ & & & & $1.54 \times 10^{-7}$ & $1.02 \times 10^{-7}$ & $4.80 \times 10^{-7}$ \\
\hline${ }^{239} \mathrm{Pu}$ & & $1.81 \times 10^{-2}$ & & $6.28 \times 10^{-4}$ & $2.82 \times 10^{-3}$ & $3.67 \times 10^{-3}$ \\
\hline${ }^{240} \mathrm{Pu}$ & & & & & $1.02 \times 10^{-4}$ & \\
\hline${ }^{242} \mathrm{Pu}$ & & & & & & $2.49 \times 10^{-3}$ \\
\hline${ }^{241} \mathrm{Am}$ & & $4.51 \times 10^{-6}$ & & $1.66 \times 10^{-5}$ & $6.07 \times 10^{-5}$ & $6.58 \times 10^{-5}$ \\
\hline${ }^{243} \mathrm{Am}$ & & & & & $2.11 \times 10^{-4}$ & $7.66 \times 10^{-4}$ \\
\hline${ }^{244} \mathrm{Cm}$ & & & & $1.09 \times 10^{-6}$ & $1.11 \times 10^{-6}$ & $1.35 \times 10^{-6}$ \\
\hline${ }^{249} \mathrm{Cf}$ & & & & & $8.47 \times 10^{-6}$ & $2.35 \times 10^{-6}$ \\
\hline
\end{tabular}

Inventory for 4 trenches.

"Inventory for 11 silos.

Inventory for 220 vaults.

inventory for 2 trenches.

'Inventory for 291 vaults.

Inventory for 105 silos. 
Table 4.6. Radioactivity of radionuclides by zone and disposal unit for radionuclides disposed of in SWSA 6 after September 1988

\begin{tabular}{|c|c|c|c|c|c|c|}
\hline \multirow[b]{2}{*}{ Nuclide } & \multicolumn{6}{|c|}{ Radioactivity (Ci) } \\
\hline & $\begin{array}{c}\mathbf{3} \\
\text { High-range } \\
\text { silos }^{a}\end{array}$ & $\begin{array}{c}\mathbf{5} \\
\text { High-range } \\
\text { wells }^{b}\end{array}$ & $\begin{array}{c}\mathbf{5} \\
\text { High-range } \\
\text { wells-in-silos }\end{array}$ & $\begin{array}{c}7 \\
\text { Fissile } \\
\text { wells }\end{array}$ & $\begin{array}{c}8 \\
\text { Quadrex } \\
\text { trenches }\end{array}$ & $\begin{array}{c}8 \\
\text { Low-range } \\
\text { silos }^{f}\end{array}$ \\
\hline${ }^{3} \mathrm{H}$ & $1.00 \times 10^{1}$ & & & & & $1.69 \times 10^{1}$ \\
\hline${ }^{14} \mathrm{C}$ & $4.11 \times 10^{-2}$ & & & & & $6.21 \times 10^{-3}$ \\
\hline${ }^{41} \mathrm{Ca}$ & & & $6.80 \times 10^{-1}$ & & & \\
\hline${ }^{40} \mathrm{~K}$ & $1.74 \times 10^{-3}$ & & & & & \\
\hline${ }^{50} \mathrm{Co}$ & & & $2.32 \times 10^{3}$ & & & \\
\hline${ }^{63} \mathrm{Ni}$ & $1.41 \times 10^{-1}$ & & & & & $1.00 \times 10^{-1}$ \\
\hline${ }^{90} \mathrm{Sr}$ & $1.35 \times 10^{1}$ & $1.33 \times 10^{3}$ & $2.08 \times 10^{2}$ & & $4.25 \times 10^{-4}$ & $1.88 \times 10^{1}$ \\
\hline${ }^{99} \mathrm{Tc}$ & & & $4.00 \times 10^{-1}$ & & & $5.74 \times 10^{-2}$ \\
\hline${ }^{137} \mathrm{Cs}$ & $1.62 \times 10^{1}$ & $1.33 \times 10^{3}$ & $1.10 \times 10^{3}$ & $4.25 \times 10^{1}$ & $6.51 \times 10^{-1}$ & $1.47 \times 10^{1}$ \\
\hline${ }^{152} \mathrm{Eu}$ & $3.03 \times 10^{0}$ & & $1.34 \times 10^{3}$ & & & $4.67 \times 10^{0}$ \\
\hline${ }^{154} \mathrm{Eu}$ & $1.27 \times 10^{0}$ & & $5.79 \times 10^{2}$ & & & $2.67 \times 10^{0}$ \\
\hline${ }^{155} \mathrm{Eu}$ & $2.90 \times 10^{-2}$ & & & & & \\
\hline \multicolumn{7}{|l|}{${ }^{194} \mathrm{Os}$} \\
\hline \multicolumn{7}{|l|}{${ }^{210} \mathrm{~Pb}$} \\
\hline${ }^{226} \mathrm{Ra}$ & & & & & & $6.40 \times 10^{-3}$ \\
\hline${ }^{229} \mathrm{Th}$ & & & $7.50 \times 10^{-3}$ & & & \\
\hline${ }^{230} \mathrm{Th}$ & & $\therefore$ & & & $1.95 \times 10^{-3}$ & \\
\hline${ }^{232} \mathrm{Th}$ & $1.36 \times 10^{-4}$ & & $3.73 \times 10^{-5}$ & $1.21 \times 10^{-6}$ & $1.25 \times 10^{-3}$ & $6.94 \times 10^{-3}$ \\
\hline${ }^{232} \mathrm{U}$ & & & & & & $9.90 \times 10^{-5}$ \\
\hline${ }^{233} \mathrm{U}$ & & & & & & $9.71 \times 10^{-3}$ \\
\hline${ }^{235} \mathrm{U}$ & & & & $5.87 \times 10^{-4}$ & $1.70 \times 10^{-4}$ & $8.31 \times 10^{-4}$ \\
\hline${ }^{233} \mathrm{U}$ & $9.97 \times 10^{-3}$ & & & $4.89 \times 10^{-3}$ & $1.25 \times 10^{-3}$ & $1.61 \times 10^{-2}$ \\
\hline \multicolumn{7}{|l|}{${ }^{237} \mathrm{~Np}$} \\
\hline${ }^{238} \mathrm{Pu}$ & & & & & $1.70 \times 10^{-3}$ & $6.82 \times 10^{-4}$ \\
\hline${ }^{239} \mathrm{Pu}$ & $1.03 \times 10^{-3}$ & & & & & $1.09 \times 10^{-1}$ \\
\hline \multicolumn{7}{|l|}{${ }^{240} \mathrm{Pu}$} \\
\hline \multicolumn{7}{|l|}{${ }^{242} \mathrm{Pu}$} \\
\hline${ }^{241} \mathrm{Am}$ & & & & & & $9.80 \times 10^{-2}$ \\
\hline${ }^{243} \mathrm{Am}$ & & & & & & $2.63 \times 10^{-4}$ \\
\hline${ }^{244} \mathrm{Cm}$ & $5.11 \times 10^{-1}$ & & & & $1.20 \times 10^{-3}$ & $3.20 \times 10^{-2}$ \\
\hline${ }^{249} \mathrm{Cf}$ & & & & & & $1.13 \times 10^{-3}$ \\
\hline & $\begin{array}{l}\text { aventory for } 3 ? \\
\text { aventory for } 9 \\
\text { iventory for } 53\end{array}$ & is-in-silos. & & $\begin{array}{l}\text { nventory for } 2 \\
\text { nventory for } 5 \\
\text { aventory for } 2\end{array}$ & $\begin{array}{l}\text { Ils. } \\
\text { aches. } \\
\text { los. }\end{array}$ & \\
\hline
\end{tabular}


(Table 4.6 continued)

\begin{tabular}{|c|c|c|c|c|c|c|}
\hline \multirow[b]{2}{*}{ Nuclide } & \multicolumn{6}{|c|}{ Radioactivity (Ci) } \\
\hline & $\begin{array}{c}15 \\
\text { Biological } \\
\text { trenches }\end{array}$ & $\begin{array}{c}16 \\
\text { Asbestos } \\
\text { silos }^{h}\end{array}$ & $\begin{array}{c}20 \\
\text { Biological } \\
\text { trenches }\end{array}$ & $\begin{array}{c}26 \\
\text { Tumulus IY }\end{array}$ & $\begin{array}{c}27 \\
\text { Tumulus I }^{k}\end{array}$ & $\begin{array}{c}30 \\
\begin{array}{c}\text { Low-range } \\
\text { silos }^{\prime}\end{array}\end{array}$ \\
\hline${ }^{3} \mathrm{H}$ & & & & $1.51 \times 10^{0}$ & $2.70 \times 10^{0}$ & $9.65 \times 10^{0}$ \\
\hline${ }^{14} \mathrm{C}$ & & $1.69 \times 10^{-3}$ & & $4.24 \times 10^{-3}$ & $3.83 \times 10^{-2}$ & $6.92 \times 10^{-2}$ \\
\hline \multicolumn{7}{|l|}{${ }^{41} \mathrm{Ca}$} \\
\hline \multicolumn{7}{|l|}{${ }^{40} \mathrm{~K}$} \\
\hline \multicolumn{7}{|l|}{${ }^{60} \mathrm{Co}$} \\
\hline${ }^{63} \mathrm{Ni}$ & & & & & $2.02 \times 10^{-1}$ & \\
\hline${ }^{90} \mathrm{Sr}$ & $1.21 \times 10^{-2}$ & $2.78 \times 10^{-2}$ & $5.88 \times 10^{-3}$ & $2.81 \times 10^{0}$ & $1.20 \times 10^{3}$ & $9.26 \times 10^{0}$ \\
\hline${ }^{99} \mathrm{Tc}$ & & $1.37 \times 10^{-3}$ & & & $7.31 \times 10^{-2}=$ & \\
\hline${ }^{137} \mathrm{Cs}$ & $2.86 \times 10^{-3}$ & $8.37 \times 10^{-2}$ & & $7.66 \times 10^{0}$ & $2.47 \times 10^{1}$ & $1.25 \times 10^{1}$ \\
\hline${ }^{152} \mathrm{Eu}$ & & $1.00 \times 10^{-3}$ & & $1.08 \times 10^{-1}$ & $8.56 \times 10^{-1}$ & $5.00 \times 10^{0}$ \\
\hline${ }^{154} \mathrm{Eu}$ & & & & $1.08 \times 10^{-1}$ & $1.13 \times 10^{\circ}$ & $4.57 \times 10^{0}$ \\
\hline${ }^{1 s s} \mathrm{Eu}$ & & & & & & $2.81 \times 10^{-1}$ \\
\hline${ }^{194} \mathrm{Os}$ & & & & $9.52 \times 10^{-2}$ & & \\
\hline${ }^{210} \mathrm{~Pb}$ & & & & & $1.71 \times 10^{-2}$ & \\
\hline${ }^{226} \mathrm{Ra}$ & & & & & $1.70 \times 10^{-3}$ & $5.50 \times 10^{-4}$ \\
\hline${ }^{229} \mathrm{Th}$ & & & . & & & $1.70 \times 10^{-4}$ \\
\hline${ }^{230} \mathrm{Th}$ & & & & & & $1.17 \times 10^{-3}$ \\
\hline${ }^{232} \mathrm{Th}$ & & $8.41 \times 10^{-5}$ & & $5.02 \times 10^{-4}$ & $6.21 \times 10^{-4}$ & $3.79 \times 10^{-3}$ \\
\hline \multicolumn{7}{|l|}{${ }^{232} \mathrm{U}$} \\
\hline${ }^{233} \mathrm{U}$ & & & & $4.18 \times 10^{-2}$ & $4.87 \times 10^{-2}$ & $6.15 \times 10^{-2}$ \\
\hline \multicolumn{7}{|l|}{${ }^{235} \mathrm{U}$} \\
\hline${ }^{238} \mathrm{U}$ & & $4.80 \times 10^{-4}$ & & $3.49 \times 10^{-3}$ & $7.63 \times 10^{-3}$ & $2.88 \times 10^{-2}$ \\
\hline${ }^{237} \mathrm{~Np}$ & & & & & $8.00 \times 10^{-3}$ & $1.17 \times 10^{-3}$ \\
\hline${ }^{238} \mathrm{Pu}$ & & & & $5.77 \times 10^{-4}$ & $5.10 \times 10^{-4}$ & $8.61 \times 10^{-4}$ \\
\hline${ }^{239} \mathrm{Pu}$ & & $1.24 \times 10^{-2}$ & & $8.55 \times 10^{-3}$ & $5.10 \times 10^{-2}$ & $2.40 \times 10^{-2}$ \\
\hline${ }^{240} \mathrm{Pu}$ & & & & & $6.80 \times 10^{-3}$ & \\
\hline${ }^{242} \mathrm{Pu}$ & & & & & & $1.00 \times 10^{-3}$ \\
\hline${ }^{241} \mathrm{Am}$ & & $1.70 \times 10^{-4}$ & & $1.25 \times 10^{-2}$ & $6.06 \times 10^{-2}$ & $2.37 \times 10^{-2}$ \\
\hline${ }^{243} \mathrm{Am}$ & & & & & $1.22 \times 10^{-2}$ & $1.60 \times 10^{-2}$ \\
\hline${ }^{244} \mathrm{Cm}$ & & & & $1.94 \times 10^{-2}$ & $2.62 \times 10^{-2}$ & $1.15 \times 10^{-2}$ \\
\hline${ }^{249} \mathrm{Cf}$ & & & & & $1.01 \times 10^{-2}$ & $1.01 \times 10^{-3}$ \\
\hline
\end{tabular}

${ }^{8}$ Inventory for 4 trenches.

inventory for 220 vaults.

hinventory for 11 silos.

"Inventory for 291 vaults.

inventory for 2 trenches.

Inventory for 105 silos. 
Table 4.7. Concentration of radionuclides by zone and disposal unit for radionuclides disposed of in SWSA 6 after September 1988

\begin{tabular}{|c|c|c|c|c|c|c|}
\hline \multirow[b]{2}{*}{ Nuclide } & \multicolumn{6}{|c|}{ Concentration $(\mu \mathrm{Ci} / \mathrm{L})$} \\
\hline & $\begin{array}{c}3 \\
\text { High-range } \\
\text { silos }^{\alpha}\end{array}$ & $\begin{array}{c}5 \\
\substack{\text { High-range } \\
\text { wells }^{b}}\end{array}$ & $\begin{array}{c}\quad 5 \\
\text { High-range }_{\text {wells-in-silos }}^{c}\end{array}$ & $\begin{array}{c}\quad 7 \\
\text { Fissile } \\
\text { wells }^{d}\end{array}$ & $\begin{array}{c}8 \\
\text { Quadrex } \\
\text { trenches }^{e}\end{array}$ & $\begin{array}{c}8 \\
\text { Low-range } \\
\text { silos }^{\prime}\end{array}$ \\
\hline${ }^{3} \mathrm{H}$ & $2.33 \times 10^{1}$ & & & & & $6.08 \times 10^{1}$ \\
\hline${ }^{14} \mathrm{C}$ & $9.58 \times 10^{-2}$ & & & & & $2.23 \times 10^{-2}$ \\
\hline${ }^{41} \mathrm{Ca}$ & & & $5.69 \times 10^{1}$ & & & \\
\hline${ }^{40} \mathrm{~K}$ & $4.05 \times 10^{-3}$ & & & & & \\
\hline${ }^{60} \mathrm{Co}$ & & & $1.94 \times 10^{5}$ & & & \\
\hline${ }^{63} \mathrm{Ni}$ & $3.29 \times 10^{-1}$ & & & & & $3.60 \times 10^{-1}$ \\
\hline${ }^{90} \mathrm{Sr}$ & $3.15 \times 10^{1}$ & $2.38 \times 10^{5}$ & $1.74 \times 10^{4}$ & & $7.57 \times 10^{-3}$ & $6.76 \times 10^{1}$ \\
\hline${ }^{99} \mathrm{Tc}$ & & & $3.35 \times 10^{1}$ & & & $2.06 \times 10^{-1}$ \\
\hline${ }^{137} \mathrm{Cs}$ & $3.77 \times 10^{1}$ & $2.38 \times 10^{5}$ & $9.21 \times 10^{4}$ & $1.25 \times 10^{5}$ & $1.16 \times 10^{1}$ & $5.29 \times 10^{1}$ \\
\hline${ }^{152} \mathrm{Eu}$ & $7.07 \times 10^{0}$ & & $1.12 \times 10^{5}$ & & & $1.68 \times 10^{1}$ \\
\hline${ }^{154} \mathrm{Eu}$ & $2.95 \times 10^{0}$ & & $4.85 \times 10^{4}$ & & & $9.60 \times 10^{0}$ \\
\hline${ }^{155} \mathrm{Eu}$ & $6.76 \times 10^{-2}$ & & & & & \\
\hline \multicolumn{7}{|l|}{${ }^{194} \mathrm{Os}$} \\
\hline \multicolumn{7}{|l|}{${ }^{210} \mathrm{~Pb}$} \\
\hline${ }^{226} \mathrm{Ra}$ & & & & & & $2.30 \times 10^{-2}$ \\
\hline${ }^{229} \mathrm{Th}$ & & & $6.28 \times 10^{-1}$ & & & \\
\hline${ }^{230} \mathrm{Th}$ & & & & & $3.47 \times 10^{-2}$ & \\
\hline${ }^{232} \mathrm{Th}$ & $3.17 \times 10^{-4}$ & & $3.12 \times 10^{-3}$ & $3.56 \times 10^{-3}$ & $2.23 \times 10^{-2}$ & $2.50 \times 10^{-2}$ \\
\hline${ }^{232} \mathrm{U}$ & & & & & & $3.56 \times 10^{-4}$ \\
\hline${ }^{233} \mathrm{U}$ & & & & & & $3.49 \times 10^{-2}$ \\
\hline${ }^{235} \mathrm{U}$ & & & & $1.73 \times 10^{0}$ & $3.03 \times 10^{-3}$ & $2.99 \times 10^{-3}$ \\
\hline${ }^{238} \mathrm{U}$ & $2.32 \times 10^{-2}$ & & & $1.44 \times .10^{1}$ & $2.23 \times 10^{-2}$ & $5.79 \times 10^{-2}$ \\
\hline \multicolumn{7}{|l|}{${ }^{237} \mathrm{~Np}$} \\
\hline${ }^{238} \mathrm{Pu}$ & & & & & $3.03 \times 10^{-2}$ & $2.45 \times 10^{-3}$ \\
\hline${ }^{239} \mathrm{Pu}$ & $2.40 \times 10^{-3}$ & & & & & $3.92 \times 10^{-1}$ \\
\hline \multicolumn{7}{|l|}{${ }^{240} \mathrm{Pu}$} \\
\hline \multicolumn{7}{|l|}{${ }^{242} \mathrm{Pu}$} \\
\hline${ }^{241} \mathrm{Am}$ & & & & & & $3.52 \times 10^{-1}$ \\
\hline${ }^{243} \mathrm{Am}$ & & & & & & $9.46 \times 10^{-4}$ \\
\hline${ }^{244} \mathrm{Cm}$ & $1.19 \times 10^{0}$ & & & & $2.14 \times 10^{-2}$ & $1.15 \times 10^{-1}$ \\
\hline${ }^{249} \mathrm{Cf}$ & & & & & & $4.06 \times 10^{-3}$ \\
\hline & $\begin{array}{l}\text { aventory for } 3 \\
\text { nventory for } 9 \\
\text { aventory for } 5\end{array}$ & is-in-silos. & & $\begin{array}{l}\text { nventory for } \\
\text { nventory for } \\
\text { nventory for }\end{array}$ & $\begin{array}{l}\text { hes. } \\
\text { s. }\end{array}$ & \\
\hline
\end{tabular}


(Table 4.7 continued)

\begin{tabular}{|c|c|c|c|c|c|c|}
\hline \multirow[b]{2}{*}{ Nuclide } & \multicolumn{6}{|c|}{ Concentration $(\mu \mathrm{Ci} / \mathrm{L})$} \\
\hline & $\begin{array}{c}15 \\
\text { Biological } \\
\text { trenches }^{g}\end{array}$ & $\begin{array}{c}16 \\
\text { Asbestos } \\
\text { silos }^{h}\end{array}$ & $\begin{array}{c}20 \\
\text { Biological } \\
\text { trenches }\end{array}$ & $\begin{array}{c}26 \\
\text { Tumulus II }\end{array}$ & $\begin{array}{c}27 \\
\text { Tumulus } \mathrm{I}^{k}\end{array}$ & $\begin{array}{c}30 \\
\text { Low-range } \\
\text { silos }^{\prime}\end{array}$ \\
\hline${ }^{3} \mathrm{H}$ & & & & $2.54 \times 10^{0}$ & $3.63 \times 10^{\circ}$ & $8.81 \times 10^{0}$ \\
\hline${ }^{14} \mathrm{C}$ & & $1.14 \times 10^{-2}$ & & $7.12 \times 10^{-3}$ & $5.15 \times 10^{-2}$ & $6.32 \times 10^{-2}$ \\
\hline \multicolumn{7}{|l|}{${ }^{41} \mathrm{Ca}$} \\
\hline \multicolumn{7}{|l|}{${ }^{40} \mathrm{~K}$} \\
\hline \multicolumn{7}{|l|}{${ }^{80} \mathrm{Co}$} \\
\hline${ }^{63} \mathrm{Ni}$ & & & & & $2.72 \times 10^{-1}$ & \\
\hline${ }^{90} \mathrm{Sr}$ & $3.67 \times 10^{-2}$ & $1.88 \times 10^{-1}$ & $5.23 \times 10^{-2}$ & $4.72 \times 10^{\circ}$ & $1.61 \times 10^{1}$ & $8.46 \times 10^{\circ}$ \\
\hline${ }^{99} \mathrm{Tc}$ & & $9.25 \times 10^{-3}$ & & & $9.83 \times 10^{-2}$ & \\
\hline${ }^{137} \mathrm{Cs}$ & $8.67 \times 10^{-3}$ & $5.65 \times 10^{-1}$ & & $1.29 \times 10^{1}$ & $3.32 \times 10^{1}$ & $1.14 \times 10^{1}$ \\
\hline${ }^{152} \mathrm{Eu}$ & & $6.75 \times 10^{-3}$ & & $1.81 \times 10^{-1}$ & $1.15 \times 10^{\circ}$ & $4.57 \times 10^{0}$ \\
\hline${ }^{154} \mathrm{Eu}$ & & & & $1.81 \times 10^{-1}$ & $1.52 \times 10^{0}$ & $4.17 \times 10^{0}$ \\
\hline${ }^{155} \mathrm{Eu}$ & & & & & & $2.57 \times 10^{-1}$ \\
\hline${ }^{194} \mathrm{Os}$ & & & & $1.60 \times 10^{-1}$ & & \\
\hline${ }^{210} \mathrm{~Pb}$ & & & & & $2.30 \times 10^{-2}$ & \\
\hline${ }^{226} \mathrm{Ra}$ & & & & & $2.29 \times 10^{-3}$ & $5.02 \times 10^{-4}$ \\
\hline${ }^{229} \mathrm{Th}$ & & & & & & $1.55 \times 10^{-4}$ \\
\hline${ }^{230} \mathrm{Th}$ & & & & & & $1.07 \times 10^{-3}$ \\
\hline${ }^{232} \mathrm{Th}$ & & $5.68 \times 10^{-4}$ & & $8.43 \times 10^{-4}$ & $8.35 \times 10^{-4}$ & $3.46 \times 10^{-3}$ \\
\hline \multicolumn{7}{|l|}{${ }^{232} \mathrm{U}$} \\
\hline${ }^{233} \mathrm{U}$ & & & & $7.02 \times 10^{-2}$ & $6.55 \times 10^{-2}$ & $5.62 \times 10^{-2}$ \\
\hline \multicolumn{7}{|l|}{${ }^{235} \mathrm{U}$} \\
\hline${ }^{238} \mathrm{U}$ & & $3.24 \times 10^{-3}$ & & $5.86 \times 10^{-3}$ & $1.03 \times 10^{-2}$ & $2.63 \times 10^{-2}$ \\
\hline${ }^{237} \mathrm{~Np}$ & & & & & $1.08 \times 10^{-2}$ & $1.07 \times 10^{-3}$ \\
\hline${ }^{238} \mathrm{Pu}$ & & & & $9.69 \times 10^{-4}$ & $6.86 \times 10^{-4}$ & $7.86 \times 10^{-4}$ \\
\hline${ }^{239} \mathrm{Pu}$ & & $8.37 \times 10^{-2}$ & & $1.44 \times 10^{-2}$ & $6.86 \times 10^{-2}$ & $2.19 \times 10^{-2}$ \\
\hline${ }^{240} \mathrm{Pu}$ & & & & & $9.15 \times 10^{-3}$ & \\
\hline${ }^{242} \mathrm{Pu}$ & & & & & & $9.13 \times 10^{-4}$ \\
\hline${ }^{241} \mathrm{Am}$ & & $1.15 \times 10^{-3}$ & & $2.10 \times 10^{-2}$ & $8.15 \times 10^{-2}$ & $2.16 \times 10^{-2}$ \\
\hline${ }^{243} \mathrm{Am}$ & & & & & $1.64 \times 10^{-2}$ & $1.46 \times 10^{-2}$ \\
\hline${ }^{244} \mathrm{Cm}$ & & & & $3.26 \times 10^{-2}$ & $3.52 \times 10^{-2}$ & $1.05 \times 10^{-2}$ \\
\hline${ }^{249} \mathrm{Cf}$ & & & & & $1.36 \times 10^{-2}$ & $9.23 \times 10^{-4}$ \\
\hline & $\begin{array}{l}\text { entory for } \\
\text { entory for } \\
\text { entory for } 2\end{array}$ & tes. & & $\begin{array}{l}\text { aventory for } 22 \\
\text { nventory for } 29 \\
\text { aventory for } 10\end{array}$ & $\begin{array}{l}\text { aults. } \\
\text { aults. } \\
\text { ilos. }\end{array}$ & \\
\hline
\end{tabular}


Table 4.8. Simulated monthly seepage results used in SOURCE1 calculations for SWSA 6 disposal units

\begin{tabular}{|c|c|c|c|c|c|c|c|c|c|c|c|c|}
\hline \multirow{2}{*}{$\begin{array}{c}\text { Year of } \\
\text { simulation }\end{array}$} & \multicolumn{12}{|c|}{ Monthly seepage $(\mathrm{cm})$} \\
\hline & Jan & Feb & Mar & Apr & May & Jun & Jul & Aug & Sep & Oct & Nov & Dec \\
\hline \multicolumn{13}{|c|}{ Zone 25, IWMF } \\
\hline $1-11$ & 12.4 & 12.4 & 11.7 & 10.9 & 15.8 & 8.5 & 23.4 & 6.2 & 8.0 & 6.4 & 5.5 & 16.0 \\
\hline $12-21$ & 0.0 & 0.4 & 1.1 & 1.1 & 0.8 & 0.3 & 0.2 & 0.1 & 0.0 & 0.0 & 0.0 & 0.0 \\
\hline 22 & 0.9 & 1.2 & 2.0 & 1.7 & 1.8 & 0.6 & 0.3 & 0.2 & 0.2 & 0.2 & 0.1 & 0.1 \\
\hline 23 & 1.8 & 2.1 & 3.0 & 2.3 & 2.9 & 0.9 & 0.4 & 0.4 & 0.3 & 0.3 . & 0.3 & 0.2 \\
\hline 24 & 2.7 & 3.0 & 3.9 & 2.9 & 4.0 & 1.1 & 0.5 & 0.5 & 0.5 & 0.4 & 0.4 & 0.2 \\
\hline 25 & 3.6 & 3.8 & 4.8 & 3.5 & 5.0 & 1.4 & 0.7 & 0.7 & 0.6 & 0.6 & 0.5 & 0.3 \\
\hline 26 & 4.4 & 4.7 & 5.7 & 4.1 & 6.1 & 1.6 & 0.8 & 0.8 & 0.8 & 0.7 & 0.6 & 0.4 \\
\hline 27 & 5.3 & 5.5 & 6.6 & 4.6 & 7.1 & 1.9 & 0.9 & 1.0 & 0.9 & 0.9 & 0.7 & 0.5 \\
\hline 28 & 6.2 & 6.4 & 7.6 & 5.2 & 8.2 & 2.2 & 1.1 & 1.1 & 1.1 & 1.0 & 0.9 & .0 .5 \\
\hline 29 & 7.1 & 7.3 & 8.5 & 5.8 & 9.3 & 2.4 & 1.2 & 1.3 & 1.2 & 1.1 & 1.0 & 0.6 \\
\hline 30 & 8.0 & 8.1 & 9.4 & 6.4 & 10.3 & 2.7 & 1.3 & 1.4 & 1.4 & 1.3 & 1.1 & 0.7 \\
\hline 31 & 8.9 & 9.0 & 10.3 & 7.0 & 11.4 & 2.9 & 1.5 & 1.6 & 1.5 & 1.4 & 1.2 & 0.8 \\
\hline $32-9,999,999^{a}$ & 9.7 & 9.9 & 11.3 & 7.6 & 12.4 & 3.2 & 1.6 & 1.7 & 1.6 & 1.5 & 1.4 & 0.9 \\
\hline \multicolumn{13}{|c|}{ Zones 26 and 27, Tumulus II and Tumulus I } \\
\hline $1-5$ & 12.4 & 12.4 & 11.7 & 10.9 & 15.8 & 8.5 & 23.4 & 6.2 & 8.0 & 6.4 & 5.5 & 16.0 \\
\hline $6-15$ & 0.0 & 0.4 & 1.1 & 1.1 & 0.8 & 0.3 & 0.2 & 0.1 & 0.0 & 0.0 & 0.0 & 0.0 \\
\hline 16 & 0.9 & 1.2 & 2.0 & 1.7 & 1.8 & 0.6 & 0.3 & 0.2 & 0.2 & 0.2 & 0.1 & 0.1 \\
\hline 17 & 1.8 & 2.1 & 3.0 & 2.3 & 2.9 & 0.9 & 0.4 & 0.4 & 0.3 & 0.3 & 0.3 & 0.2 \\
\hline 18 & 2.7 & 3.0 & 3.9 & 2.9 & 4.0 & 1.1 & 0.5 & 0.5 & 0.5 & 0.4 & 0.4 & 0.2 \\
\hline 19 & 3.6 & 3.8 & 4.8 & 3.5 & 5.0 & 1.4 & 0.7 & 0.7 & 0.6 & 0.6 & 0.5 & 0.3 \\
\hline 20 & 4.4 & 4.7 & 5.7 & 4.1 & 6.1 & 1.6 & 0.8 & 0.8 & 0.8 & 0.7 & 0.6 & 0.4 \\
\hline 21 & 5.3 & 5.5 & 6.6 & 4.6 & 7.1 & 1.9 & 0.9 & 1.0 & 0.9 & 0.9 & 0.7 & 0.5 \\
\hline 22 & 6.2 & 6.4 & 7.6 & 5.2 & 8.2 & 2.2 & 1.1 & 1.1 & 1.1 & 1.0 & 0.9 & 0.5 \\
\hline 23 & 7.1 & 7.3 & 8.5 & 5.8 & 9.3 & 2.4 & 1.2 & 1.3 & 1.2 & 1.1 & 1.0 & 0.6 \\
\hline 24 & 8.0 & 8.1 & 9.4 & 6.4 & 10.3 & 2.7 & 1.3 & 1.4 & 1.4 & 1.3 & 1.1 & 0.7 \\
\hline 25 & 8.9 & 9.0 & 10.3 & 7.0 & 11.4 & 2.9 & 1.5 & 1.6 & 1.5 & 1.4 & 1.2 & 0.8 \\
\hline $26-9,999,999^{a}$ & 9.7 & 9.9 & 11.3 & 7.6 & 12.4 & 3.2 & 1.6 & 1.7 & 1.6 & 1.5 & 1.4 & 0.9 \\
\hline
\end{tabular}

${ }^{\circ}$ Since simulations for different radionuclides are of varying lengths, this number is set to a large value to ensure that the seepage values on this line will be used through the maximum year of the SOURCE1 simulations. 
Table 4.9. Simulated monthly seepage results used in SOURCE2 calculations for SWSA 6 disposal units

\begin{tabular}{|c|c|c|c|c|c|c|c|c|c|c|c|c|}
\hline \multirow{2}{*}{$\begin{array}{l}\text { Year of } \\
\text { simulation }\end{array}$} & \multicolumn{12}{|c|}{ Monthly seepage $(\mathrm{cm})$} \\
\hline & Jan & Feb & Mar & Apr & May & Jun & Jul & Aug & Sep & Oct & Nov & Dec \\
\hline \multicolumn{13}{|c|}{ Zone 3, high-range silos } \\
\hline $1-24$ & 14.6 & 15.3 & 16.0 & 12.9 & 16.6 & 5.9 & 11.1 & 7.4 & 2.2 & 3.7 & 1.8 & 11.2 \\
\hline $25-9,999,999^{a}$ & 15.2 & 15.5 & 17.7 & 11.7 & 19.7 & 4.4 & 1.6 & 1.8 & 1.8 & 1.5 & 1.4 & 0.9 \\
\hline \multicolumn{13}{|c|}{ Zone 5, high-range wells and high-range wells-in-silos } \\
\hline $1-24$ & 121.5 & 131.4 & 138.2 & 121.7 & 182.7 & 72.0 & 191.5 & 133.9 & 33.9 & 64.7 & 28.9 & 154.3 \\
\hline $25-9,999,999^{a}$ & 112.1 & 115.5 & 132.5 & 83.7 & 148.6 & 24.6 & 2.0 & 3.7 & 3.5 & 1.5 & 1.4 & 0.9 \\
\hline \multicolumn{13}{|c|}{ Zone 7, fissile wells } \\
\hline $1-23$ & 16.2 & 16.9 & 17.8 & 14.5 & 19.4 & 7.0 & 14.6 & 10.9 & 3.7 & 6.1 & 3.5 & 14.9 \\
\hline $24-9,999,999^{a}$ & 16.6 & 16.9 & 19.4 & 12.7 & 21.6 & 4.6 & 1.6 & 1.8 & 1.8 & 1.5 & 1.4 & 0.9 \\
\hline \multicolumn{13}{|c|}{ Zone 8, Quadrex trenches and low-range silos } \\
\hline $1-24$ & 13.4 & 13.9 & 14.6 & 11.6 & 13.3 & 3.8 & 5.9 & 2.2 & 1.4 & 1.4 & 0.5 & 6.7 \\
\hline $25-9,999,999^{\alpha}$ & 14.2 & 14.4 & 16.5 & 10.9 & 18.3 & 4.1 & 1.6 & 1.8 & 1.7 & 1.5 & 1.4 & 0.9 \\
\hline \multicolumn{13}{|c|}{ Zone 15, biological trenches } \\
\hline $1-23$ & 22.8 & 24.2 & 25.2 & 21.2 & 24.8 & 6.8 & 15.2 & 5.1 & 3.0 & 3.3 & 0.8 & 13.1 \\
\hline $24-9,999,999^{a}$ & 22.8 & 23.4 & 26.8 & 17.3 & 29.9 & 5.9 & 1.6 & 2.0 & 1.9 & 1.5 & 1.4 & 0.9 \\
\hline \multicolumn{13}{|c|}{ Zone 16, asbestos silos } \\
\hline $1-23$ & 12.9 & 13.4 & 14.1 & 11.2 & 12.7 & 3.7 & 5.5 & 2.0 & 1.3 & 1.4 & 0.5 & 6.4 \\
\hline $24-9,999,999^{a}$ & 13.8 & 14.0 & 16.0 & 10.6 & 17.8 & 4.0 & 1.6 & 1.8 & 1.7 & 1.5 & 1.4 & 0.9 \\
\hline \multicolumn{13}{|c|}{ Zone 20, biological trenches } \\
\hline $1-24$ & 22.4 & 23.8 & 24.8 & 20.8 & 24.4 & 6.7 & 14.8 & 5.0 & 3.0 & 3.3 & 0.8 & 12.9 \\
\hline $25-9,999,999^{a}$ & 22.5 & 23.0 & 26.4 & 17.1 & 29.4 & 5.9 & 1.6 & 2.0 & 1.9 & 1.5 & 1.4 & 0.9 \\
\hline \multicolumn{13}{|c|}{ Zone 30, low-range silos } \\
\hline $1-24$ & 8.8 & 9.0 & 9.4 & 7.1 & 7.7 & 2.3 & 1.5 & 0.7 & 0.6 & 0.5 & 0.4 & 3.6 \\
\hline $25-9,999,999^{a}$ & 10.0 & 10.1 & 11.5 & 7.8 & 12.8 & 3.3 & 1.6 & 1.7 & 1.7 & 1.5 & 1.4 & 0.9 \\
\hline
\end{tabular}

${ }^{a}$ Since simulations for different radionuclides are of varying lengths, this number is set to a large value to ensure that the seepage values on this line will be used through the maximum year of the SOURCE2 simulations. 


\subsubsection{Source Terms for Air Pathways Analysis}

For the air pathways analysis, source terms were calculated only for the volatile radionuclides, tritium $\left({ }^{3} \mathrm{H}\right)$ and ${ }^{14} \mathrm{C}$. All of the ${ }^{14} \mathrm{C}$ in the disposal unit is assumed to be in the volatile form of ${ }^{14} \mathrm{CO}_{2}$. This is an extremely conservative assumption since ${ }^{14} \mathrm{CO}_{2}$ would likely be a small fraction of the total ${ }^{14} \mathrm{C}$, most of which would probably exist in a nonvolatile form. Tritium and ${ }^{14} \mathrm{C}$ may be transported from the waste disposal unit to the soil surface through a variety of mechanisms, including diffusion, burrowing animals, plant root uptake, and desiccation cracks. When these volatile radionuclides reach the soil surface, they may become airborne and then transported via atmospheric dispersion to receptors located downwind of the waste disposal unit.

The diffusion mechanism was selected to estimate impacts of volatile radionuclide emissions from SWSA 6. Assumptions (detailed in Appendix $\mathrm{H}$ ) were incorporated into the calculation to provide an upper bound estimate of emissions that may occur due to diffusion. These assumptions conservatively bound any combination of subsurface pathway mechanism such as burrowing animals, desiccation cracks, or plant root uptake.

Source terms for ${ }^{3} \mathrm{H}$ and ${ }^{14} \mathrm{C}$, expressed in terms of diffusive flux from the soil to atmosphere, are listed in Appendix $\mathrm{H}$.

\subsubsection{Source Terms for Water Resources Protection Analysis}

The source terms for the all-pathways analysis, described in Sect. 4.1.1, include assessments of radionuclide source terms for the analysis of both surface water and groundwater. The source terms for the all-pathways analysis are the same as the source terms for water resources protection.

\subsubsection{Source Terms for Direct Intrusion}

The SOURCE1 program was used to generate source terms for intruder scenario calculations for the IWMF and for the long-lived actinides in all disposal units at SWSA 6. Because the actinides are relatively insoluble and are leached at very low rates, the remaining inventory at very long times (i.e., greater than 10,000 years) will be independent of the type of disposal unit used. To be conservative for the intruder scenarios, several of the input parameters for SOURCE1 were adjusted. The methodology for estimating radionuclide inventories for intruder scenarios is described in the following paragraphs.

Fig. 4.4 through Fig. 4.6 represent the estimates of inventory depletion from the IWMF used for evaluating intruder scenarios. These figures portray the fraction of initial inventory remaining in the IWMF at specific times (i.e., $100,300,500,1000,2000,5000$, and 10,000 years) as a function of waste $K_{d}$. These figures were generated using SOURCE1. The basic assumptions in these calculations were that (1) there was no transport by diffusion, (2) there was no radioactive decay, (3) the release of a radionuclide would not be limited by solubility, and (4) the rate of degradation of the disposal vaults was reduced as compared to the degradation rate used in the environmental transport calculations. 


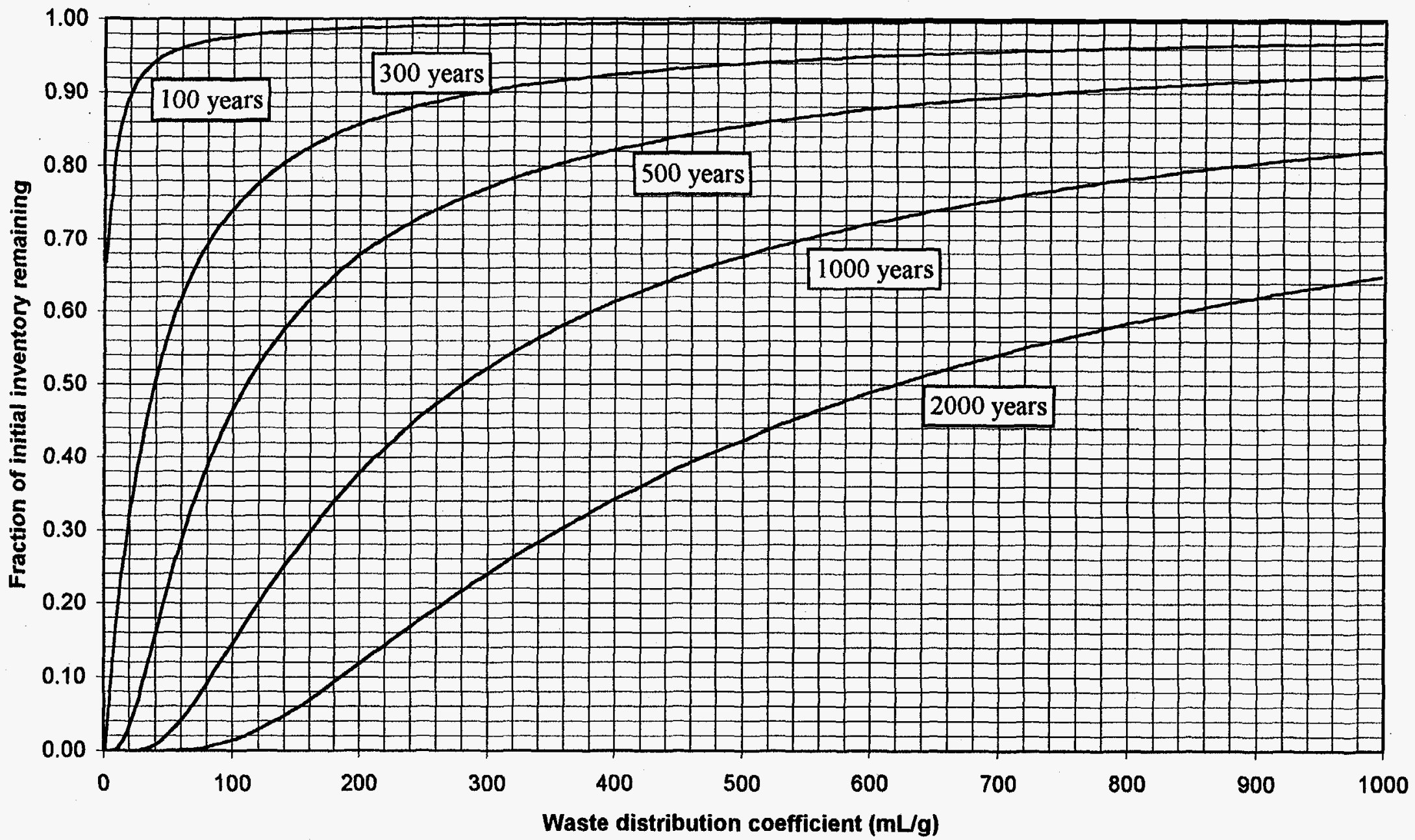

Fig. 4.4. Fraction of initial radionuclide inventory remaining in the IWMF as a function of $K_{d}$ for years $100,300,500,1000$, and 2000. (Assumes no diffusive transport, no radioactive decay, transport not solubility-limited, and reduced degradation of the unit.) 


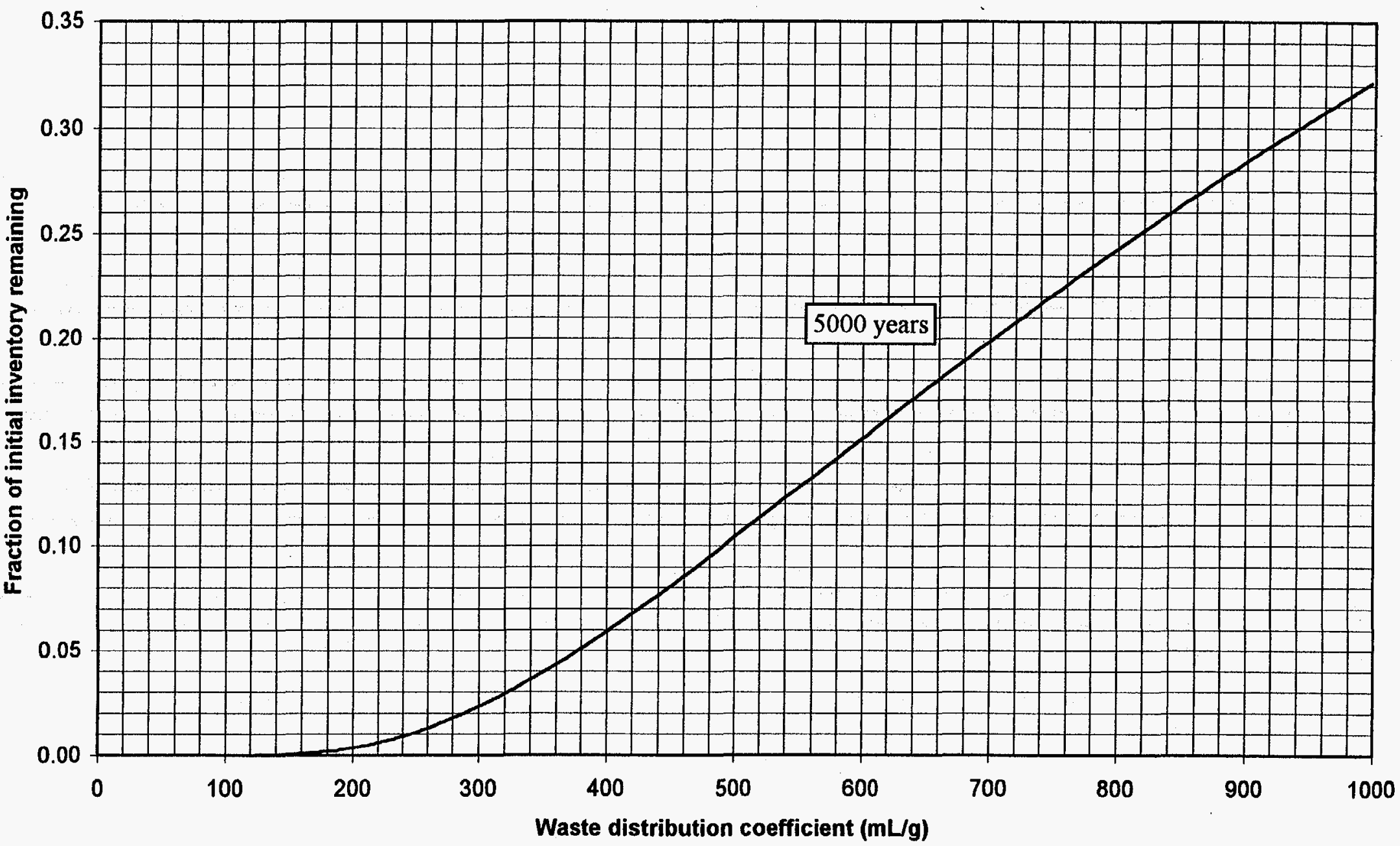

Fig. 4.5. Fraction of initial radionuclide inventory remaining in the IWMF as a function of $K_{d}$ for year 5000. (Assumes no diffusive transport, no radioactive decay, transport not solubility-limited, and reduced degradation of the unit.) 


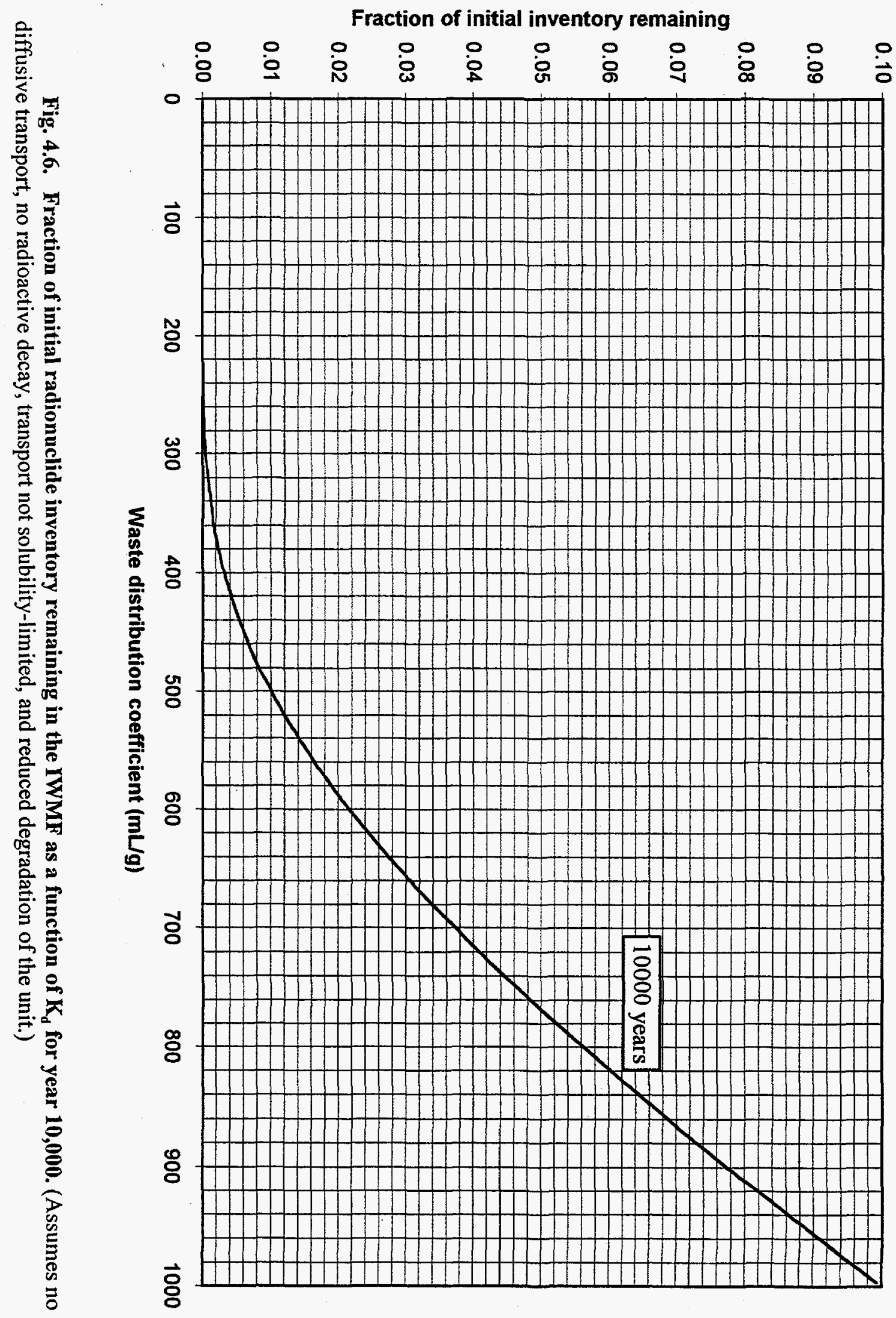


These assumptions imply that the release of radionuclides is by advection only and that this release is delayed when compared to releases used in the environmental transport calculations.

The parameters used in the concrete-degradation calculations in SOURCE1 were adjusted to delay disposal vault failure. Based on sensitivity analyses of the SOURCE1 program for the expected environmental conditions at SWSA 6, sulfate attack has been identified as the primary degradation mechanism for the disposal vaults (Icenhour and Tharp 1995). Hence, sulfate-attack input parameters (i.e., sulfate diffusion coefficient and sulfate concentration in groundwater) were adjusted within reasonable bounds to cause reduced, simulated degradation of the vaults. Groundwater data were used to evaluate a mean and standard deviation for the sulfate concentration (Jardine 1994). The concentration selected for the intruder inventory calculations was two standard deviations below the mean value. In addition, the concentration used was $23 \%$ lower than the value used for the environmental transport calculations. The sulfate diffusion coefficient was reduced by $25 \%$ from the value used for environmental transport calculations. With the exception of the sulfate parameters, all other input parameters that describe the IWMF are the same as those presented in Table 4.3 and Table 4.8. For the radionuclide-specific parameters, half-life was set to a large value $\left(10^{20}\right.$ years), and the diffusion coefficients were set to small values $\left(10^{-20} \mathrm{~m} / \mathrm{s}\right)$. A unit inventory ( $1 \mathrm{~g} /$ vault) was assumed, and the solubility limit was verified to not be exceeded. The combined effect of the adjustments in the sulfate attack parameters was that the lifetime of each of the disposal vaults was extended by about $65 \%$. The change in the simulated lifetimes of the disposal vaults is presented in Table 4.10.

Table 4.10. Year of vault failure from environmental transport calculations and from direct intrusion calculations

\begin{tabular}{lcc}
\hline Vault layer & Environmental transport & Direct intrusion \\
\hline Lower & 42 & 69 \\
Middle & 94 & 156 \\
Upper & 162 & 270 \\
\hline
\end{tabular}

Table 4.11 provides $K_{d}$ values for use in conjunction with Fig. 4.4 through Fig. 4.6. The values reported in this table are at the high end of the expected range of distribution coefficients for a given element. The $K_{d}$ values used for the environmental transport calculations are lower than those in Table 4.11 (see Table 4.4), and were selected to provide a conservative release rate. Recall that, for Fig. 4.4 through Fig. 4.6, the solubility limit for the radionuclide under consideration was assumed to not be exceeded. Therefore, even considering the conservative nature of Fig. 4.4 through Fig. 4.6 and Table 4.11, for nuclides limited by solubility the fraction of initial inventory obtained from the figures may be an underestimate. Table 6.9 lists solubility-limited concentrations for selected elements evaluated for the IWMF. 
Table 4.11. Waste distribution coefficient $\left(K_{d}\right)$ values for intruder scenario inventory estimation ${ }^{a}$

\begin{tabular}{lr|lr}
\hline Element & $\begin{array}{r}\text { Waste } K_{d} \\
(\mathrm{~mL} / \mathrm{g})\end{array}$ & Element & \multicolumn{1}{|c}{$\begin{array}{c}\text { Waste } K_{d} \\
(\mathrm{~mL} / \mathrm{g})\end{array}$} \\
\hline $\mathrm{Al}$ & $2,000,000$ & $\mathrm{Ni}$ & 64 \\
$\mathrm{Am}$ & 40,000 & $\mathrm{~Np}$ & 40,000 \\
$\mathrm{Be}$ & $31,000,000$ & $\mathrm{~Pa}$ & 40,000 \\
$\mathrm{Bi}$ & 48 & $\mathrm{~Pb}$ & 460 \\
$\mathrm{C}$ & 11 & $\mathrm{Pd}$ & $10,000,000$ \\
$\mathrm{Ca}$ & 46 & $\mathrm{Pu}$ & 40,000 \\
$\mathrm{Cd}$ & $1,000,000$ & $\mathrm{Ra}$ & 200 \\
$\mathrm{Cf}$ & 40,000 & $\mathrm{Rb}$ & 130 \\
$\mathrm{Cl}$ & 2 & $\mathrm{Se}$ & 220 \\
$\mathrm{Cm}$ & 40,000 & $\mathrm{Sm}$ & 600 \\
$\mathrm{Co}$ & $20,000,000$ & $\mathrm{Sn}$ & 120 \\
$\mathrm{Cs}$ & 200 & $\mathrm{Sr}$ & 90 \\
$\mathrm{Eu}$ & 600 & $\mathrm{Tc}$ & 13 \\
$\mathrm{H}$ & 2 & $\mathrm{Th}$ & 40,000 \\
$\mathrm{I}$ & 2 & $\mathrm{U}$ & 40,000 \\
$\mathrm{~K}$ & 40 & $\mathrm{Zr}$ & 500 \\
$\mathrm{Nb}$ & 240 & & \\
\hline
\end{tabular}

"Values shown are at the high end of the expected range of values for a given element.

To estimate disposal limits for the IWMF based on direct intrusion, concentration limits (as described in Sect. 6.3.1) are determined for the time of intrusion. Table 4.11 and Fig. 4.4 through Fig. 4.6 provide estimates of the inventory depletion during the period from disposal to intrusion. The inventory depletion obtained from the figure for a specific radionuclide at a specified time of intrusion (which is also called the mobilization and transport factor), and any radioactive decay and waste dilution adjustments, are then used to convert the concentration limit at the time of intrusion to a concentration limit at the time of disposal.

Sect. 6.3.1.3 provides a detailed description of the application of the mobilization and transport factors and tables of the factors used in the intruder calculations.

Fig. 4.7 was prepared for estimation of the actinide inventory remaining in disposal units at long times (i.e., up to $1,000,000$ years). Because actinides are highly insoluble and immobile, the predicted actinide inventory remaining at long times will be independent of the type of disposal technology used. As indicated in Table 4.11 and Fig. 4.7, the assumed actinide $K_{d}$ value used for intruder source term estimations was $40,000 \mathrm{~mL} / \mathrm{g}$. Fig. 4.7 was prepared by using the same basic assumptions that were used for Fig. 4.4 through Fig. 4.6. Solubility limits and solubility-limited release rates of actinide elements are presented in Table 6.9 . 


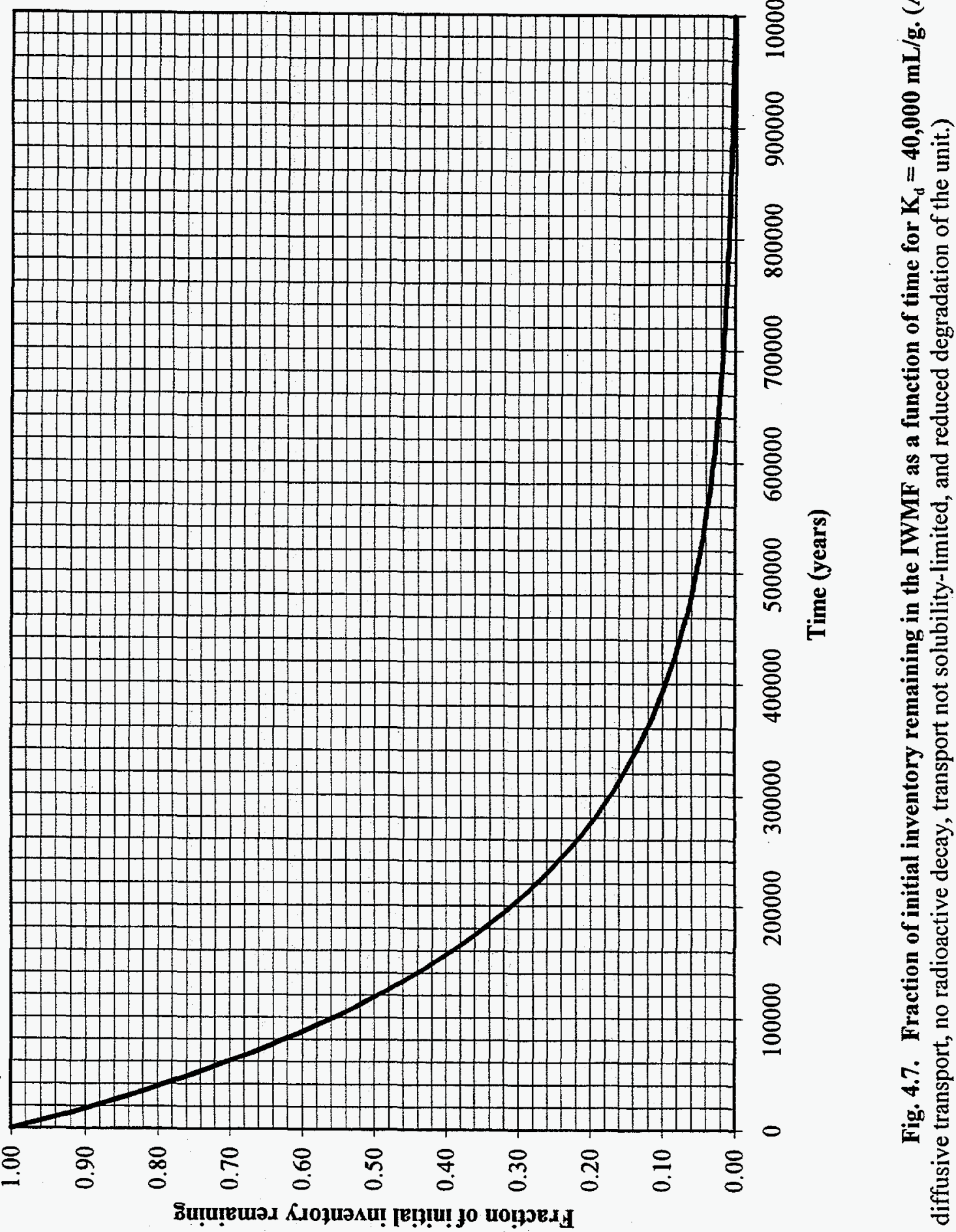




\subsection{PATHWAYS AND SCENARIOS}

This section describes the scenarios for environmental transport and exposure used in the analysis of the performance of SWSA 6 and the rationale for their selection. The scenarios identified for detailed analysis represent reasonable, yet conservative, representations of the transport of radionuclides in the environment and potential exposures of the public that could arise from LLW disposal. The selected scenarios are not intended to include all of the possible transport mechanisms or exposure pathways that could occur in the future, but are intended to include all of those transport mechanisms and exposure pathways that are needed to provide reasonable assurance that the facility meets the performance objectives of DOE O 5820.2A. The selected scenarios are considered to have a reasonable probability of occurrence and are analyzed deterministically to demonstrate compliance with the performance objectives from closed disposal units, and to provide limiting average concentrations and inventories for radionuclides in wastes currently disposed of and to be disposed of in the IWMF. Environmental transport scenarios are used for addressing the performance objectives for exposures to the general public and the protection of water resources. Direct intrusion scenarios, discussed in Sect. 6, are used to address the performance objective for the protection of inadvertent intruders. The description of each scenario includes the features, events, and mechanisms that lead to the transport of and exposure to radionuclides disposed of in the unit.

The scenarios for analyzing the performance of SWSA 6 consider three different time periods: (1) the operational period, (2) the institutional control period, and (3) the period after institutional control. The operational period is the time during which waste is actively emplaced and the facility is closed. During this period, ending in 2015, access to the facility by individuals is denied, and the facility is actively maintained. The institutional control period is prescribed to be the 100 years following the completion of facility closure, during which time the site is maintained and access by the public is denied. The post-institutional control period begins with the presumed loss of institutional control and extends for an indefinite period of time. Access to the facility by the public is assumed to occur, and no maintenance of the facility is assumed to occur during this time period.

Section 4.2.1 provides a discussion of the water transport pathway, which is considered in detail in this revised PA, and the biotic transport pathway, which is not considered in detail in this revised PA. This section includes the justification for not considering the biotic pathway and the major elements for analyzing the water pathway, which is addressed in greater detail in the analysis methodology in Sect. 4.3.1. The analysis of the water pathway considers both groundwater and surface water transport of radionuclides that could lead to potential off-site exposures. The discussion of the air transport pathway is presented in Sect. 4.2.2. The discussion of the air pathway identifies the major elements of the analysis methodology presented in detail in Sect. 4.3.2. The air pathways analysis is included as a subpart of the all-pathways analysis.

A detailed description of the exposure scenarios and pathways analyzed for the air and water transport pathways is provided in Sect. 4.3.2 and Sect. 4.3.1.3. The all-pathways analysis considers exposures from the direct consumption of contaminated water and the inhalation of contaminated air. Additional exposures from the consumption of contaminated water by dairy and beef cattle, which 
produce contaminated milk and meat, ingestion of fish from contaminated water, and external exposure while swimming in contaminated water are considered in this revised PA. This discussion includes the justification for not considering other potential exposure scenarios, which are not important in this revised PA.

\subsubsection{Pathways and Scenarios for All-Pathways Analysis}

The all-pathways analysis considers the transport of radionuclides from the disposed waste to locations beyond the site boundary and the potential exposures of individual members of the public at these locations. This analysis is based on the source terms for the all-pathways analysis discussed in Sects. 4.1.1 and 4.1.2. The potential pathways for the transport of radionuclides from SWSA 6 to offsite locations are by water, air, or biota (Stevens 1990). Once radionuclides have been transported to off-site locations, a member of the public could receive radiation doses by a variety of exposure scenarios and exposure pathways.

This section provides the description and rationale for the selection of the release and environmental transport scenarios. Radionuclides in waste can be released from a disposal unit once the capability of the disposal unit to isolate the wastes has been diminished by natural processes such as diffusion or by degradation of the disposal unit features (e.g., cover, pad, vaults, leachate collection system). The subsequent transport of contamination from the disposal unit to a point of exposure is influenced by physical, chemical, and biological processes. A comprehensive understanding of all of the natural processes likely to influence the transport of contamination from SWSA 6 to a point of exposure at some time in the future is not available. Nevertheless, as discussed in Sect. 3.1.5, the abundance of precipitation, the presence of shallow groundwater, and abundant surface water resources are primary environmental factors influencing the transport of contaminants from waste disposal units.

\subsubsection{Closure Scenario}

As noted above, the timetable of SWSA 6 site activities involves three main periodsoperation, institutional control, and post-institutional control-each with different hydrological circumstances and influences. The various components of the closure scenario, based on completion of the last waste disposal unit (IWMF), are as follows:

1. Operation

(a) Waste unit filling operations, 1988-2013, simulation years 1-25

(b) Construction of IWMF cap, 2 years, 2014-2015, simulation years 26-27

2. Institutional control

(a) Effective cap with grass cover, 10 years, 2016-2025, simulation years 28-37

(b) Linear increase in cap leakage, 10 years, 2026-2035, simulation years 38-47

(c) Leaking cap with mown grass, 80 years, 2036-2115, simulation years 48-127 


\section{Post-institutional control}

(a) Succession from grass to forest, 30 years, 2116-2145, simulation years 128-158

(b) Deciduous forest cover over site, after 2145, simulation years after 159

The first time period assessed in this analysis [1 $(a)$ above] accounts for the filling of various waste units in the period after September 1988, including the sequential construction and loading of the six-pad IWMF. Completion of pad loading with vaults is followed by the construction of a compacted soil cap. Compacted soil caps have already been placed over Tumulus I and II.

The 100-year institutional control period for the IWMF consists of a 10-year period with effective cap operation, followed by a second 10-year period of progressive cap failure represented by a linear increase in drainage through the cap (Table 4.14). The final cap condition is complete hydrologic failure associated with the development of preferential flow paths in the soil and seam separation in the geotextile layers, allowing soil water drainage to interact freely with the concrete vaults $[2(c)]$. Most waste zones do not have a cap, so a simpler hydrologic regime is used (see Sect. 4.3.1.1.4). The site is abandoned during the post-institutional control period, and the grass vegetation is gradually replaced by naturally invading forest vegetation (Sect. 3.2.4).

\subsubsection{Releases from Disposal Units to Environmental Pathways}

At SWSA 6, several types of disposal units are situated both above and below ground. The below-ground units include low-range silos, high-range silos, high-range wells, high-range wells-insilos, fissile wells, asbestos silos, Quadrex trenches, and biological trenches. The above-ground units include Tumulus I, Tumulus II, and the IWMF. Detailed descriptions of these units are given in Sect. 3.2.

The durability of concrete and bulk movement of water through concrete are significant elements in the performance model for the release of contamination from the various types of wells, silos, and tumuli, all of which rely on concrete for waste isolation. Leachate generated after water reaches the waste in the disposal units may be released through leaks in containment and by advection and diffusion through the concrete in the wells, silos, and tumuli. In this analysis, diffusion of contaminants through concrete is assumed to be the primary mechanism of release during the period of time that the concrete remains intact. When the concrete degrades and cracks are assumed to form, advection becomes the primary mechanism for release of radionuclides. Radionuclides released from below-ground silos and wells are assumed to enter soils and groundwater. Leachate moves out of the units by diffusion or through cracks in the concrete to the saturated or unsaturated zones. The performance of the various disposal units and the source term assumptions used in modeling are discussed in Sect. 4.1 and Appendixes B and C.

Releases of radionuclides from the Quadrex and biological trenches also occur mostly to groundwater and soils. These units do not include engineered barriers to inhibit flow and transport. Leachate is generated following precipitation events and is transported to surface water after being discharged through the shallow subsurface or groundwater. 
Radionuclides could be released from disposal units into the environment as a result of biotic intrusion into the waste (e.g., by burrowing animals or plant roots). Although biotic intrusion and its consequences have been studied, using largely generic models (see, e.g., McKenzie et al. 1982a, 1982b, 1983, 1984, 1985, and 1986; Kennedy, Caldwell, and McKenzie 1985), the magnitude of such releases from near-surface waste disposal units as compared to releases due to infiltrating water or inadvertent human intrusion has not been firmly established, nor has the importance of these releases for exposures of humans, especially for units constructed with engineered barriers. However, the following arguments can be made to indicate that radionuclide releases due to biotic intrusion would probably be relatively unimportant for SWSA 6 and, thus, need not be considered explicitly in the PA.

First, biotic intrusion could redistribute radionuclides throughout the soil column between the disposal unit and the ground surface, and the redistributed radionuclides in the soil column could be readily transported in water. However, during the time after disposal when the concrete barriers in the disposal unit remain intact, only a small fraction of the waste should be transportable into the soil column by biotic intrusion, primarily because extensive penetration of the intact barriers by burrowing animals and plant roots should not occur. Rather than modeling this phenomenon explicitly, the possibility that a small amount of waste could be transported in water as a result of biotic intrusion is taken into account implicitly by using pessimistic assumptions about the lifetime of the concrete barriers. Furthermore, in the absence of concrete barriers, transport of radionuclides that have been moved into the soil column by biotic intrusion would essentially be the same as transport of radionuclides that have remained in the disposal unit. Therefore, once the concrete barriers are assumed to have failed, biotic intrusion should not significantly enhance transport in water.

Second, biotic intrusion also could transport some radioactive waste to the ground surface. However, it is inconceivable that the amount of waste that could be brought to the surface would be more than a small fraction of the inventory in the disposal unit. Furthermore, the amount of waste deposited on the ground surface that could be suspended in the atmosphere and transported to off-site locations by the wind should be insignificant because of the extensive vegetative ground cover that would be established naturally at the disposal site and the generally high levels of soil moisture and low wind speeds on the ORR.

Finally, biotic transport of radioactive waste from the disposal unit to the ground surface at the site (e.g., due to intrusion by tree roots and production of above-ground biomass and litter) could, under some circumstances, increase exposures of inadvertent intruders. However, the scenarios for inadvertent intrusion evaluated in this revised PA (see Sect. 6) assume either that undisturbed waste in the disposal unit is accessed directly or that the concrete barriers are intact. Therefore, when exposure to undisturbed waste in the disposal units is assumed to occur, transport to the surface by biotic intrusion could not result in significant increases in exposure. An assumption that waste is accessed directly maximizes the assumed concentrations of radionuclides to which an inadvertent intruder would be exposed. If transport of waste into the overlying soil column or to the ground surface by biotic intrusion were taken into account, the primary effect would be to dilute the concentrations of radionuclides to which an intruder would be exposed when solid waste in the disposal unit is accessed directly. If the concrete barriers are assumed to be intact, the amount of waste that could be transported 
from the unit by biotic intrusion should be unimportant, as noted above. Therefore, it does not seem reasonable that biotic intrusion could increase radiation exposures by significant amounts for the scenarios for inadvertent intrusion evaluated in this revised PA. Based on these arguments, the effects of biotic intrusion on the mobilization and transport of radionuclides are not considered in the PA.

\subsubsection{Environmental Transport via Biotic Pathways}

Radionuclides could be transported to off-site locations by biotic pathways, particularly when the contamination has been transported to the ground surface or to surface water on the disposal site. Based on available information described below, however, transport of radionuclides by biotic pathways does not appear to be an important concern for waste disposal on the ORR.

Routine monitoring has indicated that contamination of wildlife, particularly deer and waterfowl, has occurred on the ORR, presumably as a result of past discharges of contaminated water or ongoing discharges to the land surface or surface streams from old radioactive waste disposal sites. However, the observed levels of contamination in wildlife have been low. For example, fewer than $2 \%$ of the deer killed on the ORR during 1991 contained measurable levels of radionuclides, and the estimated maximum annual dose equivalent to an individual from consumption of contaminated deer meat was only about 1 mrem (Kornegay et al. 1992). A similar dose estimate was obtained for consumption of contaminated geese or ducks.

Transport of contamination through biological uptake has led to contamination of deer, waterfowl, and fish on the ORR. Contamination of biota is primarily the result of historical discharges of contaminated water or existing discharges from historical disposal operations. Wildlife are routinely monitored, and the results are reported (Kornegay et al. 1992). The maximum annual dose attributable to the consumption of fish contaminated as a result of ORNL operations past and present is less than $0.8 \mathrm{mrem}$. The maximum annual dose attributable to the consumption of $310 \mathrm{~L}$ ( $82 \mathrm{gal}$ ) of contaminated milk is reported to be $0.2 \mathrm{mrem}$. The maximum annual dose from the consumption of two contaminated deer is reported to be $1 \mathrm{mrem}$. The maximum annual dose from the consumption of a contaminated goose and a contaminated duck was reported to be $1 \mathrm{mrem}$. These reported doses are associated with releases of radioactivity significantly exceeding the potential releases from SWSA 6 . In addition, fewer than $2 \%$ of the deer killed in 1991 were contaminated. As a result, the transport of contamination through biota to humans from SWSA 6 can reasonably be concluded to be less than that reported in Kornegay et al. (1992). Because the doses from consuming contaminated biota are much less than the performance objectives for LLW disposal, and the potential releases from SWSA 6 are certain to be less than releases from the ORR that have already occurred and are occurring, the transport of contamination by biota has not been considered in this revised PA.

\subsubsection{Exposure Pathways Resulting from Biotic Recycling}

Release of radionuclides due to biotic intrusion into the disposal unit and biotic transport of radionuclides from the disposal site to off-site locations in contaminated wildlife and vegetation are 
considered in Sects. 4.2.1.2 and 4.2.1.3, respectively. These release and transport mechanisms are judged to be unimportant on the ORR compared with release and transport of radionuclides in water and thus are not considered in this revised PA.

An additional possibility that should be considered is biotic recycling of radionuclides in contaminated areas, which could result in enhanced exposures of off-site individuals or inadvertent intruders at the same locations. Biotic recycling of radionuclides has been observed on the ORR; for example, see Garten, Gardner, and Dahlman (1980); Garten, Trabalka, and Bogle (1982); and Trabalka and Garten (1983).

A plausible scenario for biotic recycling is the following. Plants-including vegetables consumed by individuals as well as trees-could absorb water from a surface or shallow subsurface environment that has been contaminated by radionuclides released from the disposal unit to off site locations. Increased exposures then could occur through consumption of vegetables that had absorbed radionuclides from the contaminated water or through external exposure to contaminated leaves and other plant litter deposited on the ground surface. However, simple bounding analyses can be used to show that the vegetable and external exposure pathways resulting from root uptake of contaminated water from a particular source should not be important compared with direct consumption by humans of drinking water from a source at the same location.

For consumption of contaminated vegetables, consider a simple model which assumes that (1) all of the water in vegetables consumed by an individual comes from the contaminated source, (2) the concentrations of radionuclides in vegetable water are the same as the concentrations in the source, and (3) the vegetables consist entirely of water. All of these assumptions are conservative for any radionuclide and thus would bound actual exposures from consumption of contaminated vegetables. If an individual then is assumed to consume $90 \mathrm{~kg} / \mathrm{year}$ of contaminated vegetables (see Appendix $\mathrm{G}$ ) and, as described above, the vegetables are assumed to consist entirely of water with a density of $1000 \mathrm{~kg} / \mathrm{m}^{3}$, the volume of contaminated water consumed in the contaminated vegetables would be $90 \mathrm{~L}$. However, the same individual is assumed to consume $730 \mathrm{~L} /$ year of drinking water (see Appendix G) from the same location, an amount which is nearly an order of magnitude greater than the consumption in contaminated vegetables. Therefore, given the conservative assumptions in the model for intakes in vegetables, it is evident that uptake of radionuclides by vegetables from contaminated water should result in ingestion intakes which are only a small fraction of the ingestion intakes in drinking water itself.

For external exposure to contaminated leaves and other plant litter deposited on the ground surface, the conditions described above for contaminated vegetables, which again are conservative, are assumed. In addition, it is assumed that $2 \mathrm{~kg} / \mathrm{m}^{2}$ of vegetation, which is a typical areal density of vegetation consumed by humans (NRC 1977), is deposited on the ground surface annually. It is then easy to show that even if the concentrations of radionuclides in the contaminated litter deposited on the ground surface are depleted only by radioactive decay, the external dose from continuous exposure to the contaminated ground surface would be only a small fraction of the dose from ingestion of the contaminated water, which provided the source of the contamination in the plant litter. It also should 
be noted that the assumption of continuous external exposure at the location of the deposited litter is itself quite conservative.

The discussions in this section on biotic recycling of radionuclides in contaminated water and the previous discussions on biotic intrusion into waste disposal units and environmental transport in biota illustrate a general conclusion in PAs about the importance of these processes for disposal of LLW. Under some circumstances, biointrusion, transport of biota in the environment, and biotic recycling can be important processes for transporting radionuclides in disposed waste or the environment to the ground surface, into vegetation and animals, and to other locations in the environment; and radiation exposures of off-site individuals or inadvertent intruders could result from these processes. However, if exposures of off-site individuals or inadvertent intruders to radionuclides in the particular source media that are impacted by biointrusion, biotic transport, or biotic recycling (i.e., contaminated water, contaminated soil, or disposed waste itself) are presumed to occur, exposures to radionuclides in the source media themselves should always be considerably greater than exposures that would result from biointrusion, biotic transport, or biotic recycling. In other words, biotic processes normally would be of concern for LLW disposal only if exposure to the source media for the biotic processes were presumed not to occur.

\subsubsection{Environmental Transport Pathways}

As discussed elsewhere (Stevens 1990), the environmental transport pathways for radionuclides that could result in exposures of off-site individuals or inadvertent intruders include transport in air, surface water, groundwater (in the saturated and unsaturated zones), and biota. Available data for facilities on the ORR (Lee and Kocher 1990) and the discussions in Sect. 4.2.1.2 and 4.2.1.3 indicate that surface water and groundwater are the most important transport pathways that could result in doses to off-site members of the public.

The hydrologic framework for the ORR, discussed in Sect. 3.1.5, forms the basis for modeling the transport of radionuclides through the landscape. The model for transport of radionuclides in surface water and the unsaturated zone takes into account precipitation, infiltration, percolation, preferential flow adsorption, radioactive decay, matrix diffusion, storm hydrology, and stream flow (see Appendix D, Sect. D.3). Discharges from the shallow subsurface provide the flow in ephemeral creeks in SWSA 6 and contribute to the flow in perennial streams and WOL. The model includes dilution in the surface streams during transport. It also predicts flow of water through the unsaturated zone to surface water, recharge to the saturated zone, concentration and flux of leachate to surface water, and concentration and flux of leachate to the saturated zone.

The model for transport of radionuclides in the saturated zone includes recharge, advection, some diffusion, adsorption, and some dilution in groundwater. The model predicts flow of water in the saturated zone, concentration and flux of leachate in the groundwater, and concentration and arrival time of radionuclides at compliance points within SWSA 6 and at the boundary of SWSA 6, as described in Sect. 2. The model for groundwater transport includes radioactive decay from the time the 
contaminant enters the groundwater and a conservative estimate of radionuclide retardation during transport.

\subsubsection{Pathways for Air Analysis}

Once contamination has been released from the disposal units in the form of leachate, the most likely pathways for the transport of contamination are surface water and groundwater. Nevertheless, transport of contamination as a gas or vapor could occur from volatilization (e.g., of ${ }^{3} \mathrm{H}$ or ${ }^{14} \mathrm{C}$ ) or evaporation of leachate. Observations at radioactive waste disposal units over the last few decades suggest that emission of radionuclides to the atmosphere is not an important release mechanism on the ORR (ORNL 1994; Bechtel 1991b). Gaseous emissions at SWSA 6 are not routinely monitored. However, an ambient air monitoring station at WOD, just south of SWSA 6, takes biweekly samples of both airborne particulates and remote air monitoring stations at Norris Dam and Fort Loudoun Dam collect the same data. Table 4.12 summarizes the data collected at these locations in 1994 (LMES 1995). These data indicate little difference in the radionuclide concentrations in air adjacent to a radioactive waste disposal unit on the ORR as compared with the radionuclide concentrations at significant distances from the ORR.

Table 4.12. Mean radionuclide concentrations in air, 1994

\begin{tabular}{lcc}
\hline \multirow{2}{*}{ Nuclide } & \multicolumn{2}{c}{ Concentration $\left(10^{-15} \mu \mathrm{Ci} / \mathrm{mL}\right)$} \\
\cline { 2 - 3 } & White Oak Dam & Remote network \\
\hline${ }^{7} \mathrm{Be}$ & $2.85 \times 10^{1}$ & $8.31 \times 10^{1}$ \\
${ }^{60} \mathrm{Co}$ & $3.93 \times 10^{-2}$ & $2.08 \times 10^{-2}$ \\
Total Sr & $3.14 \times 10^{-2}$ & $2.31 \times 10^{-2}$ \\
${ }^{137} \mathrm{Cs}$ & $4.91 \times 10^{-2}$ & $1.68 \times 10^{-2}$ \\
${ }^{238} \mathrm{Pu}$ & $0.00 \times 10^{0}$ & $2.85 \times 10^{-4}$ \\
${ }^{239} \mathrm{Pu}$ & $0.00 \times 10^{0}$ & $2.85 \times 10^{-4}$ \\
${ }^{228} \mathrm{Th}$ & $4.32 \times 10^{-3}$ & $1.96 \times 10^{-3}$ \\
${ }^{230} \mathrm{Th}$ & $7.50 \times 10^{-3}$ & $2.17 \times 10^{-3}$ \\
${ }^{232} \mathrm{Th}$ & $5.30 \times 10^{-3}$ & $2.07 \times 10^{-3}$ \\
${ }^{234} \mathrm{U}$ & $4.32 \times 10^{-2}$ & $1.32 \times 10^{-2}$ \\
${ }^{235} \mathrm{U}$ & $1.77 \times 10^{-3}$ & $2.04 \times 10^{-3}$ \\
${ }^{238} \mathrm{U}$ & $2.26 \times 10^{-2}$ & $6.09 \times 10^{-3}$ \\
${ }^{241} \mathrm{Am}$ & $0.00 \times 10^{0}$ & $6.89 \times 10^{-4}$ \\
${ }^{244} \mathrm{Cm}$ & $0.00 \times 10^{0}$ & $1.88 \times 10^{-4}$ \\
\hline
\end{tabular}

Source: LMES 1995. 
Suspension of particulates by natural processes has not been identified as an important pathway for the transport of contamination. Observations in Oak Ridge and nearby areas clearly show that extensive vegetative ground cover is quickly established on any cleared lands and that reforestation of unattended lands naturally occurs within a few decades. Extensive vegetation and forestation at the disposal units, combined with the high annual rainfall and low average wind speeds in Oak Ridge, provide conditions that minimize the suspension of radionuclides in particulate form by natural processes. Even if some waste should become exposed due to natural erosion at the site, the amount of waste that could be suspended in the atmosphere by natural processes would be small.

Assuming that the airborne activity measured at the WOD monitoring station is indicative of releases from SWSA 6, the annual effective dose to an individual would be $<0.10 \mathrm{mrem}$. In reality, these data represent activity from all operations at ORNL, the Y-12 Plant, and ETTP, including stack releases and releases from 50 years of operations. Over the period of historical operations in Oak Ridge, millions of curies of radioactive materials have been placed in nearby disposal units and discharged directly to surface water. The data in Table 4.12 suggest that the release of radioactivity as gases and particulate matter in the atmosphere is not significant. Consequently, nonvolatile airborne releases of contamination are not considered in this revised PA. Volatiles are not measured at the ambient air monitoring station and need to be considered separately, and are discussed in Sect. 4.3.2.1. A detailed analysis is presented in Appendix $\mathrm{H}$.

\subsubsection{Pathways and Scenarios for Water Resources Protection Analysis}

The all-pathways analysis, described in Sect. 4.2.1, includes assessments of radionuclide contamination of both surface water and groundwater. The discussion in Sect. 4.2.1 describing the pathways and scenarios for the transport of radionuclides in groundwater and surface water addresses the water resources protection analysis.

\subsection{ANALYSIS METHODOLOGY}

This section presents the methods used to analyze the long-term performance of SWSA 6 . The methods selected address the scenarios for environmental transport and exposure identified in Sect. 4.2 and use the source terms developed in Sect. 4.1. The important pathways for the transport of contamination for SWSA 6 are by groundwater and surface water. The potential transport of volatile radionuclides by the air pathway is also considered by the use of a bounding analysis.

The methodology presented describes the approach for meeting the performance criteria presented in Sect. 2.5 for the all-pathways analysis, air pathways analysis, and water resources protection analysis. The models used in the analysis are described, and the interpretations of available data for input to the models are discussed. The composite of the models is used to calculate the transport of radionuclides from the source, through the shallow subsurface, to groundwater and surface water. The composite model also provides a comprehensive treatment of the water budget of the 
SWSA 6 site throughout the time period of assessment and incorporates the effect of the complex terrain on the movement of water across the landscape. The important physical and chemical mechanisms are identified, and the incorporation of these mechanisms into the composite model of site performance is discussed.

The exposure pathway modeling and methods for dose estimation are presented. Exposure pathway models for releases of radionuclides to surface water and groundwater and for releases to the atmosphere are described.

The potential exposure to individuals from the inhalation of volatile airborne radionuclides (i.e., ${ }^{3} \mathrm{H}$ and ${ }^{14} \mathrm{C}$ ) is an air pathway that was considered by performing a bounding analysis. The volatile radionuclides were assumed to diffuse from the waste disposal unit to the soil surface in vapor form, and then to mix with the ambient air and disperse downwind. Conservative parameter values were selected to ensure that the diffusion mechanism bounded other harder-to-quantify release mechanisms (e.g., soil desiccation and cracking, burrowing animals, and plant root uptake) (see Appendix $\mathrm{H}$ ). The analysis of radon emissions for the IWMF and for all of the closed disposal units is also provided.

\subsubsection{All-Pathways Analysis Methodology}

Demonstration of compliance with the performance objectives listed in Sect. 2.1 involves the estimation of environmental contaminant concentrations due to releases from existing disposal units within SWSA 6 for the pathways described in Sect. 4.2.1. In addition, this requires the determination of inventory limits for the IWMF, the only active disposal unit within SWSA 6, that would result in all of SWSA 6 being in compliance with the requirements listed in Sect. 2.5. Therefore, following development of the conceptual model for environmental transport in SWSA 6 is the development of numerical and analytical models to determine water concentrations of contaminants released from the closed disposal units at SWSA 6, and to calculate allowable concentrations in wastes suitable for disposal at the IWMF. The following sections describe the methods and approach used to model the transport of radionuclides through the environment at SWSA 6. The models are developed using the scenarios described in Sect. 4.2.1 and the source terms discussed in Sect. 4.1. The data used in model development are discussed, and any interpretations of these data are presented.

Several models are used for representation of nuclide transport at the SWSA 6 site, and the results from these models are linked in the simulation of various components of geochemical transport at the site (Fig. 4.8). The models are UTM, SOURCE1 and SOURCE2, PADSIM and HOLSIM, and MOC. UTM is used to determine the water budget of the SWSA 6 site. This hydrologic modeling is supplemented with terrain analysis for estimation of spatial variation in recharge to groundwater. The SOURCE1 and SOURCE2 programs calculate diffusive and advective fluxes of nuclides from waste disposal units (Sect. 4.1.1). Output from SOURCE1 and SOURCE2 gives the vertical and lateral component fluxes of nuclides into the vadose zone. These programs are described in Appendix B. The PADSIM and HOLSIM programs use annual time-step simulations of nuclide transport and account for nuclide-adsorption on the subsurface soil materials and radioactive decay of nuclides (Appendix D, Sect. D.3). The PADSIM and HOLSIM programs take results from the SOURCE1 and SOURCE2 


\section{Linkage of Contaminant Transport Models for Performance Assessment of SWSA 6}

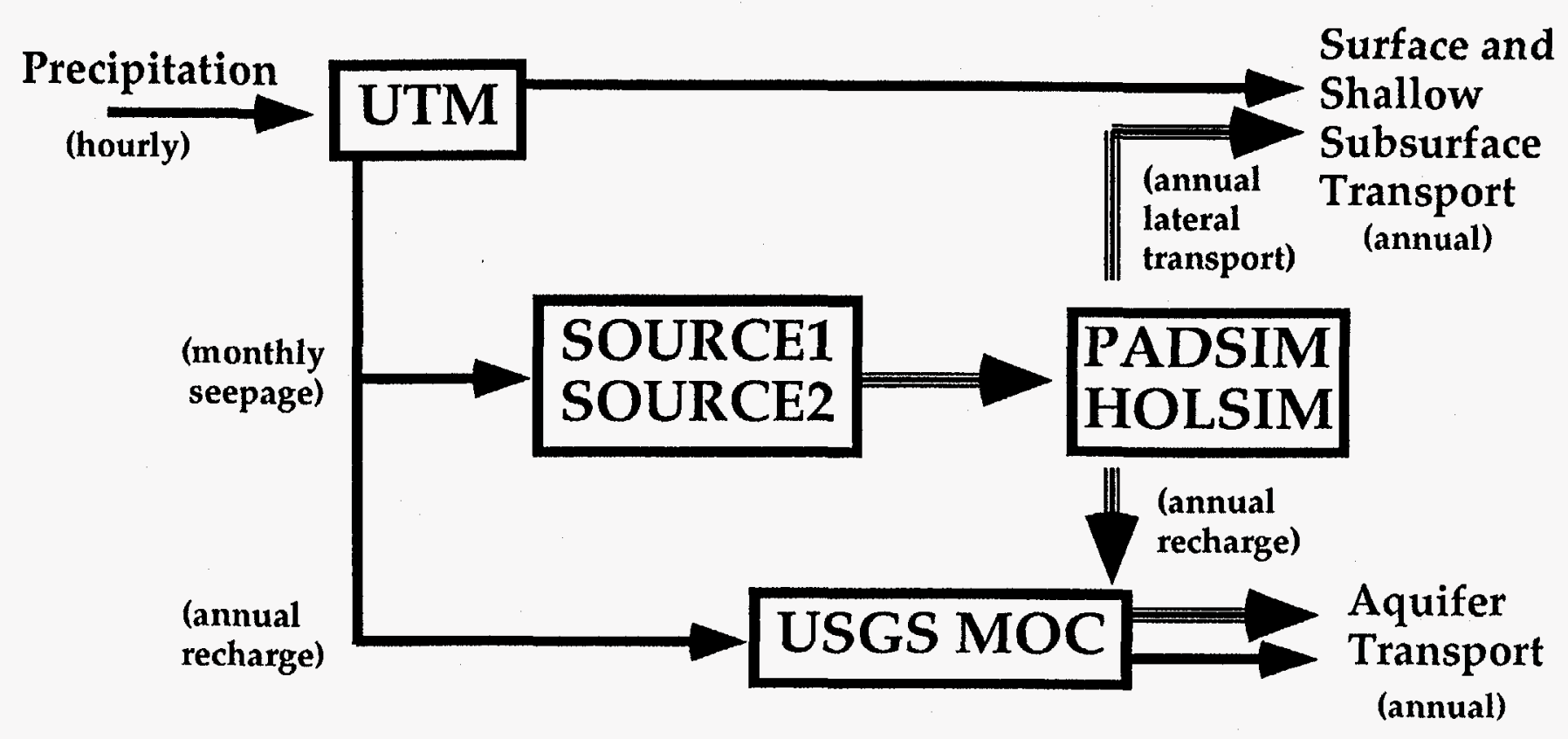

W Water and chemical transport from waste units

Water transport from the surroundings

Fig. 4.8. Linkage of simulation results from four simulation models for quantifying nuclide transport in the environment and surroundings of SWSA 6. 
models and estimate the recharge flux of nuclides to the groundwater model, MOC, and the flux of nuclides to surface waters through shallow subsurface transport. MOC determines nuclide concentrations at compliance points in the landscape and the flux of nuclides to surface water. The shallow subsurface and groundwater sources of surface discharge are added for dose assessment calculations. Both UTM and MOC are approved by the DOE code center.

\subsubsection{Site Hydrology}

The hydrology of the SWSA 6 site was characterized with terrain analysis and water budget modeling. Terrain analysis was conducted independently of the linkage of models (Fig. 4.8) and was used to determine spatial variation in recharge to the water table. These recharge values were used in the calibration of the groundwater flow model. Historical precipitation records for the Oak Ridge area were reviewed, and data representative of dry, average, and wet years were selected. Water budget estimates were made for these three contrasting climate years to examine a range of climatic conditions. For the dose assessment, the average climate conditions were used.

Characteristics of vegetation and soil conditions were input to UTM to represent the site during all phases of the closure scenario. Soil was modeled as disturbed and uncovered during the active operations period, covered by mown grass or other shallow-rooted vegetation during the period of institutional control, and forested during post-institutional control. The UTM calculations included variations in the integrity of compacted soil caps for the IWMF and tumulus waste zones, which were modeled with both functional and leaking caps.

The UTM calculations estimated total annual surface and shallow subsurface water flow in each disposal site for dry, wet, and average years for various closure time periods. In addition, recharge for each disposal unit in the same time periods was predicted. The climate conditions used by UTM included the effects of storms (hourly precipitation) for dry, wet, and average years.

Results from terrain analysis and site water budget modeling provided the hydrologic basis needed for site-specific nuclide transport calculations applicable to the SWSA 6 site. Terrain analysis gave the basis for determining elevated recharge in zones with greater durations of elevated soil water status. The spatially varying groundwater recharge results were input for calibration of the MOC groundwater flow model. In addition, water budget calculations provided monthly seepage values used in nuclide transport from the tumulus pads modeled with the SOURCEI code and from below-ground waste zones analyzed with the SOURCE2 code. Results from the hydrologic calculations are presented in the next two subsections.

\subsection{Terrain Analysis}

Surface and subsurface movement of water can be inferred from the dominant influence of topography on gravitational and convergent flow processes. The significance of topography for modeling surface hydrology has been described by Dawes and Short (1994). The soil wetness of any location is affected by the degree of convergence of flow, with convergent places (valleys) being 
wetter than divergent places (ridges). Terrain analysis methods have been verified in previous investigations of Walker Branch watershed and Center 7 Creek in Melton Valley on the ORR (Timmins, Huston, and Clapp 1989).

The steps involved in terrain analysis are (1) preparation of a suitable contour map for the proposed waste site and surroundings; (2) conversion of this vector map into a fine digital grid of elevation cells [i.e., a DEM (Schwartz et al. 1995)]; and (3) determination of the spatial distribution of a topographic index which represents surface water flow convergence over the landform using slope and topography (Appendix D, Sect. D.3).

A DEM with a $0.1-\mathrm{ft}$ vertical resolution and a $10-\mathrm{ft}$ horizontal resolution was derived. The nominal 0.1-ft vertical resolution is needed for slope calculations. Spurious features (dams in streams and ponds in the landscape) were removed from the raw DEM as appropriate, and the terrain model was smoothed through adjustment of about 3.3\% of the digital elevations (Fig. 4.9).

Hydrologic analysis of the DEM produced a map and a frequency distribution of the Beven and Kirkby (1979) topographic index, $\ln (a / \tan \beta)$, where $a$ is the upslope area above a unit length of contour with average slope angle $\beta$ (Fig. 4.10). The histogram for the SWSA 6 site shows a characteristic log normal distribution indicating large areas with low soil wetness (uplands, ridges) and relatively few areas of wetlands. The results of the analysis show that the DEM was created with sufficient information to capture the flow pathways present in the terrain map (Fig. 4.9). This analysis was used to derive spatially varying estimates of recharge for use in groundwater modeling. Areas with greater wetness were given higher recharge values.

\subsection{Results of Terrain Analysis}

The topographic index results from the digital terrain analysis were grouped (Fig. 4.10) to identify stream channels with ephemeral flow (shown in black) and some areas (shown in light gray) where water flow through ephemeral wetlands is expected. Most (87\%) of the SWSA 6 site and its surroundings (dark grey areas) contributes water flow to ephemeral wetlands and stream channels. Recharge estimates for the three differing wetness conditions were estimated from UTM simulations and recharge values determined from hydrologic modeling for the ORR (Sect. 4.3.1.2). Locations with greater ephemeral wetness were given higher recharge values. The annual recharge estimates in Table 4.13 were provided as spatial input (Fig. 4.11) for groundwater modeling of the SWSA 6 site with the MOC model. The $\ln (\alpha / \tan \beta)$ values are the topographic index ranges from Fig. 4.10 associated with the three landscape components, as discussed in Sect. 4.3.1.1.4.

\subsection{Water Budget Modeling}

The UTM (Appendix D, Sect. D.2) was used to determine monthly water budget values for the SWSA 6 site. The flow diagram for the model (Fig. 4.12) shows the input of precipitation passing through a series of hydrologic processes generating outflow and vapor loss. The basic concepts of the UTM involve four equations and four unknowns that are solved at each time step (Fig. 4.13). The 


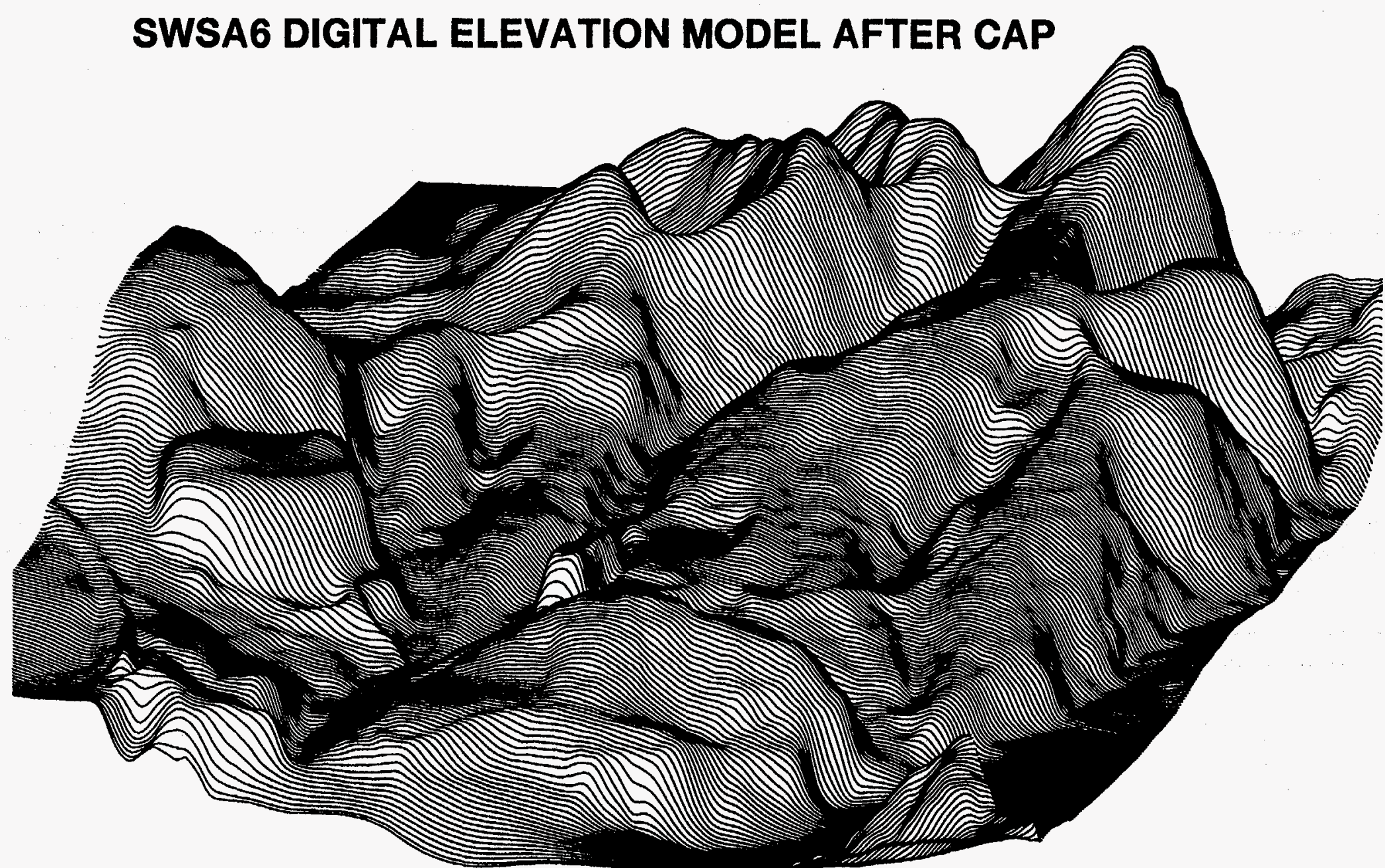

Fig. 4.9. The landscape surface generated from the digital elevation model of the SWSA 6 site. Vertical exaggeration is $10: 1$. 

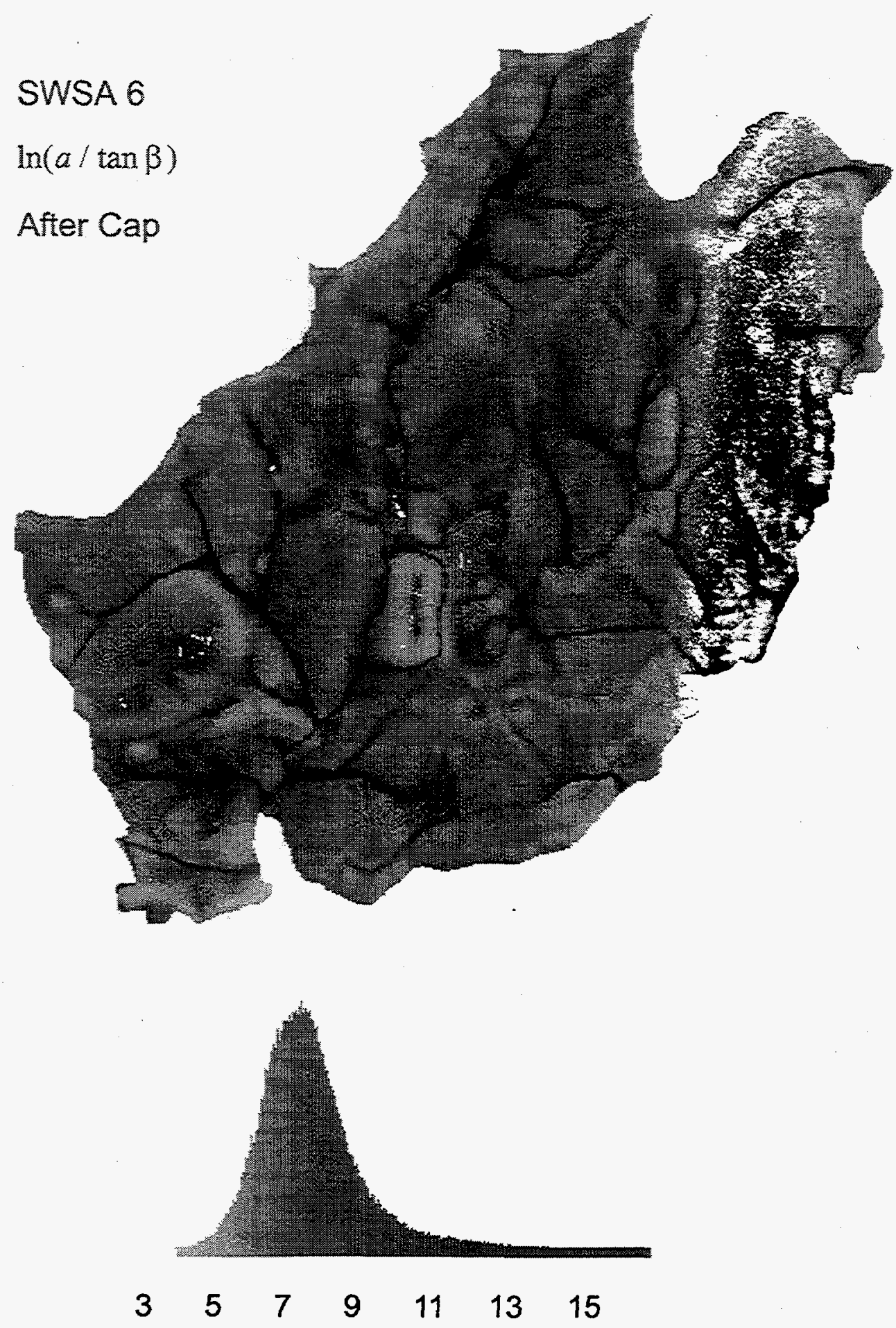

Fig. 4.10. Map and frequency distribution of topographic index for the SWSA 6 site used for estimation of spatial variation in groundwater recharge. 


\section{Surface Recharge Map for the SWSA 6 Groundwater Model}

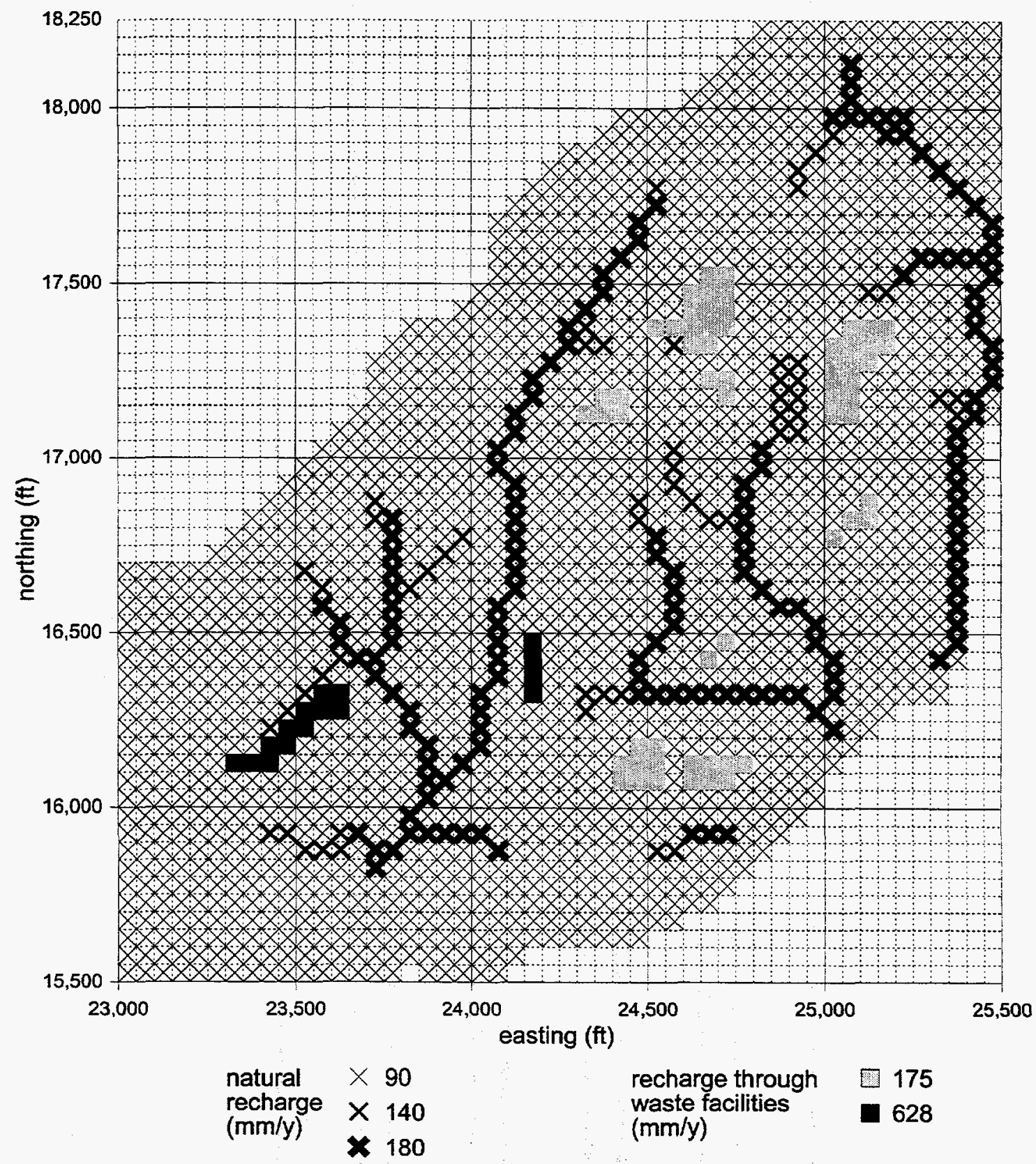

Fig. 4.11. Annual recharge rates used in the groundwater modeling of SWSA 6. 
Table 4.13. Estimates of diffuse recharge to the groundwater system

\begin{tabular}{lccl}
\hline Land unit & $\begin{array}{c}\text { Recharge } \\
(\mathrm{mm} / \mathrm{year})\end{array}$ & $\begin{array}{c}\text { Proportional area } \\
(\%)\end{array}$ & $\ln (\alpha / \tan \beta)$ \\
\hline Stream channels & 180 & 2.4 & $>11.0$ \\
Ephemeral wetlands & 140 & 10.6 & $9.0-11.0$ \\
Remaining landscape & 90 & 87.0 & $<9.0$ \\
\hline
\end{tabular}

Penman-Monteith equation (Eq. 4.1) is used for calculation of water vapor loss from the vegetated surface (the "big-leaf" approach). The vapor flux is a function of surface resistance. A relationship between surface resistance and surface water potential (Eq. 4.2) is provided as input for the vegetation of interest. The flux of water from the soil to the evaporating surface is a function of the water potential of the vegetated surface (Eq. 4.3). This flux is calculated with Darcy flow (Fickian conductivity-water potential gradient) equations for the soil and plant components. The fourth equation (Eq. 4.4) is the assumption that the flux of vapor from the evaporating surface is equal to the flux of liquid water to the surface (steady-state assumption). The four unknowns-vapor flux, surface resistance, surface water potential, and liquid flux-are determined for a given set of hourly weather conditions. After completion of these calculations, drainage through the soil profile layers is calculated with one-dimensional Darcy flow calculations.

The UTM simulations provide surface runoff, drainage, and lateral flow of water in response to hourly inputs of precipitation. The model accounts for the nonlinear flow dynamics using variable time steps (0.5-60 min.) as needed. These flow values are summed to give monthly totals that are used in the SOURCE1 and SOURCE2 simulations of chemical leaching from disposal units and in the groundwater transport simulations with MOC (Fig. 4.8).

The PA calculations are carried out for a minimum of 1000 years for each nuclide. Each simulation for the IWMF was divided into three main periods to reflect changing conditions at the SWSA 6 site. These time periods consist of the active use of SWSA 6 for radionuclide disposal, an institutional control period of 100 years, and a post-institutional-control period that extends for 1000 years, or until a maximum annual radionuclide flux is obtained in both the vertical and lateral flow calculations. Water budget calculations are not used for the period of pad loading and the two years of cap construction for Tumulus I and II and the IWMF. The vaults for these waste zones are exposed to precipitation, and monthly rainfall is used as seepage values for SOURCE1 calculations. The vegetation for the institutional control period is mown grass with a leaf area index of 4.9 and high infiltration rates for the topsoil. The same leaf area index and infiltration properties are used for the post-institutional-control period even though the vegetation is projected to change from grass to deciduous forest by natural succession (Sect. 3.2.4). 


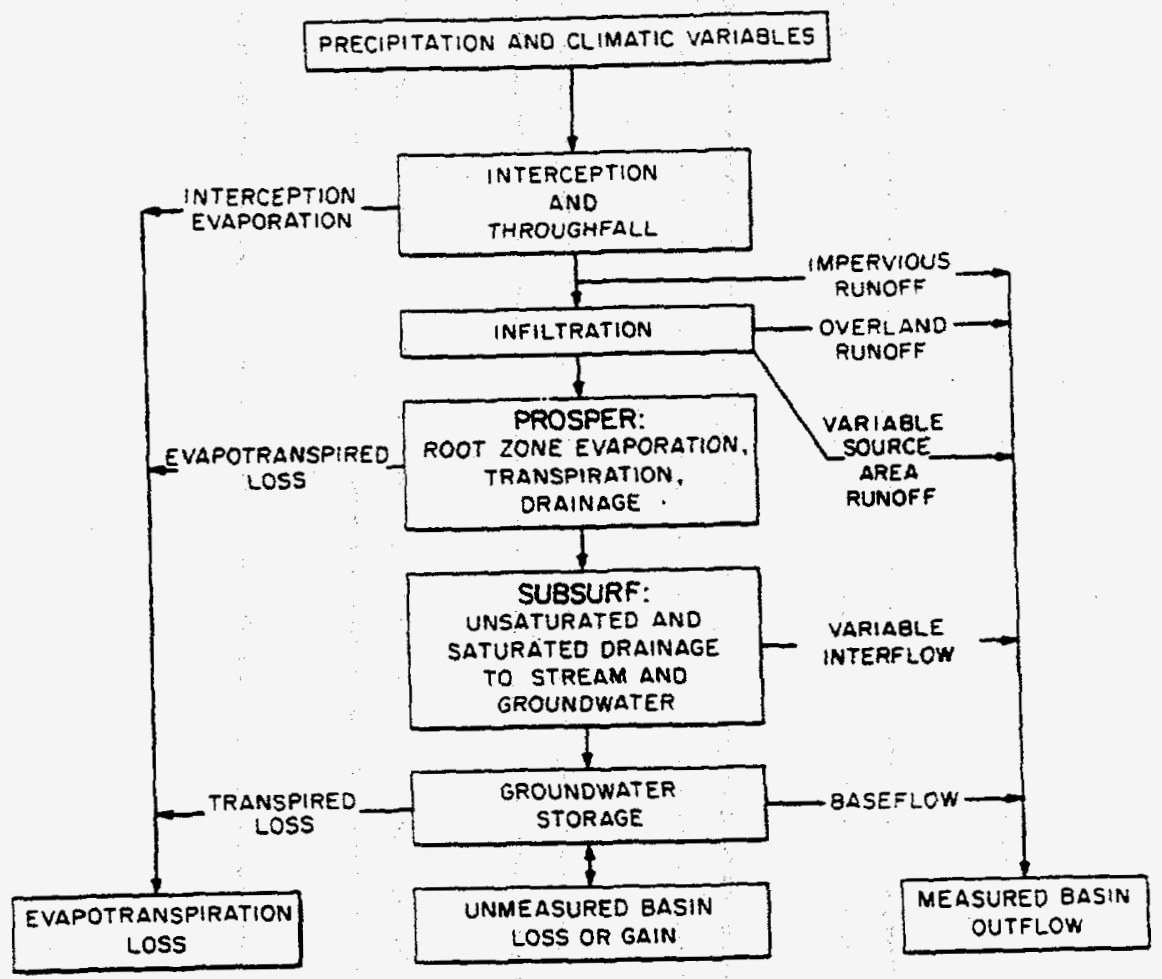

Fig. 4.12. Flow chart of the major components of hydrologic simulation with the Unified Transport Model. The PROSPER component estimated the seepage used by the SOURCE1 model. 


\begin{tabular}{|c|c|c|}
\hline Location & Properties & Structural Equations \\
\hline Atmosphere & $\begin{array}{l}\text { Environmental conditions: } \\
\text { Solar radiation } \\
\text { Precipitation } \\
\text { Dew point temperature } \\
\text { Max. and min. air temperature } \\
\text { Average wind speed }\end{array}$ & $\begin{array}{l}\text { Vapor flux from surface } \\
\qquad F_{v}=f\left(R_{x}\right) \\
\text { Calculation uses combined } \\
\text { energy balance-aerodynamic } \\
\text { method }\end{array}$ \\
\hline $\begin{array}{l}\text { Boundary } \\
\text { Layer }\end{array}$ & $\begin{array}{l}\text { Resistance to vapor and heat } \\
\text { flow }\end{array}$ & \\
\hline $\begin{array}{l}\text { Evaporating } \\
\text { Surface }\end{array}$ & $\begin{array}{l}\text { Resistance to vapor flow }\left(R_{x}\right) \\
\text { Surface water potential }(\varphi)\end{array}$ & $\begin{array}{l}\text { Surface characteristic } \\
\qquad R_{x}=f(\psi)\end{array}$ \\
\hline $\begin{array}{l}\text { Plant and } \\
\text { Soil } \\
\text { System }\end{array}$ & $\begin{array}{l}\text { Plant and root resistances } \\
\text { Root distribution in upper two } \\
\text { soil layers } \\
\text { Soil water characteristic for } \\
\quad \text { each soil layer } \\
\text { Hydraulic conductivity vs water } \\
\text { content for each soil } \\
\text { layer } \\
\text { Soil layer thicknesses }\end{array}$ & $\begin{array}{l}\text { Liquid flux to surface } \\
\qquad \mathrm{F}_{\mathrm{w}}=\mathrm{f}(\psi) \\
\text { Calculation uses electrical } \\
\text { network equations }\end{array}$ \\
\hline $\begin{array}{l}\text { Whole } \\
\text { System }\end{array}$ & Steady state & $\begin{array}{l}\text { Vapor flux }=\text { Liquid flux } \\
F_{v}=F_{w}\end{array}$ \\
\hline
\end{tabular}

Fig. 4.13. The properties and structural equations of the PROSPER component of the Unified Transport Model used for calculation of evapotranspiration and soil water drainage.

\subsection{Results of Water Budget Modeling}

The site water budgets are used to estimate the quantity of seepage water interacting with above- and below-ground waste units during all phases of SWSA 6 operations and closure. The UTM provides hydrologic estimates of soil water drainage, lateral flow, and surface runoff using inputs of hourly precipitation and daily weather conditions for three selected years, as well as representative soil and vegetation characteristics (Appendix D, Sect. D.2). Data from the ORR for three years having high $(1895 \mathrm{~mm})$, average $(1372 \mathrm{~mm})$, and low $(933 \mathrm{~mm})$ annual precipitation are used to compare a range of simulated hydrologic conditions. In some cases monthly precipitation values for a wet year are less 
than those for the dry year, since actual weather data are used. This use of actual weather data in the calculations preserves the natural relationships between meteorological variables needed for calculation of evapotranspiration. The simulated monthly water flow values in Table 4.14 are shown on a per unit area basis $\left(\mathrm{mm}^{3} / \mathrm{mm}^{2}\right)$. These results (Table 4.14) show seasonal differences with reduced drainage and lateral flow occurring in the July-November period, when evapotranspiration is high or soils are storing water. Lateral flow increases as annual precipitation increases from a dry to a wet year. The UTM drainage and lateral flow results for the average year are summed and used to determine seepage flow for use in the SOURCE models. Surface runoff and subsurface flow contributions from upslope areas into the waste zones are included in the determination of monthly seepage flux interacting with waste units.

The monthly values for surface runoff, lateral flow, and drainage are obtained from UTM calculations for various periods of site operation, institutional control, and post-institutional control. Five groups of monthly water fluxes (Table 4.14) are developed for estimation of seepage into waste zone structures. For the first group, the case of the tumulus zones (Tumulus I and II, IWMF), seepage is estimated directly from precipitation for the period of pad construction, the loading of pads with concrete vaults, and construction of the RCRA caps. The assumption is made that the vaults are exposed to precipitation during this period. Monthly precipitation values for the average year are used as seepage values for the SOURCE1 modeling during this period, including two years for construction of a compacted soil cap over the tumulus pads following pad loading.

The second group of water budget results (2A and $2 \mathrm{~B}$ in Table 4.14) apply to zones with below-ground waste units (silos, wells, trenches) as well as to the upslope areas draining into the waste zones. Two types of surface are simulated. Waste zones and upslope areas with grass vegetation and moderate disturbance $(2 \mathrm{~A})$ are assigned a leaf area index ( $\mathrm{LAI}$ ) of 2.0 for evapotranspiration calculations, whereas highly disturbed areas with a gravel surface (2B) are assigned a low LAI of 0.001 . The lower evapotranspiration in the highly disturbed areas leads to enhanced lateral flow.

The third set of water budget results applies to tumulus zones (Tumulus I and II, IWMF) with RCRA caps installed. The caps greatly reduce but do not eliminate drainage into tumulus zones. Lateral flow is excluded from interaction with vaults during the period of effective cap operation. A low hydraulic conductivity value is used for the geotextile and compacted soil layer in the cap (saturated conductivity of $1.16 \times 10^{-7} \mathrm{~m} / \mathrm{s}$; see Table D.1). During this period, some drainage enters each tumulus as seepage through leaks in the seams of the flexible geomembrane within the cap. The influence of caps is not simulated for below-ground waste zones since substantial caps were not included in the closure design at the time of this assessment.

The fourth set of results also applies to tumulus zones but for a later period in which hydrologic failure of the RCRA caps develops. A linear ramp increase in drainage and lateral flow from group 3 to group 5 is interpolated annually for each month to represent progressive failure of the RCRA cap over a 10-year period. These results change each year and are not specifically shown in Table 4.14. 
Table 4.14. Monthly precipitation, soil water drainage, lateral subsurface flow, and surface runoff results from the UTM for three sets of weather conditions (dry, average, and wet) and five periods of waste site operation

\begin{tabular}{|c|c|c|c|c|c|c|c|c|c|}
\hline \multirow[t]{2}{*}{ Site operation } & \multicolumn{3}{|c|}{$\begin{array}{l}\text { Precipitation } \\
\text { (mm/month) }\end{array}$} & \multirow[b]{2}{*}{ Month $^{b}$} & & & & & \\
\hline & Dry & Average $^{a}$ & Wet & & & & & & \\
\hline \multirow{14}{*}{$\begin{array}{l}\text { 1. Tumulus zones; } \\
\text { pad loading and cap } \\
\text { construction; } \\
\text { exposed vaults }\end{array}$} & 106.2 & 124.2 & 111.3 & \multirow{12}{*}{\multicolumn{6}{|c|}{\begin{tabular}{|l} 
Jan \\
Feb \\
Mar \\
Apr \\
May \\
Jun \\
Jul \\
Aug \\
Sep \\
Oct \\
Nov \\
Dec \\
\end{tabular}}} \\
\hline & 17.5 & 124.2 & 98.3 & & & & & & \\
\hline & 117.1 & 116.8 & 284.2 & & & & & & \\
\hline & 113.5 & 109.2 & 126.5 & & & & & & \\
\hline & 93.5 & 157.5 & 268.0 & & & & & & \\
\hline & 104.9 & 84.8 & 140.5 & & & & & & \\
\hline & 53.1 & 234.4 & 151.4 & & & & & & \\
\hline & 49.3 & 62.0 & 39.9 & & & & & & \\
\hline & 55.6 & 80.0 & 73.2 & & & & & & \\
\hline & 56.6 & 63.8 & 86.6 & & & & & & \\
\hline & 56.9 & 55.4 & 274.1 & & & & & & \\
\hline & 108.7 & 159.8 & 241.3 & & & & & & \\
\hline & \multicolumn{3}{|c|}{$\begin{array}{c}\text { Drainage } \\
\text { (mm/month) }\end{array}$} & \multicolumn{3}{|c|}{$\begin{array}{l}\text { Lateral flow } \\
\text { (mm/month) }\end{array}$} & \multicolumn{3}{|c|}{$\begin{array}{c}\text { Runoff } \\
\text { (mm month) }\end{array}$} \\
\hline & Dry & Average & Wet & Dry & Average & Wet & Dry & Average & Wet \\
\hline \multirow{12}{*}{$\begin{array}{l}2 \mathrm{~A} . \text { Belowground } \\
\text { zones; active use; } \\
\text { disturbed vegetation } \\
\mathrm{LAI}^{c}=2.0\end{array}$} & 2.8 & 15.5 & 15.5 & 42.3 & 70.3 & 99.5 & 0.0 & 18.3 & 15.1 \\
\hline & 14.1 & 14.0 & 14.0 & 19.9 & 72.8 & 78.7 & 1.0 & 23.9 & 15.7 \\
\hline & 15.5 & 15.5 & 15.5 & 25.0 & 75.8 & 125.9 & 9.7 & 24.9 & 90.6 \\
\hline & 15.0 & 15.0 & 15.0 & 70.3 & 52.8 & 65.3 & 13.1 & 37.3 & 20.7 \\
\hline & 15.5 & 15.5 & 15.5 & 28.2 & 7.6 & 58.0 & 8.5 & 51.0 & 118.7 \\
\hline & 15.0 & 15.0 & 15.0 & 4.2 & 0.0 & 40.0 & 46.0 & 20.9 & 58.3 \\
\hline & 13.3 & 12.0 & 15.3 & 0.0 & 0.0 & 3.3 & 15.3 & 87.3 & 67.1 \\
\hline & 7.0 & 6.6 & 10.4 & 0.0 & 0.0 & 0.0 & 18.9 & 27.7 & 7.0 \\
\hline & 4.5 & 5.1 & 5.5 & 0.0 & 0.0 & 0.0 & 7.5 & 15.7 & 20.6 \\
\hline & 3.6 & 4.8 & 4.4 & 0.0 & 0.0 & 0.0 & 3.4 & 17.9 & 22.6 \\
\hline & 2.7 & 3.9 & 3.4 & 0.0 & 0.0 & 0.0 & 7.3 & 2.8 & 149.3 \\
\hline & 2.4 & 5.9 & 8.5 & 0.0 & 28.2 & 85.5 & 15.2 & 32.6 & 85.8 \\
\hline
\end{tabular}


Table 4.14 (continued)

\begin{tabular}{|c|c|c|c|c|c|c|c|c|c|}
\hline & \multicolumn{3}{|c|}{$\begin{array}{c}\text { Drainage } \\
\text { (mm/month) }\end{array}$} & \multicolumn{3}{|c|}{$\begin{array}{l}\text { Lateral flow } \\
(\mathrm{mm} / \mathrm{month})\end{array}$} & \multicolumn{3}{|c|}{$\begin{array}{c}\text { Runoff } \\
\text { (mm/month) }\end{array}$} \\
\hline & Dry & Average & Wet & Dry & Average & Wet & Dry & Average & Wet \\
\hline \multirow{12}{*}{$\begin{array}{l}\text { 2B. Belowground } \\
\text { zones; active use; } \\
\text { gravel surface } \\
\mathrm{LAI}^{c}=0.001\end{array}$} & 15.5 & 15.5 & 15.5 & 110.1 & 71.8 & 101.8 & 0.0 & 18.4 & 15.3 \\
\hline & 14.5 & 14.0 & 14.0 & 22.3 & 73.9 & 81.2 & 1.0 & 24.2 & 15.7 \\
\hline & 15.5 & 15.5 & 15.5 & 26.6 & 77.7 & 128.8 & 9.9 & 25.4 & 90.8 \\
\hline & 15.0 & 15.0 & 15.0 & 72.7 & 54.5 & 67.7 & 13.6 & 37.3 & 20.9 \\
\hline & 15.5 & 15.5 & 15.5 & 47.6 & 86.5 & 109.9 & 8.9 & 51.5 & 120.3 \\
\hline & 15.0 & 15.0 & 15.0 & 51.6 & 31.1 & 76.9 & 45.5 & 22.8 & 60.2 \\
\hline & 15.5 & 15.5 & 15.5 & 19.0 & 57.0 & 31.1 & 16.0 & 90.4 & 69.7 \\
\hline & 15.5 & 15.5 & 15.5 & 9.5 & 70.5 & 43.5 & 20.7 & 29.7 & 7.5 \\
\hline & 15.0 & 15.0 & 15.0 & 3.1 & 9.0 & 10.6 & 8.3 & 16.2 & 21.9 \\
\hline & 15.5 & 15.5 & 15.5 & 14.6 & 30.0 & 19.9 & 3.4 & 18.1 & 22.7 \\
\hline & 15.0 & 15.0 & 15.0 & 16.6 & 17.7 & 65.7 & 7.3 & 2.8 & 149.3 \\
\hline & 15.5 & 15.5 & 15.5 & 40.8 & 82.6 & 121.8 & 15.4 & 33.0 & 86.0 \\
\hline \multirow{12}{*}{$\begin{array}{l}\text { 3. Monitored } \\
\text { closure; grass cover; } \\
\text { functional cap } \\
\mathrm{LAI}^{c}=4.9\end{array}$} & 0.1 & 0.3 & 2.9 & 0.0 & 0.0 & 0.0 & 0.0 & 0.0 & 0.0 \\
\hline & 0.7 & 3.8 & 7.8 & 0.0 & 0.0 & 0.0 & 0.0 & 0.0 & 0.0 \\
\hline & 2.6 & 11.2 & 20.1 & 0.0 & 0.0 & 0.0 & 0.0 & 0.0 & 0.0 \\
\hline & 8.0 & 11.2 & 18.3 & 0.0 & 0.0 & 0.0 & 0.0 & 0.0 & 0.0 \\
\hline & 7.8 & 7.7 & 9.0 & 0.0 & 0.0 & 0.0 & 0.0 & 0.0 & 0.0 \\
\hline & 2.9 & 3.4 & 4.6 & 0.0 & 0.0 & 0.0 & 0.0 & 0.0 & 0.0 \\
\hline & 1.5 & 1.6 & 2.4 & 0.0 & 0.0 & 0.0 & 0.0 & 0.0 & 0.0 \\
\hline & 0.7 & 0.8 & 1.1 & 0.0 & 0.0 & 0.0 & 0.0 & 0.0 & 0.0 \\
\hline & 0.4 & 0.4 & 0.6 & 0.0 & 0.0 & 0.0 & 0.0 & 0.0 & 0.0 \\
\hline & 0.2 & 0.2 & 0.3 & 0.0 & 0.0 & 0.0 & 0.0 & 0.0 & 0.0 \\
\hline & 0.1 & 0.1 & 0.2 & 0.0 & 0.0 & 0.0 & 0.0 & 0.0 & 0.0 \\
\hline & 0.1 & 0.1 & 0.2 & 0.0 & 0.0 & 0.0 & 0.0 & 0.0 & 0.0 \\
\hline $\begin{array}{l}\text { 4. Monitored } \\
\text { closure; 10-year } \\
\text { linear ramp in } \\
\text { drainage with cap } \\
\text { failure }\end{array}$ & & & & & & & & & \\
\hline
\end{tabular}


Table 4.14 (continued)

\begin{tabular}{l|rrr|rrr|rrr|}
\hline & \multicolumn{3}{|c|}{$\begin{array}{c}\text { Drainage } \\
\text { (mm/month) }\end{array}$} & \multicolumn{3}{c|}{$\begin{array}{c}\text { Lateral flow } \\
\text { (mm/month) }\end{array}$} & \multicolumn{3}{c|}{$\begin{array}{c}\text { Runoff } \\
\text { (mm/month) }\end{array}$} \\
\cline { 2 - 10 } & Dry & Average & Wet & Dry & Average & Wet & Dry & Average & Wet \\
\hline 5. Monitored & 3.3 & 15.5 & 15.5 & 0.0 & 81.9 & 84.0 & 0.0 & 0.0 & 0.0 \\
closure; grass cover; & 13.3 & 14.0 & 14.0 & 0.0 & 84.5 & 94.5 & 0.0 & 0.0 & 0.0 \\
leaking cap; forest & 15.5 & 15.5 & 15.5 & 24.9 & 97.0 & 215.6 & 0.0 & 0.0 & 0.0 \\
cover & 15.0 & 15.0 & 15.0 & 73.1 & 60.9 & 84.7 & 0.0 & 0.0 & 0.0 \\
LAI $^{c}=4.9$ & 15.5 & 15.5 & 15.5 & 24.9 & 108.9 & 139.4 & 0.0 & 0.0 & 0.0 \\
& 15.0 & 15.0 & 15.0 & 5.6 & 17.1 & 35.1 & 0.0 & 0.0 & 0.0 \\
& 15.5 & 15.5 & 15.5 & 0.0 & 0.3 & 12.5 & 0.0 & 0.0 & 0.0 \\
& 14.7 & 15.5 & 15.5 & 0.0 & 1.6 & 0.0 & 0.0 & 0.0 & 0.0 \\
& 6.3 & 15.0 & 15.0 & 0.0 & 1.5 & 0.0 & 0.0 & 0.0 & 0.0 \\
& 4.6 & 15.5 & 15.5 & 0.0 & 0.0 & 0.0 & 0.0 & 0.0 & 0.0 \\
& 3.8 & 13.6 & 9.6 & 0.0 & 0.0 & 105.2 & 0.0 & 0.0 & 0.0 \\
& 3.4 & 8.5 & 15.5 & 0.0 & 0.0 & 166.7 & 0.0 & 0.0 & 0.0 \\
\hline
\end{tabular}

${ }^{a}$ The values for the average case were used to determine seepage for simulation by SOURCE1 ans SOURCE2 models (see Table 4.8 and Table 4.9).

${ }^{b}$ Each column shows twelve monthly values, beginning with January.

'LAI $=$ leaf area index $\left(\mathrm{m}^{2} / \mathrm{m}^{2}\right)$.

The last set of water budget results (group 5) applies to the remainder of the PA calculations. This includes the 100-year institutional control period for below-ground waste zones and the last 80 years of institutional control for the IWMF (the period with complete cap failure). During these 80 years, a macropore flow algorithm in the UTM generates high drainage through the failed RCRA cap layers. The entire SWSA 6 area is expected to be vegetated with shallow-rooted grass that is regularly mown during institutional control. Following the end of institutional control, all zones are expected to revert to deciduous forest vegetation through successional changes in plant species. The water budgets for well-vegetated surfaces are similar, and the choice of one set of results for the various changes in vegetation management is a justifiable convenience. Strong seasonality is shown in the last set of water budget results, with high lateral flow occurring in the late winter and spring months.

The water budget results from the UTM were combined with specific site characteristics for each waste zone to estimate the contributions of infiltration and lateral subsurface flow to the quantity of seepage entering waste units. The area immediately upslope that drains into each waste zone (area B,Fig. 4.14) is estimated from terrain analysis. The area of each waste zone (area A, Fig. 4.14) is also determined. The ratio of $B / A$ is then used in water seepage calculations. The set of $\mathrm{B} / \mathrm{A}$ values (Table 4.15) shows a wide range, from zero for the tumulus zones to more than 12 for the high-range wells (Zone 5). 


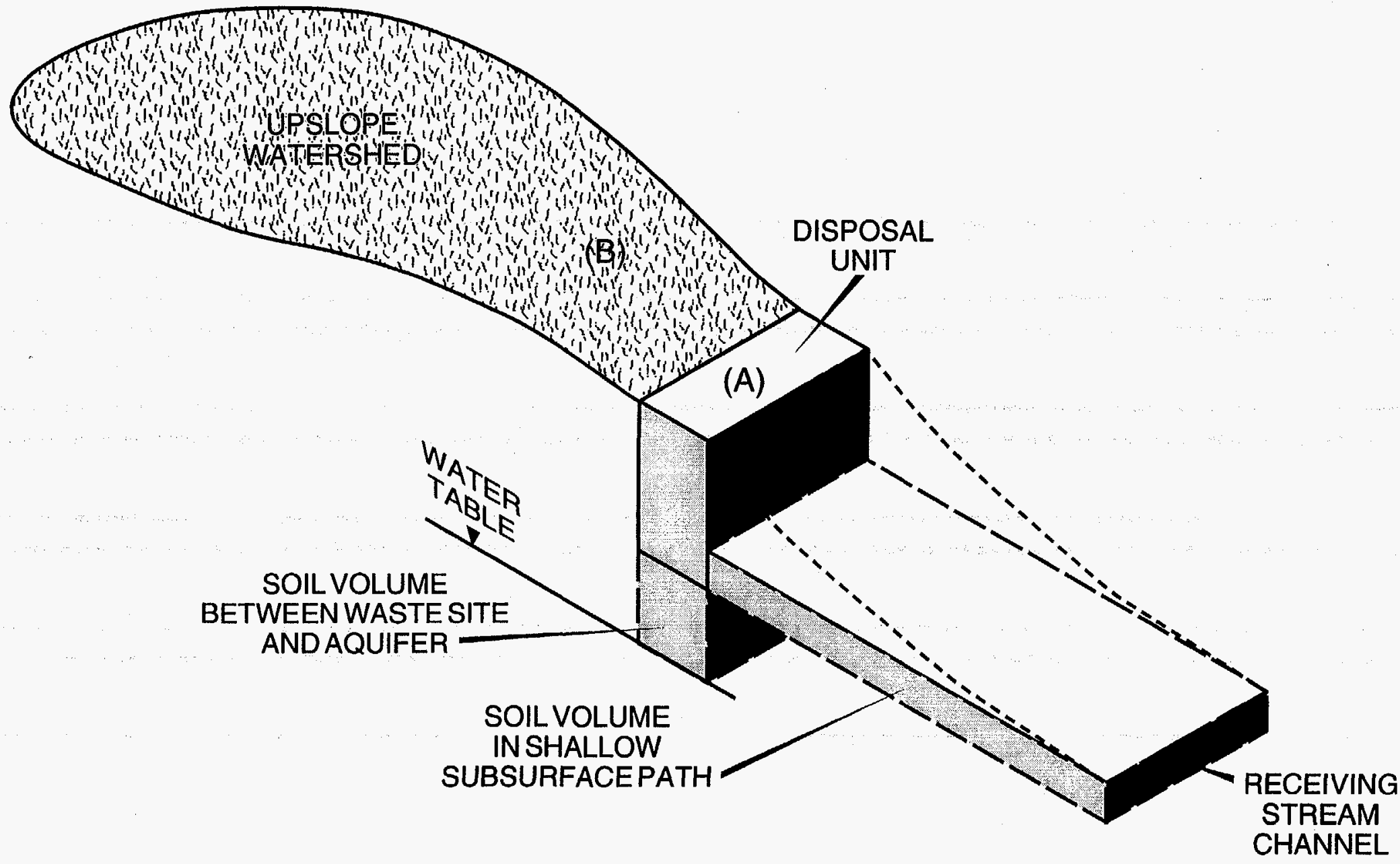

Fig. 4.14. Diagram of a disposal unit area (A) in relation to its upslope watershed area (B) and the soil volumes in the vertical path to groundwater and the lateral path to a receiving stream channel. 
Table 4.15. B/A ratios for SWSA 6 waste disposal units

\begin{tabular}{|c|c|c|c|c|c|c|}
\hline Waste disposal units & Zone & $\begin{array}{c}\text { Zone area } \\
\left(\mathrm{m}^{2}\right) \\
\mathrm{A}\end{array}$ & $\begin{array}{c}\text { Upslope } \\
\text { area }\left(\mathrm{m}^{2}\right) \\
\text { B }\end{array}$ & $\begin{array}{l}\text { Ratio } \\
\text { (B/A) }\end{array}$ & $\begin{array}{l}\text { Zone } \\
\text { surface }\end{array}$ & $\begin{array}{l}\text { Upslope } \\
\text { surface }\end{array}$ \\
\hline High-range silos & 3 & 500 & 335 & 0.67 & Grassy & Gravel \\
\hline High-range wells-in-silos & 5 & 60 & 750 & 12.5 & Gravel & Gravel \\
\hline High-range wells & 5 & 12 & 150 & 12.5 & Gravel & Gravel \\
\hline Fissile wells & 7 & 1 & 0.84 & 0.84 & Gravel & Grassy \\
\hline Quadrex trenches & 8 & 230 & 124 & 0.54 & Grassy & Grassy \\
\hline Low-range silos (north) & 8 & 230 & 124 & 0.54 & Grassy & Grassy \\
\hline Biological trenches (east) & 15 & 180 & 288 & 1.60 & Grassy & Grassy \\
\hline Asbestos silos & 16 & 170 & 83 & 0.49 & Grassy & Grassy \\
\hline Biological trenches (west) & 20 & 90 & 140 & 1.56 & Grassy & Grassy \\
\hline IWMF pad 1 & 25 & 499 & 0 & 0 & Concrete & None \\
\hline IWMF pad 2 & 25 & 499 & 0 & 0 & Concrete & None \\
\hline IWMF pad 3 & 25 & 499 & 0 & 0 & Concrete & None \\
\hline IWMF pad 4 & 25 & 499 & 0 & 0 & Concrete & None \\
\hline IWMF pad 5 & 25 & 499 & 0 & 0 & Concrete & None \\
\hline IWMF pad 6 & 25 & 499 & 0 & 0 & Concrete & None \\
\hline Tumulus II & 26 & 499 & 0 & 0 & Concrete & None \\
\hline Tumulus I & 27 & 634 & 0 & 0 & Concrete & None \\
\hline Low-range silos (south) & 30 & 15,745 & 409 & 0.3 & Grassy & Grassy \\
\hline
\end{tabular}

The surface characteristic of each zone and its associated upslope area is classified as either grassy or gravelly (Table 4.15), corresponding to the two major surface conditions at SWSA 6 during the active use period (see water budget results for cases $2 A$ and $2 B$, Table 4.14). Monthly seepage values for waste zones are determined as combinations of drainage, lateral flow, and runoff results from Table 4.14 as follows:

$$
\begin{gathered}
{[\text { Drainage }+ \text { Lateral flow })+[(\text { Lateral flow }+ \text { Runoff }) \times B / A]} \\
\text { for a waste zone } \quad \text { for the upslope area }
\end{gathered}
$$

These calculations are on a volume per unit area basis $(\mathrm{cm})$ and are presented earlier in Table 4.8 and Table 4.9.

The recharge at each waste zone is determined from SOURCE model calculations, using input values for saturated conductivity for each waste zone at the water table depth. The seepage values used 
in the SOURCE models are partitioned into recharge with any remaining seepage becoming lateral flow. These calculations result in recharge of $628 \mathrm{~mm} /$ year for the tumulus units (Zones $25,26,27$ ) with all other zones having recharge of $175 \mathrm{~mm} /$ year (see Fig. 4.11). The higher recharge values for the tumulus units reflect the higher hydraulic conductivity value for the shallow water table in upper soil layers at these locations.

\subsubsection{Environmental Transport}

Estimation of leachate migration from SWSA 6 disposal sites to compliance points in the landscape involves a linked series of models for the major components of nuclide containment and transport (Fig. 4.8). Soil water drainage rates from water budget calculations are provided by UTM and are used by the SOURCE1 and SOURCE2 models as seepage to determine advective releases of nuclides from disposal units into the unsaturated vadose zone. The SOURCE simulations partition the mass release into vertical and lateral subsurface flow components. These two flow components are subjected to transport through the vadose zone using the PADSIM and HOLSIM programs. These programs calculate chemical adsorption in the unsaturated zone as well as preferential flow in lateral subsurface transport to the surface. Results of nuclide transport to the water table are taken as recharge to the groundwater model, $\mathrm{MOC}$, to calculate groundwater nuclide concentrations at various receptor locations as well as transport to surface water. Outlines of the PADSIM and HOLSIM and MOC transport models are given below.

This linked system of models is used to demonstrate compliance of the closed disposal units in SWSA 6, as well as to determine disposal limits for the IWMF, based on predicted nuclide concentrations in ground and surface water for the following three cases:

- Case 1. Limiting inventory at IWMF based on maximum groundwater concentrations at wells located $100 \mathrm{~m}$ from SWSA 6 disposal units (see Fig. 4.15);

- Case 2. Limiting inventory at IWMF based on maximum combined surface water concentration at WOD;

- Case 3. Limiting inventory at IWMF based on maximum groundwater concentrations at wells located at the expanded buffer zone (see Fig. 4.16).

This is an iterative procedure in which environmental concentrations for the pathways described in Sect. 4.2.1 are initially calculated, assuming a unit inventory at the IWMF and fixed inventories at the closed SWSA 6 disposal units. This initial result is compared to the concentration limit corresponding to the allowable dose (Sect. 4.3.1.3) and used to estimate a new limiting inventory at the IWMF, assuming (temporarily) a linear relationship between inventory and environmental radionuclide concentrations. Using this updated IWMF inventory, the entire model calculation process is then rerun, and modified environmental concentrations are determined. This procedure is repeated 


\section{Receptor Locations for the SWSA 6 Groundwater Model Based on a $100 \mathrm{~m}$ Buffer Zone}

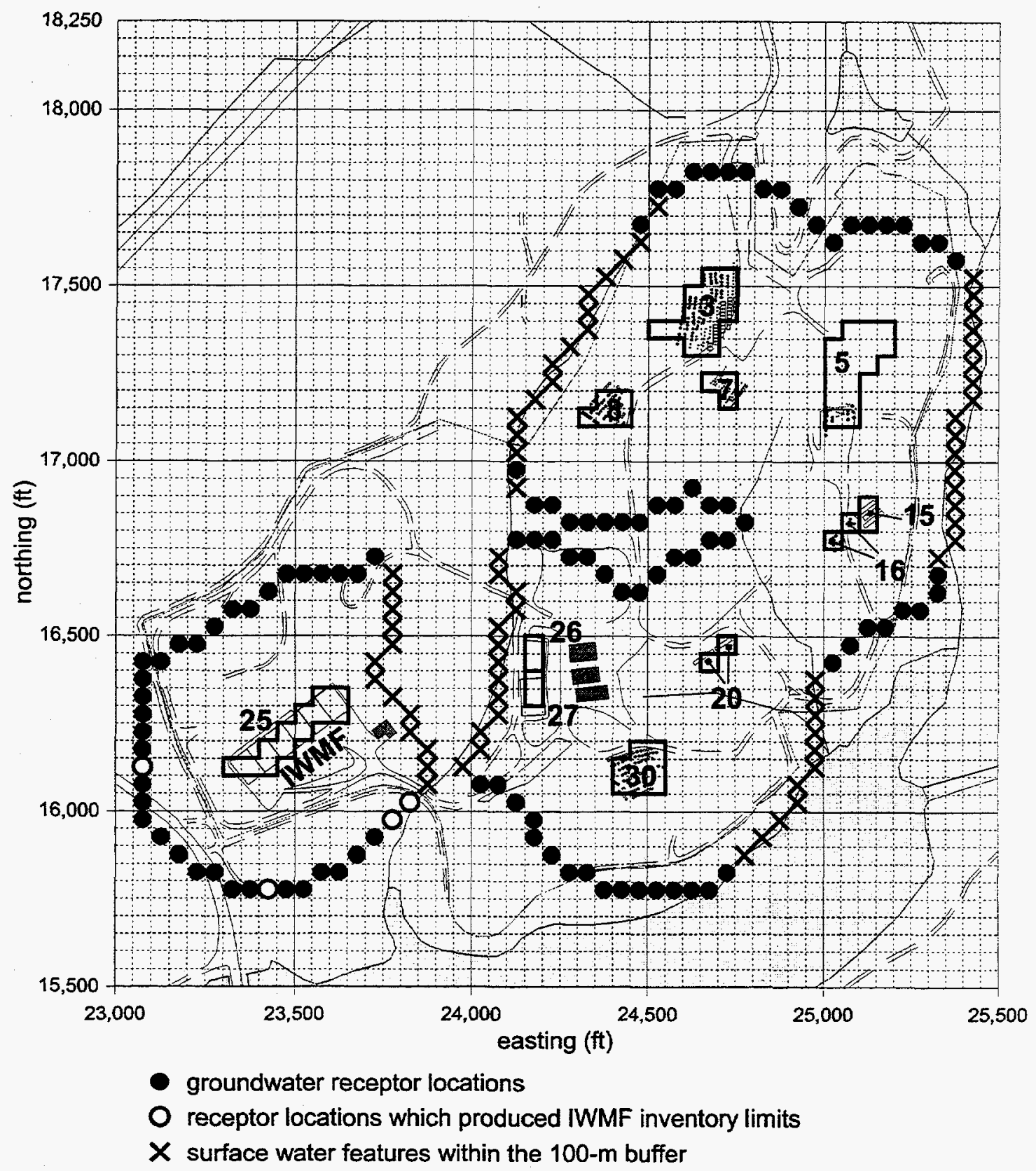

Fig. 4.15. Receptor locations for the water pathway based on a $100-\mathrm{m}$ buffer zone. 


\section{Receptor Locations for SWSA 6 Water Pathway Modeling Based on an Expanded Buffer Zone}

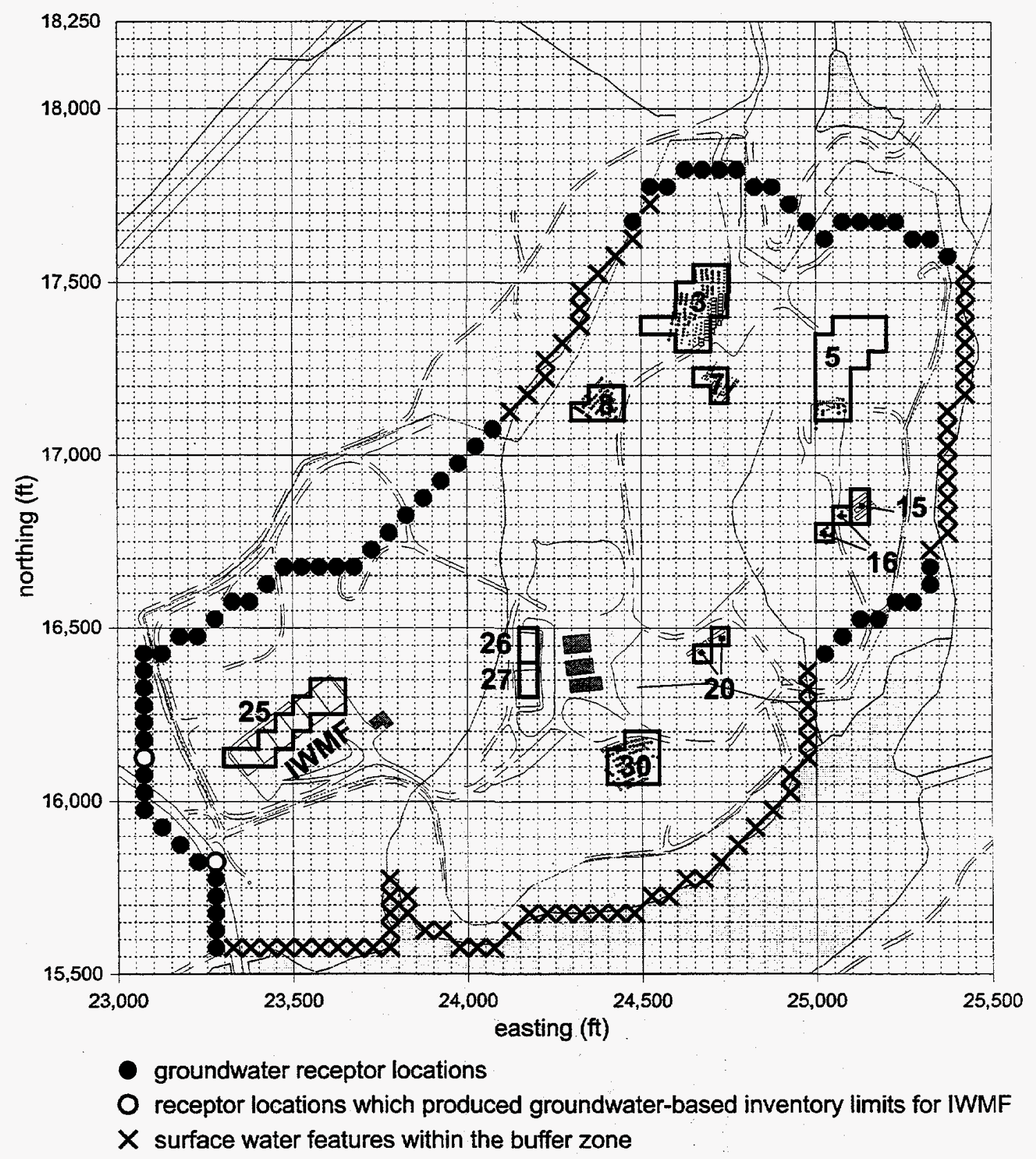

Fig. 4.16. Receptor locations for the water pathway based on the expanded buffer zone. 
until IWMF inventories are determined to result in either a peak groundwater or surface water concentration equal to the concentration limits detailed in Sect. 4.3.1.3. In most cases, the initial linear assumption was found to be valid, and the new estimate was accurate. In some cases, however, the relationship between inventory and predicted environmental concentration became nonlinear, due principally to solubility limitations in the waste form. These cases required several iterations to arrive at a limiting inventory that corresponded to the concentration limit.

\subsection{Shallow Subsurface Transport}

The PADSIM and HOLSIM programs calculate nuclide flux in recharge to groundwater and in lateral subsurface transport to receiving surface drainage channels (Fig. 4.17). These two programs account for the position of the disposal units in the landscape and the distances from the disposal units to the nearest receiving stream channels for subsurface discharge and to the water table for recharge (Fig. 4.14). The distances from the waste zones to the nearest receiving stream channel and to the water table (Table 4.16) show differences that influence the significance of chemical retardation, bypass flow, and matrix diffusion. Fluctuations in water table elevation due to seasonal changes in water budgets are not considered in calculations performed in this PA. The consequences of fluctuating water tables are considered in the uncertainty analysis. The calculated results and the results of the uncertainty analysis are used in the interpretation of results. The features of the unsaturated zone calculations with PADSIM and HOLSIM, applicable to the shallow subsurface flow paths, are given in Appendix D, Sect. D.3 and are outlined as follows:

- Bypass flow. Soils to a depth of $3.5 \mathrm{~m}$ have considerable capacity for transporting chemicals through preferential flow paths, and these tend to follow the dip of saprolite structure (Wilson et al. 1993). An algorithm representing bypass flow results in decreasing proportions of bypass flow with increase in $K_{d}$ (Table 4.17). There is no bypass flow for the vertical paths greater than $3.5 \mathrm{~m}$ thickness; they are not expected to show a continuous network of preferential flow paths to the water table. Some nuclide movement from the preferential flow path to the matrix is calculated to represent matrix diffusion (see below).

- Interaction soil volume. Nuclide movement through the unsaturated soil matrix is represented by an expanding soil volume according to an algorithm that depends on the $K_{d}$. The soil matrix volumes were incremented annually after the first arrival of nuclides, resulting in increasing times for full soil-matrix exposure to nuclides with increasing $K_{d}$ (Table 4.18).

- Radioactive decay. Each year the nuclide mass in the shallow subsurface is reduced to account for decay according to the applicable half-life for each nuclide (Table 4.2). 


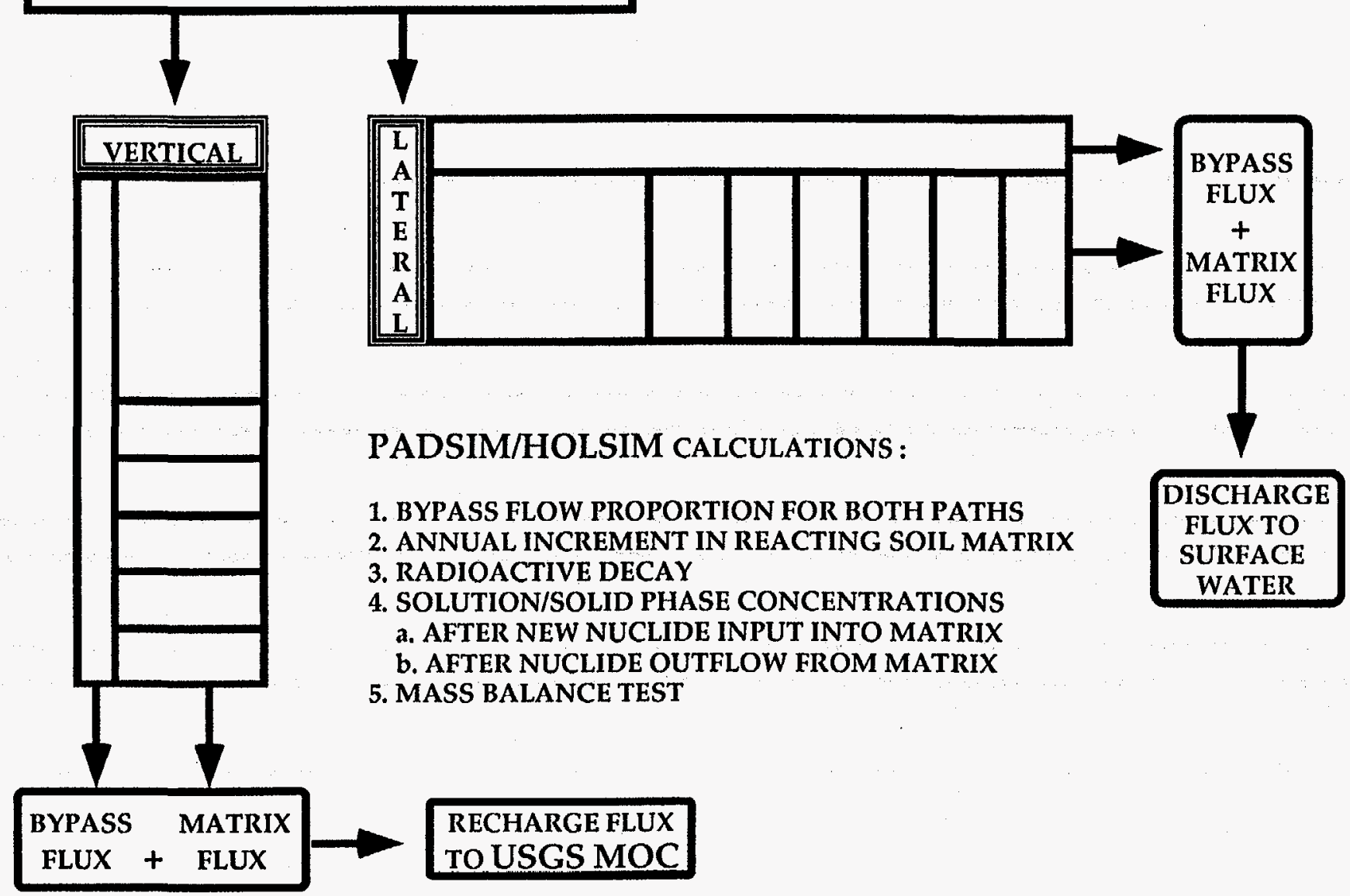

Fig. 4.17. Essential features of PADSIM and HOLSIM in the linkage between SOURCE1 and SOURCE2, and MOC for nuclide transport to groundwater and for lateral subsurface transport to surface water. 
Table 4.16. Distances to groundwater and receiving streams for SWSA 6 disposal units

\begin{tabular}{lcccc}
\hline \multicolumn{1}{c}{ Waste disposal units } & Zone & $\begin{array}{c}\text { Number } \\
\text { of units }\end{array}$ & $\begin{array}{c}\text { Distance to } \\
\text { groundwater } \\
(\mathrm{m})\end{array}$ & $\begin{array}{c}\text { Distance to } \\
\text { stream } \\
(\mathrm{m})\end{array}$ \\
\hline High-range silos & 3 & 37 & 2.9 & 170 \\
High-range wells-in-silos & 5 & 53 & 4.7 & 190 \\
High-range wells & 5 & 9 & 4.3 & 190 \\
Fissile wells & 7 & 2 & 4.0 & 140 \\
Quadrex trenches & 8 & 5 & 4.7 & 100 \\
Low-range silos (north) & 8 & 24 & 3.1 & 100 \\
Biological trenches (east) & 15 & 4 & 0.8 & 110 \\
Asbestos silos & 16 & 11 & 0.6 & 160 \\
Biological trenches (west) & 20 & 2 & 0.6 & 170 \\
IWMF pad 1 & 25 & 1 & 1.2 & 100 \\
IWMF pad 2 & 25 & 1 & 1.2 & 100 \\
IWMF pad 3 & 25 & 1 & 1.2 & 100 \\
IWMF pad 4 & 25 & 1 & 1.2 & 100 \\
IWMF pad 5 & 25 & 1 & 1.2 & 100 \\
IWMF pad 6 & 25 & 1 & 1.2 & 100 \\
Tumulus II & 26 & 1 & 0.5 & 50 \\
Tumulus I & 27 & 1 & 1.8 & 50 \\
Low-range silos (south) & 30 & 105 & 2.5 & 160 \\
\hline & & & & \\
\hline
\end{tabular}

- Chemical adsorption (retardation). The nuclide leachate entering the soil matrix is assumed to come to equilibrium between the solution phase and the adsorbed phase on soil surfaces according to the $K_{d}$ values and the current interacting soil volume and density. This updated solute concentration is used to determine nuclide outflow from the matrix. Following removal of the nuclide outflow, solution phase/solid phase calculations are conducted to determine a new nuclide equilibrium between the solid and solution phases of the soil matrix.

- Matrix diffusion. Matrix diffusion is partially represented in PADSIM by allowing some nuclides to be added to the matrix during preferential flow to represent matrix diffusion. The proportion of nuclides retained by matrix diffusion is greater for nuclides with higher $K_{d}$ and for longer bypass flow path lengths. Furthermore, the annual averaging of added nuclides into the reacting soil matrix volume provides numerical dispersion that results in an equivalent effect of "diffusing" nuclides through the soil matrix. Matrix diffusion is considered an important mechanism in contaminant transport (Solomon et al. 1992), and is facilitated by small-scale preferential flow 
Table 4.17. The proportion of bypass flow for selected vertical and lateral flow path lengths and the maximum first-year transport distance through the soil matrix as a function of $K_{d}$

\begin{tabular}{|c|c|c|c|c|c|c|c|}
\hline \multirow{2}{*}{$\begin{array}{c}K_{d} \\
(\mathrm{~mL} / \mathrm{g})\end{array}$} & \multicolumn{3}{|c|}{ Vertical path } & \multicolumn{3}{|c|}{ Lateral path } & \multirow{2}{*}{$\begin{array}{l}\text { Maximum } \\
\text { transport } \\
\text { (m) }\end{array}$} \\
\hline & $0.5 \mathrm{~m}$ & $1.2 \mathrm{~m}$ & $>3.5 \mathrm{~m}$ & $47 \mathrm{~m}$ & $96 \mathrm{~m}$ & $189 \mathrm{~m}$ & \\
\hline 0 & .998 & .996 & .000 & .826 & .644 & .300 & 270.0 \\
\hline 50 & .949 & .878 & .000 & .000 & .000 & .000 & 9.8 \\
\hline 100 & .948 & .876 & .000 & .000 & .000 & .000 & 9.7 \\
\hline 500 & .940 & .859 & .000 & .000 & .000 & .000 & 8.5 \\
\hline 1000 & .929 & .829 & .000 & .000 & .000 & .000 & 7.0 \\
\hline 3000 & .5000 & .000 & .000 & .000 & .000 & .000 & 1.0 \\
\hline
\end{tabular}

Table 4.18. Annual increment in soil matrix path length and times to full matrix exposure to nuclides as a function of $K_{d}$ for selected vertical and lateral flow path distances

\begin{tabular}{|c|c|c|c|c|c|c|c|}
\hline \multirow{2}{*}{$\begin{array}{c}K_{d} \\
(\mathrm{~mL} / \mathrm{g})\end{array}$} & \multirow{2}{*}{$\begin{array}{c}\text { Path } \\
\text { increment } \\
(\mathrm{cm} / \text { year) }\end{array}$} & \multicolumn{3}{|c|}{$\begin{array}{l}\text { Time (years) to full vertical path } \\
\text { exposure }\end{array}$} & \multicolumn{3}{|c|}{$\begin{array}{l}\text { Time (years) to full lateral path } \\
\text { exposure }\end{array}$} \\
\hline & & $0.5 \mathrm{~m}$ & $1.2 \mathrm{~m}$ & $4.7 \mathrm{~m}$ & $47 \mathrm{~m}$ & $96 \mathrm{~m}$ & $189 \mathrm{~m}$ \\
\hline 0 & 1350.0 & 1 & 1 & 1 & 1 & 1 & 1 \\
\hline 50 & 49.0 & 1 & 1 & 1 & 77 & 177 & 367 \\
\hline 100 & 48.5 & 1 & 1 & 1 & 78 & 179 & 371 \\
\hline 500 & 42.5 & 1 & 1 & 1 & 92 & 207 & 426 \\
\hline 1000 & 35.0 & 1 & 1 & 1 & 116 & 256 & 521 \\
\hline 3000 & 5.0 & 1 & 5 & 75 & 921 & 1901 & 3761 \\
\hline
\end{tabular}

paths that distribute nuclides through the soil, allowing solute diffusion into micropores along the flow paths.

\subsection{Contaminant Transport in Groundwater}

Groundwater flow and transport of radioactive contaminants leached from SWSA 6 disposal units in the saturated groundwater zone are modeled using the USGS MOC computer program. Groundwater modeling is discussed in detail in Appendix E. The modeling methods used to calculate groundwater flow and radionuclide transport in the saturated zone of SWSA 6 follow those used successfully in the contaminant transport model validation study for Bear Creek Valley (Lee and Ketelle 1989), a region geologically similar to the SWSA 6 area. 
To evaluate contaminant transport in groundwater, a groundwater flow model is constructed and calibrated to existing conditions (as derived from hydrogeological data) for geologic material properties, water table elevations, spatially variable recharge values, and types and locations of boundaries. SWSA 6 is assumed to be hydrologically isolated, which is supported by the available monitoring data. Consequently, water inflow is assumed to occur by infiltration of precipitation through overlying soils and subsurface strata, seepage of leachate through disposal units, or recharge from losing streams. Water exits the groundwater model as discharge to surface streams that ultimately pass over WOD.

Input to the MOC program is site-specific. Historical water elevation data from wells in the SWSA 6 area are integrated to produce an average water table, which is used as the initial condition for hydraulic head in the models as well as a norm for hydraulic parameter determination.

Groundwater recharge values at each disposal unit are those calculated from PADSIM or HOLSIM (see Sect. 4.3.1.2.1). Hydraulic conductivity parameters are based on estimates at SWSA 6 by Bechtel (1989) and are adjusted to conserve mass and to match the data-derived hydraulic head surface (see Appendix E). Other parameters are based on measurements or are derived from modeling and tracer test results in similar geological materials in Bear Creek Valley (Lee and Ketelle 1989) and the Engineered Test Facility in SWSA 6 (Davis et al. 1984). The ephemeral streams within SWSA 6, as well as WOC and WOL, are treated as constant head locations.

Radionuclide transport in the groundwater is modeled principally as advective flow, with dispersivity added to account for heterogeneities in the system. Contaminant sorption onto soil particles is assumed to follow a linear isotherm and is modeled using a retardation factor based on a nuclide-specific distribution coefficient (Table 2.3). While the effects of radioactive decay are also quantified using half lives in Table 4.2.

Each radionuclide is introduced to the saturated groundwater system as contaminated recharge beneath each disposal unit known to be contaminated with the particular isotope. Mass flux rates correspond to the time-variant fluxes calculated in the PADSIM and HOLSIM calculations

(Sect. 4.3.1.2.1). The six proposed pads for the IWMF are assumed to be filled at the rate of one pad every 18 months, to allow some pads to release contamination before others are loaded. For shortlived, highly mobile nuclides, this loading pattern could have a considerable effect on the time, location, and magnitude of ground and surface water concentrations. For nuclides that are long lived or readily adsorbed onto the solid media, the effects of this variable loading pattern are expected to be much less critical, and all six IWMF pads are assumed to be loaded in the first time step.

The calibrated groundwater model is used to predict groundwater concentrations and arrival times at the groundwater receptor locations shown in both Fig. 4.15 and Fig. 4.16, as well as mass flux rates and associated arrival times for radioactive contaminants discharged to SWSA 6 surface waters from the groundwater aquifer.

\subsection{Transport of Contaminants in Surface Water}

The limiting inventory for each radionuclide for IWMF that is based on the surface water performance criterion was calculated using WOD as the point of compliance. For each radionuclide, 
both the contaminant fluxes from all disposal units calculated in the shallow subsurface analysis (Sect. 4.3.1.2.1) and the contaminant flux from groundwater (calculated in Sect. 4.3.1.2.2) are combined to give the total contaminant discharge to surface water. These flux rates are diluted by the average flow rate of WOC at WOD $(15 \mathrm{cfs})$ to determine average contaminant concentrations in surface water.

As with the calculation of disposal limits based on groundwater concentration, determination of the limiting inventory of each radionuclide based on surface water concentrations may require several iterations to solve for the inventory corresponding to the performance criterion of 4 mrem per year. This process involves choosing an initial estimate of the inventory limit (based on the drinking water pathway) and running the environmental transport calculations to produce a concentration at WOD. This initial result is compared to the concentration limit corresponding to the allowable dose (from Sect. 4.3.1.3), and a new inventory limit was estimated, assuming (temporarily) a linear relationship between inventory and surface water concentrations. In most cases, the linear assumption was found to be valid, and the new estimate was accurate. In some cases, however, the relationship became nonlinear, due principally to solubility limitations in the waste form. These cases required several iterations to arrive at a limiting inventory that corresponded to the performance criterion for surface water.

\subsubsection{Exposure Pathway Modeling and Dose Estimation}

Exposure pathway modeling and dose estimation for the all-pathways analysis includes the estimation of doses to an individual member of the public from radionuclides transported through the air and water pathways. The method for evaluating the radionuclides transported through the air pathway is discussed in Sect. 4.3.2. This section discusses the method for exposure modeling and dose estimation from radionuclides transported through the water pathway, and the incorporation of the air pathway analysis into the all-pathways analysis.

The models used in estimating releases of radionuclides from the various disposal units in SWSA 6 and transport through the environment by water pathways provide estimates of concentrations of radionuclides in groundwater and surface water at locations beyond the boundary of the buffer zone around the disposal unit where the highest concentrations are predicted to occur. The maximum concentrations at any time after disposal provide the input to models for estimating maximum annual EDEs to off-site individuals from assumed exposure pathways involving use of the contaminated groundwater or surface water. The boundary of the buffer zone defining possible locations of off-site individuals is discussed in the previous section and depicted in Fig. 4.15 and Fig. 4.16.

For off-site releases in groundwater, the following exposure pathways involving use of the water for domestic purposes are assumed to occur:

- direct ingestion of contaminated water, and

- ingestion of milk and meat obtained from dairy and beef cattle that drink contaminated water. 
Off-site individuals also are assumed to use contaminated surface water for domestic purposes, and the following exposure pathways are assumed to occur:

- direct ingestion of contaminated water;

- ingestion of milk and meat obtained from dairy and beef cattle that drink contaminated water;

- ingestion of fish obtained from contaminated water; and

- external exposure while swimming in contaminated water.

The first two surface-water pathways are the same as those for contaminated groundwater, but the two additional pathways are relevant only for contaminated surface water. The fish pathway is assumed to be relevant only for exposure to water in the Clinch River, but the other three surface-water pathways are applied to WOC, where the concentrations of radionuclides would be substantially higher. Exclusion of the fish pathway for exposure to water in WOC is based on the reasonable assumptions that fish consumed by off-site individuals would be obtained primarily from the Clinch River and that fish obtained from the creek would spend most of their time in the river and, thus, the concentrations of radionuclides in the fish would be based primarily on the concentrations in the river.

The dose assessments for off-site individuals for releases to groundwater or surface water based on the assumed exposure pathways listed above are used to evaluate compliance with two different performance objectives. The dose estimates for the drinking water pathway alone are used to evaluate compliance with the performance criterion of 4 mrem per year EDE for this pathway (see Table 4.19), and the dose estimates for all exposure pathways combined are used to evaluate compliance with the performance objective of 25 mrem per year EDE for all exposure pathways. However, based on the assumptions about exposure pathways described above, the performance criterion of 4 mrem per year for drinking water only is more restrictive for all radionuclides than the performance criterion of 25 mrem per year for all pathways. This conclusion is based on (1) the doses for the milk, meat, and swimming pathways relative to the dose for drinking water (see Tables G.7, G.10, G.11, and G.14 of Appendix G), and (2) the dose for the fish pathway relative to the dose for the drinking water pathway (see Table G.7 and Table G.13 of Appendix G), taking into account the reduction in radionuclide concentrations from dilution in the Clinch River by a factor of 330 . Specifically the dose from all exposure pathways exceeds the dose from the drinking water pathway by a factor of 2.7 or less for any radionuclide. Thus, for off-site individuals exposed either to groundwater or surface water from WOC, the contributions to dose from the milk, meat, swimming, and fish pathways are small for all radionuclides compared with the difference between the two performance criteria (i.e., the difference between 4 and $25 \mathrm{mrem}$ ), and only the dose from the drinking water pathway needs to be evaluated for release to groundwater or surface water.

The air pathway analysis (Sect. 4.3.2) evaluates doses for ${ }^{14} \mathrm{C}$ and ${ }^{3} \mathrm{H}$ against the performance criterion of 10 mrem per year. Combining the air pathway dose of 10 mrem for these radionuclides with the dose from the water pathway of 4 mrem per year, and taking into account the doses per unit concentration for the milk, meat, swimming and fish pathways given in Appendix $G$ and the applicable dilution factor in the Clinch River of 330 for the fish pathway, the total dose from all pathways combined would be less than 25 mrem per year. Consequently, if the performance criteria for the 
Table 4.19. Drinking water pathway effective dose equivalents and corresponding maximum allowable concentrations in drinking water

\begin{tabular}{|c|c|c|c|c|c|}
\hline Nuclide & $\begin{array}{c}\text { Annual dose } \\
\text { (rem/year } \\
\text { per } \\
\mu \mathrm{Ci} / \mathrm{L} \text { ) }\end{array}$ & $\begin{array}{c}\text { Maximum } \\
\text { allowable } \\
\text { concentration }^{b} \\
(\mu \mathrm{Ci} / \mathrm{L})\end{array}$ & Nuclide & $\begin{array}{c}\text { Annual dose }^{a} \\
\text { (rem/year } \\
\text { per } \\
\mu \mathrm{Ci} / \mathrm{L} \text { ) }\end{array}$ & $\begin{array}{c}\text { Maximum } \\
\text { allowable } \\
\text { concentration } \\
(\mu \mathrm{Ci} / \mathrm{L})\end{array}$ \\
\hline${ }^{3} \mathrm{H}$ & $4.7 \times 10^{-2}$ & $8.5 \times 10^{-2}$ & ${ }^{228} \mathrm{Ra}$ & $1.6 \times 10^{3}$ & $2.5 \times 10^{-6}$ \\
\hline${ }^{10} \mathrm{Be}$ & $3.4 \times 10^{0}$ & $1.2 \times 10^{-3}$ & ${ }^{227} \mathrm{Ac}$ & $1.1 \times 10^{4}$ & $3.6 \times 10^{-7}$ \\
\hline${ }^{14} \mathrm{C}$ & $1.5 \times 10^{0}$ & $2.7 \times 10^{-3}$ & ${ }^{229} \mathrm{Th}$ & $2.9 \times 10^{3}$ & $1.4 \times 10^{-6}$ \\
\hline${ }^{26} \mathrm{Al}$ & $1.1 \times 10^{1}$ & $3.6 \times 10^{-4}$ & ${ }^{230} \mathrm{Th}$ & $4.0 \times 10^{2}$ & $1.0 \times 10^{-5}$ \\
\hline${ }^{36} \mathrm{Cl}$ & $2.2 \times 10^{\circ}$ & $1.8 \times 10^{-3}$ & ${ }^{232} \mathrm{Th}$ & $2.0 \times 10^{3}$ & $1.1 \times 10^{-6}$ \\
\hline${ }^{40} \mathrm{~K}$ & $1.4 \times 10^{1}$ & $2.9 \times 10^{-4}$ & ${ }^{231} \mathrm{~Pa}$ & $8.0 \times 10^{3}$ & $2.1 \times 10^{-7}$ \\
\hline${ }^{41} \mathrm{Ca}$ & $9.5 \times 10^{-1}$ & $4.2 \times 10^{-3}$ & ${ }^{232} \mathrm{U}$ & $1.5 \times 10^{3}$ & $2.7 \times 10^{-6}$ \\
\hline${ }^{60} \mathrm{Co}$ & $2.0 \times 10^{1}$ & $2.0 \times 10^{-4}$ & ${ }^{233} \mathrm{U}$ & $2.1 \times 10^{2}$ & $1.9 \times 10^{-5}$ \\
\hline${ }^{59} \mathrm{Ni}$ & $1.5 \times 10^{-1}$ & $2.7 \times 10^{-2}$ & ${ }^{234} \mathrm{U}$ & $2.0 \times 10^{2}$ & $2.0 \times 10^{-5}$ \\
\hline${ }^{63} \mathrm{Ni}$ & $4.2 \times 10^{-1}$ & $9.5 \times 10^{-3}$ & ${ }^{235} \mathrm{U}$ & $2.0 \times 10^{2}$ & $2.0 \times 10^{-5}$ \\
\hline${ }^{79} \mathrm{Se}$ & $6.4 \times 10^{0}$ & $6.3 \times 10^{-4}$ & ${ }^{236} \mathrm{U}$ & $2.0 \times 10^{2}$ & $2.0 \times 10^{-5}$ \\
\hline${ }^{87} \mathrm{Rb}$ & $3.6 \times 10^{0}$ & $1.1 \times 10^{-3}$ & ${ }^{238} \mathrm{U}$ & $1.9 \times 10^{2}$ & $2.1 \times 10^{-5}$ \\
\hline${ }^{90} \mathrm{Sr}$ & $1.1 \times 10^{2}$ & $3.6 \times 10^{-5}$ & ${ }^{237} \mathrm{~Np}$ & $3.2 \times 10^{3}$ & $1.3 \times 10^{-6}$ \\
\hline${ }^{93} \mathrm{Zr}$ & $1.2 \times 10^{0}$ & $2.5 \times 10^{-3}$ & ${ }^{238} \mathrm{Pu}$ & $2.3 \times 10^{3}$ & $1.7 \times 10^{-6}$ \\
\hline${ }^{93 \mathrm{~m}} \mathrm{Nb}$ & $3.8 \times 10^{-1}$ & $1.1 \times 10^{-2}$ & ${ }^{239} \mathrm{Pu}$ & $2.6 \times 10^{3}$ & $1.5 \times 10^{-6}$ \\
\hline${ }^{94} \mathrm{Nb}$ & $5.2 \times 10^{0}$ & $7.7 \times 10^{-4}$ & ${ }^{240} \mathrm{Pu}$ & $2.6 \times 10^{3}$ & $1.5 \times 10^{-6}$ \\
\hline${ }^{99} \mathrm{Tc}$ & $1.1 \times 10^{\circ}$ & $3.6 \times 10^{-3}$ & ${ }^{241} \mathrm{Pu}$ & $5.0 \times 10^{1}$ & $8.0 \times 10^{-5}$ \\
\hline${ }^{107} \mathrm{Pd}$ & $1.1 \times 10^{-1}$ & $3.6 \times 10^{-2}$ & ${ }^{242} \mathrm{Pu}$ & $2.5 \times 10^{3}$ & $1.6 \times 10^{-6}$ \\
\hline${ }^{113 \mathrm{~m}} \mathrm{Cd}$ & $1.2 \times 10^{2}$ & $3.3 \times 10^{-5}$ & ${ }^{244} \mathrm{Pu}$ & $2.4 \times 10^{3}$ & $1.7 \times 10^{-6}$ \\
\hline${ }^{121 \mathrm{~m}} \mathrm{Sn}$ & $1.2 \times 10^{0}$ & $3.3 \times 10^{-3}$ & ${ }^{241} \mathrm{Am}$ & $2.6 \times 10^{3}$ & $1.5 \times 10^{-6}$ \\
\hline${ }^{126} \mathrm{Sn}$ & $1.5 \times 10^{1}$ & $2.7 \times 10^{-4}$ & ${ }^{242 \mathrm{~m}} \mathrm{Am}$ & $2.6 \times 10^{3}$ & $8.2 \times 10^{-7}$ \\
\hline${ }^{129} \mathrm{I}$ & $2.0 \times 10^{2}$ & $2.0 \times 10^{-5}$ & ${ }^{243} \mathrm{Am}$ & $2.6 \times 10^{3}$ & $1.5 \times 10^{-6}$ \\
\hline${ }^{135} \mathrm{Cs}$ & $5.2 \times 10^{0}$ & $7.7 \times 10^{-4}$ & ${ }^{243} \mathrm{Cm}$ & $1.8 \times 10^{3}$ & $2.2 \times 10^{-6}$ \\
\hline${ }^{137} \mathrm{Cs}$ & $3.7 \times 10^{1}$ & $1.1 \times 10^{-4}$ & ${ }^{244} \mathrm{Cm}$ & $1.5 \times 10^{3}$ & $2.7 \times 10^{-6}$ \\
\hline${ }^{151} \mathrm{Sm}$ & $2.8 \times 10^{-1}$ & $1.4 \times 10^{-2}$ & ${ }^{245} \mathrm{Cm}$ & $2.7 \times 10^{3}$ & $1.5 \times 10^{-6}$ \\
\hline${ }^{152} \mathrm{Eu}$ & $4.7 \times 10^{0}$ & $8.5 \times 10^{-4}$ & ${ }^{246} \mathrm{Cm}$ & $2.7 \times 10^{3}$ & $1.5 \times 10^{-6}$ \\
\hline${ }^{154} \mathrm{Eu}$ & $6.9 \times 10^{0}$ & $5.8 \times 10^{-4}$ & ${ }^{247} \mathrm{Cm}$ & $2.5 \times 10^{3}$ & $1.6 \times 10^{-6}$ \\
\hline${ }^{155} \mathrm{Eu}$ & $1.1 \times 10^{0}$ & $3.6 \times 10^{-3}$ & ${ }^{248} \mathrm{Cm}$ & $1.0 \times 10^{4}$ & $4.0 \times 10^{-7}$ \\
\hline${ }^{194} \mathrm{Os}$ & $8.0 \times 10^{0}$ & $5.0 \times 10^{-4}$ & ${ }^{249} \mathrm{Cf}$ & $3.4 \times 10^{3}$ & $1.2 \times 10^{-6}$ \\
\hline${ }^{207} \mathrm{Bi}$ & $4.0 \times 10^{0}$ & $9.8 \times 10^{-4}$ & ${ }^{250} \mathrm{Cf}$ & $1.5 \times 10^{3}$ & $2.7 \times 10^{-6}$ \\
\hline${ }^{210} \mathrm{~Pb}$ & $5.3 \times 10^{3}$ & $7.5 \times 10^{-7}$ & ${ }^{251} \mathrm{Cf}$ & $3.5 \times 10^{3}$ & $1.1 \times 10^{-6}$ \\
\hline${ }^{226} \mathrm{Ra}$ & $9.5 \times 10^{2}$ & $6.3 \times 10^{-7}$ & & & \\
\hline
\end{tabular}

${ }^{a}$ Annual effective dose equivalents (EDEs) per unit concentration for the drinking water pathway are from Table G.7 (Appendix G).

${ }^{b}$ Maximum allowable drinking water concentration assumes a consumption rate of $2 \mathrm{~L} /$ day and a maximum allowable EDE of 4 mrem per year. 
drinking water pathway and air pathway are met, then the performance criteria for all pathways also is met without the need for further analysis.

Use of contaminated groundwater or surface water to irrigate food crops or pasturelandwhich would result in additional exposure pathways for off-site individuals involving, for example, consumption of contaminated foodstuffs or soil, external exposure to radionuclides in surface soil, and inhalation of radionuclides suspended from surface soil into the air-is not considered to be a credible occurrence and, thus, is not considered in the dose assessment. The relevant exposure pathways for a performance assessment are those that are reasonably likely to occur at the disposal site, but unlikely exposure pathways need not be evaluated (DOE 1996c). Rainfall normally is abundant in Oak Ridge, and irrigation is not commonly practiced near the disposal site at the present time. Thus, exposure pathways involving irrigation with contaminated water are ignored. Moreover, inclusion of the irrigation pathways would not change the results of the performance assessment significantly, because the performance criterion for the drinking water pathway is considerably more restrictive than the performance criterion for all exposure pathways in determining allowable releases of radionuclides in water and the dose per unit concentration of radionuclides in water for the irrigation pathways is expected to be comparable to or less than the dose per unit concentration for the drinking water pathway only (MMES et al. 1994).

Simple multiplicative-chain models are used to estimate doses for the different exposure pathways listed above, based on the calculated concentrations of radionuclides in water at the assumed locations of off-site individuals. These models, which are presented in Appendix G, Sect. G.5.1, take into account transfers of radionuclides through foodchain pathways, intakes of water and foodstuffs or exposure times, and the dose per unit intake or exposure for each radionuclide. The simple doseassessment models assume that the concentrations of radionuclides throughout the human exposure environment are in equilibrium with the concentrations in the source region (i.e., water). This assumption is appropriate for long-term prospective dose assessments involving continuous releases to the environment, especially when the releases are expected to vary only slowly over the lifetime of exposed individuals.

In this assessment, exposure pathway modeling and dose estimation for inadvertent intruders are considered separately from the dose assessment for off-site individuals. The dose analysis for inadvertent intruders is presented in Sect. 6.

\subsubsection{Air Pathways Analysis Methodology}

This section discusses the method used for analyzing the air pathway. As mentioned in Sect. 4.2.2, nonvolatile transport of radionuclides by the air pathway is not considered in this revised PA, the existing data for the ORR indicate that airborne releases of radionuclides in particulate form should be unimportant. The method used for this revised PA addresses the transport of volatile radionuclides to an off-site individual member of the public for the purpose of demonstrating compliance with the performance criterion of 10 mrem per year for airborne releases. Also, the method used for evaluating the radon performance criterion is discussed. The results of the air pathway analysis are considered in the all-pathways analysis, as discussed in Sect. 4.3.1.3. 


\subsubsection{Analysis for Volatile Radionuclides}

The volatile radionuclides ${ }^{3} \mathrm{H}$ and ${ }^{14} \mathrm{C}$ are assumed to diffuse to the soil surface, become airborne, and then be transported via atmospheric dispersion to receptors located downwind of the waste disposal unit. The Industrial Source Complex-Version 3 Long-Term Air Dispersion Model (ISCLT3) (EPA 1995) is used to determine ambient ${ }^{3} \mathrm{H}$ and ${ }^{14} \mathrm{C}$ concentrations for receptors located downwind of SWSA 6. ISCLT3 is a Gaussian dispersion model approved by the EPA for refined analyses in which annual average atmospheric concentrations in simple terrain are to be calculated (40 CFR 51, App. W).

For the air pathways analysis, each waste disposal unit is treated as an area source. Atmospheric pathway receptor locations are shown in Fig. 4.18. On-site meteorological data recorded between 1989 and 1993 are used in the analysis.

The performance objective for atmospheric releases, 10 mrem per year, includes doses from all potential exposure pathways associated with atmospheric releases. The annual doses for the two volatiles of interest, ${ }^{3} \mathrm{H}$ and ${ }^{14} \mathrm{C}$, are calculated from four exposure pathways:

1. inhalation of airborne radionuclides,

2. ingestion of vegetation exposed to airborne radionuclides (i.e., airborne-contaminated vegetation),

3. ingestion of beef from cattle that have consumed airborne-contaminated vegetation, and

4. ingestion of milk from cattle that have consumed airborne-contaminated vegetation.

No external doses are expected, since these beta-emitting radionuclides have external dose conversion factors equal to zero (DOE 1988b). The total dose from the atmospheric transport pathway is the sum of the doses from each of the four exposure pathways listed above. The equations used to calculate each exposure pathway dose are described in Appendix H. The exposure pathway methodology is based on a conservative specific-activity model presented in NRC Regulatory Guide 1.109 (NRC 1977). Because this is an upper-bound screening assessment, radioactive decay is not included in the calculations.

\subsubsection{Analysis for Radon Emanation}

The performance objectives for exposure of off-site individuals of 25 mrem per year from all release and exposure pathways and 10 mrem per year from airborne releases only do not include doses from inhalation of radon and its short-lived decay products. Rather, as discussed in Sect. 2.5.1, a separate performance objective for the average emanation rate of radon at the ground surface of $20 \mathrm{pCi} / \mathrm{m}^{2} / \mathrm{s}$ for 1000 years after disposal is applied (DOE 1996c). This section presents an analysis to demonstrate compliance with the performance objective for radon emanations for the various disposal units in SWSA 6.

The radon isotopes of concern to this assessment include ${ }^{222} \mathrm{Rn}\left(\mathrm{T}_{1 / 2}=3.8235 \mathrm{~d}\right)$ and ${ }^{220} \mathrm{Rn}$ $\left(\mathrm{T}_{1 / 2}=55.61 \mathrm{~s}\right)$. The amounts of these isotopes that would be present in disposal units at any time are determined by the amounts of their longer-lived parent isotopes, ${ }^{226} \mathrm{Ra}\left(\mathrm{T}_{1 / 2}=1600\right.$ years $)$ and ${ }^{228} \mathrm{Ra}$ 


\section{Receptor Locations for SWSA 6 Air Pathway Modeling Based on an Expanded Buffer Zone}

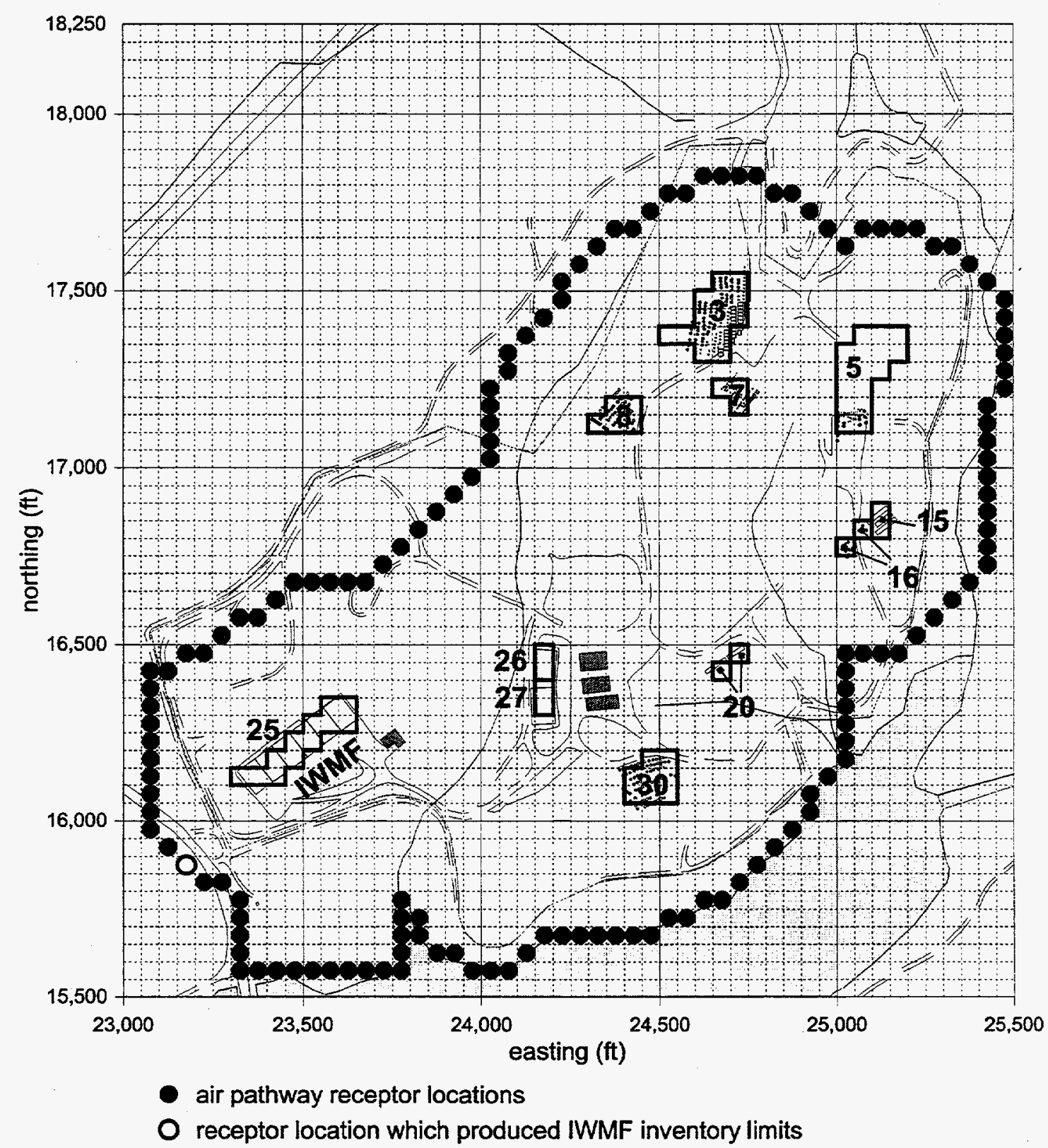

Fig. 4.18. Receptor locations for the air pathway based on the expanded buffer zone. 
$\left(T_{1 / 2}=5.75\right.$ years), respectively. Furthermore, for times beyond a few decades after disposal, the amount of ${ }^{228} \mathrm{Ra}$ would be determined by the amount of its long-lived parent isotope, ${ }^{232} \mathrm{Th}$.

In natural soils, which contain approximately the same concentrations of ${ }^{226} \mathrm{Ra}$ and ${ }^{232} \mathrm{Th}$ (NCRP 1984), the emanation rate of ${ }^{222} \mathrm{Rn}$ is substantially higher than for ${ }^{220} \mathrm{Rn}$ (NCRP 1989), due to the much shorter half-life of ${ }^{220} \mathrm{Rn}$ and, thus, the much thinner layer of surface soil from which emanations of ${ }^{220} \mathrm{Rn}$ can occur. Therefore, emanation of ${ }^{220} \mathrm{Rn}$ would be of concern to this assessment only if the concentrations of ${ }^{232} \mathrm{Th}$ or ${ }^{228} \mathrm{Ra}$ in disposed waste were much higher than the concentrations of ${ }^{226} \mathrm{Ra}$ or its longer-lived parent isotopes ${ }^{230} \mathrm{Th},{ }^{234} \mathrm{U}$, and ${ }^{238} \mathrm{U}$.

\subsection{Analysis for the IWMF}

For the IWMF, the results of the dose analysis for off-site releases of radionuclides in water presented in Sect. 5.1.2 and the results of the dose analysis for inadvertent intruders presented in Sect. 6.3.2 are used in establishing limits on average concentrations and inventories of radionuclides for disposal. Results summarized in Table 5.28 show that there are no disposal limits for the radium, thorium, or uranium parent isotopes of radon, based on the analysis for off-site releases in water. Therefore, allowable disposals of these radionuclides in the IWMF are based on the results of the dose analysis for inadvertent intruders, which are summarized in Table 6.13. The concentration limits in this table can be used in conjunction with data on radon emanations from natural soil and the effect of the cover materials on the disposal unit in attenuating emanations of radon to evaluate whether the disposal limits for the parent isotopes of radon based on the intruder dose analysis for the IWMF would provide compliance with the performance objective for radon emanations. The analyses for ${ }^{222} \mathrm{Rn}$ and ${ }^{220} \mathrm{Rn}$ are described in the following paragraphs.

\section{Analysis for ${ }^{222} \mathbf{R n}$}

As noted previously, the amount of ${ }^{222} \mathrm{Rn}$ that would be present in the IWMF at any time is determined by the amount of the parent isotope, ${ }^{226} \mathrm{Ra}$. For the IWMF, the limit on the allowable average concentration of ${ }^{226} \mathrm{Ra}$ in waste prior to disposal, as obtained from Table 6.13 , is $130 \mu \mathrm{Ci} / \mathrm{m}^{3}$, or $130 \mathrm{pCi} / \mathrm{cm}^{3}$. This limit is conservative for actual waste, because it would apply only if there were no other radionuclides in waste disposed in the IWMF. After disposal, the average concentration of ${ }^{226} \mathrm{Ra}$ in the IWMF would be reduced because of the presence of uncontaminated material within the disposal unit. As described in Sect. 6.3.1.1, about $40 \%$ of the total volume of the IWMF is occupied by waste after disposal. Therefore, the concentration limit for ${ }^{226} \mathrm{Ra}$ given above corresponds to a limit on average concentration in the IWMF after disposal of about $50 \mathrm{pCi} / \mathrm{cm}^{3}$.

In the absence of data on radon emanations from the IWMF, it is assumed in this assessment that the emanation rate from uncovered waste can be represented by the emanation rate from natural soil. The average emanation rate of ${ }^{222} \mathrm{Rn}$ over dry land is about $0.43 \mathrm{pCi} / \mathrm{m}^{2} / \mathrm{s}$ (NCRP 1989). This emanation rate results from an average concentration of ${ }^{226} \mathrm{Ra}$ in surface soil of about $0.6 \mathrm{pCi} / \mathrm{g}$ (NCRP 1984), which, for an average bulk density of soil of $1.4 \mathrm{~g} / \mathrm{cm}^{3}$ (Baes and Sharp 1983), corresponds to $0.84 \mathrm{pCi} / \mathrm{cm}^{3}$. Therefore, the average emanation rate of ${ }^{222} \mathrm{Rn}$ at the ground surface per unit 
concentration of ${ }^{226} \mathrm{Ra}$ in soil is assumed to be $0.43 / 0.84=0.5 \mathrm{pCi} / \mathrm{m}^{2} / \mathrm{s}$ per $\mathrm{pCi} / \mathrm{cm}^{3}$. Applying this result to the limit on average concentration of ${ }^{226} \mathrm{Ra}$ in the IWMF after disposal of $50 \mathrm{pCi} / \mathrm{cm}^{3}$ gives an estimated average emanation rate of ${ }^{222} \mathrm{Rn}$ from uncovered waste of $25 \mathrm{pCi} / \mathrm{m}^{2} / \mathrm{s}$ for the maximum allowable disposals.

The effect of the cover material on the IWMF in attenuating emanations of ${ }^{222} \mathrm{Rn}$ at the ground surface is taken into account as follows. As described in Sect. 2.6.3.6, the total thickness of cover material on the IWMF after closure is expected to be $1.5 \mathrm{~m}$. The EPA (1982) has evaluated the effectiveness of various thicknesses of different cover materials in attenuating emanations of ${ }^{222} \mathrm{Rn}$. For average soil, the half-value layer, which is defined as the thickness of a cover that would reduce the emanation rate from uncovered materials by a factor of 2 , was estimated to be $0.5 \mathrm{~m}$ (EPA 1982, Fig. 5-1). Therefore, for average soil, a cover thickness of $1.5 \mathrm{~m}$ is estimated to reduce the ${ }^{222} \mathrm{Rn}$ emanation rate at the ground surface by a factor of 8 . This estimate should be somewhat conservative for the cover material on the IWMF, because the current cover design includes a clay layer, and clay should be considerably more effective than average soil in attenuating radon emanations (EPA 1982).

Therefore, taking into account the estimated average emanation rate of ${ }^{222} \mathrm{Rn}$ from an uncovered disposal unit corresponding to the disposal limit for ${ }^{226} \mathrm{Ra}$ and the effect of the cover material in attenuating emanations of ${ }^{222} \mathrm{Rn}$, the maximum emanation rate of ${ }^{222} \mathrm{Rn}$ at the ground surface for the IWMF is estimated to be about $3 \mathrm{pCi} / \mathrm{m}^{2} / \mathrm{s}$. Although this estimate is subject to considerable uncertainty - due, for example, to the variability in the emanation rate of radon depending on soil type (NCRP 1989), the uncertainty in applying data on radon emanations from natural soils to waste in the IWMF, and the uncertainty in the performance of the cover material in attenuating radon emanations from the IWMF - it nonetheless seems reasonable to conclude that the rate of emanation of radon from the IWMF should be considerably less than the performance objective of $20 \mathrm{pCi} / \mathrm{m}^{2} / \mathrm{s}$. This is especially the case when disposals of other radionuclides, which would substantially reduce the allowable disposals of ${ }^{226} \mathrm{Ra}$, are taken into account. In addition, the attenuation of radon emanations provided by the cover on the IWMF could be somewhat higher than assumed in this analysis, due to the presence of clay materials.

As noted previously, ${ }^{230} \mathrm{Th},{ }^{234} \mathrm{U}$, and ${ }^{238} \mathrm{U}$ are parent isotopes of ${ }^{226} \mathrm{Ra}$, and their disposals could result in emanations of ${ }^{222} \mathrm{Rn}$ following buildup of ${ }^{226} \mathrm{Ra}$ in the waste. However, because the disposal limits for the parent isotopes of ${ }^{226} \mathrm{Ra}$ given in Table 6.13 take into account the contributions to dose to inadvertent intruders from isotopes that are not present in disposals of ${ }^{226} \mathrm{Ra}$ alone, disposals of these isotopes at their limits would result in concentrations of ${ }^{226} \mathrm{Ra}$ in the waste during the 1000 year time period of concern for applying the performance objective that are less than the limiting concentration for disposal of ${ }^{226} \mathrm{Ra}$ given in Table 6.13. Therefore, the presence of any parent isotopes of ${ }^{226} \mathrm{Ra}$ in the waste would reduce the resulting emanation rate of ${ }^{222} \mathrm{Rn}$ from the IWMF compared with the value for disposal of ${ }^{226} \mathrm{Ra}$ alone, and compliance with the performance objective for radon emanations can be evaluated based only on the disposal limit for ${ }^{226} \mathrm{Ra}$. 


\section{Analysis for ${ }^{220} \mathrm{Rn}$}

As noted previously, the amount of ${ }^{220} \mathrm{Rn}$ that would be present in the IWMF at any time after disposal is determined by the amounts of the parent isotopes ${ }^{228} \mathrm{Ra}$ and ${ }^{232} \mathrm{Th}$. Based on the concentration limits for the two parent isotopes given in Table 6.13, allowable disposals of the shorterlived ${ }^{228} \mathrm{Ra}$ clearly are much more important than allowable disposals of ${ }^{232} \mathrm{Th}$ in determining the maximum potential emanations of ${ }^{220} \mathrm{Rn}$ from the IWMF. However, based only on the following consideration of the effectiveness of the cover material on the IWMF, emanations of ${ }^{220} \mathrm{Rn}$ from the IWMF should be insignificant, in spite of the high concentration limit for disposal of ${ }^{228} \mathrm{Ra}$.

Upward transport of radon in soil generally is assumed to be controlled by diffusion. In a diffusion model, the effectiveness of a layer of cover material in attenuating emanations of radon from an uncovered source is inversely proportional to the square root of the half-life of the particular isotope (Tanner 1964). For example, the thickness of cover material required to attenuate emanations of ${ }^{220} \mathrm{Rn}$ by a given amount would be a factor of 80 less than the required thickness for ${ }^{222} \mathrm{Rn}$. In the analysis for

${ }^{222} \mathrm{Rn}$ presented above, the attenuation provided by the cover on the IWMF was assumed to be described by a half-value layer of $0.5 \mathrm{~m}$. Therefore, the half-value layer for ${ }^{220} \mathrm{Rn}$ provided by the cover is assumed to be $0.5 / 80=0.006 \mathrm{~m}$, and the expected thickness of the cover on the IWMF of $1.5 \mathrm{~m}$ corresponds to $1.5 / 0.006=250$ half-value layers for ${ }^{220} \mathrm{Rn}$. The emanation rate of ${ }^{220} \mathrm{Rn}$ from the IWMF thus should be essentially zero for any disposals of ${ }^{228} \mathrm{Ra}$.

\subsection{Analysis for Other Disposal Units}

For all disposal units except the IWMF, an assessment of potential releases of radon to the air can be based on the reported concentrations of the parent isotopes of radium, thorium, and uranium in waste and the considerations of radon emanation from uncovered waste and the effectiveness of cover materials on the disposal units in attenuating radon emanations discussed in Sect. 4.3.2.2.1. The analyses for ${ }^{222} \mathrm{Rn}$ and ${ }^{220} \mathrm{Rn}$ are described in the following paragraphs.

\section{Analysis for ${ }^{222} \mathbf{R n}$}

For the parent isotopes of ${ }^{222} \mathrm{Rn}$, the highest reported concentrations in waste prior to disposal, as given in Table 4.7, are $23 \mathrm{pCi} / \mathrm{cm}^{3}$ for ${ }^{226} \mathrm{Ra}$ in the north low-range silos and $1.4 \times 10^{4} \mathrm{pCi} / \mathrm{cm}^{3}$ for ${ }^{238} \mathrm{U}$ in the fissile wells. For the fissile wells, however, the maximum concentration of ${ }^{226} \mathrm{Ra}$ that would result from decay of the ${ }^{238} \mathrm{U}$ over the 1000 -year period of concern for applying the performance objective for radon emanations would be a factor of about $6 \times 10^{5}$ less than the initial concentration of ${ }^{238} \mathrm{U}$ (see the decay factors for the ${ }^{238} \mathrm{U}$ decay chain in the third column of Table 6.10 ). Therefore, during the 1000-year period of concern, potential radon emanations from the fissile wells would be much less than from the north low-range silos. These silos represent the worst case for potential radon emanations from the closed disposal units, given the reported disposals of the parent isotopes of ${ }^{222} \mathrm{Rn}$ in the other units (see Table 4.7) and the thickness of the cover on the other units (see Sect. 2.6.3.6). 
As described in Sect. 6.3.1.1, about $25 \%$ of the total volume of the north low-range silos is occupied by waste after disposal. Therefore, the reported disposals of ${ }^{226} \mathrm{Ra}$ in these silos correspond to an average concentration after disposal of about $6 \mathrm{pCi} / \mathrm{cm}^{3}$. As described in Sect. 4.3.2.2.1, the average emanation rate of ${ }^{222} \mathrm{Rn}$ from uncovered waste is assumed to be $0.5 \mathrm{pCi} / \mathrm{m}^{2} / \mathrm{s}$ per $\mathrm{pCi} / \mathrm{cm}^{3}$ of ${ }^{226} \mathrm{Ra}$ in the waste. Therefore, the average emanation rate of ${ }^{222} \mathrm{Rn}$ from uncovered waste in the north low-range silos is estimated to be about $3 \mathrm{pCi} / \mathrm{m}^{2} / \mathrm{s}$, which is nearly an order of magnitude less than the performance objective. Taking into account the expected thickness of the cover material of $0.6 \mathrm{~m}$, (based on the thickness of the caps on the silos described in Sect. 3.2.1.1.1 and the thickness of soil that will be added as a cover described in Sect. 2.6.3.6) and the assumed half-value layer of $0.5 \mathrm{~m}$ for attenuation of ${ }^{222} \mathrm{Rn}$ emanations by the cover material, (as described in Sect. 4.3.2.2.1) the cover on the north low-range silos should reduce the ${ }^{222} \mathrm{Rn}$ emanation rate by about a factor of 2 , to less than $1.5 \mathrm{pCi} / \mathrm{m}^{2} / \mathrm{s}$.

Therefore, based on the assessment of ${ }^{222} \mathrm{Rn}$ emanations from the north low-range silos, which should have the highest emanation rate during the 1000-year period of concern for any of the closed disposal units, potential ${ }^{222} \mathrm{Rn}$ emanations from all closed disposal units should be substantially less than the performance criterion of $20 \mathrm{pCi} / \mathrm{m}^{2} / \mathrm{s}$.

\section{Analysis for ${ }^{220} \mathbf{R n}$.}

For all closed disposal units in which disposals of the parent isotopes of ${ }^{220} \mathrm{Rn}$ have been reported in Table 4.7, the expected thickness of the cover is $0.6 \mathrm{~m}$ or greater (see Sect. 3.2.1.1 and 2.6.3.6). Taking into account only the cover thickness and the assumed half-value layer of $0.006 \mathrm{~m}$ for attenuation of ${ }^{220} \mathrm{Rn}$ emanations provided by the cover material, as described in Sect. 4.3.2.2.1, the thickness of the cover on the closed disposal units corresponds to at least 100 half-value layers for ${ }^{220} \mathrm{Rn}$. Therefore, the ${ }^{220} \mathrm{Rn}$ emanation rate from all closed disposal units should be essentially zero, regardless of the actual disposals of the parent isotopes of ${ }^{220} \mathrm{Rn}$.

\subsection{Summary of Analysis for Radon}

The results of the assessment of radon emanations from the various disposal units in SWSA 6 presented in this section may be summarized as follows.

- For the IWMF, the maximum potential emanation rate of ${ }^{222} \mathrm{Rn}$ at the ground surface for 1000 years after disposal should be about an order of magnitude less than the performance criterion of $20 \mathrm{pCi} / \mathrm{m}^{2} / \mathrm{s}$, based on the limits on allowable disposals of ${ }^{226} \mathrm{Ra}$ and the other parent isotopes of ${ }^{222} \mathrm{Rn}$, as obtained from the dose analysis for inadvertent intruders, and the expected thickness of the cover on the IWMF.

- For all closed disposal units, the emanation rate of ${ }^{222} \mathrm{Rn}$ at the ground surface for 1000 years after disposal should be at least an order of magnitude less than the performance criterion of 
$20 \mathrm{pCi} / \mathrm{m}^{2} / \mathrm{s}$, based on the reported disposals of the parent isotopes of ${ }^{222} \mathrm{Rn}$ and the expected thickness of the cover on these units.

- For the IWMF and all closed disposal units, the emanation rate of ${ }^{220} \mathrm{Rn}$ at the ground surface should be essentially zero, based on the expected thickness of the cover on these units, regardless of the allowable or actual disposals of the parent isotopes of ${ }^{220} \mathrm{Rn}$.

Therefore, based on this analysis, there is a reasonable expectation that all disposals in SWSA 6 will comply with the performance criterion of $20 \mathrm{pCi} / \mathrm{m}^{2} / \mathrm{s}$ for the radon emanation rate at the ground surface for 1000 years after disposal.

\subsubsection{Water Resources Protection Analysis Methodology}

The discussion of the all-pathways analysis methodology in Sect. 4.3.1 includes the method for determining the concentrations of radionuclides in groundwater and surface water from the closed disposal units in SWSA 6 and the limiting radionuclide concentrations in waste for IWMF disposals that meet the performance criterion of 4 mrem per year for groundwater and surface water. The method applied to the all-pathways analysis for evaluating water resources is the same as the method for water resources protection because both analyses rely upon meeting the 4 mrem per year performance criterion for groundwater and surface water. 


\section{RESULTS OF ANALYSIS}

This section presents the results of the all pathways, air pathways, and water resource protection analyses described in Sect. 4.3, a discussion of the sensitivity and uncertainty of these results, and the ALARA analysis for the SWSA 6 facility. The inadvertent intruder analysis and its results are presented in Sect. 6. The results from the pathways analysis for transport of radionuclides in the environment represent reasonably conservative estimates of the long-term performance of the facility for demonstrating compliance with the performance objectives of DOE O 5820.2A. Furthermore, these results represent the final iteration of the many calculations made for this revised $\mathrm{PA}$, and provide waste inventories for future disposal of IWMF that are consistent with the performance objectives of DOE O 5820.2A.

The results of the dose analysis for inadvertent intruders for all disposal limits in SWSA 6 and derivation of limits on allowable inventories of radionuclides for the IWMF based on the intruder dose analysis are presented in Sect. 6. For the IWMF, the limits on allowable inventories obtained from the analyses for off-site releases and inadvertent intruders then are combined to obtain the disposal limits for the IWMF that are consistent with all of the performance objectives in DOE O 5820.2A. These disposal limits are then used to evaluate the existing disposal at IWMF to demonstrate compliance with the DOE O 5820.2A in Sect. 7.

\subsection{RESULTS OF ALL-PATHWAYS ANALYSIS}

The summary and intermediate results presented in this section are for the transport of radionuclides from the SWSA 6 facility by groundwater and surface water. As discussed in Section 4.3.1, the all-pathways performance criterion of 25 mrem per year is met if the performance criterion of 4 mrem per year from drinking water, which is also the water resources protection criterion, is met for both surface water and groundwater, and if the air pathways performance criterion is met. This section presents the results of the analysis of the transport of radionuclides from the SWSA 6 facility for groundwater and surface water that demonstrate the performance criteria are met for the closed disposal units at SWSA 6 and provide inventory limits for the IWMF which meet the performance criteria for the water pathways. The results demonstrate that SWSA 6 meets the performance criteria for the all-pathways analysis.

The organization of this section follows the logic of the modeling process. First to be determined are the source terms, calculated as release rates of radionuclides leached from the closed disposal units. Following the estimation of the fixed-inventory source terms from closed disposal units is the iterative estimation of inventories for IWMF which correspond to the maximum allowable EDE, at the point of exposure. This process is iterative, since the chain of computer programs (which calculate releases from the waste form, partitioning of leachate into the shallow subsurface and 
groundwaters, and the transport of contaminants through the aqueous environment) works from the waste inventory to produce a concentration in drinking water, not vice versa. The relationship between inventory and concentration at the exposure point is often non-linear, due to the effects of solubility limits for many radionuclides and the result (the maximum allowable inventory) is obtained only by successive estimation of the inventory.

An objective of the PA is to determine an inventory limit for each radionuclide that might be disposed of at the IWMF. This inventory limit is interpreted as that largest (activity) of a single radionuclide placed in the IWMF which results in an EDE below or equivalent to the 4 mrem per year EDE to a hypothetical person consuming $2 \mathrm{~L}$ /day of drinking water at a specified exposure location. Also contributing to that concentration (and corresponding dose) are other disposals of the same radionuclide in other disposal units in SWSA 6 (and disposed of after September 26, 1988, as specified in the DOE Order). The non-IWMF disposed inventories are fixed, since the disposal units are now closed. The total dose from all of these disposals, including IWMF, must be less than the 4 mrem per year limit. Thus, the amount of a given radionuclide allowed in IWMF corresponds to the difference between the dose attributed to the closed units and the dose limit. For example, if the closed facilities together generate an estimated EDE of 1 mrem per year from a given radionuclide at an exposure point, then the IWMF could accept an inventory which is estimated to produce an EDE of 3 mrem per year at the same point of maximum exposure, ignoring all other radionuclides. In cases where there are no non-IWMF disposals of a given radionuclide, the maximum allowable IWMF inventory accounts for all of the dose.

Given the fixed inventories of the closed disposal units, the contribution to doses from each radionuclide within the closed units is calculated in order to determine the allowable inventory remaining for that radionuclide at IWMF. For all radionuclides, the calculated results provided some allowable inventory for disposal at IWMF. Since IWMF contains a variety of radionuclides, however, in no case would the maximum allowable inventory for any one of them be actually disposed. The cumulative dose from all disposed radionuclides needs to be considered by the use of the sum of fractions rule. The application of the sum of fractions rule is discussed in Sect. 7 , since it is not considered in the calculations or in the presentation of results. The application of the sum-of-fractions to waste management has no unique solution (in terms of specific inventories) without additional information about relative amounts of radionuclides disposed. This information evolves as part of the operations of IWMF. The tables of results presented below consider each radionuclide independently.

The allowable IWMF inventory for a given radionuclide depends on the choice of exposure locations. Three scenarios are considered for the drinking water pathway: (1) all points in groundwater located beyond the $100 \mathrm{~m}$ buffer zone boundary, (2) the surface water integration point at White Oak Dam (WOD), and (3) all points in groundwater located beyond the expanded buffer zone. The three sets of allowable inventories for IWMF resulting from each of these scenarios are presented in Sect. 5.1.2.

A review of the chain of models helps to understand the results presented in this section. The SOURCE1 and SOURCE2 model calculations discussed in Sect. 4.1 provide radionuclide release rates over time from each disposal unit (the above-ground tumulus units and the below-ground units, 
respectively) into the subsurface environment. These fluxes are used as input into the PADSIM and HOLSIM models, which accept vertical and lateral radionuclide flux components from the disposal units (above-ground and below-ground units, respectively), determine nuclide flux through the recharge and lateral subsurface paths of the vadose zone, and account for chemical absorption and radioactive decay. Transport through the lateral subsurface path involves retarded migration of nuclides through the shallow subsurface and subsequent discharge into the surface water system. This produces a time-dependent radionuclide flux into surface waters, contributing one component to the surface water exposure analysis. Contaminants transported as part of groundwater recharge are used as input to the MOC groundwater model, which calculates transport through the saturated system. Groundwater calculations are evaluated as contaminants migrate past the hypothetical well locations, and the peak concentration is recorded for comparison to the performance criterion. Groundwater discharges to surface waters are also calculated and added to fluxes from the lateral component of the shallow subsurface model to produce the total radionuclide flux to surface water. Surface water concentrations are calculated from these fluxes and the discharge of water over WOD, and are compared to the drinking water limits (Table 4.19).

Calculations for the fixed-inventory (closed) disposal units are presented in Sect. 5.1.1. Intermediate results, which show peak lateral and recharge contaminant fluxes calculated during the source term and shallow subsurface transport analyses, are presented for each of the disposal units or zones. The purpose of these intermediate results is to provide the reader with a means of evaluating the degree of attenuation that each segment of the composite transport model has on the migration of radioactive contamination passing through the environment. Furthermore, due to the site-specific nature of parameters used to quantify environmental transport of radionuclides for each disposal unit, these results also give insight as to the primary sources and pathways of contamination of each radionuclide.

Results are presented for maximum release rates from individual waste units and subsequent maximum contaminant flux rates from each zone into lateral subsurface flow and into groundwater. Peak values are presented for each radionuclide disposed at each modeled facility. Complete time release curves for selected radionuclides are shown in Appendix F. These results are intermediate to the final results of the water pathway - the aqueous concentration at the point of exposure. The results for the closed disposal units are based on fixed inventories, and so are not part of the iterative recalculation process.

The results for IWMF, presented in Sect. 5.1.2, also include these intermediate calculations. Rather than tabulate intermediate values for each exposure scenario, only those for the expanded buffer zone are shown, which is the scenario used for calculating the allowable inventories for the groundwater pathway. In other words, the inventories used to generate this particular set of intermediate calculations are the final inventories for IWMF (arrived at through the iterative modeling process) for the expanded buffer zone. The results of the water pathway calculations-the maximum allowable IWMF inventories which satisfy the performance objective-are then presented for each water pathway exposure scenario. 
For most radionuclides, no realistic inventory is large enough to result in an exposure point concentration which corresponds to the 4 mrem per year EDE limit. As a theoretical upper bound, these cases used an inventory based on the density and activity of the pure element in a single isotopic state (see Table 4.2). For example, even if ${ }^{232} \mathrm{Th}$ were disposed of at the IWMF as 1980 vaults of pure ${ }^{232} \mathrm{Th}$, the drinking water dose at the exposure point attributable to ${ }^{232} \mathrm{Th}$ would still be below the performance objective. This behavior is often the result of solubility limitations in the leaching of the waste form.

The disposals of only 15 radionuclides were actually limited by the water pathway, rather than by the theoretical maximum inventory. The disposal limits for these 15, presented in Table 5.33, are the minimum of either the surface water or groundwater pathway. In all cases, the groundwater pathway is the more restrictive.

\subsubsection{Results for Closed Disposal Units}

The following section presents results from the analysis of the source term, transport of radionuclides in the shallow subsurface, and transport of radionuclides in the groundwater and surface water for the closed disposal units in SWSA 6. The results were calculated using the methodology presented in Sect. 4. The results are compared to the performance criterion of 4 mrem per year for the consumption of drinking water as part of demonstrating compliance with DOE O 5820.2A for all pathways, and water resource protection (Sect. 5.3).

\subsubsection{Output from the Modeling of Releases from Closed Disposal Units}

The SOURCE1 and SOURCE2 programs calculate radionuclide mass release rates from the individual disposal units which are closed in SWSA 6. Peak annual releases for the closed disposal units are presented in Table 5.1 through Table 5.12. For each radionuclide, these tables present the average recorded inventory in the waste management data base which were used in the calculations. The tables present the peak releases and year(s) of occurrence calculated by the SOURCE codes. The calculated releases are divided into two components: 1) a vertical component, which recharges to groundwater, and 2) a lateral component, which flows in the shallow subsurface region and discharges to surface water. These components are provided as inputs to the PADSIM and HOLSIM programs. For entries which have a range of years indicated for the year of occurrence, the release is limited by solubility during that period. Note that in Table 5.10 and Table 5.11 for Tumulus II and Tumulus I, respectively, there is no lateral component. This lack of a lateral component is a result of the close proximity of the tumulus-type disposal units to the saturated zone (this is also true for IWMF). Hence, all leachate from the tumulus disposal units is released to the vertical (groundwater recharge) path. The results presented in the tables include the radioactive decay from the time of the disposal to the time of release from the disposal unit. 
Table 5.1. Maximum annual release rate from a single high-range silo in Zone 3 and year of occurrence for vertical and lateral release components of SOURCE2 calculations

\begin{tabular}{lcccccc}
\hline \multirow{2}{*}{ Nuclide } & $\begin{array}{c}\text { Inventory } \\
(\mathrm{g} / \mathrm{silo})\end{array}$ & $\begin{array}{c}\text { Peak flux } \\
\text { (g/year) }\end{array}$ & $\begin{array}{c}\text { Time of peak } \\
\text { (year) }\end{array}$ & & $\begin{array}{c}\text { Peak flux } \\
\text { (g/year) }\end{array}$ & $\begin{array}{c}\text { Time of peak } \\
\text { (year) }\end{array}$ \\
\hline${ }^{3} \mathrm{H}$ & $2.9 \times 10^{-5}$ & $2.4 \times 10^{-8}$ & 8 & & $6.7 \times 10^{-8}$ & 8 \\
${ }^{14} \mathrm{C}$ & $2.6 \times 10^{-4}$ & $1.1 \times 10^{-5}$ & 250 & & $4.9 \times 10^{-5}$ & 250 \\
${ }^{40} \mathrm{~K}$ & $6.8 \times 10^{\circ}$ & $6.7 \times 10^{-2}$ & 250 & & $2.9 \times 10^{-1}$ & 250 \\
${ }^{63} \mathrm{Ni}$ & $6.4 \times 10^{-5}$ & $1.2 \times 10^{-7}$ & 250 & & $5.4 \times 10^{-7}$ & 250 \\
${ }^{90} \mathrm{Sr}$ & $2.8 \times 10^{-3}$ & $5.1 \times 10^{-8}$ & 250 & & $2.3 \times 10^{-7}$ & 250 \\
${ }^{137} \mathrm{Cs}$ & $5.2 \times 10^{-3}$ & $6.0 \times 10^{-8}$ & 250 & & $2.6 \times 10^{-7}$ & 250 \\
${ }^{152} \mathrm{Eu}$ & $4.9 \times 10^{-4}$ & $6.5 \times 10^{-12}$ & 25 & & $9.3 \times 10^{-12}$ & 19 \\
${ }^{154} \mathrm{Eu}$ & $1.3 \times 10^{-4}$ & $8.8 \times 10^{-13}$ & 25 & & $1.6 \times 10^{-12}$ & 13 \\
${ }^{155} \mathrm{Eu}$ & $1.7 \times 10^{-6}$ & $4.2 \times 10^{-15}$ & 7 & & $1.2 \times 10^{-14}$ & 7 \\
${ }^{232} \mathrm{Th}$ & $3.4 \times 10^{13}$ & $7.2 \times 10^{-4}$ & 250 & & $3.1 \times 10^{-3}$ & 250 \\
${ }^{238} \mathrm{U}$ & $8.2 \times 10^{2}$ & $1.2 \times 10^{-4}$ & $250-50,000$ & & $5.4 \times 10^{-4}$ & $250-50,000$ \\
${ }^{239} \mathrm{Pu}$ & $4.6 \times 10^{-4}$ & $9.2 \times 10^{-9}$ & 250 & & $4.0 \times 10^{-8}$ & 250 \\
${ }^{244} \mathrm{Cm}$ & $1.8 \times 10^{-4}$ & $2.3 \times 10^{-13}$ & 250 & & $1.0 \times 10^{-12}$ & 250 \\
\hline
\end{tabular}

${ }^{a}$ Inventory is for 1 of 37 silos.

Table 5.2. Maximum annual release rate from a single high-range well in Zone 5 and year of occurrence for vertical and lateral release components of SOURCE2 calculations

\begin{tabular}{|c|c|c|c|c|c|}
\hline \multirow[b]{2}{*}{ Nuclide } & \multirow{2}{*}{$\begin{array}{c}\text { Inventory }^{a} \\
\text { (g/well) }\end{array}$} & \multicolumn{2}{|c|}{ Vertical component } & \multicolumn{2}{|c|}{ Lateral component } \\
\hline & & $\begin{array}{c}\text { Peak flux } \\
\text { (g/year) }\end{array}$ & $\begin{array}{c}\text { Time of peak } \\
\text { (year) }\end{array}$ & $\begin{array}{c}\text { Peak flux } \\
\text { (g/year) }\end{array}$ & $\begin{array}{l}\text { Time of peak } \\
\text { (year) }\end{array}$ \\
\hline${ }^{90} \mathrm{Sr}$ & $1.1 \times 10^{0}$ & $2.5 \times 10^{-3}$ & 74 & $8.6 \times 10^{-2}$ & 74 \\
\hline${ }^{137} \mathrm{Cs}$ & $1.7 \times 10^{0}$ & $2.6 \times 10^{-3}$ & 74 & $9.3 \times 10^{-2}$ & 74 \\
\hline
\end{tabular}

Inventory is for 1 of 9 wells.

Inventories in these tables are listed in terms of mass per disposal unit (well, silo, tumulus pad, etc.) For example, the inventories for the high-range silos in Table 5.1 are given in the units " $\mathrm{g} / \mathrm{silo"}$. Since there are 37 silos modeled in the entire zone, the total inventory for Zone 3 is 37 times the second column. Mass releases are also for individual units. This note applies similarly to the other tables. 
Table 5.3. Maximum annual release rate from a single high-range well-in-silo in Zone 5 and year of occurrence for vertical and lateral release components of SOURCE2

\begin{tabular}{|c|c|c|c|c|c|}
\hline \multirow[b]{2}{*}{ Nuclide } & \multirow{2}{*}{$\begin{array}{c}\text { Inventory }^{a} \\
(\mathrm{~g} / \mathrm{well})\end{array}$} & \multicolumn{2}{|c|}{ Vertical component } & \multicolumn{2}{|c|}{ Lateral component } \\
\hline & & $\begin{array}{c}\text { Peak flux } \\
\text { (g/year) }\end{array}$ & $\begin{array}{l}\text { Time of peak } \\
\text { (year) }\end{array}$ & $\begin{array}{c}\text { Peak flux } \\
\text { (g/year) }\end{array}$ & $\begin{array}{c}\text { Time of peak } \\
\text { (year) }\end{array}$ \\
\hline${ }^{4 !} \mathrm{Ca}$ & $1.6 \times 10^{-1}$ & $3.3 \times 10^{-3}$ & 450 & $1.0 \times 10^{-1}$ & 450 \\
\hline${ }^{60} \mathrm{Co}$ & $4.2 \times 10^{-2}$ & $7.8 \times 10^{-15}$ & 25 & $6.0 \times 10^{-14}$ & 8 \\
\hline${ }^{90} \mathrm{Sr}$ & $3.1 \times 10^{-2}$ & $2.4 \times 10^{-8}$ & 41 & $2.9 \times 10^{-7}$ & 450 \\
\hline${ }^{99} \mathrm{Tc}$ & $4.8 \times 10^{-1}$ & $1.2 \times 10^{-2}$ & 450 & $3.3 \times 10^{-1}$ & 450 \\
\hline${ }^{137} \mathrm{Cs}$ & $2.6 \times 10^{-1}$ & $9.1 \times 10^{-8}$ & 43 & $2.9 \times 10^{-6}$ & 450 \\
\hline${ }^{152} \mathrm{Eu}$ & $1.6 \times 10^{-1}$ & $7.4 \times 10^{-9}$ & 25 & $1.9 \times 10^{-8}$ & 19 \\
\hline${ }^{154} \mathrm{Eu}$ & $4.4 \times 10^{-2}$ & $1.0 \times 10^{-9}$ & 25 & $3.5 \times 10^{-9}$ & 13 \\
\hline${ }^{229} \mathrm{Th}$ & $7.2 \times 10^{-4}$ & $7.0 \times 10^{-8}$ & 450 & $2.4 \times 10^{-6}$ & 450 \\
\hline${ }^{232} \mathrm{Th}$ & $6.9 \times 10^{0}$ & $7.0 \times 10^{-4}$ & 450 & $2.4 \times 10^{-2}$ & 450 \\
\hline
\end{tabular}

Inventory is for 1 of 53 wells-in-silos.

Table 5.4. Maximum annual release rate from a single fissile well in Zone 7 and year of occurrence for vertical and lateral release components of SOURCE2 calculations

\begin{tabular}{lcccccc}
\hline \multirow{2}{*}{ Nuclide } & $\begin{array}{c}\text { Inventory } \\
\text { (g/well) }\end{array}$ & $\begin{array}{c}\text { Peak flux } \\
\text { (g/year) }\end{array}$ & $\begin{array}{c}\text { Time of peak } \\
\text { (year) }\end{array}$ & & $\begin{array}{c}\text { Peak flux } \\
\text { (g/year) }\end{array}$ & $\begin{array}{c}\text { Time of peak } \\
\text { (year) }\end{array}$ \\
\hline${ }^{137} \mathrm{Cs}$ & $2.4 \times 10^{-1}$ & $5.1 \times 10^{-4}$ & 75 & & $2.5 \times 10^{-3}$ & 75 \\
${ }^{232} \mathrm{Th}$ & $5.5 \times 10^{0}$ & $1.2 \times 10^{-4}$ & $75-5,300$ & & $5.8 \times 10^{-4}$ & $75-5,300$ \\
${ }^{235} \mathrm{U}$ & $1.4 \times 10^{2}$ & $1.2 \times 10^{-5}$ & $75-50,000$ & & $5.9 \times 10^{-5}$ & $75-50,000$ \\
${ }^{238} \mathrm{U}$ & $7.3 \times 10^{3}$ & $1.2 \times 10^{-5}$ & $75-50,000$ & & $5.9 \times 10^{-5}$ & $75-50,000$ \\
\hline
\end{tabular}

${ }^{a}$ Inventory is for 1 of 2 wells.

Table 5.5. Maximum annual release rate from a single Quadrex trench in Zone 8 and year of occurrence for vertical and lateral release components of SOURCE2 calculations

\begin{tabular}{lccccccc}
\hline \multirow{2}{*}{ Nuclide } & $\begin{array}{c}\text { Inventory } \\
\text { (g/trench) }\end{array}$ & $\begin{array}{c}\text { Peak flux } \\
\text { (g/year) }\end{array}$ & $\begin{array}{c}\text { Time of peak } \\
\text { (year) }\end{array}$ & & $\begin{array}{c}\text { Leak flux } \\
\text { (g/year) }\end{array}$ & $\begin{array}{c}\text { Time of peak } \\
\text { (year) }\end{array}$ \\
\hline${ }^{{ }^{90} \mathrm{Sr}}$ & $7.8 \times 10^{-7}$ & $2.5 \times 10^{-9}$ & 1 & & $1.1 \times 10^{-8}$ & 1 \\
${ }^{137} \mathrm{Cs}$ & $1.9 \times 10^{-3}$ & $2.7 \times 10^{-6}$ & 1 & & $1.1 \times 10^{-5}$ & 1 \\
${ }^{230} \mathrm{Th}$ & $2.3 \times 10^{-2}$ & $1.3 \times 10^{-5}$ & 1 & & $5.4 \times 10^{-5}$ & 1 \\
${ }^{232} \mathrm{Th}$ & $2.8 \times 10^{3}$ & $2.8 \times 10^{-2}$ & $1-20,000$ & & $1.1 \times 10^{-1}$ & $1-20,000$ \\
${ }^{235} \mathrm{U}$ & $2.0 \times 10^{1}$ & $1.1 \times 10^{-2}$ & 1 & & $4.5 \times 10^{-2}$ & 1 \\
${ }^{238} \mathrm{U}$ & $9.3 \times 10^{2}$ & $5.0 \times 10^{-1}$ & 1 & & $2.1 \times 10^{\circ}$ & 1 \\
${ }^{238} \mathrm{Pu}$ & $2.5 \times 10^{-5}$ & $1.3 \times 10^{-8}$ & 1 & & $5.5 \times 10^{-8}$ & 1 \\
${ }^{244} \mathrm{Cm}$ & $3.7 \times 10^{-6}$ & $1.8 \times 10^{-9}$ & 1 & & $7.7 \times 10^{-9}$ & 1 \\
\hline
\end{tabular}

${ }^{a}$ Inventory is for 1 of 5 trenches. 
Table 5.6. Maximum annual release rate from a single low-range silo in Zone 8 and year of occurrence for vertical and lateral release components of SOURCE2 calculations

\begin{tabular}{|c|c|c|c|c|c|}
\hline \multirow[b]{2}{*}{ Nuclide } & \multirow{2}{*}{$\begin{array}{c}\text { Inventory } \\
(\mathrm{g} / \mathrm{silo})\end{array}$} & \multicolumn{2}{|c|}{ Vertical component } & \multicolumn{2}{|c|}{ Lateral component } \\
\hline & & $\begin{array}{l}\text { Peak flux } \\
\text { (g/year) }\end{array}$ & $\begin{array}{l}\text { Time of peak } \\
\text { (year) }\end{array}$ & $\begin{array}{l}\text { Peak flux } \\
\text { (g/year) }\end{array}$ & $\begin{array}{l}\text { Time of peak } \\
\text { (year) }\end{array}$ \\
\hline${ }^{3} \mathrm{H}$ & $7.3 \times 10^{-5}$ & $9.9 \times 10^{-8}$ & 8 & $1.3 \times 10^{-7}$ & 8 \\
\hline${ }^{14} \mathrm{C}$ & $5.8 \times 10^{-5}$ & $2.5 \times 10^{-6}$ & 250 & $1.0 \times 10^{-5}$ & 251 \\
\hline${ }^{63} \mathrm{Ni}$ & $6.8 \times 10^{-5}$ & $1.3 \times 10^{-7}$ & 250 & $5.3 \times 10^{-7}$ & 251 \\
\hline${ }^{90} \mathrm{Sr}$ & $5.8 \times 10^{-3}$ & $1.1 \times 10^{-7}$ & 250 & $4.3 \times 10^{-7}$ & 250 \\
\hline${ }^{99} \mathrm{Tc}$ & $1.4 \times 10^{-1}$ & $2.9 \times 10^{-3}$ & 250 & $1.2 \times 10^{-2}$ & 250 \\
\hline${ }^{137} \mathrm{Cs}$ & $7.0 \times 10^{-3}$ & $8.2 \times 10^{-8}$ & 250 & $3.3 \times 10^{-7}$ & 250 \\
\hline${ }^{152} \mathrm{Eu}$ & $1.1 \times 10^{-3}$ & $1.5 \times 10^{-11}$ & 25 & $1.7 \times 10^{-11}$ & 19 \\
\hline${ }^{154} \mathrm{Eu}$ & $4.1 \times 10^{-4}$ & $3.0 \times 10^{-12}$ & 13 & $4.0 \times 10^{-12}$ & 13 \\
\hline${ }^{226} \mathrm{Ra}$ & $2.7 \times 10^{-4}$ & $9.1 \times 10^{-7}$ & 250 & $3.7 \times 10^{-6}$ & 250 \\
\hline${ }^{232} \mathrm{Th}$ & $2.6 \times 10^{3}$ & $1.2 \times 10^{-3}$ & $250-210,000$ & $4.9 \times 10^{-3}$ & $250-210,000$ \\
\hline${ }^{232} \mathrm{U}$ & $1.9 \times 10^{-7}$ & $3.2 \times 10^{-13}$ & 250 & $1.3 \times 10^{-12}$ & 250 \\
\hline${ }^{233} \mathrm{U}$ & $4.2 \times 10^{-2}$ & $8.6 \times 10^{-7}$ & 250 & $3.4 \times 10^{-6}$ & 250 \\
\hline${ }^{235} \mathrm{U}$ & $1.6 \times 10^{1}$ & $1.2 \times 10^{-4}$ & $250-17,000$ & $4.9 \times 10^{-4}$ & $250-17,000$ \\
\hline${ }^{238} \mathrm{U}$ & $2.0 \times 10^{3}$ & $1.2 \times 10^{-4}$ & $250-50,000$ & $5.0 \times 10^{-4}$ & $250-50,000$ \\
\hline${ }^{238} \mathrm{Pu}$ & $1.7 \times 10^{-6}$ & $4.6 \times 10^{-12}$ & 250 & $1.8 \times 10^{-11}$ & 250 \\
\hline${ }^{239} \mathrm{Pu}$ & $7.3 \times 10^{-2}$ & $1.5 \times 10^{-6}$ & 250 & $5.8 \times 10^{-6}$ & 250 \\
\hline${ }^{241} \mathrm{Am}$ & $1.2 \times 10^{-3}$ & $1.6 \times 10^{-8}$ & 250 & $6.4 \times 10^{-8}$ & 250 \\
\hline${ }^{243} \mathrm{Am}$ & $5.7 \times 10^{-5}$ & $1.1 \times 10^{-9}$ & 250 & $4.4 \times 10^{-9}$ & 250 \\
\hline${ }^{244} \mathrm{Cm}$ & $1.7 \times 10^{-5}$ & $2.2 \times 10^{-14}$ & 250 & $8.7 \times 10^{-14}$ & 250 \\
\hline${ }^{249} \mathrm{Cf}$ & $1.2 \times 10^{-5}$ & $1.4 \times 10^{-10}$ & 250 & $5.4 \times 10^{-10}$ & 250 \\
\hline
\end{tabular}

anventory is for 1 of 24 silos.

Table 5.7. Maximum annual release rate from a single biological trench in Zone $\mathbf{1 5}$ and year of occurrence for vertical and lateral release components of SOURCE2 calculations

\begin{tabular}{lccccccc}
\hline \multirow{2}{*}{ Nuclide } & $\begin{array}{c}\text { Inventory } \\
\text { (g/trench) }\end{array}$ & $\begin{array}{c}\text { Peak flux } \\
\text { (g/year) }\end{array}$ & $\begin{array}{c}\text { Time of peak } \\
\text { (year) }\end{array}$ & & $\begin{array}{c}\text { Peak flux } \\
\text { (g/year) }\end{array}$ & $\begin{array}{c}\text { Time of peak } \\
\text { (year) }\end{array}$ \\
\hline${ }^{90} \mathrm{Sr}$ & $2.2 \times 10^{-5}$ & $2.5 \times 10^{-8}$ & & 2 & & $2.1 \times 10^{-7}$ & 2 \\
${ }^{137} \mathrm{Cs}$ & $8.2 \times 10^{-6}$ & $4.2 \times 10^{-9}$ & 2 & & $3.6 \times 10^{-8}$ & 2 \\
\hline
\end{tabular}

Inventory is for 1 of 4 trenches. 
Table 5.8. Maximum annual release rate from a single asbestos silo in Zone 16 and year of occurrence for vertical and lateral release components of SOURCE2 calculations

\begin{tabular}{|c|c|c|c|c|c|}
\hline \multirow[b]{2}{*}{ Nuclide } & \multirow{2}{*}{$\begin{array}{l}\text { Inventory }^{a} \\
(\mathrm{~g} / \text { silo })\end{array}$} & \multicolumn{2}{|c|}{ Vertical component } & \multicolumn{2}{|c|}{ Lateral component } \\
\hline & & $\begin{array}{c}\text { Peak flux } \\
\text { (g/year) }\end{array}$ & $\begin{array}{c}\text { Time of peak } \\
\text { (year) }\end{array}$ & $\begin{array}{c}\text { Peak flux } \\
\text { (g/year) }\end{array}$ & $\begin{array}{c}\text { Time of peak } \\
\text { (year) }\end{array}$ \\
\hline${ }^{14} \mathrm{C}$ & $3.5 \times 10^{-5}$ & $1.5 \times 10^{-6}$ & 0 & $6.0 \times 10^{-6}$ & 250 \\
\hline${ }^{90} \mathrm{Sr}$ & $1.9 \times 10^{-5}$ & $3.5 \times 10^{-10}$ & 250 & $1.4 \times 10^{-9}$ & 250 \\
\hline${ }^{99} \mathrm{Tc}$ & $7.3 \times 10^{-3}$ & $1.5 \times 10^{-4}$ & 250 & $6.0 \times 10^{-4}$ & 250 \\
\hline${ }^{137} \mathrm{Cs}$ & $8.8 \times 10^{-5}$ & $1.0 \times 10^{-9}$ & 250 & $3.9 \times 10^{-9}$ & 250 \\
\hline${ }^{152} \mathrm{Eu}$ & $5.3 \times 10^{-7}$ & $7.3 \times 10^{-15}$ & 25 & $7.6 \times 10^{-15}$ & 20 \\
\hline${ }^{232} \mathrm{Th}$ & $7.0 \times 10^{1}$ & $1.2 \times 10^{-3}$ & $250-2,200$ & $4.7 \times 10^{-3}$ & $250-2,200$ \\
\hline${ }^{238} \mathrm{U}$ & $1.3 \times 10^{2}$ & $1.2 \times 10^{-4}$ & $250-50,000$ & $4.8 \times 10^{-4}$ & $250-50,000$ \\
\hline${ }^{239} \mathrm{Pu}$ & $1.8 \times 10^{-2}$ & $3.6 \times 10^{-7}$ & 250 & $1.4 \times 10^{-6}$ & 250 \\
\hline${ }^{241} \mathrm{Am}$ & $4.5 \times 10^{-6}$ & $6.0 \times 10^{-11}$ & 250 & $2.3 \times 10^{-10}$ & 250 \\
\hline
\end{tabular}

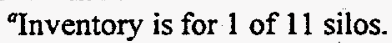

Table 5.9. Maximum annual release rate from a single biological trench in Zone 20 and year of occurrence for vertical and lateral release components of SOURCE2 calculations

\begin{tabular}{|c|c|c|c|c|c|}
\hline \multirow[b]{2}{*}{ Nuclide } & \multirow{2}{*}{$\begin{array}{l}\text { Inventory } \\
\text { (g/trench) }\end{array}$} & \multicolumn{2}{|c|}{ Vertical component } & \multicolumn{2}{|c|}{ Lateral component } \\
\hline & & $\begin{array}{l}\text { Peak flux } \\
\text { (g/year) }\end{array}$ & $\begin{array}{c}\text { Time of peak } \\
\text { (year) }\end{array}$ & $\begin{array}{c}\text { Peak flux } \\
\text { (g/year) }\end{array}$ & $\begin{array}{l}\text { Time of peak } \\
\text { (year) }\end{array}$ \\
\hline${ }^{90} \mathrm{Sr}$ & $2.2 \times 10^{-5}$ & $2.5 \times 10^{-8}$ & 1 & $2.0 \times 10^{-7}$ & 1 \\
\hline
\end{tabular}

Table 5.10. Maximum annual release rate from Tumulus $\mathrm{II}$ in Zone 26 and year of occurrence for vertical and lateral release components of SOURCE1 calculations

\begin{tabular}{lcccccc}
\hline & & \multicolumn{2}{c}{ Vertical component } & & \multicolumn{2}{c}{ Lateral component } \\
\cline { 3 - 4 } Nuclide & $\begin{array}{c}\text { Inventory } \\
\text { (g/pad) }\end{array}$ & $\begin{array}{c}\text { Peak flux } \\
\text { (g/year) }\end{array}$ & $\begin{array}{c}\text { Time of peak } \\
\text { (year) }\end{array}$ & & $\begin{array}{c}\text { Peak flux } \\
\text { (g/year) }\end{array}$ & $\begin{array}{c}\text { Time of peak } \\
\text { (year) }\end{array}$ \\
\hline${ }^{3} \mathrm{H}$ & $1.6 \times 10^{-4}$ & $8.0 \times 10^{-6}$ & 18 & & \\
${ }^{14} \mathrm{C}$ & $9.6 \times 10^{-4}$ & $6.9 \times 10^{-5}$ & 96 & & \\
${ }^{90} \mathrm{Sr}$ & $2.1 \times 10^{-2}$ & $2.7 \times 10^{-5}$ & 96 & & \\
${ }^{137} \mathrm{Cs}$ & $8.8 \times 10^{-2}$ & $5.8 \times 10^{-5}$ & 96 & & & \\
${ }^{152} \mathrm{Eu}$ & $6.3 \times 10^{-4}$ & $8.5 \times 10^{-9}$ & 96 & & & \\
${ }^{154} \mathrm{Eu}$ & $4.0 \times 10^{-4}$ & $4.5 \times 10^{-10}$ & 96 & & & \\
${ }^{194} \mathrm{Os}$ & $3.1 \times 10^{-4}$ & $2.0 \times 10^{-11}$ & 96 & & & \\
${ }^{232} \mathrm{Th}$ & $4.6 \times 10^{3}$ & $2.2 \times 10^{-1}$ & $160-5,700$ & & & \\
${ }^{233} \mathrm{U}$ & $4.3 \times 10^{0}$ & $2.7 \times 10^{-4}$ & 160 & & & \\
${ }^{238} \mathrm{U}$ & $1.0 \times 10^{4}$ & $2.2 \times 10^{-2}$ & $96-50,000$ & & & \\
${ }^{238} \mathrm{Pu}$ & $3.4 \times 10^{-5}$ & $5.7 \times 10^{-10}$ & 160 & & & \\
${ }^{239} \mathrm{Pu}$ & $1.4 \times 10^{-1}$ & $8.2 \times 10^{-6}$ & 160 & & & \\
${ }^{241} \mathrm{Am}$ & $3.7 \times 10^{-3}$ & $1.7 \times 10^{-7}$ & 160 & & & \\
${ }^{244} \mathrm{Cm}$ & $2.4 \times 10^{-4}$ & $1.9 \times 10^{-10}$ & 96 & & & \\
\hline
\end{tabular}

${ }^{\circ}$ Inventory is for 220 vaults on the single pad. 
Table 5.11. Maximum annual release rate from Tumulus $I$ in Zone 27 and year of occurrence for vertical and lateral release components of SOURCE1 calculations

\begin{tabular}{|c|c|c|c|c|c|}
\hline \multirow[b]{2}{*}{ Nuclide } & \multirow{2}{*}{$\begin{array}{c}\text { Inventory } \\
(\mathrm{g} / \mathrm{pad})\end{array}$} & \multicolumn{2}{|c|}{ Vertical component } & \multicolumn{2}{|c|}{ Lateral component } \\
\hline & & $\begin{array}{l}\text { Peak flux } \\
\text { (g/year) }\end{array}$ & $\begin{array}{c}\text { Time of peak } \\
\text { (year) }\end{array}$ & $\begin{array}{c}\text { Peak flux } \\
\text { (g/year) }\end{array}$ & $\begin{array}{l}\text { Time of peak } \\
\text { (year) }\end{array}$ \\
\hline${ }^{3} \mathrm{H}$ & $2.8 \times 10^{-4}$ & $1.4 \times 10^{-5}$ & 16 & & \\
\hline${ }^{14} \mathrm{C}$ & $8.6 \times 10^{-3}$ & $6.2 \times 10^{-4}$ & 94 & & \\
\hline${ }^{63} \mathrm{Ni}$ & $3.3 \times 10^{-3}$ & $3.2 \times 10^{-5}$ & 94 & & \\
\hline${ }^{90} \mathrm{Sr}$ & $8.8 \times 10^{-2}$ & $1.2 \times 10^{-4}$ & 94 & & \\
\hline${ }^{99} \mathrm{Tc}$ & $4.3 \times 10^{0}$ & $1.4 \times 10^{-1}$ & 160 & & \\
\hline${ }^{137} \mathrm{Cs}$ & $2.8 \times 10^{-1}$ & $1.9 \times 10^{-4}$ & 94 & & \\
\hline${ }^{152} \mathrm{Eu}$ & $5.0 \times 10^{-3}$ & $6.8 \times 10^{-8}$ & 94 & & \\
\hline${ }^{154} \mathrm{Eu}$ & $4.2 \times 10^{-3}$ & $4.7 \times 10^{-9}$ & 94 & & \\
\hline${ }^{210} \mathrm{~Pb}$ & $2.2 \times 10^{-4}$ & $2.8 \times 10^{-8}$ & 94 & & \\
\hline${ }^{226} \mathrm{Ra}$ & $1.7 \times 10^{-3}$ & $1.3 \times 10^{-5}$ & 160 & & \\
\hline${ }^{232} \mathrm{Th}$ & $5.7 \times 10^{3}$ & $2.8 \times 10^{-1}$ & $160-5,300$ & & none \\
\hline${ }^{233} \mathrm{U}$ & $5.0 \times 10^{\circ}$ & $3.1 \times 10^{-4}$ & 160 & & \\
\hline${ }^{238} \mathrm{U}$ & $2.3 \times 10^{4}$ & $2.8 \times 10^{-2}$ & $94-50,000$ & & \\
\hline${ }^{237} \mathrm{~Np}$ & $1.1 \times 10^{1}$ & $7.0 \times 10^{-4}$ & 160 & & \\
\hline${ }^{238} \mathrm{Pu}$ & $3.0 \times 10^{-5}$ & $5.0 \times 10^{-10}$ & 160 & & \\
\hline${ }^{239} \mathrm{Pu}$ & $8.2 \times 10^{-1}$ & $5.0 \times 10^{-5}$ & $\cdot 160$ & & \\
\hline${ }^{240} \mathrm{Pu}$ & $3.0 \times 10^{-2}$ & $1.8 \times 10^{-6}$ & 160 & & \\
\hline${ }^{241} \mathrm{Am}$ & $1.8 \times 10^{-2}$ & $8.2 \times 10^{-7}$ & 160 & & \\
\hline${ }^{243} \mathrm{Am}$ & $6.1 \times 10^{-2}$ & $3.6 \times 10^{-6}$ & 160 & & \\
\hline${ }^{244} \mathrm{Cm}$ & $3.2 \times 10^{-4}$ & $2.6 \times 10^{-10}$ & 94 & & \\
\hline${ }^{249} \mathrm{Cf}$ & $2.5 \times 10^{-3}$ & $1.0 \times 10^{-7}$ & 160 & & \\
\hline
\end{tabular}

a Inventory is for 291 vaults on the single pad.

\subsubsection{Output from the Modeling of Shallow Subsurface Transport for Closed Disposal Units}

The results from Table 5.1 through Table 5.12 are used as input into the PADSIM and HOLSIM programs, which first convert leachate fluxes from individual units into leachate fluxes for collections of units. For example, the fluxes from Table 5.12 are multiplied by 105 to get the fluxes for all of the low-range silos in Zone 30. The fluxes of radionuclides and water to groundwater (as recharge in USGS MOC calculations), and to the nearest receiving stream channel by the lateral subsurface path are calculated for the tumulus disposal units using PADSIM and below-ground waste units using HOLSIM. 
Table 5.12. Maximum annual release rate from a single low-range silo in Zone $\mathbf{3 0}$ and year of occurrence for vertical and lateral release components of SOURCE2 calculations

\begin{tabular}{|c|c|c|c|c|c|}
\hline \multirow[b]{2}{*}{ Nuclide } & \multirow{2}{*}{$\begin{array}{l}\text { Inventory }^{a} \\
(\mathrm{~g} / \mathrm{silo})\end{array}$} & \multicolumn{2}{|c|}{ Vertical component } & \multicolumn{2}{|c|}{ Lateral component } \\
\hline & & $\begin{array}{l}\text { Peak flux } \\
\text { (g/year) }\end{array}$ & $\begin{array}{c}\text { Time of peak } \\
\text { (year) }\end{array}$ & $\begin{array}{c}\text { Peak flux } \\
\text { (g/year) }\end{array}$ & $\begin{array}{l}\text { Time of peak } \\
\text { (year) }\end{array}$ \\
\hline${ }^{3} \mathrm{H}$ & $9.5 \times 10^{-6}$ & $1.7 \times 10^{-8}$ & 8 & $1.3 \times 10^{-8}$ & 8 \\
\hline${ }^{34} \mathrm{C}$ & $1.5 \times 10^{-4}$ & $6.9 \times 10^{-6}$ & 250 & $1.9 \times 10^{-5}$ & 250 \\
\hline${ }^{90} \mathrm{Sr}$ & $6.5 \times 10^{-4}$ & $1.2 \times 10^{-8}$ & 250 & $3.3 \times 10^{-8}$ & 250 \\
\hline${ }^{137} \mathrm{Cs}$ & $1.4 \times 10^{-3}$ & $1.6 \times 10^{-8}$ & 250 & $4.2 \times 10^{-8}$ & 250 \\
\hline${ }^{152} \mathrm{Eu}$ & $2.8 \times 10^{-4}$ & $4.1 \times 10^{-12}$ & 19 & $3.0 \times 10^{-12}$ & 19 \\
\hline${ }^{154} \mathrm{Eu}$ & $1.6 \times 10^{-4}$ & $1.6 \times 10^{-12}$ & 13 & $1.2 \times 10^{-12}$ & 13 \\
\hline${ }^{155} \mathrm{Eu}$ & $5.8 \times 10^{-6}$ & $3.1 \times 10^{-14}$ & 7 & $2.3 \times 10^{-14}$ & 7 \\
\hline${ }^{226} \mathrm{Ra}$ & $5.3 \times 10^{-6}$ & $.1 .8 \times 10^{-8}$ & 250 & $4.8 \times 10^{-8}$ & 250 \\
\hline${ }^{229} \mathrm{Th}$ & $7.6 \times 10^{-6}$ & $1.6 \times 10^{-10}$ & 250 & $4.2 \times 10^{-10}$ & 250 \\
\hline${ }^{230} \mathrm{Th}$ & $5.3 \times 10^{-4}$ & $1.1 \times 10^{-8}$ & 250 & $3.0 \times 10^{-8}$ & 250 \\
\hline${ }^{232} \mathrm{Th}$ & $3.3 \times 10^{2}$ & $1.2 \times 10^{-3}$ & $250-61,000$ & $3.3 \times 10^{-3}$ & $250-61,000$ \\
\hline${ }^{233} \mathrm{U}$ & $6.1 \times 10^{-2}$ & $1.2 \times 10^{-6}$ & 250 & $3.3 \times 10^{-6}$ & 250 \\
\hline${ }^{238} \mathrm{U}$ & $8.2 \times 10^{2}$ & $1.2 \times 10^{-4}$ & $250-50,000$ & $3.3 \times 10^{-4}$ & $250-50,000$ \\
\hline${ }^{237} \mathrm{~Np}$ & $1.6 \times 10^{-2}$ & $3.2 \times 10^{-7}$ & 250 & $8.7 \times 10^{-7}$ & 250 \\
\hline${ }^{238} \mathrm{Pu}$ & $4.8 \times 10^{-7}$ & $1.3 \times 10^{-12}$ & 250 & $3.6 \times 10^{-12}$ & 250 \\
\hline${ }^{239} \mathrm{Pu}$ & $3.7 \times 10^{-3}$ & $7.4 \times 10^{-8}$ & 250 & $2.0 \times 10^{-7}$ & 250 \\
\hline${ }^{242} \mathrm{Pu}$ & $2.5 \times 10^{-3}$ & $5.0 \times 10^{-8}$ & 250 & $1.3 \times 10^{-7}$ & 250 \\
\hline${ }^{241} \mathrm{Am}$ & $6.6 \times 10^{-5}$ & $8.8 \times 10^{-10}$ & 250 & $2.4 \times 10^{-9}$ & 250 \\
\hline${ }^{243} \mathrm{Am}$ & $7.7 \times 10^{-4}$ & $1.5 \times 10^{-8}$ & 250 & $4.0 \times 10^{-8}$ & 250 \\
\hline${ }^{244} \mathrm{Cm}$ & $1.4 \times 10^{-6}$ & $1.8 \times 10^{-15}$ & 250 & $4.8 \times 10^{-15}$ & 250 \\
\hline${ }^{249} \mathrm{Cf}$ & $2.4 \times 10^{-6}$ & $2.8 \times 10^{-11}$ & 250 & $7.4 \times 10^{-11}$ & 250 \\
\hline
\end{tabular}

anventory is for 1 of 105 silos.

The annual results from calculations for each of the twelve closed waste zones are evaluated to determine the maximum flux and maximum concentration of each radionuclide, that account for radionuclide decay and chemical absorption, and the years of occurrence for both the vertical and lateral path calculations. These results, given in Table 5.13 through Table 5.24, show early peak fluxes for unretarded nuclides (e.g., ${ }^{3} \mathrm{H},{ }^{14} \mathrm{C}$ ). In the case of Tumulus I and II (and the IWMF), all of the subsurface flux enters the groundwater due to the close proximity of the units to the saturated zone. There are no lateral subsurface fluxes entering surface stream channels from the tumulus-type units. The lateral transport of ${ }^{137} \mathrm{Cs}$ is zero for waste zones $3,5,7,8,15,16$ and 30 because the Cs retention in soil is high $\left(K_{d}=3000\right)$, the path lengths are long $(99-189 \mathrm{~m})$, and the half-life of ${ }^{137} \mathrm{Cs}$ is relatively short (30 years). This combination of factors results in ${ }^{137} \mathrm{Cs}$ decaying during transport in the lateral flow path. Other radionuclides with $K_{d}$ values of 3000 , such as ${ }^{226} \mathrm{Ra}$ and ${ }^{232} \mathrm{Th}$, have much longer half- 
Table 5.13. Simulated annual peak flux and concentration of radionuclides in soil solution and the years of occurrence in the recharge and lateral flow paths obtained from HOLSIM for the high-range silos in Zone 3

\begin{tabular}{|c|c|c|c|c|c|c|c|c|}
\hline \multirow[b]{2}{*}{ Nuclide } & \multicolumn{4}{|c|}{ Recharge } & \multicolumn{4}{|c|}{ Lateral flow } \\
\hline & $\underset{\text { (g/year) }}{\text { Flux }}$ & $\begin{array}{l}\text { Time } \\
\text { (year) }\end{array}$ & $\begin{array}{l}\text { Conc'n } \\
(\mathrm{g} / \mathrm{mL})\end{array}$ & $\begin{array}{c}\text { Time } \\
\text { (year) }\end{array}$ & $\underset{\text { (g/year) }}{\text { Flux }}$ & $\begin{array}{l}\text { Time } \\
\text { (year) }\end{array}$ & $\begin{array}{l}\text { Conc'n } \\
(\mathrm{g} / \mathrm{mL})\end{array}$ & $\begin{array}{l}\text { Time } \\
\text { (year) }\end{array}$ \\
\hline${ }^{3} \mathrm{H}$ & $8.5 \times 10^{-7}$ & 11 & $1.3 \times 10^{-14}$ & 11 & $9.1 \times 10^{-7}$ & 17 & $2.4 \times 10^{-15}$ & 17 \\
\hline${ }^{14} \mathrm{C}$ & $2.2 \times 10^{-4}$ & 260 & $3.4 \times 10^{-12}$ & 260 & $2.5 \times 10^{-4}$ & 260 & $9.1 \times 10^{-13}$ & 260 \\
\hline${ }^{40} \mathrm{~K}$ & $1.5 \times 10^{0}$ & 260 & $2.3 \times 10^{-8}$ & 260 & $8.6 \times 10^{-2}$ & 340 & $3.1 \times 10^{-10}$ & 340 \\
\hline${ }^{63} \mathrm{Ni}$ & $1.1 \times 10^{-6}$ & 260 & $1.6 \times 10^{-14}$ & 260 & $4.0 \times 10^{-11}$ & 830 & $1.4 \times 10^{-19}$ & 830 \\
\hline${ }^{90} \mathrm{Sr}$ & $1.1 \times 10^{-6}$ & 260 & $1.7 \times 10^{-14}$ & 260 & $1.3 \times 10^{-8}$ & 330 & $4.8 \times 10^{-17}$ & 330 \\
\hline${ }^{137} \mathrm{Cs}$ & $3.9 \times 10^{-10}$ & 280 & $6.0 \times 10^{-18}$ & 280 & $0.0 \times 10^{0}$ & 0 & $0.0 \times 10^{\circ}$ & 0 \\
\hline${ }^{152} \mathrm{Eu}$ & $1.6 \times 10^{-10}$ & 30 & $2.5 \times 10^{-18}$ & 30 & $8.4 \times 10^{-14}$ & 330 & $3.0 \times 10^{-22}$ & 330 \\
\hline${ }^{154} \mathrm{Eu}$ & $2.1 \times 10^{-11}$ & 30 & $3.2 \times 10^{-19}$ & 30 & $4.0 \times 10^{-18}$ & 330 & $1.4 \times 10^{-26}$ & 330 \\
\hline${ }^{155} \mathrm{Eu}$ & $1.1 \times 10^{-13}$ & 10 & $1.6 \times 10^{-21}$ & 10 & $1.2 \times 10^{-28}$ & 330 & $4.4 \times 10^{-37}$ & 330 \\
\hline${ }^{232} \mathrm{Th}$ & $2.6 \times 10^{-3}$ & 21,000 & $4.0 \times 10^{-11}$ & 21,000 & $4.0 \times 10^{-3}$ & 30,000 & $1.4 \times 10^{-11}$ & 29,000 \\
\hline${ }^{238} \mathrm{U}$ & $4.6 \times 10^{-3}$ & 23,000 & $7.1 \times 10^{-11}$ & 26,000 & $2.0 \times 10^{-2}$ & 25,000 & $7.1 \times 10^{-11}$ & 29,000 \\
\hline${ }^{239} \mathrm{Pu}$ & $2.4 \times 10^{-7}$ & 260 & $3.7 \times 10^{-15}$ & 260 & $7.5 \times 10^{-7}$ & 4,600 & $2.7 \times 10^{-15}$ & 4,600 \\
\hline${ }^{244} \mathrm{Cm}$ & $5.4 \times 10^{-12}$ & 260 & $8.3 \times 10^{-20}$ & 260 & $5.4 \times 10^{-14}$ & 330 & $1.9 \times 10^{-22}$ & 330 \\
\hline
\end{tabular}

Table 5.14. Simulated annual peak flux and concentration of radionuclides in soil solution and the years of occurrence in the recharge and lateral flow paths obtained from HOLSIM for the high-range wells in Zone 5

\begin{tabular}{|c|c|c|c|c|c|c|c|c|}
\hline \multirow[b]{2}{*}{ Nuclide } & \multicolumn{4}{|c|}{ Recharge } & \multicolumn{4}{|c|}{ Lateral flow } \\
\hline & $\begin{array}{c}\text { Flux } \\
\text { (g/year) }\end{array}$ & $\begin{array}{l}\text { Time } \\
\text { (year) }\end{array}$ & $\begin{array}{l}\text { Conc'n } \\
(\mathrm{g} / \mathrm{mL})\end{array}$ & $\begin{array}{l}\text { Time } \\
\text { (year) }\end{array}$ & $\begin{array}{c}\text { Flux } \\
\text { (g/year) }\end{array}$ & $\begin{array}{l}\text { Time } \\
\text { (year) }\end{array}$ & $\begin{array}{l}\text { Conc'n } \\
\text { (g/mL) }\end{array}$ & $\begin{array}{l}\text { Time } \\
\text { (year) }\end{array}$ \\
\hline${ }^{90} \mathrm{Sr}$ & $3.9 \times 10^{-5}$ & 81 & $2.5 \times 10^{-12}$ & 81 & $4.5 \times 10^{-6}$ & 364 & $8.2 \times 10^{-15}$ & 364 \\
\hline${ }^{137} \mathrm{Cs}$ & $6.1 \times 10^{-7}$ & 83 & $3.9 \times 10^{-14}$ & 83 & $0.0 \times 10^{0}$ & 0 & $0.0 \times 10^{0}$ & 0 \\
\hline
\end{tabular}


Table 5.15. Simulated annual peak flux and concentration of radionuclides in soil solution and the years of occurrence in the recharge and lateral flow paths obtained from HOLSIM for the high-range wells-in-silos in Zone 5

\begin{tabular}{|c|c|c|c|c|c|c|c|c|}
\hline \multirow{2}{*}{ Nuclide } & \multicolumn{4}{|c|}{ Recharge } & \multicolumn{4}{|c|}{ Lateral flow } \\
\hline & $\begin{array}{c}\text { Flux } \\
\text { (g/year) }\end{array}$ & $\begin{array}{l}\text { Time } \\
\text { (year) }\end{array}$ & $\begin{array}{l}\text { Conc'n } \\
(\mathrm{g} / \mathrm{mL})\end{array}$ & $\begin{array}{l}\text { Time } \\
\text { (year) }\end{array}$ & $\underset{\text { (g/year) }}{\text { Flux }}$ & $\begin{array}{l}\text { Time } \\
\text { (year) }\end{array}$ & $\begin{array}{l}\text { Conc'n } \\
(\mathrm{g} / \mathrm{mL})\end{array}$ & $\begin{array}{c}\text { Time } \\
\text { (year) }\end{array}$ \\
\hline${ }^{41} \mathrm{Ca}$ & $2.5 \times 10^{-4}$ & 460 & $2.7 \times 10^{-12}$ & 460 & $2.5 \times 10^{-2}$ & 460 & $7.7 \times 10^{-12}$ & 460 \\
\hline${ }^{60} \mathrm{Co}$ & $5.5 \times 10^{-17}$ & 34 & $5.9 \times 10^{-25}$ & 34 & $2.1 \times 10^{-36}$ & 480 & $6.4 \times 10^{-46}$ & 480 \\
\hline${ }^{90} \mathrm{Sr}$ & $2.9 \times 10^{-8}$ & 76 & $3.1 \times 10^{-16}$ & 76 & $7.5 \times 10^{-8}$ & 460 & $2.3 \times 10^{-17}$ & 460 \\
\hline${ }^{99} \mathrm{Tc}$ & $6.2 \times 10^{-2}$ & 456 & $6.7 \times 10^{-10}$ & 460 & $3.3 \times 10^{0}$ & 460 & $1.0 \times 10^{-9}$ & 460 \\
\hline${ }^{137} \mathrm{Cs}$ & $1.2 \times 10^{-9}$ & 79 & $1.3 \times 10^{-17}$ & 79 & $0.0 \times 10^{\circ}$ & 0 & $0.0 \times 10^{\circ}$ & 0 \\
\hline${ }^{152} \mathrm{Eu}$ & $2.9 \times 10^{-9}$ & 51 & $3.1 \times 10^{-17}$ & 51 & $6.1 \times 10^{-13}$ & 460 & $1.9 \times 10^{-22}$ & 460 \\
\hline${ }^{154} \mathrm{Eu}$ & $2.5 \times 10^{-10}$ & 41 & $2.6 \times 10^{-18}$ & 41 & $8.4 \times 10^{-19}$ & 460 & $2.6 \times 10^{-28}$ & 460 \\
\hline${ }^{229} \mathrm{Th}$ & $8.2 \times 10^{-9}$ & 1,423 & $8.8 \times 10^{-17}$ & 1,400 & $8.3 \times 10^{-7}$ & 3,800 & $2.6 \times 10^{-16}$ & 3,800 \\
\hline${ }^{232} \mathrm{Th}$ & $9.2 \times 10^{-5}$ & 2.024 & $9.9 \times 10^{-13}$ & 2,000 & $1.1 \times 10^{-2}$ & 3.800 & $3.5 \times 10^{-12}$ & 3.800 \\
\hline
\end{tabular}

Table 5.16. Simulated annual peak flux and concentration of radionuclides in soil solution and the years of occurrence in the recharge and lateral flow paths obtained from HOLSIM for the fissile wells in Zone 7

\begin{tabular}{|c|c|c|c|c|c|c|c|c|}
\hline \multirow[b]{2}{*}{ Nuclide } & \multicolumn{4}{|c|}{ Recharge } & \multicolumn{4}{|c|}{ Lateral now } \\
\hline & $\underset{\text { (g/year) }}{\text { Flux }}$ & $\begin{array}{l}\text { Time } \\
\text { (year) }\end{array}$ & $\begin{array}{l}\text { Conc'n } \\
(\mathrm{g} / \mathrm{mL})\end{array}$ & $\begin{array}{l}\text { Time } \\
\text { (year) }\end{array}$ & $\underset{\text { (g/year) }}{\text { Flux }}$ & $\begin{array}{l}\text { Time } \\
\text { (year) }\end{array}$ & $\begin{array}{l}\text { Conc'n } \\
(\mathrm{g} \mathrm{mL})\end{array}$ & $\begin{array}{l}\text { Time } \\
\text { (year) }\end{array}$ \\
\hline${ }^{137} \mathrm{Cs}$ & $7.9 \times 10^{-8}$ & 95 & $2.3 \times 10^{-13}$ & 95 & $0.0 \times 10^{0}$ & 0 & $00 \times 10^{\circ}$ & 0 \\
\hline${ }^{232} \mathrm{Th}$ & $1.8 \times 10^{-5}$ & 11,767 & $5.3 \times 10^{-13}$ & 12,000 & $4.9 \times 10^{-5}$ & 13,000 & $3.0 \times 10^{-11}$ & 13,000 \\
\hline${ }^{235} \mathrm{U}$ & $2.5 \times 10^{-5}$ & 14,383 & $7.1 \times 10^{-11}$ & 12,000 & $1.2 \times 10^{-4}$ & 21,000 & $7.1 \times 10^{-11}$ & 22,000 \\
\hline${ }^{238} \mathrm{U}$ & $2.5 \times 10^{-5}$ & 10,629 & $7.1 \times 10^{-11}$ & 12,000 & $1.2 \times 10^{-4}$ & 21,000 & $7.1 \times 10^{-11}$ & 22,000 \\
\hline
\end{tabular}

Table 5.17. Simulated annual peak flux and concentration of radionuclides in soil solution and the years of occurrence in the recharge and lateral flow paths obtained from HOLSIM for the Quadrex trenches in Zone 8

\begin{tabular}{|c|c|c|c|c|c|c|c|c|}
\hline \multirow[b]{2}{*}{ Nuclide } & \multicolumn{4}{|c|}{ Recharge } & \multicolumn{4}{|c|}{ Lateral flow } \\
\hline & $\begin{array}{c}\text { Flux } \\
\text { (g/year) }\end{array}$ & $\begin{array}{l}\text { Time } \\
\text { (year) }\end{array}$ & $\begin{array}{l}\text { Conc'n } \\
(\mathrm{g} / \mathrm{mL})\end{array}$ & $\begin{array}{l}\text { Time } \\
\text { (year) }\end{array}$ & $\begin{array}{c}\text { Flux } \\
\text { (g/year) }\end{array}$ & $\begin{array}{l}\text { Time } \\
\text { (year) }\end{array}$ & $\begin{array}{l}\text { Conc'n } \\
(\mathrm{g} / \mathrm{mL})\end{array}$ & $\begin{array}{l}\text { Time } \\
\text { (year) }\end{array}$ \\
\hline${ }^{90} \mathrm{Sr}$ & $1.3 \times 10^{-10}$ & 31 & $1.7 \times 10^{-17}$ & 31 & $2.5 \times 10^{-11}$ & 182 & $8.0 \times 10^{-19}$ & 180 \\
\hline${ }^{137} \mathrm{Cs}$ & $1.3 \times 10^{-9}$ & 77 & $1.7 \times 10^{-16}$ & 77 & $0.0 \times 10^{\circ}$ & 0 & $0.0 \times 10^{0}$ & 0 \\
\hline${ }^{230} \mathrm{Th}$ & $2.0 \times 10^{-7}$ & 1,700 & $2.6 \times 10^{-14}$ & 1,700 & $6.3 \times 10^{-7}$ & 2,000 & $2.0 \times 10^{-14}$ & 2,000 \\
\hline${ }^{232} \mathrm{Th}$ & $2.4 \times 10^{-2}$ & 21,000 & $3.0 \times 10^{-9}$ & 21,000 & $7.3 \times 10^{-2}$ & 21,000 & $2.3 \times 10^{-9}$ & 21,000 \\
\hline${ }^{235} \mathrm{U}$ & $8.5 \times 10^{-3}$ & 660 & $1.1 \times 10^{-9}$ & 650 & $2.8 \times 10^{-2}$ & 730 & $9.1 \times 10^{-10}$ & 730 \\
\hline${ }^{238} \mathrm{U}$ & $4.0 \times 10^{-1}$ & 660 & $5.1 \times 10^{-8}$ & 660 & $1.3 \times 10^{\circ}$ & 700 & $4.3 \times 10^{-8}$ & 720 \\
\hline${ }^{238} \mathrm{Pu}$ & $1.8 \times 10^{-9}$ & 100 & $2.2 \times 10^{-16}$ & 100 & $4.8 \times 10^{-9}$ & 180 & $1.5 \times 10^{-16}$ & 180 \\
\hline${ }^{244} \mathrm{Cm}$ & $6.0 \times 10^{-11}$ & 26 & $7.6 \times 10^{-18}$ & 26 & $2.7 \times 10^{-12}$ & 180 & $8.7 \times 10^{-20}$ & 180 \\
\hline
\end{tabular}


Table 5.18. Simulated annual peak flux and concentration of radionuclides in soil solution and the years of occurrence in the recharge and lateral flow paths obtained from HOLSIM for the low-range silos in Zone 8

\begin{tabular}{|c|c|c|c|c|c|c|c|c|}
\hline \multirow[b]{2}{*}{ Nuclide } & \multicolumn{4}{|c|}{ Recharge } & \multicolumn{4}{|c|}{ Lateral flow } \\
\hline & $\underset{\text { (g/year) }}{\text { Flux }}$ & $\begin{array}{l}\text { Time } \\
\text { (year) }\end{array}$ & $\begin{array}{l}\text { Conc'n } \\
(\mathrm{g} / \mathrm{mL})\end{array}$ & $\begin{array}{l}\text { Time } \\
\text { (year) }\end{array}$ & $\underset{\text { (g/year) }}{\text { Flux }}$ & $\begin{array}{c}\text { Time } \\
\text { (year) }\end{array}$ & $\begin{array}{l}\text { Conc'n } \\
(\mathrm{g} / \mathrm{mL})\end{array}$ & $\begin{array}{l}\text { Time } \\
\text { (year) }\end{array}$ \\
\hline${ }^{3} \mathrm{H}$ & $2.3 \times 10^{-6}$ & 9 & $5.6 \times 10^{-14}$ & 9 & $1.6 \times 10^{-6}$ & 11 & $9.4 \times 10^{-15}$ & 11 \\
\hline${ }^{14} \mathrm{C}$ & $4.6 \times 10^{-5}$ & 250 & $1.1 \times 10^{-12}$ & 250 & $8.8 \times 10^{-5}$ & 250 & $5.2 \times 10^{-13}$ & 250 \\
\hline${ }^{63} \mathrm{Ni}$ & $6.6 \times 10^{-7}$ & 250 & $1.6 \times 10^{-14}$ & 250 & $5.0 \times 10^{-10}$ & 480 & $3.0 \times 10^{-18}$ & 480 \\
\hline${ }^{90} \mathrm{Sr}$ & $1.6 \times 10^{-6}$ & 250 & $3.9 \times 10^{-14}$ & 250 & $6.2 \times 10^{-8}$ & 270 & $3.7 \times 10^{-16}$ & 270 \\
\hline${ }^{99} \mathrm{Tc}$ & $6.2 \times 10^{-2}$ & 250 & $1.5 \times 10^{-9}$ & 250 & $1.2 \times 10^{-1}$ & 250 & $6.9 \times 10^{-10}$ & 250 \\
\hline${ }^{137} \mathrm{Cs}$ & $3.3 \times 10^{-10}$ & 280 & $7.8 \times 10^{-18}$ & 280 & $0.0 \times 10^{0}$ & 0 & $0.0 \times 10^{0}$ & 0 \\
\hline${ }^{152} \mathrm{Eu}$ & $2.5 \times 10^{-10}$ & 27 & $5.9 \times 10^{-18}$ & 27 & $1.0 \times 10^{-12}$ & 270 & $6.0 \times 10^{-21}$ & 270 \\
\hline${ }^{154} \mathrm{Eu}$ & $4.8 \times 10^{-11}$ & 14 & $1.2 \times 10^{-18}$ & 14 & $3.2 \times 10^{-16}$ & 270 & $1.9 \times 10^{-24}$ & 260 \\
\hline${ }^{226} \mathrm{Ra}$ & $1.5 \times 10^{-8}$ & 440 & $3.5 \times 10^{-36}$ & 440 & $1.5 \times 10^{-8}$ & 2,000 & $9.2 \times 10^{-17}$ & 2,000 \\
\hline${ }^{232} \mathrm{Th}$ & $2.8 \times 10^{-2}$ & 210,000 & $6.6 \times 10^{-10}$ & 210,000 & $9.0 \times 10^{-2}$ & 210,000 & $5.3 \times 10^{-10}$ & 210,000 \\
\hline${ }^{232} \mathrm{U}$ & $5.1 \times 10^{-12}$ & 250 & $1.2 \times 10^{-39}$ & 250 & $5.7 \times 10^{-13}$ & 350 & $3.4 \times 10^{-21}$ & 350 \\
\hline${ }^{233} \mathrm{U}$ & $1.4 \times 10^{-5}$ & 1,100 & $3.4 \times 10^{-13}$ & 1,200 & $5.4 \times 10^{-5}$ & 4,000 & $3.2 \times 10^{-13}$ & 4,000 \\
\hline${ }^{235} \mathrm{U}$ & $3.0 \times 10^{-3}$ & 16,000 & $7.0 \times 10^{-11}$ & 16,000 & $1.2 \times 10^{-2}$ & 15,000 & $7.0 \times 10^{-11}$ & 16,000 \\
\hline${ }^{238} \mathrm{U}$ & $3.0 \times 10^{-3}$ & 20,000 & $7.1 \times 10^{-11}$ & 26,000 & $1.2 \times 10^{-2}$ & 15,000 & $7.1 \times 10^{-11}$ & 19,000 \\
\hline${ }^{238} \mathrm{Pu}$ & $7.4 \times 10^{-11}$ & 250 & $1.8 \times 10^{-18}$ & 250 & $1.0 \times 10^{-31}$ & 370 & $6.2 \times 10^{-20}$ & 370 \\
\hline${ }^{239} \mathrm{Pu}$ & $2.4 \times 10^{-5}$ & 630 & $5.7 \times 10^{-13}$ & 640 & $8.5 \times 10^{-5}$ & 3,700 & $5.1 \times 10^{-13}$ & 3,600 \\
\hline${ }^{241} \mathrm{Am}$ & $2.6 \times 10^{-7}$ & 250 & $6.2 \times 10^{-15}$ & 250 & $1.5 \times 10^{-7}$ & 760 & $9.2 \times 10^{-16}$ & 770 \\
\hline${ }^{243} \mathrm{Am}$ & $1.8 \times 10^{-8}$ & 250 & $4.3 \times 10^{-16}$ & 250 & $5.3 \times 10^{-8}$ & 3,000 & $3.2 \times 10^{-16}$ & 2,900 \\
\hline${ }^{244} \mathrm{Cm}$ & $3.4 \times 10^{-13}$ & 250 & $8.0 \times 10^{-21}$ & 250 & $1.1 \times 10^{-14}$ & 280 & $6.4 \times 10^{-23}$ & 280 \\
\hline${ }^{249} \mathrm{Cf}$ & $2.2 \times 10^{-9}$ & 250 & $5.3 \times 10^{-17}$ & 250 & $1.1 \times 10^{-9}$ & 670 & $6.5 \times 10^{-18}$ & 690 \\
\hline
\end{tabular}

Table 5.19. Simulated annual peak flux and concentration of radionuclides in soil solution and the years of occurrence in the recharge and lateral flow paths obtained from HOLSIM for the biological trenches in Zone 15

\begin{tabular}{|c|c|c|c|c|c|c|c|c|}
\hline \multirow[b]{2}{*}{ Nuclide } & \multicolumn{4}{|c|}{ Recharge } & \multicolumn{4}{|c|}{ Lateral flow } \\
\hline & $\underset{\text { (g/year) }}{\text { Flux }}$ & $\begin{array}{l}\text { Time } \\
\text { (year) }\end{array}$ & $\begin{array}{l}\text { Conc'n } \\
(\mathrm{g} / \mathrm{mL})\end{array}$ & $\begin{array}{l}\text { Time } \\
\text { (year) }\end{array}$ & $\underset{\text { (g/year) }}{\text { Flux }}$ & $\begin{array}{l}\text { Time } \\
\text { (year) }\end{array}$ & $\begin{array}{l}\text { Conc'n } \\
(\mathrm{g} / \mathrm{mL})\end{array}$ & $\begin{array}{l}\text { Time } \\
\text { (year) }\end{array}$ \\
\hline $90 \mathrm{Sr}$ & $8.7 \times 10^{-8}$ & 6 & $2.6 \times 10^{-15}$ & 6 & $5.4 \times 10^{-10}$ & 200 & $2.4 \times 10^{-18}$ & 200 \\
\hline${ }^{137} \mathrm{Cs}$ & $3.2 \times 10^{-9}$ & 6 & $9.6 \times 10^{-17}$ & 6 & $0.0 \times 10^{0}$ & 0 & $0.0 \times 10^{0}$ & 0 \\
\hline
\end{tabular}


Table 5.20. Simulated annual peak flux and concentration of radionuclides in soil solution and the years of occurrence in the recharge and lateral flow paths obtained from HOLSIM for the asbestos silos in Zone 16

\begin{tabular}{|c|c|c|c|c|c|c|c|c|}
\hline \multirow[b]{2}{*}{ Nuclide } & \multicolumn{4}{|c|}{ Recharge } & \multicolumn{4}{|c|}{ Lateral flow } \\
\hline & $\underset{\text { (g/year) }}{\text { Flux }}$ & $\begin{array}{l}\text { Time } \\
\text { (year) }\end{array}$ & $\begin{array}{l}\text { Conc'n } \\
(\mathrm{g} / \mathrm{mL})\end{array}$ & $\begin{array}{c}\text { Time } \\
\text { (year) }\end{array}$ & $\underset{\text { (g/year) }}{\text { Flux }}$ & $\begin{array}{c}\text { Time } \\
\text { (year) }\end{array}$ & $\begin{array}{l}\text { Conc'n } \\
(\mathrm{g} / \mathrm{mL})\end{array}$ & $\begin{array}{l}\text { Time } \\
\text { (year) }\end{array}$ \\
\hline${ }^{14} \mathrm{C}$ & $1.3 \times 10^{-5}$ & 250 & $6.8 \times 10^{-13}$ & 250 & $1.2 \times 10^{-5}$ & 250 & $1.7 \times 10^{-13}$ & 250 \\
\hline${ }^{90} \mathrm{Sr}$ & $3.4 \times 10^{-9}$ & 250 & $1.7 \times 10^{-16}$ & 250 . & $4.4 \times 10^{-11}$ & 300 & $5.9 \times 10^{-19}$ & 300 \\
\hline${ }^{99} \mathrm{Tc}$ & $1.5 \times 10^{-3}$ & 250 & $7.9 \times 10^{-11}$ & 250 & $1.4 \times 10^{-3}$ & 250 & $1.9 \times 10^{-11}$ & 250 \\
\hline${ }^{137} \mathrm{Cs}$ & $4.3 \times 10^{-9}$ & 250 & $2.2 \times 10^{-16}$ & 250 & $0.0 \times 10^{0}$ & 0 & $0.0 \times 10^{0}$ & 0 \\
\hline${ }^{152} \mathrm{Eu}$ & $7.4 \times 10^{-14}$ & 27 & $3.9 \times 10^{-21}$ & 27 & $6.8 \times 10^{-17}$ & 300 & $9.2 \times 10^{-25}$ & 300 \\
\hline${ }^{232} \mathrm{Th}$ & $6.0 \times 10^{-3}$ & 2,300 & $3.1 \times 10^{-10}$ & 2,300 & $2.3 \times 10^{-3}$ & 31,000 & $3.0 \times 10^{-11}$ & 32,000 \\
\hline${ }^{238} \mathrm{U}$ & $1.4 \times 10^{-3}$ & 17,000 & $7.1 \times 10^{-11}$ & 21,000 & $5.3 \times 10^{-3}$ & 31,000 & $7.1 \times 10^{-11}$ & 30,000 \\
\hline${ }^{239} \mathrm{Pu}$ & $3.7 \times 10^{-6}$ & 250 & $1.9 \times 10^{-13}$ & 250 & $7.9 \times 10^{-6}$ & 4,800 & $1.1 \times 10^{-13}$ & 4,600 \\
\hline${ }^{241} \mathrm{Am}$ & $6.2 \times 10^{-10}$ & 250 & $3.2 \times 10^{-17}$ & 250 & $1.7 \times 10^{-10}$ & 790 & $2.3 \times 10^{-18}$ & 800 \\
\hline
\end{tabular}

Table 5.21. Simulated annual peak flux and concentration of radionuclides in soil solution and the years of occurrence in the recharge and lateral flow paths obtained from HOLSIM for the biological trenches in Zone 20

\begin{tabular}{|c|c|c|c|c|c|c|c|c|}
\hline \multirow[b]{2}{*}{ Nuclide } & \multicolumn{4}{|c|}{ Recharge } & \multicolumn{4}{|c|}{ Lateral flow } \\
\hline & $\begin{array}{c}\text { Flux } \\
\text { (g/year) }\end{array}$ & $\begin{array}{l}\text { Time } \\
\text { (year) }\end{array}$ & $\begin{array}{l}\text { Conc'n } \\
(\mathrm{g} / \mathrm{mL})\end{array}$ & $\begin{array}{l}\text { Time } \\
\text { (year) }\end{array}$ & $\underset{\text { (g/year) }}{\text { Flux }}$ & $\begin{array}{l}\text { Time } \\
\text { (year) }\end{array}$ & $\begin{array}{l}\text { Conc'n } \\
(\mathrm{g} / \mathrm{mL})\end{array}$ & $\begin{array}{l}\text { Time } \\
\text { (year) }\end{array}$ \\
\hline${ }^{90} \mathrm{Sr}$ & $4.5 \times 10^{-8}$ & 2 & $2.7 \times 10^{-15}$ & 2 & $1.2 \times 10^{-11}$ & 320 & $1.1 \times 10^{-19}$ & 320 \\
\hline
\end{tabular}

Table 5.22. Simulated annual peak flux and concentration of radionuclides in soil solution and the years of occurrence in the recharge and lateral flow paths obtained from PADSIM for Tumulus $I I$ in Zone 26

\begin{tabular}{|c|c|c|c|c|c|c|c|c|}
\hline \multirow[b]{2}{*}{ Nuclide } & \multicolumn{4}{|c|}{ Recharge } & \multicolumn{4}{|c|}{ Lateral flow } \\
\hline & $\begin{array}{c}\text { Flux } \\
\text { (g/year) }\end{array}$ & $\begin{array}{l}\text { Time } \\
\text { (year) }\end{array}$ & $\begin{array}{l}\text { Conc'n } \\
(\mathrm{g} / \mathrm{mL})\end{array}$ & $\begin{array}{l}\text { Time } \\
\text { (year) }\end{array}$ & $\begin{array}{c}\text { Flux } \\
\text { (g/year) }\end{array}$ & $\begin{array}{l}\text { Time } \\
\text { (year) }\end{array}$ & $\begin{array}{l}\text { Conc'n } \\
(\mathrm{g} / \mathrm{mL})\end{array}$ & $\begin{array}{l}\text { Time } \\
\text { (year) }\end{array}$ \\
\hline${ }^{3} \mathrm{H}$ & $8.0 \times 10^{-6}$ & 18 & $1.7 \times 10^{-13}$ & 18 & & & & \\
\hline${ }^{14} \mathrm{C}$ & $6.8 \times 10^{-5}$ & 96 & $2.2 \times 10^{-13}$ & 96 & & & & \\
\hline${ }^{90} \mathrm{Sr}$ & $2.5 \times 10^{-5}$ & 96 & $8.1 \times 10^{-14}$ & 96 & & & & \\
\hline${ }^{137} \mathrm{Cs}$ & $2.9 \times 10^{-5}$ & 96 & $9.3 \times 10^{-14}$ & 96 & & & & \\
\hline${ }^{152} \mathrm{Eu}$ & $8.1 \times 10^{-9}$ & 96 & $2.6 \times 10^{-17}$ & 96 & & & & \\
\hline${ }^{154} \mathrm{Eu}$ & $4.2 \times 10^{-10}$ & 96 & $1.3 \times 10^{-18}$ & 96 & & & & \\
\hline${ }^{194} \mathrm{Os}$ & $1.8 \times 10^{-11}$ & 96 & $8.6 \times 10^{-20}$ & 12 & & & & \\
\hline${ }^{232} \mathrm{Th}$ & $1.7 \times 10^{-1}$ & 5,700 & $5.5 \times 10^{-10}$ & 5,700 & & & & \\
\hline${ }^{233} \mathrm{U}$ & $2.5 \times 10^{-4}$ & 160 & $8.0 \times 10^{-13}$ & 160 & & & & \\
\hline${ }^{238} \mathrm{U}$ & $2.2 \times 10^{-2}$ & 4,200 & $7.1 \times 10^{-11}$ & 5,800 & & & & \\
\hline${ }^{238} \mathrm{Pu}$ & $5.4 \times 10^{-10}$ & 160 & $1.7 \times 10^{-18}$ & 160 & & & & \\
\hline${ }^{239} \mathrm{Pu}$ & $7.8 \times 10^{-6}$ & 160 & $2.5 \times 10^{-14}$ & 160 & & & & \\
\hline${ }^{241} \mathrm{Am}$ & $1.6 \times 10^{-7}$ & 160 & $5.1 \times 10^{-16}$ & 160 & & & & \\
\hline${ }^{244} \mathrm{Cm}$ & $1.8 \times 10^{-10}$ & 96 & $5.8 \times 10^{-19}$ & 96 & & & & \\
\hline
\end{tabular}


Table 5.23. Simulated annual peak flux and concentration of radionuclides in soil solution and the years of occurrence in the recharge and lateral flow paths obtained from PADSIM for Tumulus I in Zone 27

\begin{tabular}{|c|c|c|c|c|c|c|c|c|}
\hline \multirow{2}{*}{ Nuclide } & \multicolumn{4}{|c|}{ Recharge } & \multicolumn{4}{|c|}{ Lateral flow } \\
\hline & $\underset{\text { (g/year) }}{\text { Flux }}$ & $\begin{array}{l}\text { Time } \\
\text { (year) }\end{array}$ & $\begin{array}{l}\text { Conc'n } \\
(\mathrm{g} / \mathrm{mL})\end{array}$ & $\begin{array}{l}\text { Time } \\
\text { (year) }\end{array}$ & $\underset{\text { (g/year) }}{\text { Flux }}$ & $\begin{array}{l}\text { Time } \\
\text { (year) }\end{array}$ & $\begin{array}{l}\text { Conc'n } \\
(\mathrm{g} / \mathrm{mL})\end{array}$ & $\begin{array}{l}\text { Time } \\
\text { (year) }\end{array}$ \\
\hline${ }^{3} \mathrm{H}$ & $1.4 \times 10^{-5}$ & 16 & $2.4 \times 10^{-13}$ & 16 & & & & \\
\hline${ }^{14} \mathrm{C}$ & $6.2 \times 10^{-4}$ & 94 & $1.5 \times 10^{-12}$ & 94 & & & & \\
\hline${ }^{63} \mathrm{Ni}$ & $1.7 \times 10^{-5}$ & 94 & $4.4 \times 10^{-14}$ & 94 & & & & \\
\hline${ }^{90} \mathrm{Sr}$ & $9.4 \times 10^{-5}$ & 94 & $2.4 \times 10^{-13}$ & 94 & & & & \\
\hline${ }^{99} \mathrm{Tc}$ & $1.4 \times 10^{-1}$ & 160 & $3.6 \times 10^{-10}$ & 160 & & & & \\
\hline${ }^{137} \mathrm{Cs}$ & $2.2 \times 10^{-7}$ & 130 & $5.5 \times 10^{-16}$ & 130 & & & & \\
\hline${ }^{152} \mathrm{Eu}$ & $5.5 \times 10^{-8}$ & 94 & $1.4 \times 10^{-16}$ & 94 & & & & \\
\hline${ }^{154} \mathrm{Eu}$ & $3.8 \times 10^{-9}$ & 94 & $9.6 \times 10^{-18}$ & 94 & & & & \\
\hline${ }^{210} \mathrm{~Pb}$ & $2.3 \times 10^{-8}$ & 94 & $5.8 \times 10^{-17}$ & 94 & & & & \\
\hline${ }^{226} \mathrm{Ra}$ & $1.2 \times 10^{-7}$ & 400 & $3.0 \times 10^{-16}$ & 410 & & & & \\
\hline${ }^{232} \mathrm{Th}$ & $1.5 \times 10^{-1}$ & 13,900 & $3.8 \times 10^{-10}$ & 14,000 & & & & \\
\hline${ }^{233} \mathrm{U}$ & $2.8 \times 10^{-4}$ & 1,200 & $6.9 \times 10^{-13}$ & 1,200 & & & & \\
\hline${ }^{238} \mathrm{U}$ & $2.8 \times 10^{-2}$ & 6,500 & $7.1 \times 10^{-11}$ & 6,800 & & & & \\
\hline${ }^{237} \mathrm{~Np}$ & $6.2 \times 10^{-4}$ & 1,300 & $1.6 \times 10^{-12}$ & 1,200 & & & & \\
\hline${ }^{238} \mathrm{Pu}$ & $4.1 \times 10^{-10}$ & 160 & $1.0 \times 10^{-18}$ & 160 & & & & \\
\hline${ }^{239} \mathrm{Pu}$ & $4.3 \times 10^{-5}$ & 940 & $1.1 \times 10^{-13}$ & 910 & & & & \\
\hline${ }^{240} \mathrm{Pu}$ & $1.5 \times 10^{-6}$ & 430 & $3.7 \times 10^{-15}$ & 470 & & & & \\
\hline${ }^{241} \mathrm{Am}$ & $6.7 \times 10^{-7}$ & 160 & $1.7 \times 10^{-15}$ & 160 & & & & \\
\hline${ }^{243} \mathrm{Am}$ & $3.0 \times 10^{-6}$ & 500 & $7.6 \times 10^{-15}$ & 520 & & & & \\
\hline${ }^{244} \mathrm{Cm}$ & $2.1 \times 10^{-10}$ & 94 & $5.3 \times 10^{-19}$ & 94 & & & & \\
\hline${ }^{249} \mathrm{Cf}$ & $8.6 \times 10^{-8}$ & 160 & $2.1 \times 10^{-16}$ & 160 & & & & \\
\hline
\end{tabular}

lives, and some lateral transport of the radionuclides is calculated (see Tables 5.18 and 5.24). The peak flux and concentration results may be compared with the other intermediate results to evaluate the progressive migration of peak fluxes and radionuclide concentrations through the landscape.

\subsubsection{Output from Modeling of Groundwater and Surface Water for Closed Disposal Units}

This section presents the results from the groundwater modeling and surface water modeling for the closed disposal units at SWSA 6. The analysis is performed in order to calculate the peak groundwater and surface water concentrations from the disposal of waste, the time of the peak concentrations, and the dose attributable to the peak concentrations for each of the radionuclides reported in the closed disposal units at SWSA 6. The analysis is performed for three exposure 
Table 5.24. Simulated annual peak flux and concentration of radionuclides in soil solution and the years of occurrence in the recharge and lateral flow paths obtained from HOLSIM for the low-range silos in Zone 30

\begin{tabular}{|c|c|c|c|c|c|c|c|c|}
\hline \multirow{2}{*}{ Nuclide } & \multicolumn{4}{|c|}{ Recharge } & \multicolumn{4}{|c|}{ Lateral flow } \\
\hline & $\begin{array}{c}\text { Flux } \\
\text { (g/year) }\end{array}$ & $\begin{array}{c}\text { Time } \\
\text { (year) }\end{array}$ & $\begin{array}{l}\text { Conc'n } \\
(\mathrm{g} / \mathrm{mL})\end{array}$ & $\begin{array}{c}\text { Time } \\
\text { (year) }\end{array}$ & $\begin{array}{c}\text { Flux } \\
\text { (g/year) }\end{array}$ & $\begin{array}{c}\text { Time } \\
\text { (year) }\end{array}$ & $\begin{array}{l}\text { Conc'n } \\
(\mathrm{g} / \mathrm{mL})\end{array}$ & $\begin{array}{c}\text { Time } \\
\text { (year) }\end{array}$ \\
\hline${ }^{3} \mathrm{H}$ & $1.8 \times 10^{-6}$ & 11 & $1.2 \times 10^{-14}$ & 11 & $3.5 \times 10^{-7}$ & 14 & $9.0 \times 10^{-16}$ & 14 \\
\hline${ }^{14} \mathrm{C}$ & $4.5 \times 10^{-4}$ & 260 & $2.4 \times 10^{-12}$ & 260 & $3.2 \times 10^{-4}$ & 260 & $6.5 \times 10^{-13}$ & 260 \\
\hline${ }^{90} \mathrm{Sr}$ & $8.3 \times 10^{-7}$ & 260 & $4.5 \times 10^{-15}$ & 260 & $8.6 \times 10^{-9}$ & 300 & $1.7 \times 10^{-17}$ & 300 \\
\hline${ }^{137} \mathrm{Cs}$ & $3.7 \times 10^{-10}$ & 290 & $2.0 \times 10^{-18}$ & 290 & $0.0 \times 10^{0}$ & 0 & $0.0 \times 10^{0}$ & 0 \\
\hline${ }^{152} \mathrm{Eu}$ & $3.2 \times 10^{-10}$ & 22 & $2.1 \times 10^{-18}$ & 22 & $1.8 \times 10^{-13}$ & 300 & $3.6 \times 10^{-22}$ & 300 \\
\hline${ }^{154} \mathrm{Eu}$ & $1.2 \times 10^{-10}$ & 15 & $8.1 \times 10^{-19}$ & 15 & $4.0 \times 10^{-17}$ & 300 & $8.1 \times 10^{-26}$ & 300 \\
\hline${ }^{155} \mathrm{Eu}$ & $2.3 \times 10^{-12}$ & 10 & $1.5 \times 10^{-20}$ & 10 & $2.1 \times 10^{-26}$ & 300 & $4.3 \times 10^{-35}$ & 300 \\
\hline${ }^{226} \mathrm{Ra}$ & $2.0 \times 10^{-9}$ & 490 & $1.1 \times 10^{-17}$ & 490 & $3.1 \times 10^{-10}$ & 3,100 & $6.4 \times 10^{-19}$ & 3,100 \\
\hline${ }^{229} \mathrm{Th}$ & $7.4 \times 10^{-10}$ & 7,300 & $4.1 \times 10^{-18}$ & 7,300 & $3.6 \times 10^{-10}$ & 7,800 & $7.4 \times 10^{-19}$ & 7,800 \\
\hline${ }^{230} \mathrm{Th}$ & $1.4 \times 10^{-7}$ & 19,000 & $7.5 \times 10^{-16}$ & 20,000 & $7.7 \times 10^{-8}$ & 26,000 & $1.6 \times 10^{-16}$ & 26,000 \\
\hline${ }^{232} \mathrm{Th}$ & $8.5 \times 10^{-2}$ & 66,000 & $4.6 \times 10^{-10}$ & 66,000 & $6.3 \times 10^{-2}$ & 82,000 & $1.3 \times 10^{-10}$ & 81,000 \\
\hline${ }^{233} \mathrm{U}$ & $9.9 \times 10^{-5}$ & 1,300 & $5.4 \times 10^{-13}$ & 1,200 & $1.9 \times 10^{-4}$ & 7,000 & $4.0 \times 10^{-13}$ & 7,300 \\
\hline${ }^{238} \mathrm{U}$ & $1.3 \times 10^{-2}$ & 18,000 & $7.1 \times 10^{-11}$ & 25,000 & $3.5 \times 10^{-2}$ & 39,000 & $7.1 \times 10^{-11}$ & 44,000 \\
\hline${ }^{237} \mathrm{~Np}$ & $2.6 \times 10^{-5}$ & 1,300 & $1.4 \times 10^{-13}$ & 1,300 & $5.2 \times 10^{-5}$ & 7,600 & $1.1 \times 10^{-13}$ & 7,400 \\
\hline${ }^{238} \mathrm{Pu}$ & $1.0 \times 10^{-10}$ & 260 & $5.5 \times 10^{-19}$ & 260 & $3.8 \times 10^{-12}$ & 380 & $7.8 \times 10^{-21}$ & 380 \\
\hline${ }^{239} \mathrm{Pu}$ & $5.7 \times 10^{-6}$ & 450 & $3.1 \times 10^{-14}$ & 400 & $9.8 \times 10^{-6}$ & 6,300 & $2.0 \times 10^{-14}$ & 6,200 \\
\hline${ }^{242} \mathrm{Pu}$ & $4.0 \times 10^{-6}$ & 1,300 & $2.2 \times 10^{-34}$ & 1,200 & $8.0 \times 10^{-6}$ & 7,500 & $1.6 \times 10^{-14}$ & 7,300 \\
\hline${ }^{241} \mathrm{Am}$ & $6.8 \times 10^{-8}$ & 260 & $3.7 \times 10^{-16}$ & 260 & $1.2 \times 10^{-8}$ & 800 & $2.4 \times 10^{-17}$ & 800 \\
\hline${ }^{243} \mathrm{Am}$ & $1.2 \times 10^{-6}$ & 260 & $6.4 \times 10^{-15}$ & 260 & $1.4 \times 10^{-6}$ & 4,400 & $2.9 \times 10^{-15}$ & 4,400 \\
\hline${ }^{244} \mathrm{Cm}$ & $1.2 \times 10^{-13}$ & 260 & $6.8 \times 10^{-22}$ & 260 & $9.1 \times 10^{-16}$ & 300 & $1.9 \times 10^{-24}$ & 300 \\
\hline${ }^{249} \mathrm{Cf}$ & $2.1 \times 10^{-9}$ & 260 & $1.2 \times 10^{-17}$ & 260 & $3.0 \times 10^{-10}$ & 710 & $6.1 \times 10^{-19}$ & 720 \\
\hline
\end{tabular}

scenarios of future use of groundwater and surface water. Each scenario uses the dose conversion factors for the consumption of $2 \mathrm{~L} / \mathrm{d}$ of contaminated water by an exposed individual, as described in Appendix $\mathrm{G}$ and given in Table 4.19.

The first scenario assumes consumption of drinking water from a groundwater well at any time and at any point outside a 100-m buffer zone surrounding each disposal zone associated with the closed disposal units shown in Fig. 4.15. This buffer zone is less than $100 \mathrm{~m}$ along the ephemeral stream to the east of SWSA 6. Table 5.25 presents the results of these calculations and includes the dose attributed to each radionuclide. The peak concentrations for each radionuclide do not occur at the same location, so the results represent the maximum composite in time and space for the radionuclides reported to be in the disposed waste. The radionuclide with the highest contribution to dose is ${ }^{239} \mathrm{Pu}$, with a peak dose of 3.3 mrem per year at a time of 2,900 years. Summing the doses for all of the radionuclides listed in Table 5.25, independent of the time of peak dose, yields a dose of $3.7 \mathrm{mrem}$ per year, which is less than the performance criterion for drinking water of 4 mrem per year. Using the 
Table 5.25. Maximum groundwater concentrations at the 100 -meter buffer zone due to closed disposal units inside SWSA 6 (excluding IWMF)

\begin{tabular}{|c|c|c|c|c|c|c|c|}
\hline Nuclide & $\begin{array}{c}\text { Peak } \\
\text { groundwater } \\
\text { conc'n } \\
(\mu \mathrm{Ci} / \mathrm{L})\end{array}$ & $\begin{array}{c}\text { Time to } \\
\text { peak } \\
\text { (year) }\end{array}$ & $\begin{array}{c}\text { Dose } \\
\text { (mrem/year) }\end{array}$ & Nuclide & $\begin{array}{c}\text { Peak } \\
\text { groundwater } \\
\text { conc'n } \\
(\mu \mathrm{Ci} / \mathrm{L})\end{array}$ & $\begin{array}{l}\text { Time to } \\
\text { peak } \\
\text { (year) }\end{array}$ & $\begin{array}{c}\text { Dose } \\
\text { (mrem/year) }\end{array}$ \\
\hline $\begin{array}{l}{ }^{3} \mathrm{H} \\
{ }^{10} \mathrm{Be}^{a}\end{array}$ & $5.8 \times 10^{-6}$ & 101 & $2.7 \times 10^{-4}$ & $\begin{array}{l}{ }^{228} \mathrm{Ra}^{a} \\
{ }^{227} \mathrm{Ac}^{a}\end{array}$ & & & \\
\hline${ }^{14} \mathrm{C}$ & $7.3 \times 10^{-5}$ & 104 & $1.1 \times 10^{-1}$ & ${ }^{229} \mathrm{Th}$ & $1.0 \times 10^{-17}$ & 52,800 & $2.9 \times 10^{-11}$ \\
\hline${ }^{26} \mathrm{Al}{ }^{a}$ & & & & ${ }^{230} \mathrm{Th}$ & $1.5 \times 10^{-10}$ & 97,200 & $5.8 \times 10^{-5}$ \\
\hline${ }^{36} \mathrm{Cl}^{a}$ & & & & ${ }^{232} \mathrm{Th}$ & $3.6 \times 10^{-9}$ & 294,000 & $1.3 \times 10^{-2}$ \\
\hline${ }^{40} \mathrm{~K}$ & $3.8 \times 10^{-10}$ & 1,280 & $5.2 \times 10^{-6}$ & ${ }^{231} \mathrm{~Pa}^{a}$ & & & \\
\hline${ }^{41} \mathrm{Ca}$ & $2.1 \times 10^{-13}$ & 1,980 & $2.0 \times 10^{-10}$ & ${ }^{232} U$ & $7.6 \times 10^{-17}$ & 1,040 & $1.1 \times 10^{-10}$ \\
\hline${ }^{60} \mathrm{Co}$ & $0.0 \times 10^{-0}$ & 0 & $0.0 \times 10^{0}$ & ${ }^{233} \mathrm{U}$ & $1.7 \times 10^{-7}$ & 2,800 & $3.6 \times 10^{-2}$ \\
\hline${ }^{59} \mathrm{Ni}^{a}$ & & & & ${ }^{234} \mathrm{U}^{a}$ & & & \\
\hline${ }^{63} \mathrm{Ni}$ & $3.5 \times 10^{-30}$ & 2,300 & $1.5 \times 10^{-27}$ & ${ }^{235} \mathrm{U}$ & $2.0 \times 10^{-8}$ & 3,020 & $4.0 \times 10^{-3}$ \\
\hline${ }^{79} \mathrm{Se}^{a}$ & & & & ${ }^{236} \mathrm{U}^{a}$ & & & \\
\hline${ }^{87} \mathrm{Rb}^{a}$ & & & & ${ }^{238} \mathrm{U}$ & $1.5 \times 10^{-10}$ & 2,220 & $2.9 \times 10^{-5}$ \\
\hline${ }^{90} \mathrm{Sr}$ & $1.9 \times 10^{-11}$ & 159 & $2.1 \times 10^{-6}$ & ${ }^{237} \mathrm{~Np}$ & $2.9 \times 10^{-8}$ & 2,800 & $8.8 \times 10^{-2}$ \\
\hline${ }^{93} \mathrm{Zr}^{a}$ & & & & ${ }^{238} \mathrm{Pu}$ & $5.1 \times 10^{-13}$ & 1,040 & $1.2 \times 10^{-6}$ \\
\hline${ }^{93 \mathrm{~m}} \mathrm{Nb}^{a}$ & & & & ${ }^{239} \mathrm{Pu}$ & $1.2 \times 10^{-6}$ & 2,980 & $3.3 \times 10^{\circ}$ \\
\hline${ }^{94} \mathrm{Nb}^{a}$ & & & & ${ }^{240} \mathrm{Pu}$ & $1.8 \times 10^{-8}$ & 2,800 & $4.7 \times 10^{-2}$ \\
\hline${ }^{99} \mathrm{Tc}$ & $1.6 \times 10^{-4}$ & 102 & $1.8 \times 10^{-1}$ & ${ }^{241} \mathrm{Pu}^{a}$ & & & \\
\hline $\begin{array}{l}{ }^{107} \mathrm{Pd}^{\alpha} \\
{ }_{113 \mathrm{~m}} \mathrm{Cd}^{\alpha}\end{array}$ & & & & $\begin{array}{l}{ }^{242} \mathrm{Pu} \\
{ }^{244} \mathrm{Pu}^{a}\end{array}$ & $9.6 \times 10^{-10}$ & 2,980 & $2.4 \times 10^{-3}$ \\
\hline${ }^{121 \mathrm{~m}} \mathrm{Sn}^{a}$ & & & & ${ }^{241} \mathrm{Am}$ & $1.9 \times 10^{-8}$ & 2,380 & $5.2 \times 10^{-2}$ \\
\hline${ }^{126} \mathrm{Sn}^{a}$ & & & & ${ }^{242 \mathrm{~m}} \mathrm{Am}^{a}$ & & & \\
\hline${ }^{129} \mathrm{I}^{a}$ & & & & ${ }^{243} \mathrm{Am}$ & $3.3 \times 10^{-8}$ & 2,800 & $8.7 \times 10^{-2}$ \\
\hline${ }^{135} \mathrm{Cs}^{a}$ & & & & ${ }^{243} \mathrm{Cm}^{a}$ & & & \\
\hline${ }^{137} \mathrm{Cs}$ & $3.7 \times 10^{-32}$ & 392 & $1.4 \times 10^{-27}$ & ${ }^{244} \mathrm{Cm}$ & $1.8 \times 10^{-18}$ & 143 & $2.7 \times 10^{-12}$ \\
\hline${ }^{151} \mathrm{Sm}^{\alpha}$ & & & & ${ }^{245} \mathrm{Cm}^{a}$ & & & \\
\hline${ }^{152} \mathrm{Eu}$ & $3.1 \times 10^{-18}$ & 143 & $1.5 \times 10^{-14}$ & ${ }^{246} \mathrm{Cm}^{a}$ & & & \\
\hline${ }^{154} \mathrm{Eu}$ & $5.2 \times 10^{-20}$ & 127 & $3.6 \times 10^{-16}$ & ${ }^{247} \mathrm{Cm}^{a}$ & & & \\
\hline${ }^{155} \mathrm{Eu}$ & $1.2 \times 10^{-27}$ & 115 & $1.3 \times 10^{-24}$ & ${ }^{248} \mathrm{Cm}^{a}$ & & & \\
\hline${ }^{194} \mathrm{Os}$ & $2.0 \times 10^{-39}$ & 158 & $1.6 \times 10^{-35}$ & ${ }^{249} \mathrm{Cf}$ & $1.5 \times 10^{-10}$ & 2,220 & $5.1 \times 10^{-4}$ \\
\hline${ }^{207} \mathrm{Bi}^{a}$ & & & & ${ }^{250} \mathrm{Cf}$ & & & \\
\hline${ }^{210} \mathrm{~Pb}$ & $5.2 \times 10^{-20}$ & 374 & $2.8 \times 10^{-13}$ & ${ }^{251} \mathrm{Cf}^{n}$ & & & \\
\hline${ }^{226} \mathrm{Ra}$ & $3.3 \times 10^{-18}$ & 12,100 & $2.1 \times 10^{-11}$ & & & & \\
\hline
\end{tabular}

${ }^{\circ}$ Present at IWMF only. 
time of compliance of 1000 years prescribed in the guidance of preparing this revised PA (DOE 1996c), the dose is reduced dramatically to much less than 1 mrem per year. Using one well at one location instead of the highest dose for each radionuclide at any location further reduces the dose to the extent that compliance with the performance criterion for the drinking water pathway is demonstrated with reasonable assurance for the closed disposal units. The locations for the most of the wells showing maximum concentrations of contamination are along the western edge of the $100-\mathrm{m}$ buffer zone near the ephemeral creek between IWMF and Tumulus I and Tumulus II.

The second scenario assumed consumption of drinking water from surface water at WOD. Table 5.26 presents the peak concentration for each radionuclide reported in the waste disposal records for the closed disposal units, the time of the peak concentration at WOD, and the dose from the consumption of surface water with the peak concentration of the radionuclide. Summing all of the doses, independent of the time of peak dose, yields a dose of 0.012 mrem per year, which is two orders of magnitude less than the performance criterion for drinking water of 4 mrem per year. Using the time of compliance of 1000 years, the dose is reduced to less than 0.01 mrem per year, and is primarily from ${ }^{90} \mathrm{Sr}$ and ${ }^{99} \mathrm{Tc}$. Therefore, the dose from the surface water pathway for the closed disposal units complies with the performance criterion.

The third scenario assumes the consumption of drinking water from a groundwater well located outside the expanded buffer zone shown in Fig. 4-16. Table 5.27 presents the peak concentration for each radionuclide reported in waste disposed of in the closed disposal units, the time the peak concentration occurs, and the dose from consumption of contaminated groundwater associated with the peak concentration. Summing the doses from all of the radionuclides in Table 5.27, independent of time of peak dose and independent of the location of the well associated with the peak concentration, yields a dose of 0.0013 mrem per year, primarily from ${ }^{14} \mathrm{C},{ }^{232} \mathrm{Th}$, and ${ }^{241} \mathrm{Am}$. Using a time of compliance of 1000 years reduces the dose of less than 0.0002 mrem per year, which is well below the performance criterion of 4 mrem per year. The dose is almost entirely from ${ }^{14} \mathrm{C}$. Because the maximum concentrations for different radionuclides occur at different well locations, no single well could include all of the peak concentrations. Therefore, the summation of all of the doses from all of the radionuclides is conservative. For the dlosed disposal units, compliance with the performance criterion is clearly demonstrated for the case of the use of groundwater for drinking water outside the expanded buffer zone.

The results presented in this section clearly demonstrate the compliance of the closed disposal units with the drinking water performance criterion. As discussed in Sect. 4.3.1.3, compliance with the drinking water performance criterion and the air pathways performance criterion is sufficient to demonstrate compliance with the all pathways performance criterion. Demonstration of compliance of SWSA 6 with the air pathways performance criterion is presented in Sect. 5.2. Therefore, the closed disposal units in SWSA 6 are in compliance with the all pathways performance criterion. Consequently, additional waste disposal at IWMF can be considered without exceeding the all pathways performance criterion for SWSA 6. The limitations on disposal of waste at IWMF are addressed in the Sect. 5.1.2. 
Table 5.26. Maximum surface water concentrations at WOD due to closed disposal units inside SWSA 6 (excluding IWMF)

\begin{tabular}{|c|c|c|c|c|c|c|c|}
\hline Nuclide & $\begin{array}{c}\text { Peak surface } \\
\text { water conc'n } \\
(\mu \mathrm{Ci} / \mathrm{L})\end{array}$ & $\begin{array}{l}\text { Time to } \\
\text { peak } \\
\text { (year) }\end{array}$ & $\begin{array}{c}\text { Dose } \\
\text { (mrem/year) }\end{array}$ & Nuclide & $\begin{array}{l}\text { Peak surface } \\
\text { water conc'n } \\
(\mu \mathrm{Ci} / \mathrm{L})\end{array}$ & $\begin{array}{l}\text { Time to } \\
\text { peak } \\
\text { (year) }\end{array}$ & $\begin{array}{c}\text { Dose } \\
\text { (mrem/year) }\end{array}$ \\
\hline $\begin{array}{l}{ }^{3} \mathrm{H} \\
{ }^{10} \mathrm{Be}^{a}\end{array}$ & $2.1 \times 10^{-6}$ & 13 & $9.8 \times 10^{-5}$ & $\begin{array}{l}{ }^{228} \mathrm{Ra}^{a} \\
{ }^{227} \mathrm{Ac}^{a}\end{array}$ & & & \\
\hline${ }^{14} \mathrm{C}$ & $2.2 \times 10^{-7}$ & 256 & $3.2 \times 10^{-4}$ & ${ }^{229} \mathrm{Th}$ & $1.4 \times 10^{-11}$ & 3,760 & $3.9 \times 10^{-5}$ \\
\hline${ }^{26} \mathrm{Al}^{a}$ & & & & ${ }^{230} \mathrm{Th}$ & $1.1 \times 10^{-12}$ & 3,100 & $4.2 \times 10^{-7}$ \\
\hline${ }^{36} \mathrm{Cl}^{a}$ & & & & ${ }^{232} \mathrm{Th}$ & $1.4 \times 10^{-12}$ & 89,000 & $5.2 \times 10^{-6}$ \\
\hline${ }^{40} \mathrm{~K}$ & $4.6 \times 10^{-11}$ & 336 & $6.4 \times 10^{-7}$ & ${ }^{231} \mathrm{~Pa}^{\alpha}$ & & & \\
\hline${ }^{41} \mathrm{Ca}$ & $1.6 \times 10^{-7}$ & 459 & $1.6 \times 10^{-4}$ & ${ }^{232} \mathrm{U}$ & $9.4 \times 10^{-16}$ & 347 & $1.4 \times 10^{-9}$ \\
\hline${ }^{60} \mathrm{Co}$ & $3.5 \times 10^{-46}$ & 81 & $7.0 \times 10^{-42}$ & ${ }^{233} \mathrm{U}$ & $1.8 \times 10^{-10}$ & 6,450 & $3.8 \times 10^{-5}$ \\
\hline${ }^{59} \mathrm{Ni}^{a}$ & & & & ${ }^{234} \mathrm{U}^{a}$ & & & \\
\hline${ }^{63} \mathrm{Ni}$ & $2.4 \times 10^{-12}$ & 477 & $1.0 \times 10^{-9}$ & ${ }^{235} \mathrm{U}$ & $5.3 \times 10^{-12}$ & 868 & $1.1 \times 10^{-6}$ \\
\hline${ }^{79} \mathrm{Se}^{a}$ & & & & ${ }^{236} \mathrm{U}^{a}$ & & & \\
\hline${ }^{87} \mathrm{Rb}^{a}$ & & & & ${ }^{238} \mathrm{U}$ & $3.5 \times 10^{-11}$ & 764 & $6.7 \times 10^{-6}$ \\
\hline${ }^{90} \mathrm{Sr}$ & $4.8 \times 10^{-8}$ & 364 & $5.3 \times 10^{-3}$ & ${ }^{237} \mathrm{~Np}$ & $2.8 \times 10^{-12}$ & 7,540 & $8.7 \times 10^{-6}$ \\
\hline${ }^{93} \mathrm{Zr}^{2}$ & & & & ${ }^{238} \mathrm{Pu}$ & $6.3 \times 10^{-12}$ & 183 & $1.5 \times 10^{-5}$ \\
\hline${ }^{93} \mathrm{Nb}^{a}$ & & & & ${ }^{239} \mathrm{Pu}$ & $4.9 \times 10^{-30}$ & 3,940 & $1.3 \times 10^{-3}$ \\
\hline${ }^{94} \mathrm{Nb}^{a}$ & & & & ${ }^{240} \mathrm{Pu}$ & $6.3 \times 10^{-19}$ & 822 & $1.7 \times 10^{-12}$ \\
\hline${ }^{99} \mathrm{Tc}$ & $4.4 \times 10^{-6}$ & 450 & $4.8 \times 10^{-3}$ & ${ }^{24 !} \mathrm{Pu}^{a}$ & & & \\
\hline${ }^{107} \mathrm{Pd}^{a}$ & & & & ${ }^{242} \mathrm{Pu}$ & $2.4 \times 10^{-32}$ & 7,460 & $5.9 \times 10^{-6}$ \\
\hline${ }^{113 \mathrm{~m}} \mathrm{Cd}^{\alpha}$ & & & & ${ }^{244} \mathrm{Pu}^{a}$ & & & \\
\hline${ }^{121 \mathrm{~m}} \mathrm{Sn}^{a}$ & & & & ${ }^{241} \mathrm{Am}$ & $4.4 \times 10^{-11}$ & 793 & $1.2 \times 10^{-4}$ \\
\hline${ }^{126} \mathrm{Sn}^{a}$ & & & & ${ }^{242 \mathrm{~m}} \mathrm{Am}^{\alpha}$ & & & \\
\hline${ }^{129} \mathrm{I}^{a}$ & & & & ${ }^{243} \mathrm{Am}$ & $2.3 \times 10^{-11}$ & 4,380 & $6.1 \times 10^{-5}$ \\
\hline${ }^{135} \mathrm{Cs}^{a}$ & & & & ${ }^{243} \mathrm{Cm}^{a}$ & & & \\
\hline${ }^{137} \mathrm{Cs}$ & $4.0 \times 10^{-25}$ & 230 & $1.4 \times 10^{-20}$ & ${ }^{244} \mathrm{Cm}$ & $1.7 \times 10^{-14}$ & 183 & $2.5 \times 10^{-8}$ \\
\hline${ }^{151} \mathrm{Sm}^{\alpha}$ & & & & ${ }^{245} \mathrm{Cm}^{a}$ & & & \\
\hline${ }^{152} \mathrm{Eu}$ & $1.3 \times 10^{-14}$ & 269 & $6.3 \times 10^{-11}$ & ${ }^{246} \mathrm{Cm}^{a}$ & & & \\
\hline${ }^{154} \mathrm{Eu}$ & $6.6 \times 10^{-18}$ & 263 & $4.6 \times 10^{-14}$ & ${ }^{247} \mathrm{Cm}^{a}$ & & & \\
\hline${ }^{155} \mathrm{Eu}$ & $7.7 \times 10^{-28}$ & 298 & $8.5 \times 10^{-25}$ & ${ }^{248} \mathrm{Cm}^{a}$ & & & \\
\hline${ }^{194} \mathrm{Os}$ & $2.2 \times 10^{-31}$ & 122 & $1.8 \times 10^{-27}$ & ${ }^{249} \mathrm{Cf}$ & $4.4 \times 10^{-13}$ & 780 & $1.5 \times 10^{-6}$ \\
\hline${ }^{207} \mathrm{Bi}^{a}$ & & & & ${ }^{250} \mathrm{Cf}^{a}$ & & & \\
\hline${ }^{210} \mathrm{~Pb}$ & $1.4 \times 10^{-22}$ & 150 & $7.6 \times 10^{-16}$ & ${ }^{251} \mathrm{Cf}^{p}$ & & & \\
\hline${ }^{226} \mathrm{Ra}$ & $1.2 \times 10^{-121}$ & 1,960 & $7.1 \times 10^{-5}$ & & & & \\
\hline
\end{tabular}

${ }^{\circ}$ Present at IWMF only. 
Table 5.27. Maximum groundwater concentrations at the expanded buffer zone due to closed disposal units inside SWSA 6 (excluding TWMF)

\begin{tabular}{|c|c|c|c|c|c|c|c|}
\hline Nuclide & $\begin{array}{c}\text { Peak } \\
\text { groundwater } \\
\text { conc'n } \\
(\mu \mathrm{Ci} / \mathrm{L})\end{array}$ & $\begin{array}{c}\text { Time to } \\
\text { peak } \\
\text { (year) }\end{array}$ & $\begin{array}{c}\text { Dose } \\
\text { (mrem/year) }\end{array}$ & Nuclide & $\begin{array}{l}\text { Peak } \\
\text { groundwater } \\
\text { conc'n } \\
(\mu \mathrm{Ci} / \mathrm{L})\end{array}$ & $\begin{array}{l}\text { Time to } \\
\text { peak } \\
\text { (year) }\end{array}$ & $\begin{array}{c}\text { Dose } \\
\text { (mrem/year) }\end{array}$ \\
\hline $\begin{array}{l}{ }^{3} \mathrm{H} \\
{ }^{10} \mathrm{Be}^{a}\end{array}$ & $6.5 \times 10^{-9}$ & 101 & $3.1 \times 10^{-7}$ & $\begin{array}{l}{ }^{228} \mathrm{Ra}^{a} \\
{ }^{227} \mathrm{Ac}^{a}\end{array}$ & & & \\
\hline${ }^{14} \mathrm{C}$ & $1.0 \times 10^{-3}$ & 137 & $1.5 \times 10^{-4}$ & ${ }^{229} \mathrm{Th}$ & $5.1 \times 10^{-19}$ & 32,600 & $1.5 \times 10^{-12}$ \\
\hline${ }^{26} \mathrm{Al}^{a}$ & & & & ${ }^{230} \mathrm{Th}$ & $7.8 \times 10^{-21}$ & 100,000 & $3.1 \times 10^{-15}$ \\
\hline${ }^{36} \mathrm{Cl}^{\alpha}$ & & & & ${ }^{232} \mathrm{Th}$ & $1.9 \times 10^{-10}$ & 55,200 & $6.9 \times 10^{-4}$ \\
\hline${ }^{40} \mathrm{~K}$ & $3.8 \times 10^{-10}$ & 1,280 & $5.2 \times 10^{-6}$ & ${ }^{231} \mathrm{~Pa}^{a}$ & & & \\
\hline${ }^{41} \mathrm{Ca}$ & $2.1 \times 10^{-13}$ & 892 & $2.0 \times 10^{-10}$ & ${ }^{232} \mathrm{U}$ & $1.4 \times 10^{-31}$ & 1,920 & $2.0 \times 10^{-25}$ \\
\hline${ }^{60} \mathrm{Co}$ & $0.0 \times 10^{0}$ & 0 & $0.0 \times 10^{\circ}$ & ${ }^{233} \mathrm{U}$ & $3.8 \times 10^{-16}$ & 2,980 & $7.9 \times 10^{-11}$ \\
\hline${ }^{59} \mathrm{Ni}^{a}$ & & & & ${ }^{234} \mathrm{U}^{a}$ & & & \\
\hline${ }^{63} \mathrm{Ni}$ & $3.5 \times 10^{-31}$ & 1,100 & $1.5 \times 10^{-28}$ & ${ }^{235} \mathrm{U}$ & $1.3 \times 10^{-11}$ & 8,530 & $2.6 \times 10^{-6}$ \\
\hline${ }^{79} \mathrm{Se}^{a}$ & & & & ${ }^{236} \mathrm{U}^{a}$ & & & \\
\hline${ }^{87} \mathrm{Rb}^{\alpha}$ & & & & ${ }^{238} \mathrm{U}$ & $1.2 \times 10^{-19}$ & 2,980 & $2.2 \times 10^{-14}$ \\
\hline${ }^{90} \mathrm{Sr}$ & $1.9 \times 10^{-11}$ & 159 & $2.1 \times 10^{-6}$ & ${ }^{237} \mathrm{~Np}$ & $2.2 \times 10^{-18}$ & 2,900 & $6.9 \times 10^{-12}$ \\
\hline${ }^{93} \mathrm{Zr}^{a}$ & & & & ${ }^{238} \mathrm{Pu}$ & $1.1 \times 10^{-14}$ & 1,020 & $2.7 \times 10^{-8}$ \\
\hline${ }^{93} \mathrm{Nb}^{a}$ & & & & ${ }^{239} \mathrm{Pu}$ & $1.1 \times 10^{-17}$ & 1,360 & $3.0 \times 10^{-11}$ \\
\hline${ }^{94} \mathrm{Nb}^{a}$ & & & & ${ }^{240} \mathrm{Pu}$ & $2.4 \times 10^{-22}$ & 2,980 & $6.3 \times 10^{-16}$ \\
\hline${ }^{99} \mathrm{Tc}$ & $2.0 \times 10^{-9}$ & 114 & $2.2 \times 10^{-6}$ & ${ }^{241} \mathrm{Pu}^{a}$ & & & \\
\hline 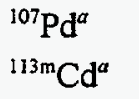 & & & & $\begin{array}{l}{ }^{242} \mathrm{Pu} \\
{ }^{244} \mathrm{Pu}^{a}\end{array}$ & $1.9 \times 10^{-18}$ & 2,900 & $4.7 \times 10^{-12}$ \\
\hline $\begin{array}{l}{ }^{121 \mathrm{~m}} \mathrm{Sn}^{a} \\
{ }^{126} \mathrm{Sn}^{a}\end{array}$ & & & & ${ }^{242 \mathrm{~m}} \mathrm{Am}^{a}$ & $1.8 \times 10^{-10}$ & 1,360 & $4.7 \times 10^{-4}$ \\
\hline${ }^{129} \mathrm{I}^{a}$ & & & & ${ }^{243} \mathrm{Am}$ & $2.3 \times 10^{-17}$ & 2,900 & $6.1 \times 10^{-11}$ \\
\hline${ }^{135} \mathrm{Cs}^{a}$ & & & & ${ }^{243} \mathrm{Cm}^{a}$ & & & \\
\hline $\begin{array}{l}{ }^{137} \mathrm{Cs} \\
{ }^{151} \mathrm{Sm}^{a}\end{array}$ & $7.8 \times 10^{-33}$ & 383 & $2.8 \times 10^{-28}$ & ${ }^{244} \mathrm{Cm}^{245} \mathrm{Cm}^{a}$ & $1.1 \times 10^{-22}$ & 568 & $1.6 \times 10^{-16}$ \\
\hline${ }^{152} \mathrm{Eu}$ & $1.4 \times 10^{-19}$ & 142 & $6.6 \times 10^{-16}$ & ${ }^{246} \mathrm{Cm}^{a}$ & & & \\
\hline${ }^{154} \mathrm{Eu}$ & $2.4 \times 10^{-23}$ & 153 & $1.6 \times 10^{-19}$ & ${ }^{247} \mathrm{Cm}^{a}$ & & & \\
\hline${ }^{155} \mathrm{Eu}$ & $1.6 \times 10^{-28}$ & 101 & $1.8 \times 10^{-25}$ & ${ }^{248} \mathrm{Cm}^{\alpha}$ & & & \\
\hline${ }^{194} \mathrm{Os}$ & $0.0 \times 10^{0}$ & 0 & $0.0 \times 10^{0}$ & ${ }^{249} \mathrm{Cf}$ & $1.2 \times 10^{-19}$ & 2,980 & $3.9 \times 10^{-13}$ \\
\hline${ }^{207} \mathrm{Bi}^{a}$ & & & & ${ }^{250} \mathrm{Cf}^{2}$ & & & \\
\hline${ }^{210} \mathrm{~Pb}$ & $0.0 \times 10^{0}$ & 0 & $0.0 \times 10^{\circ}$ & ${ }^{251} \mathrm{Cf}$ & & & \\
\hline${ }^{226} \mathrm{Ra}$ & $1.4 \times 10^{-29}$ & 26,200 & $9.0 \times 10^{-23}$ & & & & \\
\hline
\end{tabular}

"Present at IWMF only. 


\subsubsection{Results for the Interim Waste Management Facility}

This section presents results from the shallow subsurface and groundwater modeling analyses for the IWMF. Additional intermediate results from the source term and shallow subsurface transport analyses of the IWMF facility are also included, and are analogous to those presented in Sections 5.1.1.1, 5.1.2.1 and 5.1.1.2, 5.1.2.2.

A maximum allowable inventory for IWMF is determined for each of the three exposure scenarios listed in Sect. 4.3.1.2 which are the consumption of groundwater beyond the $100-\mathrm{m}$ buffer zone, the consumption of surface water at WOD, and the consumption of groundwater beyond the expanded buffer zone. In all cases, the maximum allowable drinking water concentration for any radionuclide listed in Table 4.19 is based on a dose limit for the drinking water pathway of 4 mrem per year EDE, under the assumption that the exposed individual consumes $2 \mathrm{~L} / \mathrm{d}$ of contaminated water, as described in Appendix G.

\subsubsection{Output from the Modeling of Releases from IWMF}

Table 5.28 provides the peak release rates of radionuclides from IWMF as calculated by the SOURCE1 computer program. The disposal inventories reported in Table 5.32 (i.e.. the inventory limits based on groundwater concentrations at the expanded buffer zone) are used in these calculations. For each radionuclide, Table 5.28 presents the initial inventory used in the calculations, the maximum releases, and year of occurrence. In general, the calculated releases are divided into two components: (1) a vertical component, which recharges to groundwater, and (2) a lateral component. which flows in the shallow subsurface region and discharges to surface water. For entries which have a range of years indicated (for the year of occurrence), the release is limited by solubility during that period. For IWMF, however, there is no lateral component. This lack of a lateral component is a result of the close proximity of the IWMF to the saturated zone. Hence, all releases from IWMF are transported into the vertical path as recharge to groundwater. The results in this table account for radioactive decay.

The intermediate results presented here for IWMF are analogous to those presented in Sect. 5.1.1.1 for the non-IWMF disposal units.

\subsubsection{Output from the Modeling of Shallow Subsurface Transport for IWMF}

Table 5.29 provides the peak radionuclide flux, peak concentrations, and respective times of occurrence for the recharge as determined by PADSIM. The results in this table account for radioactive decay.

The intermediate results presented here for IWMF are analogous to those presented in Sect. 5.1.1.2 for the non-IWMF disposal units. 
Table 5.28. Maximum annual release rate from a single IWMF pad and year of occurrence for vertical and lateral release components of SOURCE1 calculations

\begin{tabular}{|c|c|c|c|c|c|}
\hline \multirow{2}{*}{ Nuclide } & \multirow{2}{*}{$\begin{array}{c}\text { Allowable } \\
\text { inventory } \\
\text { (g/pad) }\end{array}$} & \multicolumn{2}{|c|}{ Vertical component } & \multicolumn{2}{|c|}{ Lateral component } \\
\hline & & $\begin{array}{c}\text { Peak flux } \\
\text { (g/year) }\end{array}$ & $\begin{array}{c}\text { Time of peak } \\
\text { (year) }\end{array}$ & $\begin{array}{c}\text { Peak flux } \\
\text { (g/year) }\end{array}$ & $\begin{array}{c}\text { Time of peak } \\
\text { (year) }\end{array}$ \\
\hline${ }^{3} \mathrm{H}$ & $1.6 \times 10^{6}$ & $1.9 \times 10^{4}$ & 46 & & \\
\hline${ }^{10} \mathrm{Be}$ & $1.6 \times 10^{9}$ & $2.5 \times 10^{1}$ & $100-50,000$ & & \\
\hline${ }^{14} \mathrm{C}$ & $7.4 \times 10^{2}$ & $4.3 \times 10^{1}$ & 170 & & \\
\hline${ }^{26} \mathrm{Al}$ & $2.8 \times 10^{7}$ & $2.5 \times 10^{4}$ & 940 & & \\
\hline${ }^{36} \mathrm{Cl}$ & $5.1 \times 10^{4}$ & $4.1 \times 10^{3}$ & 98 & & \\
\hline${ }^{40} \mathrm{~K}$ & $7.3 \times 10^{8}$ & $1.5 \times 10^{7}$ & 170 & & \\
\hline${ }^{41} \mathrm{Ca}$ & $9.7 \times 10^{5}$ & $2.0 \times 10^{3}$ & $100-520$ & & \\
\hline${ }^{60} \mathrm{Co}$ & $6.6 \times 10^{9}$ & $3.7 \times 10^{0}$ & 57 & & \\
\hline${ }^{59} \mathrm{Ni}$ & $7.6 \times 10^{9}$ & $1.4 \times 10^{4}$ & $104-50,000$ & & \\
\hline${ }^{63} \mathrm{Ni}$ & $7.6 \times 10^{9}$ & $1.5 \times 10^{4}$ & $100-1,200$ & & \\
\hline${ }^{79} \mathrm{Se}$ & $2.4 \times 10^{4}$ & $2.1 \times 10^{2}$ & 100 & & \\
\hline${ }^{87} \mathrm{Rb}$ & $1.3 \times 10^{9}$ & $1.4 \times 10^{7}$ & 170 & none & \\
\hline${ }^{90} \mathrm{Sr}$ & $2.2 \times 10^{9}$ & $2.1 \times 10^{3}$ & $100-400$ & & \\
\hline${ }^{93} \mathrm{Zr}$ & $6.9 \times 10^{7}$ & $6.4 \times 10^{4}$ & $100-910$ & & \\
\hline${ }^{93 \mathrm{~m}} \mathrm{Nb}$ & $7.3 \times 10^{9}$ & $4.0 \times 10^{5}$ & 49 & & \\
\hline${ }^{94} \mathrm{Nb}$ & $3.6 \times 10^{5}$ & $1.1 \times 10^{3}$ & 170 & & \\
\hline${ }^{99} \mathrm{Tc}$ & $5.1 \times 10^{5}$ & $1.1 \times 10^{4}$ & 170 & & \\
\hline${ }^{107} \mathrm{Pd}$ & $6.6 \times 10^{5}$ & $1.3 \times 10^{-1}$ & $140-250,000$ & & \\
\hline${ }^{113 \mathrm{~m}} \mathrm{Cd}$ & $7.3 \times 10^{9}$ & $1.7 \times 10^{2}$ & 49 & & \\
\hline${ }^{121 m} \mathrm{Sn}$ & $5.6 \times 10^{9}$ & $7.0 \times 10^{6}$ & 98 & & \\
\hline${ }^{126} \mathrm{Sn}$ & $5.0 \times 10^{5}$ & $2.5 \times 10^{3}$ & 170 & & \\
\hline${ }^{129} \mathrm{I}$ & $1.7 \times 10^{5}$ & $8.3 \times 10^{3}$ & 98 & & \\
\hline${ }^{135} \mathrm{Cs}$ & $8.6 \times 10^{8}$ & $6.0 \times 10^{6}$ & 170 & & \\
\hline${ }^{137} \mathrm{Cs}$ & $1.6 \times 10^{9}$ & $1.1 \times 10^{6}$ & 98 & & \\
\hline${ }^{151} \mathrm{Sm}$ & $6.6 \times 10^{9}$ & $7.0 \times 10^{6}$ & 98 & & \\
\hline${ }^{152} \mathrm{Eu}$ & $4.6 \times 10^{9}$ & $1.3 \times 10^{2}$ & $100-230$ & & \\
\hline${ }^{154} \mathrm{Eu}$ & $4.6 \times 10^{9}$ & $1.3 \times 10^{2}$ & $100-140$ & & \\
\hline${ }^{155} \mathrm{Eu}$ & $4.6 \times 10^{9}$ & $1.0 \times 10^{2}$ & 80 & & \\
\hline${ }^{194} \mathrm{Os}$ & $1.9 \times 10^{10}$ & $9.6 \times 10^{4}$ & 49 & & \\
\hline${ }^{207} \mathrm{Bi}$ & $8.3 \times 10^{9}$ & $3.5 \times 10^{2}$ & $100-600$ & & \\
\hline${ }^{210} \mathrm{~Pb}$ & $9.6 \times 10^{9}$ & $3.3 \times 10^{3}$ & $100-300$ & & \\
\hline${ }^{226} \mathrm{Ra}$ & $4.3 \times 10^{9}$ & $4.4 \times 10^{\circ}$ & $100-30,000$ & & \\
\hline${ }^{228} \mathrm{Ra}$ & $4.3 \times 10^{9}$ & $4.1 \times 10^{\circ}$ & $100-130$ & & \\
\hline${ }^{227} \mathrm{Ac}$ & $8.6 \times 10^{9}$ & $1.1 \times 10^{3}$ & $104-200$ & & \\
\hline${ }^{229} \mathrm{Th}$ & $7.3 \times 10^{9}$ & $2.2 \times 10^{-1}$ & $100-100,000$ & & \\
\hline${ }^{230} \mathrm{Th}$ & $7.3 \times 10^{9}$ & $2.2 \times 10^{-1}$ & $100-100,000$ & & \\
\hline${ }^{232} \mathrm{Th}$ & $7.3 \times 10^{9}$ & $2.2 \times 10^{-1}$ & $100-500,000$ & & \\
\hline${ }^{231} \mathrm{~Pa}$ & $7.0 \times 10^{3}$ & $4.3 \times 10^{-1}$ & 170 & & \\
\hline${ }^{232} \mathrm{U}$ & $8.3 \times 10^{9}$ & $2.2 \times 10^{-2}$ & $100-1,700$ & & \\
\hline${ }^{233} \mathrm{U}$ & $8.3 \times 10^{9}$ & $2.2 \times 10^{-2}$ & $100-50,000$ & & \\
\hline${ }^{234} \mathrm{U}$ & $8.3 \times 10^{9}$ & $2.2 \times 10^{-2}$ & $100-50,000$ & & \\
\hline${ }^{235} \mathrm{U}$ & $8.3 \times 10^{9}$ & $2.2 \times 10^{-2}$ & $100-100,000$ & & \\
\hline${ }^{236} \mathrm{U}$ & $8.3 \times 10^{9}$ & $2.2 \times 10^{-2}$ & $100-500,000$ & none & \\
\hline
\end{tabular}


Table 5.28. (continued)

\begin{tabular}{|c|c|c|c|c|c|}
\hline \multirow{2}{*}{ Nuclide } & \multirow{2}{*}{$\begin{array}{c}\text { Allowable } \\
\text { inventory } \\
(\mathrm{g} / \mathrm{pad})\end{array}$} & \multicolumn{2}{|c|}{ Vertical component } & \multicolumn{2}{|c|}{ Lateral component } \\
\hline & & $\begin{array}{c}\text { Peak flux } \\
\text { (g/year) }\end{array}$ & $\begin{array}{c}\text { Time of peak } \\
\text { (year) }\end{array}$ & $\begin{array}{l}\text { Peak flux } \\
\text { (g/year) }\end{array}$ & $\begin{array}{c}\text { Time of peak } \\
\text { (year) }\end{array}$ \\
\hline${ }^{238} \mathrm{U}$ & $8.3 \times 10^{9}$ & $2.2 \times 10^{-2}$ & $100-2,000,000$ & & \\
\hline${ }^{237} \mathrm{~Np}$ & $1.7 \times 10^{10}$ & $2.2 \times 10^{-1}$ & $100-50,000$ & & \\
\hline${ }^{238} \mathrm{Pu}$ & $1.7 \times 10^{10}$ & $7.4 \times 10^{-3}$ & $100-2,400$ & & \\
\hline${ }^{239} \mathrm{Pu}$ & $1.7 \times 10^{10}$ & $7.5 \times 10^{-3}$ & $100-500,000$ & & \\
\hline${ }^{240} \mathrm{Pu}$ & $1.7 \times 10^{10}$ & $7.5 \times 10^{-3}$ & $100-50,000$ & & \\
\hline${ }^{241} \mathrm{Pu}$ & $1.7 \times 10^{10}$ & $7.3 \times 10^{-3}$ & $100-390$ & & \\
\hline${ }^{242} \mathrm{Pu}$ & $1.7 \times 10^{10}$ & $7.6 \times 10^{-3}$ & $100-50,000$ & & \\
\hline${ }^{244} \mathrm{Pu}$ & $1.7 \times 10^{10}$ & $7.6 \times 10^{-3}$ & $100-500,000$ & & \\
\hline${ }^{241} \mathrm{Am}$ & $1.2 \times 10^{30}$ & $3.0 \times 10^{-2}$ & $100-11,000$ & & \\
\hline${ }^{242 \mathrm{~m}} \mathrm{Am}$ & $1.2 \times 10^{10}$ & $3.0 \times 10^{-2}$ & $100-3,500$ & & \\
\hline${ }^{243} \mathrm{Am}$ & $1.2 \times 10^{10}$ & $3.0 \times 10^{-2}$ & $100-50,000$ & & \\
\hline${ }^{243} \mathrm{Cm}$ & $1.2 \times 10^{10}$ & $7.5 \times 10^{-3}$ & $100-760$ & & \\
\hline${ }^{244} \mathrm{Cm}$ & $1.2 \times 10^{10}$ & $7.5 \times 10^{-3}$ & $100-480$ & & \\
\hline${ }^{245} \mathrm{Cm}$ & $1.2 \times 10^{10}$ & $7.7 \times 10^{-3}$ & $100-50,000$ & & \\
\hline${ }^{246} \mathrm{Cm}$ & $1.2 \times 10^{10}$ & $7.7 \times 10^{-3}$ & $100-50,000$ & & \\
\hline${ }^{247} \mathrm{Cm}$ & $1.2 \times 10^{10}$ & $7.7 \times 10^{-3}$ & $100-50,000$ & & \\
\hline${ }^{248} \mathrm{Cm}$ & $1.2 \times 10^{10}$ & $7.8 \times 10^{-3}$ & $100-50,000$ & & \\
\hline${ }^{249} \mathrm{Cf}$ & $5.5 \times 10^{3}$ & $2.3 \times 10^{-1}$ & 170 & & \\
\hline${ }^{250} \mathrm{Cf}$ & $3.3 \times 10^{9}$ & $2.4 \times 10^{3}$ & 49 & & \\
\hline${ }^{251} \mathrm{Cf}$ & $1.5 \times 10^{3}$ & $7.7 \times 10^{-2}$ & 170 & & \\
\hline
\end{tabular}

${ }^{\circ}$ Inventory is for a single pad of 330 vaults.

\subsubsection{Results of the Water Pathway Analyses for All Disposal Units}

For the first case, the peak groundwater concentration corresponding to a given inventory is defined as the maximum concentration value that occurs at any point in time and outside a $100-\mathrm{m}$ buffer zone surrounding each disposal zone, shown in Fig. 4.15. This buffer zone is in places less than $100 \mathrm{~m}$, where it is truncated by ephemeral creeks. The limiting inventory is determined to be the minimum of either (1) the theoretical maximum limit for the pure radionuclide and (2) the inventory that results in a peak groundwater concentration that is equal to the allowable drinking water limit imposed by the performance objective. Table 5.30 lists these limiting inventories and corresponding peak groundwater concentrations at 100-m receptor locations. As explained in Sect. 2.5.3, groundwater resources located in the area between IWMF, the Tumulus I and II disposal units, and White Oak Lake would certainly be protected, hence, exposure of an individual could not occur at many of the $100-\mathrm{m}$ receptor locations given reasonable land use controls. Results from this case are therefore presented for reference purposes only.

The second case evaluates surface water, and exposure via drinking water at surface water sources. The limiting inventory is determined to be the minimum of the theoretical maximum limit for the pure radionuclide and the inventory of a given radionuclide which results in a peak surface water concentration equal to the allowable drinking water limit. The maximum, combined (see 
Table 5.29. Calculated annual peak flux and concentration of radionuclides in soil solution and the years of occurrence in the recharge and lateral flow paths obtained from PADSIM for IWMF

\begin{tabular}{|c|c|c|c|c|c|c|c|c|}
\hline \multirow[b]{2}{*}{ Nuclide } & \multicolumn{4}{|c|}{ Recharge } & \multicolumn{4}{|c|}{ Lateral flow } \\
\hline & $\begin{array}{c}\text { Flux } \\
\text { (g/year) }\end{array}$ & $\begin{array}{l}\text { Time } \\
\text { (year) }\end{array}$ & $\begin{array}{l}\text { Conc'n } \\
(\mathrm{g} / \mathrm{mL})\end{array}$ & $\begin{array}{l}\text { Time } \\
\text { (year) }\end{array}$ & $\begin{array}{c}\text { Flux } \\
\text { (g/year) }\end{array}$ & $\begin{array}{l}\text { Time } \\
\text { (year) }\end{array}$ & $\begin{array}{l}\text { Conc'n } \\
(\mathrm{g} / \mathrm{mL})\end{array}$ & $\begin{array}{l}\text { Time } \\
\text { (year) }\end{array}$ \\
\hline${ }^{3} \mathrm{H}$ & $1.9 \times 10^{4}$ & 46 & $6.0 \times 10^{-5}$ & 46 & & & & \\
\hline${ }^{10} \mathrm{Be}$ & $2.5 \times 10^{1}$ & 50,000 & $7.9 \times 10^{-8}$ & 50,000 & & & & \\
\hline${ }^{14} \mathrm{C}$ & $4.2 \times 10^{1}$ & 170 & $1.4 \times 10^{-7}$ & 170 & & & & \\
\hline${ }^{26} \mathrm{Al}$ & $3.1 \times 10^{3}$ & 2,100 & $9.9 \times 10^{-6}$ & 2,100 & & & & \\
\hline${ }^{36} \mathrm{Cl}$ & $4.1 \times 10^{3}$ & 98 & $1.3 \times 10^{-5}$ & 98 & & & & \\
\hline${ }^{40} \mathrm{~K}$ & $1.3 \times 10^{7}$ & 170 & $4.3 \times 10^{-2}$ & 170 & & & & \\
\hline${ }^{41} \mathrm{Ca}$ & $1.8 \times 10^{3}$ & 520 & $5.9 \times 10^{-6}$ & 520 & & & & \\
\hline${ }^{60} \mathrm{Co}$ & $3.1 \times 10^{0}$ & 57 & $2.3 \times 10^{-8}$ & 39 & & & & \\
\hline${ }^{59} \mathrm{Ni}$ & $1.4 \times 10^{4}$ & 49,000 & $4.4 \times 10^{-5}$ & 50,000 & & & & \\
\hline${ }^{63} \mathrm{Ni}$ & $1.1 \times 10^{4}$ & 260 & $3.4 \times 10^{-5}$ & 480 & & & & \\
\hline${ }^{79} \mathrm{Se}$ & $2.0 \times 10^{2}$ & 100 & $6.5 \times 10^{-7}$ & 100 & & & & \\
\hline${ }^{87} \mathrm{Rb}$ & $1.2 \times 10^{7}$ & 170 & $3.8 \times 10^{-2}$ & 170 & & & & \\
\hline${ }^{90} \mathrm{Sr}$ & $1.8 \times 10^{3}$ & 180 & $5.8 \times 10^{-6}$ & 220 & & & & \\
\hline${ }^{93} \mathrm{Zr}$ & $6.0 \times 10^{4}$ & 910 & $1.9 \times 10^{-4}$ & 910 & & & & \\
\hline${ }^{93 \mathrm{~m}} \mathrm{Nb}$ & $3.5 \times 10^{5}$ & 49 & $1.2 \times 10^{-3}$ & 46 & & & & \\
\hline${ }^{94} \mathrm{Nb}$ & $9.8 \times 10^{2}$ & 170 & $3.1 \times 10^{-6}$ & 170 & & & & \\
\hline${ }^{99} \mathrm{Tc}$ & $1.1 \times 10^{4}$ & 170 & $3.5 \times 10^{-5}$ & 170 & & & & \\
\hline${ }^{107} \mathrm{Pd}$ & $1.3 \times 10^{-1}$ & 110,000 & $4.0 \times 10^{-10}$ & 140,000 & & & & \\
\hline${ }^{113 \mathrm{~m}} \mathrm{Cd}$ & $1.5 \times 10^{2}$ & 49 & $4.9 \times 10^{-7}$ & 46 & & none & & \\
\hline${ }^{121 \mathrm{~m}} \mathrm{Sn}$ & $6.1 \times 10^{6}$ & 98 & $2.0 \times 10^{-2}$ & 98 & & & & \\
\hline${ }^{126} \mathrm{Sn}$ & $2.2 \times 10^{3}$ & 170 & $7.1 \times 10^{-6}$ & 170 & & & & \\
\hline${ }^{129} \mathrm{I}$ & $8.2 \times 10^{3}$ & 98 & $2.6 \times 10^{-5}$ & 98 & & & & \\
\hline${ }^{135} \mathrm{Cs}$ & $1.0 \times 10^{5}$ & 410 & $3.3 \times 10^{-4}$ & 420 & & & & \\
\hline${ }^{137} \mathrm{Cs}$ & $3.3 \times 10^{3}$ & 120 & $1.0 \times 10^{-5}$ & 120 & & & & \\
\hline${ }^{151} \mathrm{Sm}$ & $5.8 \times 10^{6}$ & 98 & $1.8 \times 10^{-2}$ & 98 & & & & \\
\hline${ }^{152} \mathrm{Eu}$ & $1.1 \times 10^{2}$ & 110 & $3.7 \times 10^{-7}$ & 120 & & & & \\
\hline${ }^{154} \mathrm{Eu}$ & $1.1 \times 10^{2}$ & 110 & $3.6 \times 10^{-7}$ & 110 & & & & \\
\hline${ }^{155} \mathrm{Eu}$ & $8.9 \times 10^{1}$ & 80 & $2.8 \times 10^{-7}$ & 80 & & & & \\
\hline${ }^{194} \mathrm{Os}$ & $7.9 \times 10^{4}$ & 49 & $3.2 \times 10^{-4}$ & 46 & & & & \\
\hline${ }^{207} \mathrm{Bi}$ & $3.0 \times 10^{2}$ & 160 & $9.4 \times 10^{-7}$ & 170 & & & & \\
\hline${ }^{210} \mathrm{~Pb}$ & $2.9 \times 10^{3}$ & 140 & $9.3 \times 10^{-6}$ & 230 & & & & \\
\hline${ }^{226} \mathrm{Ra}$ & $1.0 \times 10^{\circ}$ & 13,000 & $3.2 \times 10^{-9}$ & 17,000 & & & & \\
\hline${ }^{228} \mathrm{Ra}$ & $4.6 \times 10^{-3}$ & 130 & $1.5 \times 10^{-11}$ & 130 & & & & \\
\hline${ }^{227} \mathrm{Ac}$ & $9.5 \times 10^{2}$ & 180 & $3.0 \times 10^{-6}$ & 150 & & & & \\
\hline${ }^{229} \mathrm{Th}$ & $1.2 \times 10^{-1}$ & 38,000 & $4.0 \times 10^{-10}$ & 41,000 & & & & \\
\hline${ }^{230} \mathrm{Th}$ & $2.0 \times 10^{-1}$ & 70,000 & $6.4 \times 10^{-10}$ & 77,000 & & & & \\
\hline${ }^{232} \mathrm{Th}$ & $2.2 \times 10^{-1}$ & 64,000 & $7.0 \times 10^{-10}$ & 74,000 & & & & \\
\hline${ }^{23 !} \mathrm{Pa}$ & $3.7 \times 10^{-1}$ & 170 & $1.2 \times 10^{-9}$ & 170 & & & & \\
\hline${ }^{232} \mathrm{U}$ & $1.9 \times 10^{-2}$ & 470 & $6.1 \times 10^{-11}$ & 530 & & & & \\
\hline${ }^{233} \mathrm{U}$ & $2.2 \times 10^{-2}$ & 4,900 & $7.0 \times 10^{-11}$ & 7,100 & & & & \\
\hline${ }^{234} \mathrm{U}$ & $2.2 \times 10^{-2}$ & 5,200 & $7.0 \times 10^{-11}$ & 6,700 & & & & \\
\hline
\end{tabular}


Table 5.29. (continued)

\begin{tabular}{|c|c|c|c|c|c|c|c|c|}
\hline \multirow{2}{*}{ Nuclide } & \multicolumn{4}{|c|}{ Recharge } & \multicolumn{4}{|c|}{ Lateral flow } \\
\hline & $\begin{array}{c}\text { Flux } \\
\text { (g/year) }\end{array}$ & $\begin{array}{l}\text { Time } \\
\text { (year) }\end{array}$ & $\begin{array}{l}\text { Conc'n } \\
(\mathrm{g} / \mathrm{mL})\end{array}$ & $\begin{array}{l}\text { Time } \\
\text { (year) }\end{array}$ & $\underset{\text { (g/year) }}{\text { Flux }}$ & $\begin{array}{l}\text { Time } \\
\text { (year) }\end{array}$ & $\begin{array}{l}\text { Conc'n } \\
(\mathrm{g} / \mathrm{mL})\end{array}$ & $\begin{array}{l}\text { Time } \\
\text { (year) }\end{array}$ \\
\hline${ }^{235} \mathrm{U}$ & $2.2 \times 10^{-2}$ & 5,100 & $7.1 \times 10^{-11}$ & 6,500 & & & & \\
\hline${ }^{236} \mathrm{U}$ & $2.2 \times 10^{-2}$ & 6,400 & $7.1 \times 10^{-11}$ & 6,500 & & & & \\
\hline${ }^{238} \mathrm{U}$ & $2.2 \times 10^{-2}$ & 4,900 & $7.1 \times 10^{-11}$ & 6,500 & & & & \\
\hline${ }^{237} \mathrm{~Np}$ & $2.2 \times 10^{-1}$ & 5,500 & $7.1 \times 10^{-10}$ & 7,000 & & & & \\
\hline${ }^{238} \mathrm{Pu}$ & $6.6 \times 10^{-3}$ & 700 & $2.1 \times 10^{-11}$ & 740 & & & & \\
\hline${ }^{239} \mathrm{Pu}$ & $7.5 \times 10^{-3}$ & 6,400 & $2.4 \times 10^{-11}$ & 5,900 & & & & \\
\hline${ }^{240} \mathrm{Pu}$ & $7.4 \times 10^{-3}$ & 5,400 & $2.4 \times 10^{-11}$ & 5,100 & & & & \\
\hline${ }^{241} \mathrm{Pu}$ & $6.4 \times 10^{-3}$ & 150 & $2.0 \times 10^{-11}$ & 110 & & & & \\
\hline${ }^{242} \mathrm{Pu}$ & $7.6 \times 10^{-3}$ & 6,400 & $2.4 \times 10^{-11}$ & 8,300 & & & & \\
\hline${ }^{244} \mathrm{Pu}$ & $7.6 \times 10^{-3}$ & 6,200 & $2.4 \times 10^{-11}$ & 5,600 & & none & & \\
\hline${ }^{241} \mathrm{Am}$ & $2.8 \times 10^{-2}$ & 3,100 & $8.9 \times 10^{-11}$ & 3,200 & & & & \\
\hline${ }^{242 \mathrm{~m}} \mathrm{Am}$ & $2.7 \times 10^{-2}$ & 870 & $8.7 \times 10^{-11}$ & 1,900 & & & & \\
\hline${ }^{243} \mathrm{Am}$ & $3.0 \times 10^{-2}$ & 4,800 & $9.6 \times 10^{-11}$ & 6,500 & & & & \\
\hline${ }^{243} \mathrm{Cm}$ & $6.6 \times 10^{-3}$ & 250 & $2.1 \times 10^{-11}$ & 220 & & & & \\
\hline${ }^{244} \mathrm{Cm}$ & $6.6 \times 10^{-3}$ & 170 & $2.1 \times 10^{-11}$ & 130 & & & & \\
\hline${ }^{245} \mathrm{Cm}$ & $7.6 \times 10^{-3}$ & 7,600 & $2.4 \times 10^{-11}$ & 5,400 & & & & \\
\hline${ }^{246} \mathrm{Cm}$ & $7.6 \times 10^{-3}$ & 6,100 & $2.4 \times 10^{-11}$ & 4,400 & & & & \\
\hline${ }^{247} \mathrm{Cm}$ & $7.7 \times 10^{-3}$ & 6,200 & $2.5 \times 10^{-11}$ & 5,600 & & & & \\
\hline${ }^{248} \mathrm{Cm}$ & $7.8 \times 10^{-3}$ & 6,700 & $2.5 \times 10^{-11}$ & 5,000 & & & & \\
\hline${ }^{249} \mathrm{Cf}$ & $2.0 \times 10^{-1}$ & 170 & $6.5 \times 10^{-10}$ & 170 & & & & \\
\hline${ }^{250} \mathrm{Cf}$ & $2.1 \times 10^{3}$ & 49 & $7.1 \times 10^{-6}$ & 46 & & & & \\
\hline${ }^{251} \mathrm{Cf}$ & $6.8 \times 10^{-2}$ & 170 & $2.2 \times 10^{-10}$ & 170 & & & & \\
\hline
\end{tabular}

Sect. 4.3.1.2.3) surface water concentration for a given inventory is defined as the maximum concentration which occurs at any point in time at WOD (see Sect. 2.5.3). Table 5.31 lists these limiting inventories and corresponding peak surface water concentrations at WOD.

Finally, the third case examines exposure via drinking water from a groundwater well outside the expanded buffer zone. The peak groundwater concentration corresponding to a given inventory is defined as the maximum concentration which occurs at any point in time and outside the expanded buffer zone shown in Fig. 4.16. The limiting inventory for each radionuclide is determined to be the minimum of (1) the theoretical maximum limit for the pure radionuclide and (2) the inventory that results in a peak groundwater concentration that is equal to the allowable drinking water limit. These results are presented in Table 5.32.

For many radionuclides in Tables 5.30 and Table 5.33, the limiting inventories for the expanded buffer zone scenario are much larger than the $100-\mathrm{m}$ buffer zone scenario. The interpretation of these results, and the implications of these results on IWMF disposal operations is presented in Sect. 7.1.

For the majority of nuclides listed in Table 5.31 and Table 5.32, the limiting inventories at IWMF based on both the groundwater concentrations at the expanded buffer zone and surface water 
Table 5.30. Allowable limits on inventories of radionuclides at IWMF based on groundwater concentrations at the 100 -meter buffer zone

\begin{tabular}{|c|c|c|c|c|c|c|c|}
\hline Nuclide & $\begin{array}{l}\text { Limiting } \\
\text { IWMF } \\
\text { inventory } \\
\text { (Ci/pad) }\end{array}$ & $\begin{array}{c}\text { Peak } \\
\text { groundwater } \\
\text { conc'n } \\
(\mu \mathrm{Ci} / \mathrm{L}) \\
\end{array}$ & $\begin{array}{c}\text { Time to } \\
\text { peak } \\
\text { (year) }\end{array}$ & Nuclide & $\begin{array}{l}\text { Limiting } \\
\text { IWMF } \\
\text { inventory } \\
\text { (Ci/pad) }\end{array}$ & $\begin{array}{c}\text { Peak } \\
\text { groundwater } \\
\text { conc'n } \\
(\mu \mathrm{Ci} / \mathrm{L})\end{array}$ & $\begin{array}{l}\text { Time to } \\
\text { peak } \\
\text { (year) }\end{array}$ \\
\hline${ }^{3} \mathrm{H}$ & $7.9 \times 10^{5}$ & $8.5 \times 10^{-2}$ & 100 & ${ }^{228} \mathrm{Ra}^{a}$ & $1.2 \times 10^{12}$ & $8.0 \times 10^{-32}$ & 170 \\
\hline${ }^{10} \mathrm{Be}$ & $7.4 \times 10^{0}$ & $1.2 \times 10^{-3}$ & 23,000 & ${ }^{227} \mathrm{Ac}$ & $1.1 \times 10^{9}$ & $3.6 \times 10^{-7}$ & 350 \\
\hline${ }^{14} \mathrm{C}$ & $5.0 \times 10^{-2}$ & $2.7 \times 10^{-3}$ & 100 & ${ }^{229} \mathrm{Th}$ & $8.5 \times 10^{1}$ & $1.4 \times 10^{-6}$ & 71,000 \\
\hline${ }^{26} \mathrm{Al}$ & $8.1 \times 10^{0}$ & $3.6 \times 10^{-4}$ & 92,000 & ${ }^{230} \mathrm{Th}$ & $6.7 \times 10^{-1}$ & $1.0 \times 10^{-5}$ & 87,000 \\
\hline${ }^{36} \mathrm{Cl}$ & $1.1 \times 10^{\circ}$ & $1.8 \times 10^{-3}$ & 100 & ${ }^{232} \mathrm{Th}^{a}$ & $8.0 \times 10^{2}$ & $3.9 \times 10^{-8}$ & 260,000 \\
\hline${ }^{40} \mathrm{~K}$ & $6.9 \times 10^{-2}$ & $2.9 \times 10^{-4}$ & 900 & ${ }^{231} \mathrm{~Pa}$ & $3.8 \times 10^{-3}$ & $2.1 \times 10^{-7}$ & 12,000 \\
\hline${ }^{41} \mathrm{Ca}$ & $9.1 \times 10^{-1}$ & $4.2 \times 10^{-3}$ & 900 & ${ }^{232} \mathrm{U}$ & $3.9 \times 10^{3}$ & $2.7 \times 10^{-6}$ & 980 \\
\hline${ }^{60} \mathrm{Co}^{a}$ & $7.5 \times 10^{12}$ & $2.5 \times 10^{-25}$ & 110 & ${ }^{233} \mathrm{U}$ & $2.2 \times 10^{-1}$ & $1.9 \times 10^{-5}$ & 2,300 \\
\hline${ }^{59} \mathrm{Ni}$ & $5.7 \times 10^{2}$ & $2.7 \times 10^{-2}$ & 45,800 & ${ }^{234} \mathrm{U}$ & $2.3 \times 10^{-1}$ & $2.0 \times 10^{-5}$ & 2,300 \\
\hline${ }^{63} \mathrm{Ni}^{a}$ & $4.7 \times 10^{11}$ & $1.8 \times 10^{-17}$ & 2,300 & ${ }^{235} U^{a}$ & $1.8 \times 10^{4}$ & $7.6 \times 10^{-8}$ & 50,000 \\
\hline${ }^{79} \mathrm{Se}$ & $4.9 \times 10^{-2}$ & $6.3 \times 10^{-4}$ & 110 & ${ }^{236} \mathrm{U}^{a}$ & $5.3 \times 10^{5}$ & $2.3 \times 10^{-6}$ & 118,000 \\
\hline${ }^{87} \mathrm{Rb}$ & $2.3 \times 10^{-1}$ & $1.1 \times 10^{-3}$ & 900 & ${ }^{238} \mathrm{U}^{a}$ & $2.8 \times 10^{3}$ & $1.2 \times 10^{-8}$ & $1,000,000$ \\
\hline${ }^{90} \mathrm{Sr}$ & $4.1 \times 10^{5}$ & $3.6 \times 10^{-5}$ & 570 & ${ }^{237} \mathrm{~Np}$ & $1.5 \times 10^{-2}$ & $1.3 \times 10^{-6}$ & 2,300 \\
\hline${ }^{93} \mathrm{Zr}$ & $1.2 \times 10^{0}$ & $2.5 \times 10^{-3}$ & 1,500 & ${ }^{238} \mathrm{Pu}$ & $2.9 \times 10^{2}$ & $1.7 \times 10^{-6}$ & 1,100 \\
\hline${ }^{93 \mathrm{~m}} \mathrm{Nb}^{a}$ & $2.1 \times 10^{12}$ & $9.1 \times 10^{-7}$ & 210 & ${ }^{239} \mathrm{Pu}$ & $1.9 \times 10^{-2}$ & $1.5 \times 10^{-6}$ & 2,300 \\
\hline${ }^{94} \mathrm{Nb}$ & $6.7 \times 10^{-1}$ & $7.7 \times 10^{-4}$ & 2,800 & ${ }^{240} \mathrm{Pu}$ & $2.2 \times 10^{-2}$ & $1.5 \times 10^{-6}$ & 1,700 \\
\hline${ }^{99} \mathrm{Tc}$ & $1.3 \times 10^{-1}$ & $3.6 \times 10^{-3}$ & 110 & ${ }^{241} \mathrm{Pu}^{a}$ & $1.7 \times 10^{12}$ & $5.8 \times 10^{-12}$ & 350 \\
\hline${ }^{107} \mathrm{Pd}^{b}$ & $3.4 \times 10^{2}$ & $1.1 \times 10^{-4}$ & 250,000 & ${ }^{242} \mathrm{Pu}$ & $1.9 \times 10^{-2}$ & $1.6 \times 10^{-6}$ & 2,300 \\
\hline${ }^{113 m} \mathrm{Cd}^{a}$ & $1.6 \times 10^{12}$ & $5.5 \times 10^{-16}$ & 220 & ${ }^{244} \mathrm{Pu}^{a}$ & $3.0 \times 10^{5}$ & $2.2 \times 10^{-7}$ & 120,000 \\
\hline${ }^{121 m} \mathrm{Sn}$ & $2.7 \times 10^{10}$ & $3.3 \times 10^{-3}$ & 890 & ${ }^{241} \mathrm{Am}$ & $1.8 \times 10^{-1}$ & $1.5 \times 10^{-6}$ & 1,200 \\
\hline${ }^{126} \mathrm{Sn}$ & $2.0 \times 10^{-1}$ & $2.7 \times 10^{-4}$ & 2,700 & ${ }^{242 \mathrm{~m}} \mathrm{Am}$ & $5.1 \times 10^{\circ}$ & $8.2 \times 10^{-7}$ & 1,200 \\
\hline${ }^{129} I$ & $3.7 \times 10^{-4}$ & $2.0 \times 10^{-5}$ & 110 & ${ }^{243} \mathrm{Am}$ & $2.2 \times 10^{-2}$ & $1.5 \times 10^{-6}$ & 1,700 \\
\hline${ }^{135} \mathrm{Cs}$ & $4.5 \times 10^{0}$ & $7.7 \times 10^{-4}$ & 130,000 & ${ }^{243} \mathrm{Cm}^{a}$ & $6.0 \times 10^{11}$ & $5.3 \times 10^{-9}$ & 1,200 \\
\hline${ }^{137} \mathrm{Cs}^{e}$ & $1.4 \times 10^{11}$ & $1.7 \times 10^{-22}$ & 370 & ${ }^{244} \mathrm{Cm}^{a}$ & $9.3 \times 10^{11}$ & $4.8 \times 10^{-11}$ & 630 \\
\hline${ }^{151} \mathrm{Sm}^{a}$ & $1.7 \times 10^{11}$ & $2.3 \times 10^{-12}$ & 1,200 & ${ }^{245} \mathrm{Cm}$ & $2.1 \times 10^{-2}$ & $1.5 \times 10^{-6}$ & 1,700 \\
\hline${ }^{152} \mathrm{Eu}^{a}$ & $8.0 \times 10^{11}$ & $4.9 \times 10^{-8}$ & 350 & ${ }^{246} \mathrm{Cm}$ & $3.1 \times 10^{-2}$ & $1.5 \times 10^{-6}$ & 1,700 \\
\hline${ }^{154} \mathrm{Eu}^{\alpha}$ & $1.2 \times 10^{12}$ & $1.8 \times 10^{-9}$ & 160 & ${ }^{247} \mathrm{Cm}^{a}$ & $1.1 \times 10^{6}$ & $1.1 \times 10^{-6}$ & 15,000 \\
\hline${ }^{155} \mathrm{Eu}^{a}$ & $2.1 \times 10^{12}$ & $8.6 \times 10^{-12}$ & 150 & ${ }^{248} \mathrm{Cm}$ & $4.8 \times 10^{-3}$ & $4.0 \times 10^{-7}$ & 2,300 \\
\hline${ }^{194} \mathrm{OS}^{a}$ & $6.0 \times 10^{12}$ & $4.2 \times 10^{-22}$ & 110 & ${ }^{249} \mathrm{Cf}$ & $2.3 \times 10^{-1}$ & $1.2 \times 10^{-6}$ & 1,200 \\
\hline${ }^{207} \mathrm{Bi}^{a}$ & $4.4 \times 10^{11}$ & $4.3 \times 10^{-16}$ & 570 & ${ }^{250} \mathrm{Cf}$ & $3.6 \times 10^{11}$ & $1.9 \times 10^{-7}$ & 160 \\
\hline${ }^{210} \mathrm{~Pb}^{a}$ & $7.3 \times 10^{11}$ & $9.5 \times 10^{-8}$ & 210 & ${ }^{251} \mathrm{Cf}$ & $4.3 \times 10^{-2}$ & $1.1 \times 10^{-6}$ & 1,400 \\
\hline${ }^{226} \mathrm{Ra}^{a}$ & $4.2 \times 10^{9}$ & $5.7 \times 10^{-10}$ & 49,000 & & & & \\
\hline
\end{tabular}

${ }^{a}$ Inventory based on theoretical maximum disposal limit.

${ }^{\text {hInventory for }}{ }^{107} \mathrm{Pd}$ is based on $2 \mathrm{~kg} /$ vault. 
Table 5.31. Allowable limits on inventories of radionuclides at IWMF based on surface water concentrations at WOD

\begin{tabular}{|c|c|c|c|c|c|c|c|}
\hline Nuclide & $\begin{array}{l}\text { Limiting } \\
\text { IWMF } \\
\text { inventory }^{a} \\
\text { (Ci/pad) }\end{array}$ & $\begin{array}{c}\text { Peak } \\
\text { surface water } \\
\text { concentration } \\
(\mu \mathrm{Ci} / \mathrm{L})\end{array}$ & $\begin{array}{l}\text { Time to } \\
\text { peak } \\
\text { (year) }\end{array}$ & Nuclide & $\begin{array}{l}\text { Limiting } \\
\text { IWMF } \\
\text { inventory }^{a} \\
\text { (Ci/pad) }\end{array}$ & $\begin{array}{c}\text { Peak } \\
\text { surface water } \\
\text { concentration } \\
(\mu \mathrm{Ci} / \mathrm{L})\end{array}$ & $\begin{array}{c}\text { Time to } \\
\text { peak } \\
\text { (year) }\end{array}$ \\
\hline${ }^{3} \mathrm{H}$ & $5.4 \times 10^{12}$ & $2.23 \times 10^{-3}$ & 50 & ${ }^{228} \mathrm{Ra}$ & $1.2 \times 10^{12}$ & $7.10 \times 10^{-28}$ & 150 \\
\hline${ }^{10} \mathrm{Be}$ & $3.5 \times 10^{7}$ & $8.17 \times 10^{-12}$ & 48,000 & ${ }^{227} \mathrm{Ac}$ & $6.2 \times 10^{11}$ & $4.54 \times 10^{-11}$ & 230 \\
\hline${ }^{14} \mathrm{C}$ & $4.6 \times 10^{10}$ & $2.18 \times 10^{-7}$ & 260 & ${ }^{229} \mathrm{Th}$ & $1.5 \times 10^{9}$ & $1.37 \times 10^{-11}$ & 3,800 \\
\hline${ }^{26} \mathrm{Al}$ & $4.4 \times 10^{7}$ & $9.93 \times 10^{-9}$ & 87,000 & ${ }^{230} \mathrm{Th}$ & $1.5 \times 10^{8}$ & $1.05 \times 10^{-12}$ & 3,100 \\
\hline${ }^{36} \mathrm{Cl}$ & $5.6 \times 10^{7}$ & $4.30 \times 10^{-7}$ & 110 & ${ }^{232} \mathrm{Th}$ & $8.0 \times 10^{2}$ & $1.43 \times 10^{-12}$ & 89,000 \\
\hline${ }^{40} \mathrm{~K}$ & $5.1 \times 10^{3}$ & $1.14 \times 10^{-10}$ & 910 & ${ }^{231} \mathrm{~Pa}$ & $6.2 \times 10^{8}$ & $2.31 \times 10^{-8}$ & 48,000 \\
\hline${ }^{41} \mathrm{Ca}$ & $1.1 \times 10^{8}$ & $1.63 \times 10^{-7}$ & 460 & ${ }^{232} \mathrm{U}$ & $1.8 \times 10^{11}$ & $3.90 \times 10^{-14}$ & 1,300 \\
\hline${ }^{60} \mathrm{Co}$ & $7.5 \times 10^{12}$ & $2.01 \times 10^{-22}$ & 87 & ${ }^{233} \mathrm{U}$ & $8.0 \times 10^{7}$ & $1.81 \times 10^{-10}$ & 6,400 \\
\hline${ }^{59} \mathrm{Ni}$ & $6.1 \times 10^{8}$ & $1.14 \times 10^{-8}$ & 120,000 & ${ }^{234} \mathrm{U}$ & $5.2 \times 10^{7}$ & $1.09 \times 10^{-15}$ & 4,600 \\
\hline${ }^{63} \mathrm{Ni}$ & $4.7 \times 10^{11}$ & $2.37 \times 10^{-12}$ & 480 & ${ }^{235} \mathrm{U}$ & $1.8 \times 10^{4}$ & $5.25 \times 10^{-12}$ & 870 \\
\hline${ }^{79} \mathrm{Se}$ & $2.8 \times 10^{8}$ & $5.32 \times 10^{-7}$ & 180 & ${ }^{236} \mathrm{U}$ & $5.3 \times 10^{5}$ & $1.14 \times 10^{-17}$ & 4,600 \\
\hline${ }^{87} \mathrm{Rb}$ & $1.1 \times 10^{2}$ & $2.58 \times 10^{-12}$ & 910 & ${ }^{238} \mathrm{U}$ & $2.8 \times 10^{3}$ & $3.52 \times 10^{-11}$ & 760 \\
\hline${ }^{90} \mathrm{Sr}$ & $3.0 \times 10^{11}$ & $4.87 \times 10^{-8}$ & 360 & ${ }^{237} \mathrm{~Np}$ & $1.2 \times 10^{7}$ & $2.84 \times 10^{-12}$ & 7,600 \\
\hline${ }^{93} \mathrm{Zr}$ & $1.4 \times 10^{7}$ & $2.59 \times 10^{-9}$ & 4,500 & ${ }^{238} \mathrm{Pu}$ & $2.9 \times 10^{11}$ & $6.34 \times 10^{-12}$ & 180 \\
\hline${ }^{93 \mathrm{~m}} \mathrm{Nb}$ & $2.1 \times 10^{12}$ & $3.73 \times 10^{-11}$ & 180 & ${ }^{239} \mathrm{Pu}$ & $1.0 \times 10^{9}$ & $4.92 \times 10^{-10}$ & 3,900 \\
\hline${ }^{94} \mathrm{Nb}$ & $1.4 \times 10^{9}$ & $6.90 \times 10^{-6}$ & 3,100 & ${ }^{240} \mathrm{Pu}$ & $3.8 \times 10^{9}$ & $1.20 \times 10^{-14}$ & 2,500 \\
\hline${ }^{99} \mathrm{Tc}$ & $1.7 \times 10^{8}$ & $4.38 \times 10^{-6}$ & 460 & ${ }^{241} \mathrm{Pu}$ & $1.7 \times 10^{12}$ & $1.63 \times 10^{-16}$ & 420 \\
\hline${ }^{107} \mathrm{Pd}^{b}$ & $3.4 \times 10^{2}$ & $1.05 \times 10^{-15}$ & 200,000 & ${ }^{242} \mathrm{Pu}$ & $6.4 \times 10^{7}$ & $2.37 \times 10^{-12}$ & 7,500 \\
\hline${ }^{113 \mathrm{~m}} \mathrm{Cd}$ & $1.6 \times 10^{12}$ & $5.28 \times 10^{-14}$ & 120 & ${ }^{244} \mathrm{Pu}$ & $3.0 \times 10^{5}$ & $1.07 \times 10^{-18}$ & 4,600 \\
\hline${ }^{121 \mathrm{~m}} \mathrm{Sn}$ & $3.3 \times 10^{11}$ & $6.95 \times 10^{-8}$ & 360 & ${ }^{241} \mathrm{Am}$ & $4.0 \times 10^{10}$ & $4.40 \times 10^{-11}$ & 780 \\
\hline${ }^{126} \mathrm{Sn}$ & $1.6 \times 10^{8}$ & $1.02 \times 10^{-6}$ & 2,800 & ${ }^{242 \mathrm{~m}} \mathrm{Am}$ & $1.1 \times 10^{11}$ & $1.56 \times 10^{-13}$ & 740 \\
\hline${ }^{129} \mathrm{I}$ & $7.6 \times 10^{5}$ & $5.81 \times 10^{-9}$ & 170 & ${ }^{243} \mathrm{Am}$ & $2.3 \times 10^{9}$ & $2.29 \times 10^{-11}$ & 4,400 \\
\hline${ }^{135} \mathrm{Cs}$ & $1.9 \times 10^{6}$ & $4.26 \times 10^{-10}$ & 87,100 & ${ }^{243} \mathrm{Cm}$ & $6.0 \times 10^{11}$ & $1.29 \times 10^{-15}$ & 720 \\
\hline${ }^{137} \mathrm{Cs}$ & $1.4 \times 10^{11}$ & $6.38 \times 10^{-20}$ & 280 & ${ }^{244} \mathrm{Cm}$ & $9.3 \times 10^{11}$ & $1.72 \times 10^{-14}$ & 180 \\
\hline${ }^{151} \mathrm{Sm}$ & $1.7 \times 10^{11}$ & $7.32 \times 10^{-11}$ & 670 & ${ }^{245} \mathrm{Cm}$ & $2.0 \times 10^{9}$ & $9.45 \times 10^{-15}$ & 4,600 \\
\hline${ }^{152} \mathrm{Eu}$ & $8.0 \times 10^{11}$ & $3.09 \times 10^{-12}$ & 230 & ${ }^{246} \mathrm{Cm}$ & $4.6 \times 10^{9}$ & $1.59 \times 10^{-14}$ & 2,500 \\
\hline${ }^{154} \mathrm{Eu}$ & $1.2 \times 10^{12}$ & $1.23 \times 10^{-12}$ & 140 & ${ }^{247} \mathrm{Cm}$ & $1.1 \times 10^{6}$ & $5.70 \times 10^{-18}$ & 4,600 \\
\hline${ }^{155} \mathrm{Eu}$ & $2.1 \times 10^{12}$ & $1.34 \times 10^{-13}$ & 63 & ${ }^{248} \mathrm{Cm}$ & $4.9 \times 10^{7}$ & $2.61 \times 10^{-16}$ & 4,600 \\
\hline${ }^{194} \mathrm{Os}$ & $6.0 \times 10^{12}$ & $4.37 \times 10^{-19}$ & 83 & ${ }^{249} \mathrm{Cf}$ & $1.3 \times 10^{10}$ & $7.12 \times 10^{-7}$ & 740 \\
\hline${ }^{207} \mathrm{Bi}$ & $4.4 \times 10^{11}$ & $5.84 \times 10^{-14}$ & 330 & ${ }^{250} \mathrm{Cf}$ & $3.6 \times 10^{11}$ & $1.00 \times 10^{-11}$ & 87 \\
\hline${ }^{210} \mathrm{~Pb}$ & $7.3 \times 10^{11}$ & $8.99 \times 10^{-12}$ & 360 & ${ }^{251} \mathrm{Cf}^{\mathrm{f}}$ & $4.6 \times 10^{9}$ & $1.10 \times 10^{-6}$ & 1,300 \\
\hline${ }^{226} \mathrm{Ra}$ & $4.2 \times 10^{9}$ & $1.18 \times 10^{-12}$ & 2,000 & & & & \\
\hline
\end{tabular}

${ }^{9}$ Inventory for all radionuclides except ${ }^{107} \mathrm{Pd}$ and ${ }^{251} \mathrm{Cf}$ are based on theoretical maximum disposal limits.

${ }^{b}$ Inventory for ${ }^{107} \mathrm{Pd}$ is based on $2 \mathrm{~kg} / \mathrm{vault}$.

Inventory for ${ }^{251} \mathrm{Cf}$ is imposed by drinking water limit. 
Table 5.32. Allowable limits on inventories of radionuclides at IWMF based on groundwater concentrations at the expanded buffer zone

\begin{tabular}{|c|c|c|c|c|c|c|c|}
\hline Nuclide & $\begin{array}{l}\text { Limiting } \\
\text { IWMF } \\
\text { inventory } \\
\text { (Ci/pad) }\end{array}$ & $\begin{array}{c}\text { Peak } \\
\text { groundwater } \\
\text { conc'n } \\
(\mu \mathrm{Ci} / \mathrm{L})\end{array}$ & $\begin{array}{l}\text { Time to } \\
\text { peak } \\
\text { (year) }\end{array}$ & Nuclide & $\begin{array}{l}\text { Limiting } \\
\text { IWMF } \\
\text { inventory } \\
\text { (Ci/pad) }\end{array}$ & $\begin{array}{l}\text { Peak } \\
\text { groundwater } \\
\text { conc'n } \\
(\mu \mathrm{Ci} / \mathrm{L})\end{array}$ & $\begin{array}{c}\text { Time to } \\
\text { peak } \\
\text { (year) }\end{array}$ \\
\hline${ }^{3} \mathrm{H}$ & $1.6 \times 10^{10}$ & $8.5 \times 10^{-2}$ & 100 & ${ }^{228} \mathrm{Ra}^{a}$ & $1.2 \times 10^{12}$ & $8.0 \times 10^{-32}$ & 170 \\
\hline${ }^{10} \mathrm{Be}^{a}$ & $3.5 \times 10^{7}$ & $1.0 \times 10^{-5}$ & 36,000 & ${ }^{227} \mathrm{Ac}^{a}$ & $6.2 \times 10^{11}$ & $2.1 \times 10^{-7}$ & 400 \\
\hline${ }^{14} \mathrm{C}$ & $3.3 \times 10^{3}$ & $2.7 \times 10^{-3}$ & 110 & ${ }^{229} \mathrm{Th}^{a}$ & $1.5 \times 10^{9}$ & $2.8 \times 10^{-9}$ & 520,000 \\
\hline${ }^{26} \mathrm{Al}$ & $5.4 \times 10^{5}$ & $3.6 \times 10^{-4}$ & 92,000 & ${ }^{230} \mathrm{Th}^{a}$ & $1.5 \times 10^{8}$ & $1.0 \times 10^{-7}$ & 520,000 \\
\hline${ }^{36} \mathrm{Cl}$ & $1.7 \times 10^{3}$ & $1.8 \times 10^{-3}$ & 110 & ${ }^{232} \mathrm{Th}^{a}$ & $8.0 \times 10^{2}$ & $4.7 \times 10^{-13}$ & 460,000 \\
\hline${ }^{40} \mathrm{~K}^{a}$ & $5.1 \times 10^{3}$ & $1.7 \times 10^{-4}$ & 1,000 & ${ }^{231} \mathrm{~Pa}$ & $3.3 \times 10^{2}$ & $2.1 \times 10^{-7}$ & 14,000 \\
\hline${ }^{4 !} \mathrm{Ca}$ & $8.2 \times 10^{4}$ & $4.2 \times 10^{-3}$ & 1,500 & ${ }^{232} \mathrm{U}^{a}$ & $1.8 \times 10^{11}$ & $2.7 \times 10^{-9}$ & 2,000 \\
\hline${ }^{60} \mathrm{Co}^{a}$ & $7.5 \times 10^{12}$ & $2.5 \times 10^{-25}$ & 110 & ${ }^{233} \mathrm{U}^{a}$ & $8.0 \times 10^{7}$ & $9.4 \times 10^{-9}$ & 11,000 \\
\hline${ }^{59} \mathrm{Ni}^{a}$ & $6.1 \times 10^{8}$ & $2.7 \times 10^{-2}$ & 130,000 & ${ }^{234} U^{a}$ & $5.2 \times 10^{7}$ & $5.9 \times 10^{-9}$ & 51,000 \\
\hline${ }^{63} \mathrm{Ni}^{a}$ & $4.7 \times 10^{11}$ & $1.3 \times 10^{-19}$ & 1,500 & ${ }^{235} \mathrm{U}^{a}$ & $1.8 \times 10^{4}$ & $2.0 \times 10^{-12}$ & 51,000 \\
\hline${ }^{79} \mathrm{Se}$ & $1.7 \times 10^{3}$ & $6.3 \times 10^{-4}$ & 130 & ${ }^{236} \mathrm{U}^{a}$ & $5.3 \times 10^{5}$ & $6.2 \times 10^{-11}$ & 51,000 \\
\hline${ }^{87} \mathrm{Rb}^{a}$ & $1.1 \times 10^{2}$ & $3.3 \times 10^{-6}$ & 1,000 & ${ }^{238} \mathrm{U}^{a}$ & $2.8 \times 10^{3}$ & $3.2 \times 10^{-13}$ & 51,000 \\
\hline${ }^{90} \mathrm{Sr}$ & $3.0 \times 10^{11}$ & $3.1 \times 10^{-5}$ & 600 & ${ }^{237} \mathrm{~Np}^{a}$ & $1.2 \times 10^{7}$ & $6.8 \times 10^{-9}$ & 51,000 \\
\hline${ }^{93} \mathrm{Zr}$ & $1.7 \times 10^{5}$ & $2.5 \times 10^{-3}$ & 1,800 & ${ }^{238} \mathrm{Pu}^{a}$ & $2.9 \times 10^{11}$ & $2.6 \times 10^{-9}$ & 2,500 \\
\hline${ }^{93 \mathrm{~m}} \mathrm{Nb}^{a}$ & $2.1 \times 10^{12}$ & $6.4 \times 10^{-7}$ & 200 & ${ }^{239} \mathrm{Pu}^{a}$ & $1.0 \times 10^{9}$ & $2.0 \times 10^{-8}$ & 11,000 \\
\hline${ }^{94} \mathrm{Nb}$ & $6.7 \times 10^{4}$ & $7.7 \times 10^{-4}$ & 3,300 & ${ }^{240} \mathrm{Pu}^{a}$ & $3.8 \times 10^{9}$ & $5.5 \times 10^{-8}$ & 2,000 \\
\hline${ }^{99} \mathrm{Tc}$ & $8.6 \times 10^{3}$ & $3.6 \times 10^{-3}$ & 120 & ${ }^{241} \mathrm{Pu}^{a}$ & $1.7 \times 10^{12}$ & $3.2 \times 10^{-14}$ & 410 \\
\hline${ }^{107} \mathrm{Pd}^{b}$ & $3.4 \times 10^{2}$ & $3.3 \times 10^{-10}$ & 150,000 & ${ }^{242} \mathrm{Pu}^{a}$ & $6.4 \times 10^{7}$ & $1.3 \times 10^{-9}$ & 51,000 \\
\hline${ }^{113 m} \mathrm{Cd}^{a}$ & $1.6 \times 10^{12}$ & $1.5 \times 10^{-18}$ & 200 & ${ }^{244} \mathrm{Pu}^{a}$ & $3.0 \times 10^{5}$ & $6.0 \times 10^{-12}$ & 51,000 \\
\hline${ }^{121 \mathrm{~m}} \mathrm{Sn}^{a}$ & $3.3 \times 10^{11}$ & $6.4 \times 10^{-4}$ & 630 & ${ }^{241} \mathrm{Am}^{a}$ & $4.0 \times 10^{10}$ & $5.3 \times 10^{-7}$ & 2,500 \\
\hline${ }^{126} \mathrm{Sn}$ & $1.4 \times 10^{4}$ & $2.7 \times 10^{-4}$ & 3,500 & ${ }^{242 \mathrm{~m}} \mathrm{Am}^{a}$ & $1.1 \times 10^{11}$ & $5.9 \times 10^{-8}$ & 2,500 \\
\hline${ }^{129} \mathrm{I}$ & $3.0 \times 10^{1}$ & $2.0 \times 10^{-5}$ & 130 & ${ }^{243} \mathrm{Am}^{\alpha}$ & $2.3 \times 10^{9}$ & $2.0 \times 10^{-7}$ & 2,000 \\
\hline${ }^{135} \mathrm{Cs}^{a}$ & $9.9 \times 10^{5}$ & $7.7 \times 10^{-4}$ & 100,000 & ${ }^{243} \mathrm{Cm}^{a}$ & $6.0 \times 10^{11}$ & $1.1 \times 10^{-11}$ & 800 \\
\hline${ }^{137} \mathrm{Cs}^{a}$ & $1.4 \times 10^{11}$ & $1.7 \times 10^{-22}$ & 370 & ${ }^{244} \mathrm{Cm}^{a}$ & $9.3 \times 10^{11}$ & $1.0 \times 10^{-12}$ & 410 \\
\hline${ }^{151} \mathrm{Sm}^{\alpha}$ & $1.7 \times 10^{11}$ & $1.5 \times 10^{-15}$ & 1,100 & ${ }^{245} \mathrm{Cm}^{a}$ & $2.0 \times 10^{9}$ & $5.2 \times 10^{-8}$ & 11,000 \\
\hline${ }^{152} \mathrm{Eu}^{a}$ & $8.0 \times 10^{11}$ & $3.6 \times 10^{-9}$ & 250 & ${ }^{246} \mathrm{Cm}^{a}$ & $4.6 \times 10^{9}$ & $7.2 \times 10^{-8}$ & 2,000 \\
\hline${ }^{154} \mathrm{Eu}^{a}$ & $1.2 \times 10^{12}$ & $4.9 \times 10^{-10}$ & 240 & ${ }^{247} \mathrm{Cm}^{a}$ & $1.1 \times 10^{6}$ & $3.0 \times 10^{-11}$ & 4,200 \\
\hline${ }^{155} \mathrm{Eu}^{a}$ & $2.1 \times 10^{12}$ & $4.1 \times 10^{-12}$ & 100 & ${ }^{248} \mathrm{Cm}^{a}$ & $4.9 \times 10^{7}$ & $1.4 \times 10^{-9}$ & 51,000 \\
\hline${ }^{194} \mathrm{Os}^{a}$ & $6.0 \times 10^{12}$ & $4.2 \times 10^{-22}$ & 110 & ${ }^{249} \mathrm{Cf}$ & $2.3 \times 10^{4}$ & $1.2 \times 10^{-6}$ & 1,800 \\
\hline${ }^{207} \mathrm{Bi}^{a}$ & $4.4 \times 10^{11}$ & $1.5 \times 10^{-18}$ & 680 & ${ }^{250} \mathrm{Cf}^{2}$ & $3.6 \times 10^{11}$ & $2.4 \times 10^{-9}$ & 240 \\
\hline${ }^{210} \mathrm{~Pb}^{a}$ & $7.3 \times 10^{11}$ & $6.9 \times 10^{-8}$ & 200 & ${ }^{251} \mathrm{Cf}$ & $2.4 \times 10^{3}$ & $1.1 \times 10^{-6}$ & 2,000 \\
\hline${ }^{226} \mathrm{Ra}^{a}$ & $4.2 \times 10^{9}$ & $5.1 \times 10^{-12}$ & 32,000 & & & & \\
\hline
\end{tabular}

${ }^{\circ}$ Inventory based on theoretical maximum disposal limit.

${ }^{b}$ Inventory for ${ }^{107} \mathrm{Pd}$ is based on $2 \mathrm{~kg} /$ vault. 
Table 5.33. Allowable limits on inventories of radionuclides at IWMF based on all drinking water pathways $^{a}$

\begin{tabular}{|c|c|c|c|c|}
\hline Nuclide & $\begin{array}{l}\text { Allowable } \\
\text { IWMF } \\
\text { inventory } \\
\text { (Ci/pad) }\end{array}$ & $\begin{array}{c}\text { Peak } \\
\text { groundwater } \\
\text { conc'n } \\
(\mu \mathrm{Ci} / \mathrm{L})\end{array}$ & $\begin{array}{l}\text { Time to } \\
\text { peak } \\
\text { (year) }\end{array}$ & $\begin{array}{l}\text { Limiting } \\
\text { water } \\
\text { pathway }\end{array}$ \\
\hline${ }^{3} \mathrm{H}$ & $1.6 \times 10^{10}$ & $8.5 \times 10^{-2}$ & 100 & groundwater \\
\hline${ }^{14} \mathrm{C}$ & $3.3 \times 10^{3}$ & $2.7 \times 10^{-3}$ & 110 & groundwater \\
\hline${ }^{26} \mathrm{Al}$ & $5.4 \times 10^{5}$ & $3.6 \times 10^{-4}$ & 92,000 & groundwater \\
\hline${ }^{36} \mathrm{Cl}$ & $1.7 \times 10^{3}$ & $1.8 \times 10^{-3}$ & 110 & groundwater \\
\hline${ }^{41} \mathrm{Ca}$ & $8.2 \times 10^{4}$ & $4.2 \times 10^{-3}$ & 1,500 & groundwater \\
\hline${ }^{79} \mathrm{Se}$ & $1.7 \times 10^{3}$ & $6.3 \times 10^{-4}$ & 130 & groundwater \\
\hline${ }^{93} \mathrm{Zr}$ & $1.7 \times 10^{5}$ & $2.5 \times 10^{-3}$ & 1,800 & groundwater \\
\hline${ }^{94} \mathrm{Nb}$ & $6.7 \times 10^{4}$ & $7.7 \times 10^{-4}$ & 3,300 & groundwater \\
\hline${ }^{99} \mathrm{Tc}$ & $8.6 \times 10^{3}$ & $3.6 \times 10^{-3}$ & 120 & groundwater \\
\hline${ }^{126} \mathrm{Sn}$ & $1.4 \times 10^{4}$ & $2.7 \times 10^{-4}$ & 3,500 & groundwater \\
\hline${ }^{129} I$ & $3.0 \times 10^{1}$ & $2.0 \times 10^{-5}$ & 130 & groundwater \\
\hline${ }^{135} \mathrm{Cs}$ & $9.9 \times 10^{5}$ & $7.7 \times 10^{-4}$ & 100,000 & groundwater \\
\hline${ }^{231} \mathrm{~Pa}$ & $3.3 \times 10^{2}$ & $2.1 \times 10^{-7}$ & 14,000 & groundwater \\
\hline${ }^{249} \mathrm{Cf}$ & $2.3 \times 10^{4}$ & $1.2 \times 10^{-6}$ & 1,800 & groundwater \\
\hline${ }^{251} \mathrm{Cf}$ & $2.4 \times 10^{3}$ & $1.1 \times 10^{-6}$ & 2,000 & groundwater \\
\hline
\end{tabular}

concentrations at WOD correspond to the theoretical maximum disposal limit. Hence, disposal of these species at IWMF is unlimited by the water pathways analysis. For the remaining radionuclides, disposal limits at IWMF for the water pathway are established and correspond to the minimum of the respective inventories listed in Table 5.31 and Table 5.32. For all radionuclides, the disposal limit based on groundwater concentration at the expanded buffer zone is less than the limit based on the surface water concentration at WOD. The limiting radionuclide inventories for IWMF determined from the water pathway analysis are summarized in Table 5.33.

The results of the water pathway analyses for the IWMF are calculated to identify the inventory limits for the IWMF that will meet the performance criterion for drinking water of 4 mrem per year. The application of these inventory limits to IWMF disposal operations ensures the drinking water dose in groundwater at the edge of the expanded buffer zone, and in surface water at WOD will be less than the drinking water performance criterion for all disposals in all disposal units at SWSA 6 at any time in the future. By combining the results presented in Table 5.30 with the inventory limits calculated for the air pathways (Table 5.34), and applying the most restrictive inventory limits to IWMF operations, the all pathways performance criterion will be met for all disposals in all disposal units at SWSA 6 at any time in the future. 
Table 5.34. Allowable limits on inventories of radionuclides at IWMF based on air concentrations at the expanded buffer zone

\begin{tabular}{llc}
\hline Nuclide & $\begin{array}{c}\text { Limiting IWMF inventory } \\
\text { (Ci/pad) }\end{array}$ & $\begin{array}{c}\text { Peak air concentration } \\
\left(\mathrm{Ci} / \mathrm{m}^{3}\right)^{a}\end{array}$ \\
\hline${ }^{3} \mathrm{H}$ & $8.19 \times 10^{6}$ & $9.12 \times 10^{3}$ \\
${ }^{14} \mathrm{C}$ & $1.14 \times 10^{3}$ & $1.28 \times 10^{\circ}$ \\
\hline \multicolumn{2}{c}{${ }^{\circ}$ Ambient atmospheric concentrations were calculated using the Industrial Source } \\
Complex- Version 3 Long-Term Air Dispersion Model (ISCLT3) (EPA 1995). The \\
maximum annual concentration was calculated to occur at a receptor located to the \\
southwest of the IWMF (see Fig. 4.18).
\end{tabular}

These allowable limits are compared with those limits determined by the inadvertent intruder analyses (developed in Sect. 6 and presented in Table 6.13) for evaluating the existing disposal at IWMF and establishing overall limits for IWMF future operations in Sect. 7.

\subsubsection{Discussion of Results of the Hydrologic Transport Analysis}

Many radionuclides encountered solubility limitations at some point during the analysis, as indicated by extended peak times in Table 5.1 through Table 5.12 and Table 5.28. The effect of solubility limitations in the environmental transport pathway is to truncate the maximum concentration at the chemical's solubility concentration, and to increase the duration of that maximum concentration until the source becomes exhausted. For sufficiently long durations, this results in a nonlinear relationship between the magnitude of the source inventory and the drinking water concentration.

For radionuclides with a long half-life, strong retardation (high $K_{d}$ ), and a low solubility $\left({ }^{238} \mathrm{U}\right.$ being a prime example), physically impossible inventories must be used to calculate a "peak" groundwater or surface water concentration equal to allowable drinking water limits. For these species, groundwater and surface water calculations are made using the inventory corresponding to a theoretical maximum disposal limit (see Table 4.2).

For ${ }^{107} \mathrm{Pd}$, even with the use of the theoretical maximum disposal limit $\left(4.0 \times 10^{5} \mathrm{Ci} / \mathrm{pad}\right)$, groundwater and surface water concentrations never reach a peak value. Although this radionuclide does not lend itself well to water transport analysis, it is clearly not limited by the water pathway. So for practical reasons, the maximum groundwater and surface water concentrations are calculated using an inventory set arbitrarily to $2 \mathrm{~kg} / \mathrm{vault}\left(3.4 \times 10^{2} \mathrm{Ci} / \mathrm{pad}\right)$, a large number considering that there are current no disposals of ${ }^{107} \mathrm{Pd}$ at SWSA 6 . The calculated drinking water concentration $\left(3.3 \times 10^{-10} \mu \mathrm{Ci} / \mathrm{L}\right.$, Table 5.32) is well below its allowable limit of $3.6 \times 10^{-2} \mu \mathrm{Ci} / \mathrm{L}$ (Table 4.19) when using this inventory. The intruder-based disposal limit of $1.2 \times 10^{4} \mathrm{Ci} / \mathrm{pad}$ (Table 6.13) also cannot cause excessive concentrations in drinking water. The assumption that the relationship of inventory to drinking water concentration for ${ }^{107} \mathrm{Pd}$ is linear is conservative. If this worst case were so, then the drinking water concentration corresponding to the intruder-based inventory would be 


$$
1.2 \times 10^{4} \mathrm{Ci} / \mathrm{pad} \cdot \frac{3.3 \times 10^{-10} \mu \mathrm{Ci} / \mathrm{L}}{3.4 \times 10^{2} \mathrm{Ci} / \mathrm{pad}}=1.2 \times 10^{-8} \mu \mathrm{Ci} / \mathrm{L} \text {, }
$$

which is still far below the allowable limit of $3.6 \times 10^{-2} \mu \mathrm{Ci} / \mathrm{L}$. Therefore, the water-pathway-based disposal limit cannot be more restrictive than the intruder-based disposal limit.

For ${ }^{3} \mathrm{H}$ the peak concentration in surface water occurs before the end of the institutional control period at 100 years (Table 5.31). For this radionuclide, additional calculations were performed to determine what the limiting inventory would be if concentrations before 100 years were ignored. A higher inventory limit is achieved if the maximum allowable concentration is not considered before 100 years. This higher inventory limit, from ignoring peak concentrations occurring before 100 years, was not used for establishing the limit presented in Table 5.31.

A comparison of arrival times in Table 5.30, Table 5.31, and Table 5.32 reveals that the time of occurrence of a peak concentration for a given radionuclide is not proportional to the distance traveled. In some cases (e.g., ${ }^{247} \mathrm{Cm}$ ) the peak arrival at the expanded buffer zone (in Table 5.32) is earlier than for the 100-m boundary (in Table 5.30). In other cases (e.g., ${ }^{137} \mathrm{Cs}$ ) the peak concentration at WOD (in Table 5.31) is earlier than at either of the groundwater buffer zone boundaries (in Table 5.30 and Table 5.32). The reasons for these apparent inconsistencies follow.

For ${ }^{247} \mathrm{Cm}$ and radionuclides of similar behavior, the peak at the expanded buffer zone arrives at an earlier time than the peak at the $100-\mathrm{m}$ buffer zone, but the peak for the expanded buffer zone is much smaller. The MOC groundwater model calculates contaminant advective transport using an algorithm which transports packets of contamination between cells, and then averages the concentration over each cell between annual time steps. Given the rather coarse discretization of the modeling domain into $50 \times 50 \mathrm{ft}$ cells (see Appendix E) the averaging of concentration moves material more quickly than any physical process, and introduces some numerical dispersion. For particular combinations of half-life and retardation, the early peak from this modeling dispersion register as the peak concentration at the more distant boundary, and the larger, slower-moving advective peak is recorded for the peak concentration at the closer boundary.

In the cases where surface water concentration peaks occur earlier than groundwater peaks, the explanation is simpler. Figures 4.15 and 4.16 identify with an $\times$ locations where the buffer zone boundary is transsected by surface water features such as ephemeral creeks within SWSA 6 . As contaminants are transported from individual disposal units, contaminated groundwater may be intercepted by an ephemeral creek before crossing the buffer zone boundary. Because these ephemeral creeks act as drains of the groundwater system, any radionculides in the groundwater which draining to the ephemeral creeks will not appear at a groundwater well. Furthermore, because the ephemeral creeks discharge immediately to WOL, the radionuclides transported by the creeks will appear relatively quickly at WOD. A groundwater peak may be recorded later at the buffer zone boundary, arising from contaminated groundwater which was not intercepted by an ephemeral creek. 


\subsection{RESULTS OF AIR PATHWAY ANALYSIS}

This section presents the results from the air pathways analysis described in Sect. 4.2. The method of analysis is described in detail in appendix $\mathrm{H}$. The analysis did not consider in detail nonvolatile radionuclides, but considered the volatile radionuclides ${ }^{3} \mathrm{H}$ and ${ }^{14} \mathrm{C}$. Bounding analyses were performed to the extent needed to demonstrate that the performance criterion of 10 mrem per year excluding radon would be met. The discussion of radon emissions is presented in Sect. 4.2. The results from the calculations for the air pathway from the closed disposal units demonstrated that the doses from ${ }^{3} \mathrm{H}$ and ${ }^{14} \mathrm{C}$ were less than the performance criterion of 10 mrem per year, which allowed for the determination of inventory limits for the IWMF based on the air pathway for ${ }^{3} \mathrm{H}$ and ${ }^{14} \mathrm{C}$.

The maximum permissible doses from all exposure pathways resulting from atmospheric releases from the SWSA 6 disposal facility including IWMF must meet the performance criterion of 10 mrem per year excluding radon. Concentrations in waste which correspond to this dose limit are $9.12 \times 10^{3} \mathrm{Ci} / \mathrm{m}^{3}$ for ${ }^{3} \mathrm{H}$ and $1.28 \mathrm{Ci} / \mathrm{m}^{3}$ for ${ }^{14} \mathrm{C}$. Corresponding maximum allowable inventories for IWMF were determined and are presented in Table 5.34. The inventory limits presented in this table, when applied to IWMF disposal operations, ensure compliance with the air pathway performance criterion. The application of these limits in combination with the limits presented in Table 5.33 ensure compliance with the all pathways performance criterion.

\subsection{RESULTS OF WATER RESOURCES PROTECTION ANALYSIS}

The performance criterion for water resources protection of 4 mrem per year for groundwater and surface water is discussed in Sect. 2.5.3. The method used to demonstrate compliance with this performance criterion is presented in Sect. 4.3, which explains how the water resources protection analysis is incorporated into the all pathways analysis. The results presented in Sect. 5.1.1 demonstrate that the performance criterion for surface water resource protection and groundwater resource protection are met at all points and all times for the closed disposal units in SWSA 6. The results presented in Sect 5.1.2 provide the allowable inventory limits for IWMF disposal operations which meet the performance criterion for water resource protection. Application of these allowable inventory limits to evaluate compliance of the existing disposals at IWMF and to limit future disposals at IWMF is presented in Sect. 7.

The surface water resource protection performance criterion is satisfied for all closed disposal units and is less restrictive than the groundwater resource protection criterion for IWMF disposal operations. Consequently, surface water resource protection can be assured for all SWSA 6 disposal operations.

The groundwater resource protection analysis considered a $100 \mathrm{~m}$ buffer zone and an expanded buffer zone for the disposal units in SWSA 6. The expanded buffer zone was established to include a small parcel of land within the interior of SWSA 6 facility that is beyond the $100 \mathrm{~m}$ buffer zones of the IWMF and the Tumulus I and Tumulus II disposal units. The justification of this 
expanded buffer zone is presented in Sect. 2.5.3. The expanded buffer zone is consistent with the guidance for preparing PAs, and results in higher inventory limits for the IWMF. The uncertainties in the analysis of water resources, discussed in the following section, suggest the need for additional restrictions on IWMF disposals to provide additional assurance the water resources protection performance criterion is met for all disposal units in SWSA 6. These additional restrictions are discussed in the Sect. 7.

\subsection{RESULTS OF SENSITIVITY AND UNCERTAINTY ANALYSIS}

The sensitivity of the models used to analyze the performance of SWSA 6 and the uncertainties associated with the results presented in this section are important considerations in evaluating compliance with DOE O 5820.2A. For the purpose of this discussion, the models and data bases related to waste disposal, the performance of engineered systems, and release and transport of radionuclides in the environment to an individual at an assumed location are treated separately from the models for estimating dose per unit concentration of radioncudlides at assumed receptor locations. This separation of the treatment of uncertainties can be justified on the grounds that estimates of radionuclide concentrations in the environment at assumed receptor locations are based on analyses of physical systems, whereas the analysis of doses per unit concentration of radionuclides in the environment is based on largely hypothetical constructs that do not depend on the physical disposal system.

The uncertainties associated with the reported inventory are evaluated in detail in Appendix A. The uncertainties in the evaluation of environmental transport are discussed in detail in Appendix I. The uncertainties in the results of the environmental transport analysis were evaluated by first identifying sensitive parameters in each of the models used for evaluating environmental transport. The sensitivities and uncertainties were evaluated using the Latin Hypercube sampling method which is implemented in the PRISM program (Gardner et al. 1983). Data sets were generated from specific distributions for input variables, and these data sets served as inputs to the models used in this revised PA. A statistical summary of the model results produced indices of the sensitivity and uncertainty that related the effects on model result of heterogeneity of the input variables. Additional analyses were performed to evaluate the uncertainties that could be attributed to approximations incorporated into the models. Quantitative values for these uncertainties are not explicitly calculated or measured but rather subjectively estimated by those individuals having extensive knowledge of the modeling processes. By including the effects of this subjective uncertainty additional insight into the uncertainty of the results helps identify the components of the transport modeling which have the greatest contribution to the overall uncertainty in the results.

The performance of SWSA 6 with respect to the environmental transport of radioactive contaminants was initially evaluated by calculating limiting inventories for IWMF based on maximum groundwater concentrations at $100-\mathrm{m}$ receptor locations (Fig. 4.15). As indicated in Sect. 2.5.3, these maximum concentrations occurred at a point that was interior to the facility 
boundary, between the IWMF and the Tumulus I and II disposal units. Using these limiting inventories for the IWMF facility, the parametric uncertainty analysis, detailed in Appendix I, was conducted. Later, realizing that the associated groundwaters between the $100-\mathrm{m}$ buffer zone and WOL in the vicinity of this point would certainly be protected to the same extent as the groundwaters inside the 100-m buffer zone, the buffer zone for the various SWSA 6 disposal units was expanded (See Fig. 4.16); and, revised limiting inventories for IWMF based on maximum groundwater concentrations at this expanded buffer zone were determined. The quantitative analysis of uncertainties for the $100-\mathrm{m}$ buffer zone analysis provides the needed basis for establishing any additional restrictions on IWMF operations, because the effect of uncertainties in the groundwater results are more pronounced.

Results of the parametric uncertainty analyses are presented in detail in Figures 1.2 through I.21 in Appendix I. These figures show histograms and their corresponding cumulative distribution functions for ten representative radionuclides. These can be used to determine the probability that, given the limiting inventories based on the 100-m buffer zone (Table 5.30), SWSA 6 meets the drinking water performance criterion discussed in Sect. 2.5.3. The additional effects of the inclusion of subjective uncertainties on the probabilities of compliance are also presented in Appendix I. Results from both the parametric and subjective uncertainty analyses are summarized in Table 5.35 and Table 5.36 .

Table 5.35. Probabilities and associated entropy-based uncertainties that maximum groundwater concentrations at selected receptor locations are equal to or less than the concentration corresponding to the 4-mrem per year EDE limit

\begin{tabular}{|c|c|c|c|c|c|c|c|}
\hline \multirow{2}{*}{ Nuclide } & \multirow{2}{*}{$\begin{array}{l}\text { Receptor } \\
\text { ID }\end{array}$} & \multirow{2}{*}{$\begin{array}{c}\text { Maximum } \\
\text { allowable } \\
\text { drinking water } \\
\text { concentration } \\
(\mu \mathrm{Ci} / \mathrm{L})\end{array}$} & \multicolumn{2}{|c|}{ Parametric } & \multicolumn{2}{|c|}{$\begin{array}{c}\text { Parametric } \\
+ \\
\text { Subjective }\end{array}$} & \multirow[b]{2}{*}{$\Delta \mathrm{U}^{c}$} \\
\hline & & & $\mathrm{P}_{\mathrm{C}}^{a}$ & $\mathrm{U}^{b}$ & $\mathrm{P}_{\mathrm{C}}{ }^{\alpha}$ & $\mathrm{U}^{b}$ & \\
\hline${ }^{3} \mathrm{H}$ & 16 & $8.50 \times 10^{-2}$ & 0.90 & 0.47 & 0.60 & 0.97 & +0.50 \\
\hline${ }^{14} \mathrm{C}$ & 16 & $2.70 \times 10^{-3}$ & 0.90 & 0.47 & 0.53 & 0.99 & +0.52 \\
\hline${ }^{90} \mathrm{Sr}$ & 17 & $3.60 \times 10^{-5}$ & 0.38 & 0.96 & 0.46 & 0.99 & +0.03 \\
\hline${ }^{137} \mathrm{Cs}$ & 52 & $1.10 \times 10^{-4}$ & 1.00 & 0.00 & 0.82 & 0.69 & +0.69 \\
\hline${ }^{238} \mathrm{U}$ & 16 & $2.10 \times 10^{-5}$ & 1.00 & 0.00 & 0.64 & 0.94 & +0.94 \\
\hline
\end{tabular}

${ }^{a} \mathrm{P}_{\mathrm{C}} \equiv$ probability that the deterministic result is within the drinking water performance objective

${ }^{b} \mathrm{U} \equiv$ entropy-based uncertainty (Eqn. I.1) associated with the deterministic results

${ }^{\circ} \Delta U \equiv$ change in entropy-based uncertainty due to inclusion of subjective uncertainties 
Table 5.36. Probabilities and associated entropy-based uncertainties that maximum surface water concentrations at selected receptor locations are equal to or less than the concentration corresponding to the 4-mrem per year EDE limit

\begin{tabular}{|c|c|c|c|c|c|c|}
\hline \multirow{2}{*}{ Nuclide } & \multirow{2}{*}{$\begin{array}{l}\text { Maximum } \\
\text { allowable } \\
\text { drinking water } \\
\text { concentration } \\
(\mu \mathrm{Ci} / \mathrm{L})\end{array}$} & \multicolumn{2}{|c|}{ Parametric } & \multicolumn{2}{|c|}{$\begin{array}{c}\text { Parametric } \\
+ \\
\text { Subjective }\end{array}$} & \multirow[b]{2}{*}{$\Delta \mathrm{U}^{c}$} \\
\hline & & $\mathrm{P}_{\mathrm{C}^{a}}{ }^{a}$ & $\mathrm{U}^{b}$ & $\mathrm{P}_{\mathrm{C}}{ }^{a}$ & $\mathrm{U}^{b}$ & \\
\hline${ }^{3} \mathrm{H}$ & $8.50 \times 10^{-2}$ & 0.92 & 0.40 & 0.45 & 0.99 & +0.59 \\
\hline${ }^{14} \mathrm{C}$ & $2.70 \times 10^{-3}$ & 1.00 & 0.00 & 0.32 & 0.91 & +0.91 \\
\hline${ }^{90} \mathrm{Sr}$ & $3.60 \times 10^{-5}$ & 0.94 & 0.33 & 0.50 & 1.00 & +0.67 \\
\hline${ }^{137} \mathrm{Cs}$ & $1.10 \times 10^{-4}$ & 1.00 & 0.00 & 0.65 & 0.94 & +0.94 \\
\hline${ }^{238} \mathrm{U}$ & $2.10 \times 10^{-5}$ & 1.00 & 0.00 & 0.42 & 0.98 & +0.98 \\
\hline
\end{tabular}

${ }^{a} \mathrm{P}_{\mathrm{C}} \equiv$ probability that the deterministic result is within the drinking water performance objective

${ }^{n} \mathrm{U} \equiv$ entropy-based uncertainty (Eqn. I.1) associated with the deterministic results

${ }^{c} \Delta U \equiv$ change in entropy-based uncertainty due to inclusion of subjective uncertainties.

The results of the parametric uncertainty analysis suggest that, for many radionuclides use of the disposal limits presented in Sect. 5.1.2.3 provides reasonable assurance that the performance criterion for drinking water is met. This is true for unretarded species such as ${ }^{3} \mathrm{H}$, or those with relatively long half-lives and moderate retardation such as ${ }^{238} \mathrm{U}$. However, for those with combinations of strong retardation and short half-lives $\left({ }^{137} \mathrm{Cs}\right)$, or those with both strong retardation and long half-lives $\left({ }^{232} \mathrm{Th}\right.$ ), the results presented in Table 5.35 and Table 5.36 suggest that considerable uncertainty exists in the calculated peak concentrations for the closed disposal units (Table 5.27). Hence, simply basing disposal limits on the results of the deterministic analysis is not sufficient to provide reasonable assurance that the performance criterion are met. Instead, the parametric uncertainty analysis suggests the disposal limits may need to be reduced in order to meet the performance criterion for drinking water.

The inclusion of subjective uncertainties further illustrates the limitations of any modeling procedure in accurately predicting environmental concentrations of radioactive contaminants. For example, Table 5.35, Table 5.36, and Table 5.37 (e.g., ${ }^{90} \mathrm{Sr}$ ) indicate how the convolution of subjective opinion with parametric results from the Latin Hypercube (LHC) analysis tends to drive the probability of compliance towards 0.5 for all nuclides, and the associated uncertainty (based on Eq. I.1) approaches the maximum values of 1.0. However, the effect of time on the magnitude of the increase in uncertainty associated with model predictions is demonstrated by the changes in uncertainty shown in the last column of Table 5.35 and Table 5.36. Generally, the radionuclides that experience the greatest increase in uncertainty with the inclusion of subjective opinion are those whose peak concentrations occur at large time values. For example, ${ }^{3} \mathrm{H}$ concentrations in groundwater and surface water reach maximum values within about 100 years from the time of disposal. And, as expected, there 
Table 5.37. Changes in the probabilities and associated entropy-based uncertainties that maximize groundwater concentrations at selected receptor locations $\leq \mathbf{4}$ mrem drinking water limit due to inclusion of subjective uncertainties associated with each segment of the modeling process

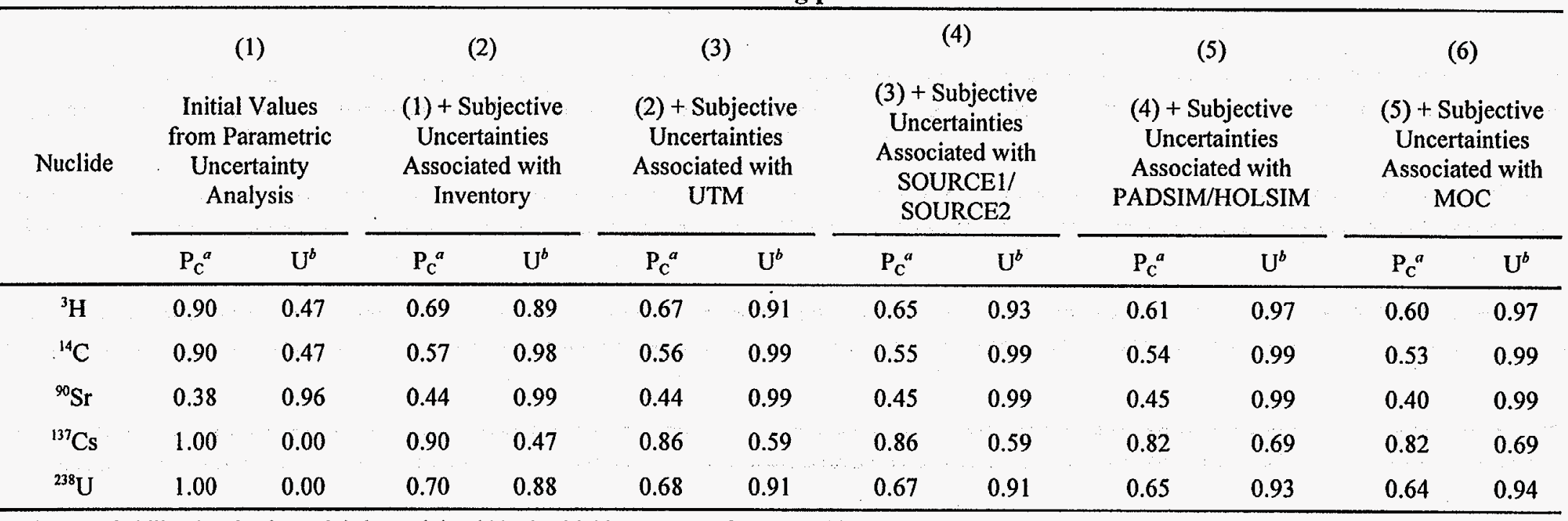

${ }^{a} \mathrm{P}_{\mathrm{C}}$ a probability that the deterministic result is within the drinking water performance objective

${ }^{b} \mathrm{U} \equiv$ entropy-based uncertainty (Eqn. I.1) associated with the deterministic results 
is only a relatively small increase in the associated uncertainty in model predictions. Conversely, environmental concentrations of ${ }^{238} \mathrm{U}$, which experience an increase in uncertainty of 0.94 , reach their maximum values thousands of years after the time of disposal. Thus, inclusion of subjective uncertainty emphasizes the fact that accurate determination of disposal limits based on environmental transport of radioactive contaminants is a difficult, subjective process that becomes even more complicated as the environmental travel time of contaminants increases.

The use of subjective uncertainty may also be used to identify the segments of the modeling process that are the chief contributors to the total uncertainty in predicted values, thereby identifying areas that would benefit most from further research. For example, consider the change in the probability of the deterministic result being less than the drinking water performance criterion (and, therefore, the change in overall uncertainty) that occurs with the successive convolution of the subjective uncertainties associated with each component of the model process with the concentration distributions obtained from the parametric uncertainty analysis. The results presented in Table 5.37 (groundwater) and Table 5.38 (surface water) show that, in all instances, inclusion of subjective uncertainties associated with disposal inventory results in the greatest overall increase in uncertainty associated with predicted radionuclide concentrations. Therefore, the logical first step to reduce the overall uncertainty associated with predicted radionuclide concentrations would be to develop more reliable estimates of the inventory of disposed radioactive material.

In addition, the differences between the initial probabilities that the deterministic result is within the drinking water performance objective (given in Table 5.35 and Table 5.36) and the corresponding values given in Tables 4.35 and 4.36 of the intitial PA are noteworthy. With the exception of ${ }^{14} \mathrm{C}$, the inventories analyzed in this analysis are significantly higher than those analyzed in the initial PA. Consequently, with the exception of ${ }^{3} \mathrm{H}$ (in groundwater) and ${ }^{90} \mathrm{Sr}$ (in surface water), the initial probabilities that the deterministic result is within the drinking water performance objective determined from the parametric analysis are now equal to or lower than those calculated in the initial PA. In the case of ${ }^{3} \mathrm{H}$, probabilities presented in the initial PA analysis are based on the maximum groundwater concentration that occurs at any point in time. For a given inventory, these concentrations were significantly higher than the maximum concentration that occurs after the 100 year institutional control period (as were used in this revised PA). For ${ }^{90} \mathrm{Sr}$, differences between calculated results and those presented in the initial PA are attributed to changes in the PADSIM and HOLSIM models, which incorporated a new sorption model, that replaced the TUMSIM and WELSIM programs used previously. For ${ }^{14} \mathrm{C}$, the inventory analyzed is less than that used in the initial PA. Hence, the initial probabilities that the deterministic result is within the drinking water performance objective increased in both groundwater and surface water.

The inventory of disposed radionuclides is identified as the largest source of uncertainty in the modeling of the environmental transport of radioactive materials by the quantitative uncertainty analysis. This conclusion was also presented in the quantitative uncertainty analysis in the initial PA. However, the initial PA incorporated the MPA factor to increase the reported inventory records for radionuclides with the greatest uncertainty. In this analysis, the reported inventory records were used for analysis without the consideration of the MPA factor. Appendix A.6 discusses the improvements 
Table 5.38. Changes in the probabilities and associated entropy-based uncertainties that maximize surface water concentrations at selected receptor locations $\leq \mathbf{4}$ mrem drinking water limit due to inclusion of subjective uncertainties associated with each segment of the modeling process

\begin{tabular}{|c|c|c|c|c|c|c|c|c|c|c|c|c|}
\hline \multirow{3}{*}{ Nuclide } & \multirow{2}{*}{\multicolumn{2}{|c|}{$\begin{array}{c}\text { (1) } \\
\text { Initial Values } \\
\text { from Parametric } \\
\text { Uncertainty } \\
\text { Analysis }\end{array}$}} & \multirow{2}{*}{\multicolumn{2}{|c|}{$\begin{array}{l}\text { (2) } \\
\text { (1) + Subjective } \\
\text { Uncertainties } \\
\text { Associated with } \\
\text { Inventory }\end{array}$}} & \multirow{2}{*}{\multicolumn{2}{|c|}{$\begin{array}{c}\text { (3) } \\
\text { (2) + Subjective } \\
\text { Uncertainties } \\
\text { Associated with } \\
\text { UTM }\end{array}$}} & \multirow{2}{*}{\multicolumn{2}{|c|}{$\begin{array}{l}\text { (4) } \\
\text { (3) + Subjective } \\
\text { Uncertainties } \\
\text { Associated with } \\
\text { SOURCE1/ } \\
\text { SOURCE2 }\end{array}$}} & \multirow{2}{*}{\multicolumn{2}{|c|}{$\begin{array}{c}\text { (5) } \\
\text { (4) + Subjective } \\
\text { Uncertainties } \\
\text { Associated with } \\
\text { PADSIM/HOLSIM }\end{array}$}} & \multirow{2}{*}{\multicolumn{2}{|c|}{$\begin{array}{c}(6) \\
\text { (5) + Subjective } \\
\text { Uncertainties } \\
\text { Associated with } \\
\text { MOC }\end{array}$}} \\
\hline & & & & & & & & & & & & \\
\hline & $\mathrm{P}_{\mathrm{C}}^{a}$ & $\mathrm{U}^{b}$ & $\mathrm{P}_{\mathrm{C}}^{a}$ & $\mathrm{U}^{b}$ & $\mathrm{P}_{\mathrm{C}}^{a}$ & $\mathrm{U}^{b}$ & $\mathrm{P}_{\mathrm{c}}{ }^{a}$ & $\mathrm{U}^{b}$ & $\mathrm{P}_{\mathrm{C}}{ }^{a}$ & $\mathrm{U}^{b}$ & $\mathrm{P}_{\mathrm{C}}{ }^{a}$ & $\mathrm{U}^{b}$ \\
\hline${ }^{3} \mathrm{H}$ & 0.92 & 0.40 & 0.53 & 0.99 & 0.49 & 0.99 & 0.49 & 0.99 & 0.45 & 0.99 & 0.45 & 0.99 \\
\hline${ }^{14} \mathrm{C}$ & 1.00 & 0.00 & 0.35 & 0.94 & 0.34 & 0.93 & 0.34 & 0.92 & 0.32 & 0.91 & 0.32 & 0.91 \\
\hline${ }^{90} \mathrm{Sr}$ & 0.94 & 0.33 & 0.61 & 0.97 & 0.57 & 0.99 & 0.56 & 0.99 & 0.52 & 0.99 & 0.50 & 1.00 \\
\hline${ }^{137} \mathrm{Cs}$ & 1.00 & 0.00 & 0.81 & 0.70 & 0.74 & 0.83 & 0.73 & 0.84 & 0.65 & 0.94 & 0.65 & 0.94 \\
\hline${ }^{238} \mathrm{U}$ & 1.00 & 0.00 & 0.48 & 0.99 & 0.46 & 0.99 & 0.45 & 0.99 & 0.43 & 0.98 & 0.42 & 0.98 \\
\hline
\end{tabular}

${ }^{a} P_{C} \equiv$ probability that the deterministic result is within the drinking water performance objective

${ }^{b} \mathrm{U} \equiv$ entropy-based uncertainty (Eqn. I.1) associated with the deterministic results 
that have been made in the characterization of wastes disposed of on the IWMF in response to the findings of the initial PA. The continued use of the MPA factor for this analysis for future disposals at IWMF is not justified after consideration of the improvements in waste characterization at IWMF. Additionally, the existing waste management records for SWSA 6 have been examined throughout the preparation of this PA to remove errors previously included in the records. These improvements support the use of the waste management records as the inventory for consideration in this revised PA without the application of a MPA factor.

The reduction in uncertainty in the inventory in this PA, however, does not change the conclusion that the uncertainty in the recorded inventories remains the greatest source of uncertainty in the results presented in the PA. This conclusion is certainly applicable to the closed disposal units where the only improvements made in reducing uncertainty have been in continuing to examine the existing waste management disposal records. The expanded buffer zone used in this analysis provides additional assurance the performance criterion for drinking water will be met in groundwater and surface water for the closed disposal units, while increasing allowable inventories at the IWMF, where improved waste characterization methods are utilized. Hence, the consideration of additional limitations on the disposal limits for the IWMF provides additional assurance the performance criterion for drinking water will be met, and addresses the uncertainties in the analysis of the performance of SWSA 6. The additional limitations on the allowable limits for disposal at IWMF are discussed in Sect. 7.

An additional mitigating measure for reducing the uncertainty in the analysis has been incorporated into the results presented in this PA. Compliance assessments of the results in PAs are based on the time of compliance of 1000 years (DOE 1996a). This guidance has not been adhered to in establishing inventory limits derived from the water pathways analysis for disposal operations at IWMF. The inventory limits were established without consideration of the time of compliance in recognition of the uncertainties incorporated into the results. Of the 15 radionuclides limited by the consideration of the drinking water pathway for SWSA 6, nine had the time for peak dose exceed 1,000 years. The peak dose was used to establish the inventory limit, without consideration of the time of compliance, in recognition of the uncertainties inherent in the modeling of the long-term performance of SWSA 6.

Radionuclides without inventory limits, based on the consideration of the drinking water pathway performance criterion, but with significant uncertainty in meeting the performance criterion for drinking water (e.g., ${ }^{3} \mathrm{H},{ }^{14} \mathrm{C}$ and ${ }^{90} \mathrm{Sr}$ ) have inventory limits determined by the intruder analysis, which is presented in Sect. 6 . The combined inventory limits for disposal at IWMF are reduced by several orders of magnitude from the inventory limits determined by the consideration of the drinking water pathway alone. Examination of the cumulative distribution functions shown in Appendix I for these radionuclides with the combined inventory limits presented in Sect. 7 demonstrate that there is reasonable assurance of compliance with the performance criterion for drinking water will be met, even with the inclusion of all of the uncertainties in the recorded inventory and transport modeling, and the subjective uncertainties associated with the analysis of the long-term performance of SWSA 6. 


\subsection{ALARA ANALYSIS}

The performance objectives for disposal of low-level waste, discussed in Section 2.5, and the DOE's current requirements for radiation protection of the public in Order 5400.5 (DOE 1990) specify that releases of radionuclides to the general environment are to be maintained as low as reasonably achievable (ALARA). The ALARA requirement implies that meeting the performance objectives for releases to the general environment does not, by itself, provide adequate protection of the public from low-level waste disposal. Rather, doses to the public should be reduced below the performance objectives to the extent reasonably achievable.

The ALARA requirement defines a process for reducing exposures, not a predetermined result in terms of doses to the public below the performance objectives that must be achieved. The ALARA process takes into account many factors, including technical, economic, and social considerations.

\subsubsection{DOE Guidance on ALARA Assessment}

In accordance with current DOE guidance (DOE 1991a; DOE 1996a), the ALARA requirement is evaluated primarily on the basis of a cost-benefit analysis involving an optimization of collective (population) dose. Thus, while the performance objectives for disposal of low-level waste are concerned only with limiting the exposure of individual members of the public, the ALARA requirement focuses on the cost of reducing radiological impacts in the exposed population in relation to the benefit in health risks averted. The DOE guidance indicates that actions to reduce releases generally are warranted if the cost of dose reduction in the exposed population is less than $\$ 1,000$ to $\$ 10,000$ per person-rem averted (DOE 1996a).

However, there also are conditions where a quantitative cost-benefit analysis for optimizing collective dose is not warranted. Such an analysis is not warranted, for example, if the projected individual and collective doses in the exposed population for the base-case assessment are so low as to be trivial (negligible).

\subsubsection{ALARA Assessment for SWSA 6 Facility}

This section describes an application of the ALARA requirement to disposal of low-level waste in the SWSA 6 facility. Essentially because projected releases of radionuclides from the facility into the general environment and the resulting projections of individual and collective doses to the public are quite low, only a qualitative ALARA assessment is needed for this facility. This conclusion is justified on the basis of a screening assessment of radiological impacts described below. The screening assessment provides conservative estimates of dose which show that the projected doses to individual members of the public and to the exposed population should be sufficiently low that further expenditures to reduce exposures would not be warranted.

The location and size of exposed populations that could be impacted by releases from the SWSA 6 facility at future times are unknown. However, for purposes of an ALARA assessment, it is appropriate to assume conditions that resemble those existing today (DOE 1996a). The ALARA 
assessment for the SWSA 6 facility assumes that the drinking water supply for a city the size of Oak Ridge would be obtained from the Clinch River near the location of WOC. Furthermore, the concentrations of radionuclides in releases from WOC are assumed to be diluted by complete mixing in the Clinch River prior to intakes by the postulated public water supply. The population served by the water supply is assumed to be 30,000 , which corresponds to the current population of the City of Oak Ridge.

In the performance assessment for The SWSA 6 facility, one of the assumed performance objectives is an individual EDE of 4 mrem per year from the drinking water pathway. This performance objective is applied to the projected concentrations of radionuclides in WOC essentially at the point of discharge into the Clinch River. Therefore, since mixing of discharges from WOC in the Clinch River is assumed to reduce the concentrations by a factor of 330 (based on a ratio of average flows), the dose to an average individual in the exposed population using the Clinch River as a drinking water supply would not exceed $4 / 330=0.012$ mrem per year, and the collective dose in the assumed population of 30,000 would not exceed 0.36 person-rem per year. In accordance with current DOE guidance (DOE 1996b), the ALARA assessment is applied only to projected doses for the first 1,000 years after disposal. Therefore, the collective dose over 1,000 years would not exceed 360 person-rem.

The estimate of collective dose given above does not include doses to individuals who might use WOC as a drinking water supply. However, given the low flow rate in WOC, only a few individuals could obtain drinking water from this source. If we assume that 10 individuals might use WOC as a drinking water supply and that the individual dose would not exceed the performance objective of 4 mrem per year, the collective dose in this population over 1,000 years would not exceed 40 person-rem. Thus, the contribution to collective dose from individuals using WOC as a drinking water supply would be negligible compared with the collective dose in the population exposed to water in the Clinch River.

The estimates of individual and collective dose given above assume that consumption of drinking water is the only exposure pathway of concern. However, a few individuals could receive exposures from other pathways, including (1) ingestion of milk and meat obtained from dairy and beef cattle that drink contaminated water, (2) external exposure while swimming in contaminated surface water, and (3) consumption of contaminated fish. The first of these exposure pathways could apply to contaminants in WOC, but the other two exposure pathways reasonably could apply only to contaminants in the Clinch River. Individual doses from the pathways other than drinking water can be estimated using the models and parameter values given in Section G.5.1 of Appendix G. The following conclusions are obtained from these models.

First, for an individual who uses contaminated water from WOC, the dose from the milk and meat pathways usually is negligible compared with the dose from the drinking water pathway. This is especially the case for radionuclides with projected releases occurring within the 1,000 -year time period of concern to this assessment.

Second, for individuals who use contaminated water from WOC or the Clinch River as a drinking water supply, the fish pathway could be important. For example, for ${ }^{14} \mathrm{C}$, which is a potentially important radionuclide in releases over the first 1,000 years, the dose from the fish pathway 
is a factor of 35 greater than the dose from the drinking water pathway for the same concentration in water (see Table G.16 of Appendix G). The contribution from the fish pathway in this case is about the highest for any radionuclide of concern in potential releases from The SWSA 6 facility. However, when the dose from the drinking water pathway in WOC is limited to 4 mrem per year in accordance with the performance objective for this exposure pathway, and taking into account the dilution in the Clinch River and the reasonable assumption that fish consumed by individuals would be obtained only from the Clinch River, the contribution to individual dose from the fish pathway would not exceed $(4 / 330) \times 35=0.4$ mrem per year. Therefore, for all radionuclides, the dose to an individual who uses contaminated water from WOC would be dominated by the dose from the drinking water pathway, and the dose to an individual who obtains drinking water from the Clinch River would not exceed 0.4 mrem per year. Again, only a few individuals who consume water from the Clinch River would also receive higher doses from the fish pathway, because consuming fish caught in the river is not a common practice in the general population, and the fish pathway would not have a significant impact on the collective dose in the exposed population.

In summary, compliance with the performance objective for limiting individual doses from the drinking water pathway for radionuclides released from the SWSA 6 facility into WOC would ensure that doses to individuals and populations who might use contaminated water from the Clinch River would be very low. In particular, the dose to maximally exposed individuals using water from the Clinch River would not exceed about 0.4 mrem per year, the dose to an average individual using water from the Clinch River would not exceed about 0.01 mrem per year, and the collective dose over the 1,000-year time period of concern to the performance assessment from use of water from WOC and the Clinch River would not exceed about 400 person-rem.

The estimated maximum individual dose of 0.4 mrem per year from use of water from the Clinch River is less than the trivial (negligible) dose of 1 mrem per year recommended by the National Council on Radiation Protection and Measurements (NCRP 1993a), as is the dose to an average individual. When individual doses are already at trivial levels, no further reductions in dose using the ALARA principle are warranted. Furthermore, based on the nominal risk factor for fatal cancers from exposure of the whole population of $5 \times 10^{-4}$ per rem (ICRP 1991; NCRP 1993b), the expected number of health effects in the exposed population over 1,000 years would be less than one (i.e., zero). Therefore, further reductions in projected collective doses clearly would not result in any reductions in projected health effects averted.

Therefore, based on the simple screening analysis presented above, projected exposures of the population at future times from releases from the SWSA 6 facility are trivial for the base-case performance assessment, and a further analysis of options for reducing the collective dose is not warranted (DOE 1996a). The screening analysis is quite conservative because it assumes that projected doses from consumption of drinking water in WOC would be as high as the performance objective for this pathway at all times over the entire 1,000-year time period of concern to the performance assessment. In essence, compliance with the performance objective for the drinking water pathway from use of water from WOC would, by itself, ensure that exposures of potentially affected populations would be as low as reasonably achievable. 


\section{INADVERTENT INTRUDER ANALYSIS}

This chapter presents an assessment of potential radiation doses resulting from inadvertent human intrusion into the different disposal units in the SWSA 6 facility. Such an assessment is required to demonstrate compliance with the current performance objective for protection of inadvertent intruders in DOE O 5820.2A. The performance objective applies at any time after loss of active institutional control at 100 years after disposal, and it specifies:

- a limit on EDE of $0.1 \mathrm{rem}(1 \mathrm{mSv})$ per year from all exposure pathways for scenarios involving continuous exposure, and

- a limit on EDE of $0.5 \mathrm{rem}(5 \mathrm{mSv})$ from all exposure pathways for scenarios involving a single, acute exposure.

In accordance with current DOE policy for implementing the performance objective for protection of inadvertent intruders (DOE 1996c), the relevant exposure scenarios to be evaluated are those that involve direct intrusion, or attempts at direct intrusion, into solid waste in the disposal units. Exposure scenarios for inadvertent intruders involving use of contaminated groundwater or surface water on the disposal site need not be considered (see also Sect. 2.5.2).

A separate assessment of potential exposures of inadvertent intruders is performed for each type of disposal unit in the SWSA 6 facility, including Tumulus I, Tumulus II, the IWMF, the lowrange silos, the high-range silos, the high-range wells, the fissile wells, the asbestos silos, the Quadrex trenches, and the biological trenches. Although the purpose of the intruder dose assessment for each type of disposal unit is to demonstrate compliance with the performance objective given above, one of two different approaches is taken in the assessment, depending on the particular disposal unit.

First, for all disposal units except the IWMF, the estimated inventories of radionuclides in disposed waste are used as input to the intruder dose assessment to obtain estimates of potential doses to inadvertent intruders, and these dose estimates then are compared with the performance objective given above. The distinguishing characteristic of the disposal units other than the IWMF is that these units are no longer receiving waste and, thus, the final inventories of radionuclides are known.

Second, for the IWMF, which is the currently operating disposal unit and is expected to continue receiving waste in the future, the intruder dose assessment is used in conjunction with the performance objective for inadvertent intruders to derive allowable limits on average concentrations or total inventories of radionuclides that would provide adequate protection of inadvertent intruders. In cases where the disposal limits of radionuclides based on the intruder dose assessment are more restrictive than the limits based on the dose assessment for off-site releases, the intruder dose assessment would determine allowable disposals in the IWMF at the time disposal operations cease. 
The remainder of this chapter is organized as follows. Sect. 6.1 describes the assumed scenarios for inadvertent intrusion involving continuous exposure and presents the estimated annual EDEs per unit concentration of radionuclides in the disposal units at the time intrusion is assumed to occur. Sect. 6.2 presents the same information for the scenario involving a single, acute exposure assumed in this assessment. Sect. 6.3 presents the results of the intruder dose assessment based on the estimated doses per unit concentration of radionuclides in the disposal units for the different scenarios. As noted above, the results of the intruder dose assessment are presented either in the form of doses, given estimates of radionuclide inventories in the units, for comparison with the performance objective, or in the form of limits on average concentrations or total inventories of radionuclides, given the performance objective. Finally, Sect. 6.4 discusses an analysis of the sensitivity/uncertainty in the results of the intruder dose assessment. The models used to estimate doses to inadvertent intruders for each scenario are presented in detail in Appendix G.

\subsection{SCENARIOS FOR CHRONIC EXPOSURE}

In this assessment, three different scenarios for chronic exposure of inadvertent intruders involving direct intrusion, or attempts at direct intrusion, into solid waste in disposal units are assumed to be credible: the agriculture, resident, and post-drilling scenarios. These scenarios essentially are the same as those considered in the initial PA for the SWSA 6 facility (ORNL 1994) as well as previous PAs for the E-Area Vaults Disposal Facility at the Savannah River Site (MMES et al. 1994) and the Class L-II Disposal Facility on the ORR (ORNL 1997d). Each of these scenarios is based on an assumption that at some time after loss of active institutional control over the SWSA 6 site, which is assumed to occur at 100 years after facility closure, inadvertent intruders, with no prior knowledge of waste disposal activities, come onto the site and establish a permanent homestead.

The scenarios for continuous exposure of inadvertent intruders are summarized in Table 6.1 and described in Sect. 6.1.1 through Sect. 6.1.3. These sections also present the annual EDEs per unit concentration of radionuclides in the disposal units at the time intrusion is assumed to occur for each of these scenarios. Finally, the assumptions about the time after disposal for occurrence of these scenarios are discussed in Sect. 6.1.4.

\subsubsection{Agriculture Scenario}

In the agriculture scenario, an inadvertent intruder is assumed to construct a home directly on top of the disposal units, with the foundation extending into the waste itself. Some of the waste exhumed during construction of the foundation, which is assumed to be indistinguishable from native soil, is assumed to be mixed with native soil in the intruder's vegetable garden. The agriculture scenario then occurs after construction of the home is completed and the vegetable garden established, and the following pathways involving chronic exposure are assumed to occur: 
Table 6.1. Summary of exposure scenarios for inadvertent intrusion into solid waste in disposal units

\begin{tabular}{|c|c|c|}
\hline Assumed scenarios & Disposal units & Discussion \\
\hline \multicolumn{3}{|c|}{ Chronic exposure } \\
\hline Agriculture & All units & $\begin{array}{l}\text { Assumed to occur beginning at } 100 \text { years after disposal } \\
\text { for biological trenches and at } 300 \text { years for all other } \\
\text { units. Scenario results from excavation into disposal } \\
\text { units and mixing of exhumed waste with garden soil. } \\
\text { Assumed exposure pathways include ingestion of } \\
\text { vegetables grown in contaminated garden soil, } \\
\text { ingestion of contaminated garden soil. external and } \\
\text { inhalation exposure while working in garden, and } \\
\text { external and inhalation exposure while residing in } \\
\text { home on top of exposed waste. }\end{array}$ \\
\hline Resident & $\begin{array}{l}\text { All units except } \\
\text { biological trenches }\end{array}$ & $\begin{array}{l}\text { Assumed to occur at } 100 \text { years after disposal as a result } \\
\text { of attempted excavation into disposal units constructed } \\
\text { with engineered barriers. Assumed exposure pathway is } \\
\text { external exposure while residing in home on top of } \\
\text { intact barriers. }\end{array}$ \\
\hline Post-drilling & $\begin{array}{l}\text { All units except } \\
\text { biological trenches }\end{array}$ & $\begin{array}{l}\text { Assumed to occur at } 100 \text { years after disposal as a result } \\
\text { of drilling through disposal units and mixing of drilling } \\
\text { waste with garden soil. Assumed exposure pathways } \\
\text { include ingestion of vegetables grown in contaminated } \\
\text { garden soil, ingestion of contaminated garden soil, and } \\
\text { external and inhalation exposure while w orking in } \\
\text { garden. }\end{array}$ \\
\hline \multicolumn{3}{|c|}{ Acute exposure } \\
\hline Discovery & $\begin{array}{l}\text { Low-range silos, high- } \\
\text { range silos, high-range } \\
\text { wells, fissile wells, and } \\
\text { asbestos silos }^{c}\end{array}$ & $\begin{array}{l}\text { Assumed to occur at } 100 \text { years after disposal as a result } \\
\text { of attempted excavation into disposal units constructed } \\
\text { with engineered barriers. Assumed exposure pathway is } \\
\text { external exposure for short period of time at side of } \\
\text { disposal units with intact barriers. }\end{array}$ \\
\hline \multicolumn{3}{|c|}{$\begin{array}{l}\text { }{ }^{\circ} \text { Scenario is not relevant for biological trenches, because units are constructed without engineered barriers and } \\
\text { excavation into units would result in agriculture scenario. } \\
\text { 'Scenario is not relevant for biological trenches, because agriculture scenario could occur at same time and } \\
\text { results in higher doses per unit concentration of radionuclides. } \\
\text { 'Scenario is relevant only for units constructed with engineered barriers in which thickness of barriers at sides } \\
\text { of units is less than thickness of barriers on top of units. For other disposal units constructed with engineered barriers, } \\
\text { resident scenario could occur at same time and results in higher doses per unit concentration of radionuclides. }\end{array}$} \\
\hline \multicolumn{3}{|c|}{$\begin{array}{l}\text { ingestion of vegetables grown in the contaminated garden soil, } \\
\text { direct ingestion of contaminated soil from the garden in conjunction with vegetable intakes, } \\
\text { external exposure to contaminated soil while working in the garden or residing in the home on } \\
\text { top of exposed waste in the disposal facility, and } \\
\text { inhalation of radionuclides suspended into air from contaminated soil while working in the } \\
\text { garden or while residing in the home. }\end{array}$} \\
\hline
\end{tabular}


The annual EDEs per unit concentration of radionuclides in disposal units for the agriculture scenario are presented in Table 6.2. These results are obtained from Table G.24 of Appendix G. Annual doses per unit concentration are presented separately for the exposure pathways involving contaminated garden soil and the pathways involving an indoor residence on top of exposed waste. As described in Sect. 6.3.1.1, this distinction is important because the ratio of the volume of radioactive waste to the volume of uncontaminated waste materials that is excavated from the disposal units and mixed with native soil in the vegetable garden generally would not be the same as the ratio of the volume of radioactive waste to the volume of uncontaminated waste materials in the exposed disposal units themselves due to the presence of uncontaminated cover material on top of the waste.

\subsubsection{Resident Scenario}

As in the agriculture scenario described in Sect. 6.1.1, the resident scenario assumes that an inadvertent intruder excavates a foundation for a home on top of disposal units. However, during excavation the intruder is assumed to encounter an intact engineered barrier on top of the disposal units that cannot be penetrated by the types of excavation equipment normally used on the ORR, and the intruder is assumed to construct a home directly on top of the intact barrier. The resident scenario then occurs after construction of the home is completed, and the only relevant exposure pathway is chronic external exposure to photon-emitting radionuclides in the waste while residing in the home on top of the disposal facility. The presence of intact engineered barriers, which are assumed not to be penetrated during excavation, would preclude any ingestion or inhalation exposures.

Because the resident scenario assumes the presence of intact engineered barriers in disposal units, this scenario is not relevant for the biological trenches. For these disposal units, which are constructed without engineered barriers, excavation into the trenches would result in exposures according to the agriculture scenario described in Sect. 6.1.1.

Table 6.3 gives the annual EDEs per unit concentration of radionuclides in disposal units for the resident scenario. These results are obtained from Table G.25 of Appendix G. For the different types of disposal units in the SWSA 6 facility constructed with engineered barriers (see Sect. 3.2), the shielding provided by the intact engineered barrier on top of the disposal units is assumed to be equivalent to the shielding provided by a layer of soil $30 \mathrm{~cm}$ thick. This assumption may be conservative for some disposal units containing the highest activity concentrations of photon-emitting radionuclides (e.g., the high-range wells) and, thus, may result in considerable overestimates of external dose. Again, this scenario applies to all disposal units except the biological trenches.

The external exposure pathway assumed in the resident scenario is conceptually the same as one of the pathways in the agriculture scenario described in Sect. 6.1.1. However, as can be seen from the results in Table 6.3 for photon-emitting radionuclides compared with the corresponding results for the residence pathways for the agriculture scenario in Table 6.2 , the external dose per unit concentration of radionuclides while residing in the home is considerably less in the resident scenario, because the resident scenario assumes the presence of an intact engineered barrier between the waste and the receptor location whereas the agriculture scenario assumes exposure directly on top of 
Table 6.2. Annual effective dose equivalents to inadvertent intruders from all exposure pathways per unit concentration of radionuclides in disposal units for agriculture scenario ${ }^{a}$

\begin{tabular}{|c|c|c|c|c|c|}
\hline \multirow[b]{2}{*}{ Nuclide $^{b}$} & \multicolumn{2}{|c|}{$\begin{array}{c}\text { Annual dose } \\
\text { (rem/year per } \mu \mathrm{Ci} / \mathrm{m}^{3} \text { ) }\end{array}$} & \multirow[b]{2}{*}{ Nuclide $^{b}$} & \multicolumn{2}{|c|}{$\begin{array}{c}\text { Annual dose } \\
\left(\mathrm{rem} / \text { year per } \mu \mathrm{Ci} / \mathrm{m}^{3}\right)\end{array}$} \\
\hline & $\begin{array}{c}\text { Garden } \\
\text { pathways }\end{array}$ & $\begin{array}{l}\text { Residence } \\
\text { pathways }^{d}\end{array}$ & & $\begin{array}{c}\text { Garden } \\
\text { pathways }\end{array}$ & $\begin{array}{l}\text { Residence } \\
\text { pathways }^{d}\end{array}$ \\
\hline${ }^{3} \mathrm{H}$ & $4.0 \times 10^{-6}$ & $2.8 \times 10^{-12}$ & ${ }^{126} \mathrm{Sn}+\mathrm{d}$ & $1.4 \times 10^{-5}$ & $2.6 \times 10^{-3}$ \\
\hline${ }^{10} \mathrm{Be}$ & $6.5 \times 10^{-8}$ & $1.0 \times 10^{-8}$ & ${ }^{129} \mathrm{I}$ & $8.2 \times 10^{-5}$ & $2.8 \times 10^{-6}$ \\
\hline${ }^{14} \mathrm{C}$ & $1.5 \times 10^{-5}$ & $6.1 \times 10^{-11}$ & ${ }^{135} \mathrm{Cs}$ & $1.2 \times 10^{-6}$ & $1.3 \times 10^{-10}$ \\
\hline${ }^{26} \mathrm{Al}$ & $1.8 \times 10^{-5}$ & $3.9 \times 10^{-3}$ & ${ }^{137} \mathrm{Cs}+\mathrm{d}$ & $1.3 \times 10^{-5}$ & $7.4 \times 10^{-4}$ \\
\hline${ }^{36} \mathrm{Cl}$ & $1.2 \times 10^{-3}$ & $6.4 \times 10^{-10}$ & ${ }^{151} \mathrm{Sm}$ & $1.1 \times 10^{-8}$ & $8.7 \times 10^{-10}$ \\
\hline${ }^{40} \mathrm{~K}$ & $6.0 \times 10^{-5}$ & $2.3 \times 10^{-4}$ & ${ }^{152} \mathrm{Eu}$ & $7.8 \times 10^{-6}$ & $1.5 \times 10^{-3}$ \\
\hline${ }^{41} \mathrm{Ca}$ & $2.5 \times 10^{-6}$ & $3.8 \times 10^{-11}$ & ${ }^{154} \mathrm{Eu}$ & $8.5 \times 10^{-6}$ & $1.7 \times 10^{-3}$ \\
\hline${ }^{60} \mathrm{Co}$ & $1.8 \times 10^{-5}$ & $3.5 \times 10^{-3}$ & ${ }^{i s s} \mathrm{Eu}$ & $2.6 \times 10^{-7}$ & $3.9 \times 10^{-5}$ \\
\hline${ }^{59} \mathrm{Ni}$ & $7.2 \times 10^{-8}$ & $3.8 \times 10^{-11}$ & ${ }^{194} \mathrm{Os}$ & $2.7 \times 10^{-7}$ & $1.9 \times 10^{-8}$ \\
\hline${ }^{63} \mathrm{Ni}$ & $2.0 \times 10^{-7}$ & $9.0 \times 10^{-11}$ & ${ }^{207} \mathrm{Bi}$ & $1.0 \times 10^{-5}$ & $2.1 \times 10^{-3}$ \\
\hline${ }^{79} \mathrm{Se}$ & $1.2 \times 10^{-6}$ & $1.9 \times 10^{-10}$ & ${ }^{210} \mathrm{~Pb}+\mathrm{d}$ & $3.1 \times 10^{-4}$ & $6.7 \times 10^{-7}$ \\
\hline${ }^{87} \mathrm{Rb}$ & $1.9 \times 10^{-6}$ & $9.3 \times 10^{-11}$ & ${ }^{226} \mathrm{Ra}+\mathrm{d}^{\mathrm{f} g}$ & $3.0 \times 10^{-5}$ & $2.4 \times 10^{-3}$ \\
\hline${ }^{90} \mathrm{Sr}+\mathrm{d}$ & $2.0 \times 10^{-4}$ & $7.3 \times 10^{-9}$ & ${ }^{222} \mathrm{Rn}$ & $1.3 \times 10^{-4}$ & $1.2 \times 10^{-1}$ \\
\hline${ }^{93} \mathrm{Zr}^{2}$ & $1.4 \times 10^{-8}$ & $9.3 \times 10^{-9}$ & ${ }^{228} \mathrm{Ra}+\mathrm{d}^{\mathrm{g}}$ & $4.6 \times 10^{-5}$ & $3.5 \times 10^{-3}$ \\
\hline${ }^{93 \mathrm{~m} m} \mathrm{Nb}$ & $1.8 \times 10^{-8}$ & $8.4 \times 10^{-10}$ & ${ }^{220} \mathrm{Rn}$ & $2.1 \times 10^{-5}$ & $1.0 \times 10^{-2}$ \\
\hline${ }^{94} \mathrm{Nb}$ & $1.1 \times 10^{-5}$ & $2.1 \times 10^{-3}$ & ${ }^{227} \mathrm{Ac}+\mathrm{d}$ & $1.2 \times 10^{-4}$ & $5.6 \times 10^{-4}$ \\
\hline${ }^{99} \mathrm{Tc}$ & $1.3 \times 10^{-5}$ & $2.9 \times 10^{-11}$ & ${ }^{229} \mathrm{Th}+\mathrm{d}$ & $3.0 \times 10^{-5}$ & $4.0 \times 10^{-4}$ \\
\hline${ }^{107} \mathrm{Pd}$ & $3.4 \times 10^{-8}$ & $3.5 \times 10^{-10}$ & ${ }^{230} \mathrm{Th}$ & $3.5 \times 10^{-6}$ & $7.5 \times 10^{-6}$ \\
\hline${ }^{113 \mathrm{~m}} \mathrm{Cd}$ & $1.4 \times 10^{-4}$ & $4.4 \times 10^{-8}$ & ${ }^{232} \mathrm{Th}^{h}$ & $1.7 \times 10^{-5}$ & $3.5 \times 10^{-5}$ \\
\hline${ }^{121 \mathrm{~m}} \mathrm{Sn}$ & $6.5 \times 10^{-8}$ & $4.2 \times 10^{-7}$ & ${ }^{231} \mathrm{~Pa}^{i}$ & $7.6 \times 10^{-5}$ & $8.0 \times 10^{-5}$ \\
\hline
\end{tabular}


Table 6.2. (continued)

\begin{tabular}{|c|c|c|c|c|c|}
\hline \multirow[b]{2}{*}{ Nuclide $^{b}$} & \multicolumn{2}{|c|}{$\begin{array}{c}\text { Annual dose } \\
\left.\text { (rem/year per } \mu \mathrm{Ci} / \mathrm{m}^{3}\right)\end{array}$} & \multirow[b]{2}{*}{ Nuclide $^{b}$} & \multicolumn{2}{|c|}{$\begin{array}{c}\text { Annual dose } \\
\text { (rem/year per } \mu \mathrm{Ci} / \mathrm{m}^{3} \text { ) }\end{array}$} \\
\hline & $\begin{array}{c}\text { Garden } \\
\text { pathways }\end{array}$ & $\begin{array}{l}\text { Residence } \\
\text { pathways }^{d}\end{array}$ & & $\begin{array}{c}\text { Garden } \\
\text { pathways }^{c}\end{array}$ & $\begin{array}{l}\text { Residence } \\
\text { pathways }^{d}\end{array}$ \\
\hline${ }^{232} U+d^{g}$ & $5.7 \times 10^{-5}$ & $2.2 \times 10^{-3}$ & ${ }^{244} \mathrm{Pu}+\mathrm{d}$ & $2.0 \times 10^{-5}$ & $4.7 \times 10^{-4}$ \\
\hline${ }^{220} \mathrm{Rn}$ & $2.1 \times 10^{-5}$ & $1.0 \times 10^{-2}$ & ${ }^{241} \mathrm{Am}$ & $2.5 \times 10^{-5}$ & $2.3 \times 10^{-5}$ \\
\hline${ }^{233} \mathrm{U}$ & $8.1 \times 10^{-6}$ & $4.1 \times 10^{-6}$ & ${ }^{242 \mathrm{~m}} \mathrm{Am}+\mathrm{d}^{j}$ & $2.5 \times 10^{-5}$ & $2.8 \times 10^{-5}$ \\
\hline${ }^{234} \mathrm{U}$ & $7.8 \times 10^{-6}$ & $3.8 \times 10^{-6}$ & ${ }^{243} \mathrm{Am}+\mathrm{d}$ & $2.6 \times 10^{-5}$ & $2.1 \times 10^{-4}$ \\
\hline${ }^{235} U+d$ & $8.5 \times 10^{-6}$ & $1.6 \times 10^{-4}$ & ${ }^{243} \mathrm{Cm}$ & $1.4 \times 10^{-3}$ & $1.4 \times 10^{-4}$ \\
\hline${ }^{236} \mathrm{U}$ & $7.5 \times 10^{-6}$ & $3.8 \times 10^{-6}$ & ${ }^{244} \mathrm{Cm}$ & $1.1 \times 10^{-5}$ & $7.3 \times 10^{-6}$ \\
\hline${ }^{238} U+d$ & $7.2 \times 10^{-6}$ & $3.3 \times 10^{-5}$ & ${ }^{245} \mathrm{Cm}$ & $2.1 \times 10^{-5}$ & $8.7 \times 10^{-5}$ \\
\hline${ }^{237} \mathrm{~Np}+\mathrm{d}$ & $2.7 \times 10^{-4}$ & $2.6 \times 10^{-4}$ & ${ }^{246} \mathrm{Cm}$ & $2.1 \times 10^{-5}$ & $1.3 \times 10^{-5}$ \\
\hline${ }^{238} \mathrm{Pu}$ & $1.8 \times 10^{-5}$ & $1.1 \times 10^{-5}$ & ${ }^{247} \mathrm{Cm}+\mathrm{d}$ & $2.1 \times 10^{-5}$ & $4.1 \times 10^{-4}$ \\
\hline${ }^{239} \mathrm{Pu}$ & $2.0 \times 10^{-5}$ & $1.2 \times 10^{-5}$ & ${ }^{248} \mathrm{Cm}$ & $7.7 \times 10^{-3}$ & $4.9 \times 10^{-5}$ \\
\hline${ }^{240} \mathrm{Pu}$ & $2.0 \times 10^{-5}$ & $1.2 \times 10^{-5}$ & ${ }^{249} \mathrm{Cf}$ & $2.8 \times 10^{-9}$ & $4.4 \times 10^{-4}$ \\
\hline${ }^{241} \mathrm{Pu}$ & $3.9 \times 10^{-7}$ & $2.4 \times 10^{-7}$ & ${ }^{250} \mathrm{Cf}$ & $1.1 \times 10^{-4}$ & $7.5 \times 10^{-6}$ \\
\hline${ }^{242} \mathrm{Pu}$ & $1.9 \times 10^{-5}$ & $1.2 \times 10^{-5}$ & ${ }^{251} \mathrm{Cf}$ & $2.7 \times 10^{-3}$ & $1.4 \times 10^{-4}$ \\
\hline
\end{tabular}

'Results obtained from Table G.24 of Appendix G give the sum of effective dose equiv alents from one year's external exposure and the 50-year committed effective dose equivalents from one year's intakes by ingestion and inhalation.

${ }^{b \prime}+d^{\prime \prime}$ with some entries denotes shorter-lived decay products that are assumed to be in secular equilibrium with parent radionuclide; see Table G.1 of Appendix G for decay products and branching fractions.

Dose from exposure to radionuclides in contaminated soil in vegetable garden is sum of doses from vegetable, soil ingestion, external exposure, and inhalation pathways given in Table G.18, G.19, G.20, and G.22, respectively, of Appendix G.

Dose from exposure to radionuclides during residence on top of disposal units is sum of doses from external exposure and inhalation pathways given in Table G.21 and Table G.23, respectively, of Appendix G

'Possible contributions to dose from ${ }^{93 \mathrm{~m}} \mathrm{Nb}$ decay product are not included.

Possible contributions to dose from ${ }^{210} \mathrm{~Pb}$ decay product are not included.

${ }^{8}$ Contribution to dose from radon decay product is listed separately.

${ }^{h}$ Possible contributions to dose from ${ }^{228} \mathrm{Ra}$ decay product are not included.

'Possible contributions to dose from ${ }^{227} \mathrm{Ac}$ decay product are not included.

jPossible contributions to dose from ${ }^{238} \mathrm{Pu}$ decay product are not included.

unshielded waste. On the other hand, as described in Sect. 6.1.4, the agriculture scenario is assumed not to occur for a substantial period of time after the resident scenario for disposal units constructed with engineered barriers, because the agriculture scenario requires that the barriers would be physically degraded and could be penetrated by normal excavation procedures and the barriers presumably will remain intact for substantially longer than the 100-year period of active institutional control over the disposal site. Therefore, for photon-emitting radionuclides, the resident scenario is potentially important (i.e., could result in doses comparable to or greater than the dose for the agriculture scenario) 
Table 6.3. Annual effective dose equivalents to inadvertent intruders per unit concentration of radionuclides in disposal units for resident scenario ${ }^{a}$

\begin{tabular}{lc|lc}
\hline Nuclide & $\begin{array}{c}\text { Annual dose } \\
\left.\text { (rem/year per } \mu \mathrm{Ci} / \mathrm{m}^{3}\right)\end{array}$ & \multicolumn{1}{|c}{ Nuclide $^{b}$} & $\begin{array}{c}\text { Annual dose } \\
\text { (rem/year per } \mu \mathrm{Ci} / \mathrm{m}^{3} \text { ) }\end{array}$ \\
\hline${ }^{26} \mathrm{Al}$ & $3.3 \times 10^{-4}$ & ${ }^{232} \mathrm{Th}^{c}$ & - \\
${ }^{40} \mathrm{~K}$ & $2.1 \times 10^{-5}$ & ${ }^{231} \mathrm{~Pa}^{d}$ & $4.6 \times 10^{-7}$ \\
${ }^{60} \mathrm{Co}$ & $2.9 \times 10^{-4}$ & ${ }^{232} \mathrm{U}+\mathrm{d}$ & $2.3 \times 10^{-4}$ \\
${ }^{94} \mathrm{Nb}$ & $1.1 \times 10^{-4}$ & ${ }^{235} \mathrm{U}+\mathrm{d}$ & $5.6 \times 10^{-7}$ \\
${ }^{126} \mathrm{Sn}+\mathrm{d}$ & $1.1 \times 10^{-4}$ & ${ }^{238} \mathrm{U}+\mathrm{d}$ & $1.2 \times 10^{-6}$ \\
${ }^{137} \mathrm{Cs}+\mathrm{d}$ & $3.2 \times 10^{-5}$ & ${ }^{237} \mathrm{~Np}+\mathrm{d}$ & $3.5 \times 10^{-6}$ \\
${ }^{152} \mathrm{Eu}$ & $9.8 \times 10^{-5}$ & ${ }^{244} \mathrm{Pu}+\mathrm{d}$ & $2.1 \times 10^{-5}$ \\
${ }^{154} \mathrm{Eu}$ & $1.1 \times 10^{-4}$ & ${ }^{242 \mathrm{~m}} \mathrm{Am}+\mathrm{d}$ & $2.5 \times 10^{-7}$ \\
${ }^{155} \mathrm{Eu}$ & $2.0 \times 10^{-8}$ & ${ }^{243} \mathrm{Am}+\mathrm{d}$ & $1.1 \times 10^{-6}$ \\
${ }^{207} \mathrm{Bi}$ & $1.2 \times 10^{-4}$ & ${ }^{243} \mathrm{Cm}$ & $7.7 \times 10^{-7}$ \\
${ }^{226} \mathrm{Ra}+\mathrm{d}$ & $1.9 \times 10^{-4}$ & ${ }^{245} \mathrm{Cm}$ & $9.8 \times 10^{-8}$ \\
${ }^{228} \mathrm{Ra}+\mathrm{d}$ & $3.0 \times 10^{-4}$ & ${ }^{247} \mathrm{Cm}+\mathrm{d}$ & $8.4 \times 10^{-6}$ \\
${ }^{227} \mathrm{Ac}+\mathrm{d}$ & $6.7 \times 10^{-6}$ & ${ }^{249} \mathrm{Cf}$ & $8.1 \times 10^{-6}$ \\
${ }^{229} \mathrm{Th}+\mathrm{d}$ & $1.1 \times 10^{-5}$ & ${ }^{251} \mathrm{Cf}$ & $3.9 \times 10^{-7}$ \\
\hline
\end{tabular}

"Results obtained from Table G.25 of Appendix G give effective dose equivalents per unit concentration of radionuclides in disposal units from one year's external exposure during indoor residence on top of waste covered with intact engineered barriers $30 \mathrm{~cm}$ thick.

$b^{b}+\mathrm{d}$ " with some entries denotes shorter-lived decay products that are assumed to be in secular equilibrium with parent radionuclide; see Table G.1 of Appendix $G$ for decay products and branching fractions.

'Possible contributions to dose from ${ }^{228} \mathrm{Ra}$ decay product are not included.

${ }^{d}$ Possible contributions to dose from ${ }^{227} \mathrm{Ac}$ decay product are not included.

only if the inventory of the radionuclide in the disposal facility would be depleted significantly over time prior to failure of the engineered barriers, either by radioactive decay or by mobilization and transport in infiltrating water. For relatively long-lived and immobile radionuclides, the resident scenario would result in considerably lower estimates of dose than the agriculture scenario and, thus, would not be important in demonstrating compliance with the performance objective for inadvertent intruders.

\subsubsection{Post-Drilling Scenario}

In the post-drilling scenario, an inadvertent intruder is assumed to drill through disposal units for the purpose of constructing a well for a domestic water supply, but no other means of accessing solid waste is assumed to occur (e.g., construction of a home on top of the disposal facility). The 
contaminated drilling waste is assumed to be indistinguishable from native soil, and all of the drilling waste is assumed to be mixed with native soil in the intruder's vegetable garden. The post-drilling scenario then occurs after the vegetable garden is established, and the following pathways involving chronic exposure are assumed to occur:

- ingestion of vegetables grown in the contaminated garden soil,

- direct ingestion of contaminated soil from the garden in conjunction with vegetable intakes,

- $\quad$ external exposure to contaminated soil while working in the garden, and

- inhalation of radionuclides suspended into air from contaminated soil while working in the garden.

Table 6.4 presents the annual EDEs per unit concentration of radionuclides in disposal units for the post-drilling scenario. These results are obtained from Table G.27 of Appendix G.

The exposure pathways assumed in the post-drilling scenario are conceptually the same as the corresponding garden pathways in the agriculture scenario described in Sect. 6.1.1. In the post-drilling scenario, however, external and inhalation exposures while residing in the home on the disposal site are not relevant, because all waste exhumed by drilling is assumed to be mixed with native soil in the intruder's vegetable garden and the intruder's home is assumed not to be located directly on top of the disposal facility or contaminated soil. As can be seen from the results in Table 6.4 compared with the corresponding results for the garden pathways for the agriculture scenario in Table 6.2, the dose per unit concentration of radionuclides in the disposal facility is considerably less for the post-drilling scenario than for the agriculture scenario, because the volume of drilling waste that would be mixed with native soil in the intruder's vegetable garden is assumed to be considerably less than the volume of waste that could be mixed with garden soil following excavation of a foundation for a home (see Sect. G.5.2.4 of Appendix G). Therefore, as in the resident scenario described in Sect. 6.1.2, the postdrilling scenario is potentially important for any radionuclide compared with the agriculture scenario only if the post-drilling scenario could occur considerably earlier and the inventory in the disposal facility would be depleted significantly over time prior to occurrence of the agriculture scenario, either by radioactive decay or by mobilization and transport in infiltrating water. For relatively long-lived and immobile radionuclides, the post-drilling scenario would result in considerably lower estimates of dose than the agriculture scenario and, thus, would not be important in demonstrating compliance with the performance objective for inadvertent intruders.

Furthermore, the post-drilling scenario is not relevant for the biological trenches because, as described in the following section, drilling through these trenches is assumed to occur at the same time as excavation into the waste and the dose per unit concentration of radionuclides is considerably less for the post-drilling scenario than for the agriculture scenario. The post-drilling scenario is relevant only for disposal units constructed with engineered barriers that would delay the time of occurrence of the agriculture scenario beyond the time of occurrence of the post-drilling scenario. 
Table 6.4. Annual effective dose equivalents to inadvertent intruders from all exposure pathways per unit concentration of radionuclides in disposal units for post-drilling scenario ${ }^{a}$

\begin{tabular}{|c|c|c|c|}
\hline Nuclide $^{b}$ & $\begin{array}{c}\text { Annual dose } \\
\left.\text { (rem/year per } \mu \mathrm{Ci} / \mathrm{m}^{3}\right)\end{array}$ & Nuclide $^{b}$ & $\begin{array}{c}\text { Annual dose } \\
\text { (rem/year per } \mu \mathrm{Ci} / \mathrm{m}^{3} \text { ) }\end{array}$ \\
\hline${ }^{3} \mathrm{H}$ & $4.0 \times 10^{-8}$ & ${ }^{137} \mathrm{Cs}+\mathrm{d}$ & $1.3 \times 10^{-3}$ \\
\hline${ }^{10} \mathrm{Be}$ & $6.5 \times 10^{-10}$ & ${ }^{151} \mathrm{Sm}$ & $1.1 \times 10^{-10}$ \\
\hline${ }^{14} \mathrm{C}$ & $1.5 \times 10^{-7}$ & ${ }^{152} \mathrm{Eu}$ & $7.8 \times 10^{-8}$ \\
\hline${ }^{26} \mathrm{Al}$ & $1.8 \times 10^{-7}$ & ${ }^{354} \mathrm{Eu}$ & $8.5 \times 10^{-8}$ \\
\hline${ }^{36} \mathrm{Cl}$ & $1.2 \times 10^{-5}$ & ${ }^{155} \mathrm{Eu}$ & $2.6 \times 10^{-9}$ \\
\hline${ }^{40} \mathrm{~K}$ & $6.0 \times 10^{-7}$ & ${ }^{194} \mathrm{Os}$ & $2.7 \times 10^{-9}$ \\
\hline${ }^{41} \mathrm{Ca}$ & $2.5 \times 10^{-8}$ & ${ }^{207} \mathrm{Bi}$ & $1.0 \times 10^{-7}$ \\
\hline${ }^{60} \mathrm{Co}$ & $1.8 \times 10^{-7}$ & ${ }^{210} \mathrm{~Pb}+\mathrm{d}$ & $3.1 \times 10^{-6}$ \\
\hline${ }^{59} \mathrm{Ni}$ & $7.2 \times 10^{-10}$ & ${ }^{226} \mathrm{Ra}+\mathrm{d}^{d e}$ & $3.0 \times 10^{-7}$ \\
\hline${ }^{63} \mathrm{Ni}$ & $2.0 \times 10^{-9}$ & ${ }^{222} \mathrm{Rn}$ & $1.3 \times 10^{-6}$ \\
\hline${ }^{79} \mathrm{Se}$ & $1.2 \times 10^{-8}$ & ${ }^{228} \mathrm{Ra}+\mathrm{d}^{e}$ & $4.6 \times 10^{-7}$ \\
\hline${ }^{87} \mathrm{Rb}$ & $1.9 \times 10^{-8}$ & ${ }^{220} \mathrm{Rn}$ & $2.1 \times 10^{-7}$ \\
\hline${ }^{90} \mathrm{Sr}+\mathrm{d}$ & $2.0 \times 10^{-6}$ & ${ }^{227} \mathrm{Ac}+\mathrm{d}$ & $1.2 \times 10^{-6}$ \\
\hline${ }^{93} \mathrm{Zr}^{\mathrm{c}}$ & $1.4 \times 10^{-10}$ & ${ }^{229} \mathrm{Th}+\mathrm{d}$ & $3.0 \times 10^{-7}$ \\
\hline${ }^{93 \mathrm{~m}} \mathrm{Nb}$ & $1.8 \times 10^{-10}$ & ${ }^{230} \mathrm{Th}$ & $3.5 \times 10^{-8}$ \\
\hline${ }^{94} \mathrm{Nb}$ & $1.1 \times 10^{-7}$ & ${ }^{232} \mathrm{Th}^{f}$ & $1.7 \times 10^{-7}$ \\
\hline${ }^{99} \mathrm{Tc}$ & $1.3 \times 10^{-7}$ & ${ }^{231} \mathrm{~Pa}^{g}$ & $7.6 \times 10^{-7}$ \\
\hline${ }^{107} \mathrm{Pd}$ & $3.4 \times 10^{-10}$ & ${ }^{232} \mathrm{U}+\mathrm{d}^{e}$ & $5.7 \times 10^{-7}$ \\
\hline${ }^{113 \mathrm{~m}} \mathrm{Cd}$ & $1.4 \times 10^{-6}$ & ${ }^{220} \mathrm{Rn}$ & $2.1 \times 10^{-7}$ \\
\hline${ }^{121 \mathrm{~m}} \mathrm{Sn}$ & $6.5 \times 10^{-10}$ & ${ }^{233} \mathrm{U}$ & $8.1 \times 10^{-8}$ \\
\hline${ }^{126} \mathrm{Sn}+\mathrm{d}$ & $1.4 \times 10^{-7}$ & ${ }^{234} \mathrm{U}$ & $7.8 \times 10^{-8}$ \\
\hline${ }^{129} \mathrm{I}$ & $8.2 \times 10^{-7}$ & ${ }^{235} \mathrm{U}+\mathrm{d}$ & $8.5 \times 10^{-8}$ \\
\hline${ }^{135} \mathrm{Cs}$ & $1.2 \times 10^{-8}$ & ${ }^{236} \mathrm{U}$ & $7.5 \times 10^{-8}$ \\
\hline
\end{tabular}


Table 6.4. (continued) ${ }^{a}$

\begin{tabular}{lc|lc}
\hline Nuclide & $\begin{array}{c}\text { Annual dose } \\
\text { (rem/year per } \mu \mathrm{Ci}^{3} \mathrm{~m}^{3} \text { ) }\end{array}$ & Nuclide $^{b}$ & $\begin{array}{c}\text { Annual dose } \\
\left(\text { rem/year per } \mu \mathrm{Ci} / \mathrm{m}^{3}\right)\end{array}$ \\
\hline${ }^{238} \mathrm{U}+\mathrm{d}$ & $7.2 \times 10^{-8}$ & ${ }^{243} \mathrm{Am}+\mathrm{d}$ & $2.6 \times 10^{-7}$ \\
${ }^{237} \mathrm{~Np}+\mathrm{d}$ & $2.7 \times 10^{-6}$ & ${ }^{243} \mathrm{Cm}$ & $1.4 \times 10^{-7}$ \\
${ }^{238} \mathrm{Pu}$ & $1.8 \times 10^{-7}$ & ${ }^{244} \mathrm{Cm}$ & $1.1 \times 10^{-7}$ \\
${ }^{239} \mathrm{Pu}$ & $2.0 \times 10^{-7}$ & ${ }^{245} \mathrm{Cm}$ & $2.1 \times 10^{-7}$ \\
${ }^{240} \mathrm{Pu}$ & $2.0 \times 10^{-7}$ & ${ }^{246} \mathrm{Cm}$ & $2.1 \times 10^{-7}$ \\
${ }^{241} \mathrm{Pu}$ & $3.9 \times 10^{-9}$ & ${ }^{247} \mathrm{Cm}+\mathrm{d}$ & $2.1 \times 10^{-7}$ \\
${ }^{242} \mathrm{Pu}$ & $1.9 \times 10^{-7}$ & ${ }^{248} \mathrm{Cm}$ & $7.7 \times 10^{-7}$ \\
${ }^{244} \mathrm{Pu}+\mathrm{d}$ & $2.0 \times 10^{-7}$ & ${ }^{249} \mathrm{Cf}$ & $2.8 \times 10^{-7}$ \\
${ }^{241} \mathrm{Am}$ & $2.5 \times 10^{-7}$ & ${ }^{250} \mathrm{Cf}$ & $1.1 \times 10^{-7}$ \\
${ }^{242 \mathrm{~m}} \mathrm{Am}+\mathrm{d}^{h}$ & $2.5 \times 10^{-7}$ & ${ }^{251} \mathrm{Cf}$ & $2.7 \times 10^{-7}$ \\
\hline
\end{tabular}

${ }^{a}$ Results obtained from Table G.27 of Appendix G; values are 1\% of annual effective dose equivalents per unit concentration in disposal units for garden pathways given in Table 6.2.

$b "+d$ " with some entries denotes shorter-lived decay products that are assumed to be in secular equilibrium with parent radionuclide; see Table G.1 of Appendix $G$ for decay products and branching fractions.

'Possible contributions to dose from ${ }^{93 \mathrm{~m}} \mathrm{Nb}$ decay product are not included.

${ }^{d}$ Possible contributions to dose from ${ }^{210} \mathrm{~Pb}$ decay product are not included.

${ }^{c}$ Contribution to dose from radon decay product is listed separately.

${ }^{f}$ Possible contributions to dose from ${ }^{228} \mathrm{Ra}$ decay product are not included.

${ }^{g}$ Possible contributions to dose from ${ }^{227} \mathrm{Ac}$ decay product are not included.

${ }^{h}$ Possible contributions to dose from ${ }^{238} \mathrm{Pu}$ decay product are not included.

\subsubsection{Time of Occurrence of Scenarios}

For the chronic exposure scenarios described in Sect. 6.1.1 through Sect. 6.1.3 involving direct intrusion, or attempts at direct intrusion, into solid waste in disposal units, an important assumption is the time after disposal at which the scenarios first occur, because the dose from relatively short-lived radionuclides is reduced significantly over time due to radioactive decay and mobilization and transport from the disposal facility into the environment can significantly reduce the dose over time for relatively mobile radionuclides. The earliest time after disposal at which the scenarios can occur depends on the time period for active institutional control over the disposal site, which is assumed to be 100 years after disposal. In addition, for the agriculture and post-drilling scenarios, the earliest time of occurrence would depend on the length of time any engineered barriers in the disposal units are assumed to maintain their integrity and preclude direct intrusion into waste by excavation or drilling, provided the barrier lifetime is longer than 100 years. The lifetime of any engineered barriers in disposal units is not relevant for the resident scenario because this scenario assumes that the barriers are intact. 


\subsubsection{Agriculture Scenario}

The agriculture scenario cannot occur unless the disposal units are penetrable by the types of excavation equipment normally used in digging a foundation for a home. Therefore, based on an assumption that normal excavation procedures cannot readily penetrate the types of intact concrete barriers used in constructing all disposal units in the SWSA 6 facility except the biological trenches, the agriculture scenario is assumed not to occur for these units until the concrete barriers have lost their structural and physical integrity.

An analysis of the degradation of concrete barriers used in various disposal units has not been performed in this revised PA for the SWSA 6 facility. Rather, the presence of concrete barriers in all disposal units except the biological trenches is assumed to preclude the agriculture scenario for 300 years after disposal. Although the expected lifetime of the concrete barriers is not known, this assumption is intended to be somewhat pessimistic for the thicknesses of concrete that have been used in the various disposal units. The concrete barriers could maintain their integrity and preclude intrusion by excavation for longer than 300 years, but a technical justification for a longer barrier lifetime cannot be provided. However, the assumed lifetime of the concrete barriers affects the estimated dose in the agriculture scenario only for shorter-lived or relatively mobile radionuclides. For long-lived and immobile radionuclides, the dose for the agriculture scenario essentially is independent of the lifetime of the concrete barriers, because the concentration in the disposal facility would change only very slowly over time periods much longer than can reasonably be assumed for the barrier lifetime.

Therefore, for all disposal units in the SWSA 6 facility constructed with engineered barriers, the agriculture scenario is assumed to occur beginning at 300 years after disposal. For the biological trenches, which are constructed without engineered barriers to preclude excavation into the waste, the scenario is assumed to occur beginning at 100 years after disposal, when active institutional control over the disposal site is no longer assumed to be effective.

For most radionuclides, the dose for the agriculture scenario decreases with time after the assumed failure of the engineered barriers at 300 years after disposal, as a result of radioactive decay or mobilization and transport from the disposal units in infiltrating water. Thus, for most radionuclides, the agriculture scenario is evaluated only at 300 years to give the highest estimate of annual dose. However, the dose can increase with time for long-lived radionuclides, such as uranium, which are relatively immobile and decay to long-lived decay products that are radiologically more significant than the parent isotope, and the highest dose may occur long after the concrete barriers are assumed to have failed, even when mobilization and transport in infiltrating water is taken into account. For radionuclides with radiologically significant long-lived decay products that build up in the waste only over long periods of time, the agriculture scenario is evaluated at two different times. The first is the time during the first 1,000 years at which the estimated dose is the highest, based on current DOE guidance that a 1,000-year time period of concern is appropriate for evaluating complying with the performance objective for inadvertent intruders (DOE 1996c). Then, additional information is provided on the highest dose beyond 1,000 years, taking into account radioactive decay and mobilization and transport of the parent radionuclide in infiltrating water. The information on doses 
beyond 1,000 years is not used in evaluating compliance with the performance objective for inadvertent intruders, but is presented only to provide an additional perspective on potential exposures of inadvertent intruders at far future times.

\subsubsection{Resident Scenario}

The resident scenario is based on an assumption that disposal units constructed with engineered barriers are not penetrable by the types of excavation procedures normally used in digging a foundation for a home. Therefore, this scenario is assumed to occur immediately upon loss of active institutional control at 100 years after disposal.

The resident scenario also could occur at any time between 100 and 300 years, when the engineered barriers are assumed to have failed and the agriculture scenario would occur instead. However, for all radionuclides for which the resident scenario could be important compared with the agriculture scenario (i.e., for relatively short-lived or mobile radionuclides), the dose decreases with time after disposal. Therefore, the resident scenario is evaluated only at 100 years.

\subsubsection{Post-Drilling Scenario}

The post-drilling scenario cannot occur unless the disposal units are penetrable by the types of equipment normally used in drilling a well. However, since drilling through hard rock is commonplace on the ORR, we assume that normal drilling procedures could easily penetrate any intact concrete barriers used in all disposal units except the biological trenches. Therefore, no credit is taken for the ability of intact engineered barriers to preclude the post-drilling scenario, and the scenario is assumed to occur at 100 years after disposal.

The post-drilling scenario also could occur at any time after 100 years. However, as in the case of the resident scenario described in Sect. 6.1.4.2, the highest dose would occur at 100 years for all radionuclides for which the post-drilling scenario is potentially important compared with the agriculture scenario, and the scenario is evaluated only at this time.

\subsection{SCENARIOS FOR ACUTE EXPOSURE}

In this assessment, a single scenario for acute exposure of inadvertent intruders, called the discovery scenario, is assumed to be credible. This scenario essentially is the same as the scenario considered in the initial PA for the SWSA 6 facility (ORNL 1994).

The discovery scenario involving a single, acute exposure of inadvertent intruders is discussed in Sect. 6.2.1. Additional scenarios involving acute exposure of inadvertent intruders were considered in this assessment but were not evaluated. These scenarios, and the reasons for excluding them from the intruder dose assessment, are discussed in Sect. 6.2.2. 


\subsubsection{Discovery Scenario}

The discovery scenario is assumed to occur only once over an intruder's lifetime. In this scenario, an intruder attempts to excavate a foundation for a home at the location of disposal units, as in the agriculture and resident scenarios described in Sect. 6.1.1 and Sect. 6.1.2, respectively, but is assumed to encounter an intact and impenetrable engineered barrier used in constructing the units. Therefore, as in the resident scenario, external exposure to photon-emitting radionuclides in the waste is the only exposure pathway of concern.

The discovery scenario involves the same assumption about the impenetrability of engineered barriers as the resident scenario, but the discovery scenario differs from the resident scenario in two respects. First, shortly after encountering the intact engineered barrier, the intruder decides to abandon digging at the location of the disposal units and moves elsewhere, thus resulting in a short-term exposure rather than a continuous exposure as in the resident scenario. Second, it is assumed that the excavation would encounter an engineered barrier at the side of the disposal units, rather than on top of the units as in the resident scenario. This difference is potentially important because several types of disposal units in the SWSA 6 facility are constructed with side walls considerably thinner than the cap (see Sect. 3.2). For these units, the external dose rate per unit concentration of radionuclides in the waste would be significantly higher for the discovery scenario than for the resident scenario.

The discovery scenario would occur at the same time as the resident scenario, i.e., at 100 years after disposal. The main difference between the two scenarios is the assumed exposure time, which is only about $100 \mathrm{~h}$ for the discovery scenario but half of the time during the year (about $4400 \mathrm{~h}$ ) for the resident scenario (see Sect. G.5.2.3 and Sect. G.5.2.4 of Appendix G). Therefore, the dose for the discovery scenario would be comparable to or greater than the dose for the resident scenario only if the thickness of the engineered barriers at the side of disposal units is considerably less than the thickness of the barriers at the top of the units. In this assessment, therefore, the discovery scenario is considered only for the low-range wells, high-range silos, high-range wells, fissile wells, and asbestos silos. For each of these types of units, the shielding provided by the intact engineered barrier at the side of the disposal units is assumed to be equivalent to the shielding provided by a layer of soil $15 \mathrm{~cm}$ thick. This assumption may be conservative for some disposal units containing the highest activity concentrations of photon-emitting radionuclides (e.g., the high-range wells) and, thus, may result in considerable overestimates of external dose.

Table 6.5 presents the EDEs per unit concentration of radionuclides in disposal units for the discovery scenario. These results are obtained from Table G.26 of Appendix G. Again, this scenario is applied only to the disposal units with thinner engineered barriers at the side than at the top.

\subsubsection{Other Scenarios Considered}

Two additional scenarios involving a single, acute exposure of inadvertent intruders were considered in this assessment: the construction and drilling scenarios. However, as discussed in the following paragraphs, these scenarios were not evaluated. 
Table 6.5. Effective dose equivalents to inadvertent intruders per unit concentration of radionuclides in disposal units for discovery scenario ${ }^{a}$

\begin{tabular}{lc|lc}
\hline Nuclide & $\begin{array}{c}\text { Dose } \\
\left.\text { (rem per } \mu \mathrm{Ci}^{b} \mathrm{~m}^{3}\right)\end{array}$ & Nuclide $^{b}$ & \multicolumn{1}{c}{$\begin{array}{c}\text { Dose } \\
\left(\text { rem per } \mu \mathrm{Ci} / \mathrm{m}^{3}\right)\end{array}$} \\
\hline${ }^{26} \mathrm{Al}$ & $3.0 \times 10^{-5}$ & ${ }^{231} \mathrm{~Pa}^{d}$ & $1.1 \times 10^{-7}$ \\
${ }^{40} \mathrm{~K}$ & $1.9 \times 10^{-6}$ & ${ }^{232} \mathrm{U}+\mathrm{d}$ & $1.8 \times 10^{-5}$ \\
${ }^{60} \mathrm{Co}$ & $2.9 \times 10^{-5}$ & ${ }^{235} \mathrm{U}+\mathrm{d}$ & $2.5 \times 10^{-7}$ \\
${ }^{94} \mathrm{Nb}$ & $1.4 \times 10^{-5}$ & ${ }^{238} \mathrm{U}+\mathrm{d}$ & $1.4 \times 10^{-7}$ \\
${ }^{126} \mathrm{Sn}+\mathrm{d}$ & $1.5 \times 10^{-5}$ & ${ }^{237} \mathrm{~Np}+\mathrm{d}$ & $8.1 \times 10^{-7}$ \\
${ }^{137} \mathrm{Cs}+\mathrm{d}$ & $4.5 \times 10^{-6}$ & ${ }^{244} \mathrm{Pu}+\mathrm{d}$ & $2.7 \times 10^{-6}$ \\
${ }^{152} \mathrm{Eu}$ & $1.1 \times 10^{-5}$ & ${ }^{241} \mathrm{Am}$ & $3.6 \times 10^{-10}$ \\
${ }^{154} \mathrm{Eu}$ & $1.2 \times 10^{-5}$ & ${ }^{242 \mathrm{~m}} \mathrm{Am}+\mathrm{d}$ & $3.4 \times 10^{-8}$ \\
${ }^{155} \mathrm{Eu}$ & $2.0 \times 10^{-8}$ & ${ }^{243} \mathrm{Am}+\mathrm{d}$ & $3.4 \times 10^{-7}$ \\
${ }^{207} \mathrm{Bi}$ & $1.4 \times 10^{-5}$ & ${ }^{243} \mathrm{Cm}$ & $2.5 \times 10^{-7}$ \\
${ }^{226} \mathrm{Ra}+\mathrm{d}$ & $1.8 \times 10^{-5}$ & ${ }^{245} \mathrm{Cm}$ & $5.6 \times 10^{-8}$ \\
${ }^{228} \mathrm{Ra}+\mathrm{d}$ & $2.7 \times 10^{-5}$ & ${ }^{247} \mathrm{Cm}+\mathrm{d}$ & $1.7 \times 10^{-6}$ \\
${ }^{227} \mathrm{Ac}+\mathrm{d}$ & $1.3 \times 10^{-6}$ & ${ }^{249} \mathrm{Cf}$ & $1.7 \times 10^{-6}$ \\
${ }^{229} \mathrm{Th}+\mathrm{d}$ & $1.5 \times 10^{-6}$ & ${ }^{251} \mathrm{Cf}$ & $1.6 \times 10^{-7}$ \\
${ }^{232} \mathrm{Th}$ & - & & \\
\hline
\end{tabular}

${ }^{\circ}$ Results obtained from Table $G .26$ of Appendix $G$ give effective dose equivalents per unit concentration of radionuclides in disposal units from external exposure for about $100 \mathrm{~h}$ next to waste shielded by intact engineered barriers $15 \mathrm{~cm}$ thick.

$b^{\prime \prime}+d^{\prime \prime}$ with some entries denotes shorter-lived decay products that are assumed to be in secular equilibrium with parent radionuclide; see Table G.1 of Appendix $G$ for decay products and branching fractions.

Possible contributions to dose from ${ }^{228} \mathrm{Ra}$ decay product are not included.

${ }^{4}$ Possible contributions to dose from ${ }^{227} \mathrm{Ac}$ decay product are not included.

The construction scenario considers doses that would be received while excavating into the waste on the disposal site (e.g., while digging a foundation for a home). The construction scenario thus can be viewed as the initiator of the agriculture scenario, which considers chronic exposures after construction of a house is completed. The potential importance of the construction scenario arises primarily from an assumption that excavation activities would result in airborne concentrations of radionuclides substantially higher than those experienced during normal residence on top of exposed waste and considered in the agriculture scenario. Ingestion exposure also could be important during excavation activities. However, external exposure during excavation should be considerably less than external exposure while residing in the house after construction is completed, due to the much shorter exposure time involved. 
Since the construction scenario would occur at the same time as the agriculture scenario, the dose assessment for each scenario would be based on the same concentrations of radionuclides. Previous calculations (Kennedy and Peloquin 1988) provide a direct comparison of doses for the two scenarios. For a few radionuclides, the dose per unit concentration could be slightly higher in the construction scenario, but for most radionuclides the dose per unit concentration is expected to be higher in the agriculture scenario. This result is based on a reasonable exposure time in the construction scenario and the use of reasonably consistent assumptions for the exposure pathways in the two scenarios. Therefore, because the performance objective for the construction scenario is five times higher than the performance objective for the agriculture scenario, the construction scenario should be relatively unimportant for all radionuclides and can be neglected in this revised PA for inadvertent intruders.

The drilling scenario considers doses that would be received while drilling through waste and constructing a well. The drilling scenario thus can be viewed as the initiator of the post-drilling scenario, which considers chronic exposures after well drilling is completed. The potential importance of the drilling scenario arises primarily from an assumption that the intruder would be located near an unshielded pile of drilling waste for a substantial period of time and, thus, would receive a significant external exposure. Ingestion and inhalation exposures during drilling activities also could be important.

Since the drilling scenario would occur at the same time as the post-drilling scenario, the dose assessment for each scenario would be based on the same concentrations of radionuclides. Previous calculations (Kennedy and Peloquin 1988) provide a direct comparison of doses for the two scenarios. For all radionuclides, the dose per unit concentration in the drilling scenario is expected to be at least an order of magnitude less than the dose in the post-drilling scenario. This result is based on a reasonable exposure time in the drilling scenario and the use of reasonably consistent assumptions for the exposure pathways in the two scenarios. Therefore, the drilling scenario should be relatively unimportant for all radionuclides and can be neglected in this revised PA for inadventent intruders.

\subsection{RESULTS OF INTRUDER DOSE ASSESSMENT}

This section presents the results of the dose assessment for inadvertent intruders for the different disposal units in the SWSA 6 facility. The dose assessment is based on the doses per unit concentration of radionuclides in the disposal units at the time intrusion is assumed to occur for the agriculture, resident, post-drilling, and discovery scenarios, as given in Table 6.2 through Table 6.5. The data in these tables are referred to as scenario dose conversion factors (SDCFs).

This section is organized as follows. Sect. 6.3.1 presents the general approach to the intruder dose assessment for all disposal units, taking into account the SDCFs in Table 6.2 through Table 6.5, the performance objective for inadvertent intruders given at the beginning of Chapter 6 , and other factors important in estimating dose (e.g., radioactive decay). Sect. 6.3.2 presents the results of the intruder dose assessment for the IWMF. For this particular disposal unit, the SDCFs for the different 
exposure scenarios and the performance objective for inadvertent intruders are used to derive allowable limits on average concentrations and total inventories of radionuclides for disposal. Sect. 6.3.3 presents the results of the intruder dose assessment for disposal units other than the IWMF. For these units, the SDCFs for the different exposure scenarios and the reported inventory of radionuclides in the units are used to obtain estimates of dose, which then are compared with the performance objective for inadvertent intruders.

\subsubsection{General Approach to Intruder Dose Assessment}

For any exposure scenario for inadvertent intruders, and regardless of whether the purpose of the assessment is to derive allowable limits on disposals of radionuclides or to estimate dose for given disposals of radionuclides, the dose, $H$, is given in terms of the SDCF and the average concentration of a radionuclide in the disposal units, $\bar{C}_{\mathrm{F}}$, at the time $t$ after disposal at which the scenario is assumed to occur by the equation

$$
H=\bar{C}_{\mathrm{F}}(t) \times \mathrm{SDCF}
$$

The average concentrations of radionuclides in all disposal units of a particular type, rather than the concentrations in an individual waste package, cask, well, silo, or trench, are the appropriate quantities for use in estimating dose, essentially because an inadvertent intruder is assumed to access any disposal units at random locations.

In deriving allowable limits on concentrations or inventories of radionuclides for disposal or in estimating dose from known disposals, the desired quantities are the average concentrations of radionuclides in waste before disposal, rather than the average concentrations in disposal units at the time intrusion is assumed to occur. These concentrations are related by the following factors: (1) the so-called waste dilution factor, which takes into account the dilution of waste following disposal due to the presence of uncontaminated material in the disposal units and the presence of a cap on top of the units; (2) changes in inventory due to radioactive decay between the time of disposal and the time the scenario is assumed to occur; and (3) reductions in inventory due to mobilization and transport in infiltrating water during this time. Thus, the average concentration of a radionuclide in waste prior to disposal, $\bar{C}_{\mathrm{w}}$, can be represented by

$$
\bar{C}_{\mathrm{W}}=\bar{C}_{\mathrm{F}}(t) /\left[G \times f_{\mathrm{D}}(t) \times f_{w}(t)\right]
$$

where $G$ denotes the waste dilution factor, $f_{\mathrm{D}}$ denotes the change in inventory due to radioactive decay, and $f_{w}$ denotes the reduction in inventory due to mobilization and transport in infiltrating water. By combining Eq. (6-1) and Eq. (6-2), the dose can be expressed in terms of the average concentration of radionuclides in the waste prior to disposal by

$$
H=\bar{C}_{\mathrm{W}} \times \mathrm{SDCF} \times G \times f_{\mathrm{D}}(t) \times f_{w}(t)
$$


The waste dilution factor, $G$, the radioactive decay factor, $f_{\mathrm{D}}$, and the mobilization and transport factor, $f_{w}$ and their application to the different exposure scenarios assumed in this assessment are described in the following sections.

\subsubsection{Waste Dilution Factor}

The waste dilution factor, $G$, in Eq. (6-3) is applied in the dose assessment for the agriculture, resident, and discovery scenarios. In these scenarios, an inadvertent intruder is assumed to be exposed to a volume of material that is considerably greater than the volume of an individual waste package, cask, well, silo, or trench. The waste dilution factor takes into account that the average concentrations of radionuclides to which an intruder would be exposed would be less than the average concentrations in waste prior to disposal, because the latter do not take into account the volume of any uncontaminated material in the disposal units (i.e., the volume within an envelope around the units not occupied by waste) as well as the thickness of the cap on top of the units. The uncontaminated volume within disposal units includes, for example, the volume of the walls of waste casks in the tumulus disposal units and the volume between individual silos, wells, or trenches in the below-grade disposal units. When the thickness of the cap on the disposal units is taken into account, separate waste dilution factors are needed for the pathways in the agriculture scenario involving exposure to contaminated garden soil and exposure during residence in a home on top of unshielded waste, because the average concentrations of radionuclides in waste excavated from the disposal units would be less than the average concentrations remaining in the disposal units. The waste dilution factor is not applied in the dose assessment for the post-drilling scenario because drilling through the waste is assumed to occur and the thickness of uncontaminated material between the ground surface and the depth of the aquifer is taken into account in obtaining the SDCFs for this scenario (see Sect. 6.5.2.4 of Appendix G).

The waste dilution factor for a particular disposal unit depends on the design and spacing of individual units and the particular exposure scenario. The waste dilution factors assumed in the dose assessment for the agriculture, resident, and discovery scenarios for the different disposal units are described as follows.

For Tumulus I, Tumulus $\Pi$, and the IWMF, the waste dilution factor for uncapped units is estimated to be 0.4 , based on the dimensions of individual waste vaults, the volume of each vault that is occupied by waste, and the close packing of vaults in the disposal units. That is, for an uncapped tumulus facility, $40 \%$ of the total volume of a stack of vaults would be occupied by waste. This waste dilution factor applies to the pathways for the agriculture scenario involving indoor residence on top of exposed waste and to the resident scenario, which also involves exposure to an uncovered array of waste vaults. The discovery scenario is not relevant for these disposal units (see Sect. 6.2.1 and Table 6.1).

The waste dilution factor of 0.4 for the tumulus units also would apply to the pathways for the agriculture scenario involving exposure to contaminated garden soil, because waste exhumed from the disposal units by excavation would include the uncontaminated material in the waste vaults. However, an additional waste dilution factor, given by the thickness of waste that would be exhumed during 
excavation of the foundation relative to the depth of the excavation below the ground surface, applies to these exposure pathways, because the excavated material that is mixed with garden soil would contain uncontaminated material from the cap on the disposal units as well as material from the waste vaults themselves. In this assessment, the depth of an excavation below the ground surface is assumed to be $3 \mathrm{~m}$ (Oztunali and Roles 1986), which is the maximum depth that normally should occur in digging a foundation for a home and, thus, would maximize the calculated doses for these exposure pathways. Based on the current cover design for the tumulus units (see Sect. 2.6.3.6), the distance between the top of the waste vaults and the ground surface (i.e., the thickness of the cap) is expected to be about $1.2 \mathrm{~m}$. In addition, in the waste vaults themselves, the thickness of the vault cap and grout above the waste boxes is about $0.3 \mathrm{~m}$. With these assumptions, the total thickness of uncontaminated material between the ground surface and the top layer of waste is about $1.5 \mathrm{~m}$. Therefore, the fraction of the depth of a $3-\mathrm{m}$ excavation that would be occupied by waste would be $1.5 / 3=0.5$, and the resulting waste dilution factor for the garden pathways for the agriculture scenario for these disposal units is 0.2 (i.e., $0.4 \times 0.5$ ).

For the low-range silos, high-range silos, asbestos silos, Quadrex trenches. and biological trenches, the waste dilution factor for the residence pathways for the agriculture scenario is estimated to be 0.25 , based on the dimensions and spacing of individual silos or trenches within these units. The same waste dilution factor applies to the resident and discovery scenarios for all units except the biological trenches. In addition, for the three types of silos, a concrete cap of about $0.3 \mathrm{~m}$ minimum thickness is placed on top of the waste, and the current closure plan for the SWSA 6 site calls for the addition of about $0.3 \mathrm{~m}$ of soil above these units. Therefore, the fraction of the depth of a 3-m excavation that would be occupied by waste would be $2.4 / 3=0.8$, and the resulting waste dilution factor for the garden pathways for the agriculture scenario for these disposal units is 0.2 (i.e., $0.25 \times 0.8$ ). No credit is taken in this assessment for any cover that might be put on top of the Quadrex trenches and biological trenches.

The high-range wells have about the same size and spacing as the three types of silos discussed above, and the current closure plan for the high-range wells is the same as for the silos. However, waste is placed in the high-range wells in cast iron pipes that occupy only about $30 \%$ of the interior volume of the wells. Therefore, the waste dilution factor for the residence pathways for the agriculture scenario and for the resident and discovery scenarios is estimated to be 0.075 (i.e., $0.25 \times 0.3$ ), and the waste dilution factor for the garden pathways for the agriculture scenario is estimated to be 0.06 (i.e., $0.2 \times 0.3$ ).

Finally, the fissile wells, which have approximately the same size and spacing as the various silos, require special consideration because only two such wells have received waste since DOE $O$ 5820.2A went into effect on September 26, 1988 (see Appendix A). Thus, disposals in only two fissile wells are of concern to this revised PA. For a single fissile well, the waste dilution factor for the residence pathways for the agriculture scenario and for the resident and discovery scenarios is given by the ratio of the area occupied by waste in the well to the area of a typical excavation in building a house. The area of the waste in a single fissile well is about $0.45 \mathrm{~m}^{2}$, and the area of a typical excavation is assumed to be about $300 \mathrm{~m}^{2}$ (Oztunali and Roles 1986). Therefore, the waste dilution 
factor for the two fissile wells is estimated to be about 0.003 [i.e., $(0.45 \times 2) / 300$ ]. If the same closure concept for the fissile wells is assumed as for the other below-grade engineered disposal units, the waste dilution factor for the garden pathways for the agriculture scenario is 0.0024 (i.e., $0.0030 \times 0.8$ ).

The waste dilution factors assumed in this assessment and described above are summarized in Table 6.6. For the agriculture scenario and for all disposal units except the Quadrex trenches and biological trenches, the separate waste dilution factors that are applied to the exposure pathways involving indoor residence on top of exposed waste and exposure pathways involving contaminated garden soil are denoted by $G_{r}$ and $G_{g}$, respectively. For the agriculture scenario for the Quadrex trenches and biological trenches, a single waste dilution factor, equal to the value of $G_{r}$ is applied to all exposure pathways because no credit is taken for any cover that might be placed on these units. Only a single waste dilution factor, again equal to the value of $G_{n}$ applies to the resident and discovery scenarios, and the waste dilution factor is not used in the dose assessment for the post-drilling scenario.

Taking into account the separate waste dilution factors, $G_{r}$ and $G_{g}$, for the residence and garden pathways for the agriculture scenario and the separate SDCFs for these pathways given in Table 6.2, Eq. (6-3) then can be written for the agriculture (ag) scenario as

$$
H=\bar{C}_{\mathrm{W}} \times\left(\mathrm{SDCF}_{a g, r} G_{r}+\mathrm{SDCF}_{a g, g} G_{g}\right) \times f_{\mathrm{D}}(t) \times f_{w}(t)
$$

\subsubsection{Radioactive Decay Factor}

The SDCFs in Table 6.2 through Table 6.5 do not take into account radioactive decay between the time of disposal and the time that exposures of inadvertent intruders are assumed to occur. For radionuclides without radiologically significant decay products or radionuclides with only short-lived decay products (e.g., ${ }^{90} \mathrm{Sr}$ ) that were taken into account in calculating the SDCFs, the correction for radioactive decay in Eq. (6-3) is given by

$$
f_{\mathrm{D}}(t)=\exp \left(-0.693 t / \mathrm{T}_{\mathrm{L} / 2}\right)
$$

where $T_{1 / 2}$ is the radionuclide half-life. However, when buildup of radiologically significant decay products could occur prior to the assumed time for intrusion (e.g., for ${ }^{234} \mathrm{U}$, which decays to ${ }^{230} \mathrm{Th}$ and

${ }^{226} \mathrm{Ra}$ ), the limit on the average concentration of the parent radionuclide in waste at the time of disposal is obtained by replacing the terms of the form SDCF $\times f_{\mathrm{D}}(t)$ in Eq. (6-3) and Eq. (6-4) by a sum of the products of the SDCFs and the decay factors for all radiologically significant members of the decay chain, including the parent, which can be represented by

$$
\Sigma\left[\mathrm{SDCF}_{i} \times f_{\mathrm{D}, i}(t)\right], i=\text { radionuclide index }
$$


Table 6.6. Waste dilution factors applied in dose assessment for inadvertent intruders ${ }^{a}$

\begin{tabular}{|c|c|c|c|}
\hline Disposal unit & Exposure scenario & $\begin{array}{l}\text { Waste dilution } \\
\text { factor }\end{array}$ & $\begin{array}{c}\text { Applicable exposure } \\
\text { pathways }\end{array}$ \\
\hline \multirow[t]{2}{*}{$\begin{array}{l}\text { Tumulus I, Tumulus II, } \\
\text { IWMF }\end{array}$} & Agriculture & $\begin{array}{l}G_{r}=0.4 \\
G_{g}=0.2\end{array}$ & $\begin{array}{l}\text { Residence pathways } \\
\text { Garden pathways } s^{d}\end{array}$ \\
\hline & Resident & $G=0.4$ & \\
\hline \multirow{2}{*}{$\begin{array}{l}\text { Low-range silos, } \\
\text { high-range silos, } \\
\text { asbestos silos }\end{array}$} & Agriculture & $\begin{array}{l}G_{r}=0.25 \\
G_{g}=0.2\end{array}$ & $\begin{array}{l}\text { Residence pathways } \\
\text { Garden pathways }\end{array}$ \\
\hline & $\begin{array}{l}\text { Resident, } \\
\text { Discovery }\end{array}$ & $G=0.25$ & \\
\hline \multirow[t]{2}{*}{ High-range wells } & Agriculture & $\begin{array}{c}G_{r}=0.075 \\
G_{g}=0.06\end{array}$ & $\begin{array}{l}\text { Residence pathways }{ }^{c} \\
\text { Garden pathways }^{d}\end{array}$ \\
\hline & $\begin{array}{l}\text { Resident, } \\
\text { Discovery }\end{array}$ & $G=0.075$ & \\
\hline \multirow[t]{2}{*}{ Fissile wells ${ }^{e}$} & Agriculture & $\begin{array}{c}G_{r}=0.003 \\
G_{g}=0.0024\end{array}$ & $\begin{array}{l}\text { Residence pathways } \\
\text { Garden pathways }^{d}\end{array}$ \\
\hline & $\begin{array}{l}\text { Resident, } \\
\text { Discovery }\end{array}$ & $G=0.003$ & \\
\hline \multirow[t]{2}{*}{ Quadrex trenches } & Agriculture & $G=0.25$ & All pathways ${ }^{\prime}$ \\
\hline & Resident & $G=0.25$ & \\
\hline Biological trenches & Agriculture & $G=0.25$ & All pathways ${ }^{f}$ \\
\hline
\end{tabular}

${ }^{a}$ Waste dilution factors take into account that average concentrations of radionuclides in disposal units would be less than average concentrations in waste prior to disposal due to the volume of uncontaminated material in disposal units and, for most units, thickness of cover material on top of disposal units [see Sect. 6.3.1.1 and Eq. (6-3) and Eq. $(6-4)]$.

${ }^{b}$ Consideration of particular exposure pathways in developing waste dilution factors is relevant only for agriculture scenario. For resident and discovery scenarios, only one external exposure pathway is assumed, and waste dilution factor is not relevant for post-drilling scenario.

${ }^{c}$ External and inhalation exposure pathways during indoor residence on top of unshielded waste in disposal units (see Sect. 6.1.1).

${ }^{d}$ External, ingestion, and inhalation exposure pathways resulting from mixing of waste exhumed from disposal units in garden soil (see Sect. 6.1.1).

Sect. 6.3.1.1)

${ }^{\circ}$ Only two fissile wells are considered in the performance assessment for the SWSA 6 facility (see

No credit is taken for any cover that might be placed on top of Quadrex trenches and biological trenches. 
where the decay factor $f_{\mathrm{D}, i}$ is the activity of the $i$ th radionuclide in the decay chain at time $t$ relative to the initial activity of the parent radionuclide $(i=1)$, as obtained from the Bateman equations for radioactive decay (Evans 1955).

\subsubsection{Mobilization and Transport Factor}

The factor $f_{w}$ in Eq. (6-3) and Eq. (6-4) represents the reduction in the inventory of a radionuclide in disposal units prior to the time intrusion is assumed to occur due to mobilization and transport in infiltrating water. This factor is based on a model, described in Sect. 4.1.4, that is intended to be conservative in describing retention of radionuclides in disposal units, so as not to underestimate exposures of inadvertent intruders. The model assumes (1) no transport in disposal units by diffusion, (2) a reduced rate of degradation of engineered barriers in disposal units compared with the degradation rate assumed in this revised PA for releases by water pathways, and (3) values of the distribution coefficient $\left(\mathrm{K}_{\mathrm{d}}\right)$ in waste for each element at the upper end of the expected range of values. Thus, the model for estimating inventories of radionuclides in disposal units over time for use in the dose assessment for inadvertent intruders gives calculated releases of radionuclides substantially less than the model used in this revised PA for estimating releases by water pathways.

The correction factor for mobilization and transport in infiltrating water can be applied to all disposal units and all radionuclides. However, this correction factor is potentially important only for radionuclides that (1) are sufficiently mobile that the reductions in inventory in the disposal units would be significant during the time period of 100 or 300 years prior to the time the scenarios for inadvertent intrusion are assumed to occur (see Sect. 6.1.4) or (2) are relatively immobile but are longlived and decay to radiologically significant long-lived decay products that build up in the waste only at times long after disposal.

Based on these considerations, the correction factor for mobilization and transport is considered in the dose assessment for inadvertent intruders in only two cases. First, the correction factor for relatively mobile radionuclides is taken into account in the assessment for the IWMF. In this case, the purpose of the intruder dose assessment is to develop limits on average concentrations and inventories of radionuclides for disposal, based on the performance objective for inadvertent intruders and the SDCFs for the different exposure scenarios, and application of the correction factor in the intruder dose assessment for the IWMF is potentially important in determining disposal limits for relatively mobile radionuclides. The correction factor for relatively mobile radionuclides also could be considered in the dose assessment for the other disposal units. However, the model for releases from the IWMF is not directly applicable to the other disposal units because of differences in construction. In addition, the purpose of the intruder dose assessment for the other disposal units is to demonstrate compliance with the performance objective for inadvertent intruders, based on the reported disposals of radionuclides and the SDCFs for the different exposure scenarios, and compliance generally can be demonstrated without including this correction (see Sect. 6.3.3).

Second, the correction factor for long-lived actinide radionuclides that decay to radiologically significant long-lived decay products is considered for all disposal units containing significant 
quantities of these radionuclides. Since these radionuclides are assumed to be relatively immobile, the correction factor becomes important only at times long after disposal (i.e., at times well beyond 1,000 years). At such long times, it is reasonable to assume that releases from all types of disposal units would be the same, independent of any differences in construction, based on the assumption that significant releases would occur only after the engineered barriers in the disposal units have failed. Although, in accordance with current DOE guidance (DOE 1996c), potential doses to inadvertent intruders need not be considered beyond 1,000 years after disposal, doses beyond this time are considered in this assessment for the purpose of providing an additional perspective on potential doses at times long after disposal.

Table 6.7 summarizes the values of the correction factor for mobilization and transport, $f_{w}$ assumed in this assessment for isotopes of elements that are assumed to be relatively mobile. Again, these results are applied only in the intruder dose assessment for the IWMF. Furthermore, the correction factor is applied only if two conditions are met. First, the concentration limit in waste prior to disposal that would be calculated from Eq. (6-3) or Eq. (6-4) without applying the correction factor must not exceed the solubility limit in the waste, because the correction factor would be nearly unity for any value of $K_{d}$ if the calculated concentration limit exceeds the solubility limit. Second, the correction factor is applied only when the assumed upper-bound value of $\mathrm{K}_{\mathrm{d}}$ in the waste is less than $250 \mathrm{~mL} / \mathrm{g}$. For higher assumed values of $\mathrm{K}_{\mathrm{d}}$, the correction factor would be greater than 0.9 and, thus, would not be significant. Table 6.7 gives values of the correction factor $f_{w}$ for two times (100 years and 300 years) after disposal. As discussed in Sect. 6.1.4, 300 years is the assumed time when the agriculture scenario first occurs, and 100 years is the time when the resident and post-drilling scenarios are assumed to occur. Again, the discovery scenario is not relevant for the IWMF.

Table 6.8 summarizes the assumed values of the correction factor for mobilization and transport, $f_{w}$ for isotopes of actinide elements that are relatively immobile but decay to radiologically significant long-lived decay products. Again, these correction factors apply to all disposal units. The correction factors are given as a function of time up to about $10^{6}$ years. As in obtaining the correction factors for relatively mobile elements in Table 6.7, an important condition for applying the correction factors in Table 6.8 in an intruder dose assessment is that the concentration of a radionuclide in the waste must not exceed its solubility limit.

Table 6.9 gives the assumed solubility limits of the actinide elements of concern. If the solubility limit is exceeded, then the constant release rate, also given in Table 6.9, could be applied to estimate reductions in inventory over time as a result of mobilization and transport. Again, these results are considered only to gain additional perspective on the potential long-term impacts on inadvertent intruders. They are not used in demonstrating compliance with the performance objective for inadvertent intruders because (1) compliance is evaluated only for the first 1,000 years after disposal (DOE 1996c) and (2) the correction factor for the actinide elements is negligible (i.e., $f_{w}=1$ ) during this time. 
Table 6.7. Reductions in inventory of elements in IWMF due to mobilization and transport in infiltrating water ${ }^{a}$

\begin{tabular}{lcc|lcc}
\hline & \multicolumn{2}{c|}{ Time after disposal $^{2}$} & \multicolumn{2}{c}{ Time after disposal $^{2}$} & \multicolumn{2}{c}{ Element $^{b}$} & 100 years $^{c}$ & 300 years $^{d}$ & Element $^{b}$ & 100 years $^{c}$ & 300 years $^{d}$ \\
\hline $\mathrm{H}$ & 0.68 & 0.002 & $\mathrm{Nb}$ & $e$ & 0.88 \\
$\mathrm{C}$ & 0.84 & 0.20 & $\mathrm{Tc}$ & 0.86 & 0.23 \\
$\mathrm{Cl}$ & 0.68 & 0.002 & $\mathrm{Sn}$ & $e$ & 0.77 \\
$\mathrm{~K}$ & $e$ & 0.51 & $\mathrm{I}$ & 0.68 & 0.002 \\
$\mathrm{Ni}$ & $e$ & 0.64 & $\mathrm{Cs}$ & $e$ & 0.86 \\
$\mathrm{Se}$ & $e$ & 0.86 & $\mathrm{Bi}$ & $e$ & 0.56 \\
$\mathrm{Rb}$ & $e$ & 0.80 & $\mathrm{Ra}$ & $e$ & 0.86 \\
$\mathrm{Sr}$ & $e$ & 0.71 & & & \\
\hline
\end{tabular}

Values are factor $f_{w}$ in Eq. (6-3) or Eq. (6-4) and give the fraction of initial inventory in waste remaining in the disposal facility at specified times.

${ }^{b}$ For elements not listed, reduction factor is assumed to be unity at either time.

${ }^{c}$ Assumed time of occurrence for resident and post-drilling scenarios for inadvertent intruders (see Sect. 6.1.4).

${ }^{d}$ Assumed time of first occurrence for agriculture scenario for inadvertent intruders (see Sect. 6.1.4).

"Reduction factor is greater than 0.9 and, thus, is assumed to be unity.

Table 6.8. Reductions in inventory of actinide elements in all disposal units due to mobilization and transport in water

\begin{tabular}{lcc}
\hline Elements & $\begin{array}{c}\text { Time after } \\
\text { disposal } \\
\text { (years) }\end{array}$ & $\begin{array}{c}\text { Reduction } \\
\text { factor }^{2}\end{array}$ \\
\hline Th, U, Np, Am, Cm & $1 \times 10^{3}$ & 1.0 \\
$1 \times 10^{4}$ & 0.94 \\
$3 \times 10^{4}$ & 0.84 \\
$7 \times 10^{4}$ & 0.67 \\
$1 \times 10^{5}$ & 0.56 \\
$2 \times 10^{5}$ & 0.31 \\
$3 \times 10^{5}$ & 0.17 \\
$5 \times 10^{5}$ & 0.055 \\
$7 \times 10^{5}$ & 0.02 \\
\hline
\end{tabular}

${ }^{a}$ Values are factor $f_{w}$ in Eq. (6-3) or Eq. (6-4) and give fraction of initial inventory in waste remaining in the disposal facility at specified times. 
Table 6.9. Solubility limits and solubility-limited release rates of actinide elements

for all disposal units

\begin{tabular}{lcc}
\hline Element & $\begin{array}{c}\text { Solubility limit in } \\
\text { waste } \\
\left(\mathrm{g} / \mathrm{m}^{3}\right)\end{array}$ & $\begin{array}{c}\text { Release rate at } \\
\text { solubility limit } \\
\left(\mathrm{g} / \mathrm{m}^{3} \text {-year) }\right.\end{array}$ \\
\hline $\mathrm{Th}, \mathrm{Np}$ & $4.2 \times 10^{1}$ & $2.6 \times 10^{-4}$ \\
$\mathrm{U}$ & $4.2 \times 10^{\circ}$ & $2.6 \times 10^{-5}$ \\
$\mathrm{Pu}, \mathrm{Cm}$ & $1.5 \times 10^{\circ}$ & $6.0 \times 10^{-5}$ \\
\hline
\end{tabular}

${ }^{a}$ Calculated values apply only at times after engineered barriers have failed and natural infiltration rate of water occurs.

\subsubsection{Intruder Dose Assessment for IWMF}

This section presents the results of the intruder dose assessment for the IWMF. The dose assessment for the IWMF is used to calculate limits on allowable average concentrations and inventories of radionuclides for disposal based on the performance objective for inadvertent intruders given at the beginning of Chapter 6 and the SDCFs for the agriculture, resident, and post-drilling scenarios given in Table 6.2 through Table 6.4. In addition, the waste dilution factors summarized in Table 6.6, the correction factor for radioactive decay discussed in Sect. 6.3.1.2, and the correction factors for mobilization and transport in water given in Table 6.7 are used in calculating the disposal limits for the IWMF based on the intruder dose assessment.

For the agriculture scenario, the calculated limits on average concentrations of radionuclides in waste prior to disposal for the IWMF are obtained from Eq. (6-4) as

$$
\bar{C}_{\mathrm{W}}=(0.1 \mathrm{rem} / \mathrm{yr}) /\left[\left(\mathrm{SDCF}_{a g, r} G_{r}+\mathrm{SDCF}_{a g, g} G_{g}\right) \times f_{\mathrm{D}}(t) \times f_{w}(t)\right]
$$

where the numerator is the performance objective for inadvertent intruders for scenarios involving continuous exposure. For the resident and post-drilling scenarios, the calculated concentration limits are obtained from Eq. (6-3) as

$$
\bar{C}_{\mathrm{W}}=(0.1 \mathrm{rem} / \mathrm{yr}) /\left[\mathrm{SDCF} \times G \times f_{\mathrm{D}}(t) \times f_{\mathrm{w}}(t)\right]
$$

In this assessment, each disposal pad in the IWMF is treated as a separate disposal unit for purposes of developing limits on inventories of radionuclides in waste prior to disposal. Each pad is assumed to contain 330 vaults, and each vault is assumed to have a waste volume of $2.6 \mathrm{~m}^{3}$. Therefore, the total volume of disposed waste per pad is assumed to be $860 \mathrm{~m}^{3}$. If the limit on average concentration of radionuclides on each pad calculated from Eq. (6-7) or Eq. (6-8) is in units of $\mu \mathrm{Ci} / \mathrm{m}^{3}$, the limit on allowable inventory of a radionuclide per pad is given by 


$$
I_{\mathrm{W}}(\mathrm{Ci})=\bar{C}_{\mathrm{w}}\left(\mu \mathrm{Ci} / \mathrm{m}^{3}\right) \times\left(10^{-6} \mu \mathrm{Ci} / \mathrm{Ci}\right) \times\left(860 \mathrm{~m}^{3}\right)=\left(8.6 \times 10^{-4}\right) \bar{C}_{\mathrm{w}}\left(\mu \mathrm{Ci} / \mathrm{m}^{3}\right)
$$

\subsubsection{Results for Agriculture Scenario}

Table 6.10 gives the limits on allowable average concentrations and inventories of radionuclides in waste prior to disposal based on the dose assessment for the agriculture scenario for the IWMF described above. Some of these results are described further as follows.

First, for the radionuclides ${ }^{60} \mathrm{Co},{ }^{87} \mathrm{Rb},{ }^{155} \mathrm{Eu},{ }^{194} \mathrm{OS}$, and ${ }^{228} \mathrm{Ra}$, the calculated limits on allowable concentrations exceed the specific activity of the radionuclide. Therefore, there is no disposal limit for these radionuclides based on the dose assessment for the agriculture scenario. The half-lives of ${ }^{60} \mathrm{Co},{ }^{155} \mathrm{Eu},{ }^{194} \mathrm{Os}$, and ${ }^{228} \mathrm{Ra}$ are very short compared with the assumed time of occurrence for the agriculture scenario of 300 years, and ${ }^{87} \mathrm{Rb}$ has a very long half-life (i.e., very low specific activity) and a low SDCF for this scenario.

Second, for the radionuclides ${ }^{93} \mathrm{Zr}$, ${ }^{226} \mathrm{Ra},{ }^{232} \mathrm{Th}$, and ${ }^{231} \mathrm{~Pa}$, the shorter-lived decay products, ${ }^{93 \mathrm{~m}} \mathrm{Nb},{ }^{210} \mathrm{~Pb},{ }^{228} \mathrm{Ra}$, and ${ }^{227} \mathrm{Ac}$, respectively, are assumed to be in activity equilibrium with the parent radionuclide. Therefore, the SDCFs for these radionuclides are the sum of the values for the parent and its decay product. The radionuclide ${ }^{242 \mathrm{~m}} \mathrm{Am}$ also decays to the shorter-lived radionuclide ${ }^{238} \mathrm{Pu}$, but the activity of the decay product at 300 years after disposal is somewhat greater than the activity of the parent and this difference is taken into account in calculating the limits on allowable disposals.

Third, for the radionuclides ${ }^{226} \mathrm{Ra},{ }^{230} \mathrm{Th},{ }^{232} \mathrm{Th},{ }^{232} \mathrm{U},{ }^{234} \mathrm{U}$, and ${ }^{238} \mathrm{U}$, all of which decay to radon (i.e., ${ }^{222} \mathrm{Rn}$ or ${ }^{220} \mathrm{Rn}$ ), the calculated disposal limits do not include contributions to dose from inhalation of radon and its short-lived decay products. In accordance with current DOE guidance (DOE 1996c), the performance objective for inadvertent intruders is assumed to exclude any contributions to dose from radon. The effect of including radon in the dose assessment is considered later in this section.

Fourth, for the radionuclides ${ }^{230} \mathrm{Th},{ }^{233} \mathrm{U},{ }^{234} \mathrm{U},{ }^{235} \mathrm{U},{ }^{238} \mathrm{U},{ }^{237} \mathrm{~Np},{ }^{245} \mathrm{Cm}$, and ${ }^{247} \mathrm{Cm}$, the buildup of radiologically significant long-lived decay products in the waste over time is taken into account. Because each of these radionuclides is long-lived and immobile, the maximum dose during the compliance period of 1,000 years after disposal (DOE 1996c) occurs at 1,000 years, and the calculated disposal limits are based on the estimated dose at this time. For ${ }^{238} \mathrm{U}$ and ${ }^{237} \mathrm{~Np}$, however, the contribution to dose at 1,000 years from the decay products is insignificant. The effect of extending the dose calculations beyond the compliance period of 1,000 years is considered later in this section.

Finally, for the relatively short-lived radionuclides ${ }^{241} \mathrm{Pu},{ }^{244} \mathrm{Cm}$, and ${ }^{250} \mathrm{Cf}$, the allowable limits on disposals are determined by the disposal limits for their longer-lived decay products, ${ }^{241} \mathrm{Am},{ }^{240} \mathrm{Pu}$, and ${ }^{246} \mathrm{Cm}$, respectively. That is, taking into account the assumption that the agriculture scenario first occurs at 300 years after disposal and the half-lives of the parent radionuclides and their longer-lived decay products, the dose from the decay product is greater than the dose from the parent itself. For the relatively short-lived radionuclide ${ }^{243} \mathrm{Cm}$, the dose from the longer-lived decay product ${ }^{239} \mathrm{Pu}$ also was 
Table 6.10. Allowable limits on concentrations and inventories of radionuclides for IWMF based on agriculture scenario for inadvertent intruders ${ }^{a}$

\begin{tabular}{|c|c|c|c|c|c|}
\hline Nuclide $^{b}$ & $\begin{array}{c}\mathrm{SDCF} \times G \\
\left(\text { rem/year per } \mu \mathrm{Ci} / \mathrm{m}^{3}\right)^{c}\end{array}$ & $f_{\mathrm{D}}^{d}$ & $f_{w}^{e}$ & $\begin{array}{c}\bar{C}_{\mathrm{w}} \\
\left(\mu \mathrm{Ci} / \mathrm{m}^{3}\right)^{\gamma}\end{array}$ & $\begin{array}{l}\text { Inventory } \\
(\mathrm{Ci} / \mathrm{pad})^{g}\end{array}$ \\
\hline${ }^{3} \mathrm{H}$ & $8.0 \times 10^{-3}$ & $4.5 \times 10^{-8}$ & $2.0 \times 10^{-3}$ & $1.4 \times 10^{15}$ & $1.2 \times 10^{12}$ \\
\hline${ }^{10} \mathrm{Be}$ & $1.7 \times 10^{-8}$ & $1.0 \times 10^{\circ}$ & $1.0 \times 10^{\circ}$ & $5.9 \times 10^{6}$ & $5.1 \times 10^{3}$ \\
\hline${ }^{14} \mathrm{C}$ & $3.0 \times 10^{-6}$ & $9.6 \times 10^{-1}$ & $2.0 \times 10^{-1}$ & $1.7 \times 10^{5}$ & $1.5 \times 10^{2}$ \\
\hline${ }^{26} \mathrm{Al}$ & $1.6 \times 10^{-3}$ & $1.0 \times 10^{0}$ & $1.0 \times 10^{0}$ & $6.4 \times 10^{2}$ & $5.5 \times 10^{-2}$ \\
\hline${ }^{36} \mathrm{Cl}$ & $2.4 \times 10^{-4}$ & $1.0 \times 10^{\circ}$ & $2.0 \times 10^{-3}$ & $2.1 \times 10^{5}$ & $1.8 \times 10^{2}$ \\
\hline${ }^{40} \mathrm{~K}$ & $1.0 \times 10^{-4}$ & $1.0 \times 10^{\circ}$ & $5.1 \times 10^{-1}$ & $2.0 \times 10^{3}$ & $1.7 \times 10^{0}$ \\
\hline${ }^{41} \mathrm{Ca}$ & $5.0 \times 10^{-7}$ & $1.0 \times 10^{0}$ & $1.0 \times 10^{0}$ & $2.0 \times 10^{5}$ & $1.7 \times 10^{2}$ \\
\hline${ }^{60} \mathrm{Co}$ & $1.4 \times 10^{-3}$ & $6.3 \times 10^{-18}$ & $1.0 \times 10^{\circ}$ & No limit & No limit \\
\hline${ }^{59} \mathrm{Ni}$ & $1.4 \times 10^{-8}$ & $1.0 \times 10^{0}$ & $6.4 \times 10^{-1}$ & $1.1 \times 10^{7}$ & $9.6 \times 10^{3}$ \\
\hline${ }^{63} \mathrm{Ni}$ & $4.0 \times 10^{-8}$ & $1.3 \times 10^{-1}$ & $6.4 \times 10^{-1}$ & $3.0 \times 10^{7}$ & $2.6 \times 10^{4}$ \\
\hline${ }^{79} \mathrm{Se}$ & $2.4 \times 10^{-7}$ & $1.0 \times 10^{\circ}$ & $8.6 \times 10^{-1}$ & $4.8 \times 10^{5}$ & $4.2 \times 10^{2}$ \\
\hline${ }^{87} \mathrm{Rb}$ & $3.8 \times 10^{-7}$ & $1.0 \times 10^{\circ}$ & $8.0 \times 10^{-1}$ & No limit ${ }^{h}$ & No limit \\
\hline${ }^{90} \mathrm{Sr}$ & $4.0 \times 10^{-5}$ & $6.8 \times 10^{-4}$ & $7.1 \times 10^{-1}$ & $5.2 \times 10^{6}$ & $4.5 \times 10^{3}$ \\
\hline${ }^{93} \mathrm{Zr}^{3}$ & $1.0 \times 10^{-8}$ & $1.0 \times 10^{0}$ & $1.0 \times 10^{\circ}$ & $1.0 \times 10^{7}$ & $8.6 \times 10^{3}$ \\
\hline${ }^{93 \mathrm{~m}} \mathrm{Nb}$ & $3.9 \times 10^{-9}$ & $2.3 \times 10^{-7}$ & $8.8 \times 10^{-1}$ & $1.3 \times 10^{14}$ & $1.1 \times 10^{11}$ \\
\hline${ }^{94} \mathrm{Nb}$ & $8.4 \times 10^{-4}$ & $1.0 \times 10^{\circ}$ & $8.8 \times 10^{-1}$ & $1.4 \times 10^{2}$ & $1.1 \times 10^{-1}$ \\
\hline${ }^{99} \mathrm{Tc}$ & $2.6 \times 10^{-6}$ & $1.0 \times 10^{0}$ & $2.3 \times 10^{-1}$ & $1.7 \times 10^{5}$ & $1.4 \times 10^{2}$ \\
\hline${ }^{107} \mathrm{Pd}$ & $6.9 \times 10^{-9}$ & $1.0 \times 10^{\circ}$ & $1.0 \times 10^{\circ}$ & $1.4 \times 10^{7}$ & $1.2 \times 10^{4}$ \\
\hline${ }^{113 m} \mathrm{Cd}$ & $2.8 \times 10^{-5}$ & $2.6 \times 10^{-7}$ & $1.0 \times 10^{\circ}$ & $1.4 \times 10^{10}$ & $1.2 \times 10^{7}$ \\
\hline${ }^{121 \mathrm{Im}} \mathrm{Sn}$ & $1.8 \times 10^{-7}$ & $2.3 \times 10^{-2}$ & $7.7 \times 10^{-1}$ & $3.1 \times 10^{7}$ & $2.7 \times 10^{4}$ \\
\hline${ }^{126} \mathrm{Sn}$ & $1.0 \times 10^{-3}$ & $1.0 \times 10^{\circ}$ & $7.7 \times 10^{-1}$ & $1.2 \times 10^{2}$ & $1.1 \times 10^{-1}$ \\
\hline${ }^{129} \mathrm{I}$ & $1.8 \times 10^{-5}$ & $1.0 \times 10^{0}$ & $2.0 \times 10^{-3}$ & $2.8 \times 10^{6}$ & $2.4 \times 10^{3}$ \\
\hline${ }^{135} \mathrm{Cs}$ & $2.4 \times 10^{-7}$ & $1.0 \times 10^{0}$ & $8.6 \times 10^{-1}$ & $4.8 \times 10^{5}$ & $4.2 \times 10^{2}$ \\
\hline${ }^{137} \mathrm{Cs}$ & $3.0 \times 10^{-4}$ & $9.8 \times 10^{-4}$ & $8.6 \times 10^{-1}$ & $4.0 \times 10^{5}$ & $3.4 \times 10^{2}$ \\
\hline${ }^{151} \mathrm{Sm}$ & $5.7 \times 10^{-9}$ & $9.9 \times 10^{-2}$ & $1.0 \times 10^{0}$ & $1.8 \times 10^{8}$ & $1.5 \times 10^{5}$ \\
\hline${ }^{152} \mathrm{Eu}$ & $6.0 \times 10^{-4}$ & $1.6 \times 10^{-7}$ & $1.0 \times 10^{0}$ & $1.0 \times 10^{9}$ & $9.0 \times 10^{5}$ \\
\hline
\end{tabular}


Table 6.10. (continued) ${ }^{a}$

\begin{tabular}{|c|c|c|c|c|c|}
\hline Nuclide $^{b}$ & $\begin{array}{c}\text { SDCF } \times G \\
\left(\text { rem/year per } \mu \mathrm{Ci} / \mathrm{m}^{3}\right)^{c} \\
\end{array}$ & $f_{\mathrm{D}}^{d}$ & $f_{w}^{e}$ & $\begin{array}{c}C_{\mathrm{w}} \\
\left(\mu \mathrm{Ci} / \mathrm{m}^{3}\right)^{\gamma}\end{array}$ & $\begin{array}{l}\text { Inventory } \\
\text { (Ci/pad)s }\end{array}$ \\
\hline${ }^{154} \mathrm{Eu}$ & $6.8 \times 10^{-4}$ & $5.4 \times 10^{-11}$ & $1.0 \times 10^{0}$ & $2.7 \times 10^{12}$ & $2.3 \times 10^{9}$ \\
\hline${ }^{155} \mathrm{Eu}$ & $1.6 \times 10^{-5}$ & $5.7 \times 10^{-19}$ & $1.0 \times 10^{\circ}$ & No limit & No limit \\
\hline${ }^{194} \mathrm{Os}$ & $6.2 \times 10^{-8}$ & $8.9 \times 10^{-16}$ & $1.0 \times 10^{\circ}$ & No limith & No limit \\
\hline${ }^{207} \mathrm{Bi}$ & $8.4 \times 10^{-4}$ & $1.6 \times 10^{-3}$ & $5.6 \times 10^{-1}$ & $1.3 \times 10^{5}$ & $1.1 \times 10^{2}$ \\
\hline${ }^{210} \mathrm{~Pb}$ & $6.2 \times 10^{-5}$ & $8.9 \times 10^{-5}$ & $1.0 \times 10^{0}$ & $1.8 \times 10^{7}$ & $1.6 \times 10^{4}$ \\
\hline${ }^{226} \mathrm{Ra}^{j}$ & $1.0 \times 10^{-3 k}$ & $8.8 \times 10^{-1}$ & $8.6 \times 10^{-1}$ & $1.3 \times 10^{2}$ & $1.1 \times 10^{-1}$ \\
\hline${ }^{228} \mathrm{Ra}$ & $1.4 \times 10^{-3 k}$ & $2.0 \times 10^{-16}$ & $8.6 \times 10^{-1}$ & No limith & No limit \\
\hline${ }^{227} \mathrm{Ac}$ & $2.4 \times 10^{-4}$ & $7.1 \times 10^{-5}$ & $1.0 \times 10^{\circ}$ & $5.9 \times 10^{6}$ & $5.1 \times 10^{3}$ \\
\hline${ }^{229} \mathrm{Th}$ & $1.7 \times 10^{-4}$ & $9.7 \times 10^{-1}$ & $1.0 \times 10^{\circ}$ & $6.1 \times 10^{2}$ & $5.2 \times 10^{-1}$ \\
\hline${ }^{230} \mathrm{Th}^{m}$ & $\begin{array}{l}3.7 \times 10^{-6} \\
1.0 \times 10^{-3 k}\end{array}$ & $\begin{array}{l}9.9 \times 10^{-1} \\
3.5 \times 10^{-1}\end{array}$ & $1.0 \times 10^{0}$ & $2.9 \times 10^{2}$ & $2.5 \times 10^{-1}$ \\
\hline${ }^{232} \mathrm{Th}^{n}$ & $1.4 \times 10^{-3 k}$ & $1.0 \times 10^{0}$ & $1.0 \times 10^{\circ}$ & $7.1 \times 10^{1}$ & $6.1 \times 10^{-2}$ \\
\hline${ }^{231} \mathrm{~Pa}^{\circ}$ & $3.0 \times 10^{-4}$ & $1.0 \times 10^{0}$ & $1.0 \times 10^{\circ}$ & $3.3 \times 10^{2}$ & $2.9 \times 10^{-1}$ \\
\hline${ }^{232} \mathrm{U}$ & $8.9 \times 10^{-4 k}$ & $4.8 \times 10^{-2}$ & $1.0 \times 10^{\circ}$ & $2.3 \times 10^{3}$ & $2.0 \times 10^{0}$ \\
\hline${ }^{233} \mathrm{U}^{m}$ & $\begin{array}{l}3.2 \times 10^{-6} \\
1.7 \times 10^{-4}\end{array}$ & $\begin{array}{l}1.0 \times 10^{0} \\
9.0 \times 10^{-2}\end{array}$ & $1.0 \times 10^{\circ}$ & $5.6 \times 10^{3}$ & $4.8 \times 10^{0}$ \\
\hline $\begin{array}{l}{ }^{234} \mathrm{U}^{m} \\
{ }^{230} \mathrm{Th} \\
{ }^{226} \mathrm{Ra}^{j}\end{array}$ & $\begin{array}{l}3.1 \times 10^{-6} \\
3.7 \times 10^{-6} \\
1.0 \times 10^{-3 k}\end{array}$ & $\begin{array}{l}1.0 \times 10^{0} \\
8.9 \times 10^{-3} \\
1.7 \times 10^{-3}\end{array}$ & $1.0 \times 10^{0}$ & $2.1 \times 10^{4}$ & $1.8 \times 10^{1}$ \\
\hline${ }^{235} \mathrm{U}^{m} \mathrm{~Pa}^{o}$ & $\begin{array}{l}6.6 \times 10^{-5} \\
3.0 \times 10^{-4}\end{array}$ & $\begin{array}{l}1.0 \times 10^{0} \\
2.1 \times 10^{-2}\end{array}$ & $1.0 \times 10^{\circ}$ & $1.4 \times 10^{3}$ & $1.2 \times 10^{\circ}$ \\
\hline${ }^{236} \mathrm{U}$ & $3.0 \times 10^{-6}$ & $1.0 \times 10^{0}$ & $1.0 \times 10^{0}$ & $3.3 \times 10^{4}$ & $2.9 \times 10^{1}$ \\
\hline $\begin{array}{l}{ }^{238} \mathrm{U}^{m} \\
{ }^{234} \mathrm{U} \\
{ }^{230} \mathrm{Th} \\
{ }^{226} \mathrm{Ra}^{j}\end{array}$ & $\begin{array}{l}1.4 \times 10^{-5} \\
3.1 \times 10^{-6} \\
3.7 \times 10^{-6} \\
1.0 \times 10^{-3 k}\end{array}$ & $\begin{array}{l}1.0 \times 10^{0} \\
2.8 \times 10^{-3} \\
1.3 \times 10^{-5} \\
1.7 \times 10^{-6}\end{array}$ & $1.0 \times 10^{0}$ & $7.1 \times 10^{3}$ & $6.1 \times 10^{0}$ \\
\hline $\begin{array}{l}{ }^{237}{ }^{233} \mathrm{Up} \\
{ }^{229} \mathrm{Th}\end{array}$ & $\begin{array}{l}1.6 \times 10^{-4} \\
3.2 \times 10^{-6} \\
1.7 \times 10^{-4}\end{array}$ & $\begin{array}{l}1.0 \times 10^{0} \\
4.3 \times 10^{-3} \\
2.0 \times 10^{-4}\end{array}$ & $1.0 \times 10^{0}$ & $6.3 \times 10^{2}$ & $5.4 \times 10^{-1}$ \\
\hline${ }^{238} \mathrm{Pu}$ & $8.0 \times 10^{-6}$ & $9.3 \times 10^{-2}$ & $1.0 \times 10^{0}$ & $1.3 \times 10^{5}$ & $1.2 \times 10^{2}$ \\
\hline
\end{tabular}


Table 6.10. (continued) ${ }^{a}$

\begin{tabular}{|c|c|c|c|c|c|}
\hline Nuclide $^{b}$ & $\begin{array}{c}\text { SDCF } \times G \\
\left(\text { rem/year per } \mu \mathrm{Ci} / \mathrm{m}^{3}\right)^{c}\end{array}$ & $f_{D}^{d}$ & $f_{w}^{e}$ & $\begin{array}{c}C_{\mathrm{w}} \\
\left(\mu \mathrm{Ci} / \mathrm{m}^{3}\right)^{f}\end{array}$ & $\begin{array}{l}\text { Inventory } \\
(\mathrm{Ci} / \text { pad })^{g}\end{array}$ \\
\hline${ }^{239} \mathrm{Pu}$ & $8.8 \times 10^{-6}$ & $9.9 \times 10^{-1}$ & $1.0 \times 10^{\circ}$ & $1.1 \times 10^{4}$ & $9.9 \times 10^{0}$ \\
\hline${ }^{240} \mathrm{Pu}$ & $8.8 \times 10^{-6}$ & $9.7 \times 10^{-1}$ & $1.0 \times 10^{0}$ & $1.2 \times 10^{4}$ & $1.0 \times 10^{1}$ \\
\hline${ }^{241} \mathrm{Pu}$ & $1.7 \times 10^{-7}$ & $5.4 \times 10^{-7}$ & $1.0 \times 10^{\circ}$ & $\begin{array}{l}1.1 \times 10^{12} \\
3.5 \times 10^{5 p}\end{array}$ & $\begin{array}{l}9.4 \times 10^{8} \\
3.0 \times 10^{2 p}\end{array}$ \\
\hline${ }^{242} \mathrm{Pu}$ & $8.6 \times 10^{-6}$ & $1.0 \times 10^{0}$ & $1.0 \times 10^{0}$ & $1.2 \times 10^{4}$ & $1.0 \times 10^{1}$ \\
\hline${ }^{244} \mathrm{Pu}$ & $1.9 \times 10^{-4}$ & $1.0 \times 10^{\circ}$ & $1.0 \times 10^{\circ}$ & $5.3 \times 10^{2}$ & $4.6 \times 10^{-1}$ \\
\hline${ }^{241} \mathrm{Am}$ & $1.4 \times 10^{-5}$ & $6.2 \times 10^{-1}$ & $1.0 \times 10^{\circ}$ & $1.2 \times 10^{4}$ & $9.9 \times 10^{0}$ \\
\hline${ }^{238} \mathrm{Pu}$ & $\begin{array}{l}1.6 \times 10^{-5} \\
8.0 \times 10^{-6}\end{array}$ & $\begin{array}{l}2.3 \times 10^{-1} \\
3.6 \times 10^{-1}\end{array}$ & $1.0 \times 10^{0}$ & $1.5 \times 10^{4}$ & $1.3 \times 10^{1}$ \\
\hline${ }^{243} \mathrm{Am}$ & $8.9 \times 10^{-5}$ & $9.7 \times 10^{-1}$ & $1.0 \times 10^{0}$ & $1.2 \times 10^{3}$ & $1.0 \times 10^{0}$ \\
\hline${ }^{243} \mathrm{Cm}$ & $5.9 \times 10^{-5}$ & $6.8 \times 10^{-4}$ & $1.0 \times 10^{\circ}$ & $2.5 \times 10^{6 q}$ & $2.1 \times 10^{3 q}$ \\
\hline${ }^{244} \mathrm{Cm}$ & $5.1 \times 10^{-6}$ & $1.0 \times 10^{-5}$ & $1.0 \times 10^{\circ}$ & $\begin{array}{l}2.0 \times 10^{9} \\
4.2 \times 10^{6 r}\end{array}$ & $\begin{array}{l}1.7 \times 10^{6} \\
3.6 \times 10^{3 r}\end{array}$ \\
\hline${ }^{245} \mathrm{Cm}^{m} \mathrm{Am}$ & $\begin{array}{l}3.9 \times 10^{-5} \\
1.4 \times 10^{-5}\end{array}$ & $\begin{array}{l}9.2 \times 10^{-1} \\
7.5 \times 10^{-1}\end{array}$ & $1.0 \times 10^{\circ}$ & $2.1 \times 10^{3}$ & $1.8 \times 10^{\circ}$ \\
\hline${ }^{246} \mathrm{Cm}$ & $9.4 \times 10^{-6}$ & $9.6 \times 10^{-1}$ & $1.0 \times 10^{\circ}$ & $1.1 \times 10^{4}$ & $9.5 \times 10^{0}$ \\
\hline${ }^{247} \mathrm{Cm}^{m} \mathrm{Am}$ & $\begin{array}{l}1.6 \times 10^{-4} \\
8.9 \times 10^{-5}\end{array}$ & $\begin{array}{l}1.0 \times 10^{0} \\
9.0 \times 10^{-2}\end{array}$ & $1.0 \times 10^{\circ}$ & $5.8 \times 10^{2}$ & $5.1 \times 10^{-1}$ \\
\hline${ }^{248} \mathrm{Cm}$ & $3.5 \times 10^{-5}$ & $1.0 \times 10^{0}$ & $1.0 \times 10^{\circ}$ & $2.9 \times 10^{3}$ & $2.5 \times 10^{0}$ \\
\hline${ }^{249} \mathrm{Cf}$ & $1.8 \times 10^{-4}$ & $5.5 \times 10^{-1}$ & $1.0 \times 10^{0}$ & $1.0 \times 10^{3}$ & $8.7 \times 10^{-1}$ \\
\hline${ }^{250} \mathrm{Cf}$ & $5.2 \times 10^{-6}$ & $1.3 \times 10^{-7}$ & $1.0 \times 10^{\circ}$ & $\begin{array}{l}1.5 \times 10^{11} \\
4.0 \times 10^{6 s}\end{array}$ & $\begin{array}{l}1.3 \times 10^{8} \\
3.4 \times 10^{3 s}\end{array}$ \\
\hline${ }^{251} \mathrm{Cf}$ & $6.1 \times 10^{-5}$ & $7.9 \times 10^{-1}$ & $1.0 \times 10^{\circ}$ & $2.1 \times 10^{3}$ & $1.8 \times 10^{0}$ \\
\hline
\end{tabular}




\section{Footnotes for Table 6.10}

${ }^{a}$ Allowable limits on average concentrations and inventories are calculated from Eq. (6-7) and Eq. (6-9),

respectively; unless otherwise noted, time of occurrence for agriculture scenario is assumed to be 300 years after disposal.

${ }^{\circ}$ Indented entries are radiologically significant long-lived decay products of parent radionuclide.

${ }^{\circ} \mathrm{Calculated}$ as $\mathrm{SDCF}_{a g . g} G_{g}+\mathrm{SDCF}_{a g . r} G_{n}$ where scenario dose conversion factors (SDCFs) for garden $(g)$ and residence $(r)$ exposure pathways for agriculture scenario are obtained from Table 6.2 and corresponding waste dilution factors $(G)$ are obtained from Table 6.6.

${ }^{d}$ Radionuclide inventory at time agriculture scenario is assumed to occur relative to inventory at time of disposal due to radioactive decay. For long-lived decay products listed with some radionuclides, factor gives inventory of decay product relative to initial inventory of parent radionuclide.

'Radionuclide inventory at time agriculture scenario is assumed to occur relative to inventory at time of disposal due to mobilization and transport in infiltrating water obtained from Table 6.7.

Limit on allowable average concentration of radionuclide in waste prior to disposal.

${ }^{g}$ Limit on allowable inventory of radionuclide in waste prior to disposal for individual disposal pads in IWMF, based on assumption of 330 vaults per pad and waste volume per vault of $2.6 \mathrm{~m}^{3}$.

${ }^{h}$ Calculated limit exceeds specific activity of radionuclide.

iCalculated limits include contribution from ${ }^{93 \mathrm{~m}} \mathrm{Nb}$ decay product, which is assumed to be in activity equilibrium with parent radionuclide.

${ }^{j}$ Calculated limits include contribution from ${ }^{210} \mathrm{~Pb}$ decay product, which is assumed to be in activity equilibrium with parent radionuclide.

${ }^{k}$ Contribution from radon decay product is excluded.

${ }^{m}$ Calculated limits are based on dose assessment at 1,000 years after disposal, in accordance with current DOE guidance (DOE 1996c); calculated dose increases beyond 1,000 years, due to buildup of radiologically significant longlived decay products.

${ }^{n} \mathrm{Calculated} \mathrm{limits} \mathrm{include} \mathrm{contribution} \mathrm{from}{ }^{228} \mathrm{Ra}$ decay product, which is assumed to be in activity equilibrium with parent radionuclide.

${ }^{\circ} \mathrm{Calculated}$ limits include contribution from ${ }^{227} \mathrm{Ac}$ decay product, which is assumed to be in activity equilibrium with parent radionuclide. radionuclide.

${ }^{p}$ Value is 30 times limit for ${ }^{241}$ Am decay product, based on ratio of half-lives of decay product and parent

"Limit based on exposure to parent radionuclide is more restrictive than 850 times limit for exposure to ${ }^{239} \mathrm{Pu}$ decay product, based on ratio of half-lives of decay product and parent radionuclide. radionuclide.

Value is 360 times limit for ${ }^{240} \mathrm{Pu}$ decay product, based on ratio of half-lives of decay product and parent radionuclide.

Value is 360 times limit for ${ }^{246} \mathrm{Cm}$ decay product, based on ratio of half-lives of decay product and parent

considered. However, the half-life of the parent radionuclide is sufficiently long in this case that the dose from the parent is greater than the dose from the decay product, and the disposal limits are based on the dose from the parent only.

As discussed previously, the disposal limits in Table 6.10 are based on the assumptions that (1) the contribution to dose from radon can be excluded and (2) the performance objective for inadvertent intruders only applies for 1,000 years after disposal. These assumptions have a significant effect on the calculated disposal limits for radionuclides that decay to radon or that decay to radiologically significant long-lived decay products. If the dose from radon were included and there were no time constraint for applying the performance objective, and if the correction factors for mobilization and transport in water given in Table 6.8 or the solubility limits given in Table 6.9 were taken into account, the results described below would be obtained. 
- $\quad$ For ${ }^{226} \mathrm{Ra}$, including the dose from radon would decrease the disposal limits by a factor of about 50 , but removing the time constraint for applying the performance objective would have no effect.

- For ${ }^{230} \mathrm{Th}$, the maximum dose would occur at about 10,000 years after disposal. Including the dose from radon at this time would decrease the disposal limits by a factor of about 130, but excluding the dose from radon at this time would decrease the limits by a factor of about 3 .

- For ${ }^{232} \mathrm{Th}$, including the dose from radon would decrease the disposal limits by a factor of about 4 , but removing the time constraint for applying the performance objective would have no effect.

- $\quad$ For ${ }^{232} \mathrm{U}$, including the dose from radon would decrease the disposal limits by a factor of about 5 , but removing the time constraint for applying the performance objective would have no effect.

- For ${ }^{233} \mathrm{U}$, the maximum dose would occur at about 20,000 years after disposal, and the disposal limits would decrease by a factor of about 6 .

- For ${ }^{234} \mathrm{U}$, the maximum dose would occur at about 100,000 years after disposal. Including the dose from radon at this time would decrease the disposal limits by a factor of about 1,000 , but excluding the dose from radon at this time would decrease the limits by a factor of about 20 .

- For ${ }^{235} \mathrm{U}$, the concentration limit bàsed on the assessment at 1,000 years after disposal is much greater than the solubility limit in water. Therefore, the maximum dose would occur at times beyond 100,000 years when the ${ }^{231} \mathrm{~Pa}$ decay product essentially would be in activity equilibrium, and the disposal limits would decrease by a factor of about 6 .

- For ${ }^{238} \mathrm{U}$, the concentration limit based on the assessment at 1,000 years after disposal is much greater than the solubility limit in water. Therefore, the maximum dose would occur at times beyond one million years when the ${ }^{234} \mathrm{U},{ }^{230} \mathrm{Th}$, and ${ }^{226} \mathrm{Ra}$ decay products essentially would be in activity equilibrium. Including the dose from radon at these times would decrease the disposal limits by a factor of about 3,000 , but excluding the dose from radon at these times would decrease the limits by a factor of about 70 .

- $\quad$ For ${ }^{237} \mathrm{~Np}$, removing the time constraint for applying the performance objective would have no effect on the disposal limits, because buildup of the ${ }^{233} \mathrm{U}$ and ${ }^{229} \mathrm{Th}$ decay products beyond 1,000 years increases the dose more slowly than the decrease in dose due to mobilization and transport of the ${ }^{237} \mathrm{~Np}$ in water. 
- For ${ }^{245} \mathrm{Cm}$, removing the time constraint for applying the performance objective would have no effect on the disposal limits, because buildup of the ${ }^{241} \mathrm{Am}$ decay product beyond 1,000 years increases the dose more slowly than the decrease in dose due to decay of the ${ }^{245} \mathrm{Cm}$ in the disposal units.

- $\quad$ For ${ }^{247} \mathrm{Cm}$, the maximum dose would occur at about 10,000 years after disposal, and the disposal limits would decrease by about $20 \%$.

\subsubsection{Results for Resident Scenario}

Table 6.11 gives the limits on allowable average concentrations and inventories of radionuclides in waste prior to disposal based on the dose assessment for the resident scenario for the IWMF. These results were calculated from Eq. (6-8) and Eq. (6-9) using the SDCFs in Table 6.3, the waste dilution factors in Table 6.6, and the mobilization and transport factors $\left(f_{w}\right)$ in Table 6.8.

Calculated disposal limits are given in Table 6.11 only if a radionuclide is relatively shortlived or if the mobilization and transport factor, $f_{w}$, is substantially less than unity. For longer-lived radionuclides or radionuclides with mobilization and transport factors near unity, it is evident from a comparison of the SDCFs for the resident scenario in Table 6.3 with those for the agriculture scenario in Table 6.2 that the agriculture scenario gives a much higher dose per unit concentration in the disposal facility and, thus, is more restrictive in determining allowable disposal limits. The much higher dose for the agriculture scenario results from (1) the shielding provided by the intact engineered barriers in the dose assessment for the resident scenario, which is not assumed in the dose assessment for the same exposure pathway in the agriculture scenario, and (2) the presence of additional exposure pathways in the agriculture scenario that are not relevant for the resident scenario. Because the concentrations of relatively long-lived and immobile radionuclides that would apply in the agriculture and resident scenarios are essentially the same, the resident scenario is unimportant for these radionuclides and allowable limits obtained from the dose analysis for this scenario need not be given in Table 6.11.

\subsubsection{Results for Post-Drilling Scenario}

Table 6.12 gives the limits on allowable average concentrations and inventories of radionuclides in waste prior to disposal based on the dose assessment for the post-drilling scenario for the IWMF. These results were calculated from Eq. (6-8) and Eq. (6-9) using the SDCFs in Table 6.4 and the mobilization and transport factors $\left(f_{w}\right)$ in Table 6.8 .

Calculated disposal limits are given in Table 6.12 only if a radionuclide is relatively shortlived or if the mobilization and transport factor, $f_{w}$ is substantially less than unity. For longer-lived radionuclides or radionuclides with a mobilization and transport factor near unity, it is evident from a comparison of the SDCFs for the post-drilling scenario in Table 6.4 with those for the agriculture scenario in Table 6.2 that the agriculture scenario gives a much higher dose per unit concentration in 
Table 6.11. Allowable limits on concentrations and inventories of radionuclides for IWMF based on resident scenario for inadvertent intruders ${ }^{a}$

\begin{tabular}{lccccc}
\hline $\mathrm{Nuclide}^{b}$ & $\begin{array}{c}\text { SDCF } \times G \\
\left(\mathrm{rem} / \mathrm{year} \text { per } \mu \mathrm{Ci} / \mathrm{m}^{3}\right)^{c}\end{array}$ & $f_{\mathrm{D}}{ }^{d}$ & $f_{w}^{e}$ & $\begin{array}{c}C_{\mathrm{W}} \\
\left(\mu \mathrm{Ci} / \mathrm{m}^{3}\right)^{\gamma}\end{array}$ & $\begin{array}{c}\text { Inventory } \\
(\mathrm{Ci} / \mathrm{pad})^{g}\end{array}$ \\
\hline${ }^{40} \mathrm{~K}$ & $8.4 \times 10^{-6}$ & $1.0 \times 10^{0}$ & $1.0 \times 10^{0}$ & $1.2 \times 10^{4}$ & $1.0 \times 10^{1}$ \\
${ }^{60} \mathrm{Co}$ & $1.2 \times 10^{-4}$ & $1.9 \times 10^{-6}$ & $1.0 \times 10^{0}$ & $4.5 \times 10^{8}$ & $3.9 \times 10^{5}$ \\
${ }^{137} \mathrm{Cs}$ & $1.3 \times 10^{-5}$ & $9.9 \times 10^{-2}$ & $1.0 \times 10^{0}$ & $7.9 \times 10^{4}$ & $6.8 \times 10^{1}$ \\
${ }^{152} \mathrm{Eu}$ & $3.9 \times 10^{-5}$ & $5.5 \times 10^{-3}$ & $1.0 \times 10^{0}$ & $4.6 \times 10^{5}$ & $4.0 \times 10^{2}$ \\
${ }^{154} \mathrm{Eu}$ & $4.4 \times 10^{-5}$ & $3.8 \times 10^{-4}$ & $1.0 \times 10^{0}$ & $6.0 \times 10^{6}$ & $5.1 \times 10^{3}$ \\
${ }^{155} \mathrm{Eu}$ & $8.0 \times 10^{-9}$ & $8.3 \times 10^{-7}$ & $1.0 \times 10^{0}$ & $1.5 \times 10^{13}$ & $1.3 \times 10^{10}$ \\
${ }^{207} \mathrm{Bi}$ & $4.8 \times 10^{-5}$ & $1.2 \times 10^{-1}$ & $1.0 \times 10^{0}$ & $1.7 \times 10^{4}$ & $1.5 \times 10^{1}$ \\
${ }^{228} \mathrm{Ra}$ & $1.2 \times 10^{-4}$ & $5.8 \times 10^{-6}$ & $1.0 \times 10^{0}$ & $1.4 \times 10^{8}$ & $1.2 \times 10^{5}$ \\
${ }^{227} \mathrm{Ac}$ & $2.7 \times 10^{-6}$ & $4.1 \times 10^{-2}$ & $1.0 \times 10^{0}$ & $9.0 \times 10^{5}$ & $7.8 \times 10^{2}$ \\
${ }^{232} \mathrm{U}$ & $9.2 \times 10^{-5}$ & $3.6 \times 10^{-1}$ & $1.0 \times 10^{\circ}$ & $3.0 \times 10^{3}$ & $2.6 \times 10^{\circ}$ \\
${ }^{242 \mathrm{~m}} \mathrm{Am}$ & $1.0 \times 10^{-7}$ & $6.1 \times 10^{-1}$ & $1.0 \times 10^{0}$ & $1.6 \times 10^{6}$ & $1.4 \times 10^{3}$ \\
${ }^{243} \mathrm{Cm}$ & $3.1 \times 10^{-7}$ & $8.8 \times 10^{-2}$ & $1.0 \times 10^{0}$ & $3.7 \times 10^{6}$ & $3.2 \times 10^{3}$ \\
${ }^{249} \mathrm{Cf}$ & $3.2 \times 10^{-6}$ & $8.2 \times 10^{-1}$ & $1.0 \times 10^{0}$ & $3.8 \times 10^{4}$ & $3.2 \times 10^{1}$ \\
\hline
\end{tabular}

${ }^{a}$ Allowable limits are calculated from Eq. (6-8) and Eq. (6-9). Time of occurrence for resident scenario is assumed to be 100 years after disposal.

${ }^{b}$ For radionuclides listed in Table 6.3 that are omitted from this table, allowable limits are much less than limits based on dose assessment for agriculture scenario given in Table 6.10.

${ }^{c}$ Product of scenario dose conversion factor (SCDF) for resident scenario given in Table 6.3 and waste dilution factor $(G)$ for resident scenario given in Table 6.6.

"Radionuclide inventory at time resident scenario is assumed to occur relative to inventory at time of disposal due to radioactive decay.

${ }^{e}$ Radionuclide inventory at time resident scenario is assumed to occur relative to inventory at time of disposal due to mobilization and transport in infiltrating water obtained from Table 6.7.

Limit on allowable average concentration of radionuclide in waste prior to disposal.

' $L$ imit on allowable inventory of radionuclide in waste prior to disposal for individual disposal pads in the IWMF, based on assumption of 330 vaults per pad and waste volume per vault of $2.6 \mathrm{~m}^{3}$.

the disposal facility and, thus, is more restrictive in determining allowable disposal limits. The much higher dose for the agriculture scenario results from (1) the assumption that a much larger volume of waste exhumed from the disposal units is mixed with native soil in the vegetable garden in the agriculture scenario compared with the post-drilling scenario and (2) the presence of additional exposure pathways during indoor residence on top of the disposal units in the agriculture scenario that are not relevant for the post-drilling scenario. Because the concentrations of relatively long-lived and immobile radionuclides that would apply in the agriculture and post-drilling scenarios are essentially the same, the post-drilling scenario is unimportant for these radionuclides and allowable limits obtained from the dose analysis for this scenario need not be given in Table 6.12. 
Table 6.12. Allowable limits on concentrations and inventories of radionuclides for IWMF based on post-drilling scenario for inadvertent intruders ${ }^{a}$

\begin{tabular}{|c|c|c|c|c|c|}
\hline Nuclide $^{b}$ & $\begin{array}{c}\text { SDCF } \\
\left.\text { (rem/year per } \mu \mathrm{Ci} / \mathrm{m}^{3}\right)^{c}\end{array}$ & $f_{\mathrm{D}}^{d}$ & $f_{w}^{e}$ & $\begin{array}{c}\bar{C}_{\mathrm{w}} \\
\left(\mu \mathrm{Ci} / \mathrm{m}^{3}\right)^{\prime}\end{array}$ & $\begin{array}{l}\text { Inventory } \\
(\mathrm{Ci} / \mathrm{pad})^{g}\end{array}$ \\
\hline${ }^{3} \mathrm{H}$ & $4.0 \times 10^{-8}$ & $3.6 \times 10^{-3}$ & $6.8 \times 10^{-3}$ & $1.0 \times 10^{9}$ & $8.8 \times 10^{5}$ \\
\hline${ }^{14} \mathrm{C}$ & $1.5 \times 10^{-7}$ & $9.9 \times 10^{-1}$ & $8.4 \times 10^{-1}$ & $8.0 \times 10^{5}$ & $6.9 \times 10^{2}$ \\
\hline${ }^{36} \mathrm{Cl}$ & $1.2 \times 10^{-5}$ & $1.0 \times 10^{0}$ & $6.8 \times 10^{-1}$ & $1.2 \times 10^{4}$ & $1.1 \times 10^{1}$ \\
\hline${ }^{40} \mathrm{~K}$ & $6.0 \times 10^{-7}$ & $1.0 \times 10^{\circ}$ & $1.0 \times 10^{\circ}$ & $1.7 \times 10^{5}$ & $1.4 \times 10^{2}$ \\
\hline${ }^{60} \mathrm{Co}$ & $1.8 \times 10^{-7}$ & $1.9 \times 10^{-6}$ & $1.0 \times 10^{\circ}$ & $2.9 \times 10^{11}$ & $2.5 \times 10^{8}$ \\
\hline${ }^{63} \mathrm{Ni}$ & $2.0 \times 10^{-9}$ & $5.0 \times 10^{-1}$ & $1.0 \times 10^{0}$ & $1.0 \times 10^{8}$ & $8.6 \times 10^{4}$ \\
\hline${ }^{79} \mathrm{Se}$ & $1.2 \times 10^{-8}$ & $1.0 \times 10^{0}$ & $6.8 \times 10^{-1}$ & $1.2 \times 10^{7}$ & $1.1 \times 10^{4}$ \\
\hline${ }^{90} \mathrm{Sr}$ & $2.0 \times 10^{-6}$ & $8.8 \times 10^{-2}$ & $1.0 \times 10^{\circ}$ & $5.7 \times 10^{5}$ & $4.9 \times 10^{2}$ \\
\hline${ }^{93 m} \mathrm{Nb}$ & $1.8 \times 10^{-10}$ & $6.1 \times 10^{-3}$ & $1.0 \times 10^{\circ}$ & $9.1 \times 10^{10}$ & $7.8 \times 10^{7}$ \\
\hline${ }^{99} \mathrm{Tc}$ & $1.3 \times 10^{-7}$ & $1.0 \times 10^{0}$ & $8.6 \times 10^{-1}$ & $8.9 \times 10^{5}$ & $7.7 \times 10^{2}$ \\
\hline${ }^{113 m} \mathrm{Cd}$ & $1.4 \times 10^{-6}$ & $6.3 \times 10^{-3}$ & $1.0 \times 10^{0}$ & $1.1 \times 10^{7}$ & $9.8 \times 10^{3}$ \\
\hline${ }^{121 \mathrm{~m}} \mathrm{Sn}$ & $6.5 \times 10^{-10}$ & $2.8 \times 10^{-1}$ & $1.0 \times 10^{\circ}$ & $5.5 \times 10^{8}$ & $4.7 \times 10^{5}$ \\
\hline${ }^{129} \mathrm{I}$ & $8.2 \times 10^{-7}$ & $1.0 \times 10^{\circ}$ & $6.8 \times 10^{-1}$ & $1.8 \times 10^{5}$ & $1.5 \times 10^{2}$ \\
\hline${ }^{137} \mathrm{Cs}$ & $1.3 \times 10^{-7}$ & $9.9 \times 10^{-2}$ & $1.0 \times 10^{\circ}$ & $7.8 \times 10^{6}$ & $6.7 \times 10^{3}$ \\
\hline${ }^{151} \mathrm{Sm}$ & $1.1 \times 10^{-10}$ & $4.6 \times 10^{-1}$ & $1.0 \times 10^{\circ}$ & $2.0 \times 10^{9}$ & $1.7 \times 10^{6}$ \\
\hline${ }^{152} \mathrm{Eu}$ & $7.8 \times 10^{-8}$ & $5.5 \times 10^{-3}$ & $1.0 \times 10^{\circ}$ & $2.3 \times 10^{8}$ & $2.0 \times 10^{5}$ \\
\hline${ }^{154} \mathrm{Eu}$ & $8.5 \times 10^{-8}$ & $3.8 \times 10^{-4}$ & $1.0 \times 10^{\circ}$ & $3.1 \times 10^{9}$ & $2.7 \times 10^{6}$ \\
\hline${ }^{155} \mathrm{Eu}$ & $2.6 \times 10^{-9}$ & $8.3 \times 10^{-7}$ & $1.0 \times 10^{0}$ & $4.6 \times 10^{13}$ & $4.0 \times 10^{10}$ \\
\hline${ }^{194} \mathrm{Os}$ & $2.6 \times 10^{-9}$ & $9.6 \times 10^{-6}$ & $1.0 \times 10^{\circ}$ & $4.0 \times 10^{12}$ & $3.4 \times 10^{9}$ \\
\hline${ }^{207} \mathrm{Bi}$ & $1.0 \times 10^{-7}$ & $1.2 \times 10^{-1}$ & $1.0 \times 10^{0}$ & $8.3 \times 10^{6}$ & $7.2 \times 10^{3}$ \\
\hline${ }^{210} \mathrm{~Pb}$ & $3.1 \times 10^{-6}$ & $4.5 \times 10^{-2}$ & $1.0 \times 10^{\circ}$ & $7.2 \times 10^{5}$ & $6.2 \times 10^{2}$ \\
\hline${ }^{228} \mathrm{Ra}$ & $4.6 \times 10^{-7 h}$ & $5.8 \times 10^{-6}$ & $1.0 \times 10^{0}$ & $3.7 \times 10^{10}$ & $3.2 \times 10^{7}$ \\
\hline${ }^{227} \mathrm{Ac}$ & $1.2 \times 10^{-6}$ & $4.1 \times 10^{-2}$ & $1.0 \times 10^{0}$ & $2.0 \times 10^{6}$ & $1.7 \times 10^{3}$ \\
\hline${ }^{232} \mathrm{U}$ & $5.7 \times 10^{-7 h}$ & $3.6 \times 10^{-1}$ & $1.0 \times 10^{0}$ & $4.9 \times 10^{5}$ & $4.2 \times 10^{2}$ \\
\hline${ }^{238} \mathrm{Pu}$ & $1.8 \times 10^{-7}$ & $4.5 \times 10^{-1}$ & $1.0 \times 10^{0}$ & $1.2 \times 10^{6}$ & $1.1 \times 10^{3}$ \\
\hline
\end{tabular}


Table 6.12. (continued) $)^{a}$

\begin{tabular}{|c|c|c|c|c|c|}
\hline Nuclide $^{b}$ & $\begin{array}{c}\text { SDCF } \\
\left(\text { rem/year per } \mu \mathrm{Ci} / \mathrm{m}^{3}\right)^{c} \\
\end{array}$ & $f_{\mathrm{D}}{ }^{d}$ & $f_{w}^{e}$ & $\begin{array}{c}C_{\mathrm{W}} \\
\left(\mu \mathrm{Ci} / \mathrm{m}^{3}\right)^{r} \\
\end{array}$ & $\begin{array}{l}\text { Inventory } \\
\text { (Ci/pad) }\end{array}$ \\
\hline${ }^{241} \mathrm{Pu}$ & $3.9 \times 10^{-9}$ & $8.1 \times 10^{-3}$ & $1.0 \times 10^{\circ}$ & $\begin{array}{l}3.2 \times 10^{9} \\
1.4 \times 10^{3 i}\end{array}$ & $\begin{array}{l}2.7 \times 10^{6} \\
1.2 \times 10^{4 i}\end{array}$ \\
\hline${ }^{241} \mathrm{Am}$ & $2.5 \times 10^{-7}$ & $8.5 \times 10^{-1}$ & $1.0 \times 10^{0}$ & $4.7 \times 10^{5}$ & $4.0 \times 10^{2}$ \\
\hline${ }^{238} \mathrm{Pu}^{i}$ & $\begin{array}{l}2.5 \times 10^{-7} \\
1.8 \times 10^{-7}\end{array}$ & $\begin{array}{l}6.1 \times 10^{-1} \\
4.2 \times 10^{-1}\end{array}$ & $1.0 \times 10^{0}$ & $4.3 \times 10^{5}$ & $3.7 \times 10^{2}$ \\
\hline${ }^{243} \mathrm{Cm}$ & $1.4 \times 10^{-7}$ & $8.8 \times 10^{-2}$ & $1.0 \times 10^{0}$ & $8.1 \times 10^{6}$ & $7.0 \times 10^{3}$ \\
\hline${ }^{244} \mathrm{Cm}$ & $1.1 \times 10^{-7}$ & $2.2 \times 10^{-2}$ & $1.0 \times 10^{0}$ & $4.1 \times 10^{7}$ & $3.6 \times 10^{4}$ \\
\hline${ }^{246} \mathrm{Cm}$ & $2.1 \times 10^{-7}$ & $9.9 \times 10^{-1}$ & $1.0 \times 10^{0}$ & $4.8 \times 10^{5}$ & $4.1 \times 10^{2}$ \\
\hline${ }^{249} \mathrm{Cf}$ & $2.8 \times 10^{-7}$ & $8.2 \times 10^{-1}$ & $1.0 \times 10^{0}$ & $4.4 \times 10^{5}$ & $3.7 \times 10^{2}$ \\
\hline${ }^{250} \mathrm{Cf}$ & $1.1 \times 10^{-7}$ & $5.0 \times 10^{-3}$ & $1.0 \times 10^{0}$ & $\begin{array}{l}1.8 \times 10^{8} \\
1.7 \times 10^{8 k}\end{array}$ & $\begin{array}{l}1.6 \times 10^{5} \\
1.5 \times 10^{5 k}\end{array}$ \\
\hline${ }^{251} \mathrm{Cf}$ & $2.7 \times 10^{-7}$ & $9.3 \times 10^{-1}$ & $1.0 \times 10^{0}$ & $4.0 \times 10^{5}$ & $3.4 \times 10^{2}$ \\
\hline
\end{tabular}

${ }^{a}$ Allowable limits are calculated from Eq. (6-8) and Eq. (6-9). Time of occurrence for post-drilling scenario is assumed to be 100 years after disposal.

${ }^{b}$ For radionuclides listed in Table 6.4 that are omitted from this table, allowable limits are much less than limits based on dose assessment for agriculture scenario given in Table 6.10.

'Scenario dose conversion factor (SDCF) for post-drilling scenario obtained from Table 6.4.

${ }^{\prime}$ Radionuclide inventory at time post-drilling scenario is assumed to occur relative to inventory at time of disposal due to radioactive decay.

'Radionuclide inventory at time post-drilling scenario is assumed to occur relative to inventory at time of disposal due to mobilization and transport in infiltrating water obtained from Table 6.7.

Limit on allowable average concentration of radionuclide in waste prior to disposal.

${ }^{2}$ Limit on allowable inventory of radionuclide in waste prior to disposal for individual disposal pads in IWMF, based on assumption of 330 vaults per pad and waste volume per vault of $2.6 \mathrm{~m}^{3}$.

${ }^{h}$ Contribution from radon decay product is excluded.

'Value is 30 times limit for ${ }^{241} \mathrm{Am}$ decay product, based on ratio of half-lives of decay product and parent radionuclide.

Indented entry is radiologically significant decay product of parent radionuclide.

${ }^{2} V$ alue is 360 times limit for ${ }^{246} \mathrm{Cm}$ decay product, based on ratio of half-lives of decay product and parent radionuclide.

The following paragraphs discuss some of the results for the post-drilling scenario in Table 6.12 in more detail.

First, for the radionuclides ${ }^{228} \mathrm{Ra}$ and ${ }^{232} \mathrm{U}$, both of which decay to radon (i.e., ${ }^{220} \mathrm{Rn}$ ), the calculated disposal limits do not include contributions to dose from inhalation of radon and its shortlived decay products. In accordance with current DOE guidance (DOE 1996c), the performance objective for inadvertent intruders is assumed to exclude any contributions to dose from radon. If the dose from radon were included, the disposal limits would decrease by about $30 \%$ for both radionuclides. 
Second, for the relatively short-lived radionuclides ${ }^{241} \mathrm{Pu}$ and ${ }^{250} \mathrm{Cf}$, the allowable limits on disposals are determined by the disposal limits for their longer-lived decay products ${ }^{241} \mathrm{Am}$ and ${ }^{246} \mathrm{Cm}$, respectively. That is, taking into account the assumption that the post-drilling scenario occurs at 100 years after disposal and taking into account the half-lives of the parent radionuclides and their longer-lived decay products, the dose from the decay product in both cases is greater than the dose from the parent. For the relatively short-lived radionuclides ${ }^{243} \mathrm{Cm}$ and ${ }^{244} \mathrm{Cm}$, the dose from their longer-lived decay products, ${ }^{239} \mathrm{Pu}$ and ${ }^{240} \mathrm{Pu}$, respectively, also was considered. However, the half-life of the parent radionuclide is sufficiently long in these cases that the dose from the parent is greater than the dose from the decay product, and the disposal limits are based on the dose from the parent only.

Finally, for the radionuclide ${ }^{242 \mathrm{~m}} \mathrm{Am}$, buildup of the decay product ${ }^{238} \mathrm{Pu}$ is taken into account in estimating the dose for the post-drilling scenario. At 100 years after disposal, the activity of the decay product has not achieved equilibrium with the activity of the parent radionuclide, and separate decay factors are applied to the parent and decay product. The dose from ${ }^{242 m} \mathrm{Am}$ and its decay product decreases with time after 100 years.

\subsubsection{Disposal Limits Based on Intruder Dose Assessment}

In the dose assessment for inadvertent intruders for the IWMF, limits on allowable average concentrations and inventories of radionuclides in waste prior to disposal were developed based on the agriculture, resident, and post-drilling scenarios, and Table 6.10 through Table 6.12 give the results for these scenarios. For any radionuclide, the allowable limits based on the dose assessment for inadvertent intruders are the most restrictive of the allowable limits for each scenario. Table 6.13 summarizes the allowable limits based on the dose assessments for the three scenarios.

The disposal limits in Table 6.13 are based on the assumptions that (1) the contribution to dose from radon can be excluded and (2) the performance objective for inadvertent intruders applies only for 1,000 years after disposal. These assumptions have a significant effect on the calculated disposal limits for radionuclides that decay to radon or that decay to radiologically significant longlived decay products. The radionuclides for which the disposal limits are affected by these assumptions include ${ }^{226} \mathrm{Ra},{ }^{228} \mathrm{Ra},{ }^{227} \mathrm{Ac},{ }^{230} \mathrm{Th},{ }^{232} \mathrm{Th},{ }^{232} \mathrm{U},{ }^{233} \mathrm{U},{ }^{234} \mathrm{U},{ }^{235} \mathrm{U},{ }^{238} \mathrm{U}$, and ${ }^{247} \mathrm{Cm}$. The effect of the time constraint for the performance objective also was considered for ${ }^{237} \mathrm{~Np}$ and ${ }^{245} \mathrm{Cm}$. However, when mobilization and transport in water and radioactive decay are taken into account, the maximum dose occurs at 1,000 years after disposal for these radionuclides. The effects of the assumptions about radon and the time constraint for applying the performance objective on the disposal limits for the radionuclides listed above are discussed in Sect. 6.3.2.1 and Sect. 6.3.2.3.

For most of the radionuclides considered in this revised PA, the allowable limits for disposal in Table 6.13 are based on the dose assessment for the agriculture scenario. The exceptions occur for shorter-lived, photon-emitting radionuclides, for shorter-lived radionuclides that are not photon emitters, and for longer-lived radionuclides that are relatively mobile. In the first case, the allowable limits are based on the dose assessment for the resident scenario and, in the latter two cases, the 
allowable limits are based on the dose assessment for the post-drilling scenario. Because the agriculture scenario generally results in the lowest dose per unit concentration of radionuclides in the disposal facility at the time intrusion occurs (see Table 6.2 through Table 6.4), the allowable limits are based on the dose assessment for the other scenarios only when the inventory of a radionuclide is depleted significantly by radioactive decay or by mobilization and transport in infiltrating water between 100 years after disposal, when the resident and post-drilling scenarios are assumed to occur, and 300 years, when the agriculture scenario is assumed to occur.

\subsubsection{Application of Disposal Limits to Mixtures of Radionuclides}

In practice, the allowable limits on inventories of radionuclides given in Table 6.13, rather than the allowable limits on average concentration, will be used to determine acceptable disposals in the IWMF based on the dose assessment for inadvertent intruders. These limits apply when only a single radionuclide is present in the waste. However, low-level waste in the IWMF generally should consist of mixtures of radionuclides, and a sum-of-fractions rule must be applied in determining allowable limits on inventories of radionuclides for actual disposals. This rule states that the ratio of the inventory of each radionuclide to its inventory limit, summed over all radionuclides, should not exceed unity.

The sum-of-fractions rule normally would be applied to all radionuclides in the waste in determining acceptable disposals based on the dose assessment for inadvertent intruders. That is, application of the rule would not take into account that the limiting exposure scenarios do not occur at the same times after disposal for all radionuclides. This approach would be somewhat conservative in ensuring compliance with the performance objective for inadvertent intruders, primarily because the maximum doses from the different exposure scenarios for inadvertent intruders generally are not additive.

An alternative approach would be to apply the sum-of-fractions rule by taking into account the time history of doses from each radionuclide for the different exposure scenarios. The basis for this approach would be the requirement that the performance objective for inadvertent intruders should not be exceeded at any time. This approach would be less conservative and, thus, would allow the highest inventories of radionuclides for disposal. However, application of this approach would be more complicated because (1) time histories of the dose per unit inventory of each radionuclide would need to be developed for each exposure scenario and (2) the total dose from all radionuclides over time would need to be recalculated as new waste is received:

The particular approach to applying the sum-of-fractions rule that would be most advantageous for determining allowable disposals in the IWMF depends on the actual inventories of radionuclides for disposal compared with the allowable limits in Table 6.13. However, we do not expect that the straightforward application of the sum-of-fractions rule to all radionuclides, without regard for the limiting exposure scenario or the time after disposal at which the maximum doses would occur, would disqualify significant amounts of waste for disposal based on the dose assessment for inadvertent intruders. In addition, any refinements of the sum-of-fractions rule based only on the dose 
Table 6.13. Allowable limits on concentrations and inventories of radionuclides for IWMF based on dose assessments for inadvertent intruders ${ }^{a}$

\begin{tabular}{|c|c|c|c|}
\hline Nuclide & Limiting scenario ${ }^{b}$ & $\begin{array}{l}\text { Concentration limit } \\
\left(\mu \mathrm{Ci} / \mathrm{m}^{3}\right)^{c}\end{array}$ & $\begin{array}{l}\text { Inventory limit } \\
(\mathrm{Ci} / \mathrm{pad})^{d}\end{array}$ \\
\hline${ }^{3} \mathrm{H}$ & Post-drilling & $1.0 \times 10^{9}$ & $8.8 \times 10^{5}$ \\
\hline${ }^{10} \mathrm{Be}$ & Agriculture & $5.9 \times 10^{6}$ & $5.1 \times 10^{3}$ \\
\hline${ }^{14} \mathrm{C}$ & Agriculture & $1.7 \times 10^{5}$ & $1.5 \times 10^{2}$ \\
\hline${ }^{26} \mathrm{Al}$ & Agriculture & $6.4 \times 10^{1}$ & $5.5 \times 10^{-2}$ \\
\hline${ }^{36} \mathrm{Cl}$ & Post-drilling & $1.2 \times 10^{4}$ & $1.1 \times 10^{1}$ \\
\hline${ }^{40} \mathrm{~K}$ & Agriculture & $2.0 \times 10^{3}$ & $1.7 \times 10^{\circ}$ \\
\hline${ }^{41} \mathrm{Ca}$ & Agriculture & $2.0 \times 10^{5}$ & $1.7 \times 10^{2}$ \\
\hline${ }^{60} \mathrm{Co}$ & Resident & $4.5 \times 10^{8}$ & $3.9 \times 10^{5}$ \\
\hline${ }^{59} \mathrm{Ni}$ & Agriculture & $6.9 \times 10^{6}$ & $6.0 \times 10^{3}$ \\
\hline${ }^{63} \mathrm{Ni}$ & Agriculture & $1.9 \times 10^{7}$ & $1.6 \times 10^{4}$ \\
\hline${ }^{79} \mathrm{Se}$ & Post-drilling & $1.2 \times 10^{7}$ & $1.1 \times 10^{4}$ \\
\hline${ }^{87} \mathrm{Rb}$ & None & No limite & No limite \\
\hline${ }^{90} \mathrm{Sr}$ & Post-drilling & $5.7 \times 10^{5}$ & $4.9 \times 10^{2}$ \\
\hline${ }^{93} \mathrm{Zr}$ & Agriculture & $1.0 \times 10^{7}$ & $8.6 \times 10^{3}$ \\
\hline${ }^{93 \mathrm{~m}} \mathrm{Nb}$ & Post-drilling & $9.1 \times 10^{10}$ & $7.8 \times 10^{7}$ \\
\hline${ }^{94} \mathrm{Nb}$ & Agriculture & $1.4 \times 10^{2}$ & $1.1 \times 10^{-1}$ \\
\hline${ }^{99} \mathrm{Tc}$ & Agriculture & $1.7 \times 10^{5}$ & $1.4 \times 10^{2}$ \\
\hline${ }^{107} \mathrm{Pd}$ & Agriculture & $1.4 \times 10^{7}$ & $1.2 \times 10^{4}$ \\
\hline${ }^{113 m} \mathrm{Cd}$ & Post-drilling & $1.1 \times 10^{7}$ & $9.8 \times 10^{3}$ \\
\hline${ }^{12 \operatorname{lm}} \mathrm{Sn}$ & Agriculture & $3.1 \times 10^{7}$ & $2.7 \times 10^{4}$ \\
\hline${ }^{126} \mathrm{Sn}$ & Agriculture & $1.2 \times 10^{2}$ & $1.1 \times 10^{-1}$ \\
\hline${ }^{129} \mathrm{I}$ & Post-drilling & $1.8 \times 10^{5}$ & $1.5 \times 10^{2}$ \\
\hline${ }^{135} \mathrm{Cs}$ & Agriculture & $4.8 \times 10^{5}$ & $4.2 \times 10^{2}$ \\
\hline${ }^{137} \mathrm{Cs}$ & Resident & $7.9 \times 10^{4}$ & $6.8 \times 10^{1}$ \\
\hline${ }^{151} \mathrm{Sm}$ & Agriculture & $3.6 \times 10^{8}$ & $3.1 \times 10^{5}$ \\
\hline${ }^{152} \mathrm{Eu}$ & Resident & $4.6 \times 10^{5}$ & $4.0 \times 10^{2}$ \\
\hline
\end{tabular}


Table 6.13. (continued) ${ }^{a}$

\begin{tabular}{|c|c|c|c|}
\hline Nuclide & Limiting scenario $^{b}$ & $\begin{array}{l}\text { Concentration limit } \\
\qquad\left(\mu \mathrm{Ci} / \mathrm{m}^{3}\right)^{c}\end{array}$ & $\begin{array}{l}\text { Inventory limit } \\
\quad(\mathrm{Ci} / \mathrm{pad})^{d}\end{array}$ \\
\hline${ }^{154} \mathrm{Eu}$ & Resident & $6.0 \times 10^{6}$ & $5.1 \times 10^{3}$ \\
\hline${ }^{155} \mathrm{Eu}$ & Resident & $1.5 \times 10^{13}$ & $1.3 \times 10^{10}$ \\
\hline${ }^{194} \mathrm{Os}$ & Post-drilling & $4.0 \times 10^{12}$ & $3.4 \times 10^{9}$ \\
\hline${ }^{207} \mathrm{Bi}$ & Resident & $1.7 \times 10^{4}$ & $1.5 \times 10^{1}$ \\
\hline${ }^{210} \mathrm{~Pb}$ & Post-drilling & $7.2 \times 10^{5}$ & $6.2 \times 10^{2}$ \\
\hline${ }^{226} \mathrm{Ra}$ & Agriculture & $1.3 \times 10^{2}$ & $1.1 \times 10^{-1}$ \\
\hline${ }^{228} \mathrm{Ra}$ & Resident & $1.4 \times 10^{8}$ & $1.2 \times 10^{5}$ \\
\hline${ }^{227} \mathrm{Ac}$ & Resident & $9.0 \times 10^{5}$ & $7.8 \times 10^{2}$ \\
\hline${ }^{229} \mathrm{Th}$ & Agriculture & $6.1 \times 10^{2}$ & $5.2 \times 10^{-1}$ \\
\hline${ }^{230} \mathrm{Th}$ & Agriculture & $2.9 \times 10^{2}$ & $2.5 \times 10^{-1}$ \\
\hline${ }^{232} \mathrm{Th}$ & Agriculture & $7.1 \times 10^{1}$ & $6.1 \times 10^{-2}$ \\
\hline${ }^{231} \mathrm{~Pa}$ & Agriculture & $3.3 \times 10^{2}$ & $2.9 \times 10^{-1}$ \\
\hline${ }^{232} \mathrm{U}$ & Agriculture & $2.3 \times 10^{3}$ & $2.0 \times 10^{0}$ \\
\hline${ }^{233} \mathrm{U}$ & Agriculture $f^{f}$ & $5.6 \times 10^{3}$ & $4.8 \times 10^{\circ}$ \\
\hline${ }^{234} \mathrm{U}$ & Agriculture $f^{f}$ & $2.1 \times 10^{4}$ & $1.8 \times 10^{1}$ \\
\hline${ }^{235} \mathrm{U}$ & Agriculture $f$ & $1.4 \times 10^{3}$ & $1.2 \times 10^{\circ}$ \\
\hline${ }^{236} \mathrm{U}$ & Agriculture & $3.3 \times 10^{4}$ & $2.9 \times 10^{1}$ \\
\hline${ }^{238} \mathrm{U}$ & Agriculture $f^{f}$ & $7.1 \times 10^{3}$ & $6.1 \times 10^{0}$ \\
\hline${ }^{237} \mathrm{~Np}$ & Agriculture & $6.3 \times 10^{2}$ & $5.4 \times 10^{-1}$ \\
\hline${ }^{238} \mathrm{Pu}$ & Agriculture & $1.3 \times 10^{5}$ & $1.2 \times 10^{2}$ \\
\hline${ }^{239} \mathrm{Pu}$ & Agriculture & $1.1 \times 10^{4}$ & $9.9 \times 10^{\circ}$ \\
\hline${ }^{240} \mathrm{Pu}$ & Agriculture & $1.2 \times 10^{4}$ & $1.0 \times 10^{1}$ \\
\hline${ }^{241} \mathrm{Pu}$ & Agriculture & $3.5 \times 10^{5 g}$ & $3.0 \times 10^{2 g}$ \\
\hline${ }^{242} \mathrm{Pu}$ & Agriculture & $1.2 \times 10^{4}$ & $1.0 \times 10^{1}$ \\
\hline${ }^{244} \mathrm{Pu}$ & Agriculture & $5.3 \times 10^{2}$ & $4.6 \times 10^{-1}$ \\
\hline${ }^{241} \mathrm{Am}$ & Agriculture & $1.2 \times 10^{4}$ & $9.9 \times 10^{\circ}$ \\
\hline
\end{tabular}


Table 6.13. (continued) ${ }^{a}$

\begin{tabular}{llcc}
\hline Nuclide & Limiting scenario & $\begin{array}{c}\text { Concentration limit } \\
\left(\mu \mathrm{Ci} / \mathrm{m}^{3}\right)^{c}\end{array}$ & $\begin{array}{c}\text { Inventory limit } \\
(\mathrm{Ci} / \mathrm{pad})^{d}\end{array}$ \\
\hline${ }^{242 \mathrm{~m}} \mathrm{Am}$ & Agriculture & $1.5 \times 10^{4}$ & $1.3 \times 10^{1}$ \\
${ }^{243} \mathrm{Am}$ & Agriculture & $1.2 \times 10^{3}$ & $1.0 \times 10^{0}$ \\
${ }^{243} \mathrm{Cm}$ & Agriculture & $2.5 \times 10^{6}$ & $2.1 \times 10^{3}$ \\
${ }^{244} \mathrm{Cm}$ & Agriculture & $4.2 \times 10^{6 h}$ & $3.6 \times 10^{3 h}$ \\
${ }^{245} \mathrm{Cm}$ & Agriculture & $2.1 \times 10^{3}$ & $1.8 \times 10^{0}$ \\
${ }^{246} \mathrm{Cm}$ & Agriculture & $1.1 \times 10^{4}$ & $9.5 \times 10^{0}$ \\
${ }^{247} \mathrm{Cm}$ & Agriculturef & $5.8 \times 10^{2}$ & $5.1 \times 10^{-1}$ \\
${ }^{248} \mathrm{Cm}$ & Agriculture & $2.9 \times 10^{3}$ & $2.5 \times 10^{0}$ \\
${ }^{249} \mathrm{Cf}$ & Agriculture & $1.0 \times 10^{3}$ & $8.7 \times 10^{-1}$ \\
${ }^{250} \mathrm{Cf}$ & Agriculture & $4.0 \times 10^{6 i}$ & $3.4 \times 10^{3 i}$ \\
${ }^{251} \mathrm{Cf}$ & Agriculture & $2.1 \times 10^{3}$ & $1.8 \times 10^{\circ}$ \\
\hline
\end{tabular}

${ }^{a}$ Allowable limits based on dose assessments for agriculture, resident, and post-drilling scenarios are obtained from Table 6.10 through Table 6.12.

${ }^{b}$ Agriculture scenario is assumed to occur at 300 years after disposal, unless otherwise noled. resident and postdrilling scenarios are assumed to occur at 100 years after disposal.

'Limit on allowable average concentration of radionuclide in waste prior to disposa!

Limit on allowable inventory of radionuclide in waste prior to disposal for individual disposal pads in IWMF, based on assumption of 330 vaults per pad and waste volume per vault of $2.6 \mathrm{~m}^{3}$.

${ }^{\circ}$ Calculated limits for all scenarios exceed specific activity of radionuclide.

${ }^{\prime}$ Scenario is evaluated at 1,000 years after disposal when maximum dose from radionuclise and is long-lived decay products during assumed 1,000-year time for compliance with performance objective for inas ertent intruders occurs.

8Value is 30 times limit for longer-lived ${ }^{241}$ Am decay product, based on ratio of half-lives of decay product and parent radionuclide; limit due to activity of parent radionuclide at time scenario is assumed to occur is less restrictive.

hValue is 360 times limit for longer-lived ${ }^{240} \mathrm{Pu}$ decay product, based on ratio of half-lives of decay product and parent radionuclide; limit due to activity of parent radionuclide at time scenario is assumed to occur is less restrictive.

'Value is 360 times limit for longer-lived ${ }^{246} \mathrm{Cm}$ decay product, based on ratio of half-lives of decay product and parent radionuclide; limit due to activity of parent radionuclide at time scenario is assumed to occur is less restrictive.

assessment for inadvertent intruders would need to take into account the limits on allowable disposals of radionuclides based on the assessment of off-site releases.

\subsubsection{Intruder Dose Assessment for Other Disposal Units}

This section presents the results of the intruder dose assessment for the SWSA 6 disposal units other than the IWMF. These disposal units are closed and are no longer receiving waste. Therefore, the dose assessment for these units is used to evaluate compliance with the performance objective for inadvertent intruders given at the beginning of Chapter 6, based on the SDCFs for the agriculture, resident, post-drilling, and discovery scenarios given in Table 6.2 through Table 6.5 and the reported 
disposals of radionuclides in each of the units. In addition, the waste dilution factors summarized in Table 6.6 and the correction factor for radioactive decay discussed in Sect. 6.3.1.2 are used in calculating potential doses to inadvertent intruders for the different scenarios. However, the correction factors for mobilization and transport in water given in Table 6.7 are not used in the intruder dose assessment for the closed disposal units, because the model used to obtain these factors was developed for the IWMF but is not directly applicable to the other units, due to their different construction. Thus, all estimates of dose to inadvertent intruders for the closed disposal units presented in this section are conservative in regard to reductions in inventories in the disposal units over time due to mobilization and transport in water, especially for radionuclides that are expected to be relatively mobile (e.g., ${ }^{3} \mathrm{H}$, ${ }^{14} \mathrm{C}$, and ${ }^{99} \mathrm{Tc}$ ). On the other hand, in the dose assessment for the agriculture scenario, potential doses beyond the 1,000-year time period of concern for applying the performance objective for inadvertent intruders also are discussed for long-lived radionuclides that decay to radiologically significant longlived decay products, and the correction factors for mobilization and transport in water given in Table 6.8, along with the solubility limits in Table 6.9, are taken into account in these discussions.

Based on Eq. (6-3) and Eq. (6-7) and ignoring the mobilization and transport factor, $f_{w}$, the annual dose for the agriculture scenario from disposals of any radionuclide in the closed disposal units can be written as

$$
H=\widetilde{C}_{\mathrm{W}} \times\left(\mathrm{SDCF}_{a g, r} G_{r}+\mathrm{SDCF}_{a g, g} G_{g}\right) \times f_{\mathrm{D}}(t)
$$

where the average concentration of the radionuclide in the waste prior to disposal, $\bar{C}_{\mathrm{w}}$, is in units of $\mu \mathrm{Ci} / \mathrm{m}^{3}$ and the SDCFs are in units of rem/year per $\mu \mathrm{Ci} / \mathrm{m}^{3}$. The average concentrations of radionuclides are estimated from the reported inventories and waste volumes for the different closed disposal units given in Appendix A. Similarly, the dose for the resident, post-drilling, and discovery scenarios can be written as

$$
H=\bar{C}_{\mathrm{W}} \times \mathrm{SDCF} \times G \times f_{\mathrm{D}}(t)
$$

except the waste dilution factor, $G$, is not used in the dose assessment for the post-drilling scenario.

Table 6.14 through Table 6.17 give the estimated doses to inadvertent intruders for the agriculture, resident, post-drilling, and discovery scenarios for the closed disposal units in the SWSA 6 facility. Results are given for particular radionuclides only if the estimated dose is greater than $1 \mathrm{mrem}$, because doses less than this from any radionuclides would not be important in demonstrating compliance with the performance objective for inadvertent intruders. Dose estimates for the agriculture scenario are given at 300 years, except at 100 years for the biological trenches, which is the earliest time when the scenario is assumed to occur, and at 1,000 years, which is the assumed time constraint for applying the performance objective for inadvertent intruders (DOE 1996c) and is the time during the compliance period when the doses from long-lived radionuclides that decay to radiologically significant long-lived decay products would attain their maximum values. The dose at any intermediate times would be bounded by the doses at 300 or 100 and 1,000 years. Dose estimates for the other three 
Table 6.14. Estimated annual effective dose equivalents to inadvertent intruders for agriculture scenario for closed disposal units in the SWSA 6 facility ${ }^{a}$

\begin{tabular}{|c|c|c|c|c|}
\hline \multirow[b]{2}{*}{ Disposal unit } & \multirow[b]{2}{*}{ Nuclide } & \multirow{2}{*}{$\begin{array}{l}\text { Concentration } \\
\left(\mu \mathrm{Ci} / \mathrm{m}^{3}\right)^{b}\end{array}$} & \multicolumn{2}{|c|}{ Annual dose (rem/year) } \\
\hline & & & 300 years & 1,000 years \\
\hline \multirow[t]{11}{*}{ Tumulus I } & ${ }^{137} \mathrm{Cs}$ & $3.3 \times 10^{4}$ & 0.010 & \\
\hline & ${ }^{226} \mathrm{Ra}$ & $2.3 \times 10^{\circ}$ & 0.002 & 0.001 \\
\hline & ${ }^{232} \mathrm{Th}$ & $8.4 \times 10^{-1}$ & 0.001 & 0.001 \\
\hline & ${ }^{233} \mathrm{U}$ & $6.6 \times 10^{1}$ & 0.001 & 0.001 \\
\hline & ${ }^{237} \mathrm{~Np}$ & $1.1 \times 10^{1}$ & 0.002 & 0.002 \\
\hline & ${ }^{239} \mathrm{Pu}$ & $6.9 \times 10^{1}$ & 0.001 & 0.001 \\
\hline & ${ }^{241} \mathrm{Am}$ & $8.2 \times 10^{1}$ & 0.001 & \\
\hline & ${ }^{243} \mathrm{Am}$ & $1.6 \times 10^{1}$ & 0.001 & 0.001 \\
\hline & ${ }^{249} \mathrm{Cf}$ & $1.4 \times 10^{1}$ & 0.001 & \\
\hline & Others & & $<0.001$ & $<0.001$ \\
\hline & Sum & & 0.020 & 0.007 \\
\hline \multirow[t]{5}{*}{ Tumulus II } & ${ }^{137} \mathrm{Cs}$ & $1.3 \times 10^{4}$ & 0.004 & \\
\hline & ${ }^{232} \mathrm{Th}$ & $8.4 \times 10^{-1}$ & 0.001 & 0.001 \\
\hline & ${ }^{233} \mathrm{U}$ & $7.0 \times 10^{2}$ & 0.001 & 0.001 \\
\hline & Others & & $<0.001$ & $<0.001$ \\
\hline & Sum & & 0.006 & 0.002 \\
\hline \multirow[t]{10}{*}{ Low-range silos $(\mathrm{N})^{c}$} & ${ }^{90} \mathrm{Sr}$ & $6.8 \times 10^{4}$ & 0.002 & \\
\hline & ${ }^{99} \mathrm{Tc}$ & $2.1 \times 10^{2}$ & 0.001 & 0.001 \\
\hline & ${ }^{137} \mathrm{Cs}$ & $5.3 \times 10^{4}$ & 0.010 & \\
\hline & ${ }^{226} \mathrm{Ra}$ & $2.3 \times 10^{1}$ & 0.014 & 0.010 \\
\hline & ${ }^{232} \mathrm{Th}$ & $2.5 \times 10^{1}$ & 0.022 & 0.022 \\
\hline & ${ }^{238} U$ & $5.8 \times 10^{1}$ & 0.001 & 0.001 \\
\hline & ${ }^{239} \mathrm{Pu}$ & $3.9 \times 10^{2}$ & 0.003 & 0.003 \\
\hline & ${ }^{241} \mathrm{Am}$ & $3.5 \times 10^{2}$ & 0.002 & 0.001 \\
\hline & Others & & $<0.001$ & $<0.001$ \\
\hline & Sum & & 0.055 & 0.038 \\
\hline
\end{tabular}


Table 6.14. (continued)

\begin{tabular}{|c|c|c|c|c|}
\hline \multirow[b]{2}{*}{ Disposal unit } & \multirow[b]{2}{*}{ Nuclide } & \multirow{2}{*}{$\begin{array}{l}\text { Concentration } \\
\qquad\left(\mu \mathrm{Ci} / \mathrm{m}^{3}\right)^{b}\end{array}$} & \multicolumn{2}{|c|}{ Annual dose (rem/year) } \\
\hline & & & 300 years & 1,000 years \\
\hline \multirow[t]{6}{*}{ Low-range silos $(\mathrm{S})^{c}$} & ${ }^{137} \mathrm{Cs}$ & $1.1 \times 10^{4}$ & 0.002 & \\
\hline & ${ }^{232} \mathrm{Th}$ & $3.5 \times 10^{0}$ & 0.003 & 0.003 \\
\hline & ${ }^{233} \mathrm{U}$ & $5.6 \times 10^{1}$ & & 0.001 \\
\hline & ${ }^{243} \mathrm{Am}$ & $1.5 \times 10^{1}$ & 0.001 & 0.001 \\
\hline & Others & & $<0.001$ & $<0.001$ \\
\hline & Sum & & 0.006 & 0.005 \\
\hline \multirow[t]{4}{*}{ High-range silos } & ${ }^{90} \mathrm{Sr}$ & $3.2 \times 10^{4}$ & 0.001 & \\
\hline & ${ }^{137} \mathrm{Cs}$ & $3.8 \times 10^{4}$ & 0.007 & \\
\hline & Others & & $<0.001$ & $<0.001$ \\
\hline & Sum & & 0.008 & $<0.001$ \\
\hline \multirow[t]{4}{*}{ Asbestos silos } & ${ }^{232} \mathrm{Th}$ & $5.7 \times 10^{-1}$ & 0.001 & 0.001 \\
\hline & ${ }^{239} \mathrm{Pu}$ & $8.4 \times 10^{1}$ & 0.001 & 0.001 \\
\hline & Others & & $<0.001$ & $<0.001$ \\
\hline & Sum & & 0.002 & 0.002 \\
\hline \multirow[t]{4}{*}{ High-range wells ${ }^{d}$} & ${ }^{90} \mathrm{Sr}$ & $8.8 \times 10^{7}$ & $0.002^{\circ}$ & \\
\hline & ${ }^{137} \mathrm{Cs}$ & $1.4 \times 10^{8}$ & $0.1^{\circ}$ & \\
\hline & Others & & $<0.001$ & $<0.001$ \\
\hline & Sum & & 0.1 & $<0.001$ \\
\hline \multirow[t]{3}{*}{ Fissile wells } & ${ }^{238} \mathrm{U}$ & $1.4 \times 10^{4}$ & $0.002^{\prime}$ & $0.002^{\prime}$ \\
\hline & Others & & $<0.001$ & $<0.001$ \\
\hline & Sum & & 0.002 & 0.002 \\
\hline \multirow[t]{5}{*}{ Quadrex trenches } & ${ }^{137} \mathrm{Cs}$ & $1.2 \times 10^{4}$ & 0.002 & \\
\hline & ${ }^{230} \mathrm{Th}$ & $3.5 \times 10^{1}$ & 0.003 & 0.008 \\
\hline & ${ }^{232} \mathrm{Th}$ & $2.2 \times 10^{1}$ & 0.020 & 0.020 \\
\hline & Others & & $<0.001$ & $<0.001$ \\
\hline & Sum & & 0.025 & 0.028 \\
\hline Biological trenches $^{g}$ & All & & $<0.001$ & $<0.001$ \\
\hline
\end{tabular}

${ }^{\circ}$ Doses are calculated from Eq. (6-10) using scenario dose conversion factors (SDCFs) given in Table 6.2, waste dilution factors given in Table 6.6, and radioactive decay factors described in Eq. (6-5) and Eq. (6-6).

${ }^{b}$ Radionuclide concentrations in waste at time of disposal obtained from reported inventories and waste volumes given in Appendix A. facility.

'Separate dose assessment is performed for low-range silos in north (N) and south (S) areas of SWSA 6

${ }^{d}$ High-range wells and high-range wells in silos are treated as single set of disposal units.

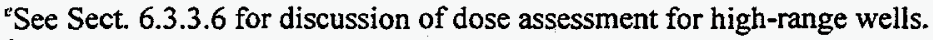

${ }^{{ }^{\prime}}$ See Sect. 6.3.3.7 for discussion of dose assessment for fissile wells.

${ }^{8}$ Biological trenches in north and south areas of SWSA 6 facility are considered as single set of disposal units for purposes of intruder dose assessment. For biological trenches, scenario first occurs at 100 years after disposal. 
Table 6.15. Estimated annual effective dose equivalents to inadvertent intruders for resident scenario for closed disposal units in the SWSA 6 facility ${ }^{a}$

\begin{tabular}{|c|c|c|c|}
\hline Disposal unit & Nuclide & $\begin{array}{c}\text { Concentration } \\
\left(\mu \mathrm{Ci} / \mathrm{m}^{3}\right)^{b}\end{array}$ & $\begin{array}{l}\text { Annual dose } \\
\text { (rem/year) }\end{array}$ \\
\hline \multirow[t]{3}{*}{ Tumulus I } & ${ }^{137} \mathrm{Cs}$ & $3.3 \times 10^{4}$ & 0.042 \\
\hline & Others & & $<0.001$ \\
\hline & Sum & & 0.042 \\
\hline \multirow[t]{3}{*}{ Tumulus II } & ${ }^{137} \mathrm{Cs}$ & $1.3 \times 10^{4}$ & 0.016 \\
\hline & Others & & $<0.001$ \\
\hline & Sum & & 0.016 \\
\hline \multirow{6}{*}{ Low-range silos $(\mathrm{N})^{c}$} & ${ }^{137} \mathrm{Cs}$ & $5.3 \times 10^{4}$ & 0.042 \\
\hline & ${ }^{152} \mathrm{Eu}$ & $1.7 \times 10^{4}$ & 0.002 \\
\hline & ${ }^{226} \mathrm{Ra}$ & $2.3 \times 10^{1}$ & 0.001 \\
\hline & ${ }^{232} \mathrm{Th}$ & $2.5 \times 10^{1}$ & 0.002 \\
\hline & Others & & $<0.001$ \\
\hline & Sum & & 0.047 \\
\hline \multirow[t]{4}{*}{ Low-range silos $(\mathrm{S})^{c}$} & ${ }^{137} \mathrm{Cs}$ & $1.1 \times 10^{4}$ & 0.009 \\
\hline & ${ }^{152} \mathrm{Eu}$ & $4.6 \times 10^{3}$ & 0.001 \\
\hline & Others & & $<0.001$ \\
\hline & Sum & & 0.010 \\
\hline \multirow[t]{4}{*}{ High-range silos } & ${ }^{137} \mathrm{Cs}$ & $3.8 \times 10^{4}$ & 0.030 \\
\hline & ${ }^{152} \mathrm{Eu}$ & $7.1 \times 10^{3}$ & 0.001 \\
\hline & Others & & $<0.001$ \\
\hline & Sum & & 0.031 \\
\hline Asbestos silos & All & & $<0.001$ \\
\hline High-range wells ${ }^{d}$ & All & & $e$ \\
\hline Fissile wells & All & & $f$ \\
\hline \multirow[t]{3}{*}{ Quadrex trenches } & ${ }^{137} \mathrm{Cs}$ & $1.2 \times 10^{4}$ & 0.010 \\
\hline & Others & & $<0.001$ \\
\hline & Sum & & 0.010 \\
\hline
\end{tabular}

${ }^{a}$ Doses are calculated from Eq. (6-11) using scenario dose conversion factors (SDCFs) given in Table 6.3, waste dilution factors given in Table 6.6, and radioactive decay factors described in Eq. (6-5) and Eq. (6-6). Time of occurrence for scenario is assumed to be 100 years after disposal.

${ }^{b}$ Radionuclide concentrations in waste at time of disposal obtained from reported inventories and waste volumes given in Appendix A. facility.

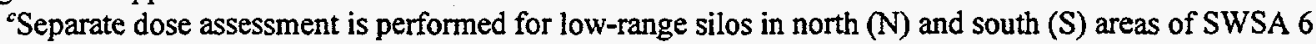

${ }^{d}$ High-range wells and high-range wells in silos are treated as single set of disposal units.

esee Sect. 6.3.3.6 for discussion of dose assessment for high-range wells; dose is essentially zero because waste is located far below ground surface.

${ }^{f}$ See Sect. 6.3.3.7 for discussion of dose assessment for fissile wells; dose is essentially zero because waste is located far below ground surface. 
Table 6.16. Estimated annual effective dose equivalents to inadvertent intruders for post-drilling scenario for closed disposal units in the SWSA 6 facility ${ }^{a}$

\begin{tabular}{|c|c|c|c|}
\hline Disposal unit & Nuclide & $\begin{array}{l}\text { Concentration } \\
\left(\mu \mathrm{Ci} / \mathrm{m}^{3}\right)^{b}\end{array}$ & $\begin{array}{l}\text { Annual dose } \\
\text { (rem/year) }\end{array}$ \\
\hline \multirow[t]{3}{*}{ Tumulus I } & ${ }^{90} \mathrm{Sr}$ & $1.6 \times 10^{4}$ & 0.003 \\
\hline & Others & & $<0.001$ \\
\hline & Sum & & 0.003 \\
\hline \multirow[t]{3}{*}{ Tumulus II } & ${ }^{90} \mathrm{Sr}$ & $4.7 \times 10^{3}$ & 0.001 \\
\hline & Others & & $<0.001$ \\
\hline & Sum & & 0.001 \\
\hline \multirow[t]{4}{*}{ Low-range silos $(\mathrm{N})^{c}$} & ${ }^{90} \mathrm{Sr}$ & $6.8 \times 10^{4}$ & 0.012 \\
\hline & ${ }^{137} \mathrm{Cs}$ & $5.3 \times 10^{4}$ & 0.001 \\
\hline & Others & & $<0.001$ \\
\hline & Sum & & 0.013 \\
\hline \multirow[t]{3}{*}{ Low-range silos $(\mathrm{S})^{c}$} & ${ }^{90} \mathrm{Sr}$ & $8.5 \times 10^{3}$ & 0.001 \\
\hline & Others & & $<0.001$ \\
\hline & Sum & & 0.001 \\
\hline \multirow[t]{3}{*}{ High-range silos } & ${ }^{90} \mathrm{Sr}$ & $3.2 \times 10^{4}$ & 0.006 \\
\hline & Others & & $<0.001$ \\
\hline & Sum & & 0.006 \\
\hline Asbestos silos & All & & $<0.001$ \\
\hline \multicolumn{4}{|l|}{ High-range wells ${ }^{d}$} \\
\hline \multicolumn{4}{|l|}{ Fissile wells ${ }^{d}$} \\
\hline Quadrex trenches & All & & $<0.001$ \\
\hline
\end{tabular}

"Doses are calculated from Eq. (6-11) using scenario dose conversion factors (SDCFs) given in Table 6.4 and radioactive decay factors described in Eq. (6-5) and Eq. (6-6), but waste dilution factors are not used in this scenario. Time of occurrence for scenario is assumed to be 100 years after disposal.

${ }^{b}$ Radionuclide concentrations in waste at time of disposal obtained from reported inventories and waste volumes given in Appendix A. facility.

'Separate dose assessment is performed for low-range silos in north $(\mathrm{N})$ and south (S) areas of SWSA 6

${ }^{d}$ Post-drilling scenario is not considered to be credible occurrence for disposal units due to very small land area occupied by waste and low probability of drilling directly through waste; see Sect. 6.3.3.6 and Sect. 6.3.3.7 for discussion of dose assessments for high-range wells and fissile wells. 
Table 6.17. Estimated effective dose equivalents to inadvertent intruders for discovery scenario for closed disposal units in the SWSA 6 facility ${ }^{a}$

\begin{tabular}{llcc}
\hline Disposal unit & Nuclide & $\begin{array}{c}\text { Concentration } \\
\left(\mu \mathrm{Ci} / \mathrm{m}^{3}\right)^{b}\end{array}$ & $\begin{array}{c}\text { Dose } \\
(\mathrm{rem})\end{array}$ \\
\hline Low-range silos $(\mathrm{N})^{c}$ & ${ }^{137} \mathrm{Cs}$ & $5.3 \times 10^{4}$ & 0.006 \\
& Others & & $<0.001$ \\
& Sum & & 0.006 \\
\hline Low-range silos $(\mathrm{S})^{c}$ & ${ }^{137} \mathrm{Cs}$ & $1.1 \times 10^{4}$ & 0.001 \\
& Others & & $<0.001$ \\
& Sum & & 0.001 \\
\hline High-range silos & ${ }^{137} \mathrm{Cs}$ & $3.8 \times 10^{4}$ & 0.004 \\
& Others & & $<0.001$ \\
& Sum & & 0.004 \\
\hline Asbestos silos & All & $1.4 \times 10^{8}$ & $<0.001$ \\
\hline High-range wells ${ }^{d}$ & ${ }^{137} \mathrm{Cs}$ & & $0.04^{e}$ \\
& Others & & $<0.001$ \\
& Sum & & 0.04 \\
\hline Fissile wells & All & $<0.001^{f}$ \\
\hline
\end{tabular}

${ }^{\circ}$ Doses are calculated from Eq. (6-11) using scenario dose conversion factors (SDCFs) given in Table 6.5, waste dilution factors given in Table 6.6, and radioactive decay factors described in Eq. (6-5) and Eq. (6-6). Time of occurrence for scenario is assumed to be 100 years after disposal.

${ }^{b}$ Radionuclide concentrations in waste at time of disposal obtained from reported inventories and waste volumes given in Appendix A. facility.

'Separate dose assessment is performed for low-range silos in north (N) and south (S) areas of SWSA 6

${ }^{d} \mathrm{High}$-range wells and high-range wells in silos are treated as single set of disposal units.

"See Sect. 6.3.3.6 for discussion of dose assessment for high-range wells.

${ }^{f}$ See Sect. 6.3.3.7 for discussion of dose assessment for fissile wells. 
Table 6.18. Summary of estimates of effective dose equivalents to inadvertent intruders for assumed exposure scenarios ${ }^{a}$

\begin{tabular}{|c|c|c|c|c|}
\hline Disposal unit & $\begin{array}{l}\text { Agriculture } \\
\text { (rem/year) }^{b}\end{array}$ & $\begin{array}{c}\text { Resident } \\
\text { (rem/year) }\end{array}$ & $\begin{array}{l}\text { Post-drilling } \\
\text { (rem/year) }\end{array}$ & $\begin{array}{l}\text { Discovery } \\
\text { (rem) }\end{array}$ \\
\hline Tumulus I & 0.020 & 0.042 & 0.003 & \\
\hline Tumulus II & 0.006 & 0.016 & 0.001 & \\
\hline Low-range silos (N) & 0.055 & 0.047 & 0.013 & 0.006 \\
\hline Low-range silos (S) & 0.006 & 0.010 & 0.001 & 0.001 \\
\hline High-range silos & 0.008 & 0.031 & 0.006 & 0.004 \\
\hline Asbestos silos & 0.002 & $<0.001$ & $<0.001$ & $<0.001$ \\
\hline High-range wells ${ }^{c}$ & 0.1 & $\approx 0$ & $d$ & 0.04 \\
\hline Fissile wells ${ }^{e}$ & 0.002 & $\approx 0$ & $d$ & $<0.001$ \\
\hline Quadrex trenches & 0.028 & 0.010 & $<0.001$ & \\
\hline Biological trenches & $<0.001$ & & & \\
\hline
\end{tabular}

${ }^{a}$ Total doses from all radionuclides for agriculture, resident, post-drilling, and discovery scenarios are obtained from Table 6.14 through Table 6.17.

${ }^{b}$ Maximum dose during 1,000-year compliance period occurs at 1,000 years for Quadrex trenches, 100 years for biological trenches, and 300 years for all other disposal units.

'See Sect. 6.3.3.6 for discussion of dose assessment for high-range wells.

“Post-drilling scenario is not considered to be credible occurrence for these disposal units.

eSee Sect. 6.3.3.7 for discussion of dose assessment for fissile wells.

exposure scenarios are given at 100 years, which is the earliest time when the scenarios are assumed to occur and is the time when the doses are the highest.

Table 6.18 summarizes the results for the different exposure scenarios in Table 6.14 through Table 6.17. For the agriculture scenario, the results in Table 6.18 are the highest annual doses at any time during the 1,000-year compliance period. The highest doses occur at 100 years for the biological trenches, 1,000 years for the Quadrex trenches, and 300 years for all other disposal units. The results for the different disposal units in Table 6.14 through Table 6.18 are described in the following sections.

\subsubsection{Assessment for Tumulus I}

For Tumulus I, the estimated annual doses for the agriculture, resident, and post-drilling scenarios are less than the performance objective of 0.1 rem per year. The resident scenario at 100 years after disposal yields the highest estimate of dose, and the dose for this scenario is due almost entirely to ${ }^{137} \mathrm{Cs}$. The discovery scenario is not relevant for Tumulus I. 
The dose estimates for the agriculture scenario in Table 6.14 do not include contributions from radon, and they assume a time of compliance of 1,000 years for the performance objective for inadvertent intruders. If the contributions to dose from radon were included and there were no time constraint for applying the performance objective, and taking into account the mobilization and transport factors in Table 6.8 and the solubility limits and solubility-limited release rates in Table 6.9, the following adjustments in the dose estimates would be obtained (see Sect. 6.3.2.1).

- For ${ }^{226} \mathrm{Ra}$ and ${ }^{232} \mathrm{Th}$, inclusion of the dose from radon would increase the dose estimates by factors of about 50 and 4, respectively.

- For ${ }^{233} \mathrm{U}$, the maximum dose would occur at about 20,000 years and would be a factor of about 6 higher than the estimate at 1,000 years.

- For ${ }^{238} \mathrm{U}$, the average concentration in the disposal units of $10 \mu \mathrm{Ci} / \mathrm{m}^{3}$ exceeds the solubility limit of $1.4 \mu \mathrm{Ci} / \mathrm{m}^{3}$, and the release rate at the solubility limit would not reduce the concentration below the solubility limit until about one million years. At this time, the estimated annual dose would be about $0.4 \mathrm{rem}$ if the dose from radon were included and about $0.01 \mathrm{rem}$ if the dose from radon were excluded.

Similar adjustments in the dose estimates would not be important for any other radionuclides in these disposal units.

\subsubsection{Assessment for Tumulus II}

The results of the dose assessment for Tumulus II are similar to the results for Tumulus I in that the annual doses for each scenario are less than the performance objective, the resident scenario at 100 years after disposal yields the highest estimate of dose, and the dose for the resident scenario is due almost entirely to ${ }^{137} \mathrm{Cs}$. However, the estimated doses for Tumulus II are about a factor of three less than for Tumulus I, due to the generally lower concentrations of the most important radionuclides in Tumulus II, particularly ${ }^{137} \mathrm{Cs}$.

If the contributions to dose from radon were included and there were no time constraint for applying the performance objective for inadvertent intruders, and taking into account the information in Table 6.8 and Table 6.9, the following adjustments in the dose estimates for the agriculture scenario in Table 6.14 would be obtained (see Sect. 6.3.2.1).

- $\quad$ For ${ }^{232} \mathrm{Th}$, inclusion of the dose from radon would increase the dose estimate by a factor of about 4.

- $\quad$ For ${ }^{233} \mathrm{U}$, the maximum dose would occur at about 20,000 years, and the dose at this time would be a factor of about 6 higher than the estimate at 1,000 years. 
- For ${ }^{238} \mathrm{U}$, the average concentration in the disposal units of $5.9 \mu \mathrm{Ci} / \mathrm{m}^{3}$ exceeds the solubility limit of $1.4 \mu \mathrm{Ci} / \mathrm{m}^{3}$, and the release rate at the solubility limit would not reduce the concentration below the solubility limit until about 500,000 years. At this time, the estimated annual dose would be about $0.1 \mathrm{rem}$ if the dose from radon were included and about 0.003 rem if the dose from radon were excluded.

Similar adjustments in the dose estimates would not be important for any other radionuclides in these disposal units.

\subsubsection{Assessment for Low-Range Silos}

For the low-range silos, separate dose assessments were performed for the north and south areas of the SWSA 6 site, because the two sets of disposal units are not in close proximity. For most radionuclides, the average concentrations in the north units and, thus, the estimated doses are considerably higher than in the south units.

For the north and south disposal units, the estimated doses for all scenarios are less than the corresponding performance objectives. In the north units, the agriculture scenario at 300 years after disposal yields the highest estimate of dose, and the dose is due primarily to ${ }^{232} \mathrm{Th},{ }^{226} \mathrm{Ra}$, and ${ }^{137} \mathrm{Cs}$. In the south units, the resident scenario at 100 years after disposal yields the highest estimate of dose, and the dose is due primarily to ${ }^{137} \mathrm{Cs}$.

If the contributions to dose from radon were included and there were no time constraint for applying the performance objective for inadvertent intruders, and taking into account the information in Table 6.8 and Table 6.9, the following adjustments in the dose estimates for the agriculture scenario in Table 6.14 would be obtained (see Sect. 6.3.2.1).

- For ${ }^{226} \mathrm{Ra}$ and ${ }^{232} \mathrm{Th}$, inclusion of the dose from radon would increase the dose estimates by factors of about 50 and 4, respectively, and the estimated annual dose for ${ }^{226} \mathrm{Ra}$ in the south disposal units would be about 0.01 rem at 300 years after disposal.

- For ${ }^{233} \mathrm{U}$, the maximum dose would occur at about 20,000 years and would be a factor of about 6 higher than the estimate at 1,000 years, and the estimated annual dose for the north disposal units at this time would be about $0.003 \mathrm{rem}$.

- For ${ }^{238} \mathrm{U}$, the average concentrations in the north and south disposal units of $58 \mu \mathrm{Ci} / \mathrm{m}^{3}$ and $26 \mu \mathrm{Ci} / \mathrm{m}^{3}$, respectively, exceed the solubility limit of $1.4 \mu \mathrm{Ci} / \mathrm{m}^{3}$, and the release rate at the solubility limit would not reduce the concentrations below the solubility limit until beyond one million years. At this time, the estimated annual dose in the north units would be about 2 rem if the dose from radon were included and about 0.03 rem if the dose from radon were excluded, and the corresponding dose estimates in the south units would be about 0.8 rem and 0.02 rem. 
Similar adjustments in the dose estimates would not be important for any other radionuclides in these disposal units.

\subsubsection{Assessment for High-Range Silos}

For the high-range silos, the doses for each scenario are less than the corresponding performance objectives. The resident scenario at 100 years after disposal yields the highest estimate of dose, and the dose for this scenario is due almost entirely to ${ }^{137} \mathrm{Cs}$.

If the contributions to dose from radon were included and there were no time constraint for applying the performance objective for inadvertent intruders, and taking into account the information in Table 6.8 and Table 6.9, the following adjustments in the dose estimates for the agriculture scenario in Table 6.14 would be obtained (see Sect. 6.3.2.1).

- For ${ }^{232} \mathrm{Th}$, inclusion of the dose from radon would result in an estimated annual dose of about $0.001 \mathrm{rem}$.

- For ${ }^{238} \mathrm{U}$, the average concentration in the disposal units of $23 \mu \mathrm{Ci} / \mathrm{m}^{3}$ exceeds the solubility limit of $1.4 \mu \mathrm{Ci} / \mathrm{m}^{3}$, and the release rate at the solubility limit would not reduce the concentration below the solubility limit until beyond one million years. At this time, the estimated annual dose would be about $0.7 \mathrm{rem}$ if the dose from radon were included and about $0.01 \mathrm{rem}$ if the dose from radon were excluded.

Similar adjustments in the dose estimates would not be important for any other radionuclides in these disposal units.

\subsubsection{Assessment for Asbestos Silos}

For the asbestos silos, the doses for each scenario are far less than the corresponding performance objectives, due to the low concentrations of all radionuclides in these units. The agriculture scenario at 300 years after disposal yields the highest estimate of dose, and the dose for this scenario is due primarily to ${ }^{232} \mathrm{Th}$ and ${ }^{239} \mathrm{Pu}$.

If the contributions to dose from radon were included and there were no time constraint for applying the performance objective for inadvertent intruders, and taking into account the information in Table 6.8 and Table 6.9 , the following adjustments in the dose estimates for the agriculture scenario in Table 6.14 would be obtained (see Sect. 6.3.2.1).

- For ${ }^{232} \mathrm{Th}$, inclusion of the dose from radon would increase the dose estimate by a factor of about 4. 
- For ${ }^{238} \mathrm{U}$, the average concentration in the disposal units of $3.2 \mu \mathrm{Ci} / \mathrm{m}^{3}$ exceeds the solubility limit of $1.4 \mu \mathrm{Ci} / \mathrm{m}^{3}$, and the release rate at the solubility limit would not reduce the concentration below the solubility limit until about 300,000 years. At this time, the estimated annual dose would be about 0.04 rem if the dose from radon were included and about $0.001 \mathrm{rem}$ if the dose from radon were excluded.

Similar adjustments in the dose estimates would not be important for any other radionuclides in these disposal units.

\subsubsection{Assessment for High-Range Wells}

The high-range wells require special consideration in the dose assessment for inadvertent intruders, primarily because most of the waste in these disposal units is located a considerable distance below the ground surface. Disposal well below ground generally was required to limit external exposures of workers to the high concentrations of photon-emitting radionuclides in the waste. The depth of burial of waste in the high-range wells is important in the dose assessment for inadvertent intruders primarily because waste at sufficient depths would not be accessed by an excavation, as is assumed, for example, in the agriculture scenario. In addition, only 63 high-range wells were used and, thus, the areal extent of the land surface occupied by waste in these units is considerably less than in the above-grade disposal units or the below-grade silos discussed previously. An intruder dose assessment for the high-range wells that takes these factors into account is described as follows.

\subsection{Dose Assessment for Agriculture Scenario}

The agriculture scenario assumes that an inadvertent intruder excavates at the disposal site while constructing a foundation for a home. Doses then result from garden pathways following mixing of exhumed waste in the intruder's vegetable garden and from residence pathways during indoor residence on top of the disposal units (see Sect. 6.1.1 and Table 6.2). Therefore, doses from the garden pathways would occur only if the waste were sufficiently close to the ground surface that it would be exhumed during excavation. Similarly, doses from the residence pathways would occur only if the waste remaining in the disposal units after excavation were sufficiently close to the surface that it would not be completely shielded. Doses for the garden and residence pathways for the high-range wells are considered separately in the following paragraphs.

\section{Garden Pathways}

As discussed in Sect. 6.3.1.1, the depth of an excavation below the ground surface is assumed to be $3 \mathrm{~m}$. Furthermore, the current closure plan for the SWSA 6 facility includes an added cover $0.3 \mathrm{~m}$ thick. Therefore, doses from the garden pathways would result only if the waste were presently located within $2.7 \mathrm{~m}$ (i.e., $9 \mathrm{ft}$ ) of the ground surface. 
Available information on waste disposals in each of the 63 high-range wells, including data on the depth and diameter of each well, the total volume of waste in each well, and the depth of the waste in wells after disposals were completed, indicates that only 9 of the 63 wells have waste located within $9 \mathrm{ft}$ of the ground surface. The distance from the ground surface to the top of the waste in these wells varies from $4 \mathrm{ft}$ to $8 \mathrm{ft}$.

The reported total activities of radionuclides in the 9 wells of concern are $312 \mathrm{Ci}$ of ${ }^{60} \mathrm{Co}$, $87 \mathrm{Ci}$ of ${ }^{90} \mathrm{Sr}, 118 \mathrm{Ci}$ of ${ }^{137} \mathrm{Cs}, 213 \mathrm{Ci}$ of ${ }^{152} \mathrm{Eu}$, and $222 \mathrm{Ci}$ of ${ }^{154} \mathrm{Eu}$. Again, however, only waste located within $9 \mathrm{ft}$ of the ground surface would contribute to the dose for the garden pathways. If the activities of radionuclides in the waste are assumed to be uniformly distributed with depth in each well, the total activity of radionuclides located within $9 \mathrm{ft}$ of the ground surface in these wells is $50 \mathrm{Ci}$ of ${ }^{60} \mathrm{Co}, 14 \mathrm{Ci}$ of ${ }^{90} \mathrm{Sr}, 20 \mathrm{Ci}$ of ${ }^{137} \mathrm{Cs}, 30 \mathrm{Ci}$ of ${ }^{152} \mathrm{Eu}$, and $27 \mathrm{Ci}$ of ${ }^{154} \mathrm{Eu}$. These are the total activities of radionuclides that would be exhumed by excavation into the high-range wells.

The activities of radionuclides estimated above can be converted to average concentrations in exhumed material using the assumed area of $300 \mathrm{~m}^{2}$ for an excavation (see Sect. 6.3.1.1). Thus, for the assumed depth of an excavation of $3 \mathrm{~m}$, the volume of exhumed material is $900 \mathrm{~m}^{3}$, and the average concentrations of radionuclides in the exhumed material are $5.6 \times 10^{4} \mu \mathrm{Ci} / \mathrm{m}^{3}$ for ${ }^{\circ} \mathrm{Co}$. $1.6 \times 10^{4} \mu \mathrm{Ci} / \mathrm{m}^{3}$ for ${ }^{90} \mathrm{Sr}, 2.2 \times 10^{4} \mu \mathrm{Ci} / \mathrm{m}^{3}$ for ${ }^{137} \mathrm{Cs}, 3.3 \times 10^{4} \mu \mathrm{Ci} / \mathrm{m}^{3}$ for ${ }^{152} \mathrm{Eu}$, and $3.0 \times 10^{4} \mu \mathrm{Ci} / \mathrm{m}^{3}$ for ${ }^{152} \mathrm{Eu}$.

The annual dose for the garden pathways then can be estimated using the average concentrations given above and the SDCFs for the garden pathways in Table 6.2. Taking into account radioactive decay over the 300 years prior to the time the agriculture scenario is assumed to occur, the estimated annual doses are 0.002 rem for ${ }^{90} \mathrm{Sr}$ and $<0.001$ rem for the other radionuclides. Therefore, the estimated annual dose for the garden pathways is $0.002 \mathrm{rem}$.

\section{Residence Pathways}

During indoor residence on top of the high-range wells, external exposure to photon-emitting radionuclides in the waste is the primary pathway of concern. A comparison of the SDCFs for the residence pathways for ${ }^{90} \mathrm{Sr}$ and ${ }^{137} \mathrm{Cs}$ given in Table 6.2 indicates that inhalation exposure can be neglected, even for exposed waste, when the concentrations of photon-emitting and non-photonemitting radionuclides are comparable. Furthermore, based on the inventories of photon-emitting radionuclides in the high-range wells, and taking into account their half-lives, the external dose during indoor residence at 300 years after disposal would be due almost entirely to ${ }^{137} \mathrm{Cs}$, and this is the only radionuclide considered in the dose assessment described below.

During indoor residence on top of the high-range wells following excavation at the site, the external dose would result almost entirely from radionuclides located near the excavated surface. Thus, since the excavation is assumed to uncover the top $9 \mathrm{ft}(2.7 \mathrm{~m})$ of the wells, only activity presently located between $9 \mathrm{ft}$ and $11 \mathrm{ft}$ of the ground surface (i.e., within the first $2 \mathrm{ft}$ of the ground surface after excavation) would contribute significantly to the external dose, because the shielding provided by 
$2 \mathrm{ft}(0.6 \mathrm{~m})$ of soil reduces the external dose from exposure to deeper sources of ${ }^{137} \mathrm{Cs}$ by more than a factor of 1,000 (Kocher and Sjoreen 1985; NCRP 1976).

The external dose rate per unit concentration of ${ }^{137} \mathrm{Cs}$ in soil decreases rapidly with the depth of the sources. Therefore, the external dose from sources presently located between $9 \mathrm{ft}$ and $10 \mathrm{ft}$ of the ground surface is considered separately from the dose from sources located between $10 \mathrm{ft}$ and $11 \mathrm{ft}$. Based on the available information on disposals of ${ }^{137} \mathrm{Cs}$ in the wells and assuming a uniform distribution of activity with depth, the total activity of ${ }^{137} \mathrm{Cs}$ presently located between $9 \mathrm{ft}$ and $10 \mathrm{ft}$ is estimated to be $14 \mathrm{Ci}$, and the activity of ${ }^{137} \mathrm{Cs}$ located between $10 \mathrm{ft}$ and $11 \mathrm{ft}$ is estimated to be $55 \mathrm{Ci}$.

As in the dose assessment for the garden pathways, the area of the excavation is assumed to be

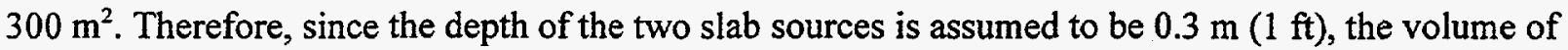
the two slabs is $90 \mathrm{~m}^{3}$, and the resulting average concentrations of ${ }^{137} \mathrm{Cs}$ are $1.6 \times 10^{5} \mu \mathrm{Ci} / \mathrm{m}^{3}$ for the upper slab and $6.1 \times 10^{5} \mu \mathrm{Ci} / \mathrm{m}^{3}$ for the lower slab.

For ${ }^{137} \mathrm{Cs}$ that is assumed to be uniformly distributed in the upper $1-\mathrm{ft}(0.3-\mathrm{m})$ slab of soil, the external dose rate per unit concentration is $2.0 \times 10^{-3} \mathrm{rem} /$ year per $\mu \mathrm{Ci} / \mathrm{m}^{3}$ (Eckerman and Ryman 1993; Kocher and Sjoreen 1985), and the dose rate per unit concentration in the second slab of soil is $6.6 \times 10^{-5} \mathrm{rem} /$ year per $\mu \mathrm{Ci} / \mathrm{m}^{3}$ (Kocher and Sjoreen 1985 ). Using the average concentrations of ${ }^{137} \mathrm{Cs}$ in the two slabs and the external dose rates per unit concentration given above, and taking into account radioactive decay over 300 years and the assumption that exposure occurs for $50 \%$ of the time in a home with a shielding factor of 0.7 (see Sect. G.5.2.1 of Appendix G), the estimated annual dose for the residence pathways is $0.1 \mathrm{rem}$.

The estimated annual dose for the residence pathways of $0.1 \mathrm{rem}$ is much larger than the value for the garden pathways of $0.002 \mathrm{rem}$. Therefore, for the high-range wells, the total annual dose from all exposure pathways for the agriculture scenario is estimated to be $0.1 \mathrm{rem}$. Again, this dose is due almost entirely to external exposure to ${ }^{137} \mathrm{Cs}$ during indoor residence.

The total annual dose of 0.1 rem is equal to the performance objective for inadvertent intruders. However, there are several factors which indicate that the estimated dose is likely to be somewhat conservative. Probably the most important is the assumption that the depth of an excavation at the disposal site would be $3 \mathrm{~m}$. This depth represents a pessimistic assumption for an excavation for a family home, rather than an average value (Oztunali and Roles 1986). If the depth of an excavation into the high-range wells were less than $3 \mathrm{~m}$, the estimated dose would be reduced, because many of the sources contributing to the dose for a 3-m excavation would be completely shielded. For example, if the depth of the excavation were assumed to be $2 \mathrm{~m}$, the estimated external dose during indoor residence would be reduced by a factor of about three.

A second potentially important factor in reducing external dose during indoor residence is the presence of shield plugs in some of the high-range wells. Disposals in many of the wells occurred over an extended period of time. In stacking waste containers in the wells prior to closure, a concrete or dirt plug often was inserted in the well immediately after a disposal to limit the external dose rate above ground from the open well. The presence of any such plugs at depths of 9 to $11 \mathrm{ft}$ in the wells of concern to this assessment would substantially reduce the contribution to external dose from those wells. For example, if a plug were $0.3 \mathrm{~m}$ ( $1 \mathrm{ft}$ ) thick, the external dose from sources below the plug 
would be reduced by a factor of about 30 (Kocher and Sjoreen 1985; Eckerman and Ryman 1993). However, there is no information indicating whether plugs occur at these depths in the wells of concern to this assessment.

A factor of somewhat lesser importance is the shielding that would be provided by the waste containers, which are drums or cans made mostly of iron. For a container with a nominal wall thickness of $2 \mathrm{~mm}$ (less than $3 / 32$ in.), the external dose rate would be reduced by about $10 \%$ (Shleien 1992). Shielding provided by the waste itself is taken into account in the dose analysis by assuming that the waste has shielding properties similar to soil.

Finally, the estimated dose depends on the time after disposal when the exposure scenario is assumed to occur, and this time depends on the assumed lifetime of engineered barriers in the highrange wells. If the barriers could be assumed to maintain their integrity for longer than 300 years, the estimated dose would be reduced in accordance with the half-life of ${ }^{137} \mathrm{Cs}$. In particular, the dose would be reduced by an order of magnitude for every 100 years that the barriers maintain their integrity and preclude excavation into the waste.

Taking into account all of the factors described above, there is a reasonable expectation that disposals in the high-range wells meet the performance objective for the agriculture scenario.

\subsection{Dose Assessment for Resident Scenario}

The resident scenario assumes that an inadvertent intruder resides in a home constructed on top of intact engineered barriers used in constructing the disposal units. The uppermost engineered barrier used in constructing the high-range wells is located at ground level and, as noted in the discussion of the garden pathways for the agriculture scenario, the waste in these wells is located at a minimum distance of $4 \mathrm{ft}$ (about $1.2 \mathrm{~m}$ ) below the ground surface.

For ${ }^{137} \mathrm{Cs}$, a thickness of soil of about $1.2 \mathrm{~m}$ between the source and receptor locations reduces the external dose by a factor of about $10^{6}$ (NCRP 1976). Therefore, taking into account that the thickness of soil between the ground surface and the top of the waste for an average well appears to be about $3 \mathrm{~m}$ or greater, it is evident that the external dose above ground from exposure to ${ }^{137} \mathrm{Cs}$ in the high-range wells would be essentially zero.

\subsection{Dose Assessment for Post-Drilling Scenario}

The post-drilling scenario assumes that an inadvertent intruder drills directly through disposed waste and that exposures occur as a result of mixing of drilling waste in the intruder's vegetable garden. Based on the reported concentrations of radionuclides in the high-range wells and the SDCFs for the post-drilling scenario in Table 6.4, and taking into account radioactive decay over the 100 years prior to the time the post-drilling scenario is assumed to occur, the following estimates of annual dose would be obtained: $15 \mathrm{rem}$ for ${ }^{90} \mathrm{Sr}, 1.8$ rem for ${ }^{137} \mathrm{Cs}$, and much lower values for other radionuclides. Thus, the estimated annual dose for the post-drilling scenario is about $17 \mathrm{rem}$. 
The estimated dose for the post-drilling scenario calculated above greatly exceeds the performance objective for inadvertent intruders. However, a reasonable argument can be made that the post-drilling scenario is not a credible occurrence for the high-range wells. As discussed in Sect. 6.3.1.1, only about $7.5 \%$ of the land area encompassed by these disposal units is occupied by waste. Therefore, the probability that an inadvertent intruder who is assumed to drill at random locations within the boundary of the high-range wells would exhume waste is less than $10 \%$. Furthermore, given the areal extent of the entire SWSA 6 site and assuming that inadvertent intruders would not drill a large number of wells on the site, the likelihood of drilling through waste in the highrange wells clearly is very low.

When performance objectives are expressed in terms of dose, the scenarios assumed in demonstrating compliance with the performance objectives must be credible, i.e., reasonably likely to occur (DOE 1996c; Wood et al. 1994). Because the post-drilling scenario clearly could occur only with a low probability for the high-range wells, evaluation of the consequences of this scenario does not provide a reasonable basis for determining compliance of these disposal units with the performance objective for inadvertent intruders. The post-drilling scenario is credible only when the waste occupies a substantial fraction of the land area within disposal units.

\subsection{Dose Assessment for Discovery Scenario}

The discovery scenario assumes that, during an excavation at the disposal site, an inadvertent intruder receives an external exposure while working for a short period of time at the side of disposal units that are constructed with engineered barriers. Given the assumed 3-m depth of an excavation and the previous discussion of the garden pathways for the agriculture scenario, the discovery scenario for

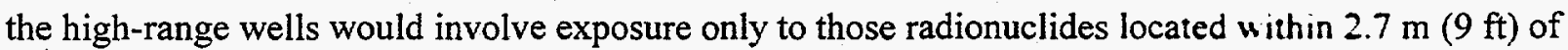
the ground surface, because sources located deeper in the wells essentially would be completely shielded.

In discussing the dose assessment for the garden pathways for the agriculture scenario, the following estimates of activities of photon-emitting radionuclides in the high-range wells located within $9 \mathrm{ft}$ of the ground surface were obtained: $50 \mathrm{Ci}$ of ${ }^{60} \mathrm{Co}, 20 \mathrm{Ci}$ of ${ }^{137} \mathrm{Cs}, 30 \mathrm{Ci}$ of ${ }^{152} \mathrm{Eu}$, and $27 \mathrm{Ci}$ of ${ }^{154} \mathrm{Eu}$. These activities represent the following percentages of the reported activities in the wells: $2.2 \%$ for ${ }^{60} \mathrm{Co}, 0.82 \%$ for ${ }^{137} \mathrm{Cs}, 2.2 \%$ for ${ }^{152} \mathrm{Eu}$, and $4.7 \%$ for ${ }^{154} \mathrm{Eu}$. The average concentrations in all disposals should be reduced by these percentages to obtain the appropriate average concentrations for input to the dose assessment for the discovery scenario. The resulting average concentrations are $4.3 \times 10^{6} \mu \mathrm{Ci} / \mathrm{m}^{3}$ for ${ }^{60} \mathrm{Co}, 1.1 \times 10^{6} \mu \mathrm{Ci} / \mathrm{m}^{3}$ for ${ }^{137} \mathrm{Cs}, 2.5 \times 10^{6} \mu \mathrm{Ci} / \mathrm{m}^{3}$ for ${ }^{152} \mathrm{Eu}$, and $2.3 \times 10^{6} \mu \mathrm{Ci} / \mathrm{m}^{3}$ for ${ }^{154} \mathrm{Eu}$.

The dose for the discovery scenario then can be estimated from Eq. (6-11) using the average concentrations given above, the SDCFs in Table 6.5, and the waste dilution factor in Table 6.6, and taking into account radioactive decay over 100 years. The estimated doses are 0.04 rem for ${ }^{137} \mathrm{Cs}$ and $<0.001$ rem for the other radionuclides. 
Thus, the estimated dose for the discovery scenario is $0.04 \mathrm{rem}$. This estimate is about an order of magnitude less than the performance objective for this scenario.

\subsubsection{Assessment for Fissile Wells}

The fissile wells also require special consideration in the dose assessment for inadvertent intruders, due to the considerable depth below ground for most of the waste disposals in these units. In addition, as noted in Sect. 6.3.1.1, disposals in only two fissile wells are of concern to this assessment. An intruder dose assessment for the fissile wells, similar to the assessment for the high-range wells presented in the previous section, that takes these factors into account is described as follows.

\subsection{Dose Assessment for Agriculture Scenario}

The dose assessment for the agriculture scenario for the fissile wells was performed in the same manner as the assessment for the high-range wells. The assessments for the garden and residence pathways are considered separately in the following paragraphs.

\section{Garden Pathways}

Doses from the garden pathways would result only if the waste is presently located within $2.7 \mathrm{~m}(9 \mathrm{ft})$ of the ground surface. Based on available information on waste disposals in the two fissile wells of concern to this assessment, the following activities of radionuclides are located within $9 \mathrm{ft}$ of the ground surface: $0.6 \mu \mathrm{Ci}$ of ${ }^{232} \mathrm{Th}, 185 \mu \mathrm{Ci}$ of ${ }^{235} \mathrm{U}$, and $11 \mu \mathrm{Ci}$ of ${ }^{238} \mathrm{U}$. It is particularly noteworthy that all of the ${ }^{137} \mathrm{Cs}$ in these wells is located at depths below $12 \mathrm{ft}$ and, thus, would not contribute to the dose from the garden pathways. For the volume of material assumed to be excavated from the fissile wells $\left(900 \mathrm{~m}^{3}\right)$, the average concentrations of radionuclides in the exhumed material thus are $7 \times 10^{-4} \mu \mathrm{Ci} / \mathrm{m}^{3}$ for ${ }^{232} \mathrm{Th}, 0.21 \mu \mathrm{Ci} / \mathrm{m}^{3}$ for ${ }^{235} \mathrm{U}$, and $0.012 \mu \mathrm{Ci} / \mathrm{m}^{3}$ for ${ }^{238} \mathrm{U}$.

The annual dose for the garden pathways then can be estimated using the average concentrations given above and the SDCFs for the garden pathways in Table 6.2, taking into account the contributions from radiologically significant decay products. The estimated annual doses for all radionuclides are much less than 0.001 rem.

\section{Residence Pathways}

For an excavation extending to a depth of $9 \mathrm{ft}$ below the ground surface, exposures of an onsite resident are assumed to result from (1) external and inhalation exposure to activity in a $1-\mathrm{ft}(0.3-\mathrm{m})$ slab at a depth of 9 to $10 \mathrm{ft}$ and (2) external exposure to activity in a $1-\mathrm{ft}(0.3-\mathrm{m})$ slab at a depth of 10 to $11 \mathrm{ft}$. External exposure to sources below $11 \mathrm{ft}$ in depth would be insignificant due to the considerable shielding provided by a $2-\mathrm{ft}(0.6-\mathrm{m})$ thickness of soil. Therefore, external exposure to ${ }^{137} \mathrm{Cs}$ is not of concern because all of the activity of this radionuclide is located at depths below $12 \mathrm{ft}$. 
The total activities of radionuclides in the 9- to $10-\mathrm{ft}$ slab are estimated to be $0.6 \mu \mathrm{Ci}$ of ${ }^{232} \mathrm{Th}$, $110 \mu \mathrm{Ci}$ of ${ }^{235} \mathrm{U}$, and $4600 \mu \mathrm{Ci}$ of ${ }^{238} \mathrm{U}$, and the total activities in the 10 - to 11 -ft slab are estimated to be $120 \mu \mathrm{Ci}$ of ${ }^{235} \mathrm{U}$ and zero for the other radionuclides. Therefore, since the volume of each slab is assumed to be $90 \mathrm{~m}^{3}$, the resulting average concentrations in the upper slab are $0.007 \mu \mathrm{Ci} / \mathrm{m}^{3}$ for ${ }^{232} \mathrm{Th}$, $1.2 \mu \mathrm{Ci} / \mathrm{m}^{3}$ for ${ }^{235} \mathrm{U}$, and $51 \mu \mathrm{Ci} / \mathrm{m}^{3}$ for ${ }^{238} \mathrm{U}$, and the average concentration of ${ }^{235} \mathrm{U}$ in the lower slab is $1.3 \mu \mathrm{Ci} / \mathrm{m}^{3}$.

For these concentrations of radionuclides in the two slabs, nearly all of the dose for the residence pathways would result from exposure to radionuclides in the upper slab. The dose per unit concentration of radionuclides in the upper slab can be approximated without significant error by the SDCFs for the residence pathways given in Table 6.2. This assumption gives a slightly conservative estimation of dose because these SDCFs assume a source of infinite depth.

Using the estimated concentrations of radionuclides in the upper slab and the SDCFs for the residence pathways given in Table 6.2, and taking into account the contributions from radiologically significant decay products, the estimated annual dose is 0.002 rem for ${ }^{238} U$ and $<0.001$ rem for ${ }^{232} T h$ and ${ }^{235} \mathrm{U}$. Thus, the estimated annual dose for the residence pathways is $0.002 \mathrm{rem}$.

The dose estimate for all exposure pathways in the agriculture scenario thus is $0.002 \mathrm{rem}$, and is far less than the performance objective for inadvertent intruders. Again, the estimated dose does not include contributions from radon, and it assumes a time period of 1,000 years for complying with the performance objective. If there were no time constraint for the performance objective, the annual dose beyond one million years due to ${ }^{238} \mathrm{U}$ would be about $0.1 \mathrm{rem}$, excluding the dose from radon, and 6 rem, including the dose from radon (see Sect. 6.3.2.1).

\subsection{Dose Assessment for Resident Scenario}

All sources in the fissile wells are located at least $7 \mathrm{ft}$ (about $2 \mathrm{~m}$ ) below the ground surface. Therefore, for residence in a home located on top of intact engineered barriers that extend to the ground surface, the external dose would be essentially zero due to the complete shielding provided by the $2 \mathrm{~m}$ of soil-equivalent material (NCRP 1976).

\subsection{Dose Assessment for Post-Drilling Scenario}

Based on the reported concentrations of radionuclides in the fissile wells and the SDCFs for the post-drilling scenario in Table 6.4, and taking into account radioactive decay over the 100 years prior to the time the post-drilling scenario is assumed to occur, the following estimates of annual dose would be obtained: 2 rem for ${ }^{137} \mathrm{Cs}, 0.001 \mathrm{rem}$ for ${ }^{238} \mathrm{U}$, and $<0.001$ rem for the other radionuclides. However, as in the dose assessment for the high-range wells discussed in the previous section, the post-drilling scenario is not considered to be a credible occurrence for the fissile wells, because only two such wells are of concern to this assessment and the probability is very low that an inadvertent intruder would drill directly through either of these wells. 
An argument also can be made that the agriculture, resident, and discovery scenarios would occur with a probability less than unity for the two fissile wells of concern to this assessment, based on the relatively small areal extent of the two wells. However, the probability of accessing these wells during a large-scale surface excavation at the site, as assumed in the agriculture, resident, and discovery scenarios, is substantially higher than the probability of drilling directly through either of the two wells, and there are no other credible scenarios for accessing the waste that would have a higher probability. Therefore, these three scenarios provide a reasonable basis for judging the acceptability of disposals in the two wells based on an intruder dose analysis.

\subsection{Dose Assessment for Discovery Scenario}

In discussing the dose assessment for the garden pathways for the agriculture scenario, the following estimates of activities of radionuclides in the fissile wells located within $9 \mathrm{ft}$ of the ground surface were obtained: $0.6 \mu \mathrm{Ci}$ of ${ }^{232} \mathrm{Th}, 185 \mu \mathrm{Ci}$ of ${ }^{235} \mathrm{U}$, and $11 \mu \mathrm{Ci}$ of ${ }^{238} \mathrm{U}$. These activities represent the following percentages of the total activities in the wells: $50 \%$ for ${ }^{232} \mathrm{Th}, 32 \%$ for ${ }^{235} \mathrm{U}$, and $0.2 \%$ for ${ }^{238} \mathrm{U}$. The average concentrations in all disposals should be reduced by these percentages to obtain the appropriate average concentrations for input to the dose assessment for the discovery scenario. The resulting concentrations are $1.8 \mu \mathrm{Ci} / \mathrm{m}^{3}$ for ${ }^{232} \mathrm{Th}, 5.5 \times 10^{2} \mu \mathrm{Ci} / \mathrm{m}^{3}$ for ${ }^{235} \mathrm{U}$, and $2.9 \times 10^{1} \mu \mathrm{Ci} / \mathrm{m}^{3}$ for ${ }^{238} \mathrm{U}$. Using Eq. (6-11) and these concentrations, the SDCFs for the discovery scenario in Table 6.5, and the waste dilution factor in Table 6.6 , the dose from all radionuclides would be much less than 0.001 rem.

\subsubsection{Assessment for Quadrex Trenches}

For the Quadrex trenches, the doses for each scenario are less than the corresponding performance objectives. The agriculture scenario at 1,000 years after disposal yields the highest estimate of dose, and the dose at this time is due essentially to ${ }^{230} \mathrm{Th}$ and ${ }^{232} \mathrm{Th}$. The Quadrex trenches are the only closed disposal units for which the maximum dose occurs at the end of the 1,000 -year compliance period, rather than at 100 or 300 years when the various scenarios first could occur. This result is due to the relatively high average concentration of ${ }^{230} \mathrm{Th}$ in these units and the buildup of the radiologically more significant ${ }^{226} \mathrm{Ra}$ decay product during the compliance period.

If the contributions to dose from radon were included and there were no time constraint for applying the performance objective for inadvertent intruders, and taking into account the information in Table 6.8 and Table 6.9, the following adjustments in the dose estimates for the agriculture scenario in Table 6.14 would be obtained (see Sect. 6.3.2.1).

- For ${ }^{230} \mathrm{Th}$, the maximum dose would occur at about 10,000 years after disposal. The dose at this time would be a factor of about 130 higher than the estimate at 1,000 years if the dose 
from radon were included, and the increase would be a factor of about 3 if the dose from radon were excluded.

- For ${ }^{232} \mathrm{Th}$, inclusion of the dose from radon would increase the dose estimate by a factor of about 4 .

- For ${ }^{238} \mathrm{U}$, the average concentration in the disposal units of $22 \mu \mathrm{Ci} / \mathrm{m}^{3}$ exceeds the solubility limit of $1.4 \mu \mathrm{Ci} / \mathrm{m}^{3}$, and the release rate at the solubility limit would not reduce the concentration below the solubility limit until beyond one million years. At this time, the estimated annual dose would be about 0.7 rem if the dose from radon were included and about 0.01 rem if the dose from radon were excluded.

Similar adjustments in the dose estimates would not be important for any other radionuclides in these disposal units.

\subsubsection{Assessment for Biological Trenches}

Only the agriculture scenario is relevant in the dose assessment for inadvertent intruders for the biological trenches, because these disposal units were constructed without engineered barriers. For this assessment, the biological trenches in the north and south areas of the SWSA 6 site are treated as a single set of disposal units, primarily because the concentrations of all radionuclides in these units are low and the concentrations of the most important radionuclides in the north and south areas are similar.

The estimated annual dose for the agriculture scenario is far less than the performance objective. Furthermore, there are no radionuclides in the biological trenches for which the dose from radon or the dose beyond the 1,000-year time of compliance for the performance objective would be of concern.

\subsubsection{Summary of Results}

Application of the models for estimating dose to inadvertent intruders according to the assumed exposure scenarios, based on the reported inventories of radionuclides in all closed disposal units, has indicated that all such units comply with the performance objective of 0.1 rem per year for the agriculture, resident, and post-drilling scenarios and the performance objective of 0.5 rem for the discovery scenario. Special considerations were required in the dose assessment for the high-range wells and the fissile wells, because most of the waste in these units is buried well below the ground surface and, thus, much of the waste would not be accessed by the normal kinds of excavation activities assumed in the agriculture, resident, and discovery scenarios. In addition, because the waste in the high-range wells and the fissile wells occupies only a small fraction of the land area encompassed by all of the units, the post-drilling scenario is not considered to be a credible occurrence for these units. Thus, in spite of the high concentrations of radionuclides in the high-range wells and 
fissile wells, a reasonable expectation of compliance with the performance objective was demonstrated based on the reported locations of radionuclides below ground and the areal extent of the waste in the disposal units.

\subsection{SENSITIVITY/UNCERTAINTY ANALYSIS}

This section discusses the sensitivity and uncertainty analysis for the models used to estimate doses to inadvertent intruders for the various disposal units in the SWSA 6 facility. As in the dose assessment for inadvertent intruders in Sect. 6.3, separate discussions of sensitivity and uncertainty are presented for the IWMF (Sect. 6.4.1) and the other disposal units in the SWSA 6 facility (Sect. 6.4.2), because the dose assessments serve different purposes in the two cases. General considerations of uncertainties in the dose assessment models for inadvertent intruders are discussed in Sect. 6.4.3.

The current guidance on performance assessments (DOE 1996c) indicates that the sensitivity and uncertainty analysis for the assumed exposure scenarios for inadvertent intrusion should be limited to qualitative arguments including, for example, discussions of the rationale for the particular scenarios and parameter values selected. These discussions have been presented in Sect. 6.1 and Sect. 6.2 and in Appendix G, Sect. G.5.2. The approach to sensitivity and uncertainty analysis for the intrusion scenarios in the current guidance is based on an assumption that active institutional controls will be maintained over disposal sites until they can be safely released in accordance with requirements in DOE O 5400.5 (or 10 CFR Part 834 when it is promulgated) and, thus, that the assumed scenarios are mostly hypothetical and are not likely to occur as postulated (DOE 1996c).

The discussion of uncertainties in the intruder dose analysis in the following sections goes beyond what is required by the current DOE guidance (DOE 1996c). The purpose of these discussions is to provide insight into the magnitude of uncertainties in the intruder dose analysis. Such insights are particularly important when the results of the intruder dose analysis are used to determine acceptable disposals of nearly all radionuclides in the IWMF (see Sect. 7.1 and Table 7.1). However, a more formal parametric uncertainty analysis, such as the analysis presented in Sect. 5.4 and Appendix I for the modeling of environmental transport of radionuclides, is not needed, because simple linear models are used in estimating dose to inadvertent intruders and only a single model parameter often is the most important in determining the estimated dose for a given radionuclide. Therefore, the estimated magnitude of uncertainties in the important parameter values directly translates into the same magnitude of uncertainties in estimated doses.

In discussing uncertainties in the intruder dose analysis for the IWMF (Sect. 6.4.1) and the closed disposal units (Sect. 6.4.2), uncertainties in the inventories of radionuclides in disposal units are considered separately from uncertainties in the parameter values used in estimating doses per unit concentrations of radionuclides in disposal units (i.e., the SDCFs for the various exposure scenarios). 


\subsubsection{Sensitivity/Uncertainty Analysis for IWMF}

In the intruder dose assessment for the IWMF, estimates of annual EDEs per unit concentration of radionuclides in the disposal units at the time intrusion is assumed to occur for the agriculture, resident, and post-drilling scenarios were used in conjunction with the performance objective for inadvertent intruders of $0.1 \mathrm{rem}$ per year to derive limits on average concentrations and inventories of radionuclides for disposal. The assessment also took into account the dilution resulting from mixing of waste with uncontaminated materials in the disposal units (i.e., the waste dilution factor), radioactive decay between the time of disposal and the time the scenarios are assumed to occur, and reductions in inventories in the disposal units due to mobilization and transport in infiltrating water.

The results of the intruder dose assessment for the IWMF, given in Table 6.13, show that all three of the assumed exposure scenarios are important in determining allowable limits on disposals of radionuclides in the IWMF based on the intruder dose assessment. As discussed in Sect. 6.1 and presented in more detail in Sect. G.5.2 of Appendix G, the agriculture and post-drilling scenarios take into account several exposure pathways. However, the relative importance of the different exposure pathways for these scenarios and the importance of uncertainties in the parameter values for these pathways depend on the particular radionuclide. The resident scenario, on the other hand, considers only a single external exposure pathway.

\subsubsection{Sensitivity/Uncertainty for Radionuclide Inventories}

In the intruder dose analysis for any disposal units, the dose is directly proportional to the assumed inventory of radionuclides. Therefore, an uncertainty in an estimated inventory of a radionuclide translates directly into the same magnitude of uncertainty in the estimated dose to an inadvertent intruder from disposal of that radionuclide. Recalling that the purpose of the intruder dose analysis for the IWMF is to determine limits on allowable inventories of radionuclides for disposal, uncertainties in radionuclide inventories will be important for disposals in the IWMF only when the estimated inventories are an appreciable fraction of the allowable limits (e.g., within about an order of magnitude) and the uncertainty in the estimated inventory is substantial (e.g., exceeds about a factor of two).

As discussed in Sect. 7.2.4, additional restrictions on allowable disposals in the IWMF beyond those required by the results in the intruder dose analysis will be applied to future disposals of many long-lived radionuclides. The additional restrictions on disposals of some radionuclides, in conjunction with the commitment to maintain institutional controls over disposal sites until such time as they can be safely released (DOE 1996c), should ensure that uncertainties in radionuclide inventories in the IWMF could not lead to doses to inadvertent intruders that would exceed the performance objective. 


\subsubsection{Sensitivity/Uncertainty for Photon-Emitting Radionuclides}

For several radionuclides in Table 6.13 (e.g., ${ }^{137} \mathrm{Cs}$ and ${ }^{226} \mathrm{Ra}$ ), the allowable limits for disposal in the IWMF are based mostly or entirely on the dose assessment for the pathway involving external exposure during indoor residence in a home on top of the disposal units. When the agriculture scenario is limiting (e.g., for ${ }^{226} \mathrm{Ra}$ ), the doses from the other exposure pathways considered in this scenario are relatively unimportant, and this is the only pathway considered in the resident scenario which is limiting for some radionuclides (e.g., ${ }^{137} \mathrm{Cs}$ ). The radionuclides for which external dose during indoor residence is the most important emit significant intensities of high-energy photons, or they have decay products which are high-energy photon emitters.

As indicated in Eq. (G.15) of Appendix G, the external dose per unit concentration of a radionuclide in the disposal facility during indoor residence is proportional to the exposure time, the external dose-rate conversion factor, and the shielding factor during indoor residence. The dose-rate conversion factor is treated as a fixed parameter for reference individuals and, thus, essentially has no uncertainty. The exposure time is subject to uncertainty, but the value of $50 \%$ of the time during a year assumed in this assessment is intended to be conservative in most cases and cannot underestimate the actual value by more than a factor of two. The shielding factor during indoor residence also is subject to uncertainty, but the assumed shielding factor of 0.7 cannot underestimate the actual value by more than $50 \%$ and probably does not overestimate actual values for typical homes in the vicinity of Oak Ridge by more than a factor of two (Kocher 1980a).

Based on these considerations, uncertainties in the dose assessment models for inadvertent intruders should not be significant for photon-emitting radionuclides. Rather, the most important factor in determining acceptable disposals of these radionuclides and, thus, potential doses to inadvertent intruders is the uncertainties in the estimated inventories of radionuclides in waste prior to disposal.

\subsubsection{Sensitivity/Uncertainty for Other Radionuclides}

For radionuclides that are not significant photon emitters (e.g., ${ }^{90} \mathrm{Sr}$ and ${ }^{239} \mathrm{Pu}$ ), only the agriculture and post-drilling scenarios are of concern in determining allowable limits for disposal in the IWMF. For such radionuclides that also are not alpha emitters (e.g., ${ }^{90} \mathrm{Sr}$ ), the exposure pathway involving consumption of vegetables grown in contaminated garden soil usually is by far the most important. However, for alpha-emitting radionuclides (e.g., ${ }^{239} \mathrm{Pu}$ ), the dose from the vegetable pathway is relatively low (see Table G.17 and Table G.18 of Appendix G), and the exposure pathways involving direct ingestion of contaminated soil from the garden and inhalation of suspended soil during indoor residence usually are the most important.

\subsection{Sensitivity/Uncertainty for Vegetable Pathway}

For the vegetable pathway, the annual dose per unit concentration of a radionuclide in the disposal units is proportional to the annual intake of contaminated vegetables, the plant-to-soil 
concentration ratio for the radionuclide, and the ingestion dose conversion factor for the radionuclide [see Eq. (G.9) and Eq. (G.10) of Appendix G]. In addition, when the agriculture scenario is the limiting scenario, the dose is proportional to the dilution factor for mixing of material exhumed from the disposal units with native soil in the vegetable garden. The ingestion dose conversion factor is treated as a fixed parameter for reference individuals and, thus, essentially has no uncertainty. The uncertainty in the other parameters for the vegetable pathway is discussed in the following paragraphs.

The dilution factor for mixing of exhumed material in the vegetable garden essentially is a nonmeasurable parameter used in defining the agriculture scenario. The value of 0.2 for this parameter assumed in this assessment was based on a previous definition of the agriculture scenario developed by the U.S. Nuclear Regulatory Commission (NRC 1982). The value of the dilution factor could be underestimated by as much as a factor of five. On the other hand, this degree of underestimation seems unreasonable, because it is unlikely that a fertile vegetable garden would consist entirely of soil containing materials exhumed from the disposal units (see discussion in Sect. G.5.2.1 of Appendix G).

The assumed intake of vegetables from a garden $(90 \mathrm{~kg}$ per year) was selected to be somewhat conservative for an average site resident. Available data (Hamby 1992) indicate that, for an unusual resident homesteader who is assumed to be largely self-sufficient, the assumed intake probably would not underestimate actual intakes by more than a factor of two.

The uncertainty in the plant-to-soil concentration ratio, as measured by the geometric standard deviation, appears to be about a factor of three for a few elements that have been well-studied (e.g., $\mathrm{Sr}$ ), but this parameter appears to be uncertain by perhaps an order of magnitude or more for most elements [e.g., see Baes et al. (1984), NRC and CEC (1997)]. The uncertainty in this parameter is likely to be particularly large for elements for which the available measurements are sparse or nonexistent. There also is considerable uncertainty in the generic factor for converting concentration ratios on a dry-weight basis to wet weight (Baes et al. 1984), which is an important parameter when the plant-to-soil concentration ratios are reported on a dry-weight basis. An important source of uncertainty that cannot be quantified is the applicability of generic data on the plant-to-soil concentration ratio, based on measurements for a variety of plant and soil types, to garden crops grown in the type of soil found at the disposal site.

Considering all of these factors, the uncertainty in the dose assessment model for the vegetable pathway appears to be significant for radionuclides that are not photon emitters (i.e., at least an order of magnitude or more in most cases). Thus, for many radionuclides, the uncertainty in the model for the vegetable pathway could be comparable to the uncertainty in the estimated inventory in waste. The most important source of uncertainty in the model appears to be the uncertainty in the plant-to-soil concentration ratio. However, in the absence of site-specific data for this parameter, there is little that can be done to reduce this uncertainty. In addition, it may be the case that the most important sources of uncertainty for this exposure pathway (e.g., the applicability of available data on plant-to-soil concentration ratios to the disposal site) are unquantifiable. 


\subsection{Sensitivity/Uncertainty for Soil Ingestion Pathway}

For the soil ingestion pathway, which is important for some alpha-emitting radionuclides (e.g., ${ }^{239} \mathrm{Pu}$ ), the dose per unit concentration of a radionuclide in the disposal units is proportional to the annual consumption of contaminated soil and the ingestion dose conversion factor for the radionuclide; see Eq. (G.11) and Eq. (G.12) of Appendix G. In addition, when the agriculture scenario is the limiting scenario, the dose is proportional to the dilution factor for mixing of material exhumed from the disposal units with native soil in the vegetable garden. The ingestion dose conversion factor again is treated as a fixed parameter for reference individuals and, thus, essentially has no uncertainty. As discussed in the previous section for the vegetable pathway, the dilution factor for mixing of exhumed material in the vegetable garden could be underestimated by as much as a factor of five, but such a degree of underestimation does not seem likely.

The annual ingestion of contaminated soil from the vegetable garden assumed in this assessment is intended to be representative of average adults (EPA 1989). In unusual cases, the annual ingestion of contaminated soil could be as much as an order of magnitude higher (EPA 1989). On the other hand, the assumed value may be conservative, because the model assumes that all intakes of soil come from the contaminated garden soil. Thus, for many radionuclides, the uncertainty in the model for the soil ingestion pathway is unlikely to be significant compared with the uncertainty in the estimated inventory in waste.

\subsection{Sensitivity/Uncertainty for Inhalation Pathway}

For the inhalation pathway during indoor residence, which is important for some alphaemitting radionuclides (e.g., ${ }^{239} \mathrm{Pu}$ ), the dose per unit concentration of a radionuclide in the disposal units is proportional to the atmospheric mass loading of surface soil, the exposure time during the year, the annual intake of air, and the inhalation dose conversion factor for the radionuclide; see Eq. (G.16) and Eq. (G.17) of Appendix G. The inhalation dose conversion factor and the annual air intake are treated as fixed parameters for reference individuals and, thus, essentially have no uncertainty. The exposure time during indoor residence is subject to uncertainty (see Sect. 6.4.1.2), but the value of $50 \%$ of the time during a year assumed in this assessment is intended to be reasonably conservative and cannot underestimate the actual value by more than a factor of two. The atmospheric mass loading of contaminated soil is highly uncertain, and its value may vary by many orders of magnitude depending on site conditions and the activity causing the suspension of surface soil (Anspaugh et al. 1975). The value of the atmospheric mass loading during indoor residence assumed in this assessment is intended to be representative of average conditions in the U.S., but the assumed value probably is conservative for the ORR due to the unusually high annual precipitation, extensive vegetation, and low average wind speed at the site.

Considering all of these factors, the estimates of dose for the inhalation pathway during indoor residence clearly are highly uncertain, and this uncertainty is likely to be greater than the uncertainty in 
the estimated inventories of radionuclides in waste. However, it also seems likely that the model and parameter values assumed in this assessment would provide overestimates of dose. Inhalation exposure while working in the vegetable garden, which is an assumed exposure pathway in the agriculture and post-drilling scenarios, is not important in determining disposal limits in the IWMF for any radionuclides.

\subsubsection{Sensitivity/Uncertainty Analysis for Other Disposal Units}

In the intruder dose analysis for the closed disposal units in SWSA 6, the reported inventories of radionuclides at the time of disposal were used to estimate doses to inadvertent intruders, which were then compared with the performance objective; see Sect. 6.3.3 and Table 6.14 through Table 6.18. The following sections discuss the importance of uncertainties in radionuclide inventories (Sect. 6.4.2.1) and uncertainties in the dose assessment models for the various exposure scenarios (Sect. 6.4.2.2) in regard to compliance with the performance objective for inadvertent intruders for the closed disposal units.

\subsubsection{Sensitivity/Uncertainty for Radionuclide Inventories}

The importance of uncertainties in reported inventories of radionuclides in the closed disposal units in SWSA 6 can be considered based on the dose estimates for the different exposure scenarios in Table 6.14 through Table 6.17 and the information on uncertainties in inventories of radionuclides in the various units presented in Appendix A, Table A.16 through Table A.27.

For Tumulus I and Tumulus II, the reported inventories of ${ }^{137} \mathrm{Cs}$ are the most important in determining the estimated doses to inadvertent intruders. However, for both disposal units, the estimated uncertainties in the inventories of ${ }^{137} \mathrm{Cs}$ are small compared with the difference between the estimated doses from this radionuclide and the performance objective. Furthermore, for both disposal units, the estimated doses from all other radionuclides are sufficiently small that the uncertainties in the radionuclide inventories are small compared with the difference between their estimated doses and the performance objective. Therefore, uncertainties in the estimated inventories of radionuclides are not important in determining compliance with the performance objective for inadvertent intruders for past disposals in Tumulus I and Tumulus II.

For the low-range silos, the reported inventories of ${ }^{137} \mathrm{Cs}$ and ${ }^{232} \mathrm{Th}$ are the most important in determining the estimated doses to inadvertent intruders. Especially for the north $(N)$ silos, the estimated uncertainty in the inventories of ${ }^{137} \mathrm{Cs}$ and ${ }^{232} \mathrm{Th}$ could increase the estimated doses from each of these radionuclides by an order of magnitude, and taking these uncertainties into account could result in an estimated dose that exceeds the performance objective by as much as a factor of about three for the agriculture scenario and a factor of about four for the resident scenario. The maximum exceedances would only be slightly greater if the reported inventories of other radionuclides and their estimated uncertainties were taken into account. For the south (S) units, however, the reported 
inventories of all radionuclides are sufficiently low that an accounting of the estimated uncertainties in these inventories could not result in doses approaching the performance objective.

For the high-range silos, the reported inventories of ${ }^{90} \mathrm{Sr}$ and ${ }^{137} \mathrm{Cs}$ are the most important in determining the estimated doses to inadvertent intruders. Taking the uncertainties in the inventories of ${ }^{90} \mathrm{Sr}$ and ${ }^{137} \mathrm{Cs}$ into account could increase the estimated doses from these radionuclide by factors of about 40 and 3, respectively. For the post-drilling scenario, an increase in the inventory of ${ }^{90} \mathrm{Sr}$ by a factor of 40 would result in an estimated dose that exceeds the performance objective by a factor of two. However, the possible increases in inventory of these radionuclides would not result in an exceedance of the performance objective for any other scenarios.

For the high-range wells, the reported inventory of ${ }^{137} \mathrm{Cs}$ is the most important in determining the estimated doses to inadvertent intruders. In this case, the estimated dose for the agriculture scenario is equal to the performance objective. However, the uncertainty in the estimated inventory of ${ }^{137} \mathrm{Cs}$ is less than $20 \%$, so this uncertainty is not particularly important in determining compliance with the performance objective. For the high-range wells, the most important consideration in determining compliance is the reported depths of burial of the different radionuclides.

For the fissile wells, the estimated doses to inadvertent intruders for all credible scenarios are much less than the performance objective. Therefore, uncertainties in the reported inventories of radionuclides in these wells are not important in determining compliance with the performance objective. For the fissile wells, the most important considerations in determining compliance are the reported depths of burial of the different radionuclides and the fact that only two wells are of concern to this assessment.

For the asbestos silos and biological trenches, the estimated doses to inadvertent intruders for all scenarios are very low, and the uncertainties in the reported inventories of radionuclides are not important in determining compliance with the performance objective.

Finally, for the Quadrex trenches, the reported inventories of ${ }^{137} \mathrm{Cs}$ and ${ }^{232} \mathrm{Th}$ are the most important in determining the estimated doses to inadvertent intruders. The estimated uncertainties in the inventories of ${ }^{137} \mathrm{Cs}$ and ${ }^{232} \mathrm{Th}$ could increase the estimated doses from each of these radionuclides by an order of magnitude, and taking these uncertainties into account could result in estimated doses that exceed the performance objective by as much as a factor of about two for the agriculture scenario. The maximum dose would be equal to the performance objective for the resident scenario. The reported inventories of all other radionuclides are sufficiently low that an accounting of the estimated uncertainties in their inventories could not result in doses approaching the performance objective.

The discussions in this section have emphasized the maximum possible doses to inadvertent intruders that could result when uncertainties in reported inventories of radionuclides in the closed disposal units are taken into account. However, two additional points should be emphasized. First, if the uncertainties in reported inventories are interpreted in terms of probability distributions, then the probability that the performance objective for inadvertent intruders would be exceeded when these uncertainties are taken into account is substantially less than unity, and the probability that the doses would attain their maximum possible values essentially is zero. Second, the assumed probability 
distributions of radionuclide inventories imply that reductions in inventories and, thus, doses to inadvertent intruders are as equally likely as increases in inventories and doses.

\subsubsection{Sensitivity/Uncertainty for Exposure Pathway Models}

In the intruder dose assessment for all disposal units in the SWSA 6 facility other than the IWMF, estimates of doses per unit concentration of radionuclides in the disposal units at the time intrusion is assumed to occur for the agriculture, resident, post-drilling, and discovery scenarios were used in conjunction with the best estimates of inventories of radionuclides in waste prior to disposal to estimate doses to inadvertent intruders. The estimated doses then were compared with the performance objective. This section considers the importance of the uncertainties in the doses per unit concentration for the different exposure scenarios for the closed disposal units.

Table 6.14 through Table 6.17 give the results of the intruder dose assessment for the disposal units other than the IWMF. For all disposal units, the estimated dose for any of the exposure scenarios is determined primarily by one of two exposure pathways: (1) external exposure during indoor residence on top of the disposal units or while working near the disposal units, which is the case for the agriculture, resident, and discovery scenarios, or (2) consumption of contaminated vegetables, which is the case for the post-drilling scenario. Furthermore, for all disposal units and exposure scenarios, only a few radionuclides contribute significantly to the total dose and, thus, are important in determining compliance with the performance objective.

The external exposure pathway is important for several radionuclides, primarily ${ }^{137} \mathrm{Cs},{ }^{226} \mathrm{Ra}$, ${ }^{230} \mathrm{Th}$, and ${ }^{232} \mathrm{Th}$. However, as discussed in Sect. 6.4.1.2, uncertainties in the dose assessment models for the external exposure pathways should not be significant. Rather, when the estimated dose for any exposure scenario is due primarily to an external exposure pathway, the most important source of uncertainty is the uncertainty in the estimated inventories of the important photon-emitting radionuclides in the waste. These uncertainties are discussed in Sect. 6.4.2.1.

The vegetable pathway is important only for ${ }^{90} \mathrm{Sr}$. As discussed in Sect. 6.4.1.3.1, the uncertainty in the estimated dose for the vegetable pathway should be less than an order of magnitude for this radionuclide. Therefore, the uncertainty in the dose from the vegetable pathway for ${ }^{90} \mathrm{Sr}$ should be less than the uncertainty in the estimated inventories of ${ }^{90} \mathrm{Sr}$ in the waste.

\subsubsection{General Consideration of Uncertainties in Dose Assessment Models}

In evaluating the importance of the different sources of uncertainty in the dose assessment models for inadvertent intruders, the most important consideration may be the definitions of the exposure scenarios themselves, notwithstanding any uncertainties in radionuclide inventories and parameter values that could be quantified and regardless of whether the results would represent the variability in doses that could be experienced on the ORR. The dose assessments for the different exposure scenarios are based on assumptions that the scenarios will occur as postulated, but many of 
the assumptions used in defining the scenarios are questionable and, furthermore, are likely to be conservative.

In defining exposure scenarios for inadvertent intruders, it is reasonable to assume that individuals will establish a homestead within the boundary of the SWSA 6 disposal facility at some time after loss of active institutional control over the site, because homesteading commonly occurred on the ORR prior to 1942. However, several of the assumptions used in developing the exposure scenarios are less certain and probably pessimistic. For example, all scenarios assume that individuals will have no knowledge of prior waste disposal activities at the site, but this assumption seems unreasonable for times soon after loss of active institutional control. Furthermore, all exposure scenarios assume that an inadvertent intruder will build a home or drill a well at the location of disposed waste, rather than in uncontaminated areas on the disposal site, and that exhumed waste from excavation or drilling activities will be indistinguishable from native soil and will be mixed with uncontaminated soil in a vegetable garden.

The assumption of loss of active institutional control at 100 years after disposal also may be quite conservative for the SWSA 6 site. Controls will not be relinquished until the disposal sites can be released safely (DOE 1996c), and the large number of contaminated sites on the ORR may require that active institutional control be maintained for a considerably longer period of time to provide adequate protection of public health and the environment. Therefore, the assumed exposure scenarios may never occur as postulated.

By their very definitions, the exposure scenarios for inadvertent intruders assume conditions that tend to maximize estimates of dose that reasonably could be experienced by individuals who might come onto the disposal site after loss of active institutional control. Therefore, a dose assessment for inadvertent intruders is not intended to provide best estimates of dose that likely would be received and a quantification of the uncertainties in these dose estimates. Rather, the primary purpose of the assessment is to indicate whether disposal practices at the site would be adequately protective of future inadvertent intruders. For the IWMF, for example, this is accomplished mainly by establishing acceptance criteria in the form of limits on average concentrations or inventories of radionuclides in waste prior to disposal. If these disposal limits are not exceeded, then future inadvertent intruders may be assumed to be protected, and there is no need to be concerned about the magnitude of doses that any such individuals might actually experience. The same approach can be used for the other disposal units by determining allowable limits on disposals after the fact. Furthermore, quantitative estimates of uncertainties in calculated doses based on parameter uncertainty analysis may not be particularly meaningful for any disposal units, because the results are conditional on the occurrence of the assumed exposure scenarios. Therefore, the most important factors in determining the acceptability of disposals are the credibility of the estimates of radionuclide inventories and the credibility of the assumed exposure scenarios (i.e., whether the assumed scenarios reasonably could occur at the disposal site), rather than any estimates of uncertainties in the results due to uncertainties in the parameters contained in the dose assessment models. 


\section{PERFORMANCE EVALUATION}

This section compares the revised PA results presented in Sect. 5 and Sect. 6 with the performance criteria presented in Sect. 2.5. The application of these results to the current and future operations of the IWMF at the SWSA 6 facility is described. This section also outlines additional future work that will contribute to continuing improvements in this revised PA.

\subsection{COMPARISON OF RESULTS TO PERFORMANCE OBJECTIVES}

The results presented in Sect. 5 demonstrate that the potential release and transport of radionuclides from the disposal units in SWSA 6 meet the performance criterion presented in Sect. 2.5 for the all-pathways analysis, the air pathway analysis, and the protection of water resources. The results include the consideration of disposals in all disposal units accepting waste from September 26, 1988 to the present, and limits for future disposals for each environmental transport pathway.

The results from the analysis of SWSA 6 demonstrate that the total effective dose equivalent from the groundwater pathway at any time outside of the $100-\mathrm{m}$ buffer zone surrounding the closed disposal units is less than 4 mrem per year. For the expanded buffer zone surrounding all of the SWSA 6 disposal units, the results demonstrate that the total effective dose equivalent from the groundwater pathway at any time from the closed disposal units is less than 0.0013 mrem per year. The results from the analysis of surface water at WOD demonstrate that the effective dose equivalent from the closed disposal units at any time is less than 0.012 mrem per year. These results demonstrate compliance with the performance criterion of 4 mrem per year for water resource protection. The results from the air pathways analysis in Sect. 5.2 demonstrate that the dose from the atmospheric transport of radionuclides, excluding radon, is less than 10 mrem per year. The all-pathways dose is demonstrated to be less than 25 mrem per year based on the analysis described in Sect. 4.3.1.3 that all exposure pathways using contaminated water from SWSA 6 as a source of contamination could not exceed 25 mrem per year if the performance criteria for water resource protection and the air pathways were met. The radon release rate was discussed in Sect. 4 and shown to be less than the performance criterion for all disposal units in SWSA 6.

The results presented in Sect. 5 continue with a determination of the allowable inventory limits for IWMF. The IWMF inventory limits are calculated such that SWSA 6 would meet the water resources protection, air pathways, and all-pathways performance criteria. Inventory limits are calculated for radionuclides transported by groundwater, surface water, and air.

The results presented in Sect. 6 demonstrate that the intruder protection performance objective is met for all disposal units in SWSA 6 for all wastes disposed of from September 26, 1988, to the present. The intruder analysis also determines the allowable inventory that could be disposed of at the 
IWMF in the future that would meet the intruder protection performance objective. Table 7.1 presents the combined results of Sect. 5 and Sect. 6 and the limitations on the disposal of LLW waste at the IWMF that will meet all of the performance objectives of DOE O 5820.2A. The limits were identified by taking the most restrictive inventory limit from the results presented in Sect. 5 and Sect. 6 . The limiting pathway for each radioisotope is also included in the table.

The combined allowable inventory limits presented in Table 7.1 provide the information needed to evaluate the existing disposals on Pads 1, 2, and 3 of the IWMF. Table 7.2 presents the radionuclide inventory of each of the IWMF pads and average radionuclide inventory for the first three pads of the IWMF. Not all of the radionuclides in this revised PA have been disposed of at the IWMF. Blank entries in Table 7.2 indicate no reported disposals of the isotope. Table 7.3 presents the fraction of the disposed inventory with the inventory limit presented in Table 7.1 for radionuclides disposed of at the IWMF. Table 7.3 also reports the sum of the fractions for each pad and the average sum of fractions for the first three pads of the IWMF. The results indicate that for each of the disposal pads the IWMF is loaded to less than $50 \%$ capacity for the allowable radionuclide loadings presented in Table 7.1. This result demonstrates that the existing disposals at IWMF are in compliance with the performance objectives of DOE O 5820.2A.

The results of this revised PA were analyzed for their sensitivity and uncertainty. The greatest uncertainty in the results is attributable to the uncertainty in the inventory, with the largest uncertainty attributable to the disposals that occurred before the initial PA. Significant effort has been dedicated to reducing the uncertainty in the existing inventory as well as to improving the characterization of wastes. While these efforts have reduced the uncertainty in the results, significant uncertainty remains. As discussed in Sect. 5.4, the uncertainty of the analysis based the uncertainty of the inventory tends to increase as the time required for the peak exposure to occur increases. This finding is to be expected because of the inherent uncertainties associated with estimating the long-term behavior of the disposal units, the characterization methods used for actinides and other problematic radionuclides in waste disposal packages, and the confidence to be attributed to the models used in the analysis over long periods of time. Since these uncertainties are unlikely to be reduced much beyond their present level, recommendations have been prepared for changes in waste disposal operations at the IWMF to provide additional assurance that the performance objectives will be met in the future. These recommendations are presented in Sect. 7.2.4.

One of the recommendations included in Sect. 7.2.4 is the use of an expanded buffer zone, which was used in the analysis presented in this revised PA. The justification for the expanded buffer zone is the recognition that the small tract of land between the $100-\mathrm{m}$ buffer zone for the IWMF and Tumulus I and Tumulus II is certain to receive the same degree of protection as the $100-\mathrm{m}$ buffer zone itself. Furthermore, the limited area of this expanded buffer zone does not have a significant impact on the overall protection of water resources that is supported further by the use of the restrictive performance criteria adopted in this revised PA for the land use boundary and the protection of surface water resources. The restrictive performance criteria used in this PA for the protection of water resources represent defense-in-depth and are a conservative interpretation of the performance criteria presented in the guidance for the preparation of PAs. Consequently, there is no reason to treat this 
Table 7.1. Allowable limits on inventories of radionuclides at the Interim Waste Management Facility based on the performance assessment

\begin{tabular}{|c|c|c|c|c|c|}
\hline Nuclide & $\begin{array}{c}\text { Allowable } \\
\text { inventory }^{b} \\
\text { (Ci/pad) }\end{array}$ & $\begin{array}{l}\text { Limiting } \\
\text { scenario }\end{array}$ & Nuclide & $\begin{array}{c}\text { Allowable } \\
\text { inventory }^{b} \\
\text { (Ci/pad) }\end{array}$ & $\begin{array}{l}\text { Limiting } \\
\text { scenario }\end{array}$ \\
\hline${ }^{3} \mathrm{H}$ & $8.8 \times 10^{5}$ & Post-drilling & ${ }^{228} \mathrm{Ra}$ & $1.2 \times 10^{5}$ & Resident \\
\hline${ }^{10} \mathrm{Be}$ & $5.1 \times 10^{3}$ & Agriculture & ${ }^{227} \mathrm{Ac}$ & $7.8 \times 10^{2}$ & Resident \\
\hline${ }^{14} \mathrm{C}$ & $1.5 \times 10^{2}$ & Agriculture & ${ }^{229} \mathrm{Th}$ & $5.2 \times 10^{-1}$ & Agriculture \\
\hline${ }^{26} \mathrm{Al}$ & $5.5 \times 10^{-2}$ & Agriculture & ${ }^{230} \mathrm{Th}$ & $2.5 \times 10^{-1}$ & Agriculture \\
\hline${ }^{36} \mathrm{Cl}$ & $1.1 \times 10^{1}$ & Post-drilling & ${ }^{232} \mathrm{Th}$ & $6.1 \times 10^{-2}$ & Agriculture \\
\hline${ }^{40} \mathrm{~K}$ & $1.7 \times 10^{0}$ & Agriculture & ${ }^{231} \mathrm{~Pa}$ & $2.9 \times 10^{-1}$ & Agriculture \\
\hline${ }^{41} \mathrm{Ca}$ & $1.7 \times 10^{2}$ & Agriculture & ${ }^{232} \mathrm{U}$ & $2.0 \times 10^{0}$ & Agriculture \\
\hline${ }^{60} \mathrm{Co}$ & $3.9 \times 10^{5}$ & Resident & ${ }^{233} \mathrm{U}$ & $4.8 \times 10^{0}$ & Agriculture \\
\hline${ }^{59} \mathrm{Ni}$ & $6.0 \times 10^{3}$ & Agriculture & ${ }^{234} \mathrm{U}$ & $1.8 \times 10^{1}$ & Agriculture \\
\hline${ }^{63} \mathrm{Ni}$ & $1.6 \times 10^{4}$ & Agriculture & ${ }^{235} \mathrm{U}$ & $1.2 \times 10^{0}$ & Agriculture \\
\hline${ }^{79} \mathrm{Se}$ & $1.7 \times 10^{3}$ & Groundwater & ${ }^{236} \mathrm{U}$ & $2.9 \times 10^{l}$ & Agriculture \\
\hline${ }^{87} \mathrm{Rb}$ & No limit & None & ${ }^{238} \mathrm{U}$ & $6.1 \times 10^{0}$ & Agriculture \\
\hline${ }^{90} \mathrm{Sr}$ & $4.9 \times 10^{2}$ & Post-drilling & ${ }^{237} \mathrm{~Np}$ & $5.4 \times 10^{-1}$ & Agriculture \\
\hline${ }^{93} \mathrm{Zr}$ & $8.6 \times 10^{3}$ & Agriculture & ${ }^{238} \mathrm{Pu}$ & $1.2 \times 10^{2}$ & Agriculture \\
\hline${ }^{93 m} \mathrm{Nb}$ & $7.8 \times 10^{7}$ & Post-drilling & ${ }^{239} \mathrm{Pu}$ & $9.9 \times 10^{0}$ & Agriculture \\
\hline${ }^{94} \mathrm{Nb}$ & $1.1 \times 10^{-1}$ & Agriculture & ${ }^{240} \mathrm{Pu}$ & $1.0 \times 10^{1}$ & Agriculture \\
\hline${ }^{99} \mathrm{Tc}$ & $1.4 \times 10^{2}$ & Agriculture & ${ }^{241} \mathrm{Pu}$ & $3.0 \times 10^{2}$ & Agriculture \\
\hline${ }^{107} \mathrm{Pd}$ & $1.2 \times 10^{4}$ & Agriculture & ${ }^{242} \mathrm{Pu}$ & $1.0 \times 10^{1}$ & Agriculture \\
\hline${ }^{113 m} \mathrm{Cd}$ & $9.8 \times 10^{3}$ & Post-drilling & ${ }^{244} \mathrm{Pu}$ & $4.6 \times 10^{-1}$ & Agriculture \\
\hline${ }^{121 \mathrm{~m}} \mathrm{Sn}$ & $2.7 \times 10^{4}$ & Agriculture & ${ }^{241} \mathrm{Am}$ & $9.9 \times 10^{0}$ & Agriculture \\
\hline${ }^{126} \mathrm{Sn}$ & $1.1 \times 10^{-1}$ & Agriculture & ${ }^{242 \mathrm{~m}} \mathrm{Am}$ & $1.3 \times 10^{1}$ & Agriculture \\
\hline${ }^{129} \mathrm{I}$ & $3.0 \times 10^{1}$ & Groundwater & ${ }^{243} \mathrm{Am}$ & $1.0 \times 10^{0}$ & Agriculture \\
\hline${ }^{135} \mathrm{Cs}$ & $4.2 \times 10^{2}$ & Agriculture & ${ }^{243} \mathrm{Cm}$ & $2.1 \times 10^{3}$ & Agriculture \\
\hline${ }^{137} \mathrm{Cs}$ & $6.8 \times 10^{1}$ & Resident & ${ }^{244} \mathrm{Cm}$ & $3.6 \times 10^{3}$ & Agriculture \\
\hline${ }^{152} \mathrm{Sm}$ & $3.1 \times 10^{5}$ & Agriculture & ${ }^{245} \mathrm{Cm}$ & $1.8 \times 10^{\circ}$ & Agriculture \\
\hline${ }^{152} \mathrm{Eu}$ & $4.0 \times 10^{2}$ & Resident & ${ }^{246} \mathrm{Cm}$ & $9.5 \times 10^{0}$ & Agriculture \\
\hline${ }^{154} \mathrm{Eu}$ & $5.1 \times 10^{3}$ & Resident & ${ }^{247} \mathrm{Cm}$ & $5.1 \times 10^{-1}$ & Agriculture \\
\hline${ }^{155} \mathrm{Eu}$ & $1.3 \times 10^{10}$ & Resident & ${ }^{248} \mathrm{Cm}$ & $2.5 \times 10^{0}$ & Agriculture \\
\hline${ }^{194} \mathrm{Os}$ & $3.4 \times 10^{9}$ & Post-drilling & ${ }^{249} \mathrm{Cf}$ & $8.7 \times 10^{-1}$ & Agriculture \\
\hline${ }^{207} \mathrm{Bi}$ & $1.5 \times 10^{1}$ & Resident & ${ }^{250} \mathrm{Cf}$ & $3.4 \times 10^{3}$ & Agriculture \\
\hline${ }^{210} \mathrm{~Pb}$ & $6.2 \times 10^{2}$ & Post-drilling & ${ }^{251} \mathrm{Cf}$ & $1.8 \times 10^{0}$ & Agriculture \\
\hline${ }^{226} \mathrm{Ra}$ & $1.1 \times 10^{-1}$ & Agriculture & & & \\
\hline
\end{tabular}

${ }^{a}$ Allowable limits based on dose assessments for intruder scenarios are obtained from Table 6.13, and for water pathways from Table 5.28.

${ }^{b} \mathrm{~L}$ imit on allowable inventory of radionuclide in waste prior to disposal for individual disposal pads in the IWMF, based on assumption of 330 vaults per pad and waste volume per vault of $2.6 \mathrm{~m}^{3}$.

${ }^{\circ}$ Calculated limits for all scenarios exceed specific activity of radionuclide. 
Table 7.2. Existing radionuclide loadings at the Interim Waste Management Facility

\begin{tabular}{|c|c|c|c|c|}
\hline \multirow{2}{*}{ Nuclide } & \multicolumn{3}{|c|}{ Radioactivity (Ci) } & \multirow{2}{*}{$\begin{array}{l}\text { Pad average } \\
\text { (Ci/pad) }\end{array}$} \\
\hline & Pad 1 & $\operatorname{Pad} 2$ & Pad 3 & \\
\hline${ }^{3} \mathrm{H}$ & $3.17 \times 10^{-2}$ & $5.07 \times 10^{0}$ & $9.86 \times 10^{-1}$ & $2.03 \times 10^{0}$ \\
\hline \multicolumn{5}{|l|}{${ }^{10} \mathrm{Be}$} \\
\hline${ }^{14} \mathrm{C}$ & $1.28 \times 10^{-2}$ & $1.01 \times 10^{-2}$ & $3.78 \times 10^{-3}$ & $8.89 \times 10^{-3}$ \\
\hline${ }^{26} \mathrm{Al}$ & $1.00 \times 10^{-3}$ & & $1.40 \times 10^{-8}$ & $3.33 \times 10^{-4}$ \\
\hline \multicolumn{5}{|l|}{${ }^{36} \mathrm{Cl}$} \\
\hline${ }^{40} \mathrm{~K}$ & $8.77 \times 10^{-4}$ & $4.00 \times 10^{-10}$ & $7.33 \times 10^{-4}$ & $5.37 \times 10^{-4}$ \\
\hline \multicolumn{5}{|l|}{${ }^{41} \mathrm{Ca}$} \\
\hline${ }^{60} \mathrm{Co}$ & $2.99 \times 10^{0}$ & $8.27 \times 10^{1}$ & $1.40 \times 10^{1}$ & $3.32 \times 10^{1}$ \\
\hline${ }^{59} \mathrm{Ni}$ & & & $2.88 \times 10^{-4}$ & $9.60 \times 10^{-5}$ \\
\hline${ }^{63} \mathrm{Ni}$ & $1.70 \times 10^{-2}$ & $9.02 \times 10^{-5}$ & $5.35 \times 10^{0}$ & $1.79 \times 10^{0}$ \\
\hline \multicolumn{5}{|l|}{${ }^{79} \mathrm{Se}$} \\
\hline \multicolumn{5}{|l|}{${ }^{87} \mathrm{Rb}$} \\
\hline${ }^{90} \mathrm{Sr}$ & $5.71 \times 10^{0}$ & $1.07 \times 10^{1}$ & $2.98 \times 10^{1}$ & $1.54 \times 10^{1}$ \\
\hline \multicolumn{5}{|l|}{${ }^{93} \mathrm{Zr}$} \\
\hline \multicolumn{5}{|l|}{${ }^{93 m} \mathrm{Nb}$} \\
\hline \multicolumn{5}{|l|}{${ }^{94} \mathrm{Nb}$} \\
\hline${ }^{99} \mathrm{Tc}$ & $3.41 \times 10^{-4}$ & $3.79 \times 10^{-4}$ & $3.48 \times 10^{-3}$ & $1.40 \times 10^{-3}$ \\
\hline \multicolumn{5}{|l|}{${ }^{107} \mathrm{Pd}$} \\
\hline \multicolumn{5}{|l|}{${ }^{113 m} \mathrm{Cd}$} \\
\hline \multicolumn{5}{|l|}{${ }^{12} \mathrm{Im} \mathrm{Sn}$} \\
\hline \multicolumn{5}{|l|}{${ }^{126} \mathrm{Sn}$} \\
\hline \multicolumn{5}{|l|}{${ }^{129} \mathrm{I}$} \\
\hline \multicolumn{5}{|l|}{${ }^{135} \mathrm{Cs}$} \\
\hline${ }^{137} \mathrm{Cs}$ & $1.24 \times 10^{1}$ & $1.79 \times 10^{1}$ & $2.44 \times 10^{1}$ & $1.83 \times 10^{1}$ \\
\hline${ }^{151} \mathrm{Sm}$ & & $1.10 \times 10^{-3}$ & & $3.67 \times 10^{-4}$ \\
\hline${ }^{152} \mathrm{Eu}$ & $1.00 \times 10^{0}$ & $8.01 \times 10^{-1}$ & $3.10 \times 10^{0}$ & $1.63 \times 10^{0}$ \\
\hline${ }^{154} \mathrm{Eu}$ & $2.73 \times 10^{-2}$ & $2.88 \times 10^{-8}$ & $2.03 \times 10^{\circ}$ & $6.85 \times 10^{-1}$ \\
\hline${ }^{155} \mathrm{Eu}$ & $9.34 \times 10^{-5}$ & $8.00 \times 10^{-9}$ & $1.07 \times 10^{-1}$ & $3.57 \times 10^{-2}$ \\
\hline${ }^{194} \mathrm{Os}$ & & $9.90 \times 10^{-3}$ & & $3.30 \times 10^{-3}$ \\
\hline${ }^{207} \mathrm{Bi}$ & $2.27 \times 10^{-2}$ & & $9.02 \times 10^{-6}$ & $7.56 \times 10^{-3}$ \\
\hline${ }^{210} \mathrm{~Pb}$ & $4.00 \times 10^{-4}$ & & $3.00 \times 10^{-11}$ & $1.33 \times 10^{-4}$ \\
\hline${ }^{226} \mathrm{Ra}$ & $5.45 \times 10^{-4}$ & $8.17 \times 10^{-7}$ & $1.55 \times 10^{-3}$ & $6.98 \times 10^{-4}$ \\
\hline
\end{tabular}


Table 7.2. (continued)

\begin{tabular}{|c|c|c|c|c|}
\hline \multirow{2}{*}{ Nuclide } & \multicolumn{3}{|c|}{ Radioactivity (Ci) } & \multirow{2}{*}{$\begin{array}{l}\text { Pad average } \\
\text { (Ci/pad) }\end{array}$} \\
\hline & Pad 1 & $\operatorname{Pad} 2$ & Pad 3 & \\
\hline${ }^{228} \mathrm{Ra}$ & $1.70 \times 10^{-4}$ & $4.93 \times 10^{-7}$ & $9.61 \times 10^{-8}$ & $5.69 \times 10^{-5}$ \\
\hline \multicolumn{5}{|l|}{${ }^{227} \mathrm{Ac}$} \\
\hline${ }^{229} \mathrm{Th}$ & & $4.50 \times 10^{-8}$ & & $1.50 \times 10^{-8}$ \\
\hline${ }^{230} \mathrm{Th}$ & & $6.54 \times 10^{-7}$ & $2.51 \times 10^{-7}$ & $3.02 \times 10^{-7}$ \\
\hline${ }^{232} \mathrm{Th}$ & $1.11 \times 10^{-4}$ & $3.89 \times 10^{-3}$ & $3.13 \times 10^{-4}$ & $1.44 \times 10^{-3}$ \\
\hline \multicolumn{5}{|l|}{${ }^{231} \mathrm{~Pa}$} \\
\hline${ }^{232} \mathrm{U}$ & $3.00 \times 10^{-7}$ & $6.00 \times 10^{-2}$ & & $2.00 \times 10^{-2}$ \\
\hline${ }^{233} \mathrm{U}$ & $2.94 \times 10^{-3}$ & $6.23 \times 10^{-4}$ & $5.62 \times 10^{-2}$ & $1.99 \times 10^{-2}$ \\
\hline${ }^{234} \mathrm{U}$ & $1.70 \times 10^{-5}$ & $1.65 \times 10^{-3}$ & $1.65 \times 10^{-3}$ & $1.10 \times 10^{-3}$ \\
\hline${ }^{235} \mathrm{U}$ & $3.62 \times 10^{-5}$ & $1.81 \times 10^{-4}$ & $2.84 \times 10^{-5}$ & $8.20 \times 10^{-5}$ \\
\hline${ }^{236} \mathrm{U}$ & & $4.00 \times 10^{-10}$ & $5.66 \times 10^{-5}$ & $1.89 \times 10^{-5}$ \\
\hline${ }^{238} \mathrm{U}$ & $4.62 \times 10^{-3}$ & $2.96 \times 10^{-2}$ & $1.89 \times 10^{-2}$ & $.1 .77 \times 10^{-2}$ \\
\hline${ }^{237} \mathrm{~Np}$ & $1.70 \times 10^{-5}$ & $1.70 \times 10^{-4}$ & $7.01 \times 10^{-5}$ & $8.57 \times 10^{-5}$ \\
\hline${ }^{238} \mathrm{Pu}$ & $2.38 \times 10^{-5}$ & $9.80 \times 10^{-7}$ & $9.85 \times 10^{-3}$ & $3.28 \times 10^{-3}$ \\
\hline${ }^{239} \mathrm{Pu}$ & $4.75 \times 10^{-3}$ & $1.31 \times 10^{-4}$ & $1.01 \times 10^{-2}$ & $4.99 \times 10^{-3}$ \\
\hline${ }^{240} \mathrm{Pu}$ & & $1.60 \times 10^{-9}$ & $1.98 \times 10^{-3}$ & $6.59 \times 10^{-4}$ \\
\hline \multicolumn{5}{|l|}{${ }^{241} \mathrm{Pu}$} \\
\hline${ }^{442} \mathrm{Pu}$ & $4.60 \times 10^{-7}$ & $1.15 \times 10^{-7}$ & $2.05 \times 10^{-6}$ & $8.75 \times 10^{-7}$ \\
\hline${ }^{244} \mathrm{Pu}$ & & $1.00 \times 10^{-6}$ & & $3.33 \times 10^{-7}$ \\
\hline${ }^{241} \mathrm{Am}$ & $1.54 \times 10^{-3}$ & $2.27 \times 10^{-2}$ & $1.48 \times 10^{-2}$ & $1.30 \times 10^{-2}$ \\
\hline \multicolumn{5}{|l|}{${ }^{242 \mathrm{~m}} \mathrm{Am}$} \\
\hline${ }^{243} \mathrm{Am}$ & $5.10 \times 10^{-5}$ & $1.51 \times 10^{-4}$ & $4.44 \times 10^{-4}$ & $2.15 \times 10^{-4}$ \\
\hline${ }^{243} \mathrm{Cm}$ & & & $5.73 \times 10^{-5}$ & $1.91 \times 10^{-5}$ \\
\hline${ }^{244} \mathrm{Cm}$ & $3.49 \times 10^{-2}$ & $4.20 \times 10^{-2}$ & $2.32 \times 10^{-1}$ & $1.03 \times 10^{-1}$ \\
\hline${ }^{245} \mathrm{Cm}$ & & & $2.90 \times 10^{-6}$ & $9.97 \times 10^{-7}$ \\
\hline \multicolumn{5}{|l|}{${ }^{246} \mathrm{Cm}$} \\
\hline \multicolumn{5}{|l|}{${ }^{247} \mathrm{Cm}$} \\
\hline${ }^{248} \mathrm{Cm}$ & $4.00 \times 10^{-10}$ & & & $1.33 \times 10^{-10}$ \\
\hline${ }^{249} \mathrm{Cf}$ & $1.34 \times 10^{-7}$ & $1.70 \times 10^{-5}$ & $7.26 \times 10^{-5}$ & $2.99 \times 10^{-5}$ \\
\hline \multicolumn{5}{|l|}{${ }^{250} \mathrm{Cf}$} \\
\hline${ }^{251} \mathrm{Cf}$ & & & & \\
\hline
\end{tabular}


Table 7.3. Sum of fractions calculations for existing radionuclide loadings at the Interim Waste Management Facility

\begin{tabular}{|c|c|c|c|c|}
\hline \multirow{2}{*}{ Nuclide } & \multicolumn{3}{|c|}{ Fraction of limit } & \multirow{2}{*}{ Average } \\
\hline & $\operatorname{Pad} 1$ & $\operatorname{Pad} 2$ & Pad 3 & \\
\hline${ }^{3} \mathrm{H}$ & $3.60 \times 10^{-8}$ & $5.76 \times 10^{-6}$ & $1.12 \times 10^{-6}$ & $2.31 \times 10^{-6}$ \\
\hline \multicolumn{5}{|l|}{${ }^{10} \mathrm{Be}$} \\
\hline${ }^{14} \mathrm{C}$ & $8.52 \times 10^{-5}$ & $6.74 \times 10^{-5}$ & $2.52 \times 10^{-5}$ & $5.93 \times 10^{-5}$ \\
\hline${ }^{26} \mathrm{Al}$ & $1.82 \times 10^{-2}$ & $0.00 \times 10^{0}$ & $2.55 \times 10^{-7}$ & $6.06 \times 10^{-3}$ \\
\hline \multicolumn{5}{|l|}{${ }^{36} \mathrm{Cl}$} \\
\hline${ }^{40} \mathrm{~K}$ & $5.16 \times 10^{-4}$ & $2.35 \times 10^{-10}$ & $4.31 \times 10^{-4}$ & $3.16 \times 10^{-4}$ \\
\hline \multicolumn{5}{|l|}{${ }^{41} \mathrm{Ca}$} \\
\hline${ }^{60} \mathrm{Co}$ & $7.67 \times 10^{6}$ & $2.12 \times 10^{-4}$ & $3.58 \times 10^{-5}$ & $8.52 \times 10^{-5}$ \\
\hline${ }^{59} \mathrm{Ni}$ & $0.00 \times 10^{0}$ & $0.00 \times 10^{0}$ & $4.80 \times 10^{-8}$ & $1.60 \times 10^{-8}$ \\
\hline${ }^{63} \mathrm{Ni}$ & $1.06 \times 10^{-5}$ & $5.64 \times 10^{-9}$ & $3.34 \times 10^{-4}$ & $1.12 \times 10^{-4}$ \\
\hline \multicolumn{5}{|l|}{${ }^{79} \mathrm{Se}$} \\
\hline \multicolumn{5}{|l|}{${ }^{87} \mathrm{Rb}$} \\
\hline${ }^{90} \mathrm{Sr}$ & $1.17 \times 10^{-2}$ & $2.18 \times 10^{-2}$ & $6.08 \times 10^{-2}$ & $3.14 \times 10^{-2}$ \\
\hline \multicolumn{5}{|l|}{${ }^{93} \mathrm{Zr}$} \\
\hline \multicolumn{5}{|l|}{${ }^{93 \mathrm{~m}} \mathrm{Nb}$} \\
\hline \multicolumn{5}{|l|}{${ }^{94} \mathrm{Nb}$} \\
\hline${ }^{99} \mathrm{Tc}$ & $2.44 \times 10^{-6}$ & $2.71 \times 10^{-6}$ & $2.49 \times 10^{-5}$ & $1.00 \times 10^{-5}$ \\
\hline \multicolumn{5}{|l|}{${ }^{107} \mathrm{Pd}$} \\
\hline \multicolumn{5}{|l|}{${ }^{113 \mathrm{~m}} \mathrm{Cd}$} \\
\hline \multicolumn{5}{|l|}{${ }^{121 \mathrm{~m}} \mathrm{Sn}$} \\
\hline \multicolumn{5}{|l|}{${ }^{126} \mathrm{Sn}$} \\
\hline \multicolumn{5}{|l|}{${ }^{129} \mathrm{I}$} \\
\hline \multicolumn{5}{|l|}{${ }^{335} \mathrm{Cs}$} \\
\hline${ }^{137} \mathrm{Cs}$ & $1.83 \times 10^{-1}$ & $2.63 \times 10^{-1}$ & $2.59 \times 10^{-1}$ & $2.68 \times 10^{-1}$ \\
\hline${ }^{151} \mathrm{Sm}$ & $0.00 \times 10^{0}$ & $3.55 \times 10^{-9}$ & $0.00 \times 10^{0}$ & $1.18 \times 10^{-9}$ \\
\hline${ }^{152} \mathrm{Eu}$ & $2.50 \times 10^{-3}$ & $2.00 \times 10^{-3}$ & $7.74 \times 10^{-3}$ & $4.08 \times 10^{-3}$ \\
\hline${ }^{154} \mathrm{Eu}$ & $5.35 \times 10^{-6}$ & $5.65 \times 10^{-12}$ & $3.97 \times 10^{-4}$ & $1.34 \times 10^{-4}$ \\
\hline${ }^{155} \mathrm{Eu}$ & $7.18 \times 10^{-15}$ & $6.15 \times 10^{-19}$ & $8.24 \times 10^{-12}$ & $2.75 \times 10^{-12}$ \\
\hline${ }^{194} \mathrm{Os}$ & $0.00 \times 10^{0}$ & $2.91 \times 10^{-12}$ & $0.00 \times 10^{0}$ & $9.71 \times 10^{-13}$ \\
\hline${ }^{207} \mathrm{Bi}$ & $1.51 \times 10^{-3}$ & $0.00 \times 10^{0}$ & $6.01 \times 10^{-7}$ & $5.04 \times 10^{-4}$ \\
\hline${ }^{210} \mathrm{~Pb}$ & $6.45 \times 10^{-7}$ & $0.00 \times 10^{0}$ & $4.84 \times 10^{-14}$ & $2.15 \times 10^{-7}$ \\
\hline${ }^{226} \mathrm{Ra}$ & $4.95 \times 10^{-3}$ & $7.43 \times 10^{-6}$ & $1.41 \times 10^{-2}$ & $6.34 \times 10^{-3}$ \\
\hline
\end{tabular}


Table 7.3. (continued)

\begin{tabular}{|c|c|c|c|c|}
\hline \multirow{2}{*}{ Nuclide } & \multicolumn{3}{|c|}{ Fraction of limit } & \multirow{2}{*}{ Average } \\
\hline & Pad 1 & $\operatorname{Pad} 2$ & $\mathrm{Pad} 3$ & \\
\hline${ }^{228} \mathrm{Ra}$ & $1.42 \times 10^{-9}$ & $4.10 \times 10^{-12}$ & $8.01 \times 10^{-13}$ & $4.74 \times 10^{-10}$ \\
\hline \multicolumn{5}{|l|}{${ }^{227} \mathrm{Ac}$} \\
\hline${ }^{229} \mathrm{Th}$ & $0.00 \times 10^{0}$ & $8.65 \times 10^{-8}$ & $0.00 \times 10^{0}$ & $2.88 \times 10^{-8}$ \\
\hline${ }^{230} \mathrm{Th}$ & $0.00 \times 10^{0}$ & $2.62 \times 10^{-6}$ & $1.00 \times 10^{-6}$ & $1.21 \times 10^{-6}$ \\
\hline${ }^{232} \mathrm{Th}$ & $1.82 \times 10^{-3}$ & $6.38 \times 10^{-2}$ & $5.13 \times 10^{-3}$ & $2.36 \times 10^{-2}$ \\
\hline \multicolumn{5}{|l|}{${ }^{231} \mathrm{~Pa}$} \\
\hline${ }^{232} \mathrm{U}$ & $1.50 \times 10^{-7}$ & $3.00 \times 10^{-2}$ & $0.00 \times 10^{0}$ & $1.00 \times 10^{-2}$ \\
\hline${ }^{233} \mathrm{U}$ & $6.12 \times 10^{-4}$ & $1.30 \times 10^{-4}$ & $1.17 \times 10^{-2}$ & $4.15 \times 10^{-3}$ \\
\hline${ }^{234} \mathrm{U}$ & $9.45 \times 10^{-7}$ & $9.16 \times 10^{-5}$ & $9.15 \times 10^{-5}$ & $6.13 \times 10^{-5}$ \\
\hline${ }^{235} \mathrm{U}$ & $3.01 \times 10^{-5}$ & $1.51 \times 10^{-4}$ & $2.37 \times 10^{-5}$ & $6.83 \cdot 10^{-5}$ \\
\hline${ }^{236} \mathrm{U}$ & $0.00 \times 10^{\circ}$ & $1.38 \times 10^{-11}$ & $1.95 \times 10^{-6}$ & $6.50 \times 10^{-7}$ \\
\hline${ }^{238} \mathrm{U}$ & $7.58 \times 10^{-4}$ & $4.85 \times 10^{-3}$ & $3.10 \times 10^{-3}$ & $2.90 \times 10^{-3}$ \\
\hline${ }^{237} \mathrm{~Np}$ & $3.15 \times 10^{-5}$ & $3.15 \times 10^{-4}$ & $1.30 \times 10^{-4}$ & $1.59 \times 10^{-4}$ \\
\hline${ }^{238} \mathrm{Pu}$ & $1.98 \times 10^{-7}$ & $8.17 \times 10^{-9}$ & $8.21 \times 10^{-5}$ & $2.74 \times 10^{-5}$ \\
\hline${ }^{239} \mathrm{Pu}$ & $4.80 \times 10^{-4}$ & $1.32 \times 10^{-5}$ & $1.02 \times 10^{-3}$ & $5.04 \times 10^{4}$ \\
\hline${ }^{240} \mathrm{Pu}$ & $0.00 \times 10^{0}$ & $1.60 \times 10^{-10}$ & $1.98 \times 10^{-4}$ & $6.59 \cdot 10^{-4}$ \\
\hline \multicolumn{5}{|l|}{${ }^{241} \mathrm{Pu}$} \\
\hline${ }^{242} \mathrm{Pu}$ & $4.60 \times 10^{-8}$ & $1.15 \times 10^{-8}$ & $2.05 \times 10^{-7}$ & $8.75 \times 10^{4}$ \\
\hline${ }^{244} \mathrm{Pu}$ & $0.00 \times 10^{\circ}$ & $2.17 \times 10^{-6}$ & $0.00 \times 10^{0}$ & $7.25 \times 10^{3}$ \\
\hline${ }^{241} \mathrm{Am}$ & $1.55 \times 10^{-4}$ & $2.30 \times 10^{-3}$ & $1.50 \times 10^{-3}$ & $1.32 \times 10^{3}$ \\
\hline \multicolumn{5}{|l|}{${ }^{242 \mathrm{~m}} \mathrm{Am}$} \\
\hline${ }^{243} \mathrm{Am}$ & $5.10 \times 10^{-5}$ & $1.51 \times 10^{-4}$ & $4.44 \times 10^{-4}$ & $2.15 \times 10^{-4}$ \\
\hline${ }^{243} \mathrm{Cm}$ & $0.00 \times 10^{0}$ & $0.00 \times 10^{0}$ & $2.73 \times 10^{-8}$ & $9.10 \times 10^{-9}$ \\
\hline${ }^{244} \mathrm{Cm}$ & $9.70 \times 10^{-6}$ & $1.17 \times 10^{-5}$ & $6.43 \times 10^{-5}$ & $2.86 \times 10^{-5}$ \\
\hline${ }^{245} \mathrm{Cm}$ & $0.00 \times 10^{0}$ & $0.00 \times 10^{0}$ & $1.61 \times 10^{-6}$ & $5.37 \times 10^{-7}$ \\
\hline \multicolumn{5}{|l|}{${ }^{246} \mathrm{Cm}$} \\
\hline \multicolumn{5}{|l|}{${ }^{247} \mathrm{Cm}$} \\
\hline${ }^{248} \mathrm{Cm}$ & $1.60 \times 10^{-10}$ & $0.00 \times 10^{0}$ & $0.00 \times 10^{\circ}$ & $5.33 \times 10^{-11}$ \\
\hline${ }^{249} \mathrm{Cf}$ & $1.54 \times 10^{-7}$ & $1.95 \times 10^{-5}$ & $8.34 \times 10^{-5}$ & $3.44 \times 10^{-5}$ \\
\hline \multicolumn{5}{|l|}{${ }^{250} \mathrm{Cf}$} \\
\hline \multicolumn{5}{|l|}{${ }^{251} \mathrm{Cf}$} \\
\hline $\begin{array}{l}\text { Sum of } \\
\text { fractions }\end{array}$ & $2.26 \times 10^{-1}$ & $3.89 \times 10^{-1}$ & $4.67 \times 10^{-1}$ & $3.61 \times 10^{-1}$ \\
\hline
\end{tabular}


small tract of land and the associated water resources any differently than the land and water resources contained within the $100-\mathrm{m}$ buffer zone. The results presented in Sect. 5 also include the results for protecting water resources without the expanded buffer zone.

Comparison of the two sets of results associated with the definition of the buffer zone provides insight into the increased loadings of LLW that are acceptable at the IWMF with an expanded buffer zone. The application of the expanded buffer zone resulted in large increases in the allowable disposal inventory for many radionuclides at IWMF; however, many of these radionuclides are problematic with respect to meeting the performance objectives, as demonstrated in the initial PA, and are associated with large uncertainties based on the uncertainty analysis. As a result, Sect. 7.2.3 was prepared to include recommended reductions in the allowable inventories to provide additional assurance that the performance objectives will be met in the future at the IWMF and SWSA 6 .

The combined results presented in Table 7.1 show that most of the disposal limits for the IWMF are based on the results of the inadvertent intruder analysis. The results of the inadvertent intruder analysis, as well as the environmental transport analysis, are significantly affected by the closure of SWSA 6 . The closure of SWSA 6 will be defined by the CERCLA process, which is incomplete at this time. No RODs have been issued to date for the WOC watershed and no closure plans have been prepared for SWSA 6 as part of the CERCLA process. This revised PA assumed a minimal cap design consistent with the Accelerated Cleanup Plan for Oak Ridge prepared by the Environmental Restoration Program. Presuming that this approach to the closure of SWSA 6 will be the same as the ROD for SWSA 6 is conservative and contributes to the conclusion that continuing and future LLW disposal operations at SWSA 6 will meet the performance objectives of DOE O 5820.2A. When a closure plan for SWSA 6 is developed that provides a basis to take additional credits for closure of the facility, the PA may need to be revised to incorporate the elements of the final closure plan as part of the PA maintenance program.

The results presented in Table 7.1 were developed using restrictive performance criteria for the protection of water resources. A limit of 4 mrem per year EDE was used in this PA and was applied to both groundwater and surface water because other criteria have not been presented in rules or agreements with the State of Tennessee. Furthermore, the point of compliance was set at WOD for the consumption of contaminated surface water and at the edge of Hwy. 95 for both the consumption of contaminated groundwater and exposure to airborne radionuclides. Both of these performance criteria are conservative and do not take credit for land-use controls, which may be considerably more effective in deterring the future use of water resources in the vicinity of SWSA 6, and prohibit the possibility of the exposure scenarios considered in this PA for the all-pathways analysis, air pathways analysis, and water resource protection analysis. Land-use plans are being revised and are incomplete at this time, but they are expected to allow for the release of some land currently controlled by DOE. There are no suggestions at this time, as part of revising the land-use plans for the ORR, to consider the release of SWSA 6 to the public, and there is no intention to consider the possibility of releasing WOL or the WOC Embayment to the public. Using WOD as a point of compliance provides additional conservatism because concentrations of radionuclides in water will decrease as additional dilution occurs downstream of WOD. The potential dilution available in WOC Embayment and subsequent 
dilution in the Clinch River is not sufficiently understood to allow for credits in this revised PA analysis. Consequently, the environmental transport analysis results from the use of these assumptions are certain to be conservative. However, the results presented in Table 7.1 show that allowable limits for disposal at the IWMF are generally defined by the performance objective to provide protection from inadvertent intrusion into the waste disposal facility. This conclusion suggests that the IWMF can continue to operate within the limits prescribed by the performance objectives of DOE O $5820.2 \mathrm{~A}$ as long as the disposal limits presented in Table 7.1 are adhered to in IWMF operations.

The results presented in Table 7.1 omit numerous radionuclides that were considered in the preparation of this revised PA. Table 7.4 presents a listing of radionuclides that were considered, but were omitted from the analysis. The omission of these radionuclides from the results presented in Table 7.1 and the justification for the omission of these radionuclides are discussed in Sect 7.2.2. The key assumptions in developing the results presented in this revised PA and the relevance of these assumptions to continuing operations at the IWMF are discussed in Sect. 7.2.1.

\subsection{USE OF PERFORMANCE ASSESSMENT RESULTS}

This section provides a discussion of the application of the revised PA results and the initial PA results to disposal operations at the IWMF. The limitations to the disposal of wastes at the IWMF are presented along with those assumptions incorporated into this revised PA that are applicable to IWMF operations. The interpretation of the results in the PA as they apply to radionuclides with half-lives less than 5 years, additional radionuclides recorded on manifests at the IWMF, and radionuclides not currently projected for disposal at the IWMF are also discussed.

\subsubsection{Summary of Assumptions Relevant to Operation of the IWMF}

The assumptions used in estimating radionuclide releases and environmental transport for this revised PA are presented in Sect. 2.6. As is done with most models, these assumptions are made to overcome limitations (e.g., computational complexity or limited data) in calculating the potential releases of radionuclides from a waste form and their subsequent transport. Each of the assumptions is based, as much as possible, on the actual design and operation of the disposal unit and on the understood behavior of the surrounding environment. Therefore, a disposal unit may be operated within reasonable bounds of the assumptions and still meet their intent. Deviations from these operational bounds would require a revision of this revised PA. In addition, a revision may be required based on results from ongoing environmental monitoring and research programs. Such programs may lead to the improvement of conceptual models that describe the performance of a disposal unit and environmental transport of radionuclides. The PA maintenance program (DOE 1996d) provides for reviews of the PA assumptions and conceptual models, waste disposal operations, and results from environmental monitoring and relevant research efforts. 
In the following paragraphs, several of the key assumptions regarding the operation of the IWMF are described. These assumptions are addressed because they were identified as sensitive parameters for the source-term model (Appendix I), and some of these parameters may be directly affected by changes in operations at the IWMF. Other assumptions, such as those for transport of radionuclides in the environment, will not be directly affected by such changes but will be evaluated as part of the PA maintenance program.

The sensitivity and uncertainty analyses conducted for this revised PA have identified the radionuclide inventory as a major source of uncertainty for the evaluation of environmental transport pathways. Such uncertainties have been used to estimate the variability in the calculated releases and doses for radionuclides from non-IWMF facilities. Recognizing the uncertainty in the disposed inventory at the IWMF, the operating facility, operational limitations have been proposed (Sect. 7.2.4) to provide additional assurance that the PA performance objectives will be met. In addition, the radionuclide inventory is assumed to be uniformly distributed throughout the IWMF. The analyses did not consider high concentrations of radionuclides disposed of in any one vault. Historical disposal records show that these types of disposals have not routinely occurred. If a large disposal of radioactivity (i.e., a large fraction of the disposal limit) is planned to be concentrated in only a few vaults, then that situation would need to be evaluated in detail and, potentially, could lead to a PA revision.

The LLW disposed of at the IWMF is initially contained inside a metal box that is assumed to fail linearly during the first 60 years and to attenuate releases somewhat for highly mobile radionuclides. For some disposals, the use of a metal box may not be practical or necessary. For example, large metal parts may be disposed of that contain either activated materials or internal contamination. In such instances, the metal part itself may serve as a containment that is at least equal to the containment provided by the metal box. Additionally, smaller packages that contain sources may provide containment equal to that of the metal box. In this example, the presence of the metal box would not be necessary for the IWMF to remain within the bounds of the conditions analyzed for this revised PA if the alternative package will retain its integrity for at least the assumed amount of time (i.e., the package integrity declines linearly during a 60-year period). Again, the metal box needs to be understood as a means to attenuate releases of highly mobile radionuclides. Hence, because the metal box will have no effect on the calculated release of relatively immobile radionuclides, its presence is not necessary for wastes that contain only such radionuclides.

The IWMF concrete vault is assumed to contain a homogeneous mixture of waste and grout. This assumption approximates the filling of the annular region between the metal box and the concrete vault wall with grout. The key part of this assumption is the presence of the grout inside the concrete vault. Because this presence of grout is considered during the development of the radionuclide transport parameters (Appendix C), the grout is a necessary component in the waste form. When developing the radionuclide transport parameters, no special materials were assumed to be added to the grout mixture to retard the release of specific radionuclides. Consequently, no specific grout recipe is prescribed for the IWMF to remain within the bounds of this revised PA. 
The dimensions of the concrete vaults modeled for the IWMF are provided in Table 4.3. In some circumstances, vaults of different sizes may be necessary (e.g, a double vault for a large component); however, as long as the structural performance of a vault is at least equivalent to that of the vault modeled, the conditions of this revised PA will be met. An analysis has been conducted to evaluate the performance of a double-length LLW vault (Icenhour 1997). The double vaults, in addition to being twice as long as the single vault that was analyzed in this revised PA, have thicker walls and have larger diameter steel reinforcing rods (MMES Drawing S3E020016A008, Rev. 0). The analysis (using SOURCE1) predicted that the double vaults would last longer than the single vaults, which would reduce calculated releases for short-lived radionuclides. For longer-lived radionuclides, calculated releases for the single and double vaults would be about the same. In addition, because the wall thickness of the double vault is thicker than that of the single vault, calculated diffusive releases would be reduced. In summary, the performance of the double vault (as modeled with SOURCE1) should be at least as good as the performance of the single vault, and no credit was taken in this revised PA for the added performance of the double vaults.

Several assumptions have been made regarding the properties of the final waste form disposed of in the IWMF. In particular, the waste density was assumed to be $1.76 \mathrm{~g} / \mathrm{cm}^{3}$; the porosity was assumed to be 0.35 ; and for each radionuclide, based on an assumed chemical compound, specific values of solubility, distribution coefficient, and diffusion coefficient were developed (Appendix C). Through the sensitivity analysis, each of the aforementioned parameters was identified as being sensitive and was, therefore, considered further in the uncertainty analysis. A range and distribution were developed for each of these parameters and are reported in Appendix I. Therefore, the variability in these parameters has been considered in the calculations for this revised PA, and the operational bounds could be based on the uncertainty ranges used. Volume-reduction practices at ORNL result in increased waste density, which, in turn, results in a lower calculated release rate from the waste form because of higher retardation. If radionuclides that have chemical characteristics significantly different from those evaluated in this revised PA (Appendix C) are to be disposed of at the IWMF, then the PA maintenance program would need to evaluate the wastes.

The degradation of concrete is assumed to be caused by sulfate attack on the concrete, calcium hydroxide leaching from the concrete, and corrosion of the reinforcing steel. The sensitivity analysis performed for this revised PA (Appendix I) has identified sulfate attack to be the major concretedegradation mechanism for the source-term calculations. If other degradation mechanisms are identified to be important contributors to the performance of the concrete disposal vaults, then the PA maintenance program would need to evaluate these additional mechanisms.

The concrete pad and associated leachate-collection system at the IWMF are assumed to be functional throughout the institutional control period. The pad and collection system are assumed to attenuate $80 \%$ of releases to the environment initially, degrading linearly to $0 \%$ attenuation at the end of the institutional control period. This assumption applies to the releases of highly mobile radionuclides only because the release of less mobile radionuclides would likely be delayed beyond the end of the institutional control period. If the concrete pad and leachate collection system do not perform as expected, then the PA maintenance program would need to consider lower concentration 
Table 7.4. Radionuclides with no limit for disposal at the Interim Waste Management Facility

\begin{tabular}{|c|c|c|c|c|c|c|c|}
\hline Nuclide & $\begin{array}{l}\text { Half-life }^{a} \\
\text { (years) }\end{array}$ & Nuclide & $\begin{array}{c}\text { Half-life }^{\alpha} \\
\text { (years) }\end{array}$ & Nuclide & $\begin{array}{c}\text { Half-life }^{a} \\
\text { (years) }\end{array}$ & Nuclide & $\begin{array}{l}\text { Half-life }^{a} \\
\text { (years) }\end{array}$ \\
\hline${ }^{225} \mathrm{Ac}$ & $2.74 \times 10^{-2}$ & ${ }^{166} \mathrm{Dy}$ & $9.32 \times 10^{-3}$ & ${ }^{99} \mathrm{Mo}$ & $7.53 \times 10^{-3}$ & ${ }^{124} \mathrm{Sb}$ & $1.65 \times 10^{-1}$ \\
\hline${ }^{108 m} \mathrm{Ag}^{b}$ & $1.30 \times 10^{2}$ & ${ }^{253} \mathrm{Es}$ & $5.61 \times 10^{-2}$ & ${ }^{22} \mathrm{Na}$ & $2.60 \times 10^{0}$ & ${ }^{125} \mathrm{Sb}$ & $2.73 \times 10^{0}$ \\
\hline${ }^{110 \mathrm{~m}} \mathrm{Ag}$ & $6.84 \times 10^{-1}$ & ${ }^{254 \mathrm{~m}} \mathrm{Es}$ & $4.49 \times 10^{-3}$ & ${ }^{24} \mathrm{Na}$ & $1.71 \times 10^{-3}$ & ${ }^{46} \mathrm{Sc}$ & $2.30 \times 10^{-1}$ \\
\hline${ }^{111} \mathrm{Ag}$ & $2.05 \times 10^{-2}$ & ${ }^{156} \mathrm{Eu}$ & $4.16 \times 10^{-2}$ & ${ }^{95} \mathrm{Nb}$ & $9.59 \times 10^{-2}$ & ${ }^{75} \mathrm{Se}$ & $3.28 \times 10^{-1}$ \\
\hline${ }^{195} \mathrm{Au}$ & $5.10 \times 10^{-1}$ & ${ }^{55} \mathrm{Fe}$ & $2.73 \times 10^{0}$ & ${ }^{144} \mathrm{Nd}^{b}$ & $2.38 \times 10^{15}$ & ${ }^{113} \mathrm{Sn}$ & $3.15 \times 10^{-1}$ \\
\hline${ }^{199} \mathrm{Au}$ & $8.60 \times 10^{-3}$ & ${ }^{59} \mathrm{Fe}$ & $1.22 \times 10^{-1}$ & ${ }^{236} \mathrm{~Np}^{b}$ & $1.55 \times 10^{5}$ & ${ }^{117 \mathrm{~m}} \mathrm{Sn}$ & $3.73 \times 10^{-2}$ \\
\hline${ }^{133} \mathrm{Ba}^{b}$ & $1.05 \times 10^{1}$ & ${ }^{153} \mathrm{Gd}$ & $6.62 \times 10^{-1}$ & ${ }^{239} \mathrm{~Np}$ & $6.45 \times 10^{-3}$ & ${ }^{119 m} \mathrm{Sn}$ & $8.03 \times 10^{-1}$ \\
\hline${ }^{137 \mathrm{~m}} \mathrm{Ba}$ & $4.86 \times 10^{-6}$ & ${ }^{68} \mathrm{Ge}$ & $7.43 \times 10^{-1}$ & ${ }^{191} \mathrm{Os}$ & $4.22 \times 10^{-2}$ & ${ }^{85} \mathrm{Sr}$ & $1.78 \times 10^{-1}$ \\
\hline${ }^{140} \mathrm{Ba}$ & $3.49 \times 10^{-2}$ & ${ }^{181} \mathrm{Hf}$ & $1.16 \times 10^{-1}$ & ${ }^{32} \mathrm{P}$ & $3.91 \times 10^{-2}$ & ${ }^{89} \mathrm{Sr}$ & $1.38 \times 10^{-1}$ \\
\hline${ }^{7} \mathrm{Be}$ & $1.46 \times 10^{-1}$ & ${ }^{182} \mathrm{Hf}^{b}$ & $9.00 \times 10^{6}$ & ${ }^{33} \mathrm{P}$ & $6.93 \times 10^{-2}$ & ${ }^{179} \mathrm{Ta}$ & $1.82 \times 10^{0}$ \\
\hline${ }^{247} \mathrm{Bk}^{b}$ & $1.40 \times 10^{3}$ & ${ }^{194} \mathrm{Hg}^{b}$ & $5.20 \times 10^{2}$ & ${ }^{233} \mathrm{~Pa}$ & $7.40 \times 10^{-2}$ & ${ }^{182} \mathrm{Ta}$ & $3.16 \times 10^{-1}$ \\
\hline${ }^{249} \mathrm{Bk}$ & $8.77 \times 10^{-1}$ & ${ }^{203} \mathrm{Hg}$ & $1.28 \times 10^{-1}$ & ${ }^{212} \mathrm{~Pb}$ & $1.22 \times 10^{-3}$ & ${ }^{160} \mathrm{~Tb}$ & $1.98 \times 10^{-1}$ \\
\hline${ }^{82} \mathrm{Br}$ & $4.03 \times 10^{-3}$ & ${ }^{166 m} \mathrm{Ho}^{b}$ & $1.20 \times 10^{3}$ & ${ }^{109} \mathrm{Pd}$ & $1.54 \times 10^{-3}$ & ${ }^{95 \mathrm{~m}} \mathrm{Tc}$ & $1.67 \times 10^{-1}$ \\
\hline${ }^{109} \mathrm{Cd}$ & $1.27 \times 10^{\circ}$ & ${ }^{122} I$ & $6.85 \times 10^{-6}$ & ${ }^{146} \mathrm{Pm}^{b}$ & $5.53 \times 10^{0}$ & ${ }^{123 \mathrm{~m}} \mathrm{Te}$ & $3.23 \times 10^{-1}$ \\
\hline${ }^{139} \mathrm{Ce}$ & $3.77 \times 10^{-1}$ & ${ }^{123} \mathrm{I}$ & $1.51 \times 10^{-3}$ & ${ }^{147} \mathrm{Pm}$ & $2.62 \times 10^{0}$ & ${ }^{228} \mathrm{Th}$ & $1.91 \times 10^{0}$ \\
\hline${ }^{141} \mathrm{Ce}$ & $8.90 \times 10^{-2}$ & ${ }^{124} \mathrm{I}$ & $1.14 \times 10^{-2}$ & ${ }^{209} \mathrm{Po}^{b}$ & $1.02 \times 10^{2}$ & ${ }^{234} \mathrm{Th}$ & $6.60 \times 10^{-2}$ \\
\hline${ }^{144} \mathrm{Ce}$ & $7.81 \times 10^{-1}$ & ${ }^{125} \mathrm{I}$ & $1.65 \times 10^{-1}$ & ${ }^{195 \mathrm{~m}} \mathrm{Pt}$ & $1.10 \times 10^{-2}$ & ${ }^{204} \mathrm{Tl}$ & $3.78 \times 10^{\circ}$ \\
\hline${ }^{252} \mathrm{Cf}$ & $2.65 \times 10^{0}$ & ${ }^{131} I$ & $2.20 \times 10^{-2}$ & ${ }^{236} \mathrm{Pu}$ & $2.85 \times 10^{\circ}$ & ${ }^{187} \mathrm{~W}$ & $2.74 \times 10^{-3}$ \\
\hline${ }^{240} \mathrm{Cm}$ & $7.40 \times 10^{-2}$ & ${ }^{133} \mathrm{I}$ & $2.37 \times 10^{-3}$ & ${ }^{223} \mathrm{Ra}$ & $3.13 \times 10^{-2}$ & ${ }^{188} \mathrm{~W}$ & $1.90 \times 10^{-1}$ \\
\hline${ }^{242} \mathrm{Cm}$ & $4.47 \times 10^{-1}$ & ${ }^{135} I$ & $7.50 \times 10^{-4}$ & ${ }^{224} \mathrm{Ra}$ & $9.86 \times 10^{-3}$ & ${ }^{135} \mathrm{Xe}$ & $1.04 \times 10^{-3}$ \\
\hline${ }^{57} \mathrm{Co}$ & $7.45 \times 10^{-1}$ & ${ }^{" 11}$ In & $7.69 \times 10^{-3}$ & ${ }^{186} \mathrm{Re}$ & $1.04 \times 10^{-2}$ & ${ }^{88} \mathrm{Y}$ & $2.92 \times 10^{-1}$ \\
\hline${ }^{58} \mathrm{Co}$ & $1.94 \times 10^{-1}$ & ${ }^{114 m} \mathrm{In}$ & $1.36 \times 10^{-1}$ & ${ }^{188} \mathrm{Re}$ & $1.94 \times 10^{-3}$ & ${ }^{90} \mathrm{Y}$ & $7.32 \times 10^{-3}$ \\
\hline${ }^{51} \mathrm{Cr}$ & $7.59 \times 10^{-2}$ & ${ }^{192} \mathrm{Ir}$ & $2.02 \times 10^{-1}$ & ${ }^{101} \mathrm{Rh}$ & $3.30 \times 10^{0}$ & ${ }^{169} \mathrm{Yb}$ & $8.77 \times 10^{-2}$ \\
\hline${ }^{129} \mathrm{Cs}$ & $3.66 \times 10^{-3}$ & ${ }^{85} \mathrm{Kr}^{6}$ & $1.07 \times 10^{1}$ & ${ }^{222} \mathrm{Rn}$ & $1.05 \times 10^{-2}$ & ${ }^{65} \mathrm{Zn}$ & $6.69 \times 10^{-1}$ \\
\hline${ }^{134} \mathrm{Cs}$ & $2.06 \times 10^{0}$ & ${ }^{140} \mathrm{La}$ & $4.60 \times 10^{-3}$ & ${ }^{103} \mathrm{Ru}$ & $1.08 \times 10^{-1}$ & ${ }^{95} \mathrm{Zr}$ & $1.75 \times 10^{-1}$ \\
\hline${ }^{136} \mathrm{Cs}$ & $3.61 \times 10^{-2}$ & ${ }^{173} \mathrm{Lu}$ & $1.37 \times 10^{0}$ & ${ }^{106} \mathrm{Ru}$ & $1.02 \times 10^{0}$ & & \\
\hline${ }^{64} \mathrm{Cu}$ & $1.45 \times 10^{-3}$ & ${ }^{54} \mathrm{Mn}$ & $8.55 \times 10^{-1}$ & ${ }^{35} \mathrm{~S}$ & $2.40 \times 10^{-1}$ & & \\
\hline
\end{tabular}

a Source: Brown and Firestone 1986 or Chart of the Nuclides, $15^{\text {th }}$ Edition.

${ }^{b}$ Radionuclide with a half life greater than five years. See discussion in Sect. 7.2.2.

limits for highly mobile radionuclides. On the other hand, if a basis can be developed for taking more credit for the pad and collection system, then limits could be increased.

The closure of SWSA 6 will be defined by the CERCLA process, which is incomplete at this time. As a result, a minimal cap design has been assumed. The assumed closure affects the calculated amount of water infiltrating into the IWMF and also affects its degradation and performance. When a closure plan for SWSA 6 is developed that provides a basis to take additional credits for closure of the facility, the PA may need to be revised.

Other assumptions identified in Sect. 2.6, but not specifically discussed in this section, will be considered in the PA maintenance program. As further environmental monitoring and investigation of conceptual models occur, a revision of the PA may be warranted. 


\subsubsection{Allowable Disposals for Radionuclides Not Analyzed in the PA for the IWMF}

In this revised PA, analyses of exposures of off-site individuals and inadvertent intruders were used in conjunction with the applicable performance objectives to develop limits on allowable inventories for disposal for a total of 63 radionuclides (see introduction to Sect. 4 and Table 4.2). These radionuclides were selected from a longer list of radionuclides that could be present in wastes to be disposed of in the IWMF (Table 4.1). The selection of radionuclides for analysis in this revised PA was based primarily on two considerations: (1) the half-life of the radionuclide and (2) its means of production (i.e., whether it could be produced in significant amounts by nuclear fission or neutron activation).

This section addresses the issue of allowable disposals for radionuclides that were not analyzed in this revised PA. An important consideration is to ensure that radionuclides that were not analyzed but are reported in present or future waste disposals could not contribute significantly to exposures of off-site individuals or inadvertent intruders. The two issues addressed in this section include the following.

First, only radionuclides with half-lives of 5 years or greater were analyzed in this revised PA. The justification for excluding all radionuclides with half-lives less than 5 years is discussed in Sect. 7.2.2.2.

Second, several radionuclides with half-lives greater than 5 years that are listed in Table 4.1 were not analyzed in the PA. The justification for excluding these radionuclides and the development of screening criteria for selecting longer-lived radionuclides not listed in Table 4.2 that would need to be analyzed in future revisions of this revised PA for the IWMF are discussed in Sect. 7.2.2.3.

The discussions in Sect. 7.2.2.2 and 7.2.2.3 are based in large part on the limits on allowable inventories for disposal for the radionuclides that were analyzed in this revised PA. Therefore, to provide an introduction to these sections, a brief summary of the disposal limits developed in the PA is presented in Sect. 7.2.2.1.

\subsubsection{Summary of Disposal Limits for Radionuclides Analyzed in the PA}

The limits on allowable inventories of radionuclides for disposal in the IWMF obtained from this revised PA are summarized in Table 7.1. These limits were based either on the calculated concentrations in groundwater beyond the site boundary and the performance criterion for the drinking water pathway for off-site individuals or on the calculated doses and the performance objective for inadvertent intruders.

The results in Table 7.1 show that the dose assessment for inadvertent intruders is more important than the dose assessment for off-site releases in groundwater in determining limits on allowable inventories of radionuclides for disposal in the IWMF. Only for ${ }^{79} \mathrm{Se}$ and ${ }^{129} \mathrm{I}$ are the disposal limits determined by the assessment for off-site releases. The groundwater release pathway is more restrictive for these two radionuclides essentially for the following reasons: (1) they are long-lived, (2) they are assumed to be considerably more mobile in water than most of the other radionuclides 
analyzed in the assessment, and (3) they are not significant photon emitters. In addition; the ingestion dose conversion factor is considerably higher for ${ }^{129} \mathrm{I}$ than for the other radionuclides in Table 7.1 that are not alpha emitters (see Appendix G, Table G.2). However, the disposal limits for ${ }^{79} \mathrm{Se}$ and ${ }^{129} \mathrm{I}$ obtained from the dose assessment for the groundwater release pathway are considerably higher than the limits for some of the other long-lived radionuclides obtained from the dose assessment for inadvertent intruders, particularly the limits for long-lived, photon-emitting radionuclides (e.g., ${ }^{26} \mathrm{Al}$, ${ }^{94} \mathrm{Nb},{ }^{226} \mathrm{Ra}$ ).

Taking these two factors into account leads to the following general conclusion from the PA for the IWMF:

For radionuclides not analyzed in the PA for the IWMF, the justification for their exclusion and the development of screening criteria for allowable inventories for disposal, with no further analysis required, can be based entirely on the limiting inventories obtained from the dose assessment for inadvertent intruders for the radionuclides analyzed in this assessment.

Two further observations about the limits on allowable disposals in Table 7.1 are important for the discussions in Sect. 7.2.2.2 and Sect. 7.2.2.3. First, for radionuclides with half-lives of about 30 years or less, the disposal limits are, in nearly all cases, higher than the limits for longer-lived radionuclides and, furthermore, the limits increase rapidly as the half-life decreases below 30 years. These results follow essentially from the assumptions about the time period for active institutional controls over the disposal site (100 years) and the time period that engineered barriers in the IWMF can preclude access to waste by normal excavation ( 300 years).

Second, the disposal limits for radionuclides that emit high intensities of high-energy photons (e.g., ${ }^{26} \mathrm{Al},{ }^{60} \mathrm{Co},{ }^{137} \mathrm{Cs},{ }^{226} \mathrm{Ra}$ plus decay products) are considerably less than the disposal limits for radionuclides with comparable half-lives that are not significant photon emitters. This result follows from the primary importance of external exposure pathways in the dose assessment for inadvertent intruders for photon-emitting radionuclides (see Appendix G, Sect. G.5.2).

Therefore, the justification for excluding radionuclides with half-lives less than 5 years from this revised PA and the development of screening criteria for radionuclides with half-lives greater than 5 years that were not analyzed in the assessment can be based primarily on considerations of the halflife of the radionuclide and the disposal limits for photon-emitting radionuclides in Table 7.1.

\subsubsection{Exclusion of Radionuclides with Half-Lives Less Than 5 Years}

All radionuclides with half-lives less than 5 years were excluded from this revised PA for the IWMF. This exclusion was based initially on the general consideration that short-lived radionuclides should decay to innocuous levels before exposures of off-site individuals or inadvertent intruders could occur, taking into account the time period for active institutional controls over the disposal site, the 
expected performance of engineered barriers in SWSA 6, and the expected travel times of radionuclides in water to off-site locations.

The exclusion of radionuclides with half-lives less than 5 years also can be justified based on the disposal limits in Table 7.1 for radionuclides with half-lives of about 5 years, which include ${ }^{60} \mathrm{Co}$ $\left(\mathrm{T}_{1 / 2}=5.271 \mathrm{y}\right)$ and ${ }^{154} \mathrm{Eu}\left(\mathrm{T}_{1 / 2}=4.96 \mathrm{y}\right)$. For radionuclides with half-lives of about 5 years, the lowest disposal limit was obtained for ${ }^{60} \mathrm{Co}$. Furthermore, the disposal limit for ${ }^{60} \mathrm{Co}$ represents a reasonable lower bound on the disposal limit for any other radionuclide with a comparable half-life, because ${ }^{60} \mathrm{Co}$ emits high intensities of high-energy photons (Kocher 1981).

Therefore, based on the disposal limit for ${ }^{60} \mathrm{Co}$ in Table 7.1, the disposal limit for any other radionuclide with a half-life less than 5 years would be at least $4 \times 10^{5} \mathrm{Ci} /$ pad. For purposes of radionuclide screening, the inventory of a radionuclide can be assumed to be neglected if it is $0.1 \%$ or less of the reasonable lower bound for its disposal limit, because potential doses to inadvertent intruders and off-site individuals would be $0.1 \%$ or less of the applicable performance objectives and, thus, would be negligible. Based on these considerations, any radionuclide with a half-life less than 5 years can be excluded from the PA if its inventory per pad at the time of disposal does not exceed $400 \mathrm{Ci}$.

Furthermore, as noted previously, the allowable inventory for disposal of short-lived radionuclides increases rapidly with decreasing half-life. For example, for any radionuclide with decay properties similar to ${ }^{60} \mathrm{Co}$, which again represents a reasonable worst case, but with a half-life of 4 years, the disposal limit would be increased by about two orders of magnitude, and the increase would be more than four orders of magnitude for a similar radionuclide with a half-life of 3 years.

The screening criterion of $400 \mathrm{Ci}$ for all radionuclides with half-lives less than 5 years is a high level of activity. In comparison, for all radionuclides with half-lives less than 5 years that were reported in past disposals in SWSA 6, the maximum inventory was about $40 \mathrm{Ci}$ for ${ }^{58} \mathrm{Co}$ in the highrange wells [see ORNL (1994), Appendix A, Table A.3 through Table A.11]. Thus, the activities of all short-lived radionuclides in prior disposals in SWSA 6 appear to be considerably less than the screening criterion obtained above.

Finally, other waste acceptance criteria for the IWMF are potentially important in limiting allowable activities of short-lived radionuclides. In particular, only $\mathrm{CH}$ waste, which is defined in terms of an external dose-equivalent rate at the surface of a waste package of $200 \mathrm{mrem} / \mathrm{h}$ or less, is acceptable for disposal (Sect. 3.2.1.2). Because many radionuclides with half-lives less than 5 years are significant photon emitters (Kocher 1981), the definition of $\mathrm{CH}$ waste can be quite restrictive in limiting disposals of short-lived radionuclides. This is indicated, for example, by the reported inventories for past disposals in Tumulus I, Tumulus II, and the IWMF [see ORNL (1994), Appendix A, Table A.3 through Table A.5], which have accepted only $\mathrm{CH}$ waste. For these disposal units, the highest reported activity for ${ }^{60} \mathrm{Ci}$ is about $4 \mathrm{Ci}$, and the highest reported activity for any radionuclide with a half-life less than 5 years is about $2 \mathrm{Ci}$. These activities are an order of magnitude less than the maximum reported activity of about $40 \mathrm{Ci}$ for any short-lived radionuclide in the highrange wells, which accepted $\mathrm{RH}$ waste with any external dose rate at the surface of a waste package. 
Taking all of the factors described above into account leads to the conclusion that any radionuclide with a half-life less than 5 years can be excluded from this revised PA, because the resulting doses to off-site individuals and inadvertent intruders would not exceed a very small fraction of the applicable performance objectives. To recapitulate, this conclusion is based primarily on the following considerations:

- the limit on allowable inventory of ${ }^{60} \mathrm{Co}$ for disposal in the IWMF, which should provide a lower bound on the disposal limit for any radionuclide with a half-life less than 5 years;

- the rapid increase in disposal limits with decreasing radionuclide half-life for half-lives less than 5 years; and

- the acceptance criterion for the IWMF on external dose rate at the surface of waste packages, which limits the concentrations of photon-emitting radionuclides and, thus, total allowable inventories of such radionuclides in the IWMF, and the observation that many radionuclides with half-lives less than 5 years are significant photon emitters.

The general exclusion of radionuclides with half-lives less than 5 years from this revised PA also is supported by the observation that the reported activities of all short-lived radionuclides in past disposals in SWSA 6 have been less than the reported activities of ${ }^{60} \mathrm{Co}$.

\subsubsection{Screening of Radionuclides with Half-Lives Greater Than 5 Years}

Only selected radionuclides with half-lives greater than 5 years were analyzed in this revised PA (see Table 4.2). With the aim of avoiding unnecessary calculations, the radionuclides initially selected were limited to those that were expected to be the most important for the PA, based on knowledge of prior disposals in SWSA 6 and other DOE sites and an assumption that fission and neutron activation would be the most important processes producing waste intended for disposal in the IWMF.

However, additional radionuclides with half-lives greater than 5 years could be present in significant quantities in waste intended for disposal in the IWMF. Therefore, it is important to consider activity levels below which such radionuclides would be unimportant for this revised PA, because the potential doses to off-site individuals or inadvertent intruders could be only a very small fraction of the applicable performance objectives or, conversely, activity levels above which such radionuclides would need to be included in any future revision of the PA to ensure that the applicable performance objectives would be met.

This section presents a simple screening approach for determining whether or not radionuclides with half-lives greater than 5 years that were not analyzed in this revised PA would need to be included in a future revision of the assessment. The screening criteria developed in this section can be applied to either of the following two cases of potential importance to disposals in the IWMF: 
- screening of radionuclides that may have been present in past disposals in the IWMF or other disposal units in SWSA 6 (e.g., as recorded on waste manifests); and

- screening of new radionuclides that may occur in future wastes but have not been reported or suspected in past disposals.

The first case applies to several radionuclides listed in Table 4.1 (e.g., ${ }^{108 \mathrm{~m}} \mathrm{Ag},{ }^{133} \mathrm{Ba},{ }^{166 \mathrm{~m}} \mathrm{Ho},{ }^{182} \mathrm{Hf}$, ${ }^{194} \mathrm{Hg},{ }^{209} \mathrm{Po}$, and ${ }^{247} \mathrm{Bk}$ ) that were not included in this revised PA because their inventories were expected to be insignificant compared with the inventories of other radionuclides included in the assessment. The second case takes into account that the types of waste intended for disposal in the IWMF in the future are somewhat unpredictable and, thus, new radionuclides of concern could be present.

In any approach to screening, the screening criteria must be clearly conservative. That is, if the screening criteria for the IWMF indicate that a particular radionuclide need not be analyzed in this revised PA, then radionuclide activities at the screening level or below must be unquestionably unimportant. The screening criteria for radionuclides with half-lives greater than 5 years developed in this section are based on the following considerations:

- the limits on allowable inventories per disposal pad for the radionuclides analyzed in this revised PA, as given in Table 7.1 ;

- $\quad$ selection of the lowest applicable disposal limit in Table 7.1, which generally is based on the dose assessment for inadvertent intruders, to provide a reasonable lower bound on the disposal limit for radionuclides not previously analyzed in this revised PA; and

- the assumption that an activity of about $0.1 \%$ of the lowest applicable disposal limit provides a suitable screening criterion for determining the importance of radionuclides not previously analyzed in this revised PA.

In addition, for purposes of radionuclide screening, the derived screening activities are rounded to the nearest order of magnitude. Given the level of conservatism embodied in the screening approach, rounding of screening activities in this manner would not have a significant effect on potential doses to off-site individuals or inadvertent intruders. Furthermore, when the screening activities are expressed as orders of magnitude, rounding on a logarithmic scale, rather than a linear scale, is appropriate.

Based on the factors described above, several activity levels for screening of radionuclides with half-lives greater than 5 years are developed in the following sections. The value of any screening activity depends on the half-life of the radionuclide and, in some cases, its decay properties. 


\subsection{Screening of Radionuclides Based Only on Half-Life}

For radionuclides with half-lives greater than 5 years, the development of screening criteria is based initially on consideration of the radionuclide half-life only. A single screening criterion could be developed for all such radionuclides. However, in this analysis, separate screening criteria are developed for radionuclides with half-lives of 5 to 30 years and radionuclides with half-lives greater than 30 years. This distinction is potentially important for two reasons: (1) for radionuclides with halflives less than 30 years, radioactive decay between the time of disposal and the time that potential exposures of inadvertent intruders could occur is significant in determining disposal limits, and (2) there are few radionuclides with half-lives between 30 years and a few hundred years (Walker et al. 1983 ) and, thus, radioactive decay usually is not significant in determining disposal limits for radionuclides with half-lives greater than 30 years. Therefore, the screening activity for radionuclides with half-lives of 5 to 30 years should be significantly higher than the value for longer-lived radionuclides.

\section{Screening of Long-Lived Radionuclides}

For any radionuclide with a half-life greater than 30 years, a screening activity can be based on the lowest disposal limit for any radionuclide in Table 7.1 because the lowest disposal limits occur for long-lived radionuclides.

The lowest limit on allowable inventory per pad for the IWMF for any radionuclide analyzed in this revised PA is $0.055 \mathrm{Ci}$ for ${ }^{26} \mathrm{Al}$. The disposal limit for ${ }^{26} \mathrm{Al}$ is the lowest because it is very longlived (i.e., it does not decay significantly during the time period for active institutional controls or the assumed lifetime of the engineered barriers in the IWMF), it is relatively immobile in water (i.e., it is not transported from the IMWF in significant amounts before exposures of inadvertent intruders are assumed to occur), and it emits the highest intensities of high-energy photons (Kocher 1981).

Based on the disposal limit for ${ }^{26} \mathrm{Al}$ described above, the use of $0.1 \%$ of this disposal limit for purposes of screening, and logarithmic rounding to the nearest order of magnitude, the following screening criterion is obtained.

For any radionuclide with a half-life greater than 30 years, an activity per disposal pad less than $10^{-4} \mathrm{Ci}$ (i.e., $100 \mu \mathrm{Ci}$ ) is unimportant for this revised PA for the IWMF.

This screening criterion should exclude many radionuclides with half-lives greater than 30 years from the need for consideration in this revised PA for the IWMF. If a radionuclide with a half-life greater than 30 years is not screened out by this criterion, a less restrictive screening criterion based on decay properties of the radionuclide developed in Sect. 7.2.2.3.2 could be considered. 


\section{Screening of Shorter-Lived Radionuclides}

For any radionuclide with a half-life of 5 to 30 years, a screening activity can be based on the lowest disposal limit for any shorter-lived radionuclide in Table 7.1. The lowest disposal limit for shorter-lived radionuclides is considerably higher than the lowest disposal limit for radionuclides with half-lives greater than 30 years.

For the radionuclides with half-lives of about 5 to 30 years listed in Table 7.1 , the lowest limit on allowable inventory per pad is $15 \mathrm{Ci}$ for ${ }^{207} \mathrm{Bi}\left(\mathrm{T}_{1 / 3}=33.4 \mathrm{y}\right)$. Since the half-life of ${ }^{207} \mathrm{Bi}$ is at the upper end of the range of interest, radioactive decay is less important in determining the disposal limit than for other radionuclides with shorter half-lives. Furthermore, ${ }^{207} \mathrm{Bi}$ emits high intensities of highenergy photons (Kocher 1981). Therefore, the disposal limit for ${ }^{207} \mathrm{Bi}$ is suitable for purposes of screening for radionuclides in this range of half-lives.

Based on the disposal limit for ${ }^{207} \mathrm{Bi}$ described above, the use of $0.1 \%$ of this disposal limit for purposes of screening, and logarithmic rounding to the nearest order of magnitude, the following screening criterion is obtained.

For any radionuclide with a half-life of 5 to 30 years, an activity per disposal pad less than $10^{-2} \mathrm{Ci}$ (i.e., $10 \mathrm{mCi}$ ) is unimportant for this revised PA for the IWMF.

This screening criterion is two orders of magnitude greater than the screening criterion for any radionuclide with a half-life greater than 30 years described previously. This difference should be useful in screening shorter-lived radionuclides. However, if radionuclides with half-lives of 5 to 30 years are not excluded by this screening criterion, a less restrictive criterion based on decay properties of the radionuclide developed in the following section could be considered.

\subsection{Further Screening of Radionuclides Based on Decay Properties}

The two screening criteria developed in Sect. 7.2.2.3.1 are based only on the half-life of the radionuclide. In this section, additional screening criteria are developed based on decay properties of the radionuclide as well as its half-life. These criteria could be used whenever a radionuclide is not excluded from further consideration in this revised PA by the screening criteria based only on half-life.

Two decay properties of radionuclides are potentially important for purposes of further screening: (1) the spectrum of emitted photons and (2) whether the radionuclide emits alpha particles. Development of separate screening criteria based on the spectrum of emitted photons is potentially useful because, for radionuclides with comparable half-lives, the disposal limits for radionuclides that are not significant photon emitters are considerably higher than the disposal limits for photon emitters, as a result of the importance of external exposure pathways in the dose assessment for inadvertent intruders for photon emitters (see Appendix G, Sect. G.5.2). Development of separate screening criteria based on the emission of alpha particles is potentially useful because, for radionuclides with comparable half-lives, the disposal limits for non-alpha emitters may be considerably higher than those 
for alpha emitters, as a result of the lower ingestion and inhalation dose conversion factors for nonalpha emitters (see Appendix G, Table G.2 and Table G.3).

Radionuclides that are not alpha emitters that could be considered for further screening include beta emitters and radionuclides that decay by electron capture and isomeric transitions (Kocher 1981). However, radionuclides that decay by positron emission would not be considered for further screening, because annihilation of the emitted positrons at rest produces two 511-keV photons (Kocher $1981)$ and, thus, positron emitters also are significant photon emitters.

Based on these considerations, additional screening criteria are developed for radionuclides that are not significant photon emitters. As in developing the screening criteria in Sect. 7.2.2.3.1 that apply to any radionuclide, separate screening criteria are developed for half-lives of 5 to 30 years and half-lives greater than 30 years. Then, within each category of half-life, separate screening criteria are considered for non-alpha-emitting and alpha-emitting radionuclides that also are not significant photon emitters.

\section{Further Screening of Long-Lived Radionuclides}

Additional screening criteria for radionuclides with half-lives greater than 30 years that also are not significant photon emitters are considered in the following paragraphs. As noted previously, screening criteria for non-alpha-emitting and alpha-emitting radionuclides are considered separately.

For the long-lived, non-alpha-emitting radionuclides listed in Table 7.1 that are not significant photon emitters, the lowest limit on allowable inventory per disposal pad is $11 \mathrm{Ci}$ for ${ }^{36} \mathrm{Cl}$. This radionuclide has the highest plant-to-soil concentration ratio for the vegetable pathway (see Appendix G, Table G.17), and this exposure pathway is the most important in the dose assessment for inadvertent intruders for non-photon emitters. However, the disposal limit for ${ }^{36} \mathrm{Cl}$ in Table 7.1 is not suitable for screening, because it includes an assumption that ${ }^{36} \mathrm{Cl}$ is highly mobile in water and, thus, is readily removed from the IWMF (see Table 6.7).

For the purpose of screening, a revised disposal limit for ${ }^{36} \mathrm{Cl}$ is developed based on an assumption that transport from the IWMF in water does not occur. With this assumption, the disposal limit for ${ }^{36} \mathrm{Cl}$ would be based on the dose assessment for the agriculture scenario for inadvertent intruders, rather than the post-drilling scenario as indicated in Table 7.1. Using the disposal limit of $180 \mathrm{Ci}$ for the agriculture scenario given in Table 6.10 and removing the mobilization and transport factor $\left(f_{w}\right)$ of 0.002 , the revised disposal limit for ${ }^{36} \mathrm{Cl}$ suitable for screening becomes $0.4 \mathrm{Ci}$.

Based on the revised disposal limit for ${ }^{36} \mathrm{Cl}$ described above, the use of $0.1 \%$ of this disposal limit for purposes of screening, and logarithmic rounding to the nearest order of magnitude, the following screening criterion is obtained.

For any non-alpha-emitting radionuclide with a half-life greater than 30 years that is not a significant photon emitter, an activity per disposal pad less than $10^{-3} \mathrm{Ci}$ (i.e., $1 \mathrm{mCi}$ ) is unimportant for this revised PA for the IWMF. 
This screening criterion is an order of magnitude greater than the screening criterion that applies to any radionuclide with a half-life greater than 30 years developed in Sect. 7.2.2.3.1.

For the long-lived, alpha-emitting radionuclides listed in Table 7.1 that do not emit high intensities of high-energy photons, the lowest limit on allowable inventory per disposal pad is $0.54 \mathrm{Ci}$ for ${ }^{237} \mathrm{~Np}$. This radionuclide has the highest plant-to-soil concentration ratio for the vegetable pathway for any alpha-emitting radionuclide (see Appendix G, Table G.17), and the ingestion and inhalation dose conversion factors are within a factor of about three of the highest values for any alpha-emitting radionuclide (see Appendix G, Table G.2 and Table G.3). Furthermore, external exposure pathways for ${ }^{237} \mathrm{~Np}$ are of some importance in the dose assessment for inadvertent intruders (see Appendix $\mathrm{G}$, Sect. G.5.2), which provides an additional level of conservatism in applying the disposal limit for ${ }^{237} \mathrm{~Np}$ to screening of radionuclides that are not significant photon emitters. Taking all of these factors into account, the disposal limit for ${ }^{237} \mathrm{~Np}$ is suitable for screening of long-lived, alpha-emitting radionuclides that are not significant photon emitters.

Based on the disposal limit for ${ }^{237} \mathrm{~Np}$ described above, the use of $0.1 \%$ of this disposal limit for purposes of screening, and logarithmic rounding to the nearest order of magnitude, the following screening criterion is obtained.

For any alpha-emitting radionuclide with a half-life greater than 30 years that is not a significant photon emitter, an activity per disposal pad less than $10^{-3} \mathrm{Ci}$ (i.e., $1 \mathrm{mCi}$ ) is unimportant for this revised PA for the IWMF.

This screening criterion is an order of magnitude greater than the screening criterion developed in Sect. 7.2.2.3.1 that applies to any radionuclide with a half-life greater than 30 years and, furthermore, is the same as the screening criterion for non-alpha-emitting radionuclides that are not significant photon emitters described above. The latter result, although somewhat surprising, is due primarily to the unusually high plant-to-soil concentration ratio for neptunium assumed in developing the screening criterion for the alpha emitters, but it does not reflect the general tendency noted previously that disposal limits for non-alpha emitters are, in most cases, higher than those for alpha emitters.

Therefore, although two different screening criteria were considered for long-lived radionuclides that are not significant photon emitters, one for non-alpha emitters and the other for alpha emitters, the single screening activity of $10^{-3} \mathrm{Ci}$ applies in both cases.

\section{Further Screening of Shorter-Lived Radionuclides}

Additional screening criteria for radionuclides with half-lives of 5 to 30 years that also are not significant photon emitters are considered in the following paragraphs. As in developing the screening criteria for radionuclides with half-lives greater than 30 years in the previous paragraphs, screening criteria for non-alpha-emitting and alpha-emitting radionuclides are considered separately.

For shorter-lived, non-alpha-emitting radionuclides that are not significant photon emitters, the disposal limits in Table 7.1 are based on the dose assessment for the post-drilling scenario for 
inadvertent intruders. For non-alpha-emitting radionuclides of any half-life, the highest annual dose per unit concentration in waste for the post-drilling scenario occurs for ${ }^{36} \mathrm{Cl}$ (see Appendix $\mathrm{G}$, Table G.27). As noted previously, this result is due to the unusually high plant-to-soil concentration ratio for the vegetable pathway. This radionuclide also is not a photon emitter. Therefore, for purposes of screening, the limit on allowable inventory per pad of $11 \mathrm{Ci}$ for ${ }^{36} \mathrm{Cl}$ given in Table 6.12 can be used if, first, a decay factor $\left(f_{D}\right)$ for a radionuclide with a half-life of 30 years (i.e., the factor of 0.1 for ${ }^{137} \mathrm{Cs}$ ) is included and, second, the mobilization and transport factor $\left(f_{w}\right)$ of 0.68 is removed. Taking these two factors into account, a revised disposal limit for ${ }^{36} \mathrm{Cl}$ suitable for screening becomes $75 \mathrm{Ci}$.

Based on the revised disposal limit for ${ }^{36} \mathrm{Cl}$ described above, the use of $0.1 \%$ of this disposal limit for the purposes of screening, and logarithmic rounding to the nearest order of magnitude, the following screening criterion is obtained.

For any non-alpha-emitting radionuclide with a half-life of 5 to 30 years that is not a significant photon emitter, an activity per disposal pad less than $10^{-1} \mathrm{Ci}$ (i.e.. $100 \mathrm{mCi}$ ) is unimportant for this revised PA for the IWMF.

This screening criterion is an order of magnitude greater than the screening criterion that applies to any radionuclide with a half-life of 5 to 30 years developed in Sect. 7.2.2.3.1.

For shorter-lived, alpha-emitting radionuclides that are not significant photon emitters, disposal limits for the post-drilling scenario for inadvertent intruders can be used in developing the screening criterion. For alpha-emitting radionuclides of any half-life, the highest annual dose per unit concentration in waste for the post-drilling scenario occurs for ${ }^{237} \mathrm{~Np}$ (see Appendix G. Table G.27). This result again is due to the unusually high plant-to-soil concentration ratio for the vegetable pathway (see Appendix G, Table G.17). This radionuclide also is a photon emitter, but the contribution from external exposure is not the most important in the dose assessment for the post-drilling scenario. Therefore, for purposes of screening, the annual dose per unit concentration for ${ }^{23} \mathrm{~Np}$ given in Appendix G, Table G.27, can be used in conjunction with the performance objective of 0.1 rem if the decay factor of 0.1 for a radionuclide with a half-life of 30 years is taken into account. Based on these considerations, the disposal limit for ${ }^{237} \mathrm{~Np}$ suitable for screening becomes about $300 \mathrm{Ci}$.

Based on the revised disposal limit for ${ }^{237} \mathrm{~Np}$ described above, the use of $0.1 \%$ of this disposal limit for purposes of screening, and logarithmic rounding to the nearest order of magnitude, the following screening criterion is obtained.

For any alpha-emitting radionuclide with a half-life of 5 to 30 years that is not a significant photon emitter, an activity per disposal pad less than $10^{-1} \mathrm{Ci}$ (i.e., $100 \mathrm{mCi}$ ) is unimportant for this revised PA for the IWMF.

This screening criterion is an order of magnitude greater than the screening criterion that applies to any radionuclide with a half-life of 5 to 30 years developed in Sect. 7.2.2.3.1 and, furthermore, is the same 
as the screening criterion for non-alpha-emitting radionuclides that are not significant photon emitters described above.

Therefore, as in the case of long-lived radionuclides considered previously, although two different screening criteria were considered for shorter-lived radionuclides that are not significant photon emitters, one for non-alpha emitters and the other for alpha emitters, the single screening activity of $10^{-1} \mathrm{Ci}$ applies in both cases.

\section{Application of Screening Criteria Based on Decay Properties}

Some caution is warranted in applying screening criteria based on the decay properties of a radionuclide as well as its half-life. A basic assumption in developing these criteria is that the radionuclide is not a significant photon emitter. However, few radionuclides are pure beta or alpha emitters and, thus, emit no photons. Therefore, for many radionuclides, an important consideration is whether the energies and intensities of emitted photons are sufficiently high that external exposure pathways could be important in the dose assessment for inadvertent intruders. In the case of ${ }^{241} \mathrm{Am}$, for example, which emits a $60-\mathrm{keV}$ photon with an intensity of $36 \%$ (Kocher 1981) and for which the average photon energy per decay is $28 \mathrm{keV}$ (Kocher 1980b), external exposure pathways are only marginally significant in the dose assessment for inadvertent intruders (see Appendix G, Sect. G.5.2). Therefore, based on the example of ${ }^{241} \mathrm{Am}$, a radionuclide reasonably could be considered an insignificant photon emitter if the average photon energy per decay is less than about $50 \mathrm{keV}$.

However, the condition for selecting radionuclides that are not significant photon emitters described above needs to be recognized as somewhat arbitrary. Therefore, the additional screening criteria based on the spectrum of emitted photons developed in this section could be ignored unless the radionuclide clearly is not a significant photon emitter (i.e., it emits no photons or only very lowenergy photons). An example of the latter would be ${ }^{239} \mathrm{Pu}$, which emits mainly $14-\mathrm{keV} \mathrm{X}$ rays (Kocher 1981).

\subsubsection{Summary of Screening Criteria}

The screening criteria developed in Sect. 7.2.2.2 and Sect. 7.2.2.3 are summarized in Table 7.5. The criteria are defined in terms of total activity per disposal pad, and they provide activity levels below which the radionuclides do not need to be analyzed in this revised PA for application to the IWMF. Conversely, if the reported activity in disposed waste for any radionuclide not listed in Table 7.1 exceeds all applicable screening criteria, the radionuclide should be analyzed for inclusion in a revised PA to ensure that the performance objectives for the disposal facility would be met as part of the PA maintenance program.

The screening criteria in Table 7.5 form a hierarchy of different screening levels that would be compared with the reported total inventory of a radionuclide per disposal pad in the IWMF. Higher levels in the hierarchy require more information about the properties of a radionuclide to apply the screening criteria. For screening at Level 1, no information about the half-life or decay properties of 
the radionuclide is required. At Level 2, information about the half-life of the radionuclide, but not its decay properties, is required. For screening at Level 2, a separate criterion for radionuclides with halflives greater than 30 years is not needed because the screening criterion for Level 1 applies to these radionuclides and a Level 2 criterion thus would be redundant. Finally, at Level 3, information about the half-life and the spectrum of emitted photons is required. The screening criteria at Level 3 can be applied to non-alpha-emitting and alpha-emitting radionuclides.

Therefore, the approach to radionuclide screening is to start at Level 1 and then, if the reported activity of a radionuclide exceeds the Level 1 screening criterion, go to the next highest applicable screening level, and similarly for screening at Level 2 . In this way, all levels of screening could be applied in deciding whether a radionuclide needs to be analyzed in this revised PA for the IWMF.

Application of the Level 1 and 2 screening criteria is straightforward because the only property of a radionuclide that needs to be considered is its half-life. Therefore, at the discretion of the site operator, screening at Level 3 could be ignored unless the radionuclide is a pure beta or alpha emitter or the energies and intensities of the emitted photons clearly are so low that they are insignificant. If Level 3 screening is ignored, then only Level 1 screening would be applied for radionuclides with halflives greater than 30 years.

The screening activities given in Table 7.5 are intended to be quite conservative. In particular, if the activity of a radionuclide does not exceed the activity for the highest applicable screening level, the potential doses to off-site individuals and inadvertent intruders should not exceed $0.1 \%$ of the performance objectives for the IWMF. In actuality, because the screening criteria are based on the lowest applicable disposal limits for radionuclides that were analyzed in this revised PA for the IWMF, the doses resulting from disposal of most radionuclides that would be excluded by the screening criteria from further consideration in this revised PA should be considerably less than $0.1 \%$ of the performance objectives.

Finally, because of the conservative assumptions used in developing the screening criteria, especially the use of $0.1 \%$ of the lowest applicable dose limit for any radionuclide analyzed in the PA as a screening activity, the screening criteria in Table 7.5 do not provide disposal limits for radionuclides not analyzed in this revised PA. Thus, for example, if the inventory of an unanalyzed radionuclide is less than the highest applicable screening criterion, the activity of the radionuclide relative to the screening criterion should not be used in applying the sum-of-fractions rule to disposals of all radionuclides in the IWMF. In effect, there are no disposal limits for unanalyzed radionuclides as long as their inventories are less than the highest applicable screening criterion. Only if the inventory of an unanalyzed radionuclide exceeds the highest applicable screening criterion would the radionuclide be included in applying the sum-of fractions rule for the IWMF, but the radionuclidespecific disposal limit obtained from a proper dose assessment for the radionuclide would be used, rather than the screening criterion, and the disposal limit generally would be much higher than the highest applicable screening criterion. 
Table 7.5 Criteria for screening radionuclides not included in the performance assessment (PA) for the Interim Waste Management Facility (IWMF) ${ }^{a}$

\begin{tabular}{|c|c|c|}
\hline $\begin{array}{l}\text { Level of } \\
\text { screening }\end{array}$ & Applicability of screening criterion & $\begin{array}{l}\text { Activity } \\
\text { (Ci/pad) }\end{array}$ \\
\hline 1 & Any radionuclide, without regard for half-life or decay properties & $10^{-4}$ \\
\hline $2 a$ & $\begin{array}{l}\text { Any radionuclide with half-life less than } 5 \text { years, without regard for decay } \\
\text { properties }\end{array}$ & Unlimited $^{b}$ \\
\hline $2 b$ & $\begin{array}{l}\text { Any radionuclide with half-life of } 5 \text { to } 30 \text { years, without regard for decay } \\
\text { properties }^{c}\end{array}$ & $10^{-2}$ \\
\hline $3 a$ & $\begin{array}{l}\text { Any radionuclide with half-life of } 5 \text { to } 30 \text { years that also is not a significant } \\
\text { photon emitter }{ }^{d}\end{array}$ & $10^{-1}$ \\
\hline $3 b$ & $\begin{array}{l}\text { Any radionuclide with half-life greater than } 30 \text { years that also is not a significant } \\
\text { photon emitter }\end{array}$ & $10^{-3}$ \\
\hline
\end{tabular}

Derivation of screening criteria is described in Sect. 7.2.2. If activity of radionuclide of concern is greater than highest applicable screening criterion, radionuclide should be included in the PA for the IWMF to develop limits on allowable disposals. Conversely, if activity is less than highest applicable screening criterion, radionuclide need not be included in PA.

${ }^{b}$ Allowable activities of radionuclides with half-lives less than 5 years should be limited by other waste acceptance criteria for the IWMF, particularly the limit on external dose-equivalent rate at surface of waste packages for $\mathrm{CH}$ waste of $200 \mathrm{mrem} / \mathrm{h}$.

For any radionuclide with half-life greater than 30 years, without regard for decay properties, Level 1 screening criterion applies and separate Level 2 screening criterion is not needed.

'Screening criteria at Level 3 apply to alpha-emitting and non-alpha-emitting radionuclides. Radionuclides suitable for screening at Level 3 need not be pure beta or alpha emitters, but average energy per decay of emitted photons should be low (e.g., less than about $50 \mathrm{keV}$ ).

\subsubsection{Application of Initial PA Results to IWMF Disposal}

After publication of the initial PA, facility inventory limits were developed for each radionuclide expected to be disposed on the IWMF. With multiple radionuclides being disposed, each with its own inventory limit, the sum-of-fractions method was employed to determine if the IWMF was being operated within the disposal unit inventory limits. In practice, as long as the sum of fractions is less than or equal to one, the IWMF is in compliance with the disposal unit inventory limit. If the sum of fractions exceeds one, the IWMF is being operated out of compliance with the disposal unit inventory limit.

Use of the sum-of-fractions method led to two concerns about disposals on the IWMF. The first concern was the case where the inventory limit was exceeded. The proper action is to remove inventory from the IWMF until the sum of fractions is again less than one. The second concern was the case where the sum of fractions did not approach unity. In this case the IWMF is not being used efficiently for the disposal of radionuclides. In addition to these two concerns, there were two operational needs. The first was the need to develop an operational tool for evaluating each waste vault to determine whether a disproportionate amount of the disposal unit inventory limit was being 
consumed. The second need was the application of the MPA factor to problematic radionuclides identified in the initial PA. The Vault Screening Value Determination Method was developed to address these concerns and operational needs.

The Vault Screening Value Determination Method, several calculations were performed before determining if a waste vault meets the IWMF inventory limits. Initially, if the waste vault contains any of the problematic radionuclides identified in the initial PA, the inventories are increased by the MPA factor. The adjusted inventory is used only for screening value determination and is not used to adjust the reported waste inventory.

A vault screening value for each radionuclide was developed by dividing the facility inventory limit by the maximum number of vaults capable of being disposed on the IWMF. Because multiple radionuclides typically are disposed in each vault, the sum of fractions is applied to each vault using the vault screening values for the radionuclides in the vault. The inventory of each radionuclide in the vault (adjusted by the MPA factor, if applicable) is divided by the vault screening value for each radionuclide and summed for all the radionuclides in the waste package. If the sum of the resulting fractions is less than one, the waste vault is acceptable for disposal.

In essence, if each waste vault has a vault screening value determination of exactly one and all the vaults were placed on the IWMF, the IWMF would have no additional radionuclide capacity. Using this approach, if a waste vault was determined to have a vault screening value determination greater that one, then the waste could only be disposed if a corresponding reduction occurred on a subsequent waste vault.

The Vault Screening Value Determination Method was applied to disposals on Pad 2 and Pad 3 of the IWMF. Vaults that exceeded the performance objectives in the initial PA were removed from $\mathrm{Pad} 1$, which reduced the disposed inventories of ${ }^{239} \mathrm{Pu},{ }^{36} \mathrm{Cl}$, and ${ }^{14} \mathrm{C}$. Additionally, radionuclides not considered in the initial $\mathrm{PA}$ were assessed for compliance with the performance objectives prior to disposal on the IWMF. The results of this revised PA are to be incorporated into waste disposal operations at the IWMF using the strategy presented in the following section that will eliminate the use of the MPA factor.

\subsubsection{Recommendations Concerning Current and Future Operations at the IWMF}

Modifications to the disposal operations at the IWMF are necessary to address the concerns of the DNFSB, to incorporate the new guidance on performance assessment and performance assessment maintenance issued by DOE headquarters, and to ensure compliance with the performance objectives of DOE O 5820.2A in future operations. A five part operating strategy has been developed, as part of this revised PA, to provide additional assurance for IWMF disposal meeting the performance objectives of DOE O 5820.2A. These recommendations are to be implemented in future waste management operations as a result of this revised $\mathrm{PA}$. 


\subsubsection{Buffer Zone Expansion}

The first part of the strategy is to expand the buffer zone of the IWMF to include the interior of SWSA 6 between the IWMF and Tumulus I and Tumulus II. The expansion of the buffer zone for a disposal unit beyond $100 \mathrm{~m}$ is allowed by the guidance for the preparation of performance assessments (DOE 1996c) when justified. Expansion of the buffer zone to include the small parcel of land between the IWMF and Tumulus I and Tumulus II is justified by the expanded area being located within the SWSA 6 facility boundary and the understanding that this land would not be accessible to the public for as long as DOE maintains land-use controls for SWSA 6. DOE has no intention of releasing SWSA 6 to the public, and the groundwater within the expanded buffer zone is not known to interact with any groundwater accessible to the public beyond the facility boundary. The expanded buffer zone (Fig. 4.16) would consolidate the area of SWSA 6 associated with waste management and environmental compliance with the other areas of SWSA 6 subject to CERCLA remediation.

\subsubsection{Post-Assessment Restriction in Disposal Limits for Problematic Radionuclides}

The second part of the strategy is to limit the disposal of problematic, long-lived radionuclides at the IWMF so that each of these disposed radionuclides is less than $1 \%$ of the allowable disposal limit for those radionuclides shown in Table 7.1, which are primarily based on inadvertent intruder scenarios. The radionuclides subject to this restriction are shown in Table 7.6 and were identified from the analysis of environmental transport of contamination using a $100-\mathrm{m}$ buffer zone. Radionuclides that are long-lived and potentially associated with exceeding the groundwater performance objective are included in this table. By using the sum of fractions method, which states that the sum of the radioactivity concentration of each radionuclide in the waste divided by the limit for that radionuclide must be less than one, and limiting the concentration of problematic radionulcides to less than $1 \%$ of the allowable disposal limit, wastes accepted for disposal are limited to the incidental presence of problematic and long-lived radionuclides. The choice of $1 \%$ as the factor for reducing allowable disposal limits is based on the uncertainties associated with the inventory in Appendix A. Two orders of magnitude spans the largest uncertainty in the inventory for all of radionuclides considered in this revised PA. This reduction is applied to the largely intruder based disposal limits, which are more restrictive than the disposal limits based on water pathways. Consequently, by reducing the disposal limits to less than $1 \%$ of the disposal limits presented in Table 7.1, future disposals of problematic radionuclides with significant uncertainty in their inventory are reduced well beyond the uncertainty in the inventory. This provides additional assurance the performance criteria for SWSA 6 will continue to be met. These modified allowable disposal limits are to be applied to each IWMF pad. When an IWMF pad is filled, the sum of fractions rule, using the modified allowable disposal limits, is applied. If the sum of radionuclides disposed exceeds unity, waste is removed until the pad sum of fractions is less than one. This provides the needed assurance that the performance objectives for IWMF disposal operations and the closed disposal units at SWSA 6 are maintained. 
Table 7.6. Radionuclides to be restricted to $1 \%$ of the performance assessment (PA) disposal limits

\begin{tabular}{llcl}
\hline Nuclide & $\begin{array}{c}\text { Half-life } \\
\text { (year) }\end{array}$ & $\begin{array}{c}\text { PA disposal limit } \\
\text { (Ci/pad) }\end{array}$ & $\begin{array}{c}1 \% \text { disposal limit } \\
\text { (Ci/pad) }\end{array}$ \\
\hline${ }^{14} \mathrm{C}$ & $5.73 \times 10^{3}$ & $1.5 \times 10^{2}$ & $1.5 \times 10^{0}$ \\
${ }^{36} \mathrm{Cl}$ & $3.01 \times 10^{5}$ & $1.1 \times 10^{1}$ & $1.1 \times 10^{-1}$ \\
${ }^{79} \mathrm{Se}$ & $6.50 \times 10^{4}$ & $1.7 \times 10^{3}$ & $1.7 \times 10^{1}$ \\
${ }^{99} \mathrm{Tc}$ & $2.13 \times 10^{5}$ & $1.4 \times 10^{2}$ & $1.4 \times 10^{0}$ \\
${ }^{129} \mathrm{I}$ & $1.57 \times 10^{7}$ & $3.0 \times 10^{1}$ & $3.0 \times 10^{-1}$ \\
${ }^{232} \mathrm{U}$ & $6.89 \times 10^{1}$ & $2.0 \times 10^{0}$ & $2.0 \times 10^{-2}$ \\
${ }^{233} \mathrm{U}$ & $1.59 \times 10^{5}$ & $4.8 \times 10^{0}$ & $4.8 \times 10^{-2}$ \\
${ }^{234} \mathrm{U}$ & $2.45 \times 10^{5}$ & $1.8 \times 10^{1}$ & $1.8 \times 10^{-1}$ \\
${ }^{235} \mathrm{U}$ & $7.04 \times 10^{8}$ & $1.2 \times 10^{0}$ & $1.2 \times 10^{-2}$ \\
${ }^{236} \mathrm{U}$ & $2.34 \times 10^{7}$ & $2.9 \times 10^{1}$ & $2.9 \times 10^{-1}$ \\
${ }^{238} \mathrm{U}$ & $4.47 \times 10^{9}$ & $6.1 \times 10^{0}$ & $6.1 \times 10^{-2}$ \\
${ }^{237} \mathrm{~Np}$ & $2.14 \times 10^{6}$ & $5.4 \times 10^{-1}$ & $5.4 \times 10^{-3}$ \\
${ }^{239} \mathrm{Pu}$ & $2.41 \times 10^{4}$ & $9.9 \times 10^{0}$ & $9.9 \times 10^{-2}$ \\
${ }^{240} \mathrm{Pu}$ & $6.56 \times 10^{3}$ & $1.0 \times 10^{1}$ & $1.0 \times 10^{-1}$ \\
${ }^{242} \mathrm{Pu}$ & $3.76 \times 10^{5}$ & $1.0 \times 10^{1}$ & $1.0 \times 10^{-1}$ \\
${ }^{244} \mathrm{Pu}$ & $8.26 \times 10^{7}$ & $4.6 \times 10^{-1}$ & $4.6 \times 10^{-3}$ \\
${ }^{241} \mathrm{Am}$ & $4.33 \times 10^{2}$ & $9.9 \times 10^{0}$ & $9.9 \times 10^{-2}$ \\
${ }^{243} \mathrm{Am}$ & $7.37 \times 10^{3}$ & $1.0 \times 10^{0}$ & $1.0 \times 10^{-2}$ \\
${ }^{245} \mathrm{Cm}$ & $8.50 \times 10^{3}$ & $1.8 \times 10^{\circ}$ & $1.8 \times 10^{-2}$ \\
${ }^{248} \mathrm{Cm}$ & $3.40 \times 10^{5}$ & $2.5 \times 10^{0}$ & $2.5 \times 10^{-2}$ \\
\hline
\end{tabular}

${ }^{a}$ Source: Brown and Firestone 1986.

${ }^{b}$ From Table 7.1.

To track the radionuclide loading of the IWMF as it is being loaded, a per vault screening value is used. This screening value is based on the sum of fractions using the modified allowable disposal limit for each radionuclide divided by the number of vaults on each pad. By using this method, a vault can be screened before placement on the IWMF. Vaults that exceed the limit can only be placed on the pad if other vaults have a corresponding reduction in radioactive inventory.

The IWMF originally was intended to be used for the disposal of short-lived radionuclides having incidental concentrations of long-lived radionuclides. By restricting problematic and long-lived radionuclides, disposal operations will more closely follow the design basis for the IWMF.

\subsubsection{Vault Removal}

The third part of the strategy is to remove IWMF vaults that have significant concentrations of the problematic and long-lived radionuclides identified in Table 7.6 from the disposal unit. Pads 1, 2, 
and 3 are already filled to capacity and will be compared to the modified allowable disposal limits in Table 7.6 using the sum of fractions rule. If the sum of fractions for the total radioactive inventory for all three pads exceeds one, then vaults will be removed until the sum of fractions for the combined three pad radioactive inventory is less than one.

\subsubsection{Discontinue Use of the MPA Factor}

The fourth part of the strategy is to discontinue the use of the MPA factor in current and future waste disposal operations. The MPA factor was introduced after the initial version of the PA to address concerns in waste characterization of problematic radionuclides. Use of the MPA factor effectively increased the reported concentrations of problematic radionuclides by a numerical value estimated from an assessment of the potential errors in waste characterization. The concerns related to errors in waste characterization have been subsequently reduced by improvements in the Waste Certification Program, which includes the proper characterization of wastes (see Appendix A).

The ORNL Waste Certification Program was implemented after the publication of the initial PA to provide assurance that wastes are properly characterized before disposal. This program consists of the following elements: (1) a Waste Certification Program Plan-a document describing the program structure, logic, and methodology for certification of ORNL wastes; (2) Waste Acceptance Criteria-a document used to inform waste generators of requirements that must be met before Waste Management's acceptance of a particular waste type; (3) an Implementation Procedure -a procedure specific to each waste type that provides specific instructions to the generator for meeting the requirements of the Waste Acceptance Criteria; and (4) a Radiological Characterization Plan-a plan that describes radiological characterization methods that are acceptable for use in characterizing waste streams. This program includes guidance on the use of process knowledge, sampling guidelines, and laboratory analysis guidelines. This program has effectively reduced errors in waste characterization, as discussed in Appendix A.

\subsubsection{Develop Off-Site Disposal Capacity}

The fifth part of the recommendation is to continue to dispose of LLW on the IWMF until the IWMF is filled to capacity. Additional expansion of the IWMF beyond six pads will not be pursued because the SWSA 6 site is not expected to be able to support the disposal of additional LLW after the existing IWMF is filled. After the facility is filled, disposal of LLW will be directed toward off-site facilities.

\subsection{FURTHER WORK}

This revised PA provides a comprehensive analysis of the performance of SWSA 6 for the disposal of wastes from ORR. The PA analyzes the uncertainties associated with the results. The 
results provide conservative estimates of limiting concentrations and inventories of radionuclides that could be disposed of at the IWMF such that the facility would operate in compliance with the performance objectives of DOE O 5820.2A. Recognizing the development of this revised PA as a process, further improvements can be expected and are appropriate for reducing uncertainty and conservatism and improving the accuracy of the assessment.

The closure plan used in this revised PA is a conservative approximation of how closure is expected to occur. Plans for the closure of the IWMF and SWSA 6 have not been completed and are subject to the CERCLA process. Continued work to identify more effective closure methods is warranted. Development and approval of a more effective closure plan can be expected to reduce exposures from potential intrusion into wastes and reduce the potential for the generation and transport of leachate from the disposal facilities. A more effective closure plan for the facilities could be expected to increase allowable concentration limits and inventories of radionuclides in waste in the IWMF.

The algorithms incorporated into the PADSIM model for determining bypass flow and reactive soil path lengths as functions of adsorption represent the best information available on the behavior of soils at SWSA 6. However, the current understanding of the behavior of SWSA 6 soils in heavily disturbed areas, such as near disposal units, is limited. Additional information on the hydrologic behavior of heavily disturbed soils would result in the removal of some of the conservative assumptions currently incorporated into the PADSIM model that limit bypass flow and significantly increase the transport of contamination to the saturated zone.

To execute calculations predicting the environmental transport of radionuclides in the distant future, a steady-state flow field was necessarily assumed. The steady-state flow field was applied to groundwater flow, shallow subsurface flow, and surface water flows. The justification for this simplifying assumption becomes more questionable in that progression of media. Continued work is necessary either to find ways to permit a relaxation of the steady-state assumption while not incurring substantially greater computational effort or to improve our understanding of what effects the assumption may have on the results. For example, the use of an average annual flow for dilution of surface water contamination in WOC may or may not be conservative when compared to a more involved integral calculation using daily fluctuations of WOC flow combined with varying subsurface flows and their discharges.

The changing missions and programs on the ORR may result in changes to the waste streams anticipated to be generated for the IWMF. Changes to the facility, site, and wastes that would affect the performance of the facility would require a revision to the performance assessment, as outlined in the guidance for DOE O 5820.2A (DOE 1996d).

Future revisions of the PA will be performed as part of the PA maintenance program. This program is directed to ensure that PAs for waste management on the ORR are representative of the performance of the respective facilities. Improvements in the performance assessment may be initiated as a result of changes in operations, improvements in the understanding of site behavior, or in response to reviews and audits by DOE. 


\section{QUALITY ASSURANCE}

This revised PA has been prepared in accordance with the Quality Assurance Program of ORNL (ORNL 1993c). The program is based on the requirements set forth in the American National Standards Institute/American Society of Mechanical Engineers Quality Assurance Standards for Nuclear Facilities (ANSI/ASME NQA-1) program requirements. Software developed for this revised PA has been prepared in accordance with Lockheed Martin Energy Systems Policy, Standards, and Procedures for software quality assurance ("Software Quality Assurance," ESS-QA-19.0). The requirements set forth in software quality assurance have been adhered.

Verification and validation of the codes used in the revised PA for SWSA 6 are necessary to assure that the results presented are meaningful. To the extent reasonable, the codes used in this PA have been verified and validated and are discussed in this section. Verification is considered to mean that the codes are correct in a mathematical and numerical sense and that the theory incorporated into the codes is correct. Validation is considered to mean that the application of the code to the SWSA 6 facility is a reasonable representation of the site. The validation efforts to date are not complete; however, providing unequivocal assurance that the codes used for this revised PA are verified and validated is not reasonable because data characterizing the long-term performance of the engineered disposal technologies in SWSA 6 are not available.

SWSA 6 has been used as a disposal facility for many years, and (as noted in Sect. 2.2) small amounts of contamination are being released to surface water from disposal units that were used prior to September 26,1988. Validating the model of site performance using current monitoring data was considered but abandoned because the data describing the inventory of the disposed wastes is of limited value in developing a representative source term.

\subsection{VERIFICATION AND VALIDATION OF UTM}

UTM has been under development for over two decades and has been applied in a number of locations, including North Carolina, Missouri, Oklahoma, and Tennessee. Water budget simulations involve algorithms for various components of the hydrologic cycle (Appendix D). These algorithms are based on well-established physical and physiological relationships. UTM is used in the revised PA for simulation of water budgets for various conditions of the SWSA 6 site during operation and closure and after closure. The paragraphs that follow outline the components of water budget calculations in UTM.

Interception. "Interception" refers to a defined volume of water caught in the canopy and litter that varies for the winter and summer seasons. The canopy is saturated with rainfall before throughfall enters the soil. Water in this modeling compartment has priority in evaporation calculations. The storage volumes were adjusted for deciduous forests so that simulated interception 
matched the empirical observations of Helvey and Patrick (1965). This model development and testing is described in Huff et al. (1977b, pp. 17-20). Input values for simulations with grass cover were obtained from a previous application (Luxmoore and Sharma 1980).

Infiltration. The time-compression method of Reeves and Miller (1975) has been implemented in UTM to partition throughfall into infiltration and surface runoff at the soil surface. Reeves and Miller describe the algorithm and have tested the method. This algorithm is not often invoked in forest simulations because of the high infiltration rates of forest soils. Runoff in forested watersheds is generally the result of exfiltration of subsurface flow in lower slope positions. Huff et al. (1977b, pp. 20-23) describe the time-compression method in the documentation report for the UTM hydrologic module.

Evapotranspiration. The complex of evaporative surfaces (foliage, litter, and soil) in a vegetated landscape is viewed as one surface in the "big leaf" approach for which the PenmanMonteith equation determines evapotranspiration. Sinclair, Murphy, and Knoeer (1976) demonstrated the utility of this approach for calculation of evapotranspiration. A number of meteorological variables (air temperature, vapor pressure, solar radiation, and uind speed) are needed along with an empirical surface resistance to vapor loss from the surface. This resistance was obtained from experimental observations for the vegetation of interest (Luxmoore et al. 1978; Luxmoore and Sharma 1980). The algorithms are described in Huff et al. (1977b, pp. 24-26). Luxmoore and Huff (1989) showed that the calculations of forest evapotranspiration are in agreement with independent estimates for the Oak Ridge area.

Recharge and Subsurface Lateral Flow. The Darcy flow equation was used in soil waterflow calculations to estimate water movement between soil layers. (The parameters for the layers of soil in question are specified by the user.) The equation uses a hydraulic gradient and hydraulic conductivity that are determined from soil hydraulic properties. These properties (u ater pressure-water content and hydraulic conductivity-water content relationships) are based on input values chosen by the user for the site of interest. The flow equations and the use of soil hydraulic properties are described in Huff et al. (1977b, pp. 26-33). The calculation of recharge to groundwater uses a hydraulic gradient of unity and a hydraulic conductivity appropriate to the water content of the lowest layer of the soil profile being simulated. Lateral flow is calculated as the excess of soil water above the saturation value flowing into a soil layer from above. Algorithms for bypass flow due to macropores are an option in the soil water-flow calculations. The basis for the macropore flow option is described in Hetrick, Holdeman, and Luxmoore (1982, pp. 25-31).

Simulation of Water Budgets for Soil-Plant Systems. UTM has been applied to a range of sites, and reasonable agreement has been obtained for the components of the water budgets at the sites as follows:

- Grassland watersheds in Oklahoma. Results are published in open literature in Sharma and Luxmoore (1979), Luxmoore and Sharma (1980), and Luxmoore (1983a). These results show the utility of UTM for grassland conditions, which are part of the SWSA 6 closure scenario. 
- Forested watershed on the ORR. Open-literature publications of UTM applications to forest stands of the ORR are given in Luxmoore et al. (1978); Luxmoore, Stolzy, and Holdeman (1981); and Luxmoore (1983b).

- Scenarios of landfill barrier designs. Luxmoore and Tharp (1993) discuss the hydrologic behavior of four alternative cap designs simulated with UTM.

- Forested watershed in southeastern Missouri. Simulation of water budgets and heavy metal transport in a watershed adjacent to a lead mining and smelter operation was reported in Luxmoore and Begovich (1979).

The experience gained from these studies provides a sound basis for simulation of water budgets for SWSA 6 operation and closure scenarios. Several sensitivity analysis reports have also been prepared, and these have given a thorough appreciation for the important vegetation and soil variables in water budget simulation. These reports are Luxmoore et al. (1976), Begovich and Luxmoore (1979), Luxmoore et al. (1981), and Sharma et al. (1987).

\subsection{VERIFICATION AND VALIDATION OF SOURCE1 AND SOURCE2}

The SOURCE1 and SOURCE2 computer codes consist of a collection of models that, taken together, simulate the performance of waste disposal units. These models-which include structural analysis, cracking analyses, concrete- and metal-barrier degradation, and radionuclide release calculations-were developed separately on the basis of established theory and, in some cases, empirical data. The individual models were then combined to form the overall conceptual model for the disposal unit performance.

To verify the SOURCE1 and SOURCE2 computer codes, a quality assurance plan (Icenhour 1994) and verification plans (Icenhour and Tharp 1994a, 1994b) were developed and implemented. The verification plans consisted of a detailed review of the algorithms used in the SOURCE1 and SOURCE2 codes, a review of code structure and programming, and a comparison of different advective transport models. In addition, tools such as sensitivity analyses and graphical representations of output were used to evaluate the performance of the codes (Icenhour 1995). Verification of SOURCE1 and SOURCE2 was completed according to the verification plans; the user's manual reflects the changes that were made during the verification process. Supporting data are available in the literature for validation of many of the individual models. However, the limited performance data available for the disposal units in SWSA 6 and the length of the performance simulations ( 21000 years) make the overall validation of SOURCE1 and SOURCE2 a complex task that cannot currently be addressed. 


\subsection{VERIFICATION AND VALIDATION OF PADSIM AND HOLSIM}

PADSIM and HOLSIM are custom-written FORTRAN codes prepared for this revised PA. The codes describe radionuclide retardation $\left(K_{d}\right)$ and radionuclide decay in annual time-step calculations of subsurface radionuclide transport from waste sites (Fig. 4.17). Radionuclide migration from each disposal unit was represented in relation to its position in the landscape using topographic characteristics to estimate transport distances between disposal units and groundwater and the nearest surface-water drainage as outlined in Sect. 4.3.1.2.1 (Fig. 4.9, Table 4.16). PADSIM was used to simulate transport from Tumulus I, Tumulus II, and the IWMF; and HOLSIM, to simulate transport from the other disposal units (wells, silos, and trenches) (Appendix D, Sect. D.2).

There are two well-established mechanistic equations in each of these two codes. One is for chemical adsorption onto soil; the other is for half-life decay calculations. Jardine, Jacobs, and Wilson (1993) have demonstrated that chemical adsorption calculations with $K_{d}$ are an appropriate representation of adsorption in unsaturated flow systems. The radionuclide decay calculations were based on the well-accepted half-life equation and the well-known half-life values for the various nuclides (Table 4.2).

Three other mechanisms are included in PADSIM and HOLSIM, representing bypass flow, temporal increase in transport volume, and matrix diffusion (Sect. 4.3.1.2.1 and Appendix D, Sect. D.3). Algorithms for these mechanisms have been verified as approximations for the respective phenomena using annual time-step calculations. These algorithms, however, have not been validated by experimental or empirical data.

\subsection{VERIFICATION AND VALIDATION OF USGS MOC}

The USGS MOC code was developed initially in 1974 and has been subjected to extensive refinement since its first release. The code has been used for numerous applications and has been verified mathematically, numerically, and experimentally throughout the period of development. The application of the USGS MOC code to a complex heterogeneous setting such as SWSA 6 involved the careful construction of a conceptual model for SWSA 6 and its application to the site using the available site data. The approach taken has not been validated directly to the SWSA 6 site but has been the subject of a validation study on the $O R R$ at a site with a nearly identical hydrogeologic setting in Bear Creek Valley (Lee and Ketelle 1988; Lee et al. 1989; Lee et al. 1991). The validation study involved the modeling of a tracer placed at the water table. The investigation demonstrated that the flow, direction, and concentrations of the tracer could be reasonably modeled using an application of the USGS MOC code. The results from the validation study in Bear Creek Valley provide justification that the application of the USGS MOC code to SWSA 6 is valid. 


\section{PREPARERS}

The following individuals were responsible for the preparation of this performance assessment for SWSA 6. All of these individuals are associated with ORNL.

Donald W. Lee; Ph.D., applied mechanics; task group leader

Jeffrey A. Chapman; M.S., nuclear engineering; source term analysis and uncertainty analysis

Gerald R. Cunningham; M.S., safety; waste characterization and waste operations

J. Robert Forgy, Jr., M.S., radiological health; waste characteristics, radionuclide inventory

Herschel W. Godbee; Ph.D. (consultant), chemical engineering; transport parameter development for source term models

Alan S. Icenhour; M.S., nuclear engineering; source term analysis and uncertainty analysis

Richard H. Ketelle; M.S., geology; site characteristics and geology

David C. Kocher; Ph.D., nuclear physics; intruder analyses and dose analysis

Steve L. Loghry; B.S., chemical engineering; source term analysis

Douglas A. Lombardi; M.S., environmental engineering; atmospheric emissions analysis

Robert J. Luxmoore; Ph.D., soil science; water budget and shallow subsurface analyses

Linda K. Mann; M.S., ecology; terrestrial ecology

Maria L. Socolof; M.S., environmental health management; dose analysis

John D. Tauxe; Ph.D., civil engineering; site characterization, groundwater transport analysis

M. Lynn Tharp; M.S., computer science; source term and shallow subsurface analyses, sensitivity and uncertainty analysis

Virginia R. Tolbert; Ph.D., ecology; aquatic ecology

Mark W. Yambert; B.S., engineering mechanics; groundwater analysis and uncertainty analysis

Loong K. Yong; M.S., nuclear engineering; source term analysis and uncertainty analysis 


\section{REFERENCES}

Algermissen, S. T. 1969. "Seismic Risk Studies in the United States," pp. 14-27 in Proceedings of the 4th World Conference on Earthquake Engineering, January 13-18, 1969, Santiago, Chile, vol. 1.

Algermissen, S. T., and D. M. Perkins 1976. A Probabilistic Estimate of Maximum Acceleration in Rock in the Contiguous United States, Open File Report 76-416, U.S. Geological Survey, Denver.

Anspaugh, L. R., et al. 1975. "Resuspension and Redistribution of Plutonium in Soils," Health Physics 29, 571.

Ashwood, T. L., et al. 1990. Active Sites Environmental Monitoring Program, Program Plan Revision 0, Oak Ridge National Laboratory, Oak Ridge, Tenn., April.

Ashwood, T. L., D. S. Hicks, and C. M. Morrissey 1992. Active Sites Environmental Monitoring Program: FY 1991 Report, ORNL/M-1792, Oak Ridge National Laboratory, Oak Ridge, Tenn.

Ashwood, T. L., D. S. Wickliff, and C. M. Morrissey 1991. Active Sites Environmental Monitoring Program: Mid-FY 1991 Report, ORNL/M-1442, Oak Ridge National Laboratory, Oak Ridge, Tenn.

Awl, D. J. 1995. JAYCOR, Oak Ridge, Tenn., personal communication to M. S. Salk, Environmental Sciences Division, Oak Ridge National Laboratory, Oak Ridge, Tenn., July 20.

Baes, C. F. III, et al. 1984. A Review and Analysis of Parameters for Assessing Transport of Environmentally Released Radionuclides Through Agriculture, ORNL-5786, Oak Ridge National Laboratory, Oak Ridge, Tennessee.

Baes, C. F. III, and R. D. Sharp 1981. "Predicting Radionuclide Leaching from Root Zone Soil for Assessment Applications," Transactions of the American Nuclear Society 38, 111-12.

Baes, C. F. III, and R. D. Sharp. 1983. "A Proposal for Estimation of Soil Leaching Constants for Use in Assessment Models," Journal of Environmental Quality 12, 17. 
Bailey, Z. C., and R. W. Lee 1991. Hydrogeology and Geochemistry in Bear Creek and Union Valleys near Oak Ridge, Tennessee, Water Resources Investigation Report 90-4088, U.S. Geological Survey, Nashville, Tenn.

Bass, J. M., W. J. Lyman, and J. P. Trantnyek 1985. Assessment of Synthetic Membrane Successes and Failures at Waste Storage and Disposal Sites, EPA/S2-85/100, U.S. Environmental Protection Agency, Washington, D.C.

Baxter, F. P. 1993. Oak Ridge National Laboratory Plant Site Groundwater Protection Program Management Plan, Oak Ridge National Laboratory, Oak Ridge, Tenn., May.

Bechtel (Bechtel National, Inc.) 1989. Draft Site Characterization Summary Report for ORNL Waste Area Grouping 6, ORNL/RAP/Sub-87/99053/XXX, Oak Ridge National Laboratory, Oak Ridge, Tenn.

Bechtel (Bechtel National, Inc.) 1991a. RCRA Facility Investigation Report for Waste Area Grouping 6 at Oak Ridge National Laboratory, Oak Ridge, Tennessee, Vol. 3, ES/ER-22/V3 \& D1, ORNL/ER/Sub-87/99053/5/V3, Oak Ridge National Laboratory, Oak Ridge, Tenn.

Bechtel (Bechtel National, Inc.) 1991b. RCRA Facility Investigation Report for Waste Area Grouping 6 at Oak Ridge National Laboratory, Oak Ridge, Tennessee, Vol. 1, ES/ER-22/V1 \& D1 ORNL/ER/Sub-87/99053/5/V1, Oak Ridge National Laboratory, Oak Ridge, Tenn.

Begovich, C. L., and R. J. Luxmoore 1979. Some Sensitivity Studies of Chemical Transport Simulated in Models of the Soil-Plant-Litter System, ORNL/TM-6791, Oak Ridge National Laboratory, Oak Ridge, Tenn.

Beven, K. J., and M. J. Kirkby 1979. “A Physically Based Variable Contributing Area Model of Basin Hydrology," Hydrological Sciences Bulletin 24, 43-69.

Boyle, J. W., et al. 1978. Preliminary Draft Impact Statement for Hot Engineering Test Project at Oak Ridge National Laboratory, ORNL/TM-6520, Oak Ridge National Laboratory, Oak Ridge, Tenn., August.

Boyle, J. W., et al. 1982. Environmental Analysis of the Operation of Oak Ridge National Laboratory ( $X$-10 Site), ORNL-5870, Oak Ridge National Laboratory, Oak Ridge, Tenn., November.

Brown, E., and R. B. Firestone 1986. Table of Radioactive Isotopes, ed. V. S. Shirley, Wiley, New York. 
10 CFR 100, Appendix A, subparagraphs III and IV: "Seismic and Geologic Siting Criteria for Nuclear Power Plants"

Clapp, R. B., 1992. Annual Report of the Environmental Restoration Monitoring and Assessment Program at Oak Ridge National Laboratory for FY 1992, ORNL/ER-124, Oak Ridge National Laboratory, Oak Ridge, Tenn.

Clapp, R. B., and D. S. Marshall 1992. SWSA 6 Interim Corrective Measures Environmental Monitoring: FY 1991 Results, ORNL/ER-87, Oak Ridge National Laboratory, Oak Ridge, Tenn.

Clapp, R. B., T. M. Scanlon, and S. Timmins n.d. Modifying TOPMODEL to Simulate the Separate Processes of Shallow Subsurface and Groundwater Discharge, Oak Ridge National Laboratory, Oak Ridge, Tenn., forthcoming.

Clark, T. H., and C. W. Stearn 1968. "The Geosynclinal Theory," pp. 83-103 in Geological Evolution of North America, $2 \mathrm{~d}$ ed., Ronald Press, New York.

Coobs, J. H., and J. R. Gissel 1986. History of Disposal of Radioactive Wastes into the Ground at Oak Ridge National Laboratory, ORNL/TM-10269, Oak Ridge National Laboratory, Oak Ridge, Tenn.

Cunningham, M., L. Pounds, and P. Parr 1988. "Vegetation of Four Sites on the Oak Ridge Reservation Proposed for Low-Level Waste Disposal," report to P. D. Parr, Environmental Sciences Division, National Environmental Research Park, Oak Ridge National Laboratory, Oak Ridge, Tenn.

Davis, E. C., C. W. Francis, and R. J. Luxmoore 1989. An Evaluation of Water Leakage into Concrete Low-Level Radioactive Waste Disposal Silos at ORNL's Solid Waste Storage Area Six, ORNL/TM-11164, Oak Ridge National Laboratory, Oak Ridge, Tenn.

Davis, E. C., and R. G. Stansfield 1984. Design and Construction of a French Drain for Groundwater Diversion in Solid Waste Storage Area Six at the Oak Ridge National Laboratory, ORNL/TM-9014, Oak Ridge National Laboratory, Oak Ridge, Tenn.

Davis, E. C., et al. 1984. Site Characterization Techniques Used at a Low-Level Waste Shallow Land Burial Field Demonstration Facility, ORNL/TM-9146, Oak Ridge National Laboratory, Oak Ridge, Tenn. 
Davis, E. C., et al. 1987. Summary of Environmental Characterization Activities at the Oak Ridge National Laboratory Solid Waste Storage Area Six, FY 1986 Through 1987, ORNL/RAP/LTR-87/68, Oak Ridge National Laboratory, Oak Ridge, Tenn.

Dawes, W. R., and D. Short 1994. "The Significance of Topography for Modeling the Surface Hydrology of Fluvial Landscapes," Water Resources Research 30, 1045-55.

DOE (U.S. Department of Energy) 1988a. External Dose-Rate Conversion Factors for Calculation of Dose to the Public, DOE/EH-0070, Washington, D.C.

DOE (U.S. Department of Energy) 1988b. Internal Dose Conversion Factors for Calculation of Dose to the Public, DOE/EH-0071, Washington, D.C.

DOE (U.S. Department of Energy) 1989. Recommended Format and Content for DOE Low-Level Waste Disposal Facility Radiological Performance Assessment Reports, DOE/LLW-81, Washington D.C.

DOE (U.S. Department of Energy) 1991a. DOE Guidance on the Procedures in Applying the ALARA Process for Compliance with DOE 5400.5, Washington, D.C., March 8.

DOE (U.S. Department of Energy) 1991b. Performance Assessment Review Guide for DOE LowLevel Radioactive Waste Disposal Facilities, DOE/LLW-93, Washington, D.C.

DOE (U.S. Department of Energy) 1995. "Headquarters Review of the 'Performance Assessment for Continuing and Future Operations at Solid Waste Storage Area 6," memorandum from J. L. Lytle, Environmental Management, to L. Radcliffe, Waste Management Division, Oak Ridge Operations Office, Oak Ridge, Tenn., September 8.

DOE (U.S. Department of Energy) 1996a. Guidance for a Composite Analysis of the Impact of Interacting Source Terms on the Radiological Protection of the Public from Department of Energy Low-Level Waste Disposal Facilities, Washington, D.C., April.

DOE (U.S. Department of Energy) 1996b, Implementation Plan, Defense Nuclear Facilities Safety Board Recommendation 94-2, Conformance with Safety Standards at Department of Energy Low-Level Nuclear Waste and Disposal Sites, Rev. 1, Washington, D.C., April.

DOE (U.S. Department of Energy) 1996c. Interim Format and Content Guide and Standard Review Plan for U.S. Department of Energy Low-Level Waste Disposal Facility Performance Assessments, Washington, D.C., October 31. 
DOE (U.S. Department of Energy) 1996d. Maintenance of U.S. Department of Energy Low-Level Waste Performance Assessments, Washington, D.C., September.

EBASCO (EBASCO Services, Inc.) 1992. OR-ERWM Program Design Criteria Studies: Results of 3DFEMWATER Modeling, ER/W6.01-002, Rev. 0, Environmental Consulting Engineers, Inc., Knoxville, Tenn., November 23.

Eckerman, K. F., A. B. Wolbarst, and A. C. B. Richardson 1988. Limiting Values of Radionuclide Intake and Air Concentration and Dose Conversion Factors for Inhalation. Submersion, and Ingestion, Federal Guidance Report No. 11, EPA-520/1-88-020, Oak Ridge National Laboratory and U.S. Environmental Protection Agency, Washington, D.C.

Eckerman, K. F., and J. C. Ryman 1993. External Exposure to Radionuclides in Air. Water, and Soil, Federal Guidance Report No. 12, EPA 402-R-93-081, Oak Ridge National Laboratory and U.S. Environmental Protection Agency, Washington, D.C.

EPA (U.S. Environmental Protection Agency). 1982. Final Environmental Impact Statement for Remedial Action Standards for Inactive Uranium Processing Sites (40 CFR 192). Vol. 1, EPA 520/4-82/013-1, Washington, D.C.

EPA (U.S. Environmental Protection Agency) 1989. Human Health Evaluation Mamual. Part A, Vol. 1 of Risk Assessment Guidance for Superfund, EPA/540/1-89/002, Washington. D.C.

EPA (U.S. Environmental Protection Agency) 1990. Environmental Radiation Data. Report No. 59, EPA/520/5-90-003, Washington, D.C.

EPA (U.S. Environmental Protection Agency) 1991. "40 CFR Parts, 141, 142-National Primary Drinking Water Regulations, Radionuclides, "Proposed Rule, Federal Register, 56,44050.

EPA (U.S. Environmental Protection Agency) 1995. User's Guide for the Industrial Source Complex (ISC3) Dispersion Models, Vol. 1, User's Instructions, EPA-454/b-95-003a, Research Triangle, N.C.

Evans, R. D. 1955. "Radioactive-Series Decay," Chap. 15 in The Atomic Nucleus, McGraw-Hill, New York.

Francis, C. W. 1990. Leachate Characteristics of Oak Ridge Low-Level Wastes, Letter Report, Oak Ridge National Laboratory, Oak Ridge, Tenn., January 9. 
Friedman, H. A., and A. D. Kelmers 1990. Laboratory Measurement of Radionuclide Sorption in Solid Waste Storage Area 6 Soil/Groundwater Systems, ORNL/TM-10561, Oak Ridge National Laboratory, Oak Ridge, Tenn.

Gardner, R. H., B. Röjder, and U. Berström 1983. PRISM, A Systematic Method for Determining the Effect of Parameter Uncertainties on Model Predictions, Report NW-83-555, Studsvik Energiteknik AB, Nykoping, Sweden.

Garten, C. T., Jr., R. H. Gardner, and R. C. Dahlman 1980. "A Model of Plutonium Dynamics in a Deciduous Forest Ecosystem," p. 513 in Transuranic Elements in the Environment, DOE/TIC-22800, ed. W. C. Hanson, U.S. Department of Energy, Washington, D.C.

Garten, C. T., Jr., J. R. Trabalka, and M. A. Bogle 1982. "Comparative Food Chain Behavior and Distribution of Actinide Elements in and Around a Contaminated Fresh-Water Pond," p. 299 in Environmental Migration of Long-Lived Radionuclides, International Atomic Energy Agency, Vienna.

Godbee, H. W. 1996. Estimated Transport Parameters for Selected Radionuclides in Low-Level Waste and Concrete Containment, D21-A20005-01-95, Delta-21 Resources, Inc., Knoxville, Tenn.

Goldman, L. J., et al. 1988. Design, Construction, and Evaluation of Clay Liners for Waste Management Facilities, EPA/530-SW-86-007-F, Risk Reduction Engineering Laboratory, U.S. Environmental Protection Agency, Cincinnati.

Hamby, D. M. 1992. "Site-Specific Parameter Values for the Nuclear Regulatory Commission's Food Pathway Dose Model," Health Physics 62, 136.

Hatcher, R. M. 1994a. Tennessee Wildlife Resources Commission Proclamation: Endangered or Threatened Species, Proclamation 94-17, Tennessee Administrative Register 20(11), 62.

Hatcher, R. M. 1994b. Tennessee Wildlife Resources Commission Proclamation: Wildlife in Need of Management, Proclamation 94-16, Tennessee Administrative Register 20(11), 58.

Healy, J. W. 1980. "Review of Resuspension Models," in Transuranic Elements in the Environment, ed. W. C. Hanson, DOE/TIC-22800, U.S. Department of Energy, Washington, D.C.

Helvey, J. D., and J. H. Patrick 1965. "Canopy and Litter Interception of Rainfall by Hardwoods of Eastern United States," Water Resources Research 1, 193-206. 
Hetrick, D. M., J. T. Holdeman, and R. J. Luxmoore 1982. AGTEHM: Documentation of Modifications to the Terrestrial Ecosystem Hydrology Model (TEHM) for Agricultural Applications, ORNL/TM-7856, Oak Ridge National Laboratory, Oak Ridge, Tenn.

Horwedel, J. E. 1990. A GRESS/ADGEN Sample Problem, ORNL/TM-1121, Oak Ridge National Laboratory, Oak Ridge, Tenn.

Huff, D. D., et al. 1977a. "The Application of Analytic and Mechanistic Hydrologic Models to the Study of Walker Branch Watershed," pp.741-63 in Watershed Research in Eastern North America, ed. D. L. Correll, Chesapeake Bay Center for Environmental Studies, Smithsonian Institution, Edgewater, Md.

Huff, D. D., et al. 1977b. TEHM: A Terrestrial Ecosystem Hydrology Model, ORNL/NSF/EATC-27, Oak Ridge National Laboratory, Oak Ridge, Tenn.

Hydzik, R. J., and M. A. Smith 1992. Guidelines for Establishing Waste Certification Plans and Procedures at Waste Generator Facilities, Oak Ridge National Laboratory, Oak Ridge, Tenn., September.

Icenhour, A. S. 1994. Addendum to QAP-X-88-CT-011 for the SOURCE1 Computer Code, Oak Ridge National Laboratory, Oak Ridge, Tenn.

Icenhour, A. S. 1995. Analysis of Source Term Modeling for Low-Level Radioactive Waste Performance Assessments, ORNL/TM-12908, Oak Ridge National Laboratory, Oak Ridge, Tenn.

Icenhour, A. S. 1997. Oak Ridge National Laboratory, Oak Ridge, Tenn., "Double Vault on IWMF," personal communication to G. R. Cunningham, Oak Ridge National Laboratory, January 30.

Icenhour, A. S., and M. L. Tharp 1994a. SOURCEI Verification Plan, Oak Ridge National Laboratory, Oak Ridge, Tenn.

Icenhour, A. S., and M. L. Tharp 1994b. SOURCE2 Verification Plan, Oak Ridge National Laboratory, Oak Ridge, Tenn.

Icenhour, A. S., and M. L. Tharp 1995. "Recent Improvements to the SOURCE1 and SOURCE2 Computer Codes," in Proceedings of the U.S. Department of Energy 17th Annual Low-Level Radioactive Waste Management Conference, Phoenix, Arizona, December 12-14, 1995, Idaho National Engineering Laboratory, Idaho Falls, Idaho. 
Icenhour, A. S., and M. L. Tharp 1996. User's Manual for the SOURCE1 and SOURCE2 Computer Codes: Models for Evaluating Low-Level Radioactive Waste Disposal Facility Source Terms (Version 2.0), ORNL/TM-13035, Oak Ridge National Laboratory, Oak Ridge, Tenn.

ICRP (International Commission on Radiological Protection) 1987. Data for Use in Protection Against External Radiation, ICRP Publication 51, Annals of the ICRP 17(2-3).

ICRP (International Commission on Radiological Protection) 1991. 1990 Recommendations of the International Commission on Radiological Protection, ICRP Publication 60, Annals of the ICRP $21(1-3)$.

Iman, R. L., and J. C. Helton 1985. A Comparison of Uncertainty and Sensitivity Analysis Techniques for Computer Models, NUREG/CR-3904, SAND/84-1461, Sandia National Laboratory, Albuquerque, N.M.

Jardine, P. M. 1994. Oak Ridge National Laboratory, Oak Ridge, Tenn., "Pore Water Chemistry of the East Hill Slope of the Site," personal communication to A. S. Icenhour and R. J. Luxmoore, Oak Ridge National Laboratory, April 15.

Jardine, P. M., G. K. Jacobs, and G. V. Wilson 1993. "Unsaturated Transpor Processes in Undisturbed Heterogeneous Porous Media: I. Inorganic Contaminants. " Soil Science Society of America Journal 57, 945-53.

Jardine, P. M., G. V. Wilson, and R. J. Luxmoore 1988. "Modeling the Transport of Inorganic Ions Through Undistributed Soil Columns from Two Contrasting Watersheds," Soil Science Society of America Journal 52, 1252-59.

Johnston, H. M., and R. W. Gillham 1980. A Review of Selected Radionuclide Distribution Coefficients of Geologic Materials, TR-90, Waterloo Research Institute, University of Waterloo, Canada.

Kaiser, L. K. 1996. Oak Ridge National Laboratory, Oak Ridge, Tenn., memorandum to G. R. Cunningham, Oak Ridge National Laboratory, on DOE Ten-Year Plan Scope for SWSA 6, December 18 .

Kennedy, W. E., Jr., L. L. Caldwell, and D. H. McKenzie 1985. "Biotic Transport of Radionuclides from a Low-Level Radioactive Waste Site," Health Physics 49, 11. 
Kennedy, W. E., Jr., and R. A. Peloquin 1988. Intruder Scenarios for Site-Specific Low-Level Waste Classification, DOE/LLW-71T, U.S. Department of Energy, Idaho Operations Office, Idaho Falls, Idaho.

Kenning, R. W., and L. K. Yong 1993. Evaluation of Uncertainty in the SWSA 6 Inventory Data, prepared for Martin Marietta Energy Systems, Inc., by Atlan-Tech, Inc., Roswell, Ga., February.

Ketelle, R. H. et al. 1995. "Groundwater," pp. 4.1-4.38 in Fourth Annual Environmental Restoration Monitoring and Assessment Report (FY 1995), DOE/OR/01-1413\&D1, ed. R. B. Clapp and J. A. Watts, Oak Ridge National Laboratory, Oak Ridge, Tenn.

Kitchings, J. T., and L. K. Mann 1976. A Description of the Terrestrial Ecology of the Oak Ridge Environmental Research Park, ORNL/TM-5073, Oak Ridge National Laboratory, Oak Ridge, Tenn.

Kocher, D. C. 1980a. "Effects of Indoor Residence on Radiation Doses from Routine Releases of Radionuclides to the Atmosphere," Nuclear Technology 48, 171.

Kocher, D. C. 1980b. A Radionuclide Decay Data Base-Index and Summary Table, NUREG/CR1413, ORNL/NUREG-70, Oak Ridge National Laboratory, Oak Ridge, Tenn.

Kocher, D. C. 1981. Radioactive Decay Data Tables, DOE/TIC-11026, U.S. Department of Energy, Washington, D.C.

Kocher, D. C., and A. L. Sjoreen 1985. "Dose-Rate Conversion Factors for External Exposure to Photon Emitters in Soil," Health Physics 48, 193.

Kornegay, F. C., et al. 1992. Oak Ridge Reservation Environmental Report for 1991, ES/ESH-22/V1, Oak Ridge National Laboratory, Oak Ridge, Tenn.

Kornegay, F. C., et al. 1993. Oak Ridge Reservation Environmental Report for 1992, ES/ESH-31/V1, Oak Ridge National Laboratory, Oak Ridge, Tenn.

Kroodsma, R. 1985. "Ecological Characterization of Terrestrial Biota of the Proposed Solid Waste Storage Area (SWSA) 7," report to L. K. Mann, Environmental Sciences Division, Oak Ridge National Laboratory, Oak Ridge, Tenn. 
Kroodsma, R. 1987. Resource Management Plan for the Oak Ridge Reservation, vol. 24, Threatened and Endangered Animal Species, ORNL/ESH-1/N24, Oak Ridge National Laboratory, Oak Ridge, Tenn.

Lee, D. W., and D. C. Kocher 1990. Scoping Analysis for the Performance Assessment for SWSA 6, ORNL/CF-90/67, Oak Ridge National Laboratory, Oak Ridge, Tenn.

Lee, R. R., and R. H. Ketelle 1988. Contaminant Transport Model Validation: The Oak Ridge Reservation, ORNL/TM-10972, Oak Ridge National Laboratory, Oak Ridge, Tenn.

Lee, R. R., and R. H. Ketelle 1989. Geology of the West Bear Creek Valley Site, ORNL/TM-10887, Oak Ridge National Laboratory, Oak Ridge, Tenn.

Lee, R. R., et al. 1989. Calibration of a Groundwater Flow and Contaminant Transport Model: Progress Toward Model Validation, ORNL/TM-11294, Oak Ridge National Laboratory, Oak Ridge, Tenn.

Lee, R. R., et al. 1991. "Aquifier Analysis and Modeling in a Fractured Heterogeneous Medium," Ground Water 30(4), 589-97.

Lee, S. Y., and D. A. Lietzke 1987. "Soils of SWSA 6," in Summary of Environmental Characterization Activity at the Oak Ridge National Laboratory Solid Waste Storage Area Six, FY 1986 Through 1987, ed. E. C. Davis, ORNL/RAP/LTR-87/68, Oak Ridge National Laboratory, Oak Ridge, Tenn.

LMES (Lockheed Martin Energy Systems, Inc.) 1995. Oak Ridge Reservation Annual Site Environmental Report for 1994, ES/ESH-57, LMES, Oak Ridge, Tennessee.

Loar, J. M., et al. 1987. First Annual Report on the ORNL Biological Monitoring and Abatement Program, ORNL/TM-10399, Oak Ridge National Laboratory, Oak Ridge, Tenn.

Loar, J. M., et al. 1988. Second Annual Report on the ORNL Biological Monitoring and Abatement Program, ORNL/TM-10804, Oak Ridge National Laboratory, Oak Ridge, Tenn.

Loar, J. M., et al. 1989. Third Annual Report on the ORNL Biological Monitoring and Abatement Program, ORNL/TM-11358, Oak Ridge National Laboratory, Oak Ridge, Tenn.

Loar, J. M., et al. 1990. Fourth Annual Report on the ORNL Biological Monitoring and Abatement Program, ORNL/TM-11544, Oak Ridge National Laboratory, Oak Ridge, Tenn. 
Loar, J. M., et al. 1991. Fifth Annual Report on the ORNL Biological Monitoring and Abatement Program: Draft Report, ORNL/TM-12143, Oak Ridge National Laboratory, Oak Ridge, Tenn.

Loar, J. M., et. al. 1992. Sixth Annual Report on the ORNL Biological Monitoring and Abatement Program: Draft Report, ORNL/TM-12083, Oak Ridge National Laboratory, Oak Ridge, Tenn.

Lozier, W. B., C. A. Spiers, and R. Pearson 1986. Aquifer Pump Test with Tracers, ORNL/Sub/8632136/2, Oak Ridge National Laboratory, Oak Ridge, Tenn.

Luxmoore, R. J. 1982. Physical Characteristics of Soils of the Southern Region, ORNL-5868, Oak Ridge National Laboratory, Oak Ridge, Tenn.

Luxmoore, R. J. 1983a. "Infiltration and Runoff Predictions for a Grassland Watershed," Journal of Hydrology 65, 271-78.

Luxmoore, R. J. 1983b. "Water Budget of an Eastern Deciduous Forest Stand," Soil Science Society of America Journal 47, 785-91.

Luxmoore, R. J., and C. L. Begovich 1979. "Simulated Heavy Metal Fluxes in Tree Microcosms and a Deciduous Forest," International Society of Ecological Modeling Journal 1, 48-60.

Luxmoore, R. J., and D. D. Huff 1989. "Water," in Analysis of Biogeochemical Cycling Processes in Walker Branch Watershed, ed. D. W. Johnson and R. I. Van Hook, Springer-Verlag, New York.

Luxmoore, R. J., and M. L. Sharma 1980. "Runoff Responses to Soil Heterogeneity: Experimental and Simulation Comparisons for Two Contrasting Watersheds," Water Resources Research $16,675-84$.

Luxmoore, R. J., B. P. Spalding, and I. M. Munro 1981. "Areal Variation and Chemical Modification of Weathered Shale Infiltration Characteristics," Soil Science Society of America Journal 45, 687-91.

Luxmoore, R. J., J. L. Stolzy, and J. T. Holdeman 1976. Some Sensitivity Analyses of an Hourly SoilPlant-Water Relations Model, ORNL/TM-5343, Oak Ridge National Laboratory, Oak Ridge, Tenn. 
Luxmoore, R. J., J. L. Stolzy, and J. T. Holdeman 1981. "Sensitivity of a Soil-Plant-Atmosphere Model to Changes in Air Temperature, Dewpoint Temperature, and Solar Radiation," Agricultural Meteorology 23, 115-29.

Luxmoore, R. J., and M. L. Tharp 1993. Simulation of Barrier Heterogeneity and Preferential Flow Effects on the Performance of Shallow Land Burial Facilities, ORNL/TM-12058, Oak Ridge National Laboratory, Oak Ridge, Tenn.

Luxmoore, R. J., et al. 1978. "Some Measured and Simulated Plant-Water Relations of Yellow Poplar," Forest Science 24, 327-41.

Mann, L. K., et al. 1996. "Protection of Biota on Nonpark Public Lands: Examples from the U.S. Department of Energy Oak Ridge Reservation," Environmental Management, 202.

McKenzie, D. H., et al. 1982a. Relevance of Biotic Pathways to the Long-Term Regulation of Nuclear Waste Disposal: A Report on Tasks 1 and 2, NUREG/CR-2675, Vol. 1, Pacific Northwest Laboratory, Richland, Wash.

McKenzie, D. H., et al. 1982b. Relevance of Biotic Pathways to the Long-Term Regulation of Nuclear Waste Disposal: Topical Report on Reference Western Arid Low-Level Sites, NUREG/CR-2675, Vol. 2, Pacific Northwest Laboratory, Richland, Wash.

McKenzie, D. H., et al. 1983. Relevance of Biotic Pathways to the Long-Term Regulation of Nuclear Waste Disposal: Topical Report on Reference Eastern Humid Low-Level Sites, NUREG/CR-2675, Vol. 3, Pacific Northwest Laboratory, Richland, Wash.

McKenzie, D. H., et al. 1984. Relevance of Biotic Pathways to the Long-Term Regulation of Nuclear Waste Disposal: Phase I-Final Report, NUREG/CR-2675, Vol. 4, Pacific Northwest Laboratory, Richland, Wash.

McKenzie, D. H., et al. 1985. Relevance of Biotic Pathways to the Long-Term Regulation of Nuclear Waste Disposal: Estimation of Radiation Dose to Man Resulting from Biotic Transport-The BIOPORT/MAXI1 Software Package, NUREG/CR-2675, Vol. 5, Pacific Northwest Laboratory, Richland, Wash.

McKenzie, D. H., et al. 1986. Relevance of Biotic Pathways to the Long-Term Regulation of Nuclear Waste Disposal: Phase 2-Final Report, NUREG/CR-2675, Vol. 6, Pacific Northwest Laboratory, Richland, Wash. 
McMaster, W. W. 1963. Geologic Map of the Oak Ridge Reservation, Tennessee, ORNL/TM-713, Oak Ridge National Laboratory, Oak Ridge, Tenn., November.

Mitchell, J. M. 1995. JAYCOR, Oak Ridge, Tenn., personal communication to M. S. Salk, Environmental Sciences Division, Oak Ridge National Laboratory, Oak Ridge, Tenn., July 20 and July 24.

MMES ( Martin Marietta Energy Systems, Inc.), EG\&G Idaho, Inc., and Westinghouse Savannah River Company 1994. Radiological Performance Assessment for the E-Area Vaults Disposal Facility, WSRC-RP-94-218, Westinghouse Savannah River Company, Aiken, S.C.

Moore, G. K. 1988. Concepts of Groundwater Occurrence and Flow near Oak Ridge National Laboratory, Tennessee, ORNL/TM-10969. Oak Ridge National Laboratory, Oak Ridge, Tenn.

Moore, G. K. 1989. Groundwater Parameters and Flow Systems near Oak Ridge National Laboratory, ORNL/TM-11368, Oak Ridge National Laboratory, Oak Ridge, Tenn.

Moore, G. K., and L. E. Toran 1992. Supplement to a Hydrologic Framework for the Oak Ridge Reservation, Oak Ridge, Tennessee, ORNL/TM-12191, Oak Ridge National Laboratory, Oak Ridge, Tenn.

NCRP (National Council on Radiation Protection and Measurements) 1976. Structural Shielding Design and Evaluation for Medical Use of X Rays and Gamma Rays of Energies up to $10 \mathrm{MeV}$, NCRP Report No. 49, NCRP, Bethesda, Md.

NCRP (National Council on Radiation Protection and Measurements). 1984. Exposures from the Uranium Series with Emphasis on Radon and Its Daughters, NCRP Report No. 77, NCRP, Bethesda, Md.

NCRP (National Council on Radiation Protection and Measurements) 1987. Ionizing Radiation Exposure of the Population of the United States, NCRP Report No. 93, NCRP, Bethesda, Md.

NCRP (National Council on Radiation Protection and Measurements). 1989. Control of Radon in Houses, NCRP Report No. 103, NCRP, Bethesda, Md..

NCRP (National Council on Radiation Protection and Measurements) 1993a. Limitation of Exposure to Ionizing Radiation, NCRP Report No. 116, NCRP, Bethesda, Md. 
NCRP (National Council on Radiation Protection and Measurements) 1993b. Risk Estimates for Radiation Protection, NCRP Report No. 115, NCRP, Bethesda, Md.

Ng, Y. C., C. S. Colsher, and S. E. Thompson 1982. Soil-to-Plant Concentration Factors for Radiological Assessments, NUREG/CR-4370, UCID-19463, Lawrence Livermore National Laboratory, Livermore, Calif.

NRC and CEC (U.S. Nuclear Regulatory Commission and Commission of the European Communities) 1997. Probabilistic Accident and Consequence Uncertainty Analysis: Food Chain Uncertainty Assessment, NUREG/CR-6523, EUR 16771, SAND97-0335, Vol. 1 and 2, CEC, Luxenbourg.

NRC (U.S. Nuclear Regulatory Commission) 1977. Regulatory Guide 1.109: Calculation of Annual Doses to Man from Routine Releases of Reactor Effluents for the Purpose of Evaluating Compliance with 10 CFR Part 50, Appendix I, Washington, D.C.

NRC (U.S. Nuclear Regulatory Commission) 1982. Final Environmental Impact Statement on 10 CFR Part 61 "Licensing Requirements for Land Disposal of Radioactive Waste," Vol. 1, NUREG-0945, Washington, D.C.

ORNL (Oak Ridge National Laboratory) 1992. Guidelines for Establishing Waste Certification Plans and Procedures at Waste Generator Facilities, WMRA-WMPC-CGD-001, Martin Marietta Energy Systems, Inc., Oak Ridge, Tenn., September.

ORNL (Oak Ridge National Laboratory) 1993a. Final Report on the Background Soil Characterization Project at the Oak Ridge Reservation, Oak Ridge, Tennessee, Vol. 1, Results of Field Sampling Program, DOE/OR/01-1175/V1, ES/ER/TM-84/V1, U.S. Department of Energy, Oak Ridge, Tenn.

ORNL (Oak Ridge National Laboratory) 1993b. Groundwater Quality Assessment Report for the Solid Waste Storage Area 6 at the Oak Ridge National Laboratory, 1992, Oak Ridge National Laboratory, Oak Ridge, Tenn.

ORNL (Oak Ridge National Laboratory) 1993c. Quality Assurance Manual, ONRL/M-811, Oak Ridge National Laboratory, Oak Ridge, Tenn., November.

ORNL (Oak Ridge National Laboratory) 1993d. Waste Acceptance Criteria for Radioactive Solid Waste Disposal at SWSA 6, WMRA-WMCP-204, Martin Marietta Energy Systems, Inc., Oak Ridge, Tenn., April. 
ORNL (Oak Ridge National Laboratory) 1994. Performance Assessment for Continuing and Future Operations at Solid Waste Storage Area 6, ORNL-6783, Oak Ridge National Laboratory, Oak Ridge, Tennessee.

ORNL (Oak Ridge National Laboratory) 1996. Waste Acceptance Criteria for Solid Low-Level Waste Treatment, Storage, and Disposal Facilities at Oak Ridge National Laboratory, WM-SWO505, Oak Ridge National Laboratory, Oak Ridge, Tenn.

ORNL (Oak Ridge National Laboratory) 1997a. Basis for Interim Operation: Interim Waste Management Facility, Building 7886, ORNL/WM-SWO/7886/BIO/R0-2, Oak Ridge National Laboratory, Oak Ridge, Tenn., May 14.

ORNL (Oak Ridge National Laboratory) 1997b. Composite Analysis for Solid Waste Storage Area 6, ORNL-6929, Oak Ridge National Laboratory, Oak Ridge, Tenn., September.

ORNL (Oak Ridge National Laboratory) 1997c. ORNL Compliance with Solid Low-Level Waste Acceptance Criteria, ORNL-WM-006, Oak Ridge National Laboratory, Oak Ridge, Tenn.

ORNL (Oak Ridge National Laboratory) 1997d. Performance Assessment for the Class L-II Disposal Facility, ORNL/TM-13401, Oak Ridge National Laboratory, Oak Ridge, Tenn., March.

Oztunali, O. I., and G. W. Roles 1986. Update of Part 61 Impacts Analysis Methodology Methodology Report, Vol. 1, NUREG/CR-4370, Envirosphere Co. and U.S. Nuclear Regulatory Commission, Washington, D.C.

Parr, P. D., and J. W. Evans 1992. Resource Management Plan for the Oak Ridge Reservation, Vol. 27, Wildlife Management Plan, ORNL/NERP-6, Oak Ridge National Laboratory, Oak Ridge, Tenn.

Patterson, M. R., et al. 1974. A User's Manual for the Fortran IV Version of the Wisconsin Hydrologic Transport Model, ORNL-NSF-EATC-7, Oak Ridge National Laboratory, Oak Ridge, Tenn.

Peterson, H. T., Jr. 1983. "Terrestrial and Aquatic Food Chain Pathways," in Radiological Assessment, ed. J. E. Till and R. H. Meyer, NUREG/CR-3332, ORNL-5968, U.S. Nuclear Regulatory Commission and Oak Ridge National Laboratory, Oak Ridge, Tenn.

Reeves, M., and E. E. Miller 1975. "Estimating Infiltration for Erratic Rainfall," Water Resources Research 11, 102-10. 
Richter, C. F. 1958. Elementary Seismology, W. H. Freeman and Co., San Francisco, Calif.

Rogers, J. G., et al. 1987. Oak Ridge Reservation Environmental Monitoring Report for 1986, ES/ESH-1/V1, Oak Ridge National Laboratory, Oak Ridge, Tenn.

Rogers, J. G., et al. 1988. Oak Ridge Reservation Environmental Monitoring Report for 1987, ES/ESH-4/V1, Oak Ridge National Laboratory, Oak Ridge, Tenn.

Rogers, J. G., et al. 1989. Oak Ridge Reservation Environmental Monitoring Report for 1988, ES/ESH-8/V1,V2, Oak Ridge National Laboratory, Oak Ridge, Tenn.

Rogers and Associates Engineering Corp. 1989. The BARRIER Code: A Tool for Estimating the Long-Term Performance of Low-Level Radioactive Waste Disposal Facilities, User's Manual, NP-6218-CCML, Electric Power Research Institute, Palo Alto, Calif.

Rosensteel, B. A. 1995. JAYCOR, Oak Ridge, Tenn., personal communication to M. S. Salk, Environmental Sciences Division, Oak Ridge National Laboratory, Oak Ridge, Tenn., July 17.

Rothschild, E. R., et al. 1984. Characterization of Soils at Proposed Solid Waste Storage Area (SWSA) 7, ORNL/TM-9326, Oak Ridge National Laboratory, Oak Ridge, Tenn.

Ryon, M. G. 1988. "Fishes," pp. 203-32 in Loar 1988.

SAIC (Science Applications International Corporation) 1995. Letter Report on Tritium Releases from the ORNL WAG 6 Tumulus Facility. Oak Ridge National Laboratory, Oak Ridge, Tenn.

Scheidegger, A. E. 1960. Physics of Flow Through Porous Media, 2d ed., Macmillan, New York.

Schwartz, P. M., et al. 1995. TERRAIN: A Computer Program to Process Digital Elevation Models for Modeling Surface Flow, ORNL/TM-13071, Oak Ridge National Laboratory, Oak Ridge, Tenn.

Sharma, M. L., and R. J. Luxmoore 1979. "Soil Spatial Variability and Its Consequence on Simulated Water Balance," Water Resources Research 15, 1567-73.

Sharma, M. L., et al. 1987. "Subsurface Water Flow Simulated for Hillslopes with Spatially Dependent Soil Hydraulic Characteristics," Water Resources Research 23, 1523-30. 
Sheppard, M. E., and D. E. Thibault 1990. "Default Soil Solid/Liquid Partition Coefficients, Ks for Four Major Soil Types: A Compendium," Health Physics 59(4), 471-82.

Sheppard, M. I., et al. 1984. Soil Nuclide Distribution Coefficients and Their Statistical Distributions, AECL-8364, Whiteshell Nuclear Research Establishment, Pinawa, Manitoba, Canada.

Shleien, B., ed. 1992. "Mass Attenuation Coefficients," Table 5.1 in The Health Physics and Radiological Health Handbook, rev. ed., Scinta, Inc., Silver Spring, Md.

Shuman, R. 1993. Rogers and Associates Engineering Corp., letter to L. E. McNeese, Oak Ridge National Laboratory, Oak Ridge, Tenn..

Shuman, R., N. Chau, and E. Jennrich 1992. The SOURCE Computer Codes: Models for Evaluating the Long-Term Performance of SWSA 6 Disposal Units, Version 1.0: User's Manual, RAE-9005/8-1, Rogers \& Associates Engineering Corp., Salt Lake City, Utah.

Sinclair, T. R., C. E. Murphy, Jr., and K. R. Knoerr 1976. "Development and Evaluation of Simplified Models for Simulating Canopy Photosynthesis and Transpiration," Journal of Applied Ecology 13, 813-29.

Smith, J. G. 1988a. “Benthic Macroinvertebrates," pp. 164-202 in Loar 1988.

Smith, J. G. 1988b. "Benthic Macroinvertebrates," pp. 109-55 in Ecological Evaluation of Bear Creek 1984-1087, Draft Report, ed. G. R. Southworth, Oak Ridge National Laboratory, Oak Ridge, Tenn.

Smith, J. G. 1992. "Benthic Macroinvertebrates," pp. 109-155 in Ecological Effects of Contaminants and Remedial Actions in Bear Creek, ORNL/TM-11977, ed. G. R. Southworth, Oak Ridge National Laboratory, Oak Ridge, Tenn.

Smith, J. G., and M. G. Ryon 1989. Environmental Sciences Division, Oak Ridge National Laboratory, Oak Ridge, Tenn., letter to J. M. Loar, Environmental Sciences Division, Oak Ridge National Laboratory, July 21.

Smith, M. A. 1991. Martin Marietta Energy Systems, Inc., Solid Waste Certification Program Plan, K/WM-14, Central Waste Management Division, Martin Marietta Energy Systems, Inc., Oak Ridge, Tenn., January.

Solomon, D. K., et al. 1992. Status Report: A Hydrologic Framework for the Oak Ridge Reservation, ORNL/TM-12026, Oak Ridge National Laboratory, Oak Ridge, Tenn. 
Stevens, M. M. 1990. Conceptual Model for Radiological Performance Assessment of Low-Level Radioactive-Waste Disposal Facility, ORNL/TM-11495, Oak Ridge National Laboratory, Oak Ridge, Tenn.

Stockdale, P. B. 1951. Geologic Conditions at the Oak Ridge National Laboratory $(X-10)$ Area Relevant to the Disposal of Radioactive Waste, ORO-58, U.S. Atomic Energy Commission, Oak Ridge, Tenn., August 1.

Suter, G. W., R. J. Luxmoore, and E. D. Smith 1993. "Compacted Soil Barriers at Abandoned Landfill Sites Are Likely to Fail in the Long Term," Journal of Environmental Quality 22, 217-26.

Suter, G.W., et al. 1995. Approach and Strategy for Performing Ecological Risk Assessments for the U.S. Department of Energy's Oak Ridge Reservation: 1995 Revision, ES/ER/TM-33/R2, Oak Ridge National Laboratory, Oak Ridge, Tenn.

Swanson, J. L. 1983. Mobility of Organic Complexes of Nickel and Cobalt in Soils, PNL/4796, Pacific Northwest Laboratory, Richland, Wash.

Tanner, A. B. 1964. "Radon Migration in the Ground: A Review," p. 161 in The Natural Radiation Environment, ed. J. A. S. Adams and W. M. Lowder, University of Chicago Press, Chicago, III.

Timmins, S. P., M. A. Huston, and R. B. Clapp 1989. "Generation of Digital Elevation Models from Contours and Comparison of Topographic Indices," Eos: Transactions, American Geophysical Union 70, 1094.

Trabalka, J. R., and C. T. Garten, Jr. 1983. "Behavior of the Long-Lived Synthetic Elements and Their Natural Analogs in Food Chains," pp. 39-103 in Advances in Radiation Biology, ed. V. K. Ehman and A. B. Cox, Academic Press, New York.

Tucci, P. 1986. Groundwater Flow in Melton Valley, Oak Ridge Reservation, Roane County, Tennessee-Preliminary Model Analysis, Water Resources Investigation Report 85-4221, U.S. Geological Survey, Nashville, Tenn.

Tull, M. W., and M. A. Smith 1990. Oak Ridge National Laboratory Certification Program Plan for Solid Low-Level Radioactive Waste, ORNL/TM-11600, Oak Ridge National Laboratory, Oak Ridge, Tenn., August. 
Turner, R. R., and K. F. Steele 1988. "Cadmium and Manganese Sorption by Soil Macropore Linings and Fillings," Soil Science 145, 79-86.

USGS MOC 1990. Computer code, with instructions, in L. F. Knoikow and J. D. Bredehoeft, "Computer Model of Two-Dimensional Solute Transport and Dispersion in Ground Water," chap. C2, book 7, of Geological Survey Techniques of Water-Resources Investigations of the United States Geological Survey, U.S. Department of the Interior, Washington, D.C., 1978.

Walker, F. W., D. G. Miller, and F. Feiner 1983. Chart of the Nuclides, 13th ed., General Electric Co., San Jose, Calif.

West, D. C., et al. 1991. Oak Ridge Reservation Environmental Report for 1990, ES ESH-18/V1, Oak Ridge National Laboratory, Oak Ridge, Tenn.

Wickliff, D. S., et al. 1989. Contaminant Transport During Storms near Solid Waste Areas 4 and 5 , ORNL/RAP/LTR-89/20, Oak Ridge National Laboratory, Oak Ridge, Tenn.

Wickliff, D. S., et al. 1990. Environmental Monitoring Program: Mid-FY 1990 Summan Report, Draft ORNL/TM, Oak Ridge National Laboratory, Oak Ridge, Tenn.

Wickliff, D. S., C. M. Morrissey, and T. L. Ashwood 1991. Active Sites Environmental . Monitoring Program: FY 1990 Report, ORNL/M-1327, Oak Ridge National Laboraton. Oah Ridge, Tenn.

Wilson, G. V., J. M. Alfonsi, and P. M. Jardine 1989. "Spatial Variability of Saturated Hydraulic Conductivity of the Subsoil of Two Forested Watersheds," Soil Science Sacien of America Journal 53, 679-85.

Wilson, G. V., and R. J. Luxmoore 1988. "Infiltration, Macroporosity, and Mesoporosity Distributions on Two Forested Watersheds," Soil Science Society of America Journal 52, 329-35.

Wilson, G. V., et al. 1993. "Field-Scale Transport from a Buried Line Source in Variably Saturated Soil," Journal of Hydrology 145, 83-109.

Wood, D. E., et al. 1994. Performance Assessment Task Team Progress Report, DOE/LLW-157, Revision 1, Idaho National Engineering Laboratory, Idaho Falls, Idaho. 


\section{Internal Distribution}

1. J. B. Berry

2. J. M. Begovich

3. H. M. Braunstein

4. J. A. Chapman

5. G. E. Courville

6. G. R. Cunningham

7. K. G. Edgemon

8. J. R. Forgy

9. S. G. Hildebrand

10. A. S. Icenhour

11. R. H. Ketelle

12. D. C. Kocher

13. G. R. Larson

14. D. W. Lee

15. S. L. Loghry

16. D. A. Lombardi

17. R. J. Luxmoore

18. L. K. Mann

19. R. C. Mason
20. C. I. Moser

21. T. E. Myrick

22. D. C. Parcyzk

23. R. M. Reed

24. T. F. Scanlan

25. R. B. Shelton

26. L. E. Stratton

27. J. D. Tauxe

28. M. L. Tharp

29. V. R. Tolbert

30. J. R. Trabalka

31. M.W. Tull

32. M. W. Yambert

33. L. K. Yong

34. ORNL Patent Office

35. Central Research Library

36. Document Reference Section

37-38. Laboratory Records

39. Laboratory Records - RC

\section{External Distribution}

40. Lilia A. Abron, President, PEER Consultants, P.C., 1460 Gulf Blvd. 11th Floor, Clearwater, FL 34630

41. Cynthia Anderson, U.S. Department of Energy, Savannah River Operations Office, Road 1, Aiken, SC 29801

42. Karen A. Balo, Lockheed Martin Energy Systems, Inc., P.O. Box 2003, Oak Ridge, TN 378317357

43. Rex J. Borders, U.S. Department of Energy, Albuquerque Operations Office, Pennsylvania \& H Street, Kirtland Air Force Base, Albuquerque, NM 87116

44. W. Fred Carden, Lockheed Martin Energy Systems, Inc., P.O. Box 2003, Oak Ridge, TN $37831-$ 7357

45. Joel T. Case, U.S. Department of Energy, Idaho Operations Office, 765 Lindsay Blvd., Idaho Falls, ID 83415

46. Robert U. Curl, Lockheed Martin Idaho Technologies, P.O. Box 1625, M.S. 2420, Idaho Falls, ID 83415 
47. Thomas E. Drabek, Professor, Department of Sociology, University of Denver, Denver, CO 80208-0209.

48. Gregory J. Duggan, U.S. Department of Energy, Idaho Operations Office, 765 Lindsay Blvd., Idaho Falls, ID 83401

49-52. William C. Gilbert, U.S. Department of Energy, Oak Ridge Operations Office, 55 Jefferson, Oak Ridge, TN 37831

53. Clayton Gist, U.S. Department of Energy, Oak Ridge Operations Office, 55 Jefferson, Oak Ridge TN 37831

54. Herschel W. Godbee, 104 Tidewater Lane, Oak Ridge, TN 37830

55. R. Douglas Hildebrand, U.S. Department of Energy, Richland Operations Office, 825 Jadwin Ave., P.O. Box 550, Richland, WA 99352

56. Randy C. Janke, U.S. Department of Energy, Fernald Field Office, 7400 Willey Rd., Cincinnati, $\mathrm{OH} 45030$

57. Marcus E. Jones, U.S. Department of Energy, Cloverleaf, EM-43, 20400 Century Blvd., Germantown, MD 20874

58. Martin J. Letourneau, U.S. Department of Energy, Trevion II, EM-35, 19901 Germantown Rd., Germantown, MD 20874

59. Virgil Lowery, U.S. Department of Energy, Trevion II, EM-35, 19901 Germantown Rd., Germantown, MD 20874

60. Beth A. Moore, U.S. Department of Energy, Nevada Operations Office, 2753 S Highland Rd., Las Vegas, NV 89109

61. William L. Noll III, U.S. Department of Energy, Savannah River Operations Office, Road 1, Aiken, SC 29801

62. ORNL Site Manager, U.S. Department of Energy, Oak Ridge National Laboratory, P.O. Box 2008, Oak Ridge, TN 37831-6269

63. Kirk W. Owens, Science Applications International Corp., 20201 Century Blvd., Germantown, MD 20874

64. Suzanne P. Riddle, U.S. Department of Energy, Oak Ridge Operations Office, 55 Jefferson, Oak Ridge, TN 37831

65. Jay E. Rhoderick, U.S. Department of Energy, Trevion II, EM-35, 19901 Germantown Rd., Germantown, MD 20874

66. P. Richard Rittelmann, FAIA, Executive Vice President, Burt Hill Kosar Rittelmann Associates, 400 Morgan Center, Butler, PA 16001-5977 
67. L. C. Roddye, U.S. Department of Energy, Oak Ridge National Laboratory, P.O. Box 2008, Oak Ridge, TN 37831-6269

68. Linda C. Suttora, U.S. Department of Energy, Cloverleaf, EM-43, 20400 Century Blvd., Germantown, MD 20874

69. Maria L. Socolof, University of Tennessee, Energy, Environment, and Resource Center, 311 Conference Office Bldg., Knoxville, TN 37996-4314

70. Susan F. Tierney, The Economic Resource Group, Inc., One Mifflin Place, Cambridge, MA 02138

71. C. Michael Walton, Ernest H. Cockrell Centennial Chair in Engineering and Chairman, Department of Civil Engineering, University of Texas at Austin, Austin, TX 78712-1076

72. Andrew Wallo III, U.S. Department of Energy, Forrestal Bldg., EH-41, 1000 Independence Ave., S.W., Washington, D.C. 20585

73-74. OSTI, U.S. Department of Energy, P.O. Box 62, Oak Ridge, TN 37831 